\title{
Nordic Energy Technology Perspectives 2016
}

Karlsson, Kenneth Bernard; Münster, Marie; Skytte, Klaus; Pérez, Cristian Hernán Cabrera; Venturini, Giada; Salvucci, Raffaele; Pedersen, Rasmus Bo Bramstoft

Publication date:

2016

Link back to DTU Orbit

Citation (APA):

Karlsson, K. B., Münster, M., Skytte, K., Pérez, C. H. C., Venturini, G., Salvucci, R., \& Pedersen, R. B. B. (2016). Nordic Energy Technology Perspectives 2016.

\section{General rights}

Copyright and moral rights for the publications made accessible in the public portal are retained by the authors and/or other copyright owners and it is a condition of accessing publications that users recognise and abide by the legal requirements associated with these rights.

- Users may download and print one copy of any publication from the public portal for the purpose of private study or research.

- You may not further distribute the material or use it for any profit-making activity or commercial gain

- You may freely distribute the URL identifying the publication in the public portal

If you believe that this document breaches copyright please contact us providing details, and we will remove access to the work immediately and investigate your claim 


\section{Nordic Energy Technology Perspectives 2016}

Cities, flexibility and pathways to carbon-neutrality

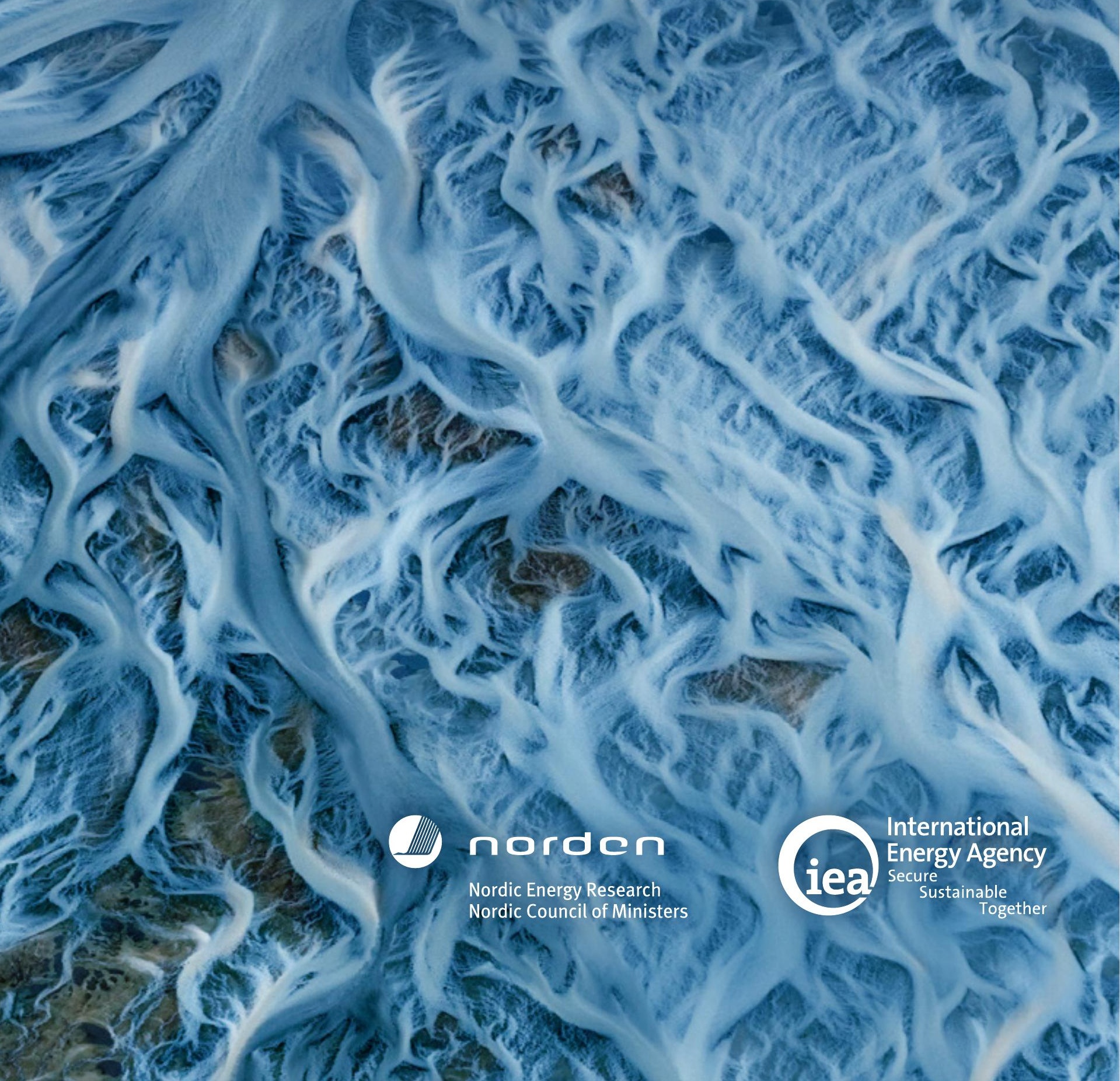


Copyright (C) 2016 Nordic Energy Technology Perspectives 2016

OECD/IEA, 9 rue de la Fédération, 75739 Paris Cedex 15, France

Nordic Energy Research, Stensberggata 25, NO-0170 Oslo, Norway,

Risø DTU, Ea Energianalyse A/S, (EAEA), VTT Technical Research Centre of Finland (VTT), University of Iceland (UI), Institute For Energy Technology (IFE), Profu Ab (Profu) and IVL Swedish Environmental Research Institute (IVL).

This Nordic ETP technology paper is the result of a collaborative effort between the International Energy Agency (IEA), Nordic Energy Research (NER), Risø DTU, Ea Energianalyse A/S, (EAEA), VTT Technical Research Centre of Finland (VTT), University of Iceland (UI), Institute For Energy Technology (IFE), Profu Ab (Profu) and IVL Swedish Environmental Research Institute (IVL). This Nordic ETP technology paper reflects the views of the IEA Secretariat, NER, Risø DTU, EAEA, VTT, UI, IFE, Profu and IVL, but does not necessarily reflect those of their respective individual Member countries or funders. The Nordic ETP technology paper does not constitute professional advice on any specific issue or situation. NER, the IEA, Risø DTU, EAEA, VTT, UI, IFE, Profu and IVL make no representation or warranty, express or implied, in respect of the contents of the Nordic ETP technology paper (including its completeness or accuracy) and shall not be responsible for any use of, or reliance on, it. For further information, please contact: rights@iea.org.

This publication reflects the views of the IEA Secretariat, but does not necessarily reflect those of their respective individual member countries [or funders]. The IEA make no representation or warranty, express or implied, in respect to the publication's contents (including its completeness or accuracy) and shall not be responsible for any use of, or reliance on, the publication

This document and any map included herein are without prejudice to the status of or sovereignty over any territory, to the delimitation of international frontiers and boundaries, and to the name of any territory, city or area.

Figures and data in this report can be downloaded at www.iea.org/etp/nordic 


\section{Nordic Energy Technology Perspectives 2016}

Cities, flexibility and pathways to carbon-neutrality

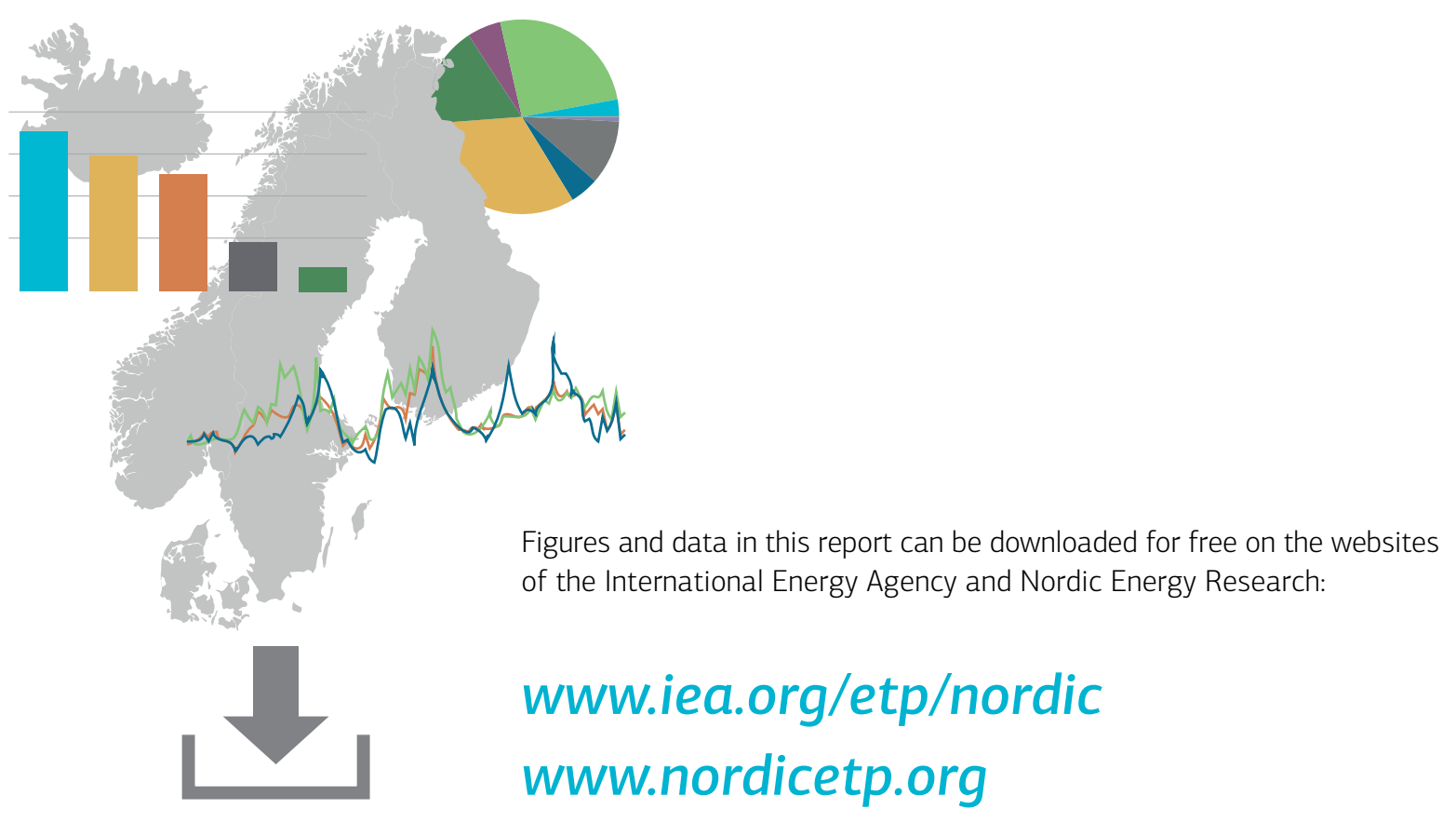

norden

Nordic Energy Research Nordic Council of Ministers
International

Energy Agency iea secure Sustainable

Together 
The International Energy Agency (IEA), an autonomous agency, was established in November 1974. Its primary mandate was - and is - two-fold: to promote energy security amongst its member countries through collective response to physical disruptions in oil supply, and provide authoritative research and analysis on ways to ensure reliable, affordable and clean energy for its 29 member countries and beyond. The IEA carries out a comprehensive programme of energy co-operation among its member countries, each of which is obliged to hold oil stocks equivalent to 90 days of its net imports. The Agency's aims include the following objectives:

- Secure member countries' access to reliable and ample supplies of all forms of energy; in particular, through maintaining effective emergency response capabilities in case of oil supply disruptions.

- Promote sustainable energy policies that spur economic growth and environmental protection in a global context - particularly in terms of reducing greenhouse-gas emissions that contribute to climate change.

- Improve transparency of international markets through collection and analysis of energy data.

- Support global collaboration on energy technology to secure future energy supplies and mitigate their environmental impact, including through improved energy

efficiency and development and deployment of low-carbon technologies.

- Find solutions to global energy challenges through engagement and dialogue with non-member countries, industry, international organisations and other stakeholders.

IEA member countries:

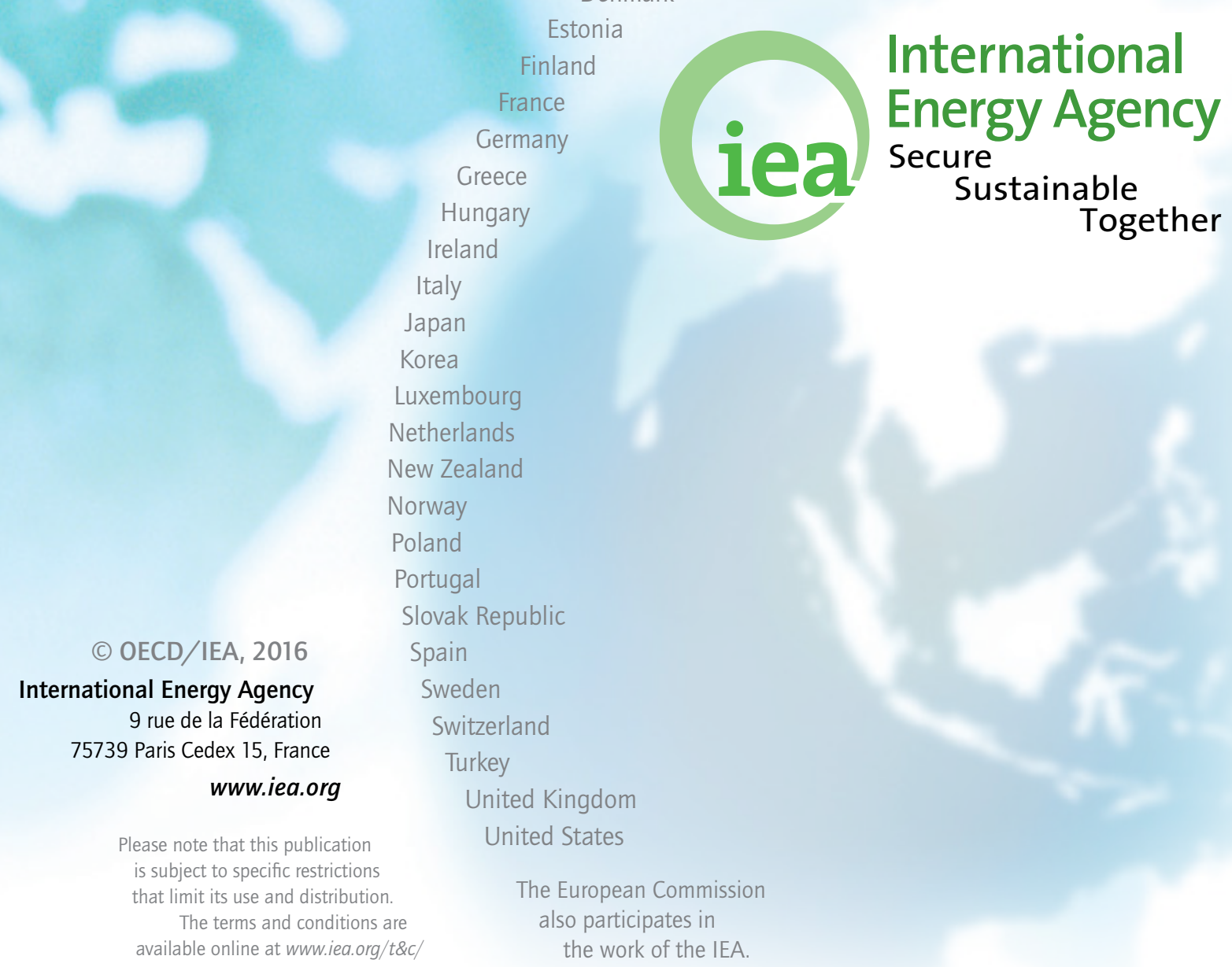




\section{Table of Contents}

Foreword 5

$\begin{array}{ll}\text { Acknowledgements } & 7\end{array}$

Contact 9

$\begin{array}{ll}\text { Executive Summary } & 10\end{array}$

$\begin{array}{ll}\text { Nordic energy-related carbon dioxide emissions } & 26\end{array}$

$\begin{array}{lll}\text { Chapter } 1 & \text { Nordic choices in a global world } & 28\end{array}$

Radical change is needed, but history gives cause for optimism 31

Three strategic issues facing Nordic countries $\quad 35$

Power generation and district heating are almost there $\quad 42$

Spotlight 1: The Nordic bioenergy market $\quad 52$

Decarbonising transport poses significant challenges $\quad 57$

Industry: Innovation will be the deal breaker $\quad 72$

Spotlight 2: Iceland's fishing sector $\quad 83$

Buildings: Accelerating deep energy renovation is critical 88

$\begin{array}{ll}\text { Decarbonising the Nordic region will not cost the world } & 101\end{array}$

$\begin{array}{lll}\text { Chapter } 2 & \text { Urban energy } & 104\end{array}$

$\begin{array}{ll}\text { Introduction } & 107\end{array}$

$\begin{array}{ll}\text { Overview of Nordic urban energy systems } & 108\end{array}$

Drivers of change in the urban context 114

$\begin{array}{ll}\text { Urban scenarios } & 119\end{array}$

Nordic capitals leading the low-carbon transition by example 129

$\begin{array}{ll}\text { Recommendations for action in urban areas } & 147\end{array}$ 
Introduction

Market integration of VRE

Electricity trade 180

Flexibility in the system and VRE integration 189

The role of nuclear in the Nordic energy system 210

Recommendations and near-term actions

Annex A (Chapter 1)

Annex B (Chapter 2) 230

Annex C (Chapter 3)

References

List of Figures 254

List of Boxes 260

List of Tables 261

Also from the IEA 264

New releases 


\section{Foreword}

Much has changed since the last edition of Nordic Energy Technology Perspectives (NETP) in 2013. Despite lower fossil fuel prices, the Nordic region has continued to reduce emissions. This decline is the result of efficiency improvements and strong renewables growth - evidence that energy policies suggested in the last report are producing results. Similar developments are evident across Europe, where the Energy Union has established a new framework for European energy policy. Globally, too, efforts to cut $\mathrm{CO}_{2}$ have gained momentum. At the time of writing, 189 countries had pledged to reduce emissions under the framework of the Paris Agreement on climate change, which has already been signed by more than 170 country representatives. Policy makers around the world are now looking to fulfil these pledges. The experiences of the Nordic region in energy system transition can offer a valuable contribution as the world takes on this challenge. The highly interconnected regional electricity market is the cornerstone of the Nordic energy system, and it can serve as a key enabler for further emission reductions towards 2050.

This report provides a case study on how to go beyond the $2^{\circ} \mathrm{C}$ target, towards a carbonneutral energy system. For Nordic policy makers, the scenarios in this report identify both challenges and opportunities on the road towards the ambitious national climate targets of the region. Their success will depend on ensuring public acceptance of new power generation and grid investments, the continued competitiveness of energy-intensive industries amidst higher electricity prices, and the sustainable supply of biofuels for long-distance transport. In addition, there are significant opportunities to benefit from supplying and balancing the European electricity grid, and to harness urban leadership in the electrification of transport.

NETP 2016 is the largest IEA collaborative analytical effort looking at regional long-term low-carbon technology pathways. The report applies the global energy scenarios of the IEA Energy Technology Perspectives report to the five Nordic countries, utilising rich national data and addressing issues specific to the Nordic countries. It builds directly on the first edition of the report from 2013, which has become a key point of reference for various subsequent analyses from Nordic governments, industry and civil society.

Just as in the global IEA Energy Technology Perspectives report, urban energy systems and electricity system integration are topics garnering special attention in this edition, where leading Nordic researchers have used specialised modelling tools to supplement the IEA model central to the scenarios. The result is a more detailed and region-specific assessment of renewables buildout and electricity trade than was possible in the first edition. Tight co-operation between IEA and Nordic researchers has been critical to this endeavour, which has benefited both sides immensely. It is our hope that this fruitful co operation will continue and be extended to other countries and regions of the world.

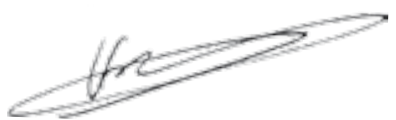

Kamel Ben Naceur

Director

Sustainability, Technology and Outlooks

International Energy Agency, Paris

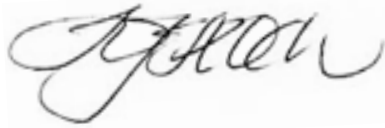

Hans Jørgen Koch

Executive Director

Nordic Energy Research, Oslo 



\section{Acknowledgements}

Nordic Energy Technology Perspectives is a collaborative project between the International Energy Agency (IEA), Nordic research institutions and Nordic Energy Research - an intergovernmental organisation under the Nordic Council of Ministers.

Benjamin Donald Smith at Nordic Energy Research was the coordinator of the project.

Markus Wråke at IVL Swedish Environmental Research Institute was the analytical project manager and had overall responsibility for the design and implementation of the study.

Daniele Poponi led the analysis at the IEA.

Special thanks go to Nordic Energy Research Executive Director Hans Jørgen Koch and Jean-Francois Gagné, head of the ETP division at the IEA, who have been driving forces behind the project.

\section{IEA team}

Pierpaolo Cazzola, Astrid Dumond, John Dulac, Araceli Fernández Palés, Marine Gorner, Lorcan Lyons, Luis Munuera, Daniele Poponi, Uwe Remme, Jacob Teter, Therese Walsh and Kira West.

\section{Nordic Energy Research}

Hans Jørgen Koch, Svend Søyland and Benjamin Donald Smith.

\section{Danish team}

Kenneth Bernard Karlsson, Marie Münster, Klaus Skytte, Cristian Hernán Cabrera Pérez, Giada Venturini, Raffaele Salvucci and Rasmus Bo Bramstoft Pedersen (DTU); Anders Kofoed-Wiuff, János Hethey, Nina Dupont and Simon Sawatzki (EA Energy Analyses).

\section{Finnish team}

Tiina Koljonen, Tomi J. Lindroos, Antti Lehtilä, Göran Koreneff and Miimu Airaksinen (VTT).

\section{Icelandic team}

Brynhildur Davidsdottir, Conor Byrne, Reza Fazeli, Ehsan Shafiei, Sigurdur Jóhannesson and Darri Eyporsson (University of Iceland); Jonas Hlynur Hallgrimsson (EFLA Engineering).

\section{Norwegian team}

Kari Aamodt Espegren, Arne Lind, Eva Rosenberg (IFE); Glen Peters, Jonas Karstensen and Robbie Andrew (CICERO).

\section{Swedish team}

Fredrik Martinsson, Marcus Liljeberg and Markus Wråke (IVL); Thomas Unger and Mattias Bisaillon (Profu). 


\section{Editing}

Justin French-Brooks, Marilyn Smith and Jonas Wiesel.

\section{Layout}

Steffen Brückner

\section{Nordic Reference group}

The work was guided by the Nordic Reference Group, consisting of:

Karsten Kapion and Peter Meibom (Danish Energy Association), Jeppe Lundbæk (Danish Energy Agency), Erla Björk Thorgeirsdottir and Jónas Ketilsson (National Energy Authority of Iceland), Jari Kostama (Finnish Energy), Petteri Kuuva (Ministry of Economy and the Employment, Birgitte Liard and Elin Økstad (Norwegian Environment Agency), Hans Otto Haaland (Norwegian Research Council), Filip Ehrle Elveling and Åsa Leander (Swedish Ministry of Environment and Energy), Klaus Hammes (Swedish Energy Agency), Estathios Peteves (EU Joint Research Centre, Petten)

In addition, we are very grateful for input and comments from the following people:

Anna Andersson (Swedish Energy Agency), Johan Berg (Heat Pump Centre), Brian Dean (IEA), Joakim Cejie (Swedish Ministry of Environment and Energy), Dag Christensen (Energy Norway), Chiara Delmastro (Politecnico di Torino), Audun Fidje (Norwegian Water Resources and Energy Directorate), Iratxe Gonzalez (JRC IET) Klaus Hammes (Swedish Energy Agency), Anders Bavnhøj Hansen (Energinet DK), Ignacio Hidalgo (JRC IET), Hrönn Hrafnsdóttir (City of Reykjavik), Eva Jernbäcker (Swedish Ministry of Environment and Energy), Sigurður Jóhannesson (University of Iceland), Andreas Kannesten (Swedish Ministry of Environment an Energy) Marc LaFrance (US Department of Energy), Ágústa Loftsdóttir (National Energy Authority of Iceland), Jukka Leskela (Finnish Energy Industries), Elisabeth Lidbaum (Swedish Ministry of Environment and Energy), Ole Løfsnæs (Norsk Industri), Fredrik Norlund (Swedish Ministry of Environment and Energy), Roger Nordman (Heat Pump Centre), Wouter Nijs (JRC IET), Mikael Odenberger (Chalmers), Lina Palm (Uniper), Martin Palm (Swedish Ministry of Environment and Energy), Julia Panzer (Danfoss), Cristian Hernán Cabrera Pérez (Technical University of Denmark), Pentti Puhakka (Finland TEM), Eva Rosenberg (Institute for Energy and Technology Norway), Pablo Ruiz (JRC IET), Caroline Haglund Stignor (Heat Pump Centre), Andreas Zucker (JRC IET), Hans Rudling (Fortum Värme), Erik Dotzauer (Fortum Värme), Christer Boberg (Fortum Värme), Jan Bråten (Statnett).

The project was made possible through funding from Nordic Energy Research. Special thanks go to then Board members: Nicolai Zarganis and Flemming G. Nielsen (Danish Energy Agency), Sebastian Johansson (Tekes, Finland), Gudni A. Jóhannesson and Erla Björk Porgeirsdóttir (Orkustofnun, Iceland), Rune Volla and Hans Otto Haaland (Research Council of Norway), Astrid Stavseng (Norwegian Ministry of Petroleum and Energy), Lars Guldbrand (Swedish Ministry of Environment and Energy) and Birgitta Palmberger (Swedish Energy Agency).

The individuals and organisations that contributed to this study are not responsible for any opinions or judgements contained in this study. Any errors and omissions are solely the responsibility of the IEA. 


\section{Contact}

Comments and questions are welcome and should be addressed to:

Dr. Daniele Poponi

International Energy Agency

e-mail: etp_project@iea.org

Dr. Markus Wråke

IVL Swedish Environmental Research Institute

e-mail: nordicetp@ivl.se

For enquiries regarding the presentation of results or distribution of the report, contact Nordic Energy Research at nordicetp@nordicenergy.org 


\section{Executive Summary}

There is a clear technological and economical pathway for the Nordic region to push towards a near carbon-neutral energy system in 2050. Together, Nordic countries can send a strong signal to the global community that the ambitious aims of the Paris Climate Agreement are achievable.

\section{Strategic actions}

The Nordic Carbon-Neutral Scenario (CNS) central to this report sets out three macro-level strategic actions that will be central in achieving the climate targets of the Nordic countries in 2050. In the context of an overarching aim to achieve a near carbon-neutral energy system, governments, policy makers and private sector decision makers should:

\section{Incentivise and plan for a Nordic electricity system that is significantly 1. more distributed, interconnected and flexible than today's.}

This analysis demonstrates that if a carbon-neutral system is the target, it will likely cost less to transition to a more distributed electricity supply with a high share of wind than to maintain a system reliant on centralised nuclear and thermal generation. The utilisation of abundant Nordic wind resources, together with more active use of existing dispatchable hydropower, creates an opportunity for the Nordic region to play a stronger European role. The Nordic region can both export electricity and balance European variable renewables, generating large economic revenues and facilitating the transformation of the European energy system.

The potential for significant net economic and climate benefits associated with greater grid interconnection and wind build-out need to be balanced against the energy security concerns of industry and the need for public acceptance of new infrastructure. Higher shares of wind will require enhanced system integration across sectors and technologies, and among the Nordic countries. In addition, it will necessitate complementing existing dispatchable hydropower with other sources of flexibility to minimise integration costs. The current challenging economic outlook for nuclear power in the face of competition from wind leads to a decrease in stable base load (especially in Sweden), further increasing the need for system flexibility. The transition to greater electricity trade and interdependence among Nordic countries must allay concerns from energy-intensive industries over security of supply. Despite low average generation costs in the Nordic region, prices to consumers vary between countries, partly as a result of different tax regimes. Greater integration with the European electricity system will likely push Nordic electricity prices for consumers and industry towards the higher prices characteristic of the continent. Higher shares of wind are also likely to lead to greater price variations. This signifies a substantial change from the low and stable prices that have long been a key competitive advantage for Nordic industry, necessitating clever policies to guide the transition. 


\section{Ramp up technology development to advance decarbonisation of long- distance transport and the industrial sector.}

Despite a broad electrification of short-distance transport, long-distance modes are unlikely to be decarbonised without utilising large volumes of biofuels. If Nordic biomass continues to be transformed into higher-value products (e.g. within the pulp and paper industry), $16 \%$ of total Nordic biomass demand across all sectors will need to be met by imports in 2050 (including for refuelling at Nordic ports). Sustainable and politically acceptable sourcing of those resources will be crucial. Decarbonising transport through local advanced biofuel production would likely be more costly than participating in global biofuel markets. Although research, development, demonstration and deployment (RDD\&D) efforts in advanced biofuels could lower costs, using Nordic biomass resources to cover the entire demand for bioenergy would mean diverting them from higher value products in industry. Competing low-carbon fuels, such as hydrogen or highway electrification, bear higher investment risks and costs, both for vehicles and distribution infrastructure. Pilot projects to improve understanding of the technical feasibility and cost profile of these solutions should be pursued.

Emissions from industry are the most challenging to reduce, requiring rapid advances in the demonstration and deployment of carbon capture and storage (CCS) and other innovative low-carbon process technologies. With substantial activity in iron and steel, cement, chemicals and aluminium sectors, Nordic industry has a relatively large share of process-related emissions that cannot be mitigated through energy efficiency or switching to lower-carbon energy mixes. If wide application of innovative low-carbon technologies, such as industrial CCS, does not materialise as envisioned in the CNS, the development and demonstration of breakthrough process technologies will need to be dramatically accelerated to reduce these emissions. Alternatively, other sectors of the economy would need to reduce emissions even further. Greater Nordic cooperation will be needed on RDD\&D, policies and infrastructure planning for CCS.

\section{Tap into the positive momentum of cities to strengthen national decarbonisation and energy efficiency efforts in transport and buildings.}

Several Nordic capitals and smaller cities have adopted climate targets that are more aggressive than national aims. Better alignment and co-operation across national and local policy allows national efforts to leverage this urban leadership. With Nordic urban areas expected to grow at twice the rate of previous decades, an opportunity exists to transition to lowcarbon, highly integrated and efficient urban energy systems. Accelerated renovation to improve the efficiency of existing buildings is critical, and areas of high population density facilitate the use of district heating and cooling in buildings - in some cases through the use of excess heat. Electric vehicles (EVs), public transport and cycling are best suited to cities and offer enhanced mobility services, improved local air quality and reductions in congestion, in addition to lower energy use and emissions. Shifting the policy focus to improving energy services (rather than just delivering energy) is the most effective way to capture such non-energy benefits of a low-carbon energy system.

Nordic Energy Technology Perspectives 2016 (NETP 2016) presents technology pathways towards a near-zero emission Nordic energy system, in direct response to the ambitious national climate targets for 2050 across the region. It is the result of a joint project involving the International Energy Agency (IEA), Nordic Energy Research and leading research institutions from all five Nordic countries. While the analytical framework (including technology assumptions and global fuel prices) is common to the IEA's Energy Technology Perspectives 
2016, NETP 2016 presents in-depth Nordic scenarios tailored to inform the decisions of Nordic policy makers. The analysis is presented around the Nordic Carbon-Neutral Scenario (CNS), which results in an 85\% reduction in emissions by 2050 (from 1990 levels). The Nordic $4^{\circ} \mathrm{C}$ Scenario (4DS) entails a $42 \%$ reduction and serves as the baseline.

\section{Figure ES.1 Nordic and global $\mathrm{CO}_{2}$ emissions}

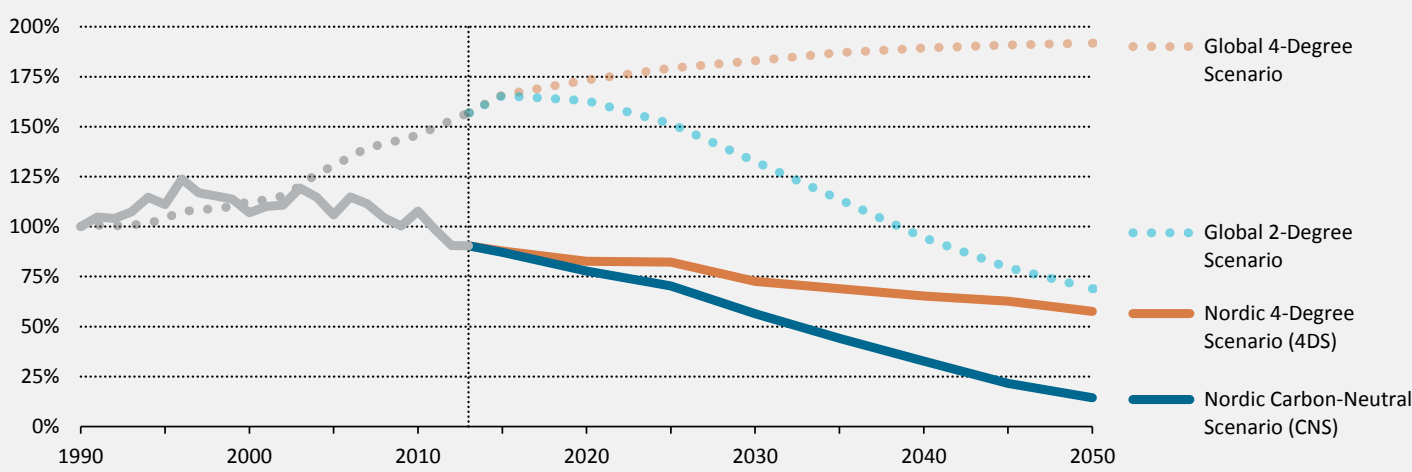

Figures and data in this report can be downloaded at www.iea.org/etp/nordic.

Key point

The CNS can be viewed as a test of the Paris Climate Agreement: Nordic $\mathrm{CO}_{2}$ emissions ${ }^{1}$ drop by $85 \%$ by 2050 (compared with 1990 levels), surpassing the $70 \%$ decline projected in the global $2^{\circ} \mathrm{C}$ Scenario ${ }^{2}$ set out in ETP 2016.

NETP 2016 updates and strengthens the scenarios presented in NETP 2013. In addition, it examines the central challenges that the 2013 edition identified, using a broader portfolio of specialised energy system models. New analysis examines how urban energy systems can stimulate decarbonisation of transport and buildings, and how increasing the flexibility of the Nordic electricity system can support integration of high shares of variable renewable electricity. NETP 2016 calculates the investments required and identifies opportunities for policy action and international cooperation that enable the CNS.

1 Unless otherwise noted, $\mathrm{CO}_{2}$ emissions are energy-related, including process- and feedstock-related emissions from industry as well as emissions from international shipping and aviation refuelling in Nordic countries.

2 The global $4^{\circ} \mathrm{C}$ Scenario represents a future in which strategic action limits global average temperature increase to $4^{\circ} \mathrm{C}$. The Nordic $4^{\circ} \mathrm{C}$ Scenario (4DS) is the Nordic contribution to the global $4^{\circ} \mathrm{C}$ Scenario and functions as the baseline scenario for this study. The global $2^{\circ} \mathrm{C}$ Scenario reflects more aggressive approaches to limit the rise to $2^{\circ} \mathrm{C}$. The Nordic Carbon-Neutral Scenario (CNS) aims for even greater emissions reduction within the Nordic region (as the rest of the world pursues the global $2^{\circ} \mathrm{C}$ Scenario). Broadly in line with statements from Nordic governments, the CNS assumes a 15\% share of emissions reduction is achieved through offsets. 


\section{Achieving a carbon-neutral Nordic energy system}

The Nordic countries have already decarbonised aspects of their energy systems, having decoupled $\mathrm{CO}_{2}$ emissions from GDP growth more than two decades ago.

Mitigation of direct emissions from buildings is most advanced, thanks to the expansion of district heating networks and the phasing-out of oil-fired boilers. Emissions from power and district heat were the next to decline (after peaking in the mid-1990s) through an expansion of renewables. Stable and ambitious carbon taxation and renewable energy incentives have stimulated a growing share of renewable energy, primarily in the forms of bioenergy and wind. The common Nordic electricity grid has facilitated decarbonisation by allowing wind power in Denmark to be partially balanced by hydropower in Norway and Sweden. The carbon intensity of Nordic electricity supply was around 59 grammes of $\mathrm{CO}_{2}$ per kilowatt-hour $\left(\mathrm{gCO}_{2} / \mathrm{kWh}\right)$ in 2013, already at the level the world must reach in 2045 to realise the global $2^{\circ} \mathrm{C}$ Scenario.

\section{Figure ES.2 Nordic $\mathrm{CO}_{2}$ emissions and economic growth in the CNS, by sector}

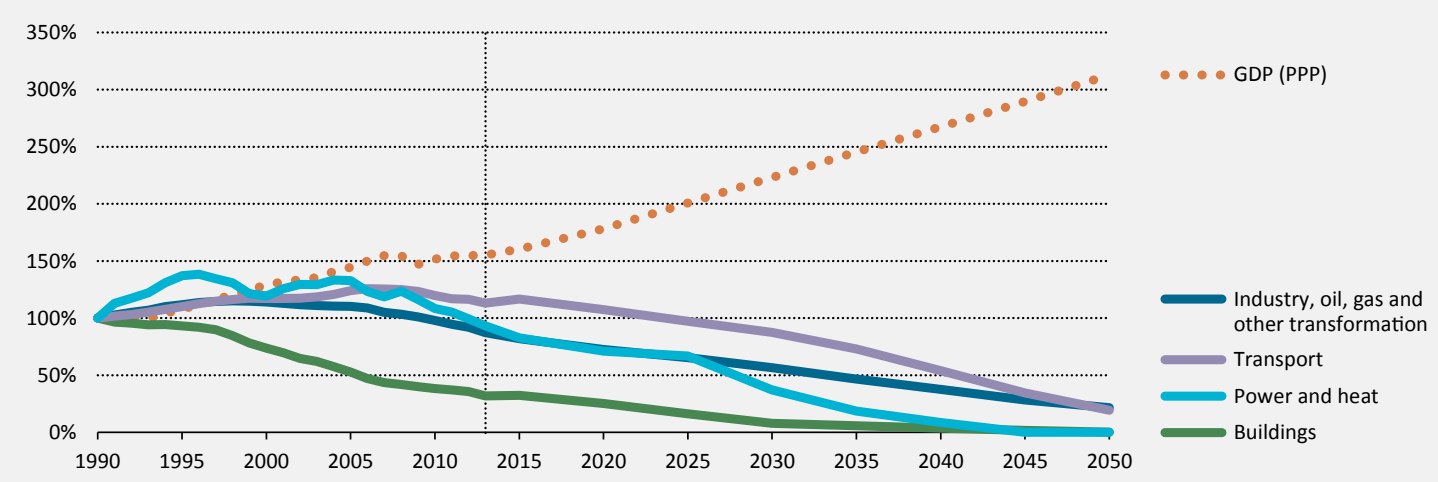

Note: Historical data smoothed using a 5-year rolling average to account for seasonal variations in emissions arising from the interplay between hydropower and coal power.

Figures and data in this report can be downloaded at www.iea.org/etp/nordic

Key point Emissions have already been decoupled from Nordic GDP across all sectors, and this must accelerate in order to achieve the CNS. Decarbonisation occurs more quickly in power and heat generation and in direct emissions from buildings, than in transport and industry.

Policy and technology innovation will be crucial to achieve the continued decoupling of economic growth and emissions in the CNS. Policies and technologies implemented to date to weaken the link between economic growth and emissions have already captured the most cost-effective opportunities, leaving bigger challenges in sectors where progress has been inherently more difficult. Transport, which currently accounts for almost $40 \%$ of Nordic $\mathrm{CO}_{2}$ emissions, delivers the greatest emissions reduction in the CNS. In the face of steadily rising demand for transport services, the success of taxation and subsidy approaches in power and heat generation provide a solid foundation for similarly assertive policies for transport. Industry, together with the oil and gas sector and other energy transformation (such as refineries), is currently the second-largest source of emissions at $28 \%$. Unique to this sector is the need for innovative policies to achieve further decarbonisation without risking that industries will relocate to countries with more lax regulation. This, combined with limited technology options for reducing process emissions, leaves industry with the slowest decarbonisation rate in the CNS. 


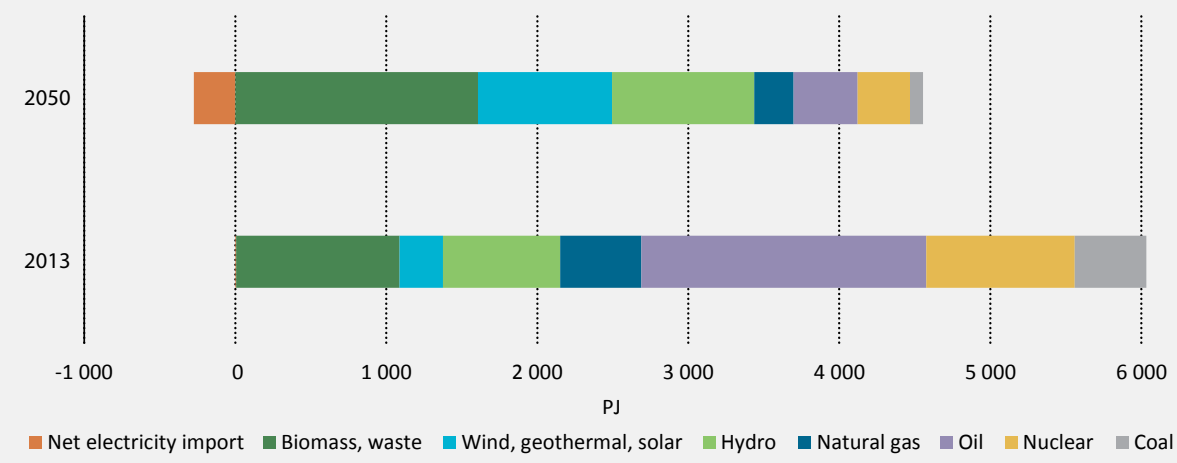

Figures and data in this report can be downloaded at www.iea.org/etp/nordic

Key point Under the CNS, Nordic primary energy supply decreases by $25 \%$ in 2050 compared with 2013 (excluding net electricity export). Energy supply from fossil fuels and nuclear decreases, while supply from bioenergy, wind and hydropower increases, as do net electricity exports.

The CNS requires a dramatic change in the composition of primary energy supply, coupled with aggressive energy efficiency policies that substantially reduce demand. Bioenergy surpasses oil as the largest energy carrier in the CNS, with total demand for biomass and waste increasing from almost 1100 Petajoules (PJ) in 2013 to over 1600 PJ in 2050, corresponding to a share increase from $18 \%$ to $35 \%$. At present, oil is the only energy source common to all five Nordic countries and its declining use in transport is the single most important source of emissions reduction in the CNS, alone accounting for almost $40 \%$ of total reductions. Primary supply for power and heat also undergoes a significant transformation, as outlined in the following section.

\section{Power and heat already close to decarbonised, but thoroughly transformed nonetheless}

Nordic electricity generation, already $87 \%$ carbon-free, is fully decarbonised by 2045 in the CNS. The most dramatic transformation of the Nordic power and heat system does not come from renewables displacing the small remaining share of fossil fuels. Rather, it comes from the combination of a decline of nuclear (reflecting the political phase-out of older capacity and the reality of increased competition from renewables) and a significant buildout of wind power (which leads to generation far exceeding domestic demand, even with the drop in nuclear generation). This facilitates the potential for net export of clean electricity to Europe, which requires increased system integration and flexibility to balance high shares of wind power. With lower implementation of energy efficiency measures, the 4DS requires greater total generation, more renewables build-out, and higher net export of electricity compared with the CNS. 


\section{Figure ES.4 Nordic electricity generation and heat production, 2013-50}
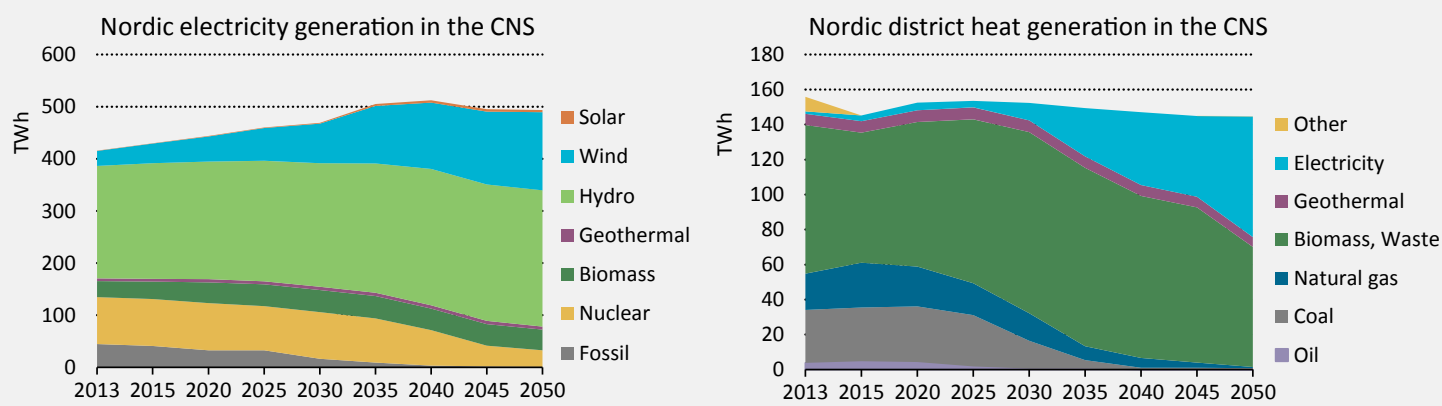

Figures and data in this report can be downloaded at www.iea.org/etp/nordic

Key point

Wind displaces fossil and nuclear as Nordic electricity generation is expanded to service European demand. Heating networks transition from fossil fuels to heat pumps and electric boilers, adding flexibility to an integrated power and heat system.

Wind generation increases five-fold, from $7 \%$ of Nordic electricity generation in 2013 to $30 \%$ in 2050 in the CNS, driven in part by the potential for greater electricity trade with Europe. This will put new demands on how the electricity system is operated and how the common Nordic electricity market is organised. The CNS shows that this transition is possible, and that the envisioned system can handle up to $70 \%$ variable renewable electricity in Denmark (as a share of demand). Two thirds of Nordic wind generation is onshore in 2050, underlining the importance of public acceptance. Nordic hydropower generation increases in the CNS though improvements to existing capacity and new smallscale capacity. Nordic hydropower will be increasingly valuable for regulating the North European power system.

Hydropower alone is not enough. The high penetration of variable wind power will require balancing though a combination of flexible supply, demand response, storage and electricity trade. With a large share of hydropower, high transmission capacity and a well-functioning electricity market, the Nord Pool area is already well suited for integration of wind resources. Denmark has demonstrated how operation measures significantly improved the flexibility of its co-generation fleet. More targeted use of dispatchable hydropower for balancing and action to enhance the flexible operation of thermal generation (mainly in cogeneration) play key roles in the CNS. Electrification of the heating and transport sectors (e.g. through heat pumps and electric boilers for district heating, and through EVs), together with flexible demand from industry, are central demand response measures in the CNS. Better system integration between electricity and district heating systems, and potentially between electricity and gas through power-to-fuel technologies, allows storage of excess electricity as heat or carbon-neutral gaseous or liquid fuels.

Greater electricity trade will reduce system costs and enhance flexibility, but long lead times for setting up interconnectors and strengthening the grid may delay achieving the full potential. With rising shares of variable renewables in both Nordic and other European countries in the CNS, it will be economically attractive to increase transmission capacities among countries. Anticipated electricity demand from continental Europe could greatly expand the market for low-cost, low-carbon electricity generated in the Nordic 
countries. This allows the Nordic region as a whole to become a major net exporter (at 53 TWh/year net in the CNS) as average generation costs in continental Europe are expected to stay higher than in the Nordic region. Seizing this trade opportunity depends on three things: build-out of wind capacity and necessary flexibility to handle variability, reducing Nordic demand through energy efficiency, and setting up the necessary interconnectors and domestic grid strengthening to enable trade.

\section{Figure ES.5 Nordic electricity trade in 2015 (left) and 2050 in the CNS (right)}
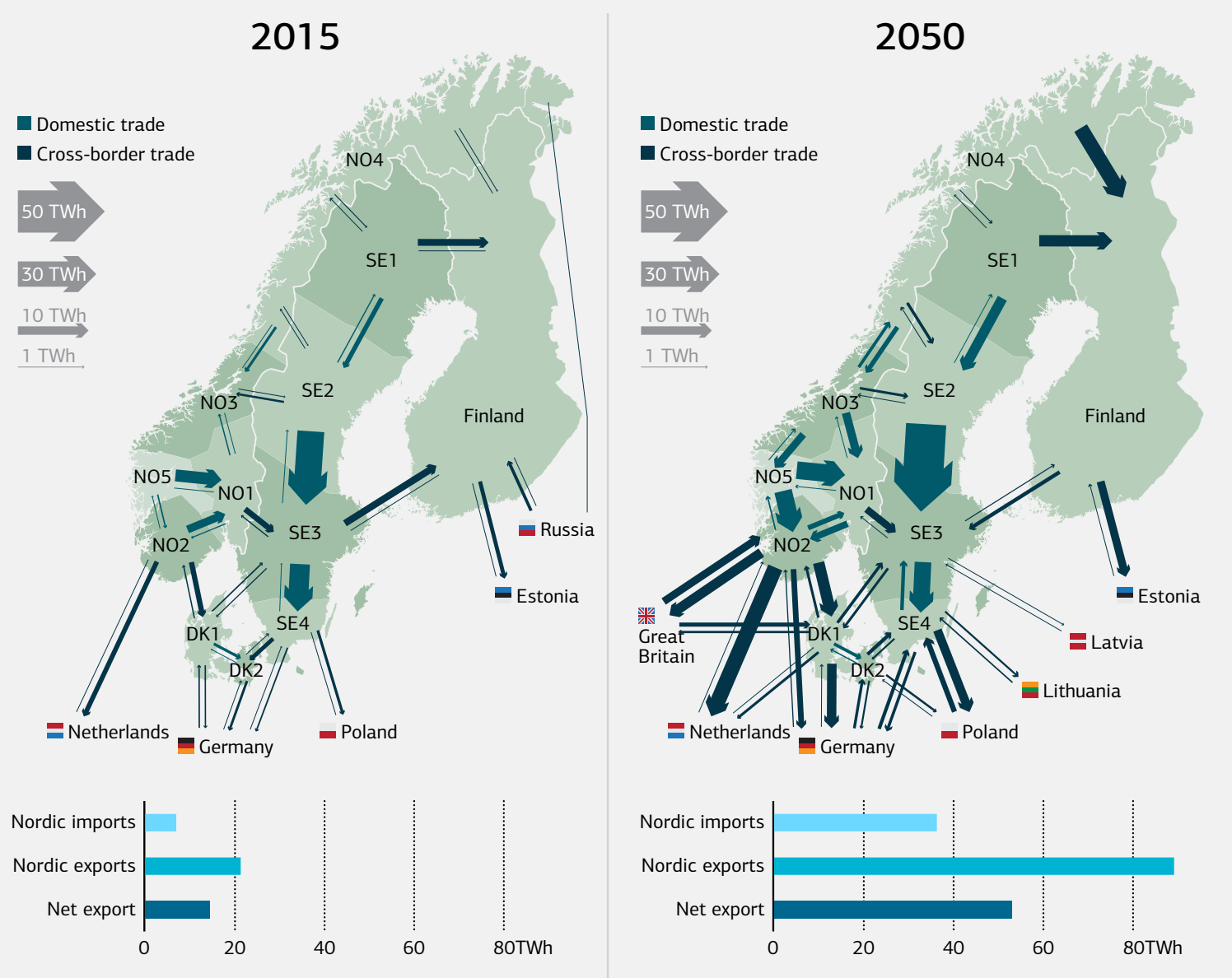

Notes: Trade with Russia is assumed to fall to zero in 2050. Iceland is not included in the figure as it is not yet connected with any other electricity system and the potential for Icelandic interconnectors was not modelled. This map is without prejudice to the status of or sovereignty over any territory, to the delimitation of international frontiers and boundaries, and to the name of any territory, city or area.

Figures and data in this report can be downloaded at www.iea.org/etp/nordic.

Key point

Anticipation that electricity prices in Europe will be higher than in the Nordic region in the CNS creates an attractive trade opportunity; expansion of variable renewables and interconnector capacity could lead to net Nordic exports of over 50 TWh in 2050

Nuclear power decreases from $22 \%$ of Nordic electricity generation in 2013 to $6 \%$ in 2050 in the CNS, as other low-carbon technologies become more competitive.

A variant scenario in which nuclear is phased out more quickly - by 2030 in Sweden and 
with no new reactors constructed in Finland after the completion of Olkiluoto 3 - sees $\mathrm{CO}_{2}$ emissions from the Nordic area increase by $7 \mathrm{Mt}$ in 2030 as it prompts an increase in gas capacity to partially make up the shortfall in generation. It also pushes up $\mathrm{CO}_{2}$ emissions in the rest of Europe by $2 \mathrm{Mt}$, mainly by reducing the export potential from Nordic countries. A higher dependence on international trade of electricity is also a potential concern for consumers, especially industry. These factors highlight the benefits of using existing nuclear capacity through the economic lifetime of each plant.

The Nordic region seems less likely to see the solar boom other countries are experiencing. Growth is constrained by a limited solar resource, dense urban areas with less rooftop area and favourable conditions for competing wind power. The economic potential of solar electricity in the CNS is 4 gigawatts (GW) peak capacity and 4 TWh of annual generation, or less than $1 \%$ of total generation in 2050. The total technical potential of rooftop PV alone is significantly higher - estimated to be 32 TWh. If met, it would account for around 6\% of electricity generation in the CNS in 2050, comparable to the annual demand from all EVs on Nordic roads in 2050. In a case study of the Helsinki metropolitan area, nearly all of the estimated suitable rooftop potential becomes utilised by 2050 under the CNS, accounting for over $20 \%$ of total electricity supply. The possibility exists that RDD\&D on electricity storage and new solar concepts (e.g. power-to-gas and to liquids) will increase the competitiveness of solar power. In sum, while installed solar capacity in Nordic countries is relatively low in the CNS, policy and technology uncertainties make it too early to rule out a pathway in which solar would play a more prominent role.

The role of district heating will increase under strict climate policy targets, but the role of co-generation may become less important. Under the CNS the amount of cogeneration decreases by $40 \%$ in Nordic urban areas. Electricity grows to account for almost half of the heat in district heating networks in 2050, through utility-scale heat pumps and electric boilers, both of which provide important flexibility for variable renewables integration.

\section{Radical transformation of transport will be most visible change to consumers}

Transport accounts for the largest share of emissions reduction. Transport requires a dramatic emissions slash in the CNS, from about 80 million tonnes of carbon dioxide $\left(\mathrm{MtCO}_{2}\right)$ in 2013 to just over $10 \mathrm{MtCO}_{2}$ in 2050. The target can be achieved through a three-pronged strategy of reducing transport activity (avoid), shifting to more efficient or less carbon-intensive transport modes (shift), and adoption of more efficient or less carbon-intensive transport technologies and fuels (improve). Improvements to technologies and fuels play the largest role in transport in the CNS, largely because Nordic countries have already introduced many policies based on avoid and shift strategies (such as road tolls, parking fees, access/parking restrictions and promoting public transport and cycling over cars). However, the potential of additional avoid/shift levers should not be discounted out of hand; it is still difficult to predict the impacts of disruptive technologies such as autonomous vehicles or shifts in cultural/ behavioural paradigms influencing the potential of shared mobility services. Over time, improved city planning can also facilitate both reduced travel demand and shifts to more efficient modes. 


\section{Figure ES.6 Decoupling of transport emissions from activity in the CNS}
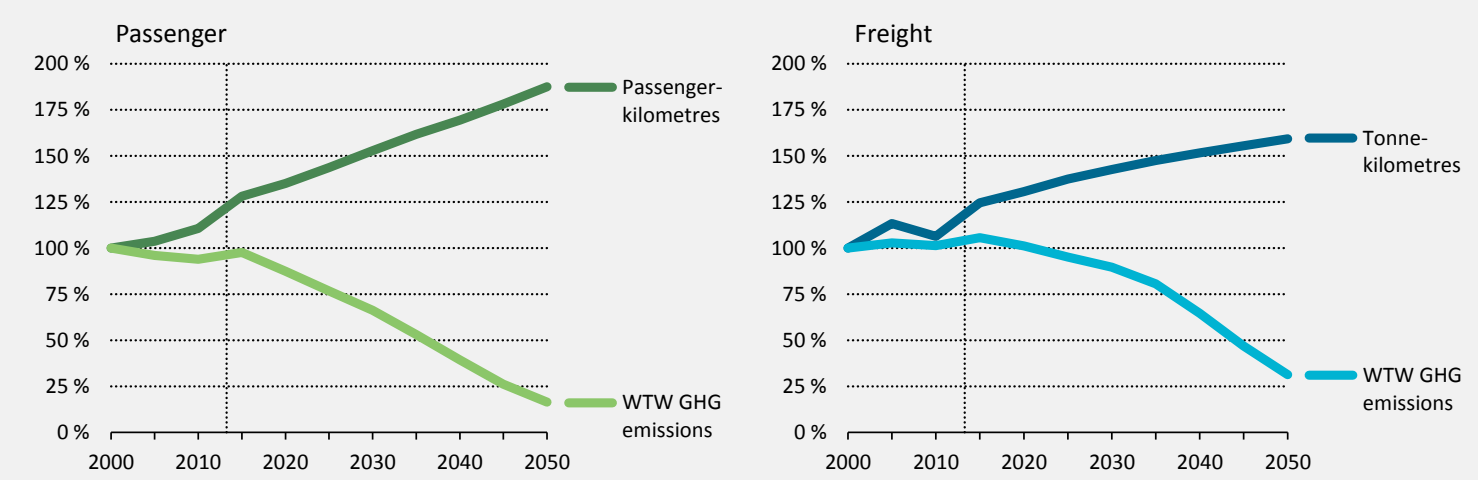

Notes: WTW GHG = well-to-wheel greenhouse gas emissions, the calculation of all emissions from the production of the fuel source to those associated with end-use in transport. Passenger-kilometres is the measure of kilometres travelled by individuals in a given year; tonne-kilometres refers to the distance associated with tonnes of freight transport.

Figures and data in this report can be downloaded at www.iea.org/etp/nordic.

Key point Despite steady growth in demand for transport services, emissions drop dramatically through efficiency, technology and fuel switching, and modal shifts.

Adoption of new technologies can spur a radical reduction in transport energy use despite rising demand for transport services. Transport's total energy use in the CNS decreases by over $20 \%$ compared with 2000 , despite a $70 \%$ increase in overall passenger and freight activity. By 2050, fossil fuels account for only $25 \%$ of transport final energy demand. Energy-savings potential is greatest in passenger cars, and is greater in urban areas (35\% reduction between 2013 and 2050) than in rural areas (22\%). Higher population densities and shorter traveling distances in urban areas facilitate greater use of energy efficient technologies such as public transport and cycling.

With EVs having a share of 60\% for the passenger vehicle stock in 2050 (compared with an average of $45 \%$ in the OECD), the CNS puts the Nordic region in a leadership role for lowcarbon transport. EVs are particularly attractive in urban areas, which have shorter driving distances, more acute air quality and noise issues, and economies of scale for charging infrastructure. EVs also make up about 70\% of light commercial vehicles (LCVs) in urban areas by 2050. Individual cities (and even countries) can be expected to lead the uptake of EVs, resulting in important learning effects that can facilitate a broader uptake across the entire Nordic region. Battery electric vehicles (BEVs) and hybrids account for the majority of EVs, with more limited prospects for hydrogen fuel-cell electric vehicles (FCEVs). This is due to greater infrastructure costs, as well as the flexible production of hydrogen facing strong competition from other technologies providing flexibility to the electricity system. Electricity accounts for $10 \%$ of final energy use in transport in 2050 , but thanks to the high powertrain efficiency of electric motors, electricity's share of transport activity is much higher: $64 \%$ of road and rail passenger kilometres and $42 \%$ of road and rail freight activity. In the CNS, transport uses 32 TWh of electricity in 2050, or 6\% of total generation. EVs alone account for $5 \%$ of total generation. 


\section{Figure ES.7}

\section{Transformation of Nordic vehicle stocks and biofuel demand in} the CNS

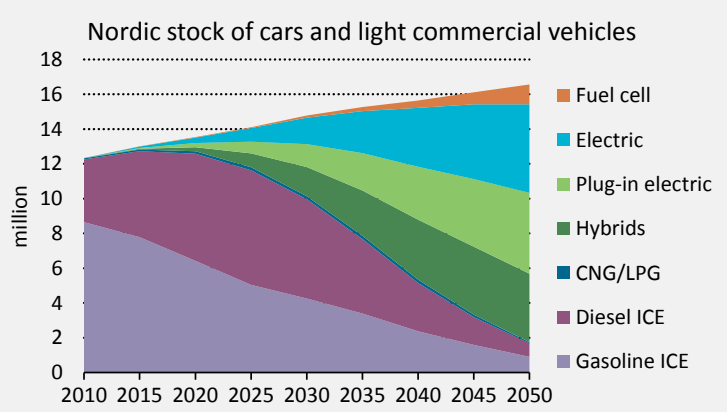

Figures and data in this report can be downloaded at www.iea.org/etp/nordic

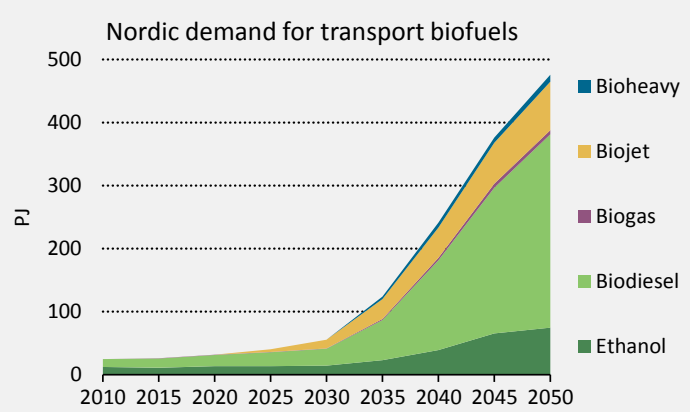

201020152020202520302035204020452050

Key point

The CNS requires an almost complete phase-out of fossil-fuelled cars and a rapid roll-out of EVs, especially in urban areas. Biofuel imports are needed to decarbonise long-distance transport modes.

Long-distance transport is less suited to electrification than urban transport and will require biofuels or significant advances in competing low-carbon technologies. The CNS sees biofuels underpinning long-distance, heavy-duty road and marine freight, as well as aviation. Electrification is rolled out where feasible, for example in medium-sized trucks serving urban environments, with plug-in hybrids accounting for 10\% of the truck stock in 2050. Development of electric highways (e-highways) and hybrid heavy-duty trucks however is not a major element of the CNS, even though e-highways on major axes of the road transport network could support the bulk of road freight transport activity while curbing costs. Incremental costs for e-highway vehicles could also be contained, thanks to the limited requirement of battery capacity. Pilot projects to build knowledge of the technical feasibility and the cost profile of this solution, already underway in Sweden, should be pursued more broadly. Highspeed rail (HSR) is developed on the major axes among larger Nordic cities in the CNS. Although constrained by the Nordic geography and population density that raises costs, HSR covers around 15\% of the transport demand that would otherwise be met by aviation in 2050.

Biofuels comprise nearly two-thirds of total final energy use in transport in 2050. Supplying this demand will depend on a well-functioning international market, sustainable production and distribution, and politically acceptable trade partners. The CNS shows $50 \%$ of the anticipated increase in biofuel use in transport is supplied by a fourfold increase in net biofuel imports. By 2050, net imports meet approximately $16 \%$ of total biomass demand from all sectors in the Nordic region, even as global demand for bioenergy increases. Aiming for greater domestic production would imply diverting biomass away from higher value uses in industry or producing biofuel from less economic domestic feedstocks. Increased RDD\&D efforts on supply of low-cost biomass feedstocks and on integrated process concepts to produce advanced biofuels could make these more cost competitive. Nordic and broader international co-operation is particularly important in this area. Hydrogen deployment for transport vehicles, which may compete with biofuels, is coupled with higher investment risks and higher investment costs for both vehicle manufacturing and the deployment of a fuel distribution infrastructure. Creating a vehicle market with sufficient volume to make it profitable for carmakers to diversify the range of models powered with hydrogen will be a challenge, and will require major policy co-ordination to support the deployment of hydrogen refuelling infrastructure within and beyond the Nordic region. 


\section{More rapid renovation of existing Nordic building stock needed to lower energy demand}

The CNS requires a tripling of the current rate of improvement in space heating energy intensity of Nordic buildings. This must occur primarily though deep energy renovation of existing buildings, which will constitute $70 \%$ of the Nordic stock in 2050. The buildings sector accounts for one-third of final energy demand in the Nordic countries, with space heating being the largest end-use (nearly $60 \%$ of total building final energy consumption). Despite dropping by $0.8 \%$ per year since 2000, the average energy intensity of space heating across the Nordic building stock remains at 126 kilowatt hours $(\mathrm{kWh})$ per square metre $\left(\mathrm{m}^{2}\right)-12 \%$ higher than the European Union (EU) average. The CNS requires energy intensity to fall by $2.2 \%$ annually. This would bring the average energy intensity of space heating in the Nordic building stock to around $60 \mathrm{kWh} / \mathrm{m}^{2}$ in 2050 . At present, long payback periods under low energy prices and split incentives in rental situations hamper efforts to accelerate energy efficiency investments.

\section{Figure ES.8 Energy efficiency improvements in Nordic buildings}
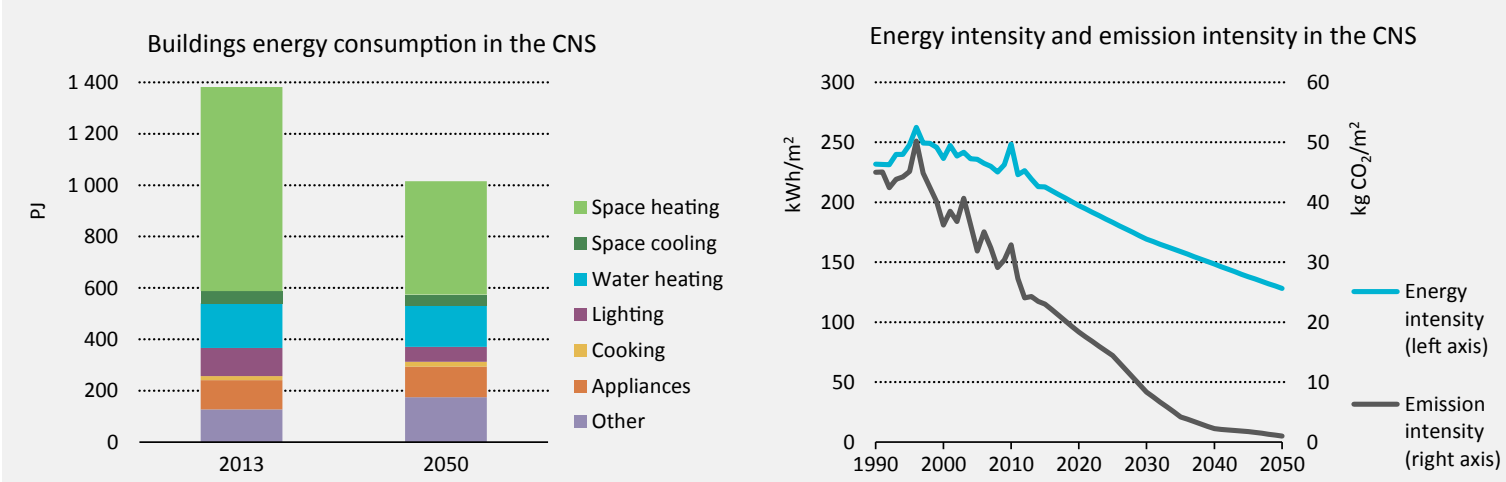

Notes: Emission intensity $\left(\mathrm{kg} \mathrm{CO}_{2} / \mathrm{m}^{2}\right)$ is the direct and indirect emissions from energy use per square meter of floor area. $\mathrm{PJ}=$ petajoule. Figures and data in this report can be downloaded at www.iea.org/etp/nordic

Key point Energy efficiency efforts cause energy demand from buildings to drop to 1990 levels in 2050, despite significant increases in floor area. Space heating and lighting have the most potential for energy efficiency improvements.

Efficiency gains in Nordic buildings can unlock biomass and electricity for use in other sectors, avoiding infrastructure investments in power and heat, and $\mathrm{CO}_{2}$ emissions in transport and other sectors. The emission intensity of buildings energy use in the Nordic countries is currently much lower than the EU average. The intensity falls to zero around 2045 as the CNS eliminates both direct emissions and upstream emissions from power and heat supply. This means that the emissions reduction gain associated with energy efficiency measures may be limited in relation to the cost. However, it is important to note that reducing buildings energy demand can facilitate Nordic electricity export, avoid grid infrastructure investments, unlock biomass to substitute fossil fuels in transport and enable deployment of new technologies such as low temperature DHC. More broadly, reduced demand also brings important energy security benefits. In the longer term, renovation efforts will be supplemented by more advanced building technologies, enhanced urban planning and roll-out of intelligent energy management systems that empower consumers and encourage behaviour change. 


\begin{abstract}
Urban buildings contribute relatively less to energy savings in the CNS than rural buildings. This reflects lower potential in urban areas for zero-energy buildings (ZEBs) and near-zero energy buildings (nZEBs), and the need to balance investments in energy efficiency and district heat supply. High urban densities, limited on-site renewable potential and cultural heritage conventions constrain the potential for broad nZEB implementation in urban areas. Despite this, energy demand in Nordic urban buildings drops to 1990 levels by 2050 in the CNS, even as floor area increases by over 25\%. Broader deployment of district heating, heat pumps and solar heating helps to transition the energy supply away from fossil fuels and direct electric heating. In cities with district heating, it may be more costeffective to pursue only moderate building energy efficiency improvements together with investments in low-carbon district heat supply with lower temperatures and peak demand. Policies to incentivise energy efficiency improvements must therefore be coordinated with concurrent developments in local district heating systems to ensure optimal investment decisions are taken.
\end{abstract}

\title{
Cities can lead the way in system integration of transport and buildings
}

- Nordic urbanisation in the coming decades is expected to occur at double the rate of recent decades, offering a unique opportunity to transition to low-carbon urban energy systems. Significant investment will be needed in new buildings, retrofits of existing buildings and new transport infrastructure to service the growing urban population. These investments should be optimised to not only lower emissions, but also to improve energy services. The greater density of urban areas leads to faster roll-out of EVs and charging infrastructure, public transport, cycling, district heating and cooling, and utilisation of excess heat. This tempers the additional costs to achieve the CNS in urban areas compared with rural areas.

- All Nordic capitals have ambitious GHG mitigation targets and most aim to achieve carbon neutrality. Copenhagen and Oslo have set earlier zero-carbon targets than are stated in national plans. Nordic capitals are up to 30\% more energy efficient than average Nordic urban areas in buildings, and up to $40 \%$ in transport, due largely to higher population densities and better infrastructure. Energy efficiency improvements contribute to per-capita energy demand of all urban transport and buil- dings decreasing by 20\% in the next 15 years (to 2030) and by another 20\% in the following 20 years (to 2050) in the CNS.

- Nordic urban areas are particularly advanced in the system integration of energy, with high penetration of district heating and cooling networks as well as electric heating and cooking. Small but growing electric transport systems are also becoming integrated. In urban areas, up to $76 \%$ of the energy consumed in buildings and transport could be delivered through smart electricity and district heating and cooling grids by 2050 , compared to $61 \%$ today. In 2013 , district heating provided $35 \%$ of heating for urban buildings in the Nordic region, substantially higher than rates in the European Union (9\%) and in OECD countries (3\%). In the Nordic capitals of Stockholm, Helsinki, Copenhagen and Reykjavik, high shares of district heating already between $80 \%$ and $100 \%$ - are expected to be maintained in the long term. The penetration of electricity and district heating networks in the Nordic region gives urban areas the potential to provide significant flexibility to balance variable renewable energy. 


\section{Industry the most difficult sector to decarbonise, requires innovation in technology and policy}

The necessary 60\% reduction in direct industrial $\mathrm{CO}_{2}$ intensity in the CNS (from 2013 levels) requires aggressive energy efficiency, fuel and feedstock switching to lowercarbon energy mixes, deployment of low-carbon innovative processes (including CCS) and international co-operation. All Nordic economies, except Denmark, are highly dependent on energy-intensive industries and use more energy per unit of GDP than the OECD average. Energy efficiency measures reduce Nordic total final industrial energy consumption by 9\% in the CNS in 2050 (compared with 2013 levels for similar industrial activity). However, industry has the slowest rate of decarbonisation due to process-related emissions and competitiveness issues for globally traded commodities; industry accounts for almost half of remaining emissions in 2050 in the CNS. As long as policies stimulate decarbonisation without compromising competitiveness, Nordic countries are in a favourable position to ensure the long-term sustainability of energy-intensive industries in the global economy. This implies balancing stringent carbon policies with measures to improve the competitiveness of industry, such as public RDD\&D support or reduction of other taxes.

The lingering challenge of process-related emissions in industry necessitates broad deployment of innovative low-carbon processes including CCS in the CNS. Processrelated emissions from iron and steel, cement, aluminium and chemicals industries contribute $19 \%$ of the Nordic region's industrial $\mathrm{CO}_{2}$, compared with an average of $13 \%$ in the OECD. Typically, such emissions can only be reduced through integration of CCS or developing breakthrough process technologies that move away from carbon-based raw materials. Even with very aggressive action to increase energy efficiency, to switch to low-carbon fuel and feedstock, and to increase recycling, the CNS shows the need for wide application of CCS in cement, iron and steel, and chemical industries, which cumulatively account for almost 30\% of total direct industrial $\mathrm{CO}_{2}$ emissions reduction over the period 2020-50. Progress to date on developing and deploying CCS has been slow and unco-ordinated; joint efforts between countries with significant industrial emissions (Sweden and Finland), and countries with storage potential and competencies within oil and gas (Norway and Denmark) must be scaled up in order to achieve the CNS. 


\section{Figure ES.9}

Nordic cumulative direct industrial $\mathrm{CO}_{2}$ emitted, and captured and stored in the CNS by sector, 2020-50

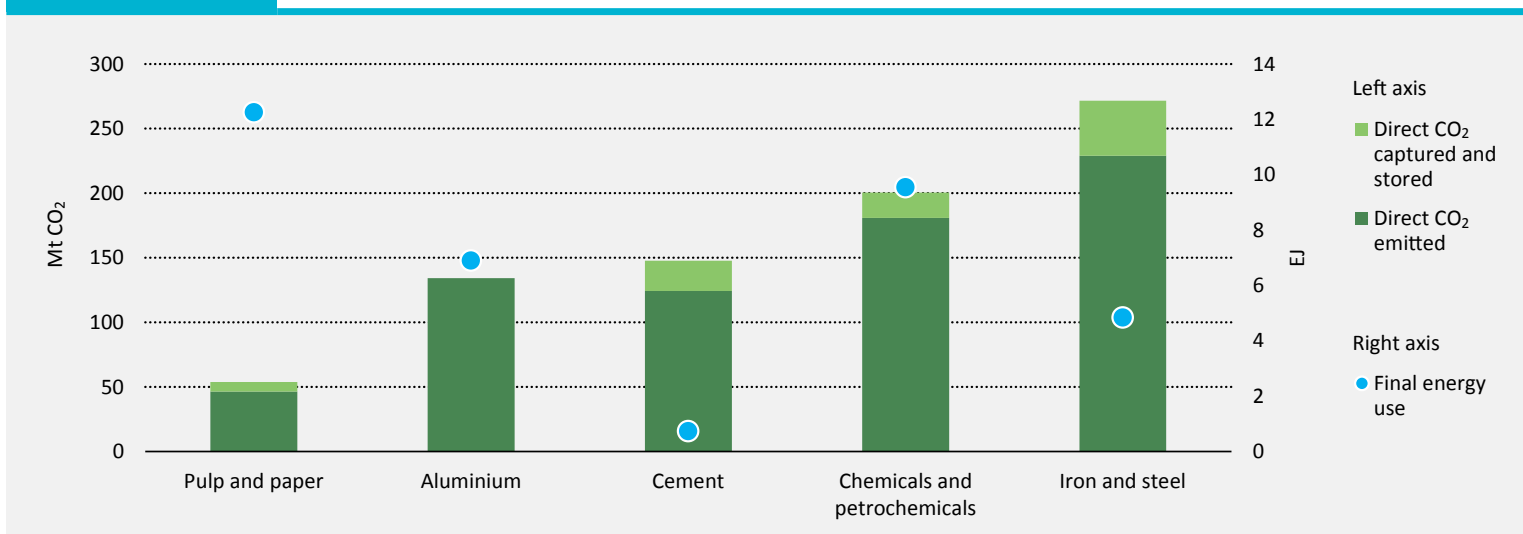

Notes: Final energy use is given in cumulative terms for the 2020-50 period in the CNS. Energy use in blast furnaces and coke ovens is included in the iron and steel sector; energy use as feedstock is included in the chemicals and petrochemicals sector.

Figures and data in this report can be downloaded at www.iea.org/etp/nordic.

Key point

CCS plays an increasingly important role in industrial sectors with high shares of process-related $\mathrm{CO}_{2}$, as no current alternative prospects exist for cost-competitive $\mathrm{CO}_{2}$ mitigation.

International co-operation, for example through international carbon pricing or energy performance auditing mechanisms, plays a crucial role in mitigating the risks of low-carbon investments that are needed to decarbonise industry, and thereby reduce potential impacts on competitiveness. It also reduces the risk of "carbon leakage", if industry investments are shifted to countries with more lax regulation. Given the size and risk involved in investments, a cross-sectoral collaborative Nordic approach should be considered — for instance, to finance demonstration and market establishment of innovative low-carbon processes and to identify systemic sustainability gains along product value chains. Specific legal frameworks and crosscountry collaboration are needed to implement technologies that are key for the CNS. Such is the case for deploying CCS, which requires adoption of internationally co-ordinated regulations that encourage the safe and effective design and operation of $\mathrm{CO}_{2}$ storage facilities. There are promising opportunities for CCS applied to bioenergy (BECCS) in Nordic industry, which could provide negative emissions.

\section{Additional investments to achieve the CNS are concentrated in buildings, industry and transport}

Achieving the CNS would entail a $10 \%$ increase in investments over that needed for the 4DS over the period 2016 to 2050. This represents additional investments beyond those of the 4DS of about USD 333 billion, ${ }^{3}$ totalling less than 1\% of the cumulative GDP over the period. Beyond climate change benefits, costs will be directly offset to a certain degree by fuel savings (which could be significant depending on the development of future oil prices). Additional benefits, such as reduced health costs due to air quality improvements and increased energy security, are likely to tip the economic equation firmly in favour of the CNS. Recent studies have estimated the external costs related to health impacts from air pollution in the 
Nordic countries (of which energy is the primary source) to be around USD 9 billion to USD 14 billion annually. These alone are roughly equal to the additional investments in the CNS.

The greatest relative investment increases are required in buildings and industry, while power is less costly in the CNS than in the 4DS. Investments in buildings need the largest acceleration to achieve the CNS, seeing a doubling of 4DS levels. Of the approximately USD 170 billion in additional cumulative buildings investments, roughly USD 155 billion goes to building envelopes to drastically reduce space heating demand. The remainder goes to more efficient space and water heating equipment, appliances and lighting. An increase of $47 \%$ is required in the five industry sectors analysed, which together account for $80 \%$ of the total final energy use by industry in the Nordic region. This represents about USD 30 billion cumulatively, mainly associated with energy efficiency improvements and the deployment of low-carbon innovative processes including CCS. Transport accounts for the largest share of additional cumulative investments at USD 200 billion, but this is less than a 10\% increase on 4DS levels. Infrastructure investments related to non-urban rail account for a significant share of additional transport investments. The CNS has around 15\% lower investments in power generation compared with the 4DS. This is mostly a result of reduced final electricity demand $(-15 \%$ in 2050), which also reduces the need for transmission and distribution investments.

\section{Figure ES.10}

\section{Relative increase in cumulative investments over 4DS levels required to achieve the CNS, 2016-50}

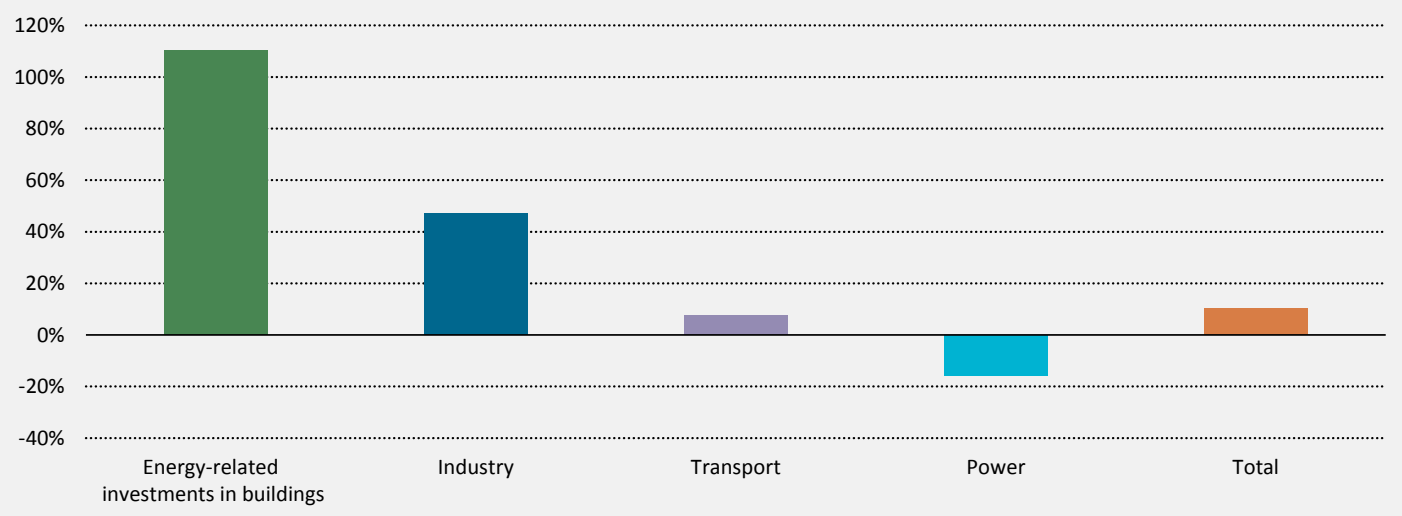

Notes: Numbers show the difference in cumulative investments between the 4DS and CNS, as a share of the 4DS ( cumulative investments in the CNS - cumulative investments in the 4DS $\times 100$ ).

This metric highlights which sectors require the greatest relative increases in investments and how significant they are, compared to investments that would be needed even under a less ambitious scenario such as the 4DS. In the power,- industry, and transport sectors all investments in new industrial capacity (for the energy-intensive subsectors), vehicles, power plants and supporting infrastructure like roads and electricity grids are included. For buildings, only improvements of the thermal envelope (i.e. not the entire building construction) and equipment for end-use services such as lighting, cooking, heating and cooling, are covered. Only additional investment needs between scenarios are comparable across sectors, but not absolute investment requirements. Figures and data in this report can be downloaded at www.iea.org/etp/nordic.

Key point Relative to the investment needed for the 4DS, achieving the CNS requires an increase of $10 \%$. Buildings require the greatest relative increase, followed by industry; power costs less in the CNS due to reduced demand. 


\section{Short-term policy recommendations}

Governments, individually and in a co-ordinated manner across the Nordic region, will need to play a lead role in stimulating actions to achieve the ambitious pathway outlined by the CNS. Specifically, they need to act in four key areas:

\section{Strengthen incentives for investment and innovation in technologies and services that increase the flexibility of the Nordic energy system. Policies should accelerate the} roll-out of key flexibility technologies (such as heat pumps for district heating and EVs) and critically, incentivise their utilisation for flexibility through market mechanisms and regulation. Markets must also adequately compensate flexibility services such as demand response in industry and buildings, as well as the flexible operation of thermal power plants. Less visible information technology (IT) infrastructure (such as smart meters) and IT platforms (such as applications to empower consumers or control systems to shave peak loads in district heating) will be important in achieving a rapid penetration of these flexibility services.

2 Boost Nordic and European co-operation on grid infrastructure and electricity markets.

2. Coordinated effort to strengthen domestic grids and install new transmission lines is needed to establish the future Nordic and European electricity system envisioned in the CNS. Regional collaboration on infrastructure planning is needed to ensure optimal investments and avoid bottlenecks in the grid. Co-ordination among Nordic governments is vital to ensure that policy accelerates technological and regulatory progress in order to reduce total costs. Co-operation in reforming the common Nordic electricity market to allow greater flexibility and accommodate higher shares of variable renewables will also be important.

Take steps to ensure long-term competitiveness of Nordic industry while reducing process-related emissions. More variable and potentially higher electricity prices will put additional pressure on energy-intensive industry in the Nordic region, stressing the need to step up low-carbon industrial innovation. Governments should act to reduce the risk of such investment and use public funding to unlock private finance in areas with significant emission reduction potential but a low likelihood for independent private-sector investment. Policy should, wherever possible, seek to incentivise reduced emissions, for instance by removing exemptions from carbon taxation. Co-operative Nordic action to decrease uncertainty regarding $\mathrm{CO}_{2}$ transport and storage infrastructure development could also mitigate risks for industry investing in CCS.

Act quickly to accelerate transport decarbonisation using proven policy tools. Even as Nordic countries pursue different technology strategies in parallel, they should not wait to draw on the wide range of available policy instruments to stimulate fuel efficiency, low carbon technologies and shifts to more efficient transport modes. Governments should build upon positive experiences with measures such as congestion charging in urban settings, differentiated vehicle registration taxes, bonus-malus regimes, and altered parking fees, while also stepping up investments in infrastructure for cycling, public transport and rail. Policies should also incentivise modal shifts from road freight to sea and rail, and from cars to public transport and cycling. Furthermore, policy makers may be able to exploit the current context of low oil prices to increase fuel taxes above current levels. Air quality, noise and congestion benefits should be considered in parallel with energy and climate objectives. Nordic collaboration can play a role, for instance through co-ordinated expansion of EV-charging infrastructure and cross-border rail networks, as well as through RDD\&D cooperation on low-carbon fuels or on large-scale demonstration of potentially disruptive solutions such as shared mobility services. 

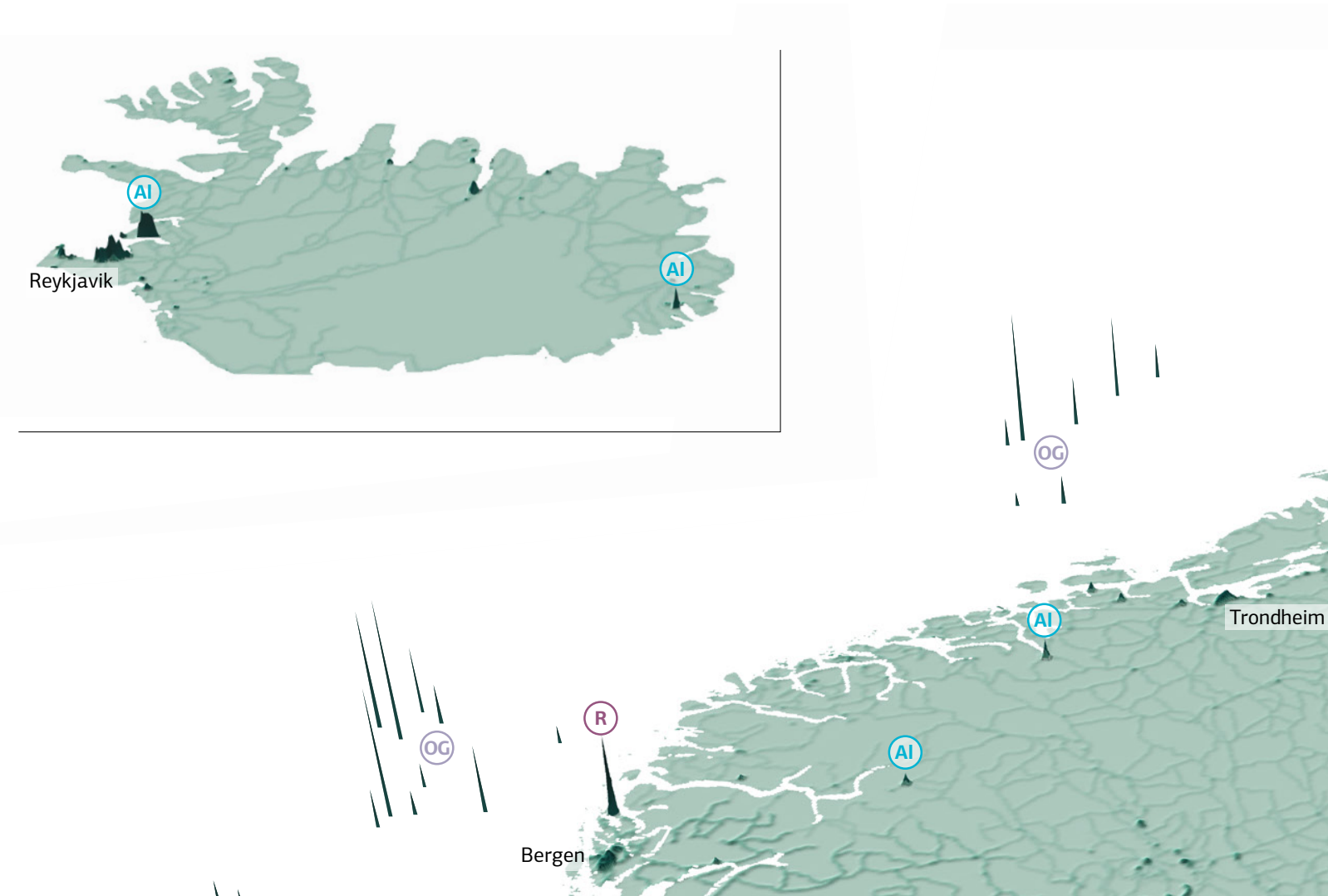

(2)

119
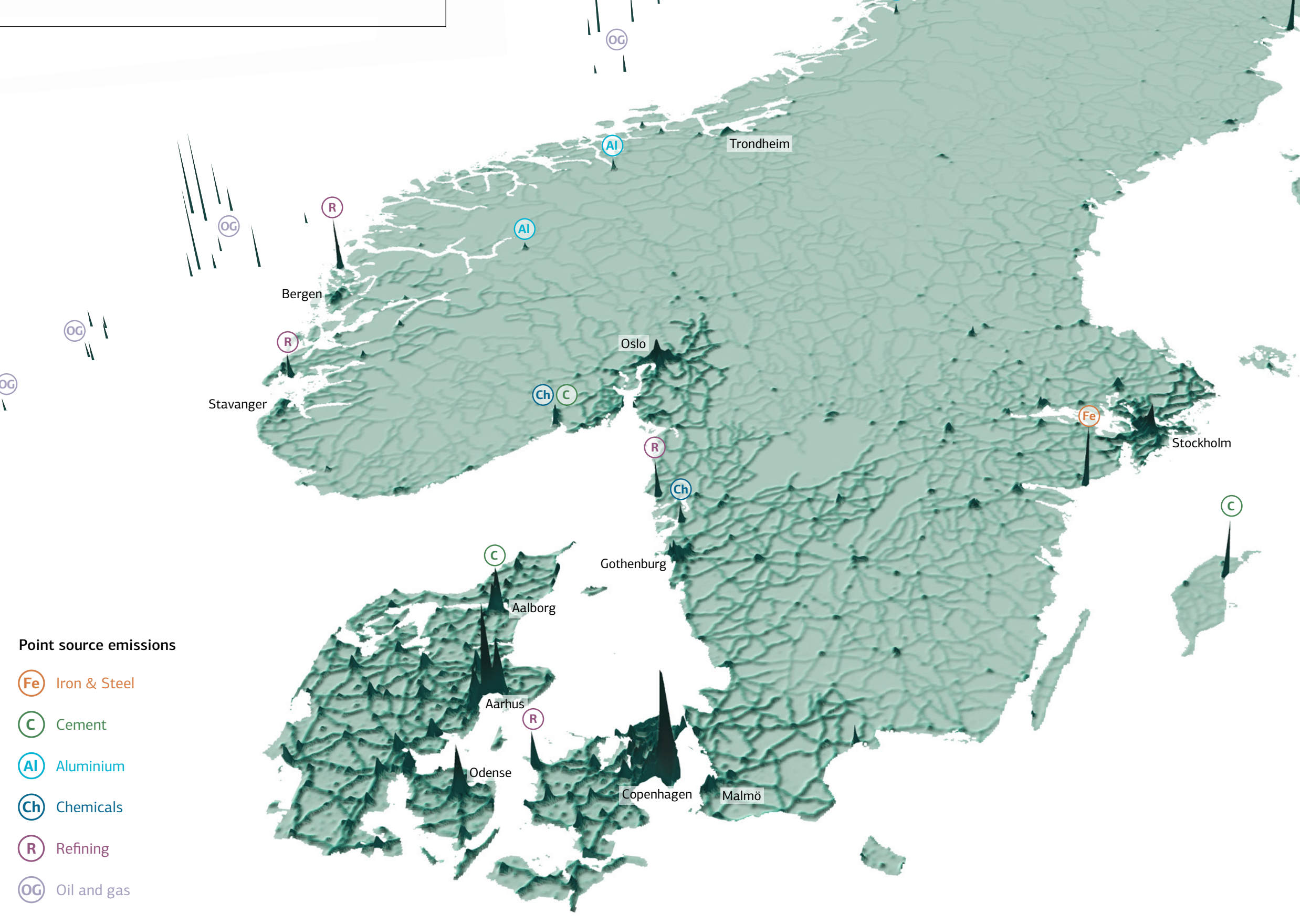

Nordic energy-related

carbon dioxide emissions 2013

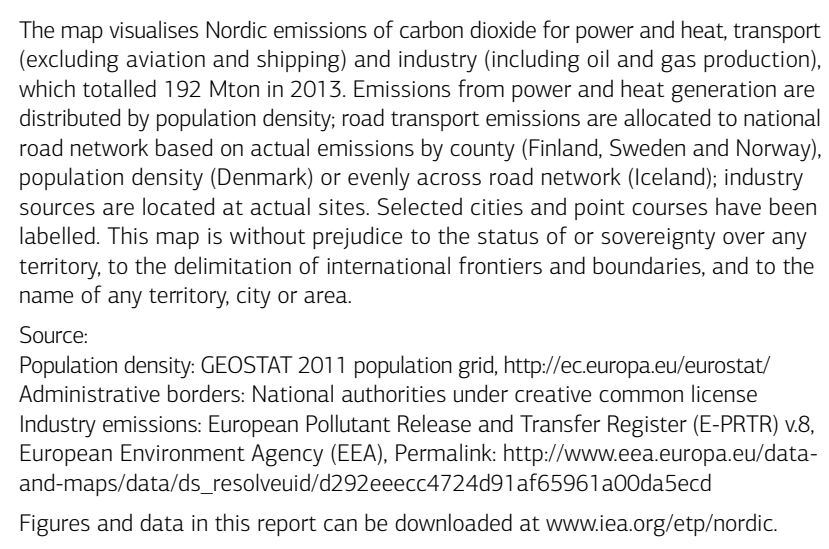

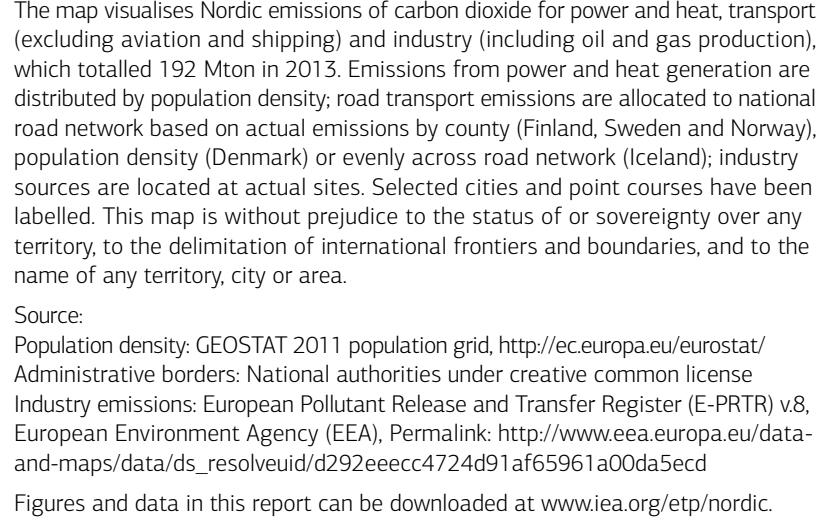




\section{4 \\ Chapter 1}
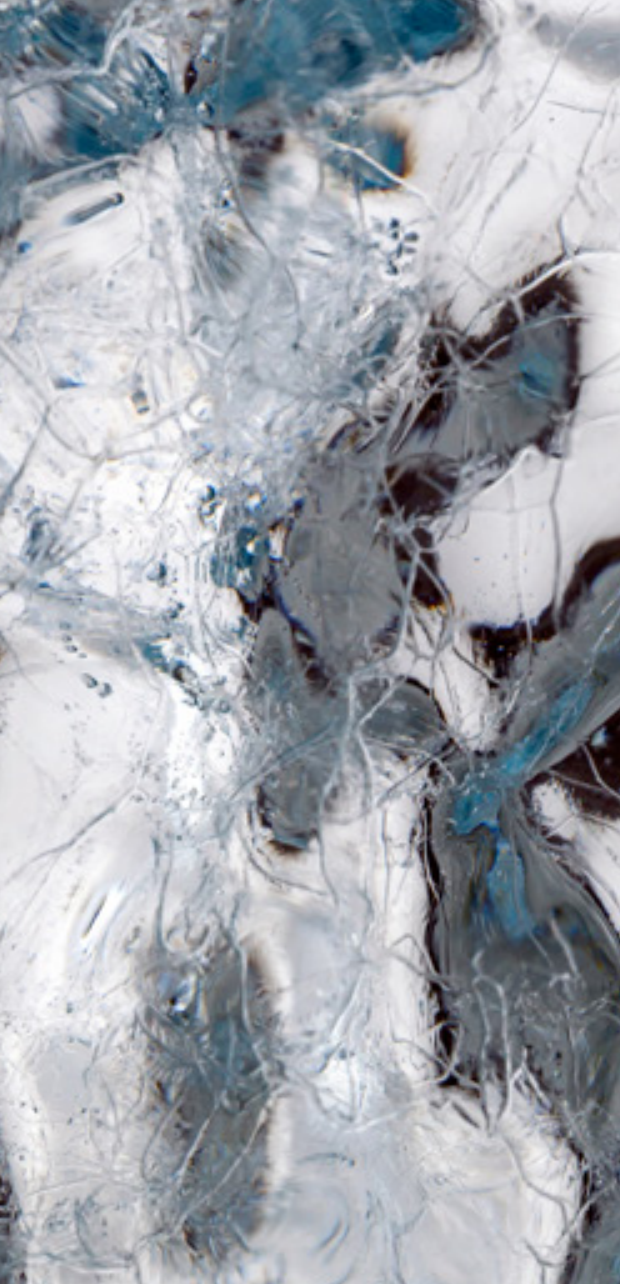

8
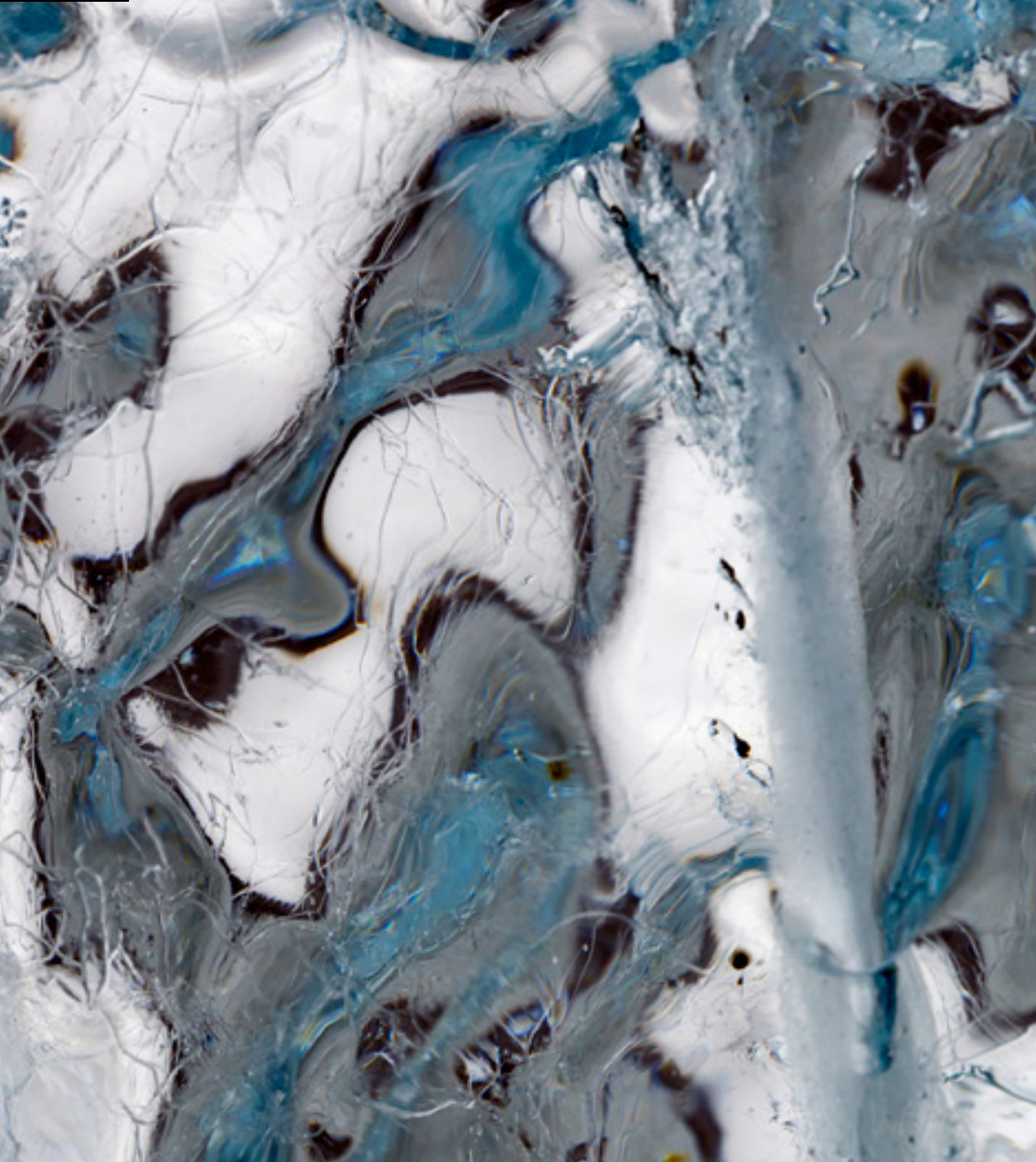

-

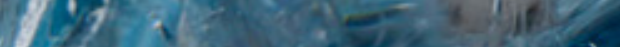

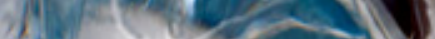




\title{
Nordic choices in a global world
}

\author{
The five Nordic countries - Denmark, Finland, Iceland, Norway and Sweden - \\ have energy and climate policy agendas that are among the most ambitious in \\ the world. This report is focused on the role of technology in supporting a \\ Nordic energy system that realises these targets and fulfils the vision laid out \\ in the Paris Climate Agreement at COP21: keeping global temperature rise \\ "well below two degrees".
}

\section{Key findings}

- The Nordic region has exhibited a steady decoupling of GDP from energy-related $\mathrm{CO}_{2}$ emissions and declining $\mathrm{CO}_{2}$ intensity in energy supply for decades. Important success factors include increased industrial productivity and energy efficiency, a shift from fossil fuels to bioenergy for heating, expansion of nuclear energy in the 1970s and 1980s in Sweden and Finland, geothermal energy in Iceland and broad use of district heating and co-generation of heat and electricity fired with biomass and waste across the region.

- Stable and ambitious carbon taxation and renewable energy incentives have stimulated a growing share of bioenergy and wind. The common Nordic electricity grid has facilitated this growth by allowing wind power in Denmark to be partially balanced by Norway and Sweden. The carbon intensity of Nordic electricity supply - $59 \mathrm{~g} / \mathrm{kWh}$ in 2013 - is already at a level the world must reach in 2045 if it is to realise the IEA's $2^{\circ} \mathrm{C}$ Scenario.

- A future energy system that is distributed, interconnected and flexible is likely less costly and delivers greater value to society than maintaining national systems that rely heavily on centralised sources.
- Wind power experiences the largest growth across all power generation technologies in the CNS, while nuclear declines in the face of challenging economics. Generation from onshore wind grows over fourfold from 24 TWh in 2013 to 110 TWh in 2050, while offshore wind grows eightfold to $40 \mathrm{TWh}$. Nuclear generation falls by two-thirds, to 32 TWh in 2050, with all remaining generation located in Finland.

- District heating networks need to become more diversified, facilitated by a shift towards lower distribution temperatures and regulation that allows more open networks. Demand for district heating decreases to $430 \mathrm{TWh}$ in 2050 from $500 \mathrm{TWh}$ in 2013 despite growing population, owing to energy efficiency measures and competition from small scale heat pumps.

- Bioenergy becomes the largest energy carrier, growing $60 \%$ and representing more than a third of total energy demand in 2050 in the CNS. Biofuels comprise nearly two-thirds of total final energy use in transport, with around $50 \%$ of the anticipated increase in biofuel use supplied by a tenfold increase in net biofuel imports, reaching 60 TWh in 2050. 
- The adoption of new technologies can spur a radical reduction in transport energy use despite rising demand for transport services. Transport's total energy use in 2050 decreases by over 20\% compared with 2000 , despite a $70 \%$ increase in overall passenger and freight activity. By 2050, fossil fuels account for only 25\% of final energy use in transport - a nearly complete phase-out of conventional ICE vehicles by 2050 will be needed in the CNS.

- Rapid advances in the deployment of carbon capture and storage (CCS) or breakthrough production technologies are needed to reduce industrial emissions. Direct industrial $\mathrm{CO}_{2}$ intensity needs to fall by $60 \%$, reaching $10+\mathrm{CO}_{2} / \mathrm{TJ}$ in the $\mathrm{CNS}$. If wide application of industrial CCS does not materialise, breakthrough production technologies will be the only means to reduce these emissions.

- Deep energy renovation of existing buildings is the single most important task at hand for energy savings in the buildings sector. Average space heating energy intensity is to be cut in half, to $60 \mathrm{kWh} / \mathrm{m}^{2}$ in 2050. That requires the residential building stock to improve by $2.5 \% / y e a r$, five times the rate exhibited in the overall Nordic building stock since 1990. However, aggressive building measures with carbon-neutral district heating, which give great energy and emissions reductions, can sometimes lead to higher life-cycle costs because district heating capacity investments would not be fully utilised.

- Investing in a carbon-neutral Nordic energy system makes economic sense. The CNS would require additional investments on the order of USD 300 billion, most of it in transport infrastructure and building renovations. This total equals about $1 \%$ of cumulative GDP between 2016 and 2050, but these numbers do not include fuel savings and avoided external costs related to health impacts of air pollution, which likely exceed the direct investment costs. Increased energy security and avoided property damage from improved air quality will further strengthen the economic case for the energy transition.

\section{Opportunities for policy action}

- The current context of low oil prices should be used to strengthen price signals throughout the economy in order to motivate the system-wide modifications to behaviour and business needed to realise the CNS. This change would mean increasing fuel taxes in transport and removing exceptions to $\mathrm{CO}_{2}$ taxation wherever possible in other sectors.

- Strengthen incentives for investments and business that increase flexibility and system efficiency. Technologies such as energy storage and smart meters, and services such as control systems to shave peak loads in district heating and IT-platforms for ride sharing are lagging behind more visible technologies such as wind power or electric vehicles.

- Energy market design and regulation should be reviewed to enable investments in key technology development and deployment. These areas include the Nordic electricity market, local markets for heat, and regulation that affects the viability of business models for enhanced energy efficiency. The current low energy prices challenge such business models, and policy can help stimulate long-term progress.

- Policy coordination within and among the Nordic countries at the municipal and national level could serve to further accelerate and diffuse innovative and successful best practices. In this context, harmonisation of EVcharging infrastructure should be a priority, given the importance of electrification and the high penetration of EVs in some Nordic countries' fleets.

- Step up investments that enable modal shifts in both passenger and freight transport. Improved supply of public transport services, including rail, is central. Car registration fees and investments in cycling infrastructure are examples of "push" measures, while operation subsidies to increase the attractiveness of public transport or congestion charges could provide "pull". 
- Governments will need to reduce the risk of low-carbon industrial innovation investments. Through results-oriented risk-mitigating mechanisms, such as funds provisions and lowinterest or preferential loans among others, public investment should unlock private finance in areas with great potential for sustainability returns but a low likelihood for independent privatesector investment.
- Carbon capture and storage presents an opportunity where Nordic collaboration could prove particularly valuable. The size and risk involved in investments, the need for a common legal framework and the potential benefit of CCS in the future Nordic energy system speak in favour of a collaborative approach for instance, to finance demonstration and market establishment of CCS.

\section{Radical change is needed, but history gives cause for optimism}

The five Nordic countries - Denmark, Finland, Iceland, Norway and Sweden - have energy and climate policy agendas that are among the most ambitious in the world. Each country has challenging targets, often expressed in wording such as "fossil free" or "carbon-neutral".

This report is focused on the role of technology in supporting a Nordic energy system that realises these targets and fulfils the vision laid out in the Paris Climate Agreement at COP21: keeping global temperature rise "well below two degrees". The Carbon-Neutral Scenario (CNS) is the central scenario of this report and is outlined in Box 1.1. Achieving such as a goal presents a formidable challenge and will require radical change.

History gives cause for optimism though. The Nordic region has exhibited a steady decoupling of GDP from energy-related $\mathrm{CO}_{2}$ emissions for almost 20 years (Figure 1.1). Similarly, $\mathrm{CO}_{2}$ intensity in energy supply has been in decline for decades (Figure 1.2). Both trends need to continue. Globally, 2014 may have seen the first decoupling of the same kind (IEA, 2015f).

The strategies to achieve decoupling have not been without controversy, however. For instance, Sweden, which together with Iceland has seen the most dramatic improvement in carbon intensity of energy supply, achieved that improvement partly through a successful shift to bioenergy for heating but also through large expansion of nuclear energy in the 1970s and 1980s. In Iceland, geothermal energy has played a big role in keeping emissions down. Other main enablers of Nordic decarbonisation are district heating and combined heat and power (CHP) fired with biomass and waste. Albeit much less contentious than nuclear, the role of waste incineration continues to cause debate. In Norway, recent emissions reductions have largely taken place in industry.

The CNS raises questions at all levels of the energy system. The uptake of clean technologies must be accelerated, markets need to be reformed and investment in infrastructure must increase. Put together, these changes will result in a very different energy situation in 2050 compared to today. This report aims to show a plausible way there. 


\section{Figure 1.1 \\ Nordic GDP, energy-related $\mathrm{CO}_{2}$ emissions and total primary energy demand}

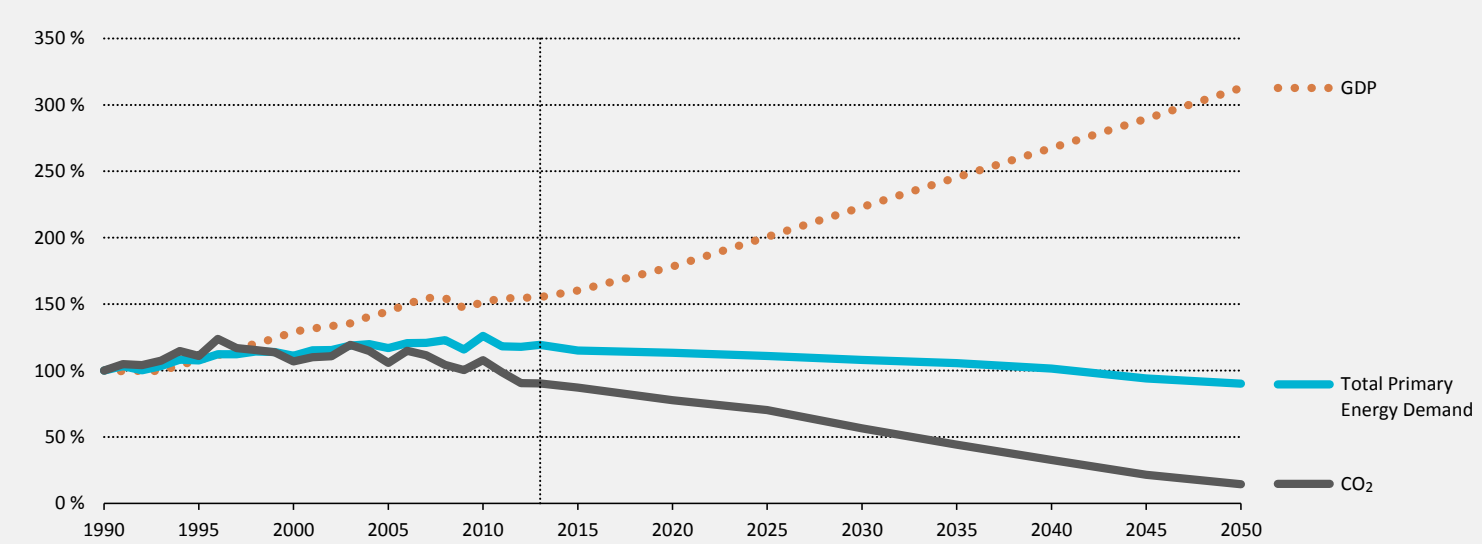

Notes: Data through 2013 are based on IEA official statistics. Data for 2014 onwards are modelled for the Carbon Neutral Scenario. The decoupling effect is likely reduced if a consumption-based emission accounting is used - see Box 1.2.

Figures and data in this report can be downloaded at www.iea.org/etp/nordic.

Key point The Nordic region needs to continue to decouple energy-related $\mathrm{CO}_{2}$ from GDP.

\section{Figure 1.2}

$\mathrm{CO}_{2}$ intensity of total primary energy demand in the Nordic countries (CNS) and OECD Europe (2DS)

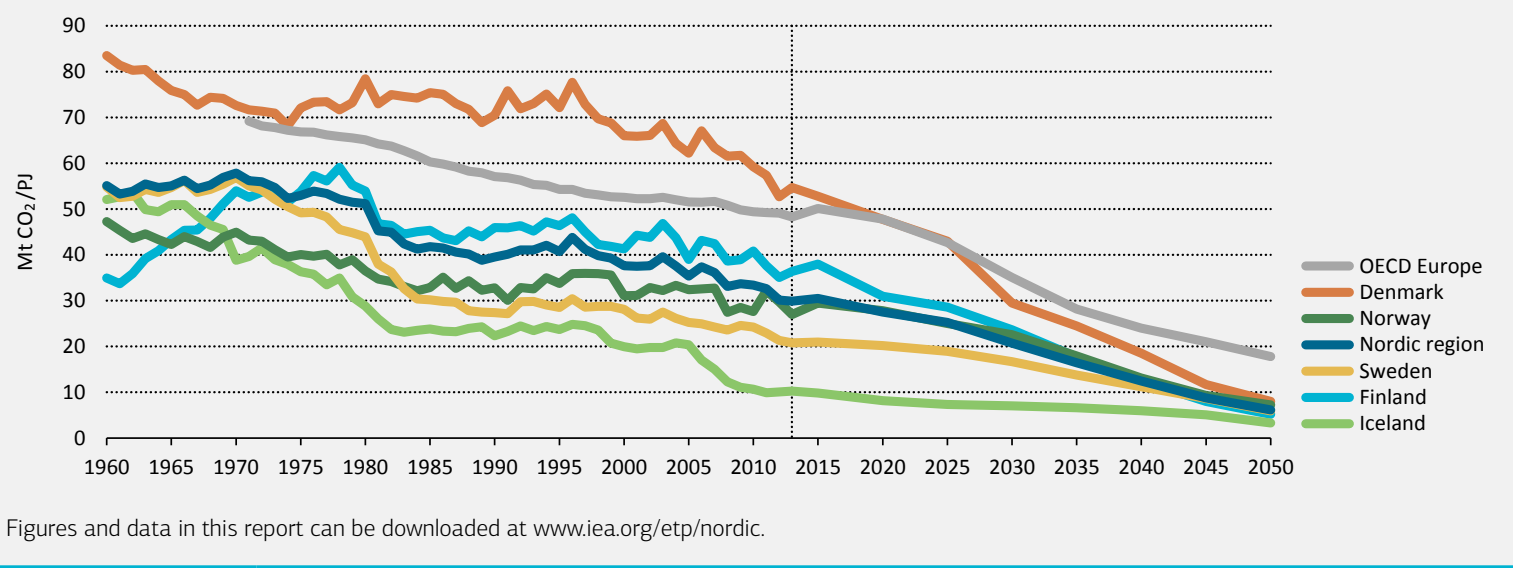

Key point

The build-out of Finnish and Swedish nuclear power in the 1990s and 1980s is evident in Figure 1.2, as is the Danish wind expansion starting in the mid-1990s. 


\section{Box $1.1 \quad$ Current Nordic energy system and Nordic ETP scenarios}

The analysis in this report is centred on a scenario where Nordic energy-related $\mathrm{CO}_{2}$ emissions drop by $85 \%$ by 2050 (Figure 1.3), and mirrors the diverse stated aims of the Nordic countries. ${ }^{1}$ The name - the Carbon Neutral Scenario (CNS) reflects wording used in official targets, although carbon neutrality requires offsets to be used for the remaining $15 \%$.
The Nordic 4 Degree Scenario (4DS) reflects the Nordic contribution to the IEA's global 4-degree scenario. The 4DS serves as a less ambitious reference scenario for the analysis in this report, but still requires strategic policy action by governments to combat climate change and improve energy security.

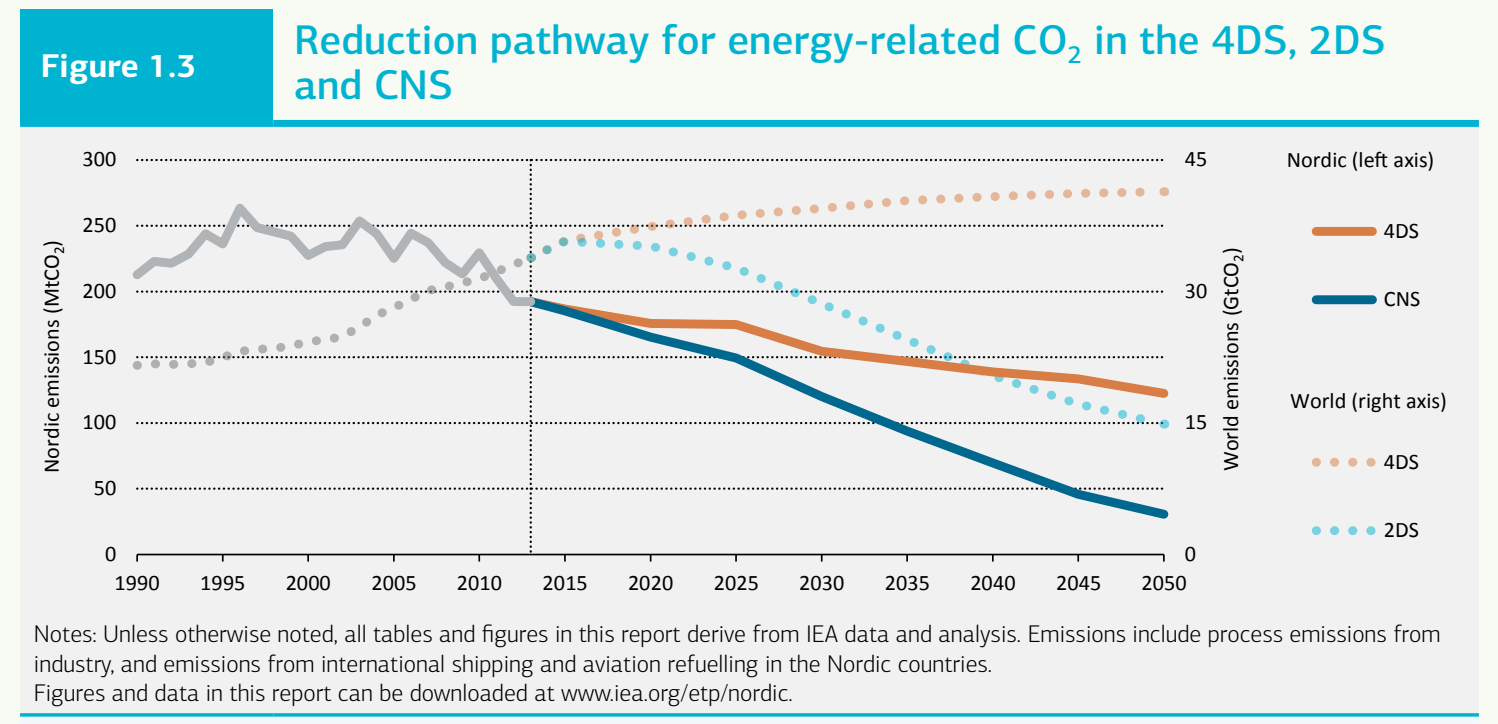

Key point The Nordic Carbon Neutral can be viewed as a test of the Paris Climate Agreement, in that it goes beyond the global 2-degree scenario set out in ETP 2016.

The Nordic scenarios have been developed as an integrated part of the global analysis set out in ETP 2016. The ETP 2 Degree Scenario (2DS) requires cutting global energy-related $\mathrm{CO}_{2}$ emissions by more than half in 2050 (compared with 2013) and ensuring that they continue to fall thereafter. The CNS is more ambitious than the global 2 degree scenario. It can thus be viewed as a test of how to realise the vision to keep temperature rise to "well below two degrees" as laid out in the Paris Climate Agreement at COP21.

This report deals with energy-related $\mathrm{CO}_{2}$ - emissions, which account for just under two-thirds of total greenhouse gas (GHG) emissions in the Nordic region (Figure 1.4).

1 Nordic climate targets: The EU's Intended Nationally Determined Contribution (INDC) submitted in advance of COP21 outlines a 2030 target of 40\% from 1990 levels. The collective delivery of this target covers member states Denmark Finland and Sweden. Non-members Norway and Iceland have both submitted INDCs with the same 2030 target and with intentions to fulfil the target under the EU's collective delivery. National targets for 2050 range from Denmark's "independent from fossil fuels by 2050", to Finland's vision of an 80\% GHG reduction, $\neg$ to Iceland's aspirational goal of 50-75\% net GHG reduction, to Norway's carbon-neutrality, to Sweden's zero net GHG emissions. 


\section{Figure 1.4 Direct Nordic GHG emissions in 2010}

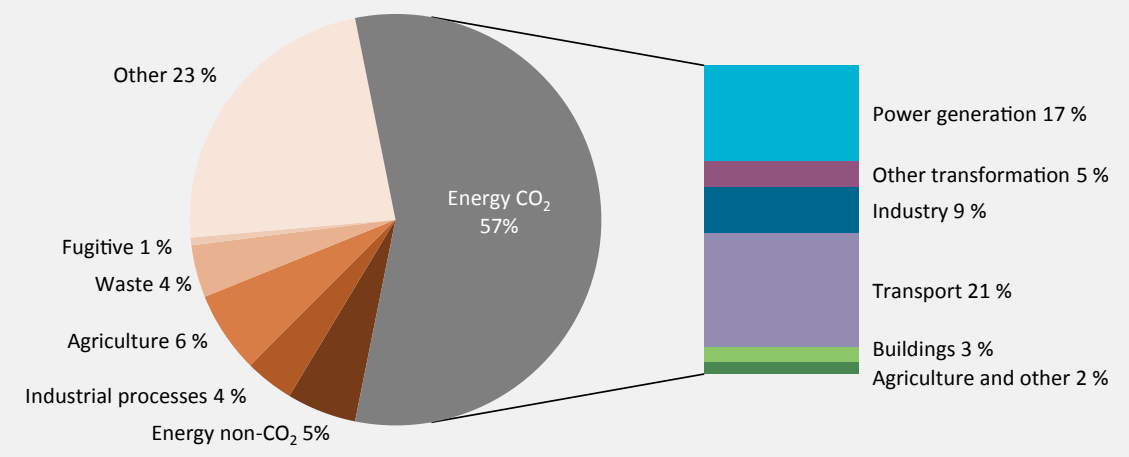

Note: GHG emissions are calculated based on the IEA sectoral approach for $\mathrm{CO}_{2}$ emissions from fuel combustion; the EDGAR 4 database is used for other emissions. In general, estimates for emissions other than $\mathrm{CO}_{2}$ from fuel combustion are subject to significantly larger uncertainties. Figures and data in this report can be downloaded at www.iea.org/etp/nordic.

Key point In 2010, the energy sector accounted for 62\% of GHG emissions in the Nordic region.

\section{Figure $1.5 \quad$ Nordic primary energy supply, 2013 and 2050 in the CNS}

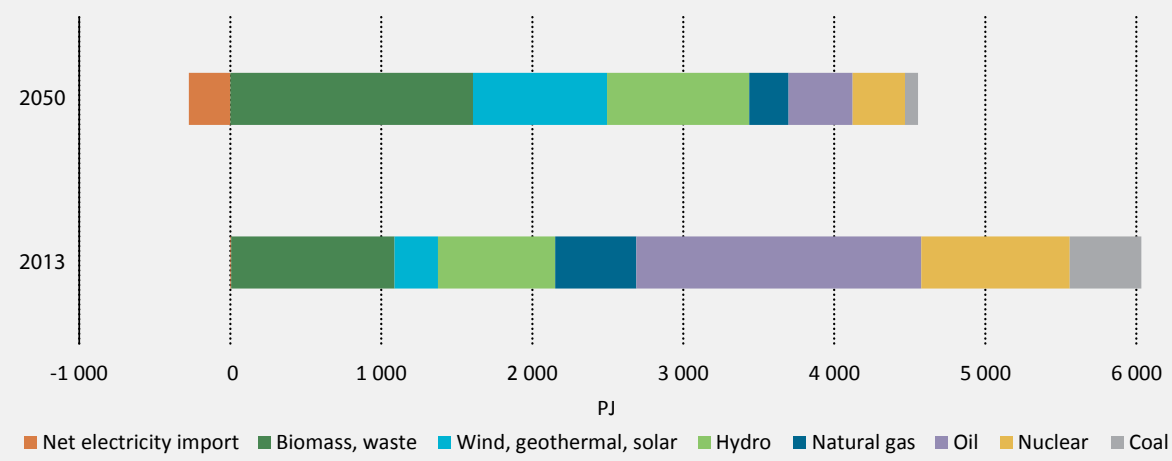

Figures and data in this report can be downloaded at www.iea.org/etp/nordic.

Key point Under the CNS, Nordic primary energy supply decreases by 25\% in 2050 compared with 2013 (excluding net electricity export). Fossil fuels and nuclear decrease, while bioenergy, wind and hydropower increase, as do net electricity exports 


\section{Three strategic issues facing Nordic countries}

Nordic governments and firms face strategic decisions. Some of these decisions need to be made soon, others are less urgent. This report seeks to identify opportunities for policy action that would enable the transformation of the energy system, the investments that are necessary, and the strategic choices that need to be made. The report gives detailed analyses and recommendations that revolve around three strategic issues: centralised or distributed energy systems; progress in industry, transport and buildings; and urbanisation.

\section{Centralised or distributed energy system - Which way forward?}

Appropriate policy strategies hinge partly on the type of future energy system that governments envision, particularly with regards to level of centralisation of supply and integration across sectors and with other countries. This vision depends on uncertain factors such as future technology costs, decisions in other countries and economic development. But a shared Nordic vision would have substantial benefits because the necessary infrastructure investments and suitable market regulations will differ depending on what that vision is.

The model for decarbonisation that has been successful to date may or may not be the best strategy going forward. Nordic energy supply has been built around centralised solutions such as nuclear, hydro and CHP, together with strong and extensive grid and district heating infrastructure. But the energy landscape is being redrawn: energy market fundamentals are being disrupted by falling costs of distributed technologies such as wind and solar; increased security requirements for nuclear; stagnating demand for space heating, which undermines district heating investments; increased competition for biomass resources and changing international fuel markets. The economic viability of the traditional organisation and technological character of the energy system is increasingly in question.

Indeed the analysis in NETP indicates that the future Nordic energy system will likely be more dependent on distributed technologies and international trade than it has in the past. The trans-formation will take place over decades. But since infrastructure investments have long lead times, and appropriate policy and market design options depend on which direction Nordic governments wish to take for the energy system, a co-ordinated Nordic approach would be helpful in the transition.

Formulating and agreeing on a common Nordic energy system vision will be difficult. Also, an element of flexibility is necessary, because future uncertainties are large. But at least a common understanding is needed of the technological and economic implications of different directions and policy choices. This report aims to contribute to such a common understanding and coordination.

Enhanced Nordic collaboration could accelerate progress in key areas. A long tradition is available to build upon. Some infrastructure investments and technology strategies can be much more effective if co-ordinated. Research collaboration and knowledge exchange can have particular benefits for the Nordic countries since they share both climatic conditions and energy infrastructure.

Integration of the Nordic electricity market and grid is perhaps the most tangible result of Nordic energy cooperation, enhancing efficiency and security of supply. Intra-Nordic trade is already high. The countries have supplementary characteristics, and a high level of interconnectivity allows Norwegian and Swedish hydropower to balance wind power generation wind in Denmark - which was 42\% of Danish electricity generation in 2015, the world's highest share. 
If the Nordic countries are to capitalise on their abundant renewable energy potential in the future, these sources must be efficiently integrated into the Nordic electricity system. Shares of wind and solar generation that reach 35\% and more will place great demands on Nordic electricity grids and markets. Although a great success in many ways, the common electricity market Nord Pool, which includes all Nordic countries except Iceland, is under scrutiny as the composition of energy supply changes. A central question in the debate is under what conditions can Nord Pool - and energy-only, liberalised electricity markets more generally deliver electricity systems with high shares of wind and solar.

A related issue is what role the Nordic region should have in the European energy system, both in terms of net export and provision of flexibility. Increasingly, European countries are looking at the flexible generation from the Nordic region as a way to complement domestic deployment of variable renewable electricity capacity. An interconnector between Iceland and the United Kingdom could provide substantial benefits, and plans are progressing (see Chapter 3 for details). Several other interconnectors are planned between the Nordic countries and other European countries.

In fact, non-Nordic demand for low-carbon electricity is an important factor in investments in generation capacity in the CNS. The potential of the Nordic countries to increase their provision of flexible and low-carbon electricity as Central Europe seeks to further decarbonise its electricity system needs to be managed carefully. As grids and interconnections expand, the Nordic region needs to ensure that domestic priorities (e.g. in relation to electricity prices) are met while also putting in place sufficient supply and grid-strengthening to enable exports to other markets.

Chapter 3 of this report looks closer at the development and further integration of the Nordic electricity system.

The common system of electricity certificates in Norway and Sweden is an example of rare international support policies for renewable energy. International collaboration of this kind can reduce the total cost of reducing emissions. A potential drawback is that, if investments systematically go to one country, public support for such policies may fall. Lessons should be learned and used to design policies in other sectors. New infrastructure will be needed if, for instance, gaseous fuels should play a significant role in transport. Such investments will be more cost efficient if more countries than one take part. The same principle is true for large investments in new and improved rail, an important component in the CNS. A co-ordinated approach between several governments will lower total costs.

\section{Progress in industry, transport and buildings is the biggest challenge}

Energy efficiency and decarbonisation of end-use sectors need to play a prominent role in the decoupling going forward. Decarbonising of supply has come a long way, aided by ambitious policies and rich renewable resources in the region. Relative to that success, progress on the demand side has been slower (Figure 1.6). When taking into account emissions embedded in imported products, decoupling is slightly less prominent but still significant (Box 1.2). 


\section{Figure 1.6 Nordic GDP and carbon dioxide emissions by sector in the CNS}

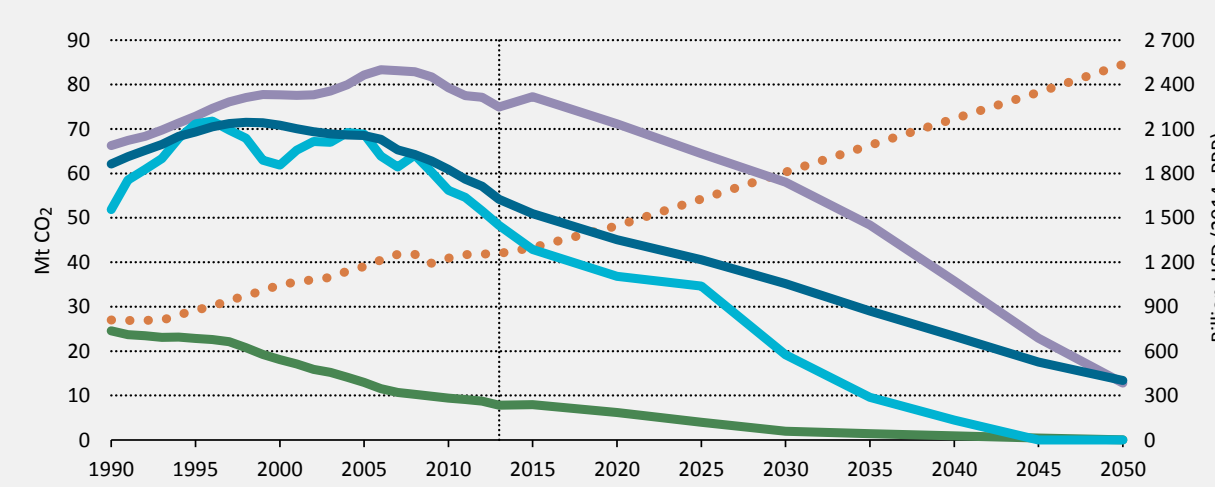

\section{Right axis}

$\ldots$ GDP

高

\section{Left axis}

Industry, oil, gas and other transformation

$\longrightarrow$ Transport

Pransport

Buildings

Note: Historical data smoothed using a 5-year rolling average to account for seasonal variations in emissions, arising from the interplay between hydropower and coal power.

Figures and data in this report can be downloaded at www.iea.org/etp/nordic.

Key point

While emissions from all sectors have already decoupled from Nordic GDP, decarbonisation is first achieved by power, heat and buildings, followed by the more challenging industry and transport.

Lagging progress on the demand side is evident in the statistics. Nordic energy use per capita has remained above the OECD average since the mid-1980s (Figure 1.7). In fact, only Denmark is better than the OECD average in this regard. This level of usage owes particularly to a high concentration of energy-intensive industries (e.g. metals and pulp and paper), the substantial petroleum sector, and high energy use for space heating (Figure 1.8). By contrast, all Nordic countries, except Denmark, have lower $\mathrm{CO}_{2}$ intensity in primary energy supply than the OECD average (Figure 1.2).

Energy demand in the Nordic region increased by 10\% between 1990 and 2013, and was just over $4200 \mathrm{PJ}$ in 2013 , equal to about $8 \%$ of energy demand in EU-27. The industry, transport and buildings (including residential and commercial) sectors each accounted for close to one-third of final energy use in the region (Figure 1.8). The largest increases in final energy use were seen in the transport and commercial buildings sectors, each with around $20 \%$ increase over the past 20 years.

Electricity consumption is particularly high, with Nordic countries (led by Iceland and Norway) ranking among the top per-capita consumers in the world. This level is linked to high rates of electricity use for space heating (except Iceland where geothermal dominates space heating) and in industry. 


\section{Figure 1.7 \\ Historic and future final energy consumption per capita, Nordic countries (CNS) and OECD average (2DS)}

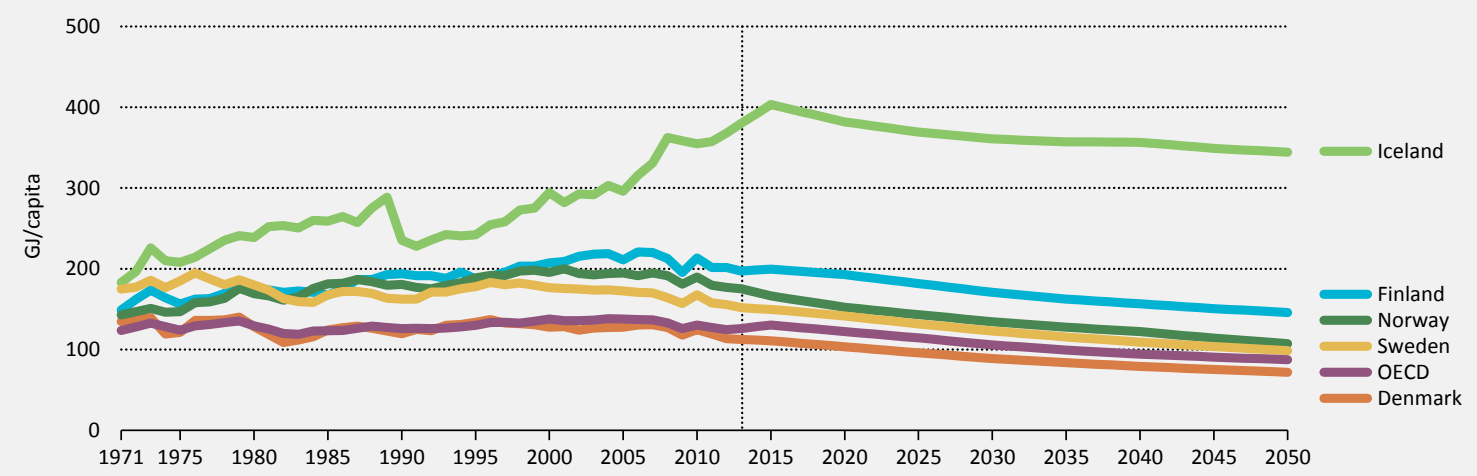

Figures and data in this report can be downloaded at www.iea.org/etp/nordic

Key point

With the exception of Denmark, energy use per capita in the Nordic region is above the OECD average but is relatively stable. Iceland's historic trajectory reflects a

dramatic rise in industrial activity, primarily in the aluminium sector.

\section{Figure 1.8 Final energy demand by sector in the Nordic countries, 1990-2013}

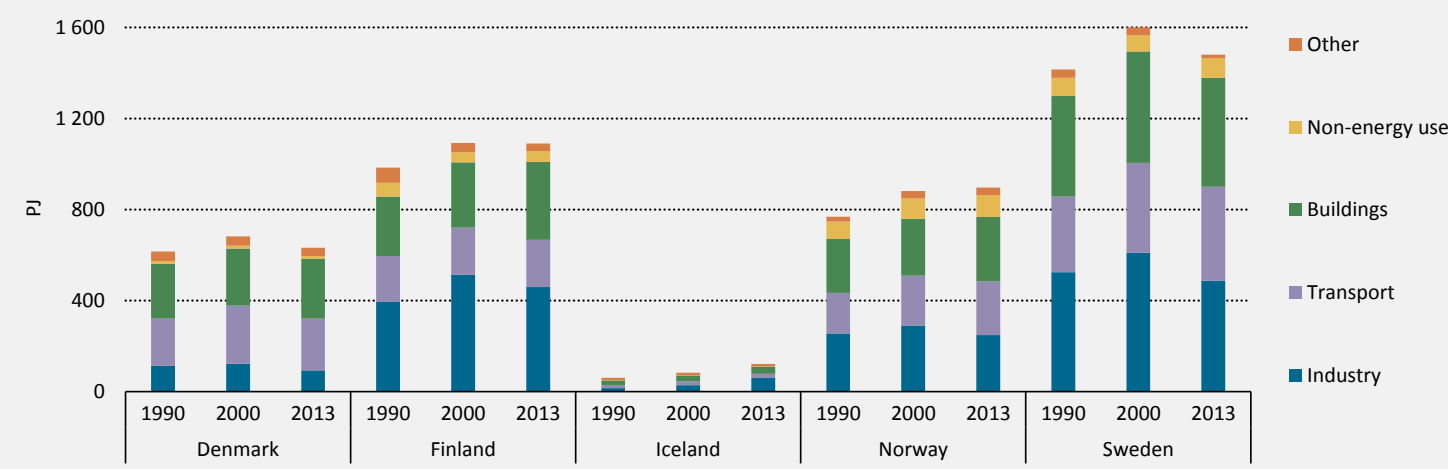

Figures and data in this report can be downloaded at www.iea.org/etp/nordic

\begin{tabular}{|c|c|c|c|c|c|c|c|c|c|c|c|c|c|c|c|}
\hline \multirow[t]{2}{*}[\mathrm{PJ}]{} & \multicolumn{3}{|c|}{ Denmark } & \multicolumn{3}{|c|}{ Finland } & \multicolumn{3}{|c|}{ Iceland } & \multicolumn{3}{|c|}{ Norway } & \multicolumn{3}{|c|}{ Sweden } \\
\hline & 1990 & 2000 & 2013 & 1990 & 2000 & 2013 & 1990 & 2000 & 2013 & 1990 & 2000 & 2013 & 1990 & 2000 & 2013 \\
\hline Industry & 113 & $\ldots 123$ & ...94 & 394 & 513 & 459 & 16 & 28 & 59 & 255 & 291 & 248 & 525 & 610 & 488 \\
\hline Transport & 208 & 255 & 227 & 203 & 207 & 208 & 13 & 17 & 19 & 179 & 219 & 236 & 332 & 395 & 413 \\
\hline Buildings & 240 & 251 & 264 & 261 & 287 & 333 & 20 & 23 & 31. & 236 & 249 & 280 & 441 & 490 & 479 \\
\hline Non-energy use & 13 & 12 & 11 & 60 & 44 & 47 & 1 & 2 & 0 & 77 & 90 & 97 & 81 & 72 & 86 \\
\hline Other & 42 & 41 & 36 & 66 & 41 & 42 & 11 & 12 & 11 & 21 & 32 & 36 & 37 & 34 & 15 \\
\hline
\end{tabular}

Key point The industry, transport and buildings sectors each represent close to one-third of final energy consumption in the Nordic region. 
Thus big questions remain over how energy is used in industry, transport and buildings. With a largely decarbonised heat and power supply, the Nordic region must look to these sectors to achieve further decoupling.

Process-related emissions in industry, together with transforming transportation, are arguably the greatest challenge for the CNS. All Nordic economies, except Denmark, are highly dependent on energy-intensive industries (Figure 1.9). Some of these industries have large processrelated emissions that can only be reduced by either breakthrough production technologies or wide application of carbon capture and storage (CCS). Nordic governments need to take this issue very seriously. Given the size and risk involved in investments, a collaborative approach should be considered - for instance, to finance demonstration and market establishment of CCS.

\section{Figure 1.9}

Nordic direct energy-related $\mathrm{CO}_{2}$ emissions in the CNS, by sector and country

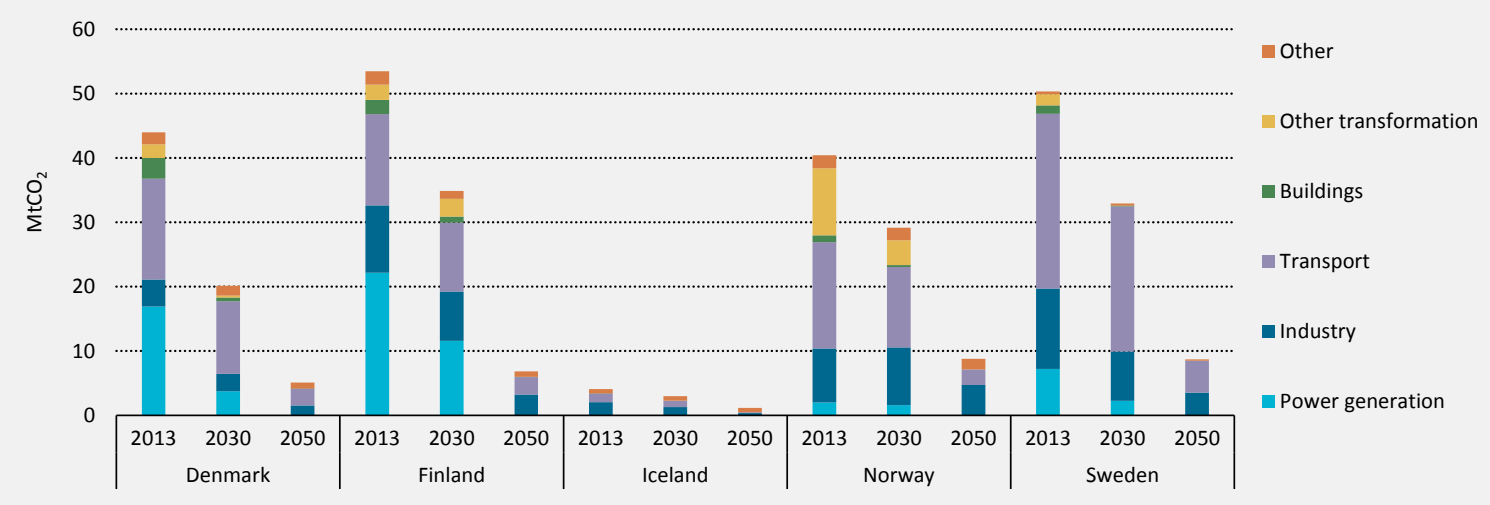

Figures and data in this report can be downloaded at www.iea.org/etp/nordic.

\begin{tabular}{|c|c|c|c|c|c|c|c|c|c|c|c|c|c|c|c|}
\hline \multirow[t]{2}{*}[\mathrm{Mt}\mathrm{CO}_{2}]{} & \multicolumn{3}{|c|}{ Denmark } & \multicolumn{3}{|c|}{ Finland } & \multicolumn{3}{|c|}{ Iceland } & \multicolumn{3}{|c|}{ Norway } & \multicolumn{3}{|c|}{ Sweden } \\
\hline & 2013 & 2030 & 2050 & 2013 & 2030 & 2050 & 2013 & 2030 & 2050 & 2013 & 2030 & 2050 & 2013 & 2030 & 2050 \\
\hline Power generation & 16.9 & 3.8 & 0.0 & 22.2 & 11.6 & 0.0 & 0.0 & 0.0 & 0.0 & 2.0 & 1.7 & 0.0 & . 7.2 & 2.2 & 0.0 \\
\hline Other transform. & 2.1 & 0.2 & 0.0 & 2.4 & 2.7 & 0.0 & 0.0 & 0.0 & 0.0 & 10.4 & 3.8 & 0.0 & 1.7 & 0.0 & 0.0 \\
\hline Industry ......... & 4.2 & 2.7 & 1.6 & 10.4 & 7.7 & 3.2 & 2.0 & 1.3 & 0.4 & 8.4 & 9.0 & 4.7 & 12.5 & 7.6 & 3.5 \\
\hline Transport & 15.7 & 11.2 & 2.6 & 14.2 & 10.7 & 2.7 & 1.4 & 1.4 & 0.2 & 16.5 & 12.1 & 2.3 & 27.1 & 22.6 & 5.0 \\
\hline Buildings & 3.2 & 0.6 & 0.0 & 2.2 & 0.9 & 0.0 & 0.0 & 0.0 & 0.0 & 1.0 & 0.3 & 0.0 & 1.3 & 0.1 & 0.0 \\
\hline Other & 1.8 & 1.5 & 0.9 & 2.1 & 1.2 & 0.9 & 0.7 & 0.7 & 0.7 & 2.1 & 1.9 & 1.7 & 0.4 & 0.3 & 0.2 \\
\hline Total & 44.0 & 20.1 & 5.1 & 53.5 & 34.9 & 6.8 & 4.1 & 3.4 & 1.3 & 40.4 & 28.8 & 8.7 & 50.3 & 32.8 & 8.7 \\
\hline
\end{tabular}

Key point

The share of direct emissions from industry and transport increases as total emissions fall in the CNS, underscoring the challenges that remain in end-use sectors.

The Nordic region faces a significant challenge in meeting growing demand for transport services while simultaneously reducing transport emissions in line with the CNS. Key technologies for the transport sector, such as electric vehicles, public transport and cycling, are best suited to urban environments and best analysed in that context. The chapter on urban energy systems looks specifically at emission reductions in urban transport and buildings.

Aggressive energy efficiency improvements in buildings are an important part of the CNS. However, a balance needs to be struck between investing in energy efficiency, on the one 
hand, and in cleaner energy supply, on the other. As demonstrated in the interaction of provision of heat and power through CHP and district heating, system-level effects need to be considered when deciding energy efficiency strategies for buildings, for example.

\section{Urbanisation raises new questions for technology strategies and policy design}

Currently $85 \%$ of the population in the Nordic region lives in urban areas. ${ }^{2}$ This level underlines the large role that densely populated areas will have in the development of Nordic region, despite their low average population densities. In addition, the rate of urbanisation in the region is expected to triple, from $0.5 \%$ in the past decades to $1.5 \%$ annually in the coming 35 years. Urban buildings accounted for $75 \%$ of final energy demand and $\mathrm{CO}_{2}$ emissions (direct and indirect) in the sector in 2013 - shares that grow to 80\% in the CNS in 2050. Chapter 2 looks at urban energy in detail.

Nordic urbanisation differs somewhat from the global picture. Municipalities are generally smaller than in most other regions; even though a large share of the population already lives in what is defined as an "urban area", most of the Nordic urbanites live in smaller communities than what many outside the region would intuitively define as a "city".

The character of urban areas has implications for what types of technologies can be expected to grow and at what rates. For instance, electric vehicles are likely to win the greatest uptake in and around larger cities, at least in the mid-term, because trip distances tend to be short, and charging infrastructure can achieve economies of scale. This character narrows the market in the Nordic countries somewhat, and favours other energy carriers such as biofuels or hydrogen outside cities. District heating and cooling, on the other hand, may be attractive even in smaller towns as long as the population density is high enough.

Technology policies should be adapted accordingly. Policy makers need to understand what different technologies can deliver and in which environments, and tailor policies accordingly. Although the potential of urban sustainable energy solutions is undeniable, the ability to achieve that potential will rely on the commitment of all levels of government to enact innovative and effective policies, business models and financing mechanisms. Policy ambitions and measures at the city level often have stronger direct impact than national or international policies. Synergies, but also conflicting agendas, may exist between different levels of government.

The rest of this chapter provides overviews of the scenario results for the power and heat, transport, industry, and buildings sectors, as well as Spotlights on the Nordic bioenergy sector and Iceland's fishing sector. Chapter 1 concludes with a summary of the investment needs in the CNS. Chapter 2 goes deeper in the role of urban energy systems, and Chapter 3 of the report presents in-depth analysis of how the Nordic electricity system needs to evolve in the CNS.

2 See chapter 2 for the definition of "urban" 
Official accounts of Nordic $\mathrm{CO}_{2}$ emissions from fossil fuel and industry reported to the UNFCCC have decoupled from GDP growth. These territorial emissions have remained relatively stable since 1990 and have shown a downwards trend in the last 10 years. However, this downward trend may be due to the reduction of production in the Nordic countries offset by expanded production in countries with weaker environmental regulations. "Consumption emissions", as shown in Figure 1.10, may be used to estimate this effect.
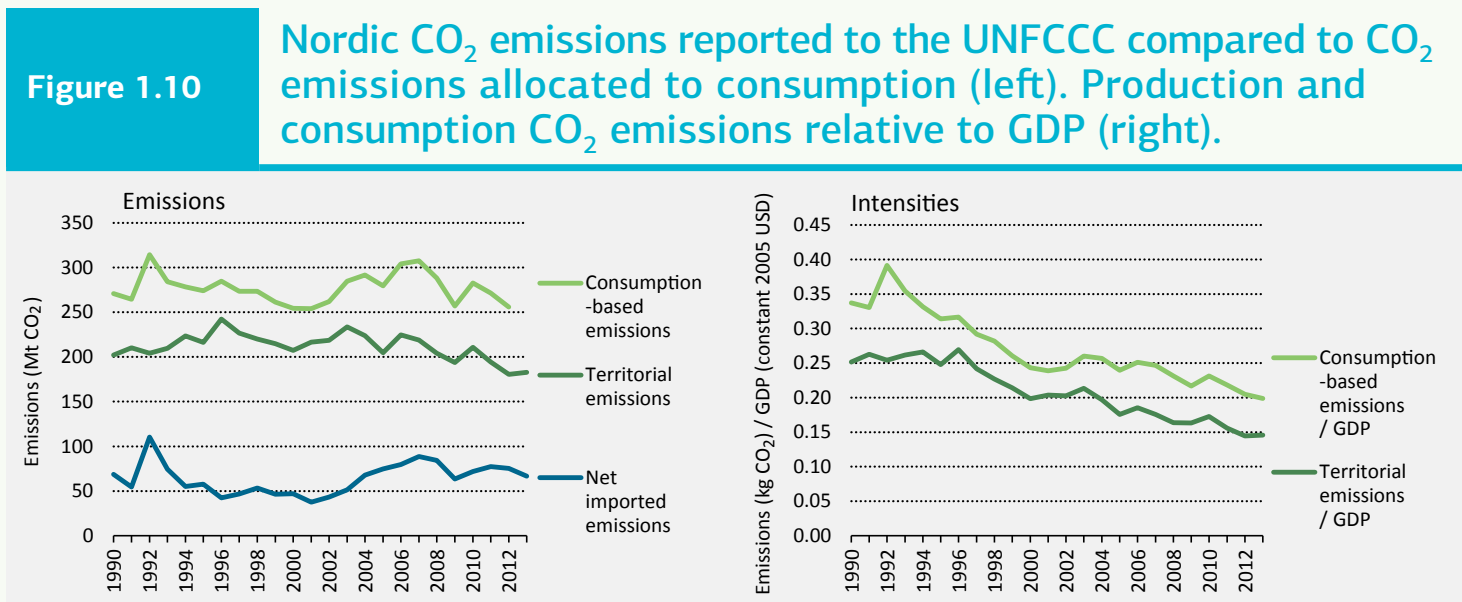

Notes: This figure and related text is the product of a co-operation between the NETP project and CICERO Center for International Climate and Environmental Research. Data includes Denmark, Finland, Norway and Sweden (no consumption results available for Iceland). The territorial $\mathrm{CO}_{2}$ emissions from fossil fuel and industry used in this box are from the official national reports to the UNFCCC, while the remainder of this report uses data constructed by the IEA, including emissions from international aviation and shipping refueling in the Nordic region. The different datasets use slightly different input data, emission factors and system boundaries, but emission trends are broadly consistent. The consumption data are from Le Quéré et al., 2015, based on Peters et al., 2011, and the GDP data are from UN, 2016.

Figures and data in this report can be downloaded at www.iea.org/etp/nordic.

Key point

While Nordic consumption emissions are significantly higher than official production emissions, they also show a clear decoupling from GDP.

The Nordic countries have high consumption emissions, meaning they are net importers of embodied $\mathrm{CO}_{2}$. Consumption-based emissions allocate the emissions to the countries where goods and services are consumed, regardless of where they are produced. In effect, consumptionbased emissions adjust the UNFCCC emissions by removing the Nordic emissions from the production of exports and adding the foreign emissions to produce imports into the Nordic countries. The net import of embodied emissions increased from 2001 to a peak around 2007, after which it has declined slightly. The peak in 1992 is due to the collapse of the Former Soviet Union and is not a reliable data point.

\section{Using consumption-based emissions does not lead to significant changes in the rate of decoupling of the Nordic countries. UNFCCC and consumption-based emissions have both decoupled.}




\section{Power generation and district heating are almost there}

Decarbonisation of Nordic power is high and continues, despite only $13 \%$ of electricity being generated from fossil fuels in 2013

The Nordic electricity mix is ahead of the rest of the world in terms of carbon intensity. Even if the world embarks on the pathway of the IEA's global 2-degree scenario and countries fulfil their pledges made at $\mathrm{COP} 21$, the global $\mathrm{CO}_{2}$ intensity will not reach the current Nordic level until after 2040 (Figures 1.11 and 1.12).

\section{Figure 1.11 Global carbon intensity of electricity supply $\left(\mathrm{gCO}_{2} / \mathrm{kWh}\right)$}

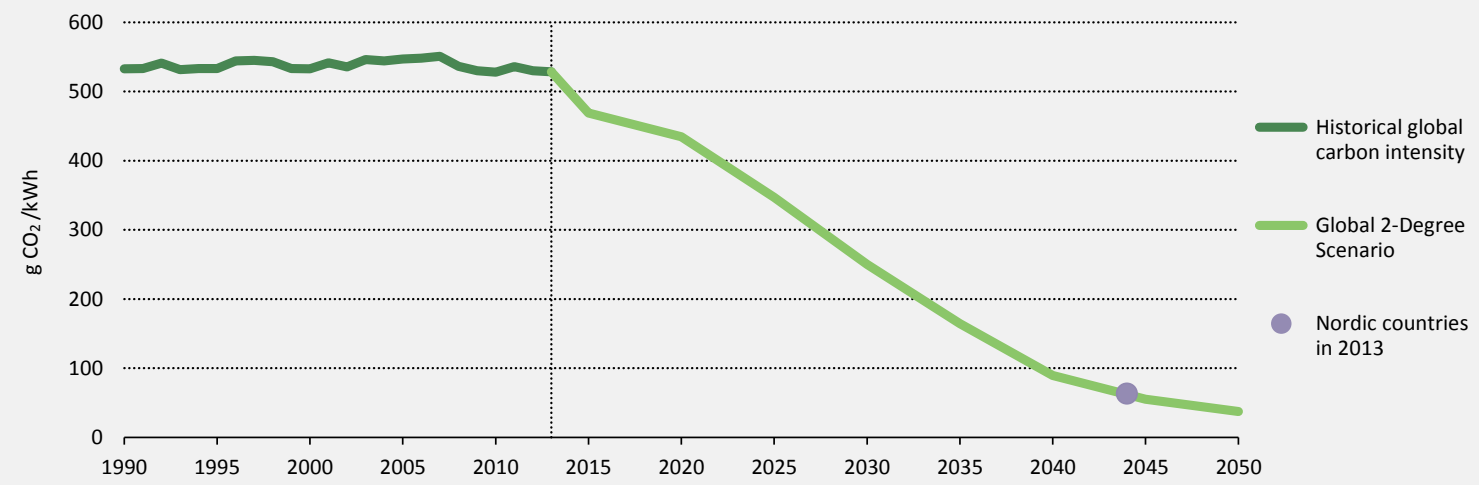

Figures and data in this report can be downloaded at www.iea.org/etp/nordic

Key point

The Nordic carbon intensity of electricity supply of $59 \mathrm{~g} / \mathrm{kWh}$ in 2013 was where it will be in 2045 in the global 2DS scenario.

\section{Figure 1.12 Electricity generation in the Nordic countries, 2013}

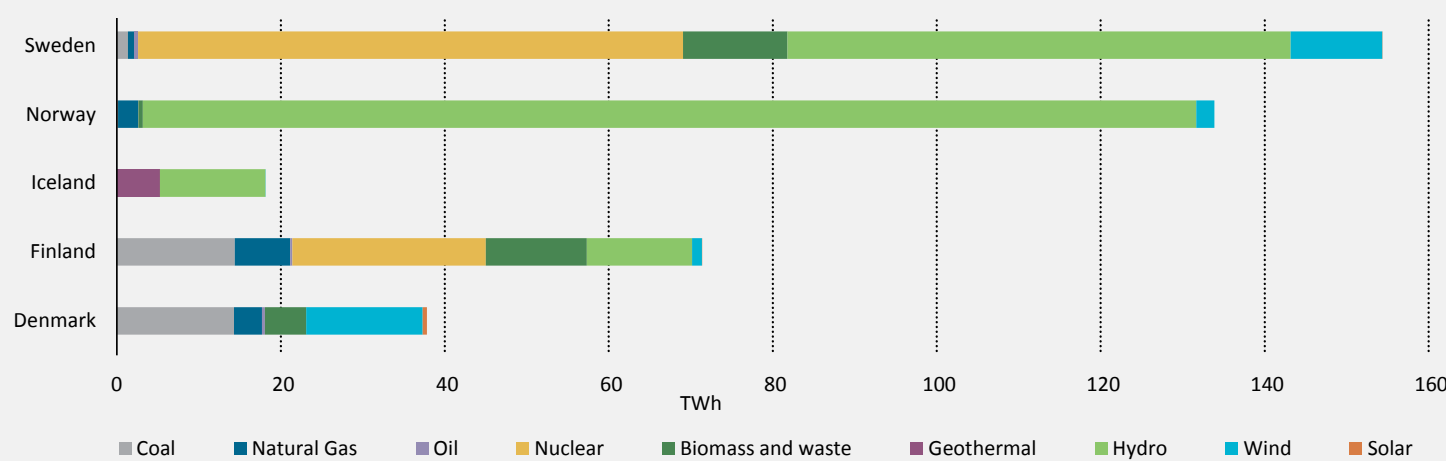

Figures and data in this report can be downloaded at www.iea.org/etp/nordic

Key point At present, $83 \%$ of the electricity production in the Nordic countries is carbon neutral, of which $63 \%$ is renewable. 


\section{Recent trends}

Electricity generation, reflecting the high levels of development of Nordic countries, remains the key pillar of the Nordic energy system - Sweden, Norway and Iceland have the three highest shares of electricity in total final consumption of all IEA countries. Electricity generation totalled 380 TWh in 2014, with consumption (i.e. after losses and exchanges) representing $13 \%$ of all electricity generated in the EU 28. Hydropower is a fundamental component of the Nordic energy system, representing $7 \%$ of all primary energy produced, and about half of all electricity generated in 2014 (Figure 1.13).

\section{Figure 1.13 \\ Primary energy supply in the Nordics: Fuels for electricity and heat production (2013)}

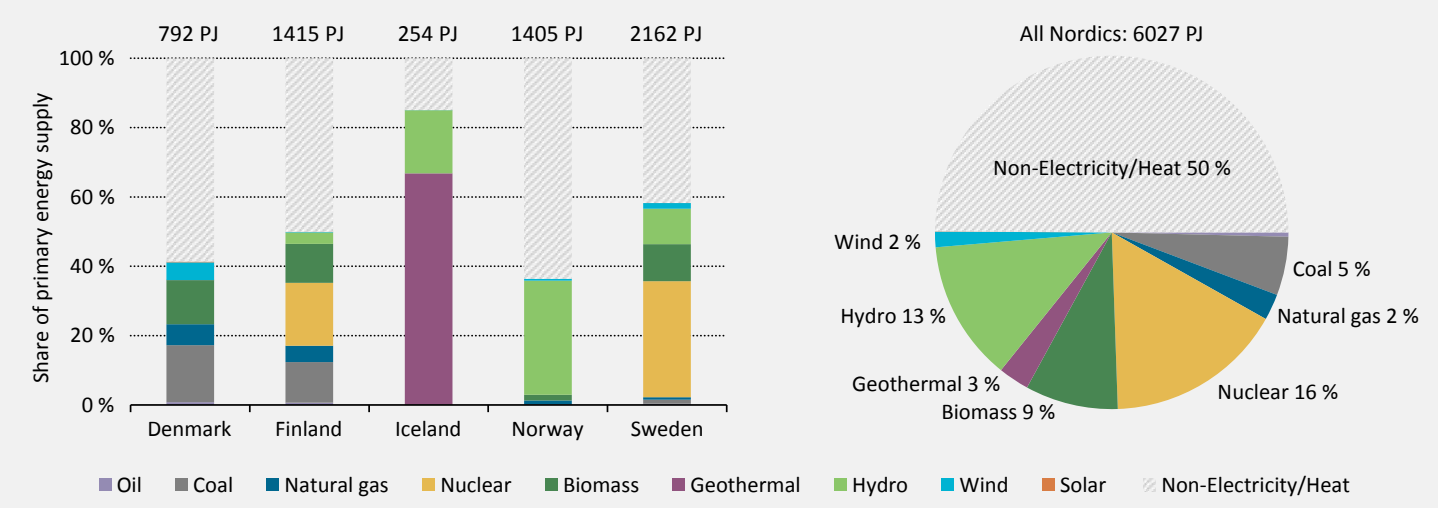

Figures and data in this report can be downloaded at www.iea.org/etp/nordic.

Key point

Electricity and heat generation have a central role in Nordic primary energy supply, with hydro and nuclear technologies leading the way.

Like elsewhere in the EU, investments in new capacity are currently low in the Nordic electricity and heating system. Drivers include a weak demand arising from macro-economic trends, a prevailing overcapacity and improved energy efficiency in end-use sectors. Regardless, policy drivers - and not market factors - are causing the share of non-hydropower renewables in the electricity mix to rise.

In Denmark, thermal power plants account for just over half of electricity generation, with the share of coal power generation remaining at a steady 41\% between 2011 and 2013 (Figure 1.14). Reflecting a common trend elsewhere in Europe, the share of natural gas-fired generation has decreased from 17\% in 2011 to 10\% in 2013. In the meantime, the share of wind power in annual power production has risen by $15 \%$ for a total of 11 TWh or $38 \%$ of total annual electricity generation, while the share of electricity fuelled by biomass and waste has remained a constant 15\% between 2011 and 2013.

In Finland, the share of coal-fired power has risen by 2\% to a total of 15\%, while nuclear accounts for a third of all electricity generated in 2013 - a similar share to that of 2011. Biomass and waste, and hydro, account for 12 and 13 TWh (or 17 and 18\%), respectively, while natural gas has dropped by almost 30\% to $6.8 \mathrm{TWh}$. 


\section{Figure 1.14 Electricity and heat mix in Nordic countries in 2013}
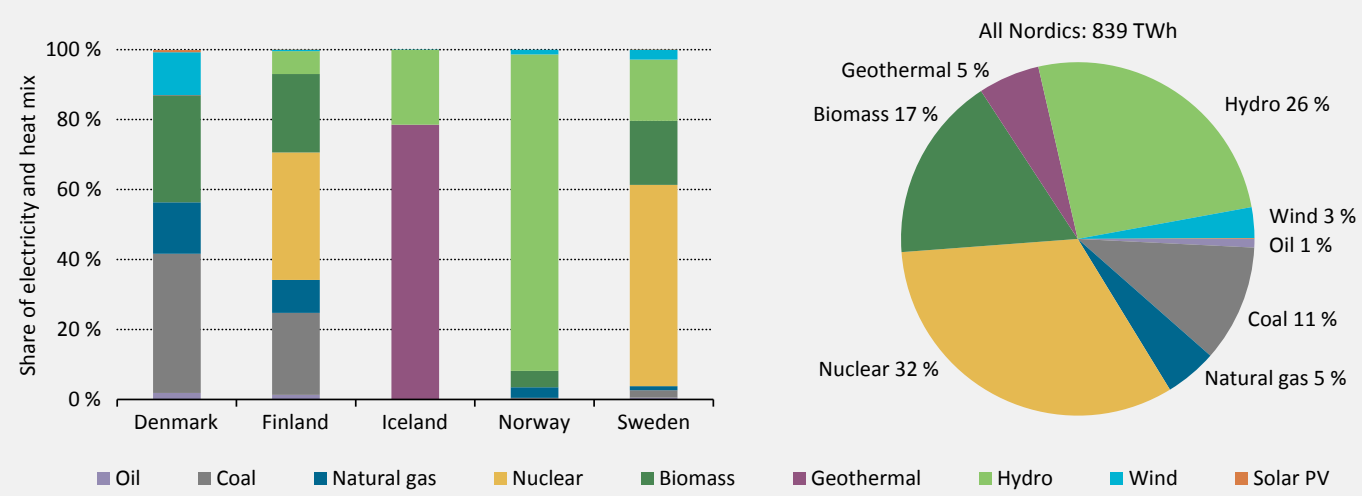

Figures and data in this report can be downloaded at www.iea.org/etp/nordic.

In Iceland, power demand increased by 5\% between 2011 and 2013 - which led to an increase in output from both hydro and geothermal, both of which account for almost all generation in the Icelandic power system. Geothermal power generation increased fastest to account for $29 \%$ of the total, while the share of hydro dropped to $71 \%$ - even if output rose slightly by $3 \%$. Almost 13 TWh out of the 17 TWh demanded in 2013 were consumed by the aluminium industry.

Following a record year in 2012, Norwegian hydro generated 128 TWh in 2013, accounting for $96 \%$ of all electricity supply in the country. Norway's single natural gas generation unit accounted for $2 \%$ of power generation, while the remaining generation was dominated by wind, which grew almost 50\% between 2011 and 2013 to 1.9 TWh.

At 153 TWh in 2013, Sweden's total power generation is more than any other Nordic country, dominated by similar shares of nuclear and hydro (43\% and $40 \%$, respectively). Biomass and waste account for $6 \%$, or 13 TWh.

Wind has experienced the largest growth of all technologies. Between 2011 and 2013, generation has grown by $62 \%$. Aided by favourable policy incentives, Sweden's onshore wind installations have dominated the Nordics, with installed capacity growing by $25 \%$ over the past year, surpassing $5 \mathrm{GW}$ at the end of 2014, and compared to Norway and Finland's $0.5 \mathrm{GW}$ each. Total wind capacity in Sweden surpassed Denmark in 2015.

Electricity trade is a key component of the Nordic power system. Nord Pool Spot is the world's oldest international market for power, and the world's first undersea interconnector was built in 1915 to link the Danish and Swedish power systems. Activity in Nord Pool Spot is decreasing; low electricity prices, overcapacities leading to reduced volatility, and increased regulatory costs following the 2008 financial crisis led to the year 2014 seeing the lowest trade volumes in 16 years.

During 2009, Swedish nuclear operators faced security issues and temporarily shut down operations of a portion of their capacity. In the period between 2009 and 2013, nuclear capacity increased in the Nordic region by $600 \mathrm{MW}$, and nuclear generation increased by $11 \mathrm{TWh}$ during the same period. Together with the capacity additions outlined above (namely, 2200 MW 
additions in wind power capacity generating an additional 9 TWh), these nuclear-based increases have contributed to downward pressure on power prices. At the time of writing, four reactors are scheduled to close: Vattenfall's Ringhals 1 and 2 by 2020 and 2019; and Eon's Oskarshamn 1 and 2 by 2017 and 2020. The prevailing overcapacity in the Nordic electricity system can drastically change if the closure of Swedish nuclear power plants is not carefully managed, or - given the cancellation of Olkiluoto's unit 4 and delays in delivery of unit 3 - if new nuclear capacity in Finland is further stalled.

Low power prices have played a key role in the closure of nuclear capacity, but over the next 10-15 years investments are likely to be driven by policy rather prices. A major driver will be the Norwegian/Swedish green certificate system, which requires an additional 28.4 TWh (normal year production) of renewable electricity generation by 2020 compared with 2012. This requirement is the result of a revision for Sweden, which put the target only slightly higher than what a continuation of current deployment rates would yield. Wind is likely to account for most of the investments, complemented by some small-scale hydro in Norway.

Siting generation closer to load can, among other benefits, reduce the need for electricity transmission infrastructure. Increased flexibility on the urban/regional level can decrease the network cost due to lower transmission capacity needed for the same installed variable renewable energy sources (VRES) capacity. However, given the solar resource and the availability of other, larger-scale low-carbon power alternatives, Nordic countries are in a somewhat disadvantaged position to capitalise from the rise of distributed generation happening in other countries.

Nordic waste and biomass availability are highly dependent on the RES investments and demand in continental Europe and North America, since many of these commodities are traded on global markets. The import of waste is likely to continue to increase in Sweden, since the installed capacity has increased rapidly the last 10 years, and some other European countries see export of waste as a cost-effective waste management option. (See Spotlight 1: The Nordic bioenergy market.)

The total heating market in Nordic countries is close to $240 \mathrm{TWh}$ - of which around $43 \%$ are accounted for by heat distributed through district heating networks (Figure 1.15). The fuel mix for district heating networks is already quite decarbonised (Figure 1.16), with an average $\mathrm{CO}_{2}$ emission factor of $240 \mathrm{~g} / \mathrm{kWh}$ of heat delivered in 2014, compared to a European average of $320 \mathrm{~g} / \mathrm{kWh}$. In Iceland, district heating is completely decarbonised, primarily thanks to application of geothermal technologies. 


\section{Figure 1.15}

\section{Heating deliveries to residential buildings in Nordic countries, by} technology type (TWh)

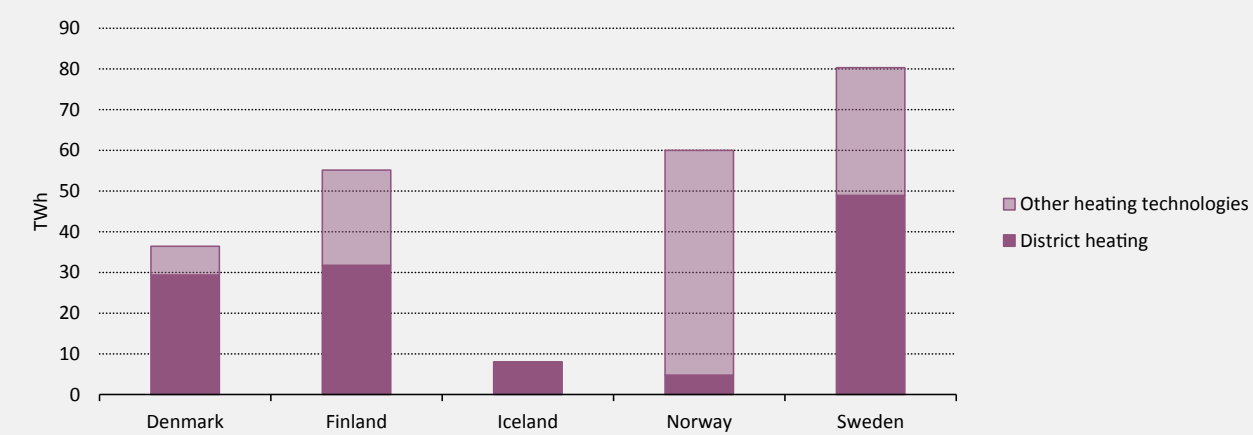

Figures and data in this report can be downloaded at www.iea.org/etp/nordic.

Key point

The share of heating demand met by district heating varies country by country, but is a key technology in all Nordic countries, with the exception of Norway.

District heating companies and CHP are challenged by decreased heat demand in buildings and competition from heat pumps. In Helsinki, Helsinki Energy, the local energy company has reported that they will not be replacing legacy large CHP plants, relying instead on other options for heat generation. This decision arises from an expected decrease in $\mathrm{DH}$ demand: coverage of homes in Helsinki with district heating networks is close to $99 \%$, so that - without the possibility of capturing new users - new energy efficiency improvements will depress heating loads. In the face of decreasing heating loads, CHP installations are quickly becoming too significant an upfront investment, and are forcing diversification of district heating producers.

\section{Figure 1.16}

District heating deliveries in Nordic countries, by energy source (terajoules)

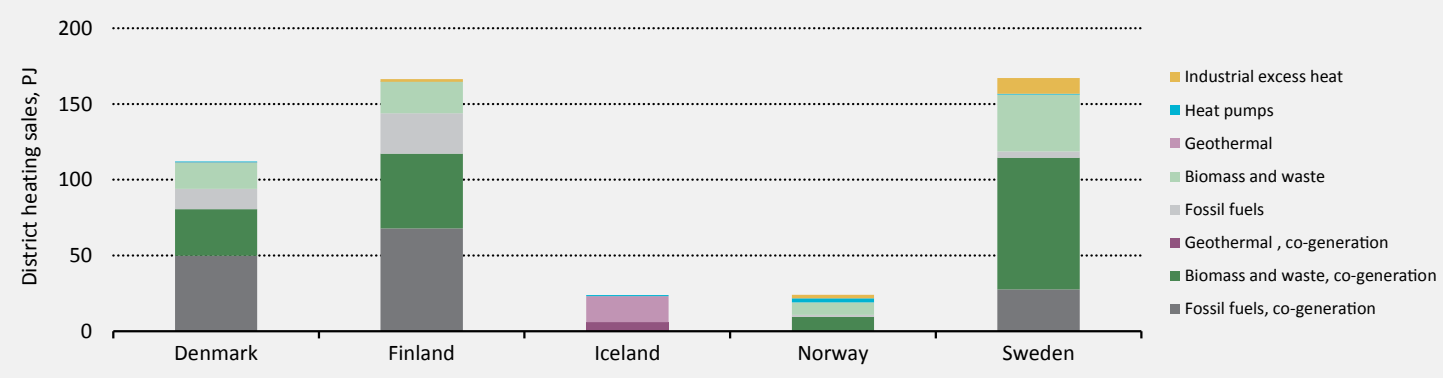

Figures and data in this report can be downloaded at www.iea.org/etp/nordic.

Key point

While the fuel mix of district heating networks varies between Nordic countries, it has already reached high levels of decarbonisation and has a significant share of CHP-generated heat. 


\section{Scenario results}

\section{Scenario assumptions}

Common to all low-carbon scenarios, the CNS includes the provisions in the National Renewable Energy Action Plans (NREAPs). Minimum targets of 6 TWh for wind in 2020 and 9 TWh in 2025 are implemented for Finland. Beyond the NREAPs, the CNS includes a complete phaseout of coal generation after 2030 - no coal generation in Norway and no new coal in Sweden, whether CCS-ready or not (Figure 1.17).

The Norwegian-Swedish renewable certificate schemes are incorporated in the CNS, translating into a 28.4 TWh increase in renewable electricity production between 2013 and 2020, reaching 320 TWh. Ambitious targets for heat generation are included in the CNS, including 100\% renewable district heating by 2035 in Denmark. In the CNS, new nuclear construction is assumed possible only in Finland and Sweden, but no other constraints are put on nuclear investments in the modelling (this differs from NETP 2013, when nuclear capacity was held constant). A more detailed analysis of the role of nuclear is presented in Chapter 3.

In the short term, all planned interconnectors by 2020 are assumed to be taken to completion, and electricity trade increases (Figure 1.18). Power generation in the carbon-neutral scenario grows by $20 \%$ between 2013 and 2050 to 494 TWh. New capacity additions from variable renewables grow sixfold in both the $4 \mathrm{DS}$ and the CNS, reflecting mainly the attractiveness of wind power across all scenarios.

Decreased heat demand in buildings and competition from heat pumps for $\mathrm{DH} / \mathrm{CHP}$ affects the residential sector in particular. In the CNS, demand for district heating in Nordic homes is reduced by over 20\% to 207 TWh in 2050, down from 262 TWh in 2013. While this rate of district heat demand reduction might appear low at around $1 \%$ annually, the pace of change and the level of adaptation required is stringent given long-lived lifetimes and structural characteristics of district energy infrastructure.

\section{Figure 1.17 Nordic electricity generation mix in the 4DS and CNS (TWh)}

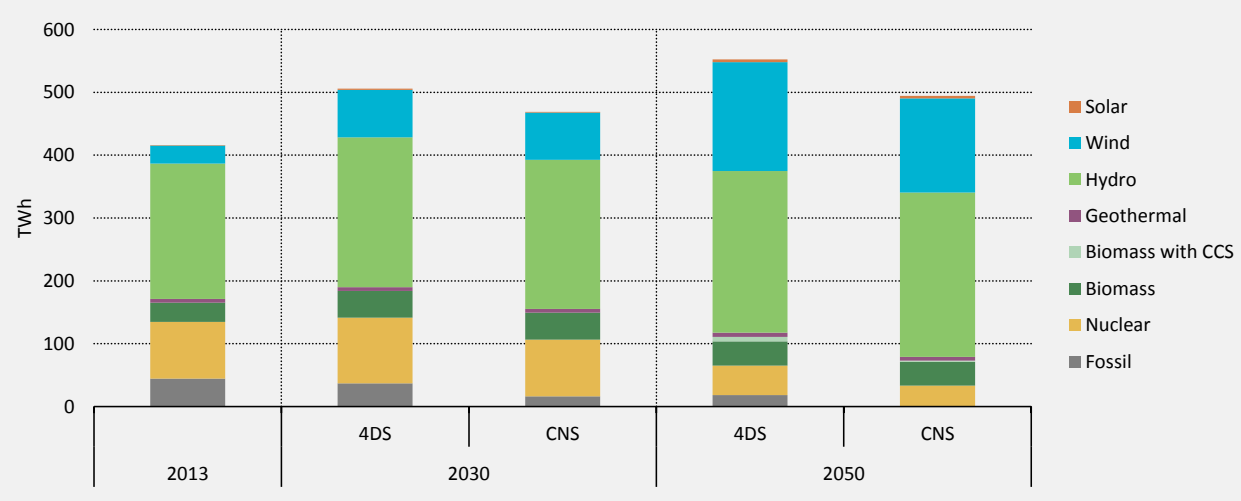

Figures and data in this report can be downloaded at www.iea.org/etp/nordic.

Key point Across all scenarios, hydro and wind power experience the largest growth in power generation, at the detriment of nuclear and unabated fossil fuel generation. 
In the CNS, wind power experiences the largest growth across all power generation technologies. Generation from on-shore wind grows over fourfold from 24 TWh in 2013 to 110 TWh in 2050, while off-shore wind grows eightfold to 40 TWh - albeit from a lower base of 5 TWh in 2013. In total, wind power generation almost doubles the total increase in power generation in the whole Nordic region out to 2050. In contrast nuclear generation falls by two-thirds, from 90 TWh in 2013 to 32 TWh in 2050, with all remaining generation in Finland.

In parallel with developments in Europe and elsewhere, the potential exists in Nordic countries for on-site generation in urban settings, which is reflected in the scenarios. The potential for distributed PV, however, is relatively small, given the quality of the solar resource and the high levels of relatively dense urbanisation. Total generation from solar is just above 4 TWh in 2050 in the CNS, although the total technical potential estimated in ETP scenarios for rooftop PV is 32 TWh. If met, it would signify around 6\% of electricity generation in the CNS. This amount of electricity is approximately equal to the annual demand from all electric vehicles on the road in 2050.

Even if the economics of other low-carbon generation technologies may be more attractive in Nordic countries, small-scale solar PV-investments are likely to develop more independently from the common Nordic electricity market because network costs and taxes are more important factors than the electricity price. From a system perspective, other options would appear more attractive, but investment subsidies are in place for solar PV, and other policies such as tax reductions for sales-to-grid could drive the economics and deployment of the technology.

Other sources could deliver additional distributed energy (Figure 1.19) - currently around 2 TWh of electricity and 20 TWh of heat are generated in urban areas from waste, with some waste imported. ETP estimates 8-10 TWh of electricity could be technically generated using indigenous waste sources, in addition to any imported resource.

\section{Figure 1.18 Net electricity trade of the Nordic Region (TWh)}

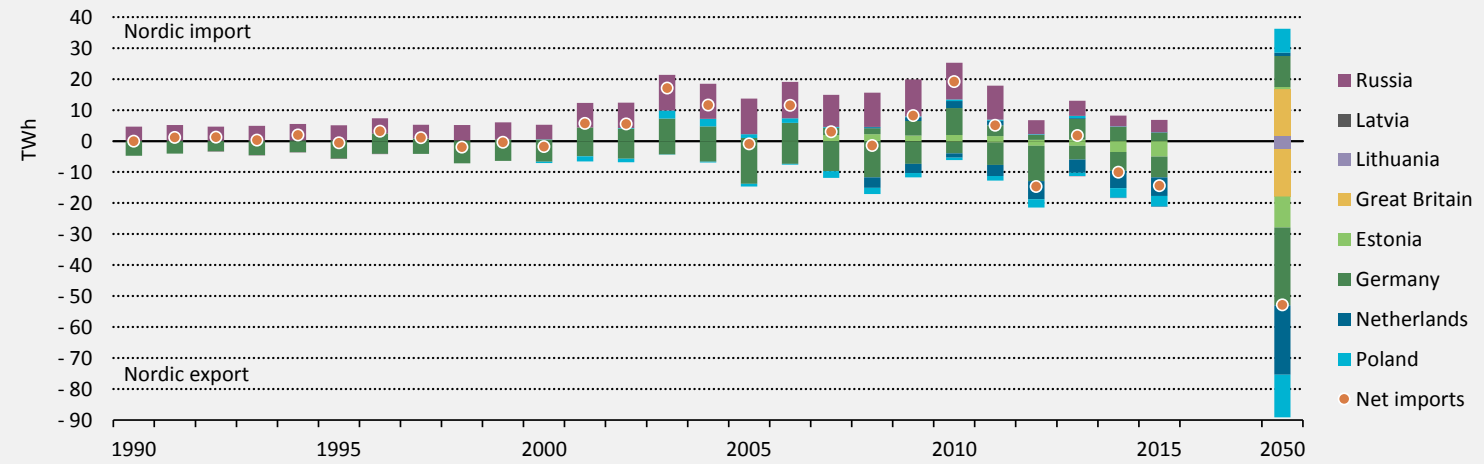

Figures and data in this report can be downloaded at www.iea.org/etp/nordic.

Key point The CNS sees a drastic increase in electricity trade flows. 


\section{Figure 1.19 Key technologies to reduce power sector $\mathrm{CO}_{2}$ emissions between 4DS and CNS}

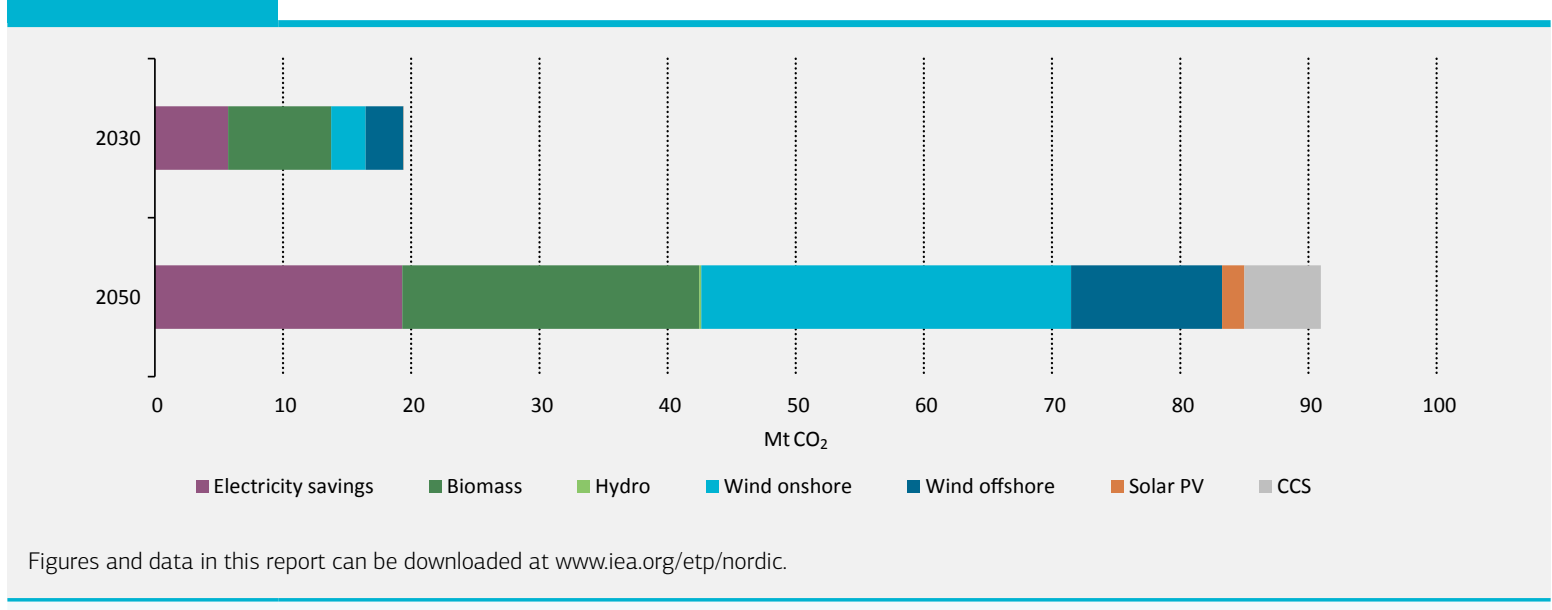

Key point

Decarbonisation in the Nordic countries requires the full spectrum of low carbon options.

\section{Biomass generation}

Plans are in place to increase deployment of biomass technologies to decarbonise electricity and heat generation, as well as transport and industry. In all low-carbon scenarios, competition increases and the sustainable biomass resource remaining in Nordic countries is not sufficient to meet demand from both. Almost 100\% of estimated sustainable biomass potential is used in the 2DS, and bioliquids need to be imported to decarbonise transport after 2030 - which implies an upward pressure on biomass prices. Given the lack of alternatives and the possibilities in the power and heat sectors, a strong rationale can be made to prioritise biomass use in the transportation and industrial sectors. However, a significant potential exists in the pulp and paper industry from on-site use of black liquor to generate power, and re-use waste heat for process use and for cascading down into district heating networks. CHP and heat generation from black liquor grows (threefold) in the CNS, with its use in district heating (doubling). In addition, biomass from co-firing and conversions of coal plant to biomass grows by $34 \%$, as refurbishment becomes attractive.

\section{Interconnection: Centralised vs decentralised decarbonisation}

The CNS sees a substantial and accelerated increase in transmission capacity (by around 5 GW before 2030), and cross-border power exchange. New interconnectors are developed both within Nordic countries and between the European continent and the Nordics. These interconnections, including a potential cable between Iceland and the United Kingdom, have the potential to further expose Nordic countries to market forces in EU28 countries, which could increase electricity prices. However, a strong counterbalance is possible, with developments in the electricity mix elsewhere in Europe into the future in the 2DS, which compensate somewhat for these effects. These issues are developed further in Chapter 3.

The CNS highlights the wide range of centralised low-carbon power generation options, the relatively high degrees of medium- to high-voltage infrastructure, and the inherent flexibility of the Nordic power system at the transmission level due to the dominance of hydropower. Coupled with a limited solar resource and relatively low density housing, the CNS sees little motivation for Nordic countries to strongly incentivise the adoption of rooftop PV and storage to achieve system-wide decarbonisation. Per capita, technical potential is estimated at 
$1100 \mathrm{kWh} / \mathrm{capita}$, out of which $40 \%$ is economically deployed. This level compares to a technical potential of $2200 \mathrm{kWh} /$ capita in the United States.

\section{Generating heat beyond 2020}

Given revised estimates of the energy efficiency potentials in Nordic buildings from the previous edition of NETP, demand for district heating decreases in NETP 2016 2DS down to 430 TWh in 2050 from 500 TWh in 2013. In the NETP 2016 4DS scenario, final energy demand for heat increases from 500 in 2013, to 530 in 2050. Both trends differ from NETP 2013, where district heating demand was projected to remain at current level (Figure 1.20). Also, the amount of CHP connected to district heating networks in NETP 2016 low-carbon scenarios declines. Industrial CHP, on the other hand, is mainly fuelled by black liquor in low-carbon scenarios, providing heat to the industry itself and some excess heat to district heating networks.

\section{Figure $1.20 \quad$ Heat production in DH networks}

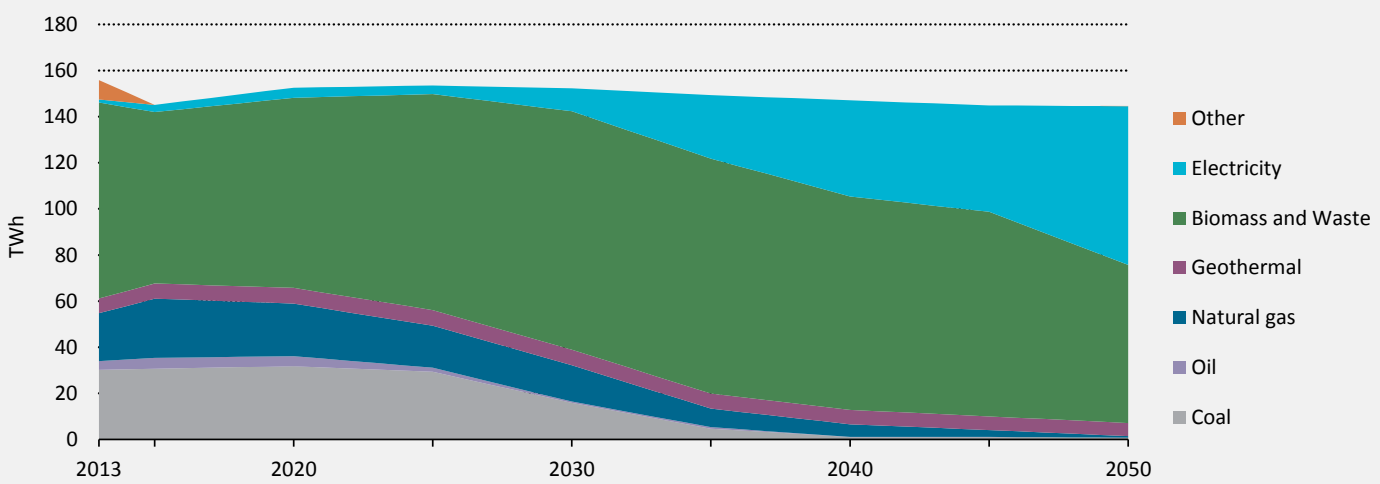

Figures and data in this report can be downloaded at www.iea.org/etp/nordic district-scale heat pumps, constrains new CHP capacity in the 2DS/CNS.

The key option for heat generation in district heating networks is the use of large-scale district heat pumps. The high COPs afforded by the larger sizes and the economies of scale make ground-source, geothermal or waste heat-driven heat pumps economic in 2DS and CNS lowcarbon scenarios. The main factor driving district-scale heat pump adoption in the 2DS and CNS is the dearth of options to generate $\mathrm{CO}_{2}$-free heat: most of the remaining biomass resource has to be prioritised for bioliquid production. While the CNS highlights the attractiveness of district-scale heat pumps from the perspective of cost-driven scenarios, strong tradeoffs exist between district- and small-scale heat pumps, because the latter are driven by private consumers with different preferences. Regardless, the diversification of district heating networks facilitated by a shift towards lower distribution temperatures requires a re-thinking of regulatory designs in future $\mathrm{DH}$ markets towards more open frameworks. 


\section{Key messages and actions}

- Nordic supply of power and heat is already quite decarbonised - emissions per unit energy delivered are below a fifth of the IEA average of $414 \mathrm{~g} \mathrm{CO}_{2} / \mathrm{kWh}$. All Nordic countries have progressed in the three years since the previous NETP, with carbon intensities averaging between a 15\% and a 38\% decline between 2011 and 2013.

- The economic and technical potential in the Nordic region is relatively limited for decentralised power generation options (namely, rooftop PV and storage), which are transforming electricity systems elsewhere in Europe. In contrast with decarbonisation strategies elsewhere, the CNS highlights the need for continued decarbonisation of large-scale power grids, which in turn drives the adoption of smaller-scale electric heating plant to both further decarbonise heat injected into district heating networks and provide balancing services for variable renewable plant.

- The uncertain future of nuclear power in the Nordic electricity system can be readily offset by other low-carbon options (see Chapter 3). The decision from Eon and Vattenfall not to invest in continued operation of existing plants is strong evidence that nuclear suffers from low electricity prices in current market conditions. Coupled with increased competition from renewables, the outlook for nuclear is weak.

- Future use of district heating requires large investments to adapt the old building stock to reduce heating loads. However, district heating could unlock large a variety of new sources of heat, including improving the attractiveness of district-scale heat pumps, low-grade waste heat and solar heat, as well as industrial waste heat from peri-urban areas.

- Increased flexibility is a key for cost-effective integration of variable renewables and more integration with continental Europe. Integration between electricity and district heating networks plays a key role with a still unlocked flexibility potential in the Nordic countries. Denmark has shown excellent examples of the possibilities for this type integration, which allow for the high levels of variable renewables in the CNS to be integrated at a lower cost

- For DH companies, the efficiency measures in buildings could be cost-beneficial if they are implemented in a system-efficient perspective. Investment in peak-load reduction (building envelope measures) will produce a much greater cost reduction, offering the possibility of expanding the network compared to measures that would only reduce the baseload. However, many areas will require that supply options for district heating be diversified and will favour a trend towards low-temperature district heating, and policies and strategies should be tailored to facilitate these options. 


\section{Spotlight 1: The Nordic bioenergy market}

\section{Recent trends}

Bioenergy plays an increasingly important role in the Nordic countries. This trend is especially the case in Denmark, Finland and Sweden, where bioenergy accounts for a substantial share of total gross consumption of energy (see Figure 1.21).

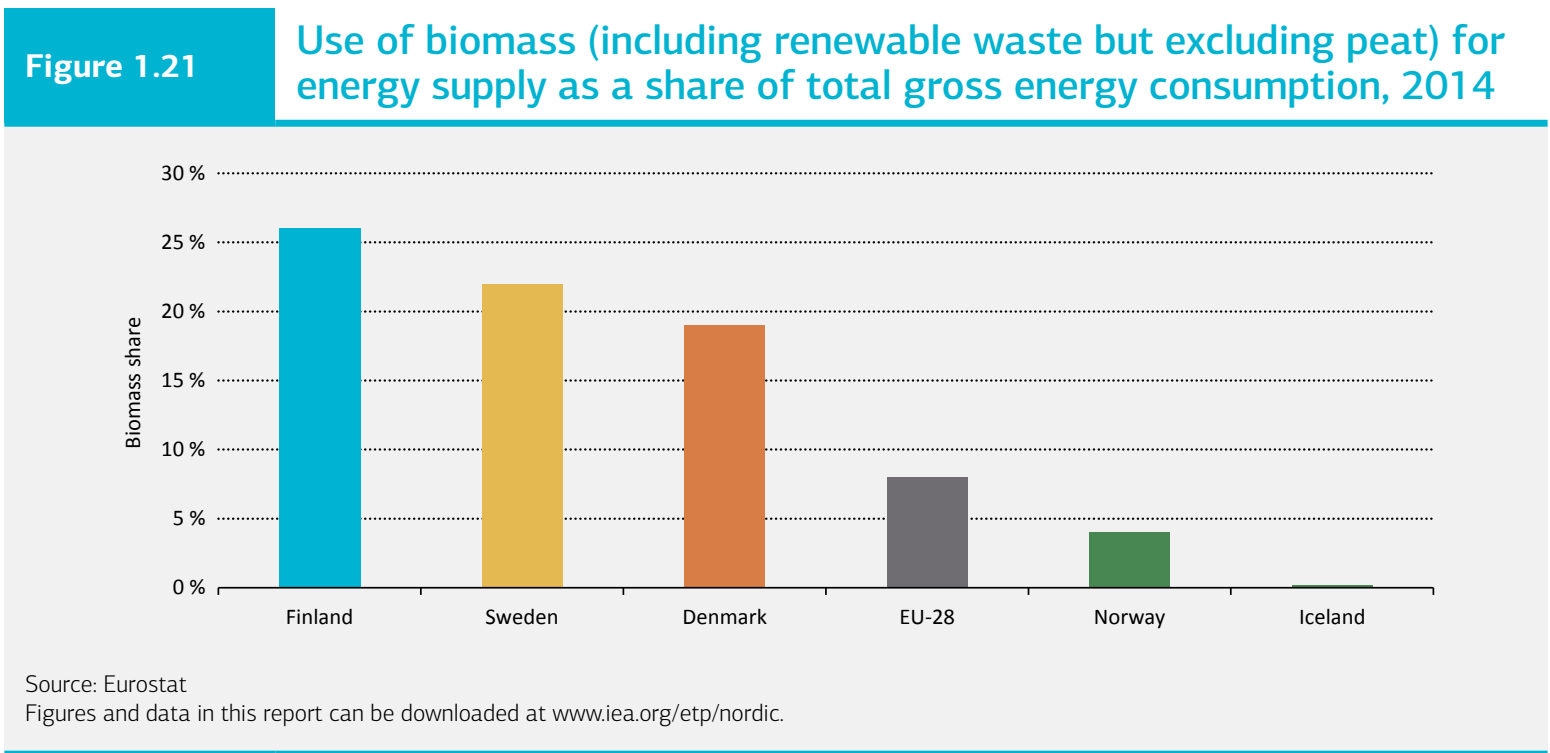

Key point

Bioenergy plays a key role in the Nordic countries and supplies a considerate amount of total gross energy consumption in Denmark, Finland and Sweden.

In Denmark, Finland and Sweden, the recent trends between 2010 and 2014 indicate a fairly stable bioenergy use within the electricity and heat sectors. In the transportation sector, however, the impacts of the EU RES targets are very clear: the use of biofuels has grown, especially in Denmark and Sweden and especially in the form of biodiesel. In Norway, the bioenergy use has grown in the district heating sector (both solid biomass and renewable municipal waste) and in the transportation sector (liquid biofuels) (NVE, 2014). In Iceland, the bioenergy use is very small and consists mainly of biodiesel and biogas use in the transportation sector.

\section{Domestic use and imports}

For 2013, a detailed assessment of biomass (different fractions), waste and imports/exports has been performed based on national surveys within the NETP research team. The results are shown in Figures 1.22 and 1.23. Sweden and Finland have the highest use, which partly can be explained by a large forest industry in both countries, which use by-products (especially spent liquors but also unrefined wood fuels ${ }^{3}$ from the production of sawn timber, pulp and

3 Unrefined wood fuels are e.g. forest residues, wood chips, wood dust and bark. Refined wood fuels, such as wood pellets and wood briquettes, are produced from unrefined wood fuels, usually through thermal treatment (e.g. drying) and mechanical treatment (e.g. grinding and compression). 
paper). Besides the forest industry, the largest consumption is within the power generation and district heating sectors; in Sweden and Finland, the fuels are mainly unrefined wood fuels. The Danish bioenergy use mainly consists of unrefined and refined wood fuels, solid agrofuels, and municipal and industrial waste. Power generation and district heating account for the largest bioenergy use in Denmark. In Norway, the bioenergy use is dominated by unrefined wood fuels in the buildings sector and municipal and industrial waste in the district heating sector.

\section{Figure 1.22}

Bioenergy use in 2013, by sector in TWh (including waste but excluding peat)

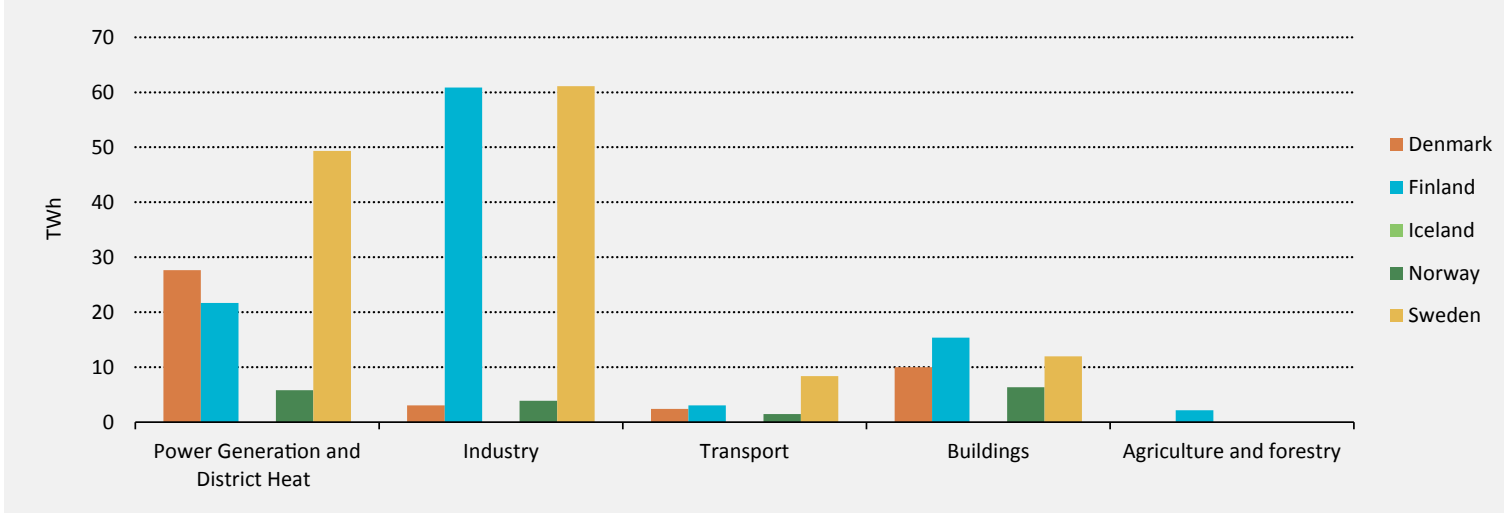

Figures and data in this report can be downloaded at www.iea.org/etp/nordic.

Key point

Power generation, district heating and industry are large users of bioenergy. Significant differences exist, however, between the countries.

Biofuels and refined wood fuels have the highest import shares in Denmark, Sweden and Norway, while Finland is a net exporter (Figure 1.23). The Danish, Swedish and Norwegian situation with imports of biomass with high energy density (biofuels for transport, refined wood fuels for power and heating) is comparable to other European countries. The import and export of municipal and industrial waste are mainly taking place between Sweden and Norway, and are explained by a large expansion of waste incineration plants within the Swedish district heating systems. Total net import of biomass for energy supply to the Nordic countries as a whole in 2013 amounted to approximately 25 TWh (total use of biomass in the Nordic countries currently amounts to roughly 300 TWh including waste). Out of this total import, net import of biofuels for transportation corresponded to some 6 TWh. 


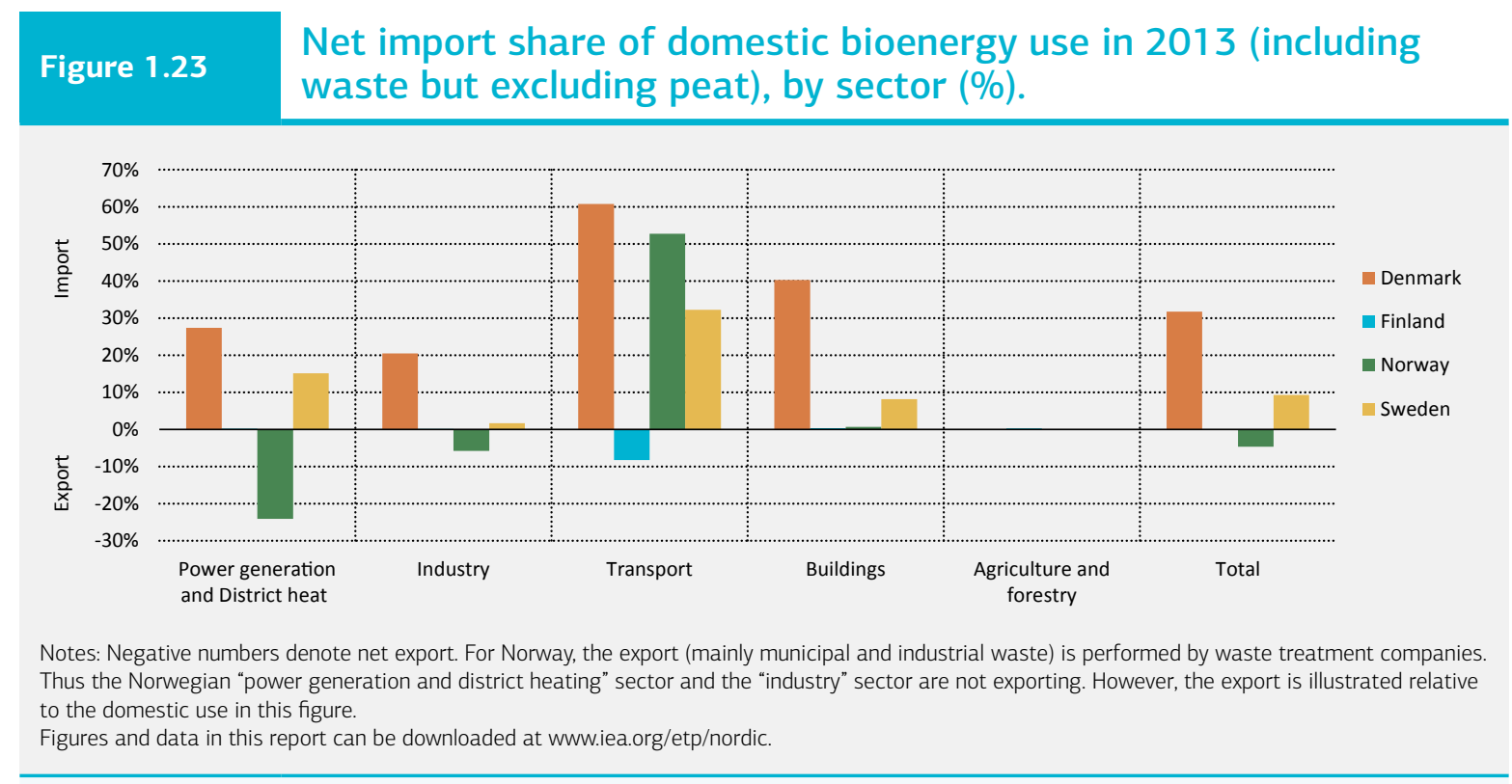

Key point Bioenergy import is significant in certain sectors, especially transportation.

\section{Medium-term outlook}

In a 2020 perspective, the use of biomass and other renewable energy sources (RES) is expected to continue to increase in the Nordic countries spurred by national and European energy and climate policy. However, circumstances exist that also may limit continued growth in the demand for bioenergy. For instance, the objectives defined in the EU Directive on renewables for 2020 (RED) have already been met or are very close to fulfilment among the Nordic countries. Sweden surpassed its overall target already in 2013 (reaching a RES share of around 55\% in gross final energy consumption compared to targeted 49\%), Finland met its 38\% overall target in 2014, while Denmark is expected to surpass its overall target in 2020 (reaching a RES share of over $40 \%$ in gross final energy consumption compared to targeted 30\%). Iceland also surpassed its overall target in 2013, while Norway performs better than its interim targets set out in both the NREAP and the RED, and is close to meeting its 2020 targets (EEA, 2015b; Danish Energy Agency, 2015).

Growth projections for bioenergy in Sweden by 2020 are somewhat limited for different reasons. One reason is the already very large share of biomass in district heating markets (which in itself exhibits limited growth and is facing strong competition from individual heat pumps and end-use efficiency measures). Another reason is the fact that targets for renewable electricity, as expressed by the common Swedish-Norwegian electricity scheme for 2020, are within reach (wind power is expected to take the major share of the remaining volume). In industry, modest economic growth within the paper and pulp sector, as well as continued energy efficiency, reduce the growth in demand for bioenergy (Swedish Energy Agency, 2014). In transportation, the RES share was almost 19\% in 2014 (including double counting of certain biofuels according to RED) and is expected to grow further to 25\% by 2017 (Swedish Energy Agency, 2015). Moreover, the Swedish government has a policy to have a fossil-free vehicle fleet by 2030 . 
In Denmark, the demand for solid biomass for energy supply is estimated to grow from around 25 TWh in 2013 to 42-43 TWh by 2020, depending on the ETS price (Danish Energy Agency, 2015). According to the Danish National Renewable Energy Action Plan (NREAP), growth of biofuels in transportation is significant and amounts to some 2 TWh between 2013 and 2020. Around $40 \%$ of the biofuel use in transportation in 2020 is reported as imported biofuels (including biodiesel and bioethanol) according to that source.

According to the Finnish NREAP, most of the RES increase is expected to come from increased use of solid biomass in energy production and, on the other hand, increased use of liquid biofuels in road transportation. This source is projected to involve mainly forest residues, which have received supports for both wood harvesting and electricity production in CHP plants. The growth of other renewables relates mainly to wind power and heat pumps. For the transportation sector, Finland has set the 20\% RES target, instead of the minimum 10\% set by the EU. Part of the biofuels are second generation, which are double-counted in the RED, resulting in a 15\% RES target in transport in energy terms.

In Norway, the goal is to double the bioenergy use by 2020 compared to the 2006 level (14 TWh) and to reach 28 TWh. The bioenergy use is expected to grow mainly in the heating and transportation sectors (NVE, 2014).

Since Iceland has abundant resources of hydro and geothermal energy for electricity and heating purposes, the use of biomass for energy supply is likely to be limited mainly to transportation (in competition with increased electrification). Thus, in a Nordic context, the potential growth of biomass for energy supply is small in Iceland.

\section{Outlook for 2050}

In a long-term perspective, the Nordic ETP modelling shows a substantially increased bioenergy use in the CNS. The total primary energy demand for biofuels and waste is expected to increase from 300 TWh in 2013 to almost 450 TWh in 2050, corresponding to an increased share of the total primary energy demand from $18 \%$ to $35 \%$.

The largest increase is seen in transportation, corresponding to almost 120 TWh by 2050 above current use. Around 50 percent of the increase in the transportation sector is supplied by increased imports (almost 60 TWh) of liquid biofuels for transportation (the current version of the Nordic ETP model does not include imports of non-liquid biomass). Thus, this increase is a dramatic change in net import of liquid biofuels from the current level of around 6 TWh as discussed in the previous section. Imported biofuels for transportation in the period 20302050 play an increasingly important role for most Nordic countries in the CNS scenario (Figure 1.24). However, the imported amounts of biofuels to the Nordic region are small in a global context, on the order of $1 \%$ of global liquid biofuel transport demand in 2050. The main exporting regions/countries for biofuels in 2050 are Russia (and some other countries of the Former Soviet Union), Latin America and Canada according to the Nordic ETP modelling.

In the other sectors, the changes in bioenergy use are less dramatic. The bioenergy use for heat and power is slowly reduced and drops by approximately 10\% during 2013-2050, while the final energy demand within industry increases by around 5\% in the same period. In the buildings sector, the final energy demand of bioenergy is reduced to one-third of its 2013 level. This amount is a large relative reduction, but in absolute terms (some 27 TWh reduction between 2013 and 2050), it is less significant compared to the changes in the transportation sector. To sum up, over the period 2013-2050, the bioenergy use for transportation grows ninefold to surpass buildings and industry and equal the demand from heat and power. 


\section{Net import of biofuels for transportation as share of each \\ Figure 1.24 country's total primary energy demand of biomass and waste for all sectors according to the CNS scenario (2015-2050)}

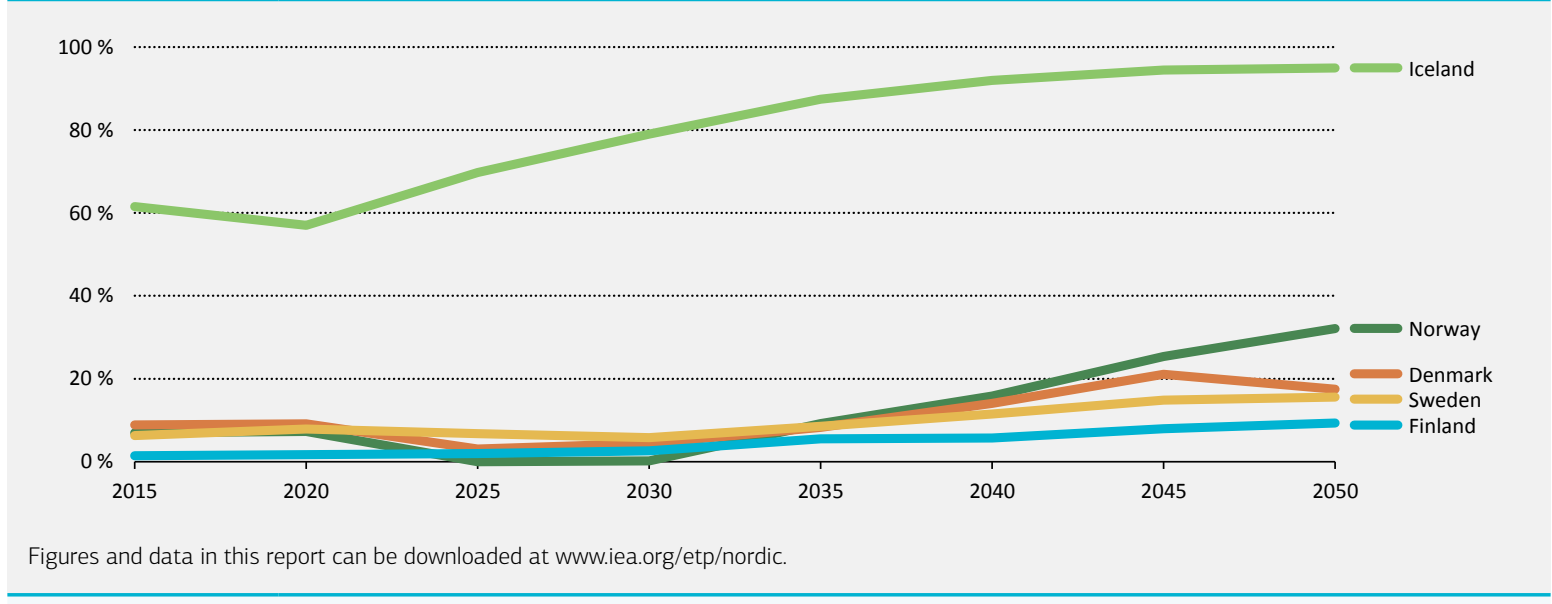

Key point A significant increase in biofuel imports is expected in the CNS scenario.

According to the Nordic Energy Research-funded research project ENERWOODS (Rytter et al., 2014), substantially increasing the harvest of forest fuels (tree tops, branches and stumps) within the Nordic region is technically possible. In 2050, the ENERWOODS project estimates technical potentials (with different restrictions and with various measures to maximise yield) in the range of 190-370 TWh/yr. Compared to current levels, these numbers indicate a possible increase in Nordic supply of at least 60-240 TWh/yr.

So, why is bioenergy import needed if large bioenergy potentials exist within the Nordic region? The most important answer is that it depends on price and availability. As mentioned, significant volumes of biomass are currently imported to the Nordic countries, both for use in the transportation sector and for stationary energy use. In Sweden, for example, several large combined heat and power plants are located close to a harbour but relatively far from domestic bioenergy resources. Import from the Baltic region by boat is an economically competitive option compared to inland transport by train or truck. The driving forces for import/export are to a large extent depending on policy instruments in each country that affect the paying ability for bioenergy. Furthermore, although the technical bioenergy potential might be large, the economic potential might be much smaller. In the case of forest fuels, for example, the major technical potential in Sweden is related to the use of stumps. The current market price and availability of other bioenergy types, however, make harvesting of stumps for energy use economically unfeasible (and potentially controversial because of biodiversity issues, for example), which explains why the current use of stumps in Sweden is very limited. Based on data from the Skogforsk annual survey among Swedish forest fuel producers (Skogforsk, 2014), and assuming the same price to the forest owner as for branches and tops, the price of stumps would be EUR 6-7/MWh higher than for branches and tops (delivered at the plant).

One reason for introducing additional policy instruments supporting domestic biomass resources could be goals on self-sufficiency (even though self-sufficiency might come at an extra cost). Another reason could be to have a larger possible influence on the sustainability aspects of the biomass production because introducing laws and regulations for domestic 
production is easier compared to imports. If and how policy instruments supporting the use of domestic/Nordic biomass resources should be developed is a question for further research.

The substantial net import of biofuels, as suggested by the NETP modelling, rests on a number of key assumptions that determine the balance between importing biofuels and producing them domestically in the Nordic region. Such assumptions include not only biomass-resource costs but also costs and technological development of conversion technologies (such as liquefaction and gasification) for producing biofuels in the Nordic countries or producing them in other regions of the world. The prospects of biofuel production are uncertain due to the relative immaturity of second-generation biofuels, for example, which are generally viewed as a key niche for the Nordic countries. Modelling an alternative development path for the technological development may alter the balance between imported and domestically produced biofuels.

Nordic cooperation and national efforts, including $R \& D$ activities, could make it competitive to further utilise the large technical potential in the Nordic region and thus decrease the Nordic import dependency of biomass compared to what is indicated by the Nordic ETP modelling, especially post 2040. Such a development would, however, require efforts to both reduce costs for domestic Nordic biofuel production and further exploit biomass resources.

\section{Decarbonising transport poses significant challenges}

\section{Recent trends}

\section{Activity}

In the first decade of the millennium, Nordic countries experienced rather stable passenger activity (measured in passenger-kilometres - pkm), with growing activity concentrated in passenger aviation (up by 55\%, in line with global growth in the sector). The share of aviation in passenger transport activity $(\mathrm{pkm})$ in each of the Nordic countries is also higher than the OECD average (26\% across all the Nordics versus $20 \%$ across the OECD). ${ }^{4}$ Iceland stands out as the Nordic country with the highest share of pkm per capita on aircrafts, ${ }^{5}$ as well as the highest share of freight (tonne-kilometres - tkm) per capita on ships.

In 2013, the most passenger transport activity took place in Sweden (one-third), followed by Finland, Norway and Denmark, each being responsible for about one-fifth (Figure 1.25). Only $3 \%$ of the pkm took place in Iceland. The national share of freight transport activity in the region was also highest in Sweden. The 25\% share of Norway in the Nordic total freight activity reflects the importance of oil trade in shipping. As in the case of passenger activity, Denmark and Finland were characterised by similar tkm, each representing $18 \%$ of the regional total. Iceland accounted for $3 \%$ of the Nordic region's freight activity.

4 From 2000 to 2013, according to IEA energy balances (IEA, 2015b), the share of domestic aviation final energy use out of total (domestic plus international aviation) final energy consumption had ranged between about 50\% and $75 \%$. No clear trend emerges from the historic time series, and IEA modelling does not delineate between domestic and international aviation activity.

5 Estimates of aviation activity include all domestic and outbound international pkm. 


\section{Figure 1.25 Passenger (pkm) and freight (tkm) activity mode shares in 2013}
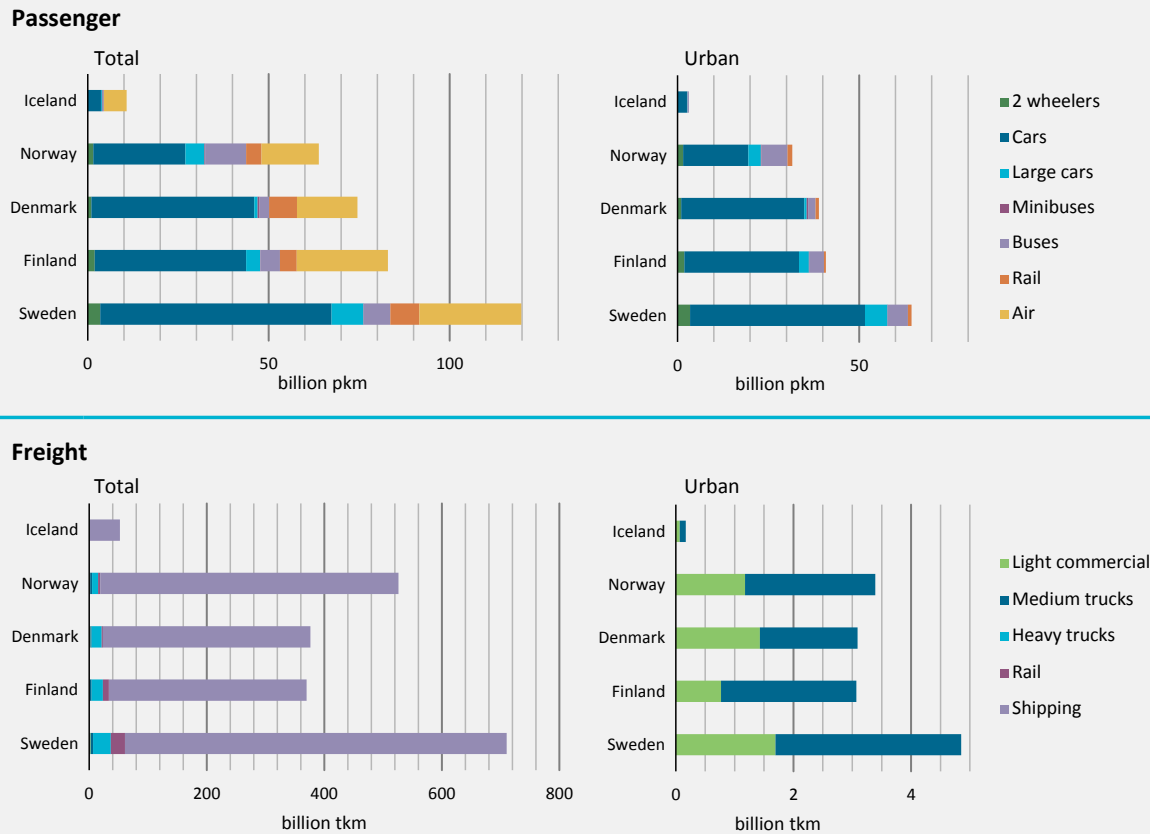

Source: IEA (2016b), Mobility Model, January 2016 version, database and simulation model, www.iea.org/etp/etpmodel/transport/. Note: Note that the volume of urban freight activity is less than ten times the total freight activity.

Figures and data in this report can be downloaded at www.iea.org/etp/nordic.

Key point

Due to their unique geography and high income levels, the Nordics are characterised by high shares of aviation in passenger activity, as well as high shares of marine shipping, complemented by low shares of rail activity in freight, relative to the OECD.

Denmark is the only Nordic country to have a significantly higher share of travel on rail (12\%) than the OECD average (6\%), while bus travel in Norway stands out with a pkm share significantly higher (18\%) than other Nordic countries and the OECD average (4\% and 7\%, respectively).

Freight in the Nordics is dominated by marine shipping - 93\% of total tkm are shipped by boat, versus $83 \%$ on average across OECD economies. In contrast, the share of freight transported by rail is much lower (2\%) than the OECD average (7\%). The combination of high shipping and low rail freight activity shares likely reflects once more the importance of oil exports from fields in the North Sea, as well as many facets of the Nordics' unique geography, including relatively low population densities, which reduce the cost-effectiveness of rail networks, coupled with relatively high ratios of urban centres accessible via navigable coastlines and river banks to landlocked populations.

\section{Energy use}

Total final energy demand by the Nordic transport sector totalled 1.2 (E)) in 2015, representing $26 \%$ of total final energy use in Nordic countries.

Passenger transport accounted for 52\% of transport energy use, and freight for the remaining $48 \%$. The share of freight on total transport energy consumption is higher than both the global 
and the OECD averages of $40 \%$ and $36 \%$, respectively. This difference is primarily a consequence of the high share of shipping activity on overall transport, the relatively energy efficient passenger vehicle fleets of Denmark and Norway and the per capita ownership level of personal vehicles (comparatively low, given the high personal income level of Nordic countries, when compared with the OECD average).

Sweden accounts for the major part of the transport energy demand in Nordic countries (more than a third total), followed by Finland, Norway and Denmark, each being responsible for an equal share of energy demand of about $20 \%$. Given its much smaller size in terms of population and economic activity compared to the other Nordic countries, Iceland only contributes marginally (about 3\%) to the region's transport energy use.

\section{GHG emissions}

In 2013, greenhouse gas (GHG) emissions from fuel consumption in the Nordic countries amounted to $42 \%$ of total energy-related emissions in the Nordic region (including international aviation and marine bunkers associated with the region). This share is far higher than the OECD average share of transport in economy-wide energy-related emissions (31\%). Iceland had the highest share of transport on total energy-related emissions (65\%), followed by Sweden (60\%), Norway (44\%) and Denmark (36\%). Only Finland (28\%) had a lower share of transport on total energy-related emissions than the OECD average (IEA, 2015a). However, these high shares are primarily attributable to the high share of renewable electricity generation sources.

Total transport emissions were evenly distributed between passenger and freight transport in 2013, with road modes being the top emitters in passenger as well as in freight transport.

From 2000 to 2013, the Nordics' transport-related GHG emissions decreased slightly (4\%), from 77.9 to $74.9 \mathrm{Mt} \mathrm{CO}_{2}$ eq (IEA, 2015a), at a slower rate than economy-wide energy-related emissions, which decreased by 15\% over the same time period. In 2013, Sweden accounted for $36 \%$ of the Nordic countries' total transport emissions, followed by Norway (22\%), Denmark (21\%), Finland (19\%) and Iceland (2\%).

In 2015, the emissions intensity of the passenger transport mix in the Nordic region (on a wellto-wheel basis) was estimated 18\% above the average of European OECD member countries, at $149 \mathrm{~g} \mathrm{CO}_{2} / \mathrm{pkm}$. The importance of shipping in the Nordic regions justifies an estimate of the GHG emission intensity of freight transport that is $18 \%$ below the average of the OCED Europe, at $21 \mathrm{~g} \mathrm{CO}_{2} / \mathrm{tkm}$.

\section{Urban transport}

The characterisation of urban and non-urban transport parameters outlined here builds on the following methodological choices:

- Passenger two- and three-wheelers have been considered to be exclusively urban modes.

- Passenger light-duty vehicles (PLDVs), buses and rail transport vehicles have been assumed to contribute both to urban and non-urban passenger transport.

- Passenger air transport has been entirely allocated to non-urban transport.

- Light commercial vehicles (LCVs) and medium freight trucks (MFTs) have been assumed to contribute both to urban and non-urban freight transport.

- Heavy freight trucks (HFTs), freight rail and shipping/navigation have been entirely allocated to non-urban freight transport. 
The methods used to disaggregate urban and non-urban vehicle stock, activity, and specific energy intensity are the same adopted for the analysis carried out in the 2016 Energy Technology Perspectives (IEA, 2016a). ${ }^{6}$

Urban passenger transport was estimated to account for $51 \%$ of the total passenger transport activity in the Nordic region in 2015. This percentage is in line with the OECD average, even if urban dwellers accounted for a larger fraction of the total population in the Nordic regions (85\% against 80\%) (UN, 2014). The urban passenger activity share was lowest in Iceland, primarily because of the high amount of pkm per capita for air transport (which is allocated to non-urban mobility).

The overwhelming majority of urban passenger transport energy use is due to cars (e.g. 79\% for Norway and 93\% for Sweden), followed by marginal contributions from urban rail, twowheelers and buses (Figure 1.28). Regional averages obscure the fact that certain Nordic cities are global leaders in implementing strong, effective road pricing schemes (cordon pricing in Stockholm; electronic urban tolls in Bergen and Oslo) and in providing accessible, reliable and safe walking and cycling infrastructure (Copenhagen). Other cities are test beds of innovative Mobility as a Service (MaaS) cooperative concepts aiming to maximise the opportunities offered by different transport providers and on a diversity of modes (Helsinki). Case studies of Nordic cities can be found in Chapter 2 .

Urban freight activity and energy demand in the Nordic countries mirror the global trend: very little freight activity (about 1\% of $\mathrm{tkm}$ ) takes place in urban regions, but urban freight transport accounts for a sizeable share (20\%) of total urban transport energy demand. This share is explained by the substantially higher energy intensity $(\mathrm{MJ} / \mathrm{tkm})$ of light commercial vehicles and mid-duty trucks operating in urban areas compared to other freight transport modes.

As such, urban freight offers opportunities for targeted action on a small subset of the truck fleet primarily used in metropolitan areas. Given their commitment to reducing transport emissions, Nordic countries could experiment with solutions such as switching to low-carbon fuels (e.g. via hybridisation and electrification, or through switching to biogas or low-carbon biodiesel sources such as food and municipal waste). Plug-in hybrid electric truck configurations, for instance, could be stimulated by local policies restricting the use of internal combustion engines (or prioritising access for trucks running in electric mode) in urban neighbourhoods subject to higher exposure to local air pollution on daily times characterised by higher congestion levels. Novel ways of optimising operations and logistics, building on the increased availability of information technologies and sharing/pooling opportunities to minimise empty running, rely more on larger vehicles and reduced travel distances (effectively a strategy allowing reducing transport activity) offer further potential in this sector to deliver significant results in pollutant and $\mathrm{GHG}$ emissions mitigation in the urban environment.

6 This disaggregation was performed using a combination of assumptions, such as the methodological choices made for the modal allocations, regression analyses and CIS methods. GIS methods were applied to characterise urban regions with differing densities and urban areas suitable for the deployment of high-capacity public transport. Regressions were used to fill data gaps, e.g. combining comprehensive information available in specific records with datasets having a wider global coverage but a lower degree of detail. In particular, the allocation of vehicle stocks into urban or non-urban categories was made according to the percentage of the population designated as urban versus non-urban by the United Nations in their 2014 World Urbanization Prospects revision (UN DESA, 2014). Estimates on urban and non-urban mileages were derived on the basis of assumptions on average travel time and data on the average speed in urban areas from the UITP Millennium Cities Database (Kenworthy and Laube, 2001) and following updates. Fuel economies have been assumed to be 10\% worse (when measured in L/100 km) in cities than average fuel economies calculated combining urban and non-urban driving. In the case of the Nordic countries, the estimated gap between urban and non-urban fuel economy reflects the magnitude of the gap emerging from testing procedures carried out on urban and non-urban driving cycles. 


\section{Current policies and goals}

The Nordic countries are among the global leaders in terms of implementing policies to promote sustainable transport and to decarbonise the transport sector. Denmark, Sweden and Norway have ambitions of complete carbon neutrality (including transport) by 2050, while Finland targets an 80\% CHG reduction and Iceland a 50\%-70\% reduction in GHG levels (both relative to 1990 levels). Even more ambitious goals have been set for Nordic cities: for instance, Copenhagen has set a goal to achieve carbon neutrality by 2025, and Oslo aims to reduce its GHG emissions by 95\% relative to 1990 levels by 2030 .

Energy and fuel taxes are ubiquitous among Nordic countries, and though the level of taxes on gasoline and diesel automotive fuel varied in each of the Nordic economies, automotive fuel taxes (both for gasoline and diesel) in the Nordics are among the highest in the world (Figure 1.26) (Parry et al., 2014; Wagner, 2014). Diesel tended to be taxed at lower rates (in both in terms of carbon emissions and in absolute terms) than gasoline.

\section{Figure 1.26 Fuel taxes as percentage of total fuel price, 2011-2013}

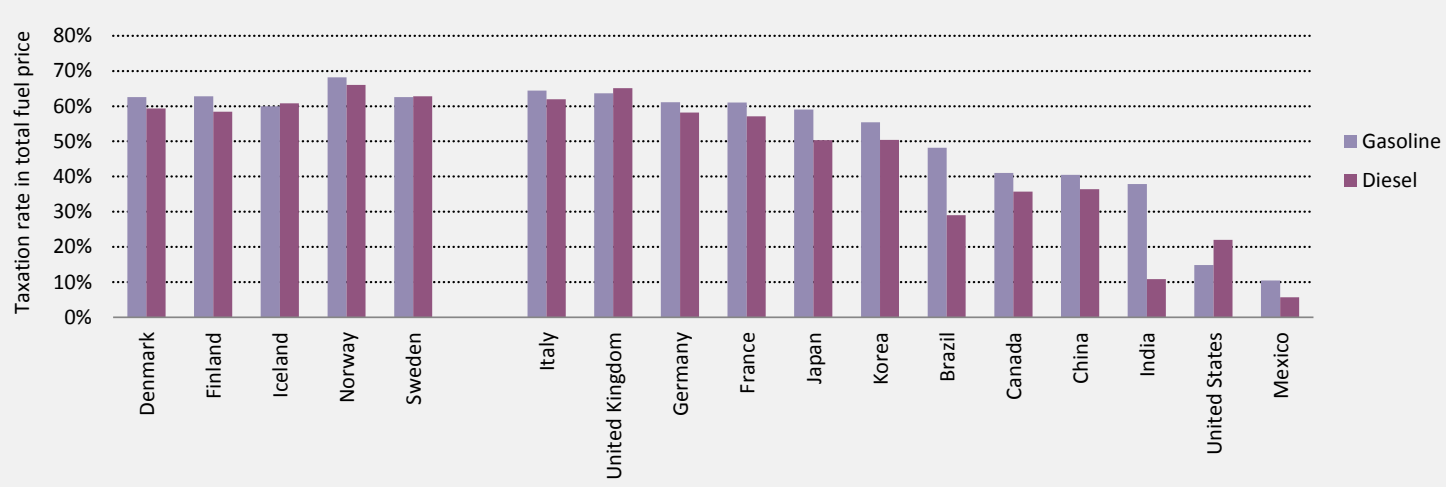

Sources: IEA analysis based on GIZ (2014), International Fuel Prices 2012/2013, Eighth Edition.

Figures and data in this report can be downloaded at www.iea.org/etp/nordic.

Key point

Fuel taxation rates in the Nordic region have a similar magnitude to those applied in major European economies and are among the highest in the world.

The 2014 GHG emissions per $\mathrm{km}$ of new passenger cars fell below the average values of the European Union (123.4 $\left.\mathrm{g} \mathrm{CO}_{2} / \mathrm{km}\right)$ in Denmark (110.2 $\left.\mathrm{g} \mathrm{CO}_{2} / \mathrm{km}\right)$, but above the EU average in Finland (127.4 $\left.\mathrm{g} \mathrm{CO}_{2} / \mathrm{km}\right)$, Sweden (131.0 g CO $\left./ \mathrm{km}\right)$ and Iceland $\left(135.5 \mathrm{~g} \mathrm{CO}_{2} / \mathrm{km}\right)(\mathrm{EEA}$, 2015a). Norway was the first country in Europe to have emissions from new cars under the $100 \mathrm{~g} \mathrm{CO}_{2} / \mathrm{km}$ threshold, with $96 \mathrm{~g} \mathrm{CO}_{2} / \mathrm{km}$ ) in the first six months of 2015 (Lagercrantz, 2015).

Norway's successful result stems from policy support that enabled it to lead the world in EV sales, with market shares close to 25\% in 2015 (Gronnbil, 2015) (Box 1.3). 
Thanks to aggressive policy actions, Norway has the world's highest sales shares of electric vehicles (EVs). In 2015, nearly $25 \%$ of cars sold were batteryelectric vehicles (BEVs) and plug-in hybrid electric vehicles (PHEVs). High sales of EVs must be seen in the context of Norway's high taxes on vehicle purchases and on fuels. The country's high registration taxes are broadly based on vehicle emissions performance. The current tax scheme incorporates four elements: $\mathrm{CO}_{2}$ emissions, $\mathrm{NO}_{\mathrm{x}}$ emissions, weight (kg) and engine size (horsepower) (Bu, 2015). Registration taxes averaged USD 13500 in 2015 (Bu, 2015). In addition, value-add taxes of 25\%, averaging USD 9500 for a new vehicle (Bu, 2015), are levied on new vehicle purchases.

The Norwegian support scheme for EVs began in 1990 with exemption from vehicle registration taxes, and was gradually strengthened through 2003 to include most of the critical elements that it retains to date $(\mathrm{Bu}, 2015)$. Those elements include road and congestion toll exemptions, free parking, zero VAT and access to dedicated bus lanes. To ensure that bus lane access for EVs does not compromise public transit operations, they are not extended in certain cases, as for instance in Oslo during peak congestion hours. Beginning in 2016, other municipalities will have the option of restricting the allotment of free parking and bus lane access at a local level (Bu, 2015). This arrangement, wherein national measures provide a supportive, but not prescriptive, framework for municipal measures to combat local impacts of transport (e.g. health, air pollution, congestion and safety), is a prime example of national policies enabling more targeted and flexible local measures.

The first coordinated, nationwide roll-out of public charging infrastructure began in 2009-2010, during which time nearly 1800 new normal charging points were installed (Bu, 2015). Over the next five years, national government subsidies for public charging installation and operations were gradually devolved to local authorities. By 2015, more than 300 fast or "semi-fast" charging stations had been built, and more than 6040 public charging points were in operation (Bu, 2015). Plans to provide charging stations across the country's entire road network by 2016 are on schedule (Bu, 2015). A public, open-source database provides data on charging stations locations to drivers, and updates the availability of charging points in real time.

Despite having already implemented the above policies for more than a decade ago, Norway's xEV sales shares are a very recent, and unforeseen, phenomenon (Holthe, 2015). The long time lag between policy adoption and market penetration may stem from an evolving vehicle offer profile, characterised by a significant evolution in terms of consumer appreciation between early models and vehicles currently available on the market, suggesting that the Norwegian EV support policy effectively contributed to the EV market development. The long time lag also offers some evidence that clear and consistent policies are necessary to achieve a successful market transformation.

Norway's purchase and VAT tax exemptions were funded through transfers of revenue accumulated from taxes levied on conventional cars. They have always been explicitly formulated to be temporary measures meant to initiate EV market development. The VAT exception is slotted for removal in 2018, and the registration tax exemption in 2020 (Holthe, 2015). The registration tax system will be reformed in the 2020s to put greater emphasis on new vehicles' combined performance on NOx and $\mathrm{CO}_{2}$ emissions, and stringency will continue to increase (Holthe, 2015).

EV support policies are based upon the possibility of decarbonising transportation (thanks to the lowcarbon intensity of the Nordic electricity mix) and on the potential of reducing costs through technological learning. Recent assessments show that battery costs (the most relevant cost component for EVs) have fallen more rapidly than researchers and analysts initially expected (Nykvist and Nilsson, 2015). Further reductions are needed for EVs to compete without subsidies with incumbent technologies. Ambitious manufacturing developments announced by electric carmakers and battery manufacturers, who aim to double production of lithium 
ion batteries over 2013 levels by 2017 (Tesla, 2014), bode well for cost savings. New chemistries, such as aluminium-ion, may enable further cost reductions.

Over the next decade, widening support for EVs across different economies may increase their competitiveness with other technologies, even if technology cost reductions tend to deliver diminishing returns over time: the EV purchase cost gap may fall to within about 10\% of the cost of a conventional car with an improved spark-ignition ICE (IEA, 2016b). Policy instruments should be conceived in a way that allows their progressive phase-out once the consumer cost differential between EVs and ICE alternatives begins to disappear.

Continued policy support is important to build on initial developments, stimulating additional savings arising from technological developments. On the other hand, the EV policy support should not underestimate effects on overall car travel, congestion, as well as impacts on the quality of public transport services. Policy makers should also consider the oft-cited critique that the existing scheme translated to extremely high costs per unit $\mathrm{CO}_{2}$ abated (Holtsmark and Skonhoft, 2014).

The declining importance of fossil fuels following the successful deployment of EVs would also lead to significant changes in the level of government revenues leveraged from fuel taxation. This observation suggests that EVs may only become economically viable in the presence of a switch in the way governments seek revenue streams, such as an evolution towards road usage charging, taking into account wider social and environmental costs of transport (e.g. road damage, congestion and fossil fuel dependence), or other relevant fiscal reforms.

Norway also has recently deployed the first electric ferry service, opening up the electrification option for maritime transport services covering short distances (Adolfsson and Breivik, 2014; Mjøs, 2014; Røe, 2014 and Späth, 2015).

Sweden announced its intentions to transition to a feebate ${ }^{7}$ vehicle tax system much like Norway's (see Box 1.3), using the revenues generated by taxation on vehicles with comparatively poor fuel economy to incentivise those having the best fuel economy performances, including EVs (Palm, 2015). Sweden is further supporting the roll-out of public charging infrastructure and electric buses, and has the intention to work on demonstration-scale inductive charging road infrastructure, which allow EV batteries to recharge while driving (Meyer et al., 2014). Sweden has also recently launched demonstration projects to test the economic and technical viability of highway electrification (Siemens, 2015).

Furthermore, Sweden has a preferential treatment of biofuels with respect to taxation. Biofuels are exempt from the tax on $\mathrm{CO}_{2}$ tax components applied to energy products (OECD, 2014), which was recently extended. This exemption helps to explain why Sweden is the leading Nordic country in terms of biofuel shares in transport, with a share of renewable fuels (excluding international bunker fuels) exceeding 16\% in 2015 (Eurostat, 2014). Compressed natural gas (CNG) and landfill methane, purified into CNG, can also reduce transport emissions, and are promising alternative fuels for long-distance transport. Sweden is leading the Nordics in refining biogas for transport, with shares of biogas in total final energy for transport reaching $1 \%$ in 2013 (IEA, 2015b).

Denmark applies high vehicle taxation rates on cars compared to global and even EU averages. The registration tax, in particular, has the magnitude of the vehicle price with VAT (OECD, 2008). These measures explain why passenger vehicle ownership in Denmark (this is also the case in Norway) is low compared with countries of comparable per capita income. A registration

7 Feebates combine fees on vehicle registration / purchase taxes on high $\mathrm{CO}_{2}$ intensity vehicles with rebates on high-efficiency and low-emitting vehicles. Differentiated taxation under feebate schemes can be constructed to be revenue neutral, or it can serve as a source of revenue (e.g. for public transit or electric vehicles) 
tax reduction is in place for energy-efficient cars. Electric and hydrogen cars were also exempted from the registration tax through 2015 (IEA, 2013), but this advantage is slated to be phased out in 2016.

Iceland introduced a carbon tax on most fossil fuels in 2010, with a rate reflecting approximately $50 \%$ of the price of emission allowances in the EU Emissions Trading System (EU ETS) at the time - i.e. about EUR 14 per tonne of $\mathrm{CO}_{2}$ (OECD, 2014; Shafiei et al., 2014). The tax was raised to 75\% of the ETS price in 2011 (Shafiei et al., 2014). Iceland is also applying a $\mathrm{CO}_{2}{ }^{-}$ related differentiation of excise tax rates (with tax exemptions for vehicles with the best fuel economy, and tax rates rising progressively, up to $65 \%$ of the vehicle value, with increases in the specific fuel consumption) on vehicle purchases since 2011, as well as a $\mathrm{CO}_{2}$-differentiated annual tax on vehicle use (OECD, 2014a).

Starting in 2007, Finland began to levy vehicle purchase and annual circulation taxes on cars, both of which are differentiated according to emissions in $\mathrm{g} \mathrm{CO}_{2} / \mathrm{km}$. Under current legislation, the purchase zero-emission vehicles is taxed at 5\%, and the maximum tax rate of 50\% applies to cars with emissions intensity exceeding $360 \mathrm{~g} \mathrm{CO}_{2} / \mathrm{km}$. Annual registration taxes are also scaled according to $\mathrm{CO}_{2}$ emissions, and range from about EUR 70 to 620 per year (MoE, 2015).

Finland also sits at the forefront of advanced biofuels industry, with a focus on the domestic production of drop-in advanced biofuels. The country is capitalising on a strong background in research and development for bio-refining and biofuels, its forest resources and a strong bio-economy. A range of private-sector companies have stepped forward, including commercialscale bio-refineries using hydro-treatment to produce renewable diesel from a range of wastes and residues. This trend includes the commissioning of a 120 million litre per year capacity plant in early 2015, as well as smaller applications focusing on installing technology on site to use industrial wastes from the food and drink industry.

\section{Prospects}

Vehicle emissions standards across the Nordics follow the ambitious EU targets of reducing average new vehicle emissions to a maximum of $95 \mathrm{~g} \mathrm{CO}_{2} / \mathrm{km}$ by 2021 . Both the $4 \mathrm{DS}$ and the CNS scenarios reflect successful achievement of this target, which require a steep downward trajectory for average fuel consumption of new vehicle sales through 2020. Thereafter, in the 4DS, the rate of improvement gradually levels off through 2050. As a result, national passenger LDV fleets improve from their current (2015) average fuel economies of 4.2 to 5.4 Lge/100 km, reaching 3.1 to $3.9 \mathrm{Lge} / 100 \mathrm{~km}$ by 2050. In the CNS scenario, the efficiency of new vehicles continues along roughly similarly ambitious trajectories from 2015 to 2020 through mid-century. The result is that national passenger LDV fleets average 2.4 to 2.9 Lge/100 km by 2050, thanks to the increased deployment of energy-saving technologies.

Realising the EU $2021 \mathrm{CO}_{2}$ emissions target on new vehicle sales requires not only fuel efficiency improvements on existing technologies but also rapid penetration of alternative drivetrain technologies such as hybrids and electric vehicles (e.g. BEVs and PHEVs). Low-carbon fuel alternatives to gasoline and diesel, such as biofuels or CNG (including CNG derived from biogas), will also need to contribute to meet the targets.

In the CNS, the rapid penetration of EVs eventually translates to a shrinking stock of conventional ICE vehicles, which begins to decline from 2025 (Figure 1.28). In the 4DS scenario, in contrast, the stock of conventional ICE vehicles stabilises and remains roughly at current levels through 2050. Strong diesel LDV sales over the second half of the 2000s have led to a high proportion of diesels in the LDV stock in 2015. However, given recent discoveries involving the discrepancies between tested and on-road emissions of local pollutants and a likely increase in the market penetration of hybrids (to comply with fuel economy standards), 
the rise of diesel in the ICE fleet will likely plateau or decline in the coming decade, even in 4DS. In the CNS, alternative powertrains such as hybrids, plug-in hybrids, and battery-electrics begin to account for substantial and increasing stock shares beginning around 2025. A nearly complete phasing-out of conventional ICE vehicles by 2050 will be needed to reach full decarbonisation ambitions. New registration shares of EVs for PLDVs reach nearly $70 \%$ in 2050, well above the OECD average of 55\%. By mid-century in the CNS, battery-electric vehicles represent the majority (60\%) of vehicles operating across the Nordics (against 45\% as OECD average). Norway's policies, oriented toward support for EVs, place the country at the forefront of the early and widespread EV adoption characterising the CNS scenario (see Box 1.3 for more on the policies that Norway adopted to achieve their EV targets).

\section{Figure 1.27 Energy flows in Nordic transport, 2015 and 2050 in the CNS}

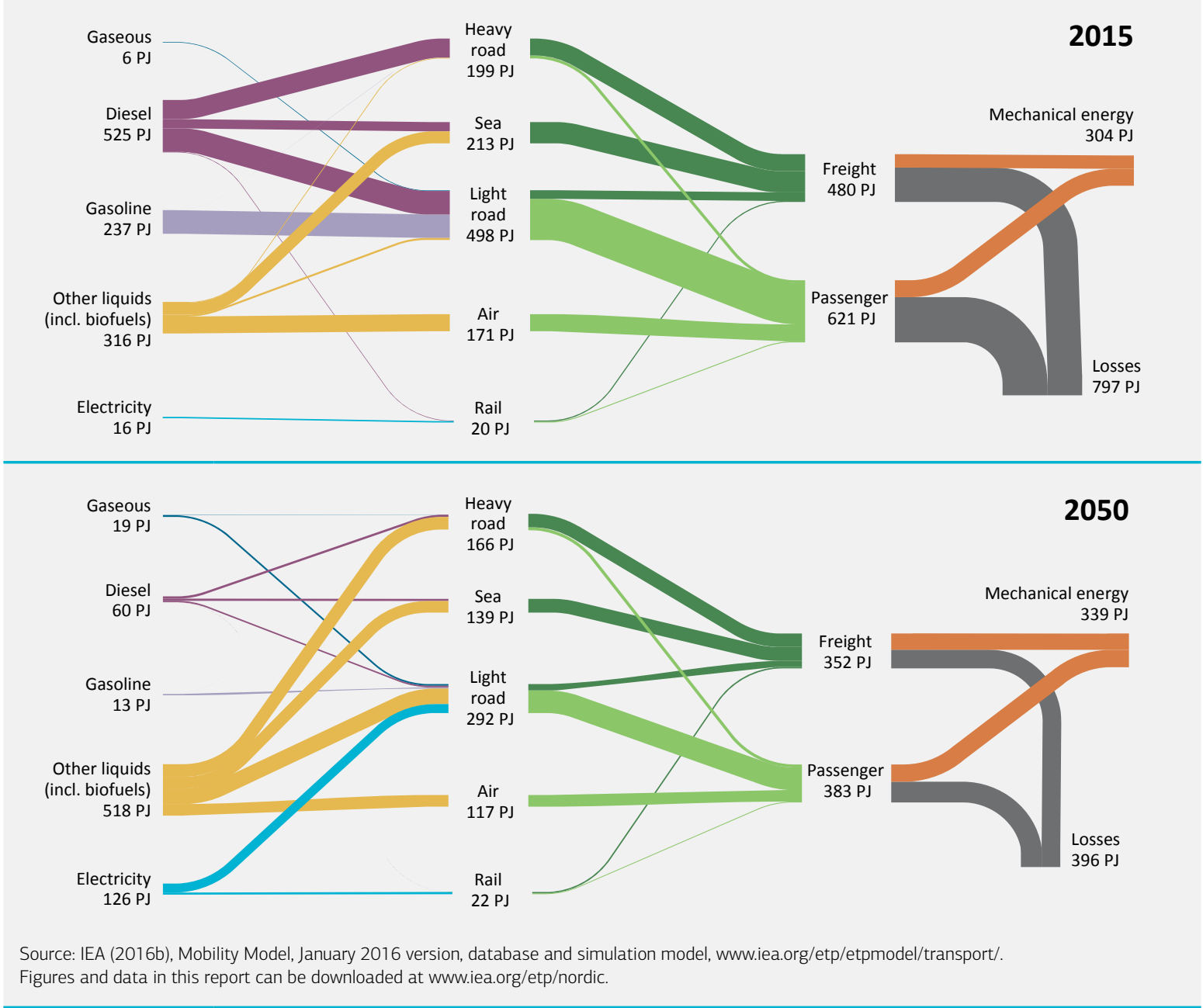

Key point Nordic transport becomes more efficient towards 2050 in the CNS, transitioning dramatically from fossil fuels to biofuels and electricity. 
By 2050 in the CNS, biofuels comprise nearly two-thirds (63\%) of total final energy use in transport, with Sweden accounting for more than one-third (36\%) of this consumption. The large Swedish share reflects that country's policy support for a diversified energy mix featuring biofuels as the primary low-carbon alternative fuel in heavy, long-distance transport modes (e.g. HDVs, shipping and aviation).

In the 2016 edition, Nordic Energy Technology Policy (NETP) scenarios are founded on a critical reassessment of the potential of biofuels in general, and of first-generation biofuels in particular. In the past five years, conventional biofuels have confronted challenges on many fronts - technological, economic, environmental and political. These challenges include continued issues related to maintaining economic competitiveness with products of petroleum in the absence of mandates or subsidies, or both, particularly in periods of low oil prices. Other challenges include growing concerns, mounting evidence, and continued controversy regarding the potentially detrimental consequences of land-use change and the impacts of marketmediated impacts on the actual carbon footprint of biofuels. The latter concern ultimately led to a reassessment of biofuel mandates in the EU. One consequence of these developments is the postponement of the market uptake of biofuels in all scenarios. In CNS, this postponement translates into a delayed development, scale-up and wide-scale market deployment of low-carbon (advanced or second- and third-generation) biofuels. This near-term deployment of low-carbon biofuels production pathways is itself technology-optimistic and based on an assumption of successful policy support (including RD\&D funding and mandates or other market-based incentives).

Nordic countries already widely implement many of the key policies that result in limiting the growth of car ownership. In addition to high national-level fuel and vehicle taxes across the Nordics (vehicle taxes are particularly high in Norway and Denmark), many regions and municipalities in the Nordics (including Stockholm, Oslo and Bergen) have implemented road pricing, road tolls and access restrictions in city centres. The result is that the potential for further decreases in vehicle ownership per capita are more limited in the Nordics than elsewhere. Vehicle ownership per capita grows at a very low rate, following similar trajectories in both the 4DS and CNS scenarios over the coming decades.

Another consequence of the already strong pricing and regulatory policies restricting the utility of owning and operating cars in the Nordics is the potentially limited efficacy and future potential of avoid/shift measures (where avoid indicates the reduction of the need to travel, e.g. due to shorter trip distances or fewer trips per day, and shift designates modal shift from personal cars to other less energy-intensive modes, such as public transit and walking/biking). In other words, since the Nordics are already global leaders in reducing dependence on personal cars (once their high average income levels are factored in), modelling results suggest that further gains in avoid/shift measures might be difficult to achieve and limited in magnitude; it is difficult to further enhance performance when the bar is high. Although these insights are valid as a matter of forecasting based on historic experience, they cannot predict the impacts of novel technologies or shifts in cultural/behavioural paradigms. As such, the potential of avoid/shift levers might indeed be limited, but it should not be discounted out of hand.

Indeed, the ambitious initiatives of cities such as Oslo and Helsinki suggest that further emission reductions could be achieved through new policies (such as Oslo's efforts to reduce car traffic by $20 \%$ by 2020) and novel mobility services (such as Helsinki's pioneering in MaaS). New paradigms and approaches seem warranted not only as a means of achieving Nordic cities' ambitious mitigation goals, but also as a way to conceive, develop, and test novel approaches that might be adopted globally. 


\section{Figure 1.28}

\section{Technology penetration in the urban and non-urban vehicle stock} in the CNS and 4DS

\section{Cars and light commercial vehicles}
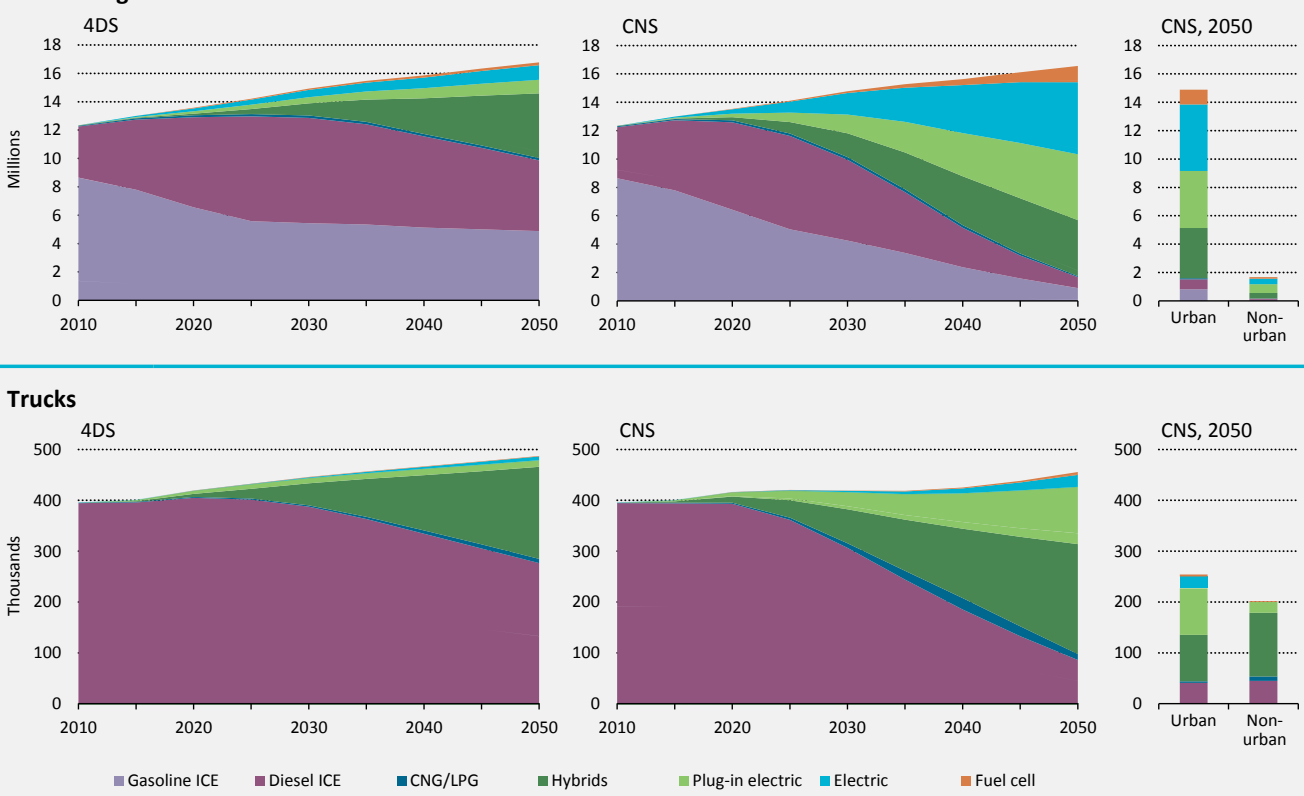

Source: IEA (2016b), Mobility Model, January 2016 version, database and simulation model, www.iea.org/etp/etpmodel/transport/. Figures and data in this report can be downloaded at www.iea.org/etp/nordic.

Key point

Electrification of light-duty vehicles and of trucks (MFTs and HFTs) is a key component of decarbonisation of the transport sector. To achieve the CNS, one-quarter of LDVs and nearly one-half (47\%) of trucks must run on hybrid drivetrains, and another twothirds of LDVs and nearly one-third (31\%) of trucks must be EVs (including PHEVs, $B E V s$, and fuel cell electric vehicles [FCEVs]).

In light of the above considerations, improve strategies toward decarbonising mobility developments in vehicle efficiency and in the production and adoption of low-carbon fuels take on increased significance in the Nordics. Strategies should pursue a portfolio of technologies aimed at maximising abatement potential and accounting for the unique characteristics of each mode. Biofuels are best suited for liquid fossil fuels for long-distance, heavy-duty road and marine freight and aviation. Electric or hydrogen vehicles relying upon electricity generated from renewable sources are best suited to replace fossil fuels in urban, light- and mid-duty freight, and short distance passenger trips. Long-term prospects for hydrogen fuelcell electric vehicles (FCEVs) are limited, even in the final decade of the CNS, by competition with conventional electricity storage technologies (namely pumped hydro storage) and to some extent limited availability of low-cost excess electricity thanks to better integration of electricity markets. The limited uptake of hydrogen and FCEVs in CNS also reflects the high investment risks represented by the need to shift to centralised hydrogen production (a requirement to make sure that hydrogen can be produced at affordable costs) (IEA, 2015d) and to build up an adequate (and costly, especially in a region with low density of population) hydrogen distribution infrastructure. A strategic decision by Nordic countries to collaborate around infrastructure for gaseous fuels could potentially make prospects for hydrogen vehicles brighter. 
The onus on technological developments to deliver the largest part of carbon savings is reflected in the continuous growth of passenger and freight activity until 2050, with broadly similar patterns in both scenarios (Figure 1.29).

\section{Figure 1.29}

Decoupling of transport GHG emissions and passenger and freight services in the CNS
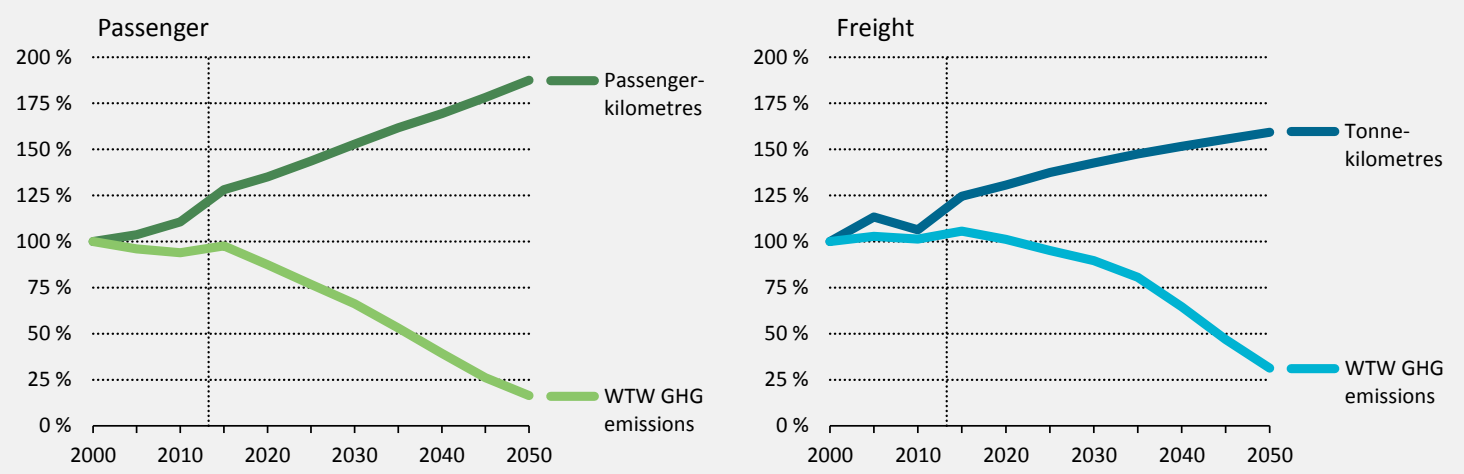

Source: IEA (2016b), Mobility Model, January 2016 version, database and simulation model, www.iea.org/etp/etpmodel/transport/. Figures and data in this report can be downloaded at www.iea.org/etp/nordic.

Key point

To achieve the CNS, recent gradual progress achieved in the Nordic countries in decoupling GHG emissions from transport services (passenger activity [pkm] and freight activity [tkm]) will need to accelerate dramatically through mid-century.

The main difference between the 4DS and CNS is the assumption under CNS that part of the growth in aviation is shifted to high-speed rail (HSR), which has the potential to provide a similar service to air travel in terms of carrying capacity and travel times. The energy and carbon intensity of HSR is comparable or even lower than that of other public intercity modes (such as bus and rail), and far lower than aviation, which is on average the most carbon-intensive passenger mode.

Developing a high-speed rail infrastructure network capable of competing with aviation, as required in the CNS, could pose significant challenges in the low-density and challenging geography of Nordic countries. In CNS, the HSR share in Nordic countries (out of the total of HSR and aviation) is 13\% by 2050, reflecting a potential restricted only to major axes (e.g. between Nordic capitals). This share compares with current shares of 23\% in France, 10\% in Germany and nearly 40\% in Japan. The 2050 HSR share is comparable to the values characterising low-density countries such as the United States (15\%) and well below the figures seen for the main EU countries (France, Germany, Italy and the United Kingdom, with an average of 38\%) in a low-carbon scenario. This share also falls below the figures applying, in the same scenario, to rapidly developing economies in Asia (China and ASEAN get close to 30\%). Despite the relatively modest share and low potential of HSR to substitute for high GHG-intensity long-distance passenger travel (i.e. by car and air), the investment costs of building the HSR system are considerable - as detailed in the investment section below. In the 4DS, transport energy demand in the Nordics remains stable through the first half of the century, at around 1.10 EJ. Fossil fuels still supply $90 \%$ of this demand in 2050 , which 
results in a decrease in overall $\mathrm{CO}_{2}$ emissions from the transport sector of only $3 \%$ by middecade relative to a 2000 baseline.

Among passenger modes, cars remain the main energy consumer by 2050, although aggregate energy demand by passenger LDVs in 2050 is about 30\% lower than in 2000, primarily thanks to increasingly reliance on low-carbon alternatives to gasoline and diesel, and to improvements in vehicle efficiency (which are the combined effect of hybridisation, electrification, and improvements in conventional ICE powertrains). The share of energy consumed by air travel grows over the same time period, and accounts for nearly $20 \%$ of total passenger transport energy demand by 2050. As a result, passenger transport emissions decrease by roughly 10\% in 2050 from 2015 levels, reaching $45 \mathrm{MtCO}_{2}$-eq.

The decrease in passenger energy demand in the 4DS scenario is coupled with a rather stable trend of freight energy use between 2000 and 2050, dictated by an increase in freight energy demand in shipping and compensating downward trends in heavy trucks and other freight modes.

The CNS scenario implies a more radical change in energy-use patterns by 2050, even in the Nordic countries. Total energy use mid-century decreases by over $20 \%$ compared with 2000 , to 0.87 EJ. By 2050, fossil fuels account for only $25 \%$ of final energy use in transport. Biofuels account for the majority (63\%) of final energy use, and electricity for 10\% (note, however, that the share of electricity in final energy is lower than its activity share due to the high powertrain efficiency of electric motors). Urban areas will see their transport energy use cut by $35 \%$, and non-urban areas by $22 \%$, in the CNS.

This reduction in energy use is realised mainly through adoption of new technologies. Final energy use decreases, despite increases in overall passenger and freight activity by over $70 \%$ from 2000 to 2050. Energy-savings potential is greatest in the largest energy-consuming mode: passenger cars, which, despite continuously increasing vehicle-kilometres (vkm), improve significantly in terms of specific energy intensity.

By 2050, 31\% of PLDVs are fully electric in the CNS, and two-thirds of PLDVs will use electric powertrains: either full battery-electric, plug-in hybrid or fuel-cell electric. International cooperation allows widening the market for technology deployment. Key advantages stemming from joint action are reduced technology deployment costs for each of the countries involved (thanks to a quicker cumulative deployment of EV technologies) and by the higher market penetration allowed by the interoperability of the electricity supply equipment across countries.

In the CNS, electrification occurs in other modes as well, with plug-in hybrids accounting for $10 \%$ of the heavy-duty vehicle stock, and EVs making up about $70 \%$ of light commercial vehicles (LCVs) in urban areas by 2050. The rapid uptake of these clean technologies, targeting key energy-intensive segments of transport - especially car use and urban freight deliveries - enables substantial energy and emissions savings.

Fuel shifts are also substantial over the 2000-50 period in the CNS. Fossil fuels give way to biofuels and electricity, which collectively represent three-quarters of overall transport energy use in 2050. Since electricity is already almost fully decarbonised in Nordic countries, and biofuels are produced via pathways with low well-to-wheel emissions in the CNS, a $72 \mathrm{MtCO}_{2} \mathrm{eq}$ decrease in annual emissions in 2050 relative to 2000 emissions levels can be achieved for the transport sector. This reduction corresponds to an average decrease of $2 \mathrm{MtCO}_{2}$-eq per year between now (2015) and 2050 and is a significant development: the magnitude of the change in 2050 exceeds Sweden's total GHG emissions in 2013 (55 MtCO ${ }_{2}$-eq) (Figure 1.30).

Sweden, which emitted the most transport-related GHGs among the Nordics in 2015, accounted for $37 \%$ of the total transport-related $\mathrm{CO}_{2}$ emitted by the five Nordic countries. Swedish transport contributes in the CNS to over a third of $\mathrm{CO}_{2}$ emissions abatements compared to 
a 4DS trajectory (see Figure 1.23). Each of the Nordic countries will need to cut its current (2015) transport emissions by $70 \%$ to $80 \%$ by 2050 to achieve CNS goals.

In all countries except Iceland, modal shifts to rail transport also contribute to energy savings from passenger cars in urban areas, from passenger cars and aviation in non-urban areas, and from trucks in freight activities, However, the share of energy reduction due to these shifts is small compared to the contributions of vehicle efficiency. As a result of these shifts, passenger rail activity is over 60\% higher in 2050 in the CNS than in the 4DS scenario, and car and aviation activity is reduced by about $25 \%$.

\section{Figure 1.30}

GHG emission reductions in the CNS in transport, by country and mode
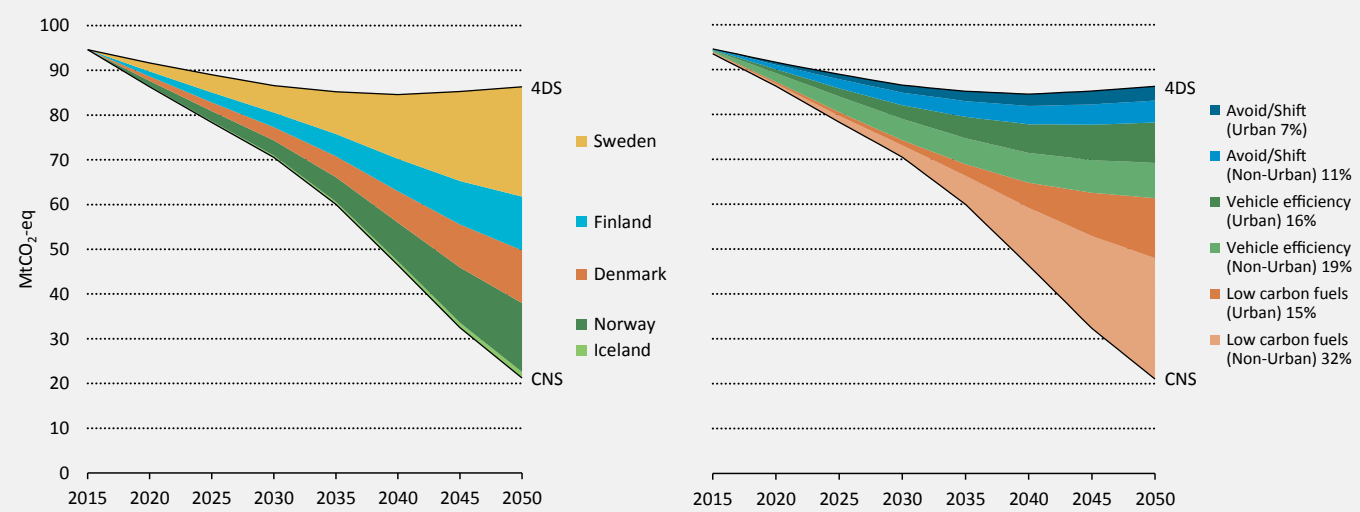

Source: IEA (2016b), Mobility Model, January 2016 version, database and simulation model, www.iea.org/etp/etpmodel/transport/. Figures and data in this report can be downloaded at www.iea.org/etp/nordic. the Nordic countries. Mitigation efforts must focus on emissions resulting from nonurban transport activity and modes (e.g. low-distance passenger and freight activity, including aviation and trucking). Reducing emissions from these sectors has proved difficult to date.

\section{Key actions - Transport}

Significant potential exists to reduce carbon emissions from the transport sector in the Nordic region. The extent to which this potential can be tapped, and in fact the feasibility of the CNS scenario itself, depend on several factors. Some of these factors are exogenous to the Nordic region, such as the costs of alternative drivetrain and fuel technologies (e.g. low-carbon biofuels pathways and electric vehicles) - which are mostly driven by learning effects and economies of scale at the global level, and the evolution of conventional fossil fuel costs (especially products of petroleum) in international markets. The capacity of Nordic policy makers to influence these factors relies primarily in their capacity to influence European and global policy development, e.g. through action carried out in international fora. In parallel, Nordic countries have to mobilise regional and domestic drivers toward decarbonisation. 
Policy makers in Nordic countries may be able to exploit the current context of low oil prices to increase fuel taxes above current levels, thereby providing even stronger price signals to motivate the system-wide modifications to behaviour and business needed to realise the CNS. Similarly, policy coordination within and among the Nordics at the municipal and national level could serve to further accelerate and diffuse innovative and successful best practices. In this context, harmonisation of EV-charging infrastructure should be a priority, given the high penetration of EVs in some Nordic countries' fleets.

Reductions in transport activity (avoid), shifts to less carbon-intensive transport modes (shift), and adoption of more efficient or innovative transport technologies (improve) are all ultimately the results of choices made by citizens, businesses, and public mobility providers. Whether or not such choices lead to long-term decarbonisation will depend largely on the degree of ambition of policies such as road tolls/parking fees, access/parking restriction and public transport support.

The potential for avoiding trips into Nordic cities is constrained by urban form. Many Nordic cities have been designed and zoned to accommodate mixed land use, multi-centric urban structures and multimodal transport options. However, continued efforts to combat suburban and exurban development and to promote densification will pay off in the long term.

Further shifts from cars to non-motorised travel (walking and cycling) and public transit will require further investments in what are in many Nordic cities already world-class transit and non-motorised systems and infrastructure. Shifting mobility towards energy efficient modes also calls for moving toward legal and fiscal frameworks that promote Transit Oriented Developments (TOD) and urban forms that are conducive to public and non-motorised transport modes.

Improving the efficiency of an already very efficient car fleet will require concerted efforts, but examples of promising paths forward exist. Norway's policies have begun to lay out the foundation for a rapid growth in electric car sales (see Box 1.3). The Norwegian policy experience (including future debates and decision on how to develop it further) will certainly offer important lessons on the promotion of electrification, not just in other Nordic countries. Electrification must extend beyond the passenger light-duty vehicle fleet to include buses, trucks, and even two-wheelers. Finally, meeting the region's ambitious decarbonisation goals in transport will require incorporating low-carbon biofuels into the transport energy mix.

Many Nordic cities are among global leaders in provision of high-quality and convenient public transit, implementation of strong pricing (such as congestion charging and tolls) and regulatory policies (such as urban access restrictions for diesel trucks). Achieving CNS goals will require maintaining the strong policy framework in place and further strengthening it with Travel Demand Management (TDM) policies such as congestion charges, parking fees, road tolls, access and parking restrictions, even in the cohort of cities that lead the world in progressive and sustainable transport policy (such as Stockholm and Oslo).

Enabling modal shifts in the CNS in both individual passenger and freight transport will also require investments for the supply of public transport services, including rail. Copenhagen provides a good example of how cycling can be stimulated, and the large increase in cycling in Stockholm in the last decade - even in the absence of major upgrades of cycling infrastructure - indicates a large untapped potential. Mode shift will need to build on the combination of "push" (e.g. car registration fees and other pricing mechanisms) and "pull" measures (e.g. operation subsidies to increase the quality and attractiveness of public transport).

The CNS is extremely ambitious; the scenario requires historically unprecedented penetration rates of advanced technologies for increasing vehicle energy efficiency and reducing or eliminating emissions from fuel production and combustion (improve). Additionally, energy efficiency improvements in conventional vehicle technologies should not be given less priority 
than alternative drivetrains, because they remain a crucial means of achieving emissions reduction for the 2030 time frame.

Substituting low-carbon biofuels for oil products across modes that require high-energy-density fuels will be a difficult but essential component of meeting long-term CNS targets. Deployment of major coordinated investments will be necessary - not just in the Nordic countries - to increase the use of hydrogen in transport applications. Long-term targets for low-carbon fuel standards are needed to stimulate the emergence of solutions capable of contributing to lowcarbon fuel production, including (but not only limited to) advanced biofuels. These targets must be complemented by technology-push measures to increase the technical viability and economic competitiveness of low-carbon biofuel production processes.

Achieving the decarbonisation targets envisioned by the CNS for the transport sector in the Nordic region requires an ambitious, systemic, long-term policy commitment. Success would put the Nordic region among the global leaders - enabling the Nordics to set the pace for other countries pursuing carbon-neutral and rapid decarbonisation targets over the long term, spurring and providing the knowledge basis needed for global transition.

\section{Industry: Innovation will be the deal breaker}

\section{Recent trends}

The Nordic industrial sector ${ }^{8}$ accounted for $36 \%$ of the total final energy use and $18 \%$ of total $\mathrm{CO}_{2}$ emissions in Nordic countries in 2013, with industrial energy consumption reaching 1510 petajoules (PJ), a 6\% decrease compared with 2010 levels. This decrease is mainly due to a moderate decrease in domestic industrial production levels, and partly to structural changes in the industrial sector and energy efficiency improvements. Since 2010, the Nordic aggregated average industrial energy intensity ${ }^{9}$ decreased by $2 \%$, and the share of energyintensive sectors ${ }^{10}$ in total industrial final energy use fell 5 percentage points in the region. As a result of all these factors, a 9\% reduction was observed in direct industrial $\mathrm{CO}_{2}$ emissions from 2010 levels, including those inherently generated in industrial processes. ${ }^{11}$

Sweden, Finland and Norway account for $90 \%$ of the Nordic industrial final energy consumption (37\%, 32\% and 21\%, respectively), with the remaining energy use in Denmark (6\%) and Iceland (4\%). In terms of sectorial distribution, pulp and paper accounts for about a third of the total industrial final energy use, followed by chemicals and petrochemicals (20\%) and by aluminium and iron and steel (13\% and 12\%, respectively). Given these large shares, the analysis in this section focuses on the five energy-intensive industrial sectors; however, other less energy-intensive industries (e.g. food and beverage, textile) jointly demand as much energy as the second largest industrial energy user, at 20\%.

The Nordic industrial system has specific, inherent features, which while posing some challenges, also offer valuable opportunities for achieving objectives for ambitious carbon emissions reduction. First, the Nordic industry has a relatively high reliance on energy-intensive sectors, at $79 \%$ of final industrial energy use in average, and as high as $93 \%$ in Iceland or $84 \%$ in Norway, compared with the global average, of $68 \%$. For instance, the aluminium sector is

8 Industrial final energy use in this report includes energy use as petrochemical feedstock and energy use in blast furnaces and coke ovens.

9 The aggregated average industrial energy intensity refers to total final industrial energy consumption over industry valueadded (G)/USD 2014 PPP). PPP = purchasing power parity.

10 Energy-intensive sectors refer to iron and steel, chemicals and petrochemicals, cement, pulp and paper and aluminium.

11 Reported industrial direct $\mathrm{CO}_{2}$ emissions include process emissions generated in cement, aluminium, crude steel and chemicals production due to the use of carbon-containing feedstocks. 
well engrained in the economies of Iceland and Norway, as is the production of pulp and paper in Sweden and Finland, because these sectors benefit from available rich natural resources.

Second, despite this dependence on energy-intensive processes, the important weight of the paper sector in the Nordic industrial structure drives down the share of fossil fuel consumption in industry, which stands at 34\% (see Figure 1.31) compared with 72\% globally or 69\% in OECD economies on average. This comparative share means that, while 27 tonnes (t) of direct $\mathrm{CO}_{2}$ are emitted on average per terajoule (TJ) of energy used in the Nordic industrial sector, an average of almost $60 \mathrm{t}$ and $43 \mathrm{t}$ of $\mathrm{CO}_{2}$ are emitted in the world and in OECD membereconomies, respectively, for the same amount of energy used. Less significant differences are observed at the sub-sector level. The Nordic iron and steel sector, for instance, emits $65.6 \mathrm{t}$ of direct $\mathrm{CO}_{2} / \mathrm{T}$ ), compared with an OECD average of $72.6 \mathrm{t}$ of direct $\mathrm{CO}_{2} / \mathrm{T}$ J for iron and steel making, mainly because of lower electricity prices on average and considerable material recycling rates that drive greater deployment of electric arc furnaces (EAFs) in the Nordic region. Lower-carbon fuel mixes in the Nordic chemicals and petrochemicals sector result in 27.0 t of direct $\mathrm{CO}_{2}$ emitted per T) consumed, which is also below the OECD average (28.2 t direct $\left.\mathrm{CO}_{2} / \mathrm{TJ}\right)$.

Furthermore, the Nordic region has been able to maintain a considerable foothold in energyintensive industries that have significantly reduced their activity or even disappeared in other industrialised countries. This trend is due to several different factors, including the availability of domestic energy and material resources, and maintaining competitiveness of Nordic industries in global markets by prioritising energy efficiency and productivity. Maintaining this industrial capacity, while decarbonising the industry sector, is a major technological and policy challenge.

\section{Figure $1.31 \quad$ Energy flows in Nordic industry, 2013}

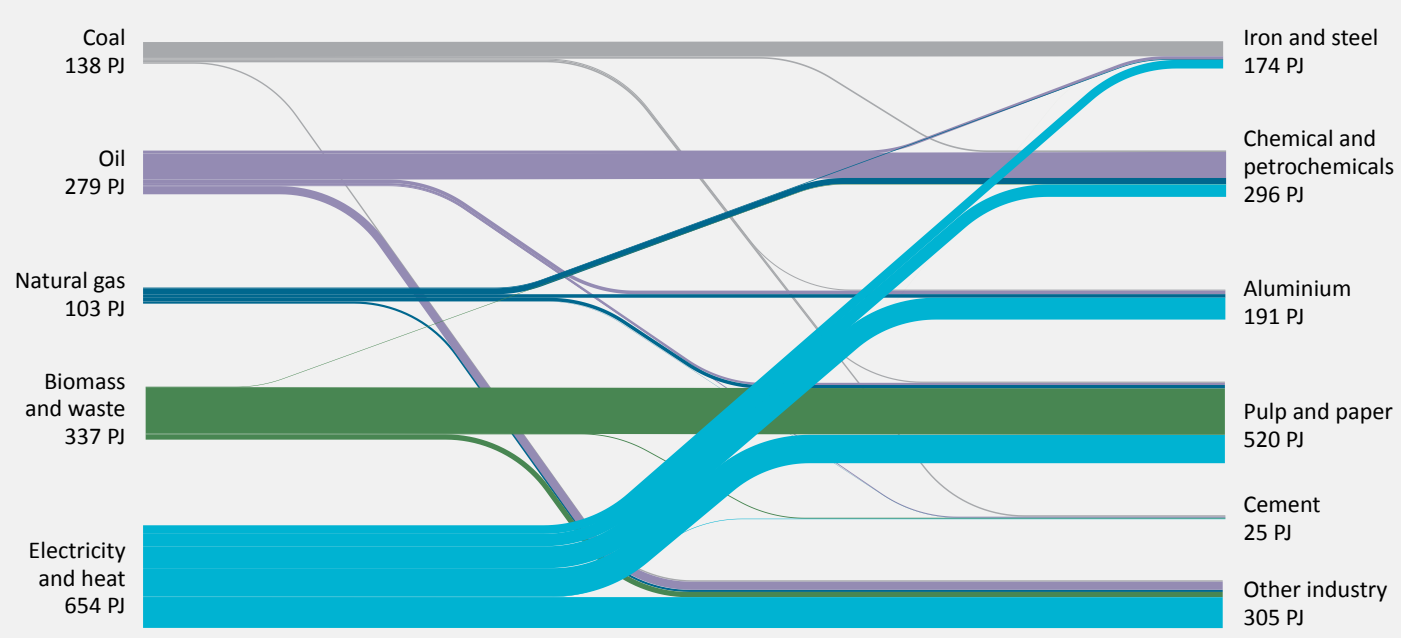

Notes: In this report, final industrial energy consumption includes energy use as petrochemical feedstock and energy use in blast furnaces and coke ovens. Other industries include non-ferrous metals (excluding aluminium), non-metallic minerals (excluding cement), transport equipment, machinery, mining and quarrying, food and tobacco, printing, wood and wood products, construction, and textile and leather.

Source: Unless otherwise noted, all tables and figures in this report derive from IEA data and analysis.

Figures and data in this report can be downloaded at www.iea.org/etp/nordic. 


\section{Scenario results}

As previously discussed (see Box 1.1), the 4DS considers concerted efforts to move away from current trends aimed at reducing both energy demand and emissions and serves as the reference scenario for the analysis. The Nordic CNS requires a much deeper carbon emissions reduction than the $4 \mathrm{DS}$, with an $85 \%$ reduction in total Nordic carbon emissions compared with 1990 levels.

The main underlying assumption of these scenarios is that only minor changes will occur in the industrial structures and materials production levels of Nordic countries due to the economic maturity in this region, though structural changes and variations in the distribution of material trade flows related to the Nordic industry are possible. The 4DS and CNS are based on the same expected level of materials produced, which is mainly driven by population and GDP development. The rationale for this basis is to enable an accurate comparison of how different process routes and technologies portfolios, as well as increasing implementation levels of resource efficiency measures, can affect final energy demand and direct carbon emissions for the same volume of materials. Paper is expected to remain the largest produced commodity in the Nordic region, staying above the 25 megatonnes per year (Mt/yr) level by 2050, followed by crude steel, cement and aluminium at around $10 \mathrm{Mt} / \mathrm{yr}, 8 \mathrm{Mt} / \mathrm{yr}$ and $7 \mathrm{Mt} / \mathrm{yr}$ annual production levels, respectively (Table 1.1).

\section{Table $1.1 \quad$ Materials production in Nordic countries}

\begin{tabular}{|c|c|c|c|}
\hline Material production (Mt) & 2013 & 2050 4DS & 2050 CNS \\
\hline Crude steel & 8.5 & 9.9 & 9.9 \\
\hline Paper and paperboard & 25.7 & 26.7 & 26.7 \\
\hline Cement & 7.4 & 8.3 & 8.3 \\
\hline Aluminium & 6.9 & 7.0 & 7.0 \\
\hline High-value chemicals & 2.3 & 2.5 & 2.5 \\
\hline Ammonia & 0.4 & 0.4 & 0.4 \\
\hline Methanol & 0.8 & 0.9 & 0.9 \\
\hline \multicolumn{4}{|c|}{$\begin{array}{l}\text { Notes: High-value chemicals include light olefins (ethylene and propylene) and aromatics (benze } \\
\text { paperboard include production from recovered paper. } \\
\text { Sources: For } 2013 \text { production levels, (FAO, 2015; IAl, 2015; USGS, 2015; and Worldsteel, 2015). }\end{array}$} \\
\hline
\end{tabular}

As a result of existing policies, a continuation of resource efficiency practices and expected progress in industry-related research, development, demonstration and deployment (RDD\&D) streams, the Nordic 4DS already considers a peak in direct $\mathrm{CO}_{2}$ industrial emissions in 2015. The scenario also incorporates an almost 30\% reduction in direct $\mathrm{CO}_{2}$ emissions intensity $\left(\mathrm{C} \mathrm{CO}_{2} / \mathrm{TJ}\right)$ for similar production volumes of industrial materials by 2050 compared with 2013 levels (Figure 1.32). Remarkably, this shift is expected to be more attributable to increased integration of low-carbon fuels and feedstock in industrial processes, as well as to innovative processes with reduced carbon footprint reaching commercial scale within the analysed time period, than to a significant reduction of the industrial energy intensity of an already relatively efficient industrial stock. 


\section{Figure 1.32}

Nordic final industrial energy use and aggregated industrial direct $\mathrm{CO}_{2}$ intensity, 4DS and CNS

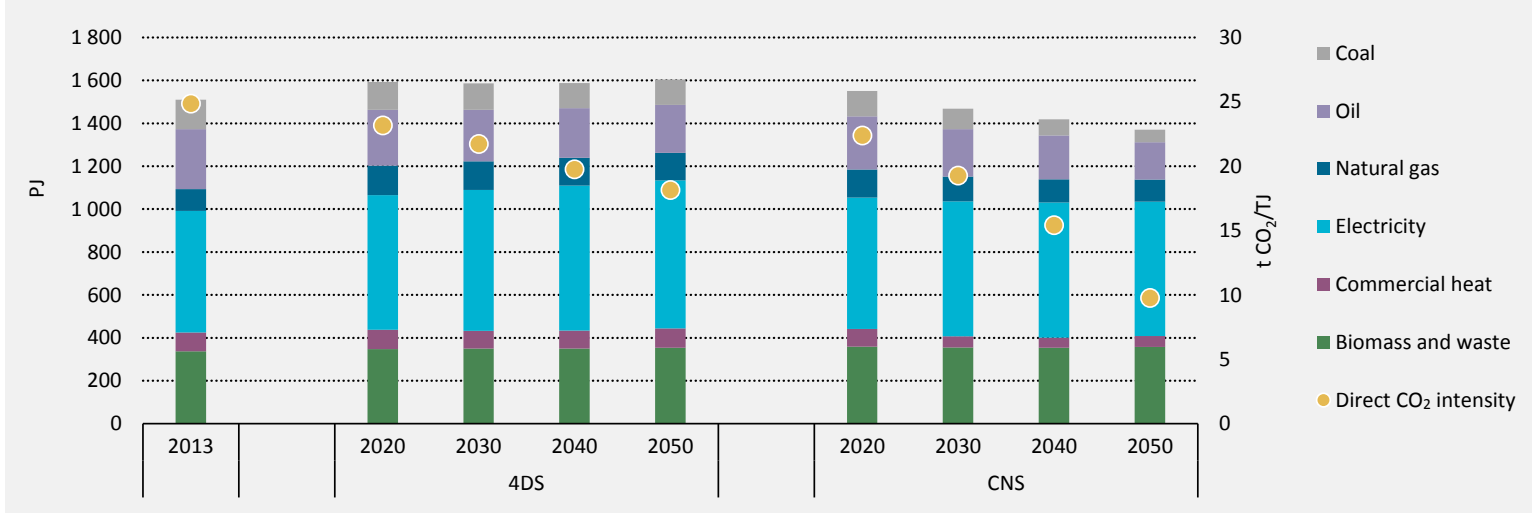

Note: Industrial direct $\mathrm{CO}_{2}$ intensity refers to energy-related and process $\mathrm{CO}_{2}$ emissions and to total final industrial energy use. Figures and data in this report can be downloaded at www.iea.org/etp/nordic.

Because the 4DS already taps reasonable levels of energy efficiency potentials, lowcarbon innovative processes are critical in the CNS to enabling $60 \%$ reduction in direct industrial $\mathrm{CO}_{2}$ intensity by 2050 .

In the Nordic CNS, more drastic requirements for direct reduction of industrial emissions make the implementation of energy efficiency measures that exploit the last incremental energy savings when reaching best energy performance level more competitive with other $\mathrm{CO}_{2}$ abatement options. Nordic total final industrial energy consumption is reduced by $9 \%$ in the CNS in 2050 compared with 2013 levels for similar industrial activity (Figure 1.32). Ambitious fuel and feedstock switching to low-carbon sources (Figure 1.33), maximisation of material efficiency techniques, more rapid commercial-scale demonstration and wider deployment of innovative sustainable processes complete the portfolio of measures that deliver a direct industrial $\mathrm{CO}_{2}$ intensity reduction of 60\% in 2050, reaching $10 \mathrm{t} \mathrm{CO}_{2} / \mathrm{T}$ ) in the CNS (Figure 1.32).

Electricity continues to be the most consumed vector within the Nordic final industrial energy demand by 2050 in the CNS, showing the greatest growth in share (8 percentage points) compared with current levels, followed by biomass, which grows by 4 percentage points (Figure 1.33). Greater electrification levels in the Nordic industry in the CNS are mainly driven by increased shares of secondary production of crude steel and a greater reliance on electricity in other industries. In contrast with 2013 (Figure 1.31), biomass and waste use result in above one-quarter of the final energy demand in that sector by 2050 in the CNS. This shift, together with increased use of biomass in cement kilns and in bio-based process routes in the chemicals and petrochemicals sector, provide the bulk of the larger share of biomass in Nordic industrial final energy demand observed in the 2050 - CNS compared with 2013. 


\section{Figure 1.33 Energy flows in Nordic industry, 2050 - CNS}

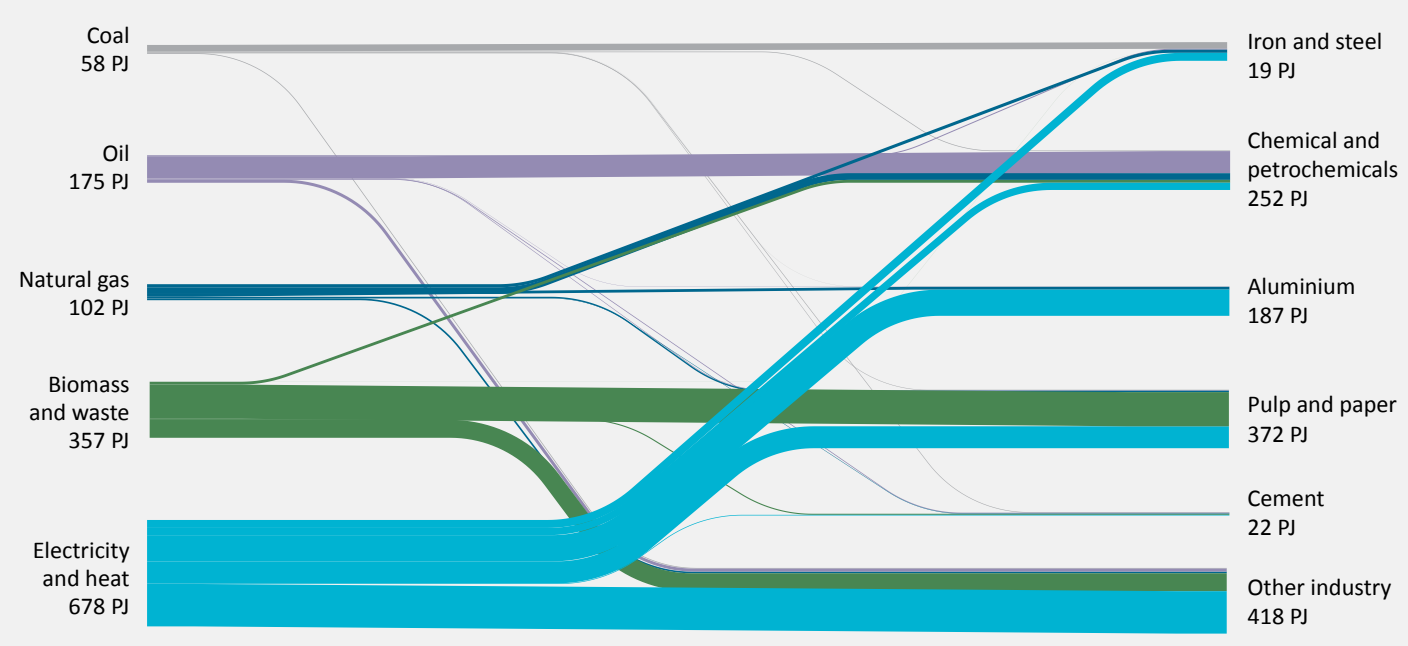

Figures and data in this report can be downloaded at www.iea.org/etp/nordic.

Key point

Other industries overtake pulp and paper as the greatest industrial energy consumer in a Nordic CNS - 2050, pushing upwards the electricity share in final industry energy demand.

In the CNS, the Nordic industrial sector produces less than half of the direct $\mathrm{CO}_{2}$ emissions in 2050 that are produced in the 4DS, a reduction of $16 \mathrm{Mt} \mathrm{CO}_{2}$ (Figure 1.34). The iron and steel sector shows the greatest cumulative reduction of direct $\mathrm{CO}_{2}$ emissions in the period 2013-2050 in the CNS (39\%), as a result of decreasing the aggregated crude steel energy intensity ${ }^{12}$ by almost $40 \%$ (reaching $12 \mathrm{GJ} / \mathrm{t}$ crude steel) and a significant deployment of smelting-reduction-based innovative processes that integrate carbon capture and storage (CCS) in the post-2030 timeframe (Table 1.2). The reduction in the energy footprint of the sector is mainly driven by production stock reaching best energy performance levels, a drastic reduction in coke making as a consequence of widely deploying upgraded smelt reduction processes, and a maximisation of the production of crude steel from refining and re-melting scrap in electric arc furnaces (EAFs), ${ }^{13}$ which reaches $70 \%$ of crude steel production in 2050.

12 Crude steel aggregated energy intensity includes energy use in iron ore agglomeration processes, coke ovens, blast furnaces, steel-making and fuel use allocated to the generation of heat that is produced and used on-site from co-generation systems.

13 100\% scrap-based EAFs have significantly lower energy requirements compared with the widely used blast furnace - basic oxygen furnace route. The requirements for the former are $6.7 \mathrm{GJ} / \mathrm{t}$ crude steel and for the latter are $18.7 \mathrm{GJ} / \mathrm{t}$ crude steel, in global average final energy performance levels covering from material input preparation to casted crude steel (Worldsteel, 2014). 


\section{Figure $1.34 \quad$ Nordic direct industrial $\mathrm{CO}_{2}$ emissions reductions by sector, 4DS and CNS}

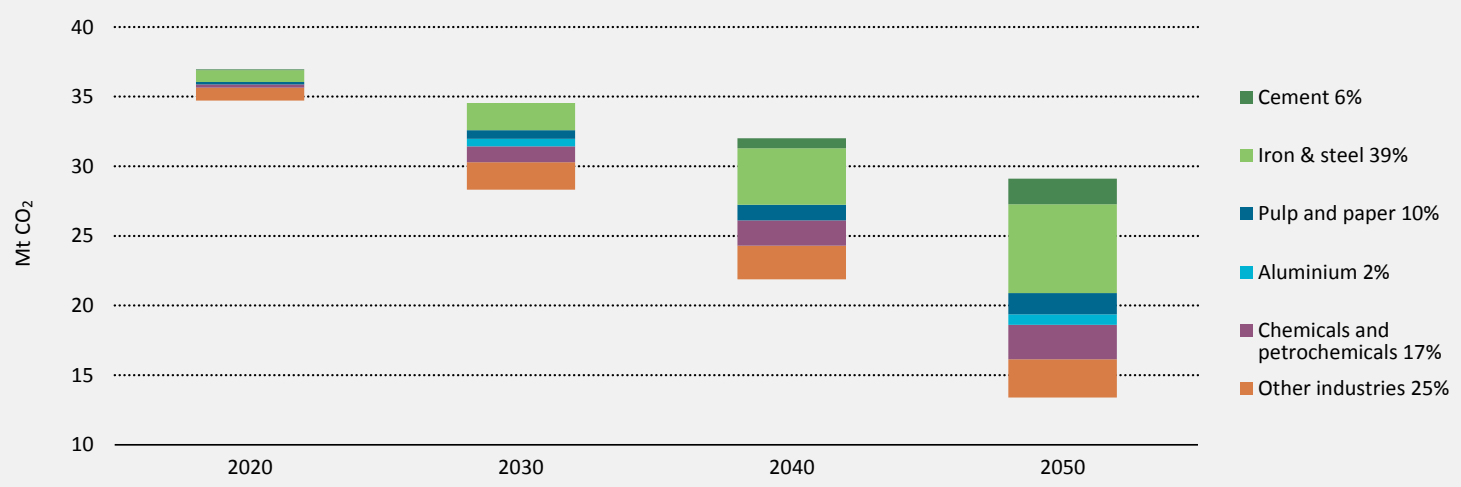

Note: Shares provided for each industrial sector are based on sector-specific cumulative direct $\mathrm{CO}_{2}$ industrial emission reductions relative to overall industrial cumulative emissions reductions over the period 2013-2050.

Figures and data in this report can be downloaded at www.iea.org/etp/nordic.

Key point Iron and steel, chemicals and petrochemicals, and pulp and paper contribute jointly to $66 \%$ of $\mathrm{CNS}$ direct industrial $\mathrm{CO}_{2}$ emissions reductions.

Chemicals and petrochemicals ${ }^{14}$ account for $17 \%$ of the cumulative direct industrial $\mathrm{CO}_{2}$ emissions reduction in the CNS by 2050, with the direct $\mathrm{CO}_{2}$ intensity in 2050 in the sector dropping from $20.4 \mathrm{t} \mathrm{CO}_{2} / \mathrm{T}$ ) in the 4DS to $15.2 \mathrm{t} \mathrm{CO}_{2} / \mathrm{T}$ ) in the CNS. Enhanced process integration measures result in fuel and electricity savings that make the share of energy consumption as feedstock over total energy use in the sector increase by $9 \%$ in 2050 in the CNS, compared with 4DS levels (Table 1.2). The greatest boost for direct $\mathrm{CO}_{2}$ emissions reductions in the chemicals sector is provided by a wide deployment of CCS, which starts modestly in 2020 in processes that inherently generate concentrated $\mathrm{CO}_{2}$ streams that facilitate capture operations, such as ammonia and methanol production. Gains from switching to low-carbon fuels and increasing the penetration of biomass-based routes are incremental, due to the limited availability of lowcost biomass resources, in competition with the pulp and paper sector, as well as the economic and technological challenges of integrating alternative energy sources in chemicals production.

The pulp and paper sector contributes $10 \%$ of cumulative direct industrial $\mathrm{CO}_{2}$ emission reductions in the CNS in the analysed period. This change in expected trends is achieved by introducing CCS in the sector in the long term, provided pulp and paper-making processes already approach best energy performing levels in the 4DS by 2050 (average intensities: $4.8 \mathrm{GJ} / \mathrm{t}$ paper and paperboard, and $9.9 \mathrm{GJ} / \mathrm{t}$ pulp). The change also relies on incorporating a slight increase in biomass-based fuels use in the sector (about 3 percentage points in the share of the sector's final energy demand), within availability limitations (Table 1.2). Similarly, thermal and electricity intensities of cement making reach technical limits, and the use of alternative fuels is maximised in the 4DS by 2050 . While the use of clinker ${ }^{15}$ substitutes still creates some incremental gains in the CNS compared with the 4DS (clinker ratio decreases by $2 \%$ ), the direct carbon emissions generated in the production of cement are mainly reduced in the CNS through more ambitious integration of CCS in the manufacturing process from 2025 (Table 1.2)

14 Five key products/product families are specifically modelled to derive the results shown for the overall chemicals and petrochemicals sector: ethylene, propylene, aromatics (benzene, toluene and xylenes), ammonia and methanol.

15 Clinker is an intermediate material, whose production is the most energy-intensive step in cement manufacturing 


\section{Table 1.2}

\section{Status of technology and key indicators for the industrial sector} under 4DS and CNS

\section{Sector status in 2050 4DS}

Cement

(20)

New kilns built perform at $3.0 \mathrm{GJ} / \mathrm{t}$ clinker and 95 $\mathrm{kWh} / \mathrm{t}$ cement. Alternative fuels reach $31 \%$, and clinker-to-cement ratio declines to $0.72 .3 \%$ of the 2020-2050 cumulative direct $\mathrm{CO}_{2}$ emissions in the sector are captured and stored; deployment starts in 2025.

Iron and steel Aggregated average energy intensity of crude steel production is $18 \mathrm{GJ} / \mathrm{t}$ crude steel. Electric arc furnaces (EAFs) account for $67 \%$ of liquid steel production. $2 \%$ of the $2020-2050$ cumulative direct $\mathrm{CO}_{2}$ emissions in the sector are captured and stored; deployment starts in 2025.

\section{Chemicals and} petrochemicals

Process integration and fuel switching result in feedstock energy use accounting for $52 \%$ of total final energy use in the sector and direct $\mathrm{CO}_{2}$ emissions intensity reaching $20.4 \mathrm{t} \mathrm{CO}_{2} / \mathrm{T}$ J. Biomass-based feedstocks make up $2 \%$ of total feedstock energy use. $2 \%$ of the 2020-2050 cumulative direct $\mathrm{CO}_{2}$ emissions in the sector are captured and stored; deployment starts in 2020.
Pulp and paper

Biomass accounts for $54 \%$ of total final energy consumption. Average energy intensity reaches $4.8 \mathrm{GJ} / \mathrm{t}$ paper and paperboard and $9.9 \mathrm{GJ} / \mathrm{t}$ pulp. Paper production from recovered paper pulp is equivalent to $16 \%$ of total paper and paperboard production. No direct $\mathrm{CO}_{2}$ emissions are captured in the sector.

\section{Aluminium}

\section{CNS}

No major differences between the 4DS and the CNS on new kilns' energy performance and alternative fuels penetration. Clinker-to-cement ratio declines to $0.70 .19 \%$ of the $2020-2050$ cumulative direct $\mathrm{CO}_{2}$ emissions in the sector are captured and stored; deployment starts in 2025. Aggregated average energy intensity of crude steel production is $12 \mathrm{GJ} / \mathrm{t}$ crude steel. EAFs account for $70 \%$ of liquid steel production, and smelting reduction integrating CCS represents almost 30\% of liquid steel production. $19 \%$ of the $2020-2050$ cumulative direct $\mathrm{CO}_{2}$ emissions in the sector are captured and stored; deployment starts in 2025.

Process integration and fuel switching result in feedstock energy use accounting for $61 \%$ of total final energy use in the sector and direct $\mathrm{CO}_{2}$ emissions intensity reaching $15.2 \mathrm{t} \mathrm{CO}_{2} / \mathrm{T}$ J. Biomass-based feedstocks make up $5 \%$ of total feedstock energy use. $11 \%$ of the $2020-2050$ cumulative direct $\mathrm{CO}_{2}$ emissions in the sector are captured and stored; deployment starts in 2020. Biomass accounts for $57 \%$ of total final energy consumption. No major differences between the 4DS and the CNS on average paper and paperboard and pulp energy intensity, as well as penetration of recovered paper production. 16\% of the 2020-2050 cumulative direct $\mathrm{CO}_{2}$ emissions generated in the sector are captured and stored; deployment starts in 2030

Electricity intensity of primary aluminium production declines to $13872 \mathrm{kWh} / \mathrm{t}$ aluminium due to the effect on the deployment of inert anodes (with lower $\mathrm{CO}_{2}$ footprint but greater energy requirements). Alumina energy intensity is reduced to $10.3 \mathrm{GJ} / \mathrm{t}$ alumina. Wide deployment of inert anodes occurs for the production of primary aluminium; deployment starts in 2030.

The aluminium sector accounts for $2 \%$ of the cumulative industrial direct $\mathrm{CO}_{2}$ emissions reductions in the CNS. Smelting electricity intensity for primary aluminium making approaches best available technology performance levels, and material efficiency measures are maximised to practical technical levels in the 4DS by 2050. The main contributing factor to deeper direct $\mathrm{CO}_{2}$ emission cuts in the sector is a wide deployment of inert anodes for primary aluminium production in the long term in the CNS, while the 4DS sees this process technology reaching commercial demonstration at a later stage. The use of inert anodes avoids the generation of process emissions when consuming carbon-based anodes in aluminium smelting with a moderate energy penalty (Table 1.2).

The sectorial analysis shows the importance of demonstrating and deploying low-carbon innovative process technologies to reach the $\mathrm{CNS} \mathrm{CO}_{2}$ emissions trajectory. This need becomes more critical in those industrial sectors that are currently bound to fossil-based fuels and 
feedstocks (e.g. cement, iron and steel), which limit the minimum carbon footprint achievable by state-of-the-art technologies. CCS, for instance, provides an alternative that can significantly reduce direct $\mathrm{CO}_{2}$ emissions from industrial processes, especially in cases where alternative low-carbon process routes present important technological challenges or are limited by the low-cost availability of certain feedstocks.

Cumulatively $93 \mathrm{MtCO}_{2}$ are captured and stored from industrial processes in the CNS in the period 2020-2050 in Nordic countries (Figure 1.35). Iron and steel shows the greatest cumulative CCS deployment in the CNS $-46 \%$ of total industrial captured emissions. The fact that coal and coke remain the main energy inputs in primary crude steel-making drives wider deployment of alternatives to facilitate integration of carbon capture in this manufacturing process. Cement and chemicals and petrochemicals are next in terms of 2020-2050 cumulative captured and stored $\mathrm{CO}_{2}$ emissions in the $\mathrm{CNS}$. Even if process emissions generated in the production of clinker considerably raise the direct $\mathrm{CO}_{2}$ footprint of cement ${ }^{16}$, because this sector is relatively small in the Nordic region, the overall cumulative level of CCS deployment (23 Mt captured and stored $\mathrm{CO}_{2}$ ) in the CNS is moderate.

Pulp and paper production has the lowest direct $\mathrm{CO}_{2}$ intensity among energy-intensive industrial activities. Because of the significant use of biomass in its fuels and feedstocks mix, the sector still integrates bioenergy-based CCS in the CNS but at a much lower rate (7 Mt cumulative captured and stored $\mathrm{CO}_{2}$ ), as one of the only ways to remove $\mathrm{CO}_{2}$ from the atmosphere. Given the considerable production levels of paper products in Nordic countries, the cumulative CNS captured and stored $\mathrm{CO}_{2}$ emissions in this region from paper production represent $8 \%$ of those captured and stored globally from this sector. In contrast, in the aluminium sector, it becomes more cost-competitive to deploy primary aluminium production based on inert anodes in the CNS to solve the problem of inherent process emissions from the use of carbon-based anodes in aluminium smelting. Thus the penetration of CCS in that sector is negligible. The decarbonisation of the power sector in the CNS provides wider system-level $\mathrm{CO}_{2}$ emission reductions benefits from electricity-intensive industrial sectors, such as aluminium.

16 Process emissions represent $67 \%$ of total cement direct $\mathrm{CO}_{2}$ emissions in 2013 in Nordic countries. 


\section{Figure 1.35 \\ Nordic 2020-2050 cumulative direct industrial $\mathrm{CO}_{2}$ emitted, and captured and stored in the CNS by sector}

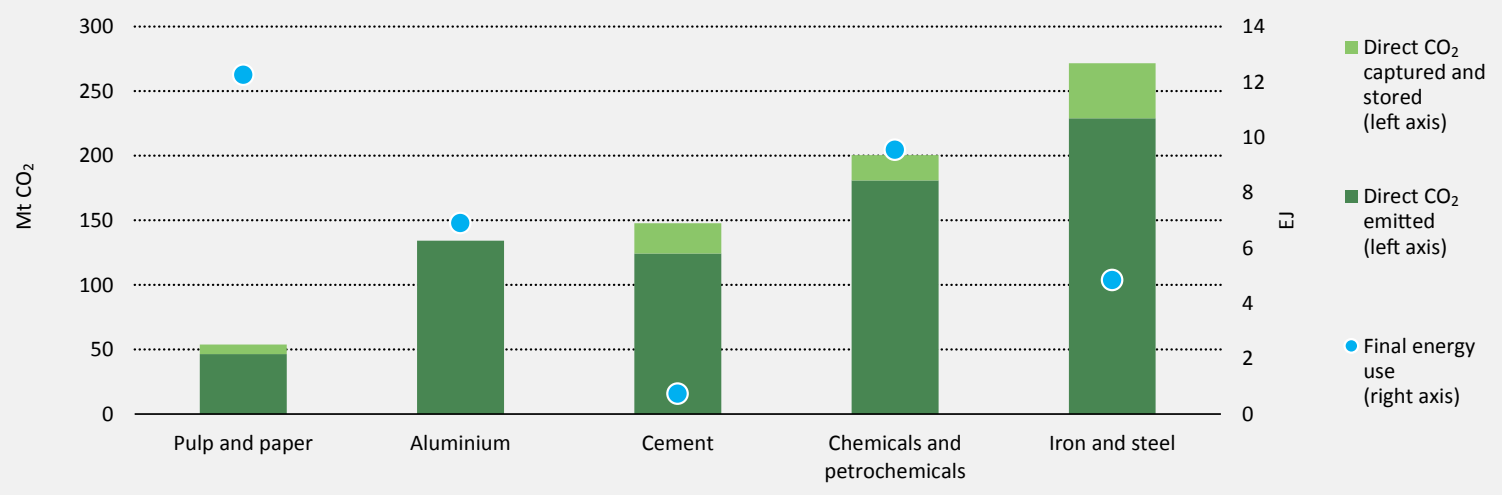

Note: Final energy use is given in cumulative terms for the 2020-2050 period in the CNS. Energy use in blast furnaces and coke ovens is included in the iron and steel sector, and energy use as feedstock is included in the chemicals and petrochemicals sector.

Figures and data in this report can be downloaded at www.iea.org/etp/nordic

Key point

CCS plays an increasing role in those industrial sectors with greater $\mathrm{CO}_{2}$ footprints, and no current prospects for future alternative cost-competitive carbon mitigation options.

Improving the business case of CCS projects is key to accelerating the deployment of carbon capture in industrial applications. Clustering industrial $\mathrm{CO}_{2}$ emissions sources, identifying adequate storage capacities and strategically designing transport infrastructure would enable benefiting from the economies of scale. The largest industrial $\mathrm{CO}_{2}$ emissions sources within the Nordic region are located in Sweden and Finland, and significant off-shore storage capacities are identified in Norway and Denmark (Mazzetti et al., 2013). Thus clear opportunities are available for collaboration among these countries to define and implement integrated CCS projects. Adapting $\mathrm{CO}_{2}$ injection used in enhanced oil recovery (EOR) for $\mathrm{CO}_{2}$ storage represents a unique opportunity to kick-starting CCS deployment. However, experience learnt from conventional EOR projects in other countries should be re-examined by operators, so that storage management and operating practices consider both oil production and $\mathrm{CO}_{2}$ storage as joint business goals (IEA, 2015c). 


\section{Figure 1.36 Nordic industrial stationary $\mathrm{CO}_{2}$ emissions sources}

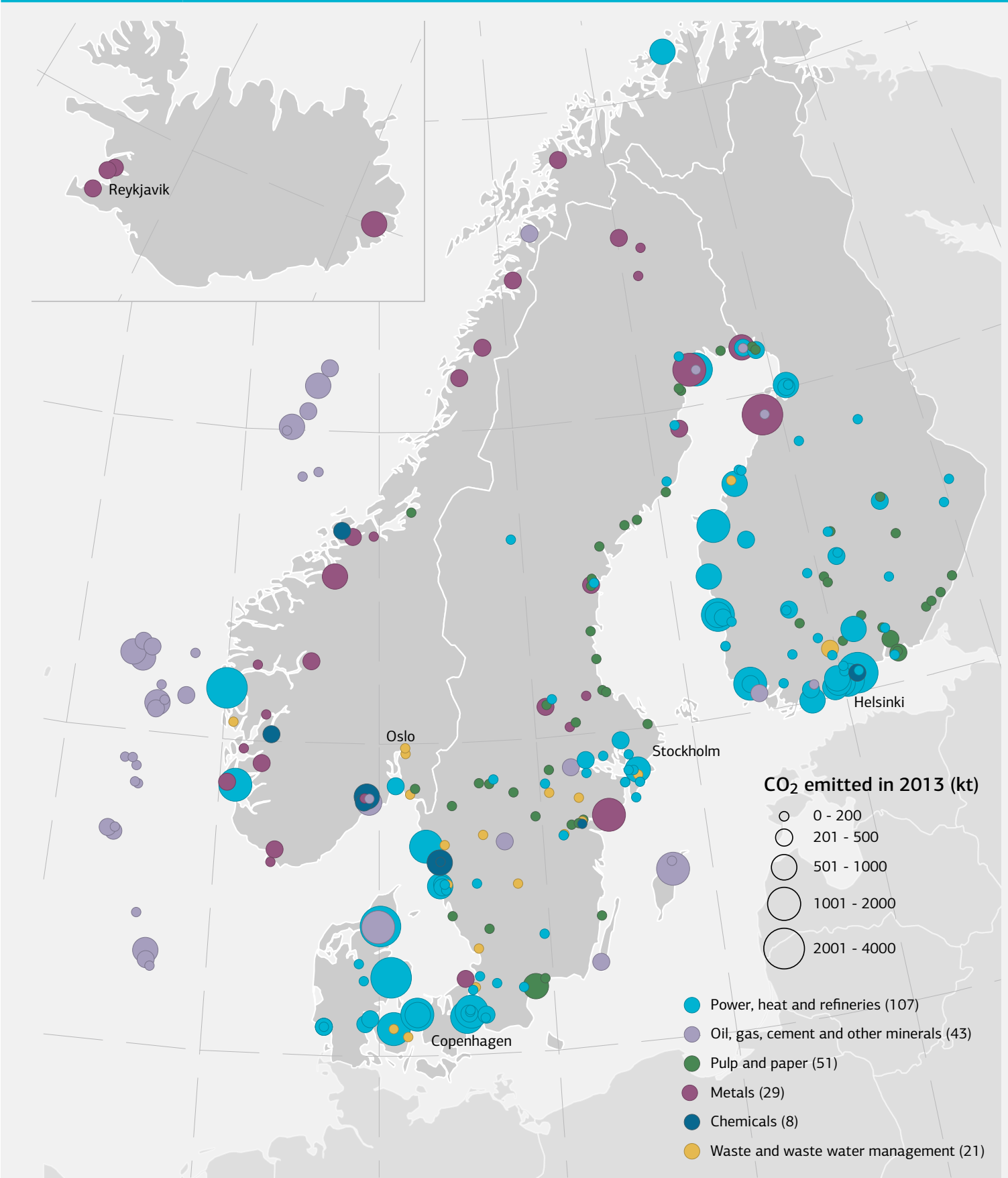

Notes: The scale for Scandinavia is 1:8000 000 but for Iceland is 1:6 300000 . The scale of the circles representing emissions is consistent across the figure. This map is without prejudice to the status of or sovereignty over any territory, to the delimitation of international frontiers and boundaries, and to the name of any territory, city or area.

Source: All data are derived from European Pollutant Release and Transfer Register (E-PRTR) v8 (2007 - 2013)

Figures and data in this report can be downloaded at www.iea.org/etp/nordic.

Key point

The greatest number of energy-intensive industrial $\mathrm{CO}_{2}$ emissions sources within the Nordic region are located in Sweden and Finland, and are mostly related to pulp and paper making. 
Maximising $\mathrm{CO}_{2}$ emission reduction impacts related to industrial activities will require breaking the sectorial boundary and exploring sustainable opportunities along product value chains, as well as maximising the use of local material and energy resources through cross-sectorial interactions. For instance, after optimising the level of process integration on-site, industries can economically benefit from the implementation of excess heat recovery technologies when a compatible thermal user is locally available, while enabling wider system-level energy and emissions savings. In Sweden, for example, business models have been pilot-tested to enable companies to deliver thermal exports to locally existing district heating networks at a market price (Open District Heating, 2015). Innovation would also have to come from sustainable product designs and applications that enable $\mathrm{CO}_{2}$ emissions savings at the systems level. For instance, materials with enhanced performance characteristics might provide greater durability of equipment and products, thus reducing maintenance costs, decreasing the demand for primary materials, or enabling energy savings at the use phase. System-level sustainable benefits can also be achieved by exploring alternative applications for materials that can be produced with low-carbon footprints, such as the use of dissolving pulp for textile applications (FPAC, 2012). Another example would be the valorisation of low-carbon industry by-products, such as lignin from pulping liquor to replace fossil fuels or modified to replace fossil fuel-based materials. A lignin extraction demonstration plant started in 2007 in Bäckhammar (Sweden) (Tomani, 2009). The first full-scale lignin extraction plant, producing 25 kilotonnes of lignin per year (kt/yr), was started in 2013 in Plymouth (North Carolina), and a second commercialscale plant of 50 kt lignin/yr was started in 2015 in Sunila (Finland) (Valmet, 2016).

\section{Key actions}

Nordic countries are in a favourable position to ensure the long-term sustainability of energyintensive industries in a global landscape, because they are already increasing efforts to reduce industry-related carbon emissions. However, maintaining a viable industrial capacity, while achieving such deep levels of decarbonisation, will be a major challenge that will require stepping up current efforts.

Continued supportive measures of industrial energy efficiency, such as energy efficiency performance audits with reward mechanisms and promotion of energy management systems, will need to be complemented with facilitating an accelerated demonstration of low-carbon innovative process technologies in the short term, which could then enable meeting CNS' ambitions through significant deployment in the long term.

Such an innovation-empowering framework will benefit from long-term, stable energy and climate policies. Where global trade exposure constrains the ability of governments to impose carbon-pricing mechanisms on large industries, governments will need to incentivise this transition by reducing the risk of low-carbon industrial innovation investments and exploring other instruments, such as passing carbon price signals on to consumers. Through resultsoriented risk-mitigating mechanisms, such as funds provisions and low-interest or preferential loans among others, public investment should unlock private finance in areas with great potential for sustainability returns but a low likelihood for independent private-sector investment.

Specific legal frameworks and cross-country collaboration would be needed for the implementation of technologies that are key for the CNS. Such is the case with CCS, whose deployment would require the adoption of internationally-coordinated regulations that encourage the safe and effective design and operation of $\mathrm{CO}_{2}$ storage facilities. Governments can take a greater ownership in this process through cross-sectoral public-private collaborations that can help identify low-carbon innovation opportunities along product-value chains. For example, in Norway, a private-led initiative supported with public funding has developed an aluminium smelter with 
greater energy efficiencies than best available technology ${ }^{17}$ in commercial-scale demonstrations. The programme has ambitions to reach further energy-intensity reductions in the long term and to export the technology with the first large-scale facility deployed in Qatar (Hydro, 2015).

System-level sustainability benefits can be further gained from the interaction among industries and with other end-users. In this vein, regional mapping exercises of thermal generation and demand can help with identification of cost-effective opportunities for the development of thermal distribution networks that can bridge the gap between producers and consumers. For instance, a study was recently performed in Sweden to explore favourable situations for the expansion or construction of DH networks based on this methodology (Liljeblad et al., 2015).

\section{Spotlight 2: Iceland's fishing sector}

The Icelandic fishing sector has an outsized importance on the country's economy compared with the fishing sector in the other Nordic countries. The sector has a significant potential to transition rapidly to low-carbon energy. Even if this industry has not yet acted on this potential, the case serves as an illustration of the ability of marine-linked sectors such as fishing, ferries, and coastal and offshore service shipping to contribute to a low-carbon future. This potential is particularly important because climate change is likely to increase shipping in the Arctic, and limiting the use of fossil fuels will have significant environmental benefits. This Spotlight also highlights the importance of incentive-based policies, because the industry is likely to transition very quickly to low-carbon fuels if proper economic incentives are in place.

The Icelandic fishing sector was the second largest in Europe by volume in 2012 at 1.4 million tonnes of harvested fish, behind Norway with 2.1 million tonnes (FAO, 2014). Denmark's fishery is also substantial at 0.7 million tonnes of landings, while Sweden and Finland have somewhat smaller fisheries (both under 200000 tonnes (EC, 2014). As can be seen in Figure 1.37, fishing is of critical economic importance to Iceland, accounting for almost half of exports, compared to Norway and Denmark, where seafood accounted for $6 \%$ and $4 \%$ of exports, respectively, in 2012 (FAO, 2013; World Bank, n.d.). Fishing is also a key driver of Icelandic fossil fuel consumption and GHG emissions, reflecting Iceland's success in switching to low-carbon power and heating technologies.

17 The aluminium smelting technology developed achieved an electricity intensity of $12.5 \mathrm{MWh} / \mathrm{t}$ primary aluminium compared considered best practice at $13.6 \mathrm{MWh} / \mathrm{t}$ primary aluminium. 


\section{Figure 1.37 Icelandic fishing industry, 2013}

Energy

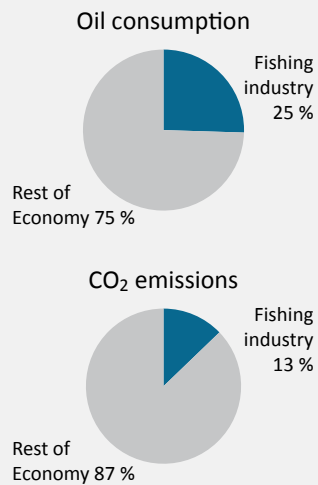
try

Economy $87 \%$
Inputs

$100 \%$

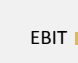

EBIT

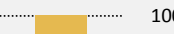

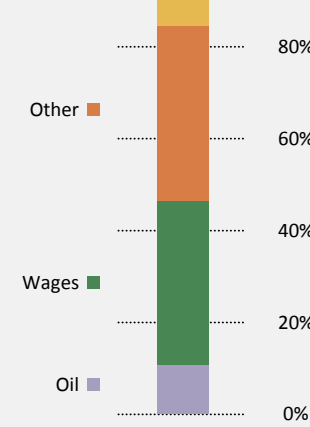

$0 \%$
Economy

GDP

Not classified

- Shellfish

- Pelagic

Rest of

Economy $92 \%$

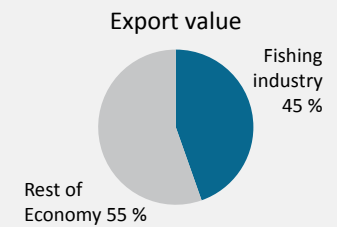

Note: "EBIT" stands for Earnings Before Interest and Tax.

Source: Statice, Energy Authority, Environment Agency.

Figures and data in this report can be downloaded at www.iea.org/etp/nordic.

Key point

Fishing plays an important role in the Icelandic economy but is a major source of GHG emissions.

\section{Trends in oil consumption}

The Icelandic fishing sector has steadily reduced its oil consumption since the turn of the century, coinciding with a decline in harvest volume and, more recently, a shift towards less fuel-intensive pelagic fisheries (species near to the sea's surface, as opposed to demersal species, which live those closer to the seafloor). Average fleet intensities cannot be easily compared across time or countries because fuel intensity can vary by orders of magnitude depending on a multitude of factors, including species harvested, gear type, vessel characteristics and operating conditions. However, research indicates that the average fuel intensity of the Norwegian fleet was stable to increasing over the period 1980-2005 (Schau et al., 2009), while average EU fuel intensity over the later period 2008-2011 fell slightly (EC, 2013). These results are consistent with the pattern in Iceland and higher oil prices in the latter years (Figure 1.38). 


\section{Figure 1.38 Evolution of the Icelandic fleet's fuel intensity (per unit harvested) and world oil prices}

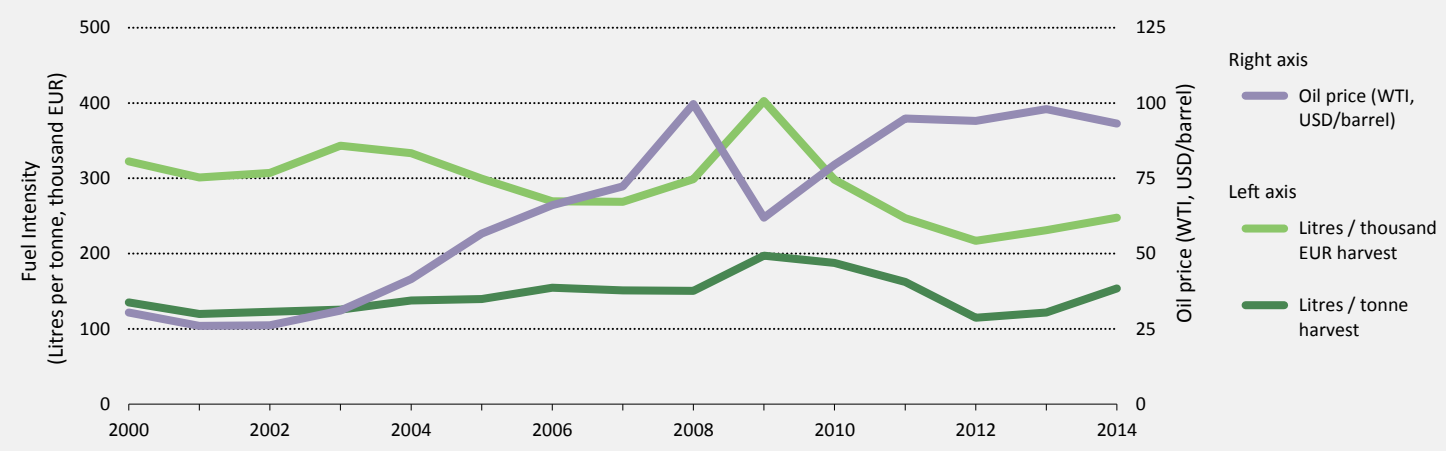

Note: "WTI" stands for West Texas Intermediate, a widely traded benchmark grade of oil.

Source: Statice, National Energy Authority, Central Bank of Iceland, IEA.

Figures and data in this report can be downloaded at www.iea.org/etp/nordic

Key point

Recent falls in fuel intensity have coincided with rising oil prices.

\section{Improving fuel efficiency}

An important driver is fleet modernisation. The savings can be substantial for both shipping and fishing, reflecting technical advances not only in engine efficiency, but also design of the propeller and hull, trim and operational optimisation. Of particular importance for fishing is innovation in fishing gear materials and design, and on-board handling and processing equipment, which are all major "consumers" of energy. For example, an estimated $85 \%$ of the energy expended during trawling is due to friction from the nets.

Fleet renewal is, however, a gradual process, with the average age of the Icelandic fleet being 27 years (comparable to the Norwegian average of 26 years in 2009, and the Danish average of 30 years in 2011). Rapid emissions reduction may, therefore, require policy intervention. A frequently cited candidate is the removal of distortionary fuel subsidies and tax concessions (Sumaila et al., 2010), which reduce the effective cost of oil to vessel operators to support the fishing industry. Such policies are not found in Iceland but are prevalent throughout the rest of the Nordic region (Martini, 2012) and can lead to substitution of oil for other inputs, as well as weaker incentives to invest in improved fuel efficiency. Another option would be wider application of existing International Maritime Organisation (IMO) regulations on air pollution (MARPOL VI) to fishing vessels. At present, some elements do not apply to the fishing sector, and others can be waived by signatories for fishing vessels operating in national waters. Iceland is the only Nordic country that has yet to adopt MARPOL VI.

Opportunities are also available in fisheries management to improve efficiency. While the widespread adoption of individual quota in the Nordic region has largely eliminated the wasteful "race to fish" associated with open access or derby fisheries, restrictions on transferability and concentration are common and limit the potential gains. In addition, total quota levels are typically based on maximising the tonnage harvested (Maximum Sustainable Yield, MSY), in line with UN and EU guidance, as opposed to profits (Maximum Economic Yield, MEY) (World Bank and FAO, 2009). A recent analysis of the Nordic fisheries estimated that an MEY approach would reduce fuel consumption by $29 \%$ and increase economic performance by over 
100\% (Waldo et al., 2014). A fishery operating at MSY may partially dissipate resource rent through overfishing, so a reduction in fishing effort can deliver the twin benefits of higher profits as well as lower fuel consumption. This gain in performance is achieved because lower harvests can lead to higher stock levels, which, in turn, reduce the effort and cost required per volume of fish harvested.

\section{Transition to renewable energy}

No material substitution away from fossil fuels to alternative energy sources has occurred in the Icelandic fishing sector or in the maritime industry in general. While the maritime sector is investing in pilot projects and addressing engine compatibility with different biofuels (Florentinus et al. 2012), alternative energy sources are not yet considered cost-competitive, and industry standards have not yet been developed. Yet, given added economic incentives to overcome the commercial barrier, the industry has the potential to make substantial headway towards renewable energy by 2020 (Davidsdottir and Agnarsson, 2010).

Financial evaluation of the alternatives clearly illustrates the commercial barrier and the need for financial incentives to realise this potential. In Iceland's case, biodiesel appears to be the most feasible alternative energy source, but Iceland's carbon tax of EUR 49 per tonne of gas oil (EUR 15 per tonne of $\mathrm{CO}_{2} \mathrm{e}$ ) would still need to at least triple for biodiesel to be cost competitive (see Figure 1.39). Aside from economic viability, technical issues will also need to be addressed, such as sensitivity of biodiesel to low temperatures necessitating heaters, chemical interaction with engine components and the need for marine biodiesel standards.

\section{Figure 1.39 Abatement cost for renewable energy options}

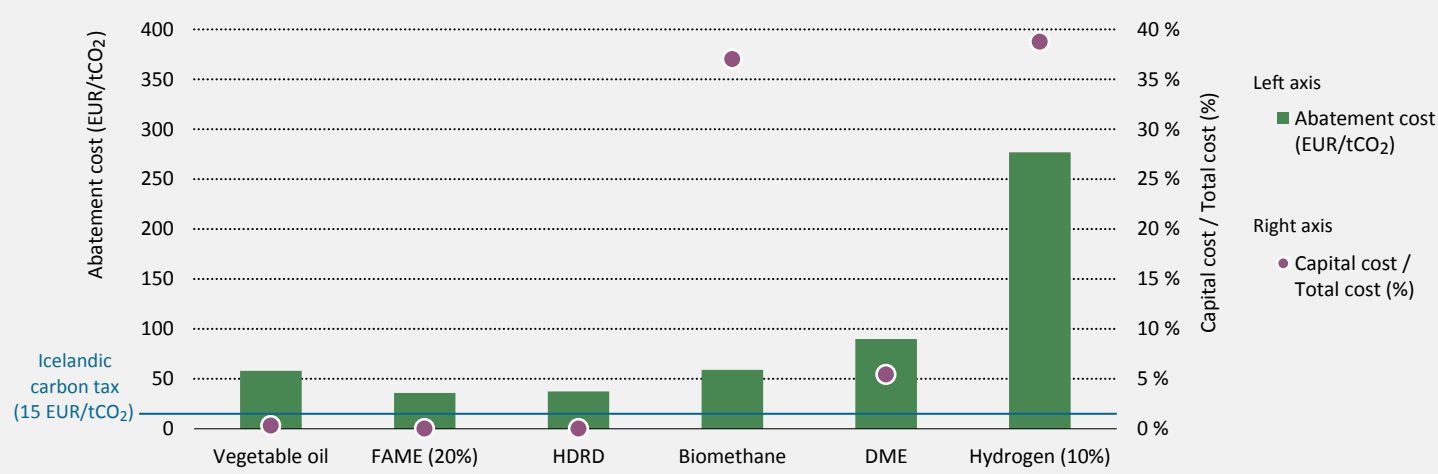

Source: Analysis by University of Iceland based on personal communication with Ásgeir Ívarsson.

Notes: Oil prices based on CNS, Dimethyl Ether (DME) and hydrogen costs track Icelandic electricity prices. Fatty Acid Methyl Esters (FAME) and hydrogen blending ratios limited to 20\% / 10\%, but cost ratios are grossed up to 100\%. HDRD = Hydrogenation-derived Renewable Diesel.

Figures and data in this report can be downloaded at www.iea.org/etp/nordic

Key point Biodiesel appears to be the most cost-effective renewable energy option. 


\section{The reduction fishery shifts to renewable electricity}

The energy-intensive downstream fishmeal and fish oil (or "reduction") sector is significant in Iceland, processing 40\% of harvest volume in 2014 in 11 factories located around the country. In Norway, by comparison, the reduction fishery accounted for $18 \%$ of landings in 2009 . While the harvesting of reduction fish species is among the most fuel-efficient, the downstream processing can be fuel-intensive, requiring up to $50 \mathrm{~kg}$ of oil per tonne of raw material in a traditional oil-powered operation. Iceland's reduction fishery has made great strides towards carbon neutrality over the last decade by switching from oil to renewable electricity. The transition has been dramatic; by 2014 , the sector met $75 \%$ of its energy requirements with renewable electricity.

The affordability of domestically produced non-secure electricity compared to imported oil was a key driver in this development. Reduction processing is highly seasonal, and the processors buy cheaper non-secure electricity and manage the risk of supply interruption by maintaining back-up oil-powered capacity. These arrangements may, however, be adversely affected by the construction of an Icelandic Interconnector due to potentially higher electricity prices (see Spotlight 2) and the resultant potential for international customers to outbid Icelandic fishmeal and fish oil producers.

\section{Critical challenges and solutions}

The following are several challenges and solutions:

- Tax carbon more heavily: Raising carbon taxes (for example, to the level required for cost parity, i.e. EUR 50 per $\mathrm{MT} \mathrm{CO}_{2} \mathrm{e}$ ) would increase the incentives for fishing companies to adopt more fuel-efficient technologies and working practices. Outside of Iceland, elimination of tax concessions and subsidies would further encourage substitution away from fossil fuels.

- Factor fleet efficiency into fishery management policy: The overall economic efficiency of the sector is influenced by several factors, including methods of quota setting (for example, harvest limits based on MSY as opposed to MEY) and allocation, as well as restrictions on quota and vessel ownership. By explicitly including efficiency as a criterion in policy-making, such as fuel economy standards in the transportation sector, fishery managers can potentially stimulate greater investment in efficient vessels and operations.

- Support marine commercialisation of alternative fuels: The growing use of alternative fuels in road transportation needs to be extended to the maritime industries, including fishing. Achieving this goal will depend on the development of technical solutions and standards tailored to maritime operational requirements, and therefore on the stance taken by governments.

- Seek international cooperation: Fish is heavily traded, and any measures to reduce emissions will need to address concerns about national interest and international cost-competitiveness. Cooperative international stock management bodies such as the International Council for Exploration of the Sea (ICES) may be a suitable venue for concerted action among Nordic and neighbouring countries to reduce emissions while maintaining a level playing field among competing fishing companies. 


\section{Buildings: Accelerating deep energy renovation is critical}

\section{Tracking progress: Energy trends in Nordic buildings since 1990}

The buildings sector has accounted for slightly more than one-third of final energy demand in the Nordic countries since 1990, consuming roughly 1.4 E) in 2013. Accelerating energy efficiency improvements in the buildings sector, especially energy efficiency improvements in space heating demand, will be critical to meeting CNS objectives for a more efficient, zerocarbon energy economy. Because buildings already in place today are expected to still constitute roughly $70 \%$ the buildings stock in 2050, deep energy renovation of existing buildings will be the single most important element of achieving those objectives.

Since 1990, total Nordic building final energy use has increased by slightly less than 1\% per year, despite energy efficiency measures and shifts away from fossil fuel use in buildings. Average building energy consumption per person grew by roughly $0.2 \%$ per year, with total building final energy per capita in Finland, in particular, having increased by nearly $60 \%$ since 1990. ${ }^{18}$ Sweden is the one exception to this trend, with both total final energy and average energy per person having capped and then slightly decreased since the early 2000s (Figure 1.40).

Several key drivers of building energy demand changed in the Nordic countries since 1990, especially in the residential sub-sector, which accounts for more than $60 \%$ of total building final energy use. While population across the Nordic countries only increased by $12 \%$ between 1990 and 2013, gross domestic product (GDP) grew by nearly 60\%, meaning that average income (as measured by GDP per capita) grew by $40 \%$ during the same period. With increasing income, average floor area per person grew by 15\% since 1990, and the total number of households grew by nearly 30\%, with average household size decreasing from 2.3 persons in 1990 to roughly two persons per household in 2013. In Finland, in particular, the number of households grew at nearly three times the rate of population growth since 1990. As a result of these trends, total residential floor area in the Nordic countries - a key driver of space heating demand and building energy consumption - grew by nearly 30\% between 1990 and 2013.

18 This change is largely explained by growth in the services sub-sector, whose floor area increased by 40\% since 1990 and whose energy consumption per $\mathrm{m}^{2}$ increased from $145 \mathrm{kWh} / \mathrm{m}^{2}$ in 1990 to $330 \mathrm{kWh} / \mathrm{m}^{2}$ in 2013 . Residential floor area in Finland grew by $30 \%$ since 1990, although residential energy per $\mathrm{m}^{2}$ remained relatively constant. 


\section{Figure 1.40 Energy by end-use and average building energy use per person}

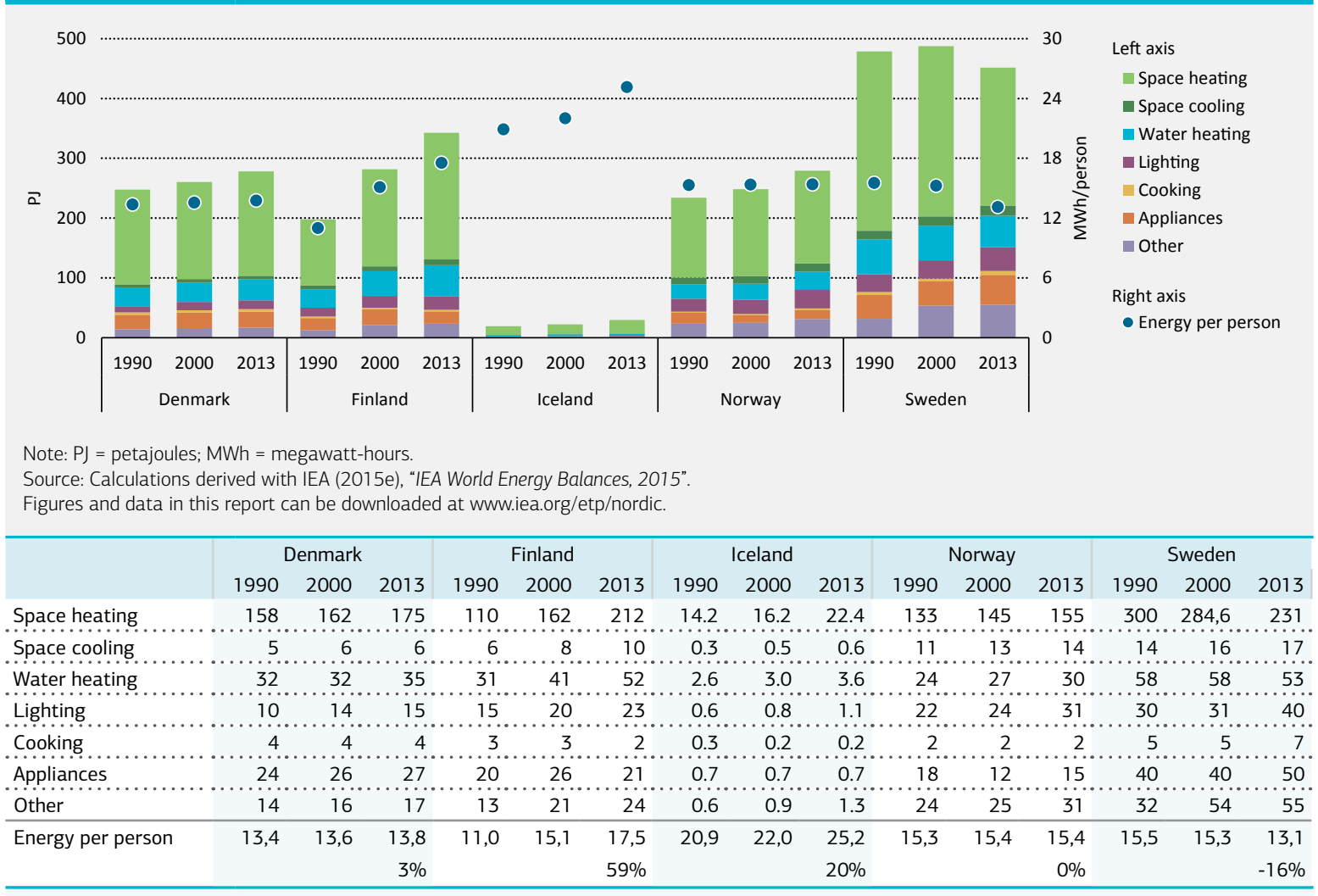

Key point

Building energy use per capita has continued to increase across the Nordic countries, despite energy efficiency measures over the last two and a half decades. Sweden is the one exception to this rule.

By contrast, the carbon intensity of Nordic buildings has improved considerably over the last two decades. Fossil fuel use declined by nearly $60 \%$ since 1990, with coal and oil energy consumption cut by nearly $75 \%$ during the same period (Figure 1.41). Natural gas use grew rather considerably at 4\% per year between 1990 and 2000, although it has remained relatively stable since then. The net effect is an overall reduction in total fossil fuel consumption, and as a result, direct emissions from the buildings sector have decreased by an average of $4 \%$ per year since 1990. Because heat and electricity generation in Iceland were already nearly completely decarbonised in 1990, emissions from the sector have remained close to zero. 


\section{Figure 1.41 Final energy consumption in the Nordic buildings sector by fuel}

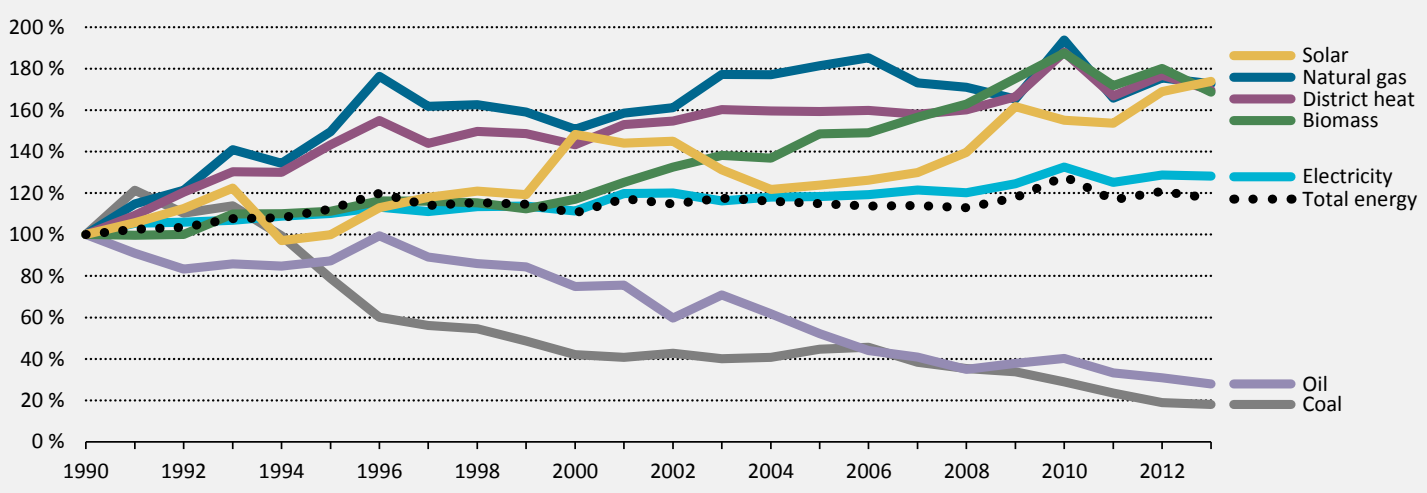

Figures and data in this report can be downloaded at www.iea.org/etp/nordic

Key point While direct fossil fuel use in the buildings sector in the Nordic countries has significantly decreased since 1990, significant effort is still needed to improve the overall energy intensity of buildings.

District heating, biomass and solar thermal energy use in buildings have all continued to grow since 1990 (roughly 2.2\% per annum for each), while electricity consumption has grown a little less rapidly, at roughly $1 \%$ per year. These trends have been paired with continued decarbonisation of the power generation sector, meaning that the net (direct and indirect) emissions impact of the buildings sector has continued to decrease over the last two and a half decades.

Given trends in building final energy demand growth since 1990, the long-term potential for deep decarbonisation across the Nordic energy economy looks challenging. In short, the Nordic countries may not meet their CNS objectives if buildings sector energy demand (accounting for roughly $60 \%$ of final electricity and commercial heat demand in 2013) continues to place greater onus on the power sector. Energy efficiency in buildings - notably envelope improvements (e.g. air sealing and insulation) and more efficient equipment and appliances - will help to reduce carbon emissions in the power sector, while also potentially helping to free up carbon-neutral and zero-carbon resources for other sectors (e.g. biofuels for transport).

Strong effort is needed to reduce energy demand in buildings beyond current decarbonisation measures. While average energy intensity (as measured by $\mathrm{kWh} / \mathrm{m}^{2}$ ) of the Nordic building stock improved slightly (around 5\% since 1990), this improvement was not enough to offset continued growth in floor area (25\% since 1990). Space heating is still the major driver of this energy demand, with average space heating intensity across the five Nordic countries still at more than $125 \mathrm{kWh} / \mathrm{m}^{2}$ in 2013, which is $10 \%$ higher than the EU average. In fact, despite improvements in new building construction and some renovation of existing stock, the total share of space heating in building energy consumption has remained more or less flat, at above $60 \%$ since 2000. ${ }^{19}$

19 This need is partly explained by efficiency improvements in other building end-uses, as well as by changes in energy demand across those other end-uses relative to the large proportional share of space heating demand. 
More aggressive improvements of building energy performance levels (e.g. deep energy renovations ${ }^{20}$ ) are needed across the Nordic countries. Accelerated renovation rates (beyond the typical $0.25 \%$ to $0.5 \%$ annual renovation rates in most countries today) between $2 \%$ and $3 \%$ per year are needed to ensure that the majority of existing buildings undergo energy efficiency renovations by 2050. Achieving this goal will not be a simple task: action is needed to remove existing market barriers (e.g. financial hurdles and other split-incentives preventing wide-scale uptake of these measures) to ensure that deep energy efficiency measures become widely available, cost-effective and standard practice.

Strategic planning for integrated building solutions (e.g. with clean district energy systems) will also be necessary to realise a CNS vision and avoid any lock-in of unnecessary investments. This strategy is particularly true for district heating networks in the Nordic countries, whose investment decisions typically rely on expected heat demand. A challenge is to adopt the baseload capacity to a decreasing demand and also to make sure that energy savings will decrease the need for peak load production. The same is also true for building owners and operators, who will need to plan energy efficiency measures strategically to avoid equipment investments (e.g. boilers and heat pumping systems) that would be oversized when deep energy renovations are performed, and vice versa.

\section{Achieving an efficient, low-carbon buildings sector by 2050}

Total energy used in the Nordic buildings sector decreases to roughly 1 E) (27\% below 2013 levels) in 2050 under the CNS, with space heating demand decreasing from roughly 800 PJ today to 440 PJ in 2050 (45\% reduction) because of rigorous energy efficiency improvements across the Nordic building stock. Total final energy use in the residential sub-sector decreases by $40 \%$ compared with 2013 energy demand, as very-low-energy new building construction (e.g. nZEBs or better) and aggressive building envelope renovations (i.e. 30\% to 50\% energy intensity improvement, or greater depending on cost-effectiveness) in existing buildings reduce residential space heating demand by nearly $55 \%$.

Average space heating energy demand across the entire Nordic building stock decreases to less than $60 \mathrm{kWh} / \mathrm{m}^{2}$ in 2050 under the CNS, compared with roughly $90 \mathrm{kWh} / \mathrm{m}^{2}$ in the 4DS that year (which is more in line with current levels of building energy renovations). Average residential space heating energy intensity improves by nearly $2.5 \%$ per year to 2050 , with aggressive building envelope measures (e.g. air sealing, improved insulation and minimally double-paned, low-emissivity windows) and increased uptake of efficient and low-carbon heating equipment (e.g. heat pumps and solar thermal systems). In the services sub-sector, energy demand for space heating and cooling decreases by 15\% below 2013 levels, despite an expected 20\% growth in Nordic services floor area by 2050.

Residential water heating energy demand decreases by 12\% below 2013 levels in 2050 under the CNS, despite continued growth in the number of households to 2050 (a 20\% addition), because of strong uptake of solar thermal water heaters and heat pump water heating. Heat losses connected to water heating are also expected to decrease drastically. By contrast, household appliances energy demand increases slightly (5\%) compared with 2013 levels because growth in the number of households and appliance ownership levels increase slightly faster than energy efficiency improvements. This level is still 10\% lower than the 4DS in 2050. Cooking demand, however, grows by slightly more than 15\% by 2050 in both the 4DS and CNS, because few energy efficiency gains in cooking are expected in the Nordic countries, barring large changes in cooking practices and preferences.

20 The Global Buildings Performance Network defines deep renovations as actions that achieve building performance levels that are not more than $60 \mathrm{kWh} / \mathrm{m}^{2}$ per year for all building code loads (i.e. space heating and cooling, water heating and installed lighting) (GBPN, 2013). This goal may not be cost-effective for all buildings in the Nordic countries but should be considered as an ambitious target with respect to building energy efficiency potential. 
Overall Nordic buildings sector energy performance (across all end-uses) improves from roughly $220 \mathrm{kWh} / \mathrm{m}^{2}$ in 2013 to less than $130 \mathrm{kWh} / \mathrm{m}^{2}$ in 2050 under the CNS (or 25\% lower than the 4DS in 2050). Final energy demand by fuel type also changes considerably to 2050 (Figure 1.42), with Iceland being the exception with geothermal district heating and electricity remaining as the main energy types. Under both the 4DS and CNS, coal and oil consumption in buildings go to zero by 2050. Natural gas use diminishes to zero under the CNS (compared with a 20\% decrease in 2050 under the 4DS), and electricity demand decreases by 30\%, compared with 2013, as Nordic buildings adopt higher efficiency electrical end-uses, such as heat pumps, lightemitting diode (LED) and higher efficiency appliances. Under the 4DS, electricity demand remains more or less constant to 2050.

\section{Figure 1.42 Buildings sector energy by fuel and space heating intensities to 2050}

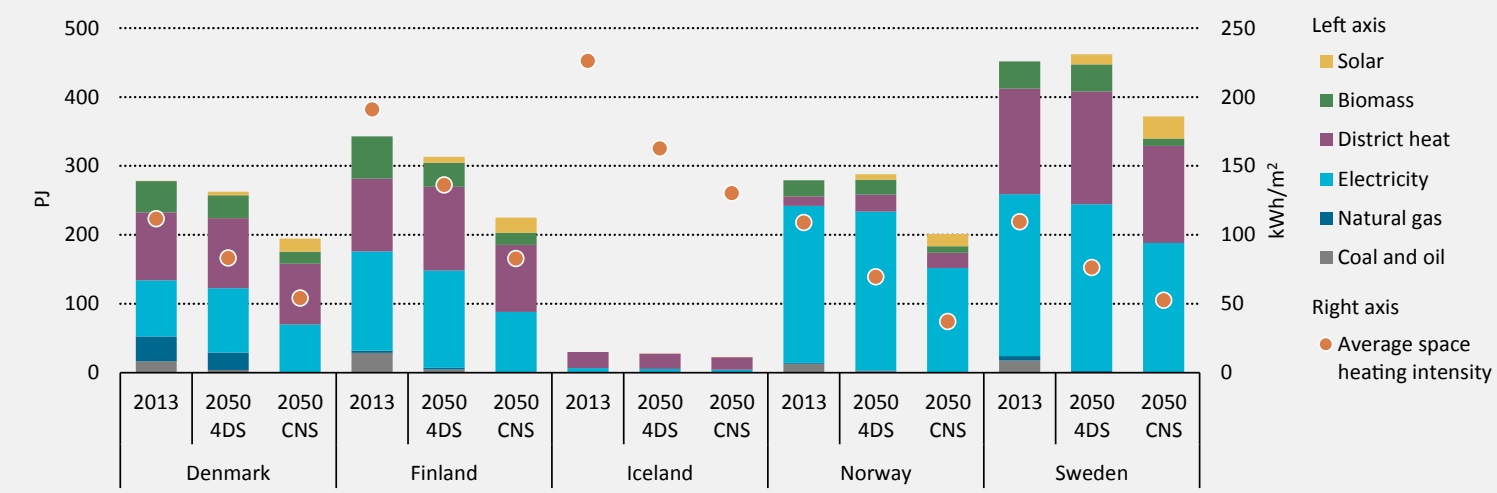

Figures and data in this report can be downloaded at www.iea.org/etp/nordic.

\begin{tabular}{|c|c|c|c|c|c|c|c|c|c|c|c|c|c|c|c|}
\hline \multirow[t]{2}{*}{ PJ } & \multicolumn{3}{|c|}{ Denmark } & \multicolumn{3}{|c|}{ Finland } & \multicolumn{3}{|c|}{ Iceland } & \multicolumn{3}{|c|}{ Norway } & \multicolumn{3}{|c|}{ Sweden } \\
\hline & 2013 & $\begin{array}{r}2050 \\
\text { 4DS }\end{array}$ & $\begin{array}{r}2050 \\
\text { CNS }\end{array}$ & 2013 & $\begin{array}{r}2050 \\
4 D S\end{array}$ & $\begin{array}{r}2050 \\
\text { CNS }\end{array}$ & 2013 & $\begin{array}{r}2050 \\
4 D S\end{array}$ & $\begin{array}{r}2050 \\
\text { CNS }\end{array}$ & 2013 & $\begin{array}{r}2050 \\
\text { 4DS }\end{array}$ & $\begin{array}{r}2050 \\
\text { CNS }\end{array}$ & 2013 & $\begin{array}{r}2050 \\
\text { 4DS }\end{array}$ & $\begin{array}{r}2050 \\
\text { CNS }\end{array}$ \\
\hline Solar & 0.2 & 5.4 & 19.0 & 0.0 & 9.0 & 22.1 & 0.0 & 0.0 & 0.1 & 0.0 & 8.1 & 17.9 & 0.0 & 14.7 & 32.2 \\
\hline Biomass & 45.6 & 32.9 & 17.4 & 61.3 & 34.5 & 17.5 & 0.0 & 0.0 & 0.0 & 23.3 & 21.5 & 9.6 & 39.5 & 39.0 & 10.8 \\
\hline District heating & 98.6 & 101.8 & 88.0 & 105.6 & 121.5 & 97.1 & 23.2 & 22.0 & 18.4 & 13.8 & 24.7 & 22.0 & 153.3 & 163.8 & 140.6 \\
\hline Electricity & 81.5 & 93.4 & 69.6 & 144 & 141.4 & 87.9 & 6.5 & 5.6 & 4.2 & 228 & 230.5 & 151.8 & 234.8 & 242.0 & 188.2 \\
\hline Natural gas & 35.8 & 25.3 & 0.3 & 3.1 & 2.1 & 0.0 & 0.0 & 0.0 & 0.0 & 1.0 & 1.2 & 0.0 & 6.4 & 1.7 & 0.0 \\
\hline Coal and oil & 16.7 & 3.9 & 0.0 & 29.0 & 4.8 & 0.2 & 0.1 & 0.0 & 0.0 & 13.2 & 1.9 & 0.0 & 17.7 & 0.7 & 0.0 \\
\hline
\end{tabular}

Key point

Nordic building energy demand is reduced by $27 \%$ under the CNS, compared with 2013, and average space heating energy intensities are improved by 55\% as a result of aggressive energy renovations across existing building stocks along with low-energyintensity new building construction.

Total biomass consumption decreases under both the 4DS and CNS, as space heating energy intensity continues to decrease in buildings. By contrast, heat pumps and solar thermal collectors grow considerably, replacing the vast majority of oil, gas boilers and direct electric resistance heating. In particular, space heating and hot water demand supplied by solar thermal systems increases exponentially, from less than 0.5 PJ in 2013 to 90 PJ in 2050 under the CNS. This increase would require more than a twofold increase in solar thermal installations in buildings compared with the $4 \mathrm{DS}$. This increase in installations could be motivated since more buildings will have low-temperature systems in the CNS as enabled by the improved envelope. Increased numbers of installations will also make those solar thermal installations more cost effective. 
District heating demand under the CNS decreases by around 7\% as space heating demand diminishes with building envelope improvements, although district heating market shares (in terms of floor area served by district heating) increase slightly through in-fill and some potential network expansions, particularly as gas and oil boilers are phased out by 2050. Planned strategically, this trend would allow district heating providers to maintain (roughly) current market sales across a wider base of consumers while also making necessary investments in low-carbon heat production and possibly eliminating expensive peak demand capacities (due to improved thermal intensities in buildings). By contrast, under the 4DS, district heating demand could increase by as much as $10 \%$, given growth in total floor area relative to improvements in building thermal demand intensities.

Overall, the energy scenarios in the Nordic buildings sector portray a continued, increasing reliance on electricity and commercial heat as fossil fuel consumption continues to diminish. Even in the CNS, total electricity and district heating demand still accounts for $85 \%$ of buildings sector final energy demand in 2050 (compared with 80\% in 2013). While solar thermal capacity increases dramatically under the CNS (and even under the 4DS, but at a slower rate), continued reliance by buildings on the power sector will require sustained investments in low-carbon electricity and heat generation to meet CNS objectives by 2050. Significant strategic improvements in building space heating intensities, along with energy efficiency improvements in energyconsuming equipment and appliances, will help allay this increased pressure on the power sector.

\section{Engaging urban areas to meet CNS targets}

Urban areas will be an important driver of building energy consumption and emissions to 2050. Around 85\% of the Nordic population lived in an urban area in 2013 (UN DESA, 2014) ${ }^{21}$, and urban buildings accounted for an estimated $80 \%$ of total building floor area that year. By 2050 , urban areas will grow to nearly $90 \%$ of the Nordic population, and urban floor area is expected to grow by 450 million $\mathrm{m}^{2}$, or nearly all of building floor area additions to 2050 (Table 1.3).

\begin{tabular}{|c|c|c|c|c|c|c|}
\hline \multirow[t]{3}{*}{ Table 1.3} & $\begin{array}{l}\text { gy co } \\
\text { lic reg }\end{array}$ & mptio & build & (urb & and na & \\
\hline & \multicolumn{3}{|c|}{ Urban total } & \multicolumn{3}{|c|}{ Nordic (national) total } \\
\hline & 2013 & 2030 & 2050 & 2013 & 2030 & 2050 \\
\hline Population (million) & 22.0 & 24.9 & 27.8 & 26.0 & 28.6 & 31.0 \\
\hline GDP (billion USD) & 1089.8 & 1610.8 & 2313.5 & 1258.8 & 1809.4 & 2535.9 \\
\hline Households (million) & 11.1 & 12.3 & 13.7 & 12.8 & 13.8 & 15.0 \\
\hline Occupancy (persons per household) & 2.0 & 2.0 & 2.0 & 2.0 & 2.1 & 2.1 \\
\hline Average dwelling size $\left(\mathrm{m}^{2}\right)$ & 124.5 & 131.7 & 132.8 & 136.6 & 145.1 & 146.9 \\
\hline Residential floor area (million $\left.\mathrm{m}^{2}\right)$ & 945.6 & 1121.0 & 1275.2 & 1253.7 & 1145.0 & 1600.1 \\
\hline Residential floor area per capita $\left(\mathrm{m}^{2}\right)$ & 43.0 & 44.9 & 45.8 & 48.2 & 50.6 & 51.7 \\
\hline Services floor area $\left(\right.$ million $\left.m^{2}\right)$ & 430.6 & 500.4 & 549.2 & 495.4 & 560.7 & 600.8 \\
\hline \multicolumn{7}{|c|}{$\begin{array}{l}\text { Note: GDP expressed in } 2014 \text { USD at purchasing power parity (PPP); further description of buildings sector drivers for urban energy estimates can be found } \\
\text { in the methodology annex. } \\
\text { Source: Population: UN DESA (2014), World Urbanisation Prospects: The } 2014 \text { Revision, United Nations Department of Economic and Social Affairs, Population } \\
\text { Division, New York. }\end{array}$} \\
\hline
\end{tabular}

21 Urban boundary definitions (i.e. what is considered urban, peri-urban and rural) vary across countries and do not distinguish important factors in buildings energy demand (e.g. building density, size and purpose). A general modelling methodology was, therefore, developed to estimate energy consumption in urban and non-urban areas. Additional information can be found in the IEA Energy Technology Perspectives 2016 (ETP 2016) methodology annex. 
Total final energy consumption in urban buildings accounted for an estimated $1 \mathrm{E}$ ) in 2013, or slightly less than $75 \%$ of total building final energy use that year. Under the 4DS, final energy consumption in urban buildings reaches 1.1 EJ in 2050 , or nearly $85 \%$ of total building final energy consumption that year. The services sub-sector accounts for nearly all of the additional energy demand, while energy use in urban residential buildings remains relatively constant, despite a nearly 25\% increase in urban households between 2013 and 2050. This relatively constant rate is due largely to improved space heating intensities in new household additions relative to continued marginal gains in existing urban residential buildings, where the average space heating and hot water energy intensity of new residential buildings is typically between $50 \mathrm{kWh} / \mathrm{m}^{2}$ and $90 \mathrm{kWh} / \mathrm{m}^{2}$, compared to existing urban residential buildings with an average space heating intensity of roughly $130 \mathrm{kWh} / \mathrm{m}^{2}$.

Under the CNS, urban building final energy consumption decreases by $15 \%$ compared with 2013 levels (or 22\% compared with the 4DS in 2050), meaning that urban buildings account for roughly $70 \%$ of total building final energy reductions in 2050 (Figure 1.43). This share, relative to the larger share of urban buildings in the total building stock ( $85 \%$ of total floor area), can be explained by certain challenges to reducing urban building final energy demand. For instance, most urban areas in the Nordic countries have high concentrations of multi-storey, multi-family buildings, which can be more challenging to achieve deep energy renovations, due to high variability of existing building conditions, multiple approaches to efficiency improvements and other external barriers, such as historical preservation restrictions, consumer lack of information and split incentives in the market (e.g. renter-occupied housing and multi-owner buildings).

\section{Figure 1.43 \\ Building energy savings by end-use, urban and non-urban buildings}

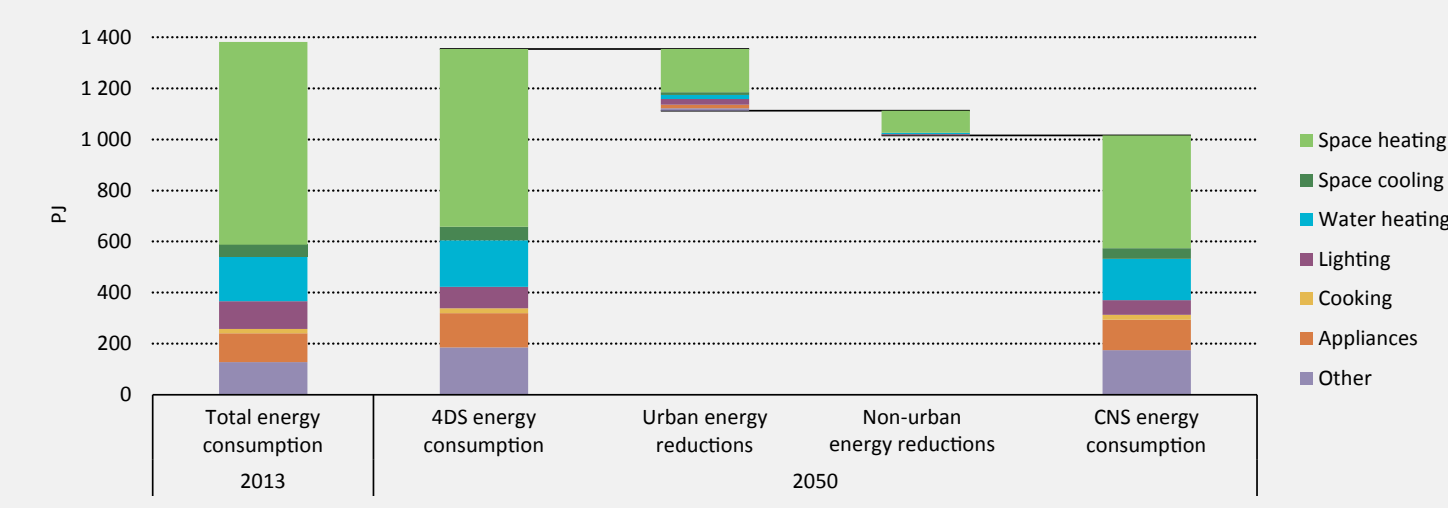

Figures and data in this report can be downloaded at www.iea.org/etp/nordic. space heating demand reductions accounting for roughly 70\% of urban building energy savings. 
Other challenges, such as high urban densities and limited on-site renewable potential may limit (n)ZEB achievement in urban areas. ${ }^{22}$ For example, solar thermal technology may not provide sufficient supply for domestic hot water demand in some multi-family buildings, because the rooftop area for renewables integration in buildings is estimated to be roughly $50 \%$ lower per person in urban areas (accounting for both low-rise urban buildings and decreasing number of people per floor area in cities). Building shading can also be an issue for renewables integration in urban buildings.

At the same time, urban areas also offer some unique opportunities because of potential synergies between buildings, district energy networks and other energy producers and consumers. While deep energy renovations in urban areas may pose certain challenges or may not be cost effective for some urban building types, building heat demand reduction strategies can be coordinated with clean heat supply solutions through district heating networks in cities. Integrated building renovation measures can also complement improved district heating efficiencies (e.g. by lower distribution temperatures) when planned strategically with district heating network investments, also potentially allowing for network expansion to meet additional building demand without increasing net supply capacity. Integrated building energy efficiency and district heating solutions in urban areas can also help to improve energy system efficiencies in an increasingly diverse energy sector (e.g. through storage of variable renewable energy as heat and through capture of low-grade waste heat using heat pumps).

Despite potential challenges to achieving deep efficiency improvements in urban buildings, urban space heating demand under the CNS could be reduced by roughly $33 \%$ compared to the 4DS, accounting for nearly $70 \%$ of total urban energy savings in 2050. Improved control and regulation of heating and ventilation in buildings, along with increased insulation, air sealing, high-efficiency windows and other technologies (e.g. ventilation exhaust recovery using heat pumps) will all play a critical role in achieving those energy efficiency improvements.

Lighting and appliances energy use reduces by $20 \%$ under the CNS as a result of energy performance standards and increased uptake of high-efficiency products, and urban water heating energy consumption improves by $10 \%$, despite a $25 \%$ increase in the number of households, because of energy efficiency measures (e.g. increased sales of heat pump water heaters) and considerable growth of solar thermal collectors.

The energy demand for urban space cooling and other services improves by $20 \%$ and $6 \%$, respectively, under the CNS compared with the 4DS. Despite a relatively cool climate and much fewer cooling degree days than other parts of Europe, space cooling demand has consistently grown in the Nordic buildings sector since 1990 (about 33\% since 1990), especially in the services sub-sector. Increased use of inoperable windows in commercial buildings, greater air tightness and improved insulation, and an overall growing demand for thermal comfort during warmer weather are all contributing to increased space cooling energy demand, which could grow as much as another $20 \%$ or more by 2050 under the 4DS. As the urban buildings sector continues to grow, and building envelopes and air sealing continue to improve under the CNS, greater use of natural ventilation and continuous improvements in cooling and ventilation equipment efficiency will help to ensure improved comfort without increasing final energy demand for cooling.

Urban building energy efficiency measures, including equipment efficiency, envelope improvements (including building controls and heat recovery when applicable), and an aggressive phase-out of fossil fuel boilers and equipment under the CNS lead to a near total reduction of direct $\mathrm{CO}_{2}$ emissions in urban buildings in 2050. Indirect emissions (from upstream generation of electricity and commercial heat) decrease by more than $95 \%$ by 2050 . Nearly $65 \%$ of CNS emission

22 In many urban areas, near-zero and net-zero energy or emissions communities may be a more realistic goal for achieving a low- or zero-emissions buildings sector. 
reduction comes from the urban residential buildings, which also constitute $55 \%$ of total $\mathrm{CO}_{2}$ emission reductions in 2050 from Nordic buildings. Total urban buildings (residential and services) account for roughly 90\% of buildings sector emission reductions to 2050 (Figure 1.44).

Urban building energy efficiency measures have considerable influence on Nordic $\mathrm{CO}_{2}$ emissions when the impact of urban buildings on power generation is considered. While the buildings sector only constituted about 5\% of (direct) energy-sector-related $\mathrm{CO}_{2}$ emissions in 2013, more than $60 \%$ of Nordic electricity and commercial heat went to buildings that year, making it responsible for roughly $43 \mathrm{MtCO}_{2}$ of upstream $\mathrm{CO}_{2}$ emissions. Urban buildings are estimated to have accounted for more than $80 \%$ of total building electricity and commercial heat consumption in 2013, and practically all of Nordic building electricity growth to 2050 is expected to come from urban buildings. Energy efficiency in urban areas, therefore, not only contributes to reducing overall buildings electricity and commercial heat demand but also plays an important role in supporting decarbonisation of the power sector, as improved efficiency and reduced buildings electricity and heat demand allow for an improved, more efficient, more resilient and lower carbon grid. This energy efficiency also frees up needed electricity for continued electrification of the transport sector (see Chapter 3) and the possibility for a greater export of lowcarbon electricity. However, the CNS will require a lot of effort to not only save energy but to increase demand flexibility to reduce the peak load demand.

\section{Figure $1.44 \quad \mathrm{CO}_{2}$ emissions reduction in urban buildings to 2050}

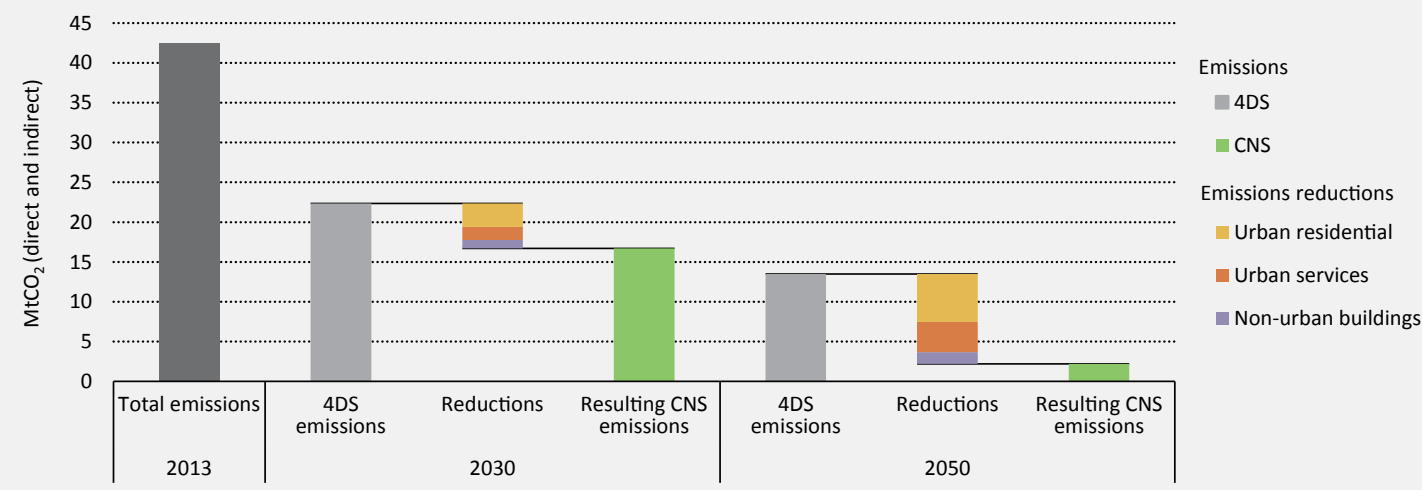

Figures and data in this report can be downloaded at www.iea.org/etp/nordic

Key point Urban building $\mathrm{CO}_{2}$ emissions go to zero in 2050 as a result of strong energy efficiency measures paired with decarbonisation of electricity and commercial heat production.

\section{District heating and buildings strategies: Possibilities in Stockholm}

The city of Stockholm has a relatively old buildings stock and one of the highest population densities in the country (SCB, 2015). Nearly $80 \%$ of total existing buildings in Stockholm are connected to the municipal district heating network, including roughly $85 \%$ of total residential buildings and nearly $95 \%$ of multi-family residential buildings. While energy efficiency measures are needed to lower heating energy demand in buildings across Stockholm, those measures 
will have an impact on the district heating network as building energy demand diminishes, especially because options for expanding to new customers within the existing system boundaries are limited. The network could expand to surrounding areas, but the costs for those expansions would typically be high, due to infrastructure costs and increased distribution losses from lower heat densities.

An initial assessment of three building renovation packages was performed for 18 common building types across Stockholm's residential building stock, for a total of 54 building renovation packages. Measures include envelope measures (e.g. insulation, window replacement and air sealing) and other energy efficiency improvements, such as heat recovery from ventilation and upgrade of equipment (e.g. electrical motors in circulation pumps). The conclusions of the assessment found that energy efficiency measures (from a building perspective only) would be cost effective down to $50 \mathrm{kWh} / \mathrm{m}^{2}$ to $70 \mathrm{kWh} / \mathrm{m}^{2}$ for most building types. However, those savings (roughly 50-60\% over existing average residential heating intensities) would have considerable impact on the district heating network.

In response, an assessment was made looking at nine possible scenarios for residential building efficiency measures with respect to district heating pathways in Stockholm (Table 1.4). Those scenarios - ranging from minimal investments in buildings and district heating to aggressive building renovation schemes (e.g. greater than $60 \%$ stock improvement) and carbon-neutral district heating investments ${ }^{23}$ - considered the effects of building energy efficiency measures on district heating investments to 2050. The scenarios also considered the discounted lifecycle cost perspective for the entire system (i.e. investments in district heating and buildings efficiency measures, as well as energy and any operations and maintenance costs) with respect to energy savings and $\mathrm{CO}_{2}$ emission reductions.

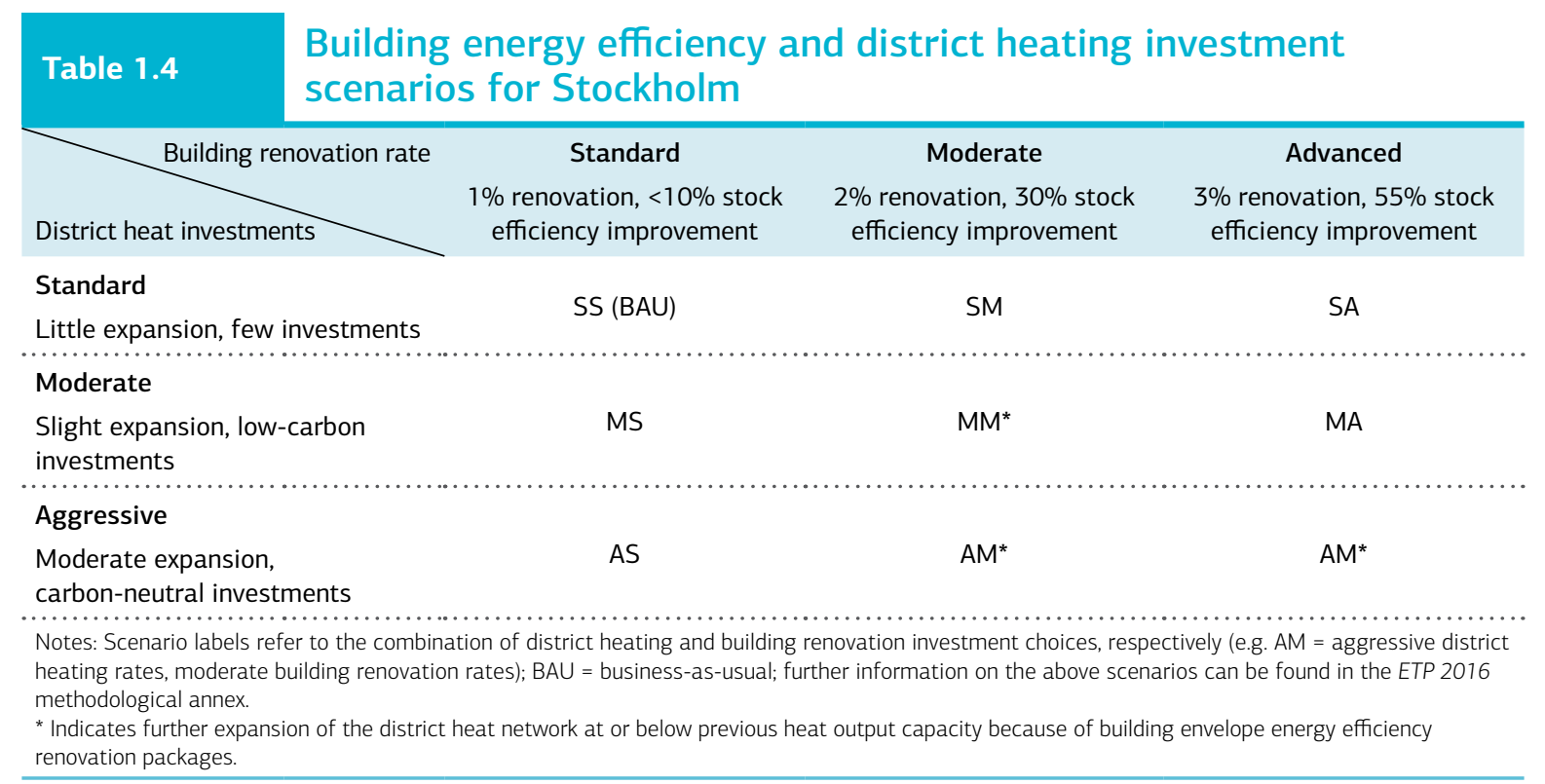


The conclusions of the analysis indicate that the most advantageous investments, in terms of meeting energy and emission reduction targets with respect to total life-cycle costs, are moderate building renovations with an aggressive district heating pathway (Figure 1.45). In this combination (scenario AM), average residential building district heating intensity is lowered to $85 \mathrm{kWh} / \mathrm{m}^{2}$ (from an average of $126 \mathrm{kWh} / \mathrm{m}^{2}$ ), and energy consumption and $\mathrm{CO}_{2}$ emissions (across buildings and district heating) are lowered by $7 \%$ and 43\%, respectively. Energy-saving measures in buildings without any intervention in the district heating network would not reduce the total life-cycle costs from a systems perspective, because capital and operational costs in the district heating network would offset savings from building energy demand reductions. Conversely, investments in low-carbon or carbon-neutral investments in the district heating network (e.g. combined heat and power using municipal solid waste and solar thermal integration with seasonal storage) would allow for important emission savings but would not reduce net energy demand. More aggressive building measures with carbon-neutral district heating would lead to greater energy and emissions reductions, but life-cycle costs would be higher because district heating capacity investments would not be fully utilised.

\section{Figure 1.45 Costs and energy and emissions savings to 2050 for integrated buildings in Stockholm}

$\begin{gathered}\text { District } \\ \text { heat } \\ \text { vation }\end{gathered}$
$\begin{array}{r}\text { Standard Standard } \\ \text { Standard Moderate }\end{array}$
Standard Aggressive

Key point
In Stockholm, moderate building efficiency measures, paired with carbon-neutral district heating investments, would lead to the greatest, most cost-effective energy and emissions reductions in 2050.

The Stockholm integrated analysis illustrates that deep energy savings and emission reductions across the building stock and district heating network are possible if energy efficiency measures and district heating investments are planned strategically together to 2050. Further energy and emission reductions are possible, but long-term strategic planning for district heating investments would be critical to achieve lower capacity in base-load production in the longer term with more flexibility in short- to medium-term capacity as buildings are renovated.

Further analysis on the influence of energy price variations (including the use of carbon taxes) is needed to improve understanding of the cost-effective targets for building and district heating investments to 2050. Continued assessment of building technology cost curves would also improve the understanding of how deeply residential buildings could be renovated relative to 
district heating investments as building energy efficiency measures become more common (and, therefore, possibly less expensive). Finally, additional research on the impact of lower heat densities (from reduced building heat demand) on network distribution losses would help to improve understanding of necessary district heating investments to 2050.

\section{Technology and policy priorities: Buildings}

Achieving deep energy renovations in the Nordic buildings sector will require assertive policy to force the market beyond current moderate building energy efficiency measures. To achieve the full savings potential in buildings, a variety of policy measures are needed to put the buildings sector on track and achieve CNS energy and emission savings objectives by 2050 (Table 1.5).

\section{Table 1.5 Policy areas for near-term action and long-term objectives}

$\begin{array}{ll}\text { Policy action area } & \text { Near-term action (through 2025) } \\ \text { Whole building systems } & \begin{array}{l}\text { Promulgate nZEBs in all new construction. Imple- } \\ \text { ment policies, including market incentives (e.g. } \\ \text { low-interest loans and tax rebates) to drive uptake } \\ \text { in deep energy renovation in existing buildings. }\end{array} \\ \text { Building envelope } & \begin{array}{l}\text { Promote very-high-performance envelopes, inclu- } \\ \text { ding air sealing, insulation, highly insulating windows } \\ \text { (e.g. triple-pane, low-emissivity windows) and high- } \\ \text { efficiency ventilation. Continue R\&D for super-thin } \\ \text { insulation, dynamic window glazing and whole } \\ \text { envelope renovation packages. }\end{array} \\ & \\ & \end{array}$

Space heating and Increase promotion of solar thermal and heat-pump cooling equipment technology, with $R \& D$ for cold climate heat pumps. Prohibit use of electric resistance heaters as primary heating source.

Water heating Encourage uptake of heat-pump water heaters and mandate instantaneous systems or standalone equipment with efficiencies about $100 \%$. Continue R\&D on low-cost solar thermal systems.

Lighting Ban all traditional incandescent and halogen light bulbs. Continue R\&D and promotion of solid-state lighting (SSL) and other innovative designs.

Appliances Implement and actively update minimum energy performance standards for appliances and equipment.

\section{Long-term objective (2025 to 2050)}

Establish rigorous energy performance standards (through integrated energy community assessment) for existing buildings with annual renovation rates above $2 \%$.

Achieve highly insulated, integrated building envelopes (e.g. nZEBs or better) at negative life-cycle cost. Mandate minimum energy performance for building envelope components.

Promulgate integrated energy solutions for heating and cooling with net-zero emissions. Mandate minimum performance standards above $120 \%$ efficiency for stand-alone heating equipment, and above $400 \%$ for stand-alone cooling equipment.

Mandate minimum performance standards above $150 \%$ efficiency for electric stand-alone equipment. Achieve solar thermal systems that meet $\geq 75 \%$ annual water heating load.

Implement minimum lighting energy performance criteria above 100 lumens/watt.

Bring to market highly efficient appliance technologies, and mandate minimum energy performance standards for all electric plug-loads including standby and networked power.

Continued effort is needed to encourage widespread adoption of high-efficiency technologies throughout the Nordic buildings sector. A systems approach that implements integrated policies can facilitate synergies across different technologies and actors with net capital cost savings. However, effective policy is needed at both the individual component level and within a systems approach to ensure that all market opportunities are realised. These policies include more assertive minimum performance standards for lighting, appliances, and heating and cooling equipment to capture existing energy efficiency potential. Rigorous and prescriptive building codes are also needed for new construction (e.g. nZEB or better), and in the short to medium term, targets and incentives for very-low-energy buildings will be necessary to send signals to 
consumers, building stakeholders and product manufacturers to help establish market demand. These initiatives will also allow district energy networks and the power generation sector to properly plan investments to achieve CNS objectives while continuing to meet building energy demand.

Over the medium to long term, more stringent standards, including mandatory energy efficiency improvements or minimum energy performance standards for existing buildings (taking into account integrated, low-carbon energy community potential), will be necessary. Continued support for R\&D is needed to bring advanced buildings products (including whole building envelope packages) to market at cost-effective prices. This shift will require tighter minimum energy performance standards (market pull) as well as market incentives and other policy measures to bring advanced technologies to full commercialisation (market push).

Action is also needed to remove existing market barriers (e.g. transaction costs) that are preventing wide-scale uptake of deep energy efficiency measures. This action includes creating a reduced risk environment (e.g. through project finance support, product performance validation and quality control, and deep energy renovation in public buildings) for long-term energy efficiency investments, working in particular through financing institutions (e.g. through lowinterest loans, green bonds and public-private partnerships).

Urban areas can play an important role in achieving building efficiency and renovation objectives, especially through local regulatory, planning and zoning functions. These measures include the critical tasks of adopting, monitoring and enforcing building energy codes for new construction and building energy renovations. Efforts can also include deep energy renovations in public and municipal buildings as well as creating local incentives (e.g. zoning exemptions) and local energy efficiency programmes that support deep energy renovations in the private sector. Action in this area is critical over the coming decade to ensure that the process is widely available and becomes standard practice. National programmes and initiatives (e.g. quality management and certification systems) can help to ensure a "common language" for all stakeholders, which will help to improve uptake and awareness of energy efficient technologies and practices.

National policies have a substantial influence in enabling effective, sustainable urban energy planning through regulation (e.g. enforcement of codes and standards), fiscal policies (e.g. tax incentives, housing loans and third-party financing), national land-use planning frameworks, and capacity-building programmes. Greater support of local energy efficiency actions, including possible devolution of some energy-related authorities to municipal governments, is needed from the Nordic governments to encourage widespread deployment of cost-effective energy efficiency measures in the buildings sector. An improved national-local policy framework could also allow urban areas to "run with the ball," seeking targeted energy efficiency measures that may go beyond national targets and that could complement multiple benefits for local communities (e.g. reduced energy poverty and local job creation).

Both national and urban policy and planning assessments need to take into account the indirect advantages of district heating networks not traditionally accounted for in energy policy, including the capacity of district energy systems to pursue numerous integrated technology solutions (e.g. co-generation, industrial waste heat, heat pumps, solar thermal energy and off-peak or seasonal thermal storage) due to economies of scale and their access to various energy sources. When paired with building efficiency measures, these integrated solutions can even lower lifecycle costs for both buildings and district heating networks. However, this improvement will require long-term visibility for district heating providers and possibly financial incentives to facilitate investments in integrated energy networks that reward efficiency and flexibility (IEA, 2014). 
Last, data, and a more acute sense of building energy needs and opportunities, are valuable tools that both Nordic national and local governments can use to shape policy decisions and prioritise energy efficiency efforts. Data can also play a critical role in targeting the right stakeholders on both the local and national scale to increase adoption of energy efficiency measures. It can also help to target more manageable market segments and critical areas for action.

\section{Decarbonising the Nordic region will not cost the world}

The Nordic CNS would require a significantly different investment pattern in the regional energy system relative to what would occur with the 4DS. Investment flows in the Nordic region would need to ensure that the mix of energy conversion and end-use technologies will deliver a carbon emissions reduction trajectory consistent with the CNS. The NETP investment analysis is based on the IEA's ETP model, which was used to estimate the differential in investments between the 4DS and the CNS over the time-frame 2016-2050.

The energy system investment costs underlying the 4DS and CNS are defined as follows 24 :

- Building investments comprise the costs of equipment purchased by final users for heating and cooling, lighting and appliances, cooking and other end-use services, as well as costs associated with improving the thermal envelope of buildings.

- Industry investments include the costs of added industrial capacity using energy sources both as fuels and feedstocks, as well as costs associated to the implementation of energy efficiency measures and emissions reductions technologies in new and existing facilities. Industrial investments refer to the energy-intensive sectors that account for about $80 \%$ of total industrial final energy use in the Nordic region (aluminium, cement, chemicals and petrochemicals, iron and steel including blast furnaces and coke ovens, and pulp and paper).

- Transport investments include the costs to purchase the vehicles as well as the capital and reconstruction costs for the needed infrastructure for passenger and freight transport in road, urban and intercity rail (including high-speed rail), and shipping.

- Power sector investments cover the costs for all power plants and decentralized power systems generating electricity, as well as transmission and distribution infrastructure.

The results of the analysis indicate that the CNS would entail additional investment costs of about USD 333 billion ${ }^{25}$ relative to the 4DS in the Nordic region over the period 2016-2050 (Figure 1.46). The CNS costs for transport would amount to USD 195 billion, which are the result of the difference between USD 200 billion of higher infrastructure additional investments and USD 5 billion of lower additional vehicle costs. Building investments account for about USD 170 billion, of which roughly USD 155 billion comes from building envelope investments to drastically reduce space heating demand. Another USD 6 billion of investments are for space heating and water heating equipment (e.g. cold-climate heat pumps and solar thermal water heaters), and more efficient appliances account for roughly USD 10 billion over 4DS purchases. More efficient lighting could actually save as much as USD 1 billion, because improved technologies such as light-emitting diodes (LEDs) have longer lifetimes than incandescent, halogens and compact fluorescent lighting (CFLs). In industry, the estimated cumulative additional investments total USD 33 billion, equivalent to about half of the absolute cumulative investments in the 4DS. Additional investments in energy-intensive industries in the CNS are mainly

24 Upstream investments in fossil fuels and biofuels are not covered in the NETP analysis. 25 USD PPP 2014. 
related to the implementation of energy efficiency measures to existing stock and the introduction of low-carbon innovative processes such as CCS. The pulp and paper sector plays an important role within the total industrial investments given the size of this industry in the Nordic region relative to the other analysed sectors. Power generation in the CNS has negative additional investment costs, mostly as a result of the reduced final electricity demand in this scenario compared to the 4DS (-15\% in 2050), which would also entail lower transmission and distribution investments. In addition, the specific investment costs for wind are lower in the CNS compared to the 4DS, due to increased global deployment in the 2DS, which would drive down technology costs as a result of economies of scale and learning effects.

Transport investments in the Nordic region exhibit a different pattern than at the global level. In fact, additional investment costs for transport at the global level are negative in the 2DS, mostly due to vehicle ownership projections embedded in the baseline scenario (IEA, 2016b). In the Nordic region, on the contrary, transport investment costs would be higher in the CNS relative to the 4DS. This difference can be explained by the limited potential for significantly reducing vehicle ownership, even with the high degree of policy ambition and effectiveness that should characterise the CNS. For example, many of the policy tools that are assumed to be implemented in the CNS in other countries (e.g. pricing via road tolls, congestion charges and parking fees, access restrictions) are already applied in the Nordic region. Furthermore, the modal shift towards rail comes with significant infrastructure costs, given that about half of the transport infrastructure investment costs in the CNS is due to the uptake of non-urban rail, including high-speed train infrastructure.

\section{Figure $1.46 \quad$ Cumulative investments by sector, 2016-2050}

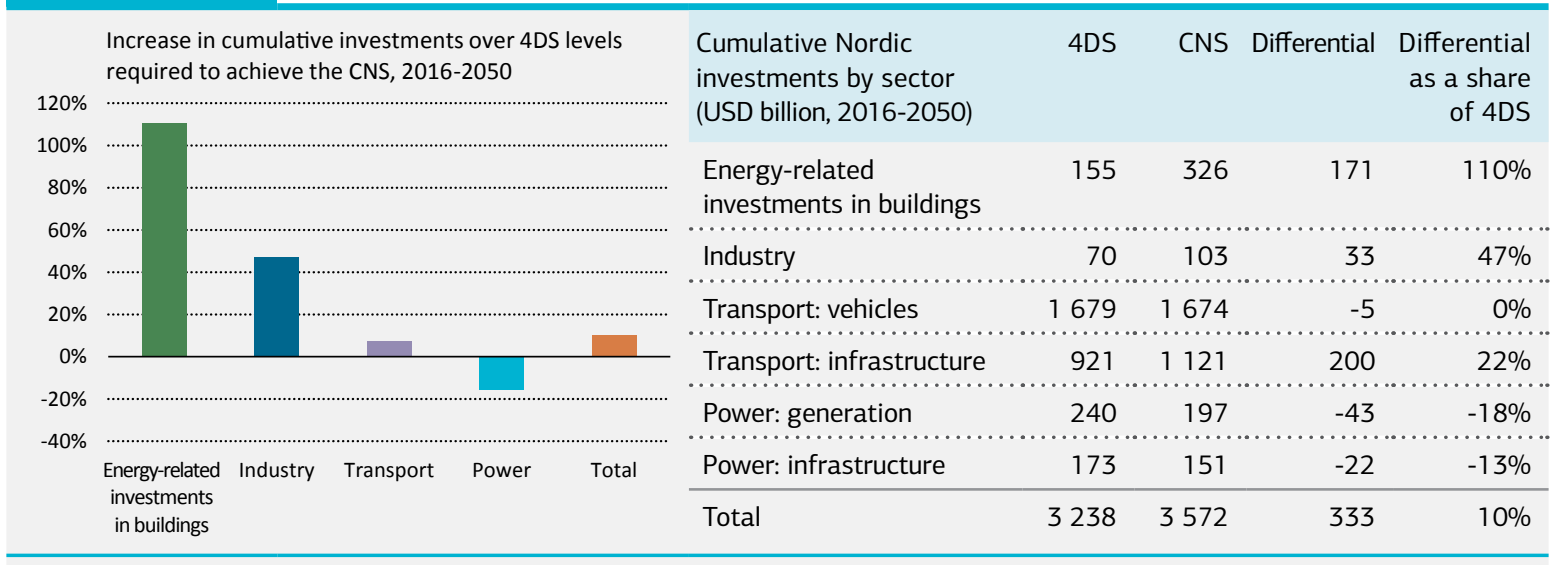

Notes: Numbers in the figure to the left show the difference in cumulative investments between the 4DS and CNS, as a share of the 4DS ( cumulative investments in the CNS - cumulative investments in the 4DS $\times 100$ )

This metric highlights which sectors require the greatest relative increases in investments and how significant they are, compared to investments that would be needed even under a less ambitious scenario such as the 4DS. The shares of buildings, industry and transport are relative to the total for these three end-use sectors. Industrial investments refer to the five-energy intensive sub-sectors and correspond to the low-demand variant of industrial activity projection; USD 39 billion are estimated for the high-demand variant. Cumulative investments are undiscounted. In the power,- industry, and transport sectors all investments in new industrial capacity (for the energy-intensive subsectors), vehicles, power plants and supporting infrastructure like roads and electricity grids are included. For buildings, only improvements of the thermal envelope (i.e. not the entire building construction) and equipment for end-use services such as lighting, cooking, heating and cooling, are covered. Only additional investment needs between scenarios are comparable across sectors, but not absolute investment requirements.

Figures and data in this report can be downloaded at www.iea.org/etp/nordic.

Key point Buildings require the greatest relative increase in investments to achieve the CNS, followed by industry. Power entails a saving over the 4DS, while the system as a whole requires an increase of $10 \%$. 
To evaluate the cost-effectiveness of the CNS, the USD 333 billion of additional investment costs need to be framed in the right perspective. While this sum might appear large in relation to the annual GDP of the Nordic region (USD 1300 billion in 2015), it only amounts to less than 1\% of the cumulative GDP between 2016 and 2050. Compared to investments under the $4 \mathrm{DS}$, it represents a $10 \%$ increase. Beyond climate change benefits, costs will be directly offset to a certain degree by fuel savings, which have not been calculated but can be significant depending on the development of future oil prices. Furthermore, reduced health costs due to air quality improvements and increased energy security are likely to tip the economic equation firmly in favour of the CNS. The external costs related to health impacts from air pollution in the Nordic countries (of which energy is the primary source) have been estimated at USD 9-14 billion annually (Geels, 2016) - alone roughly equal to the additional investments in the CNS. 


\section{Chapter 2

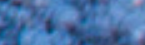

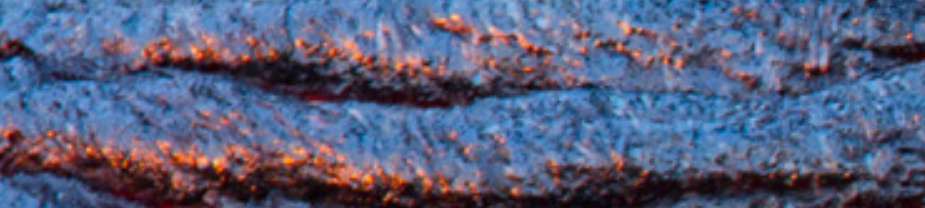

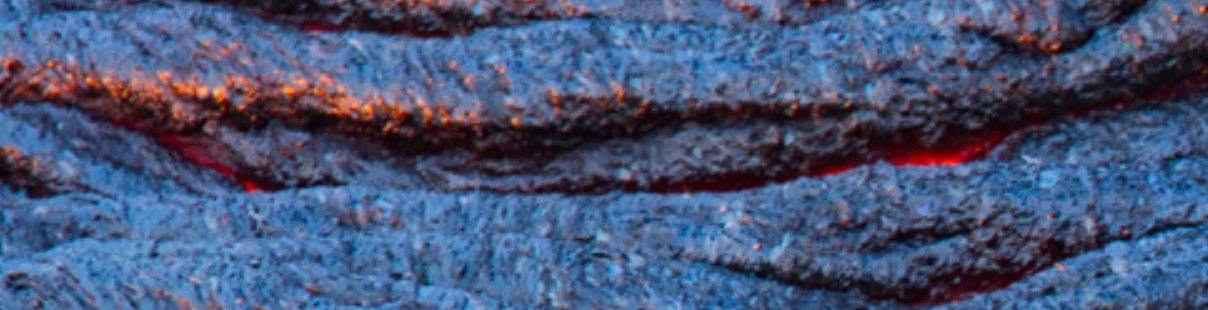
Hew

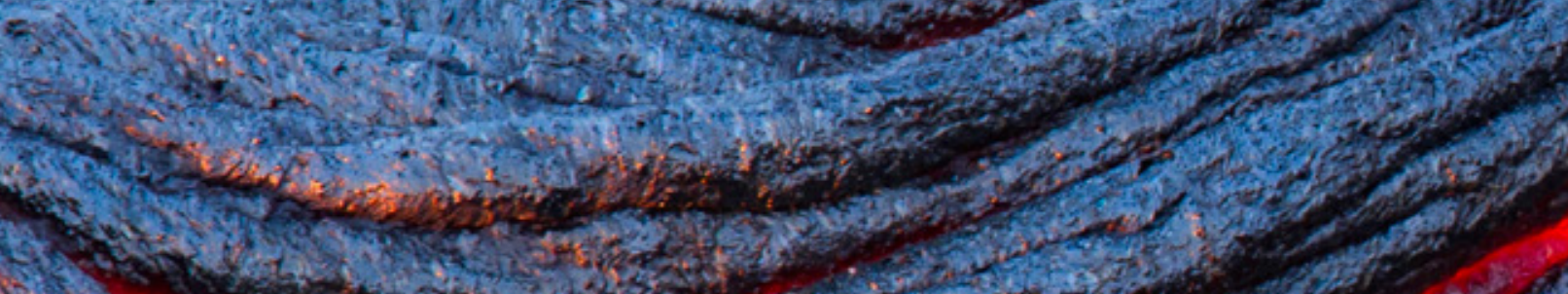
Q Q

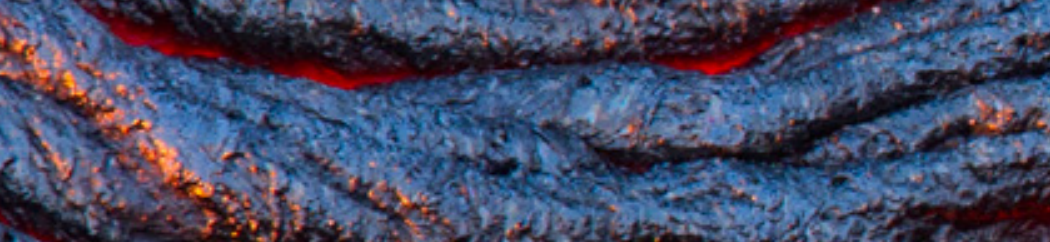
d 3.7.
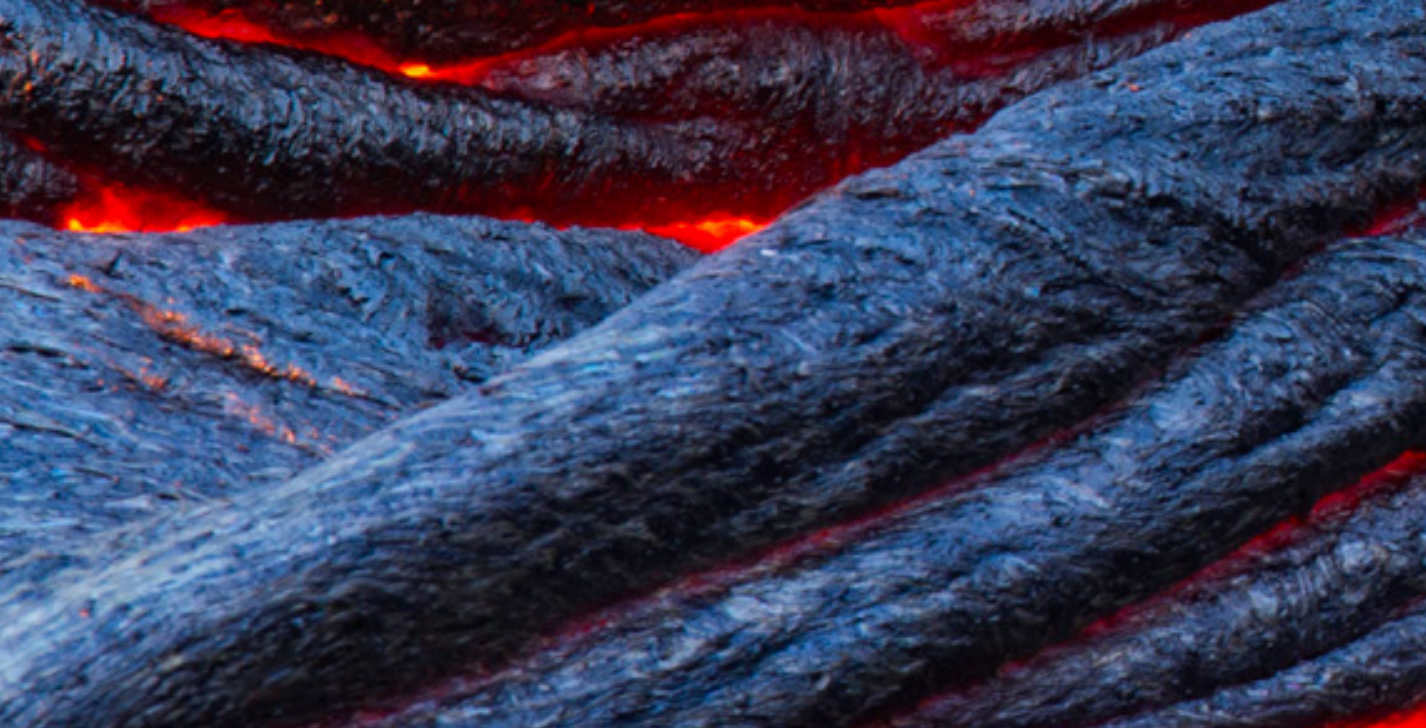
(4)

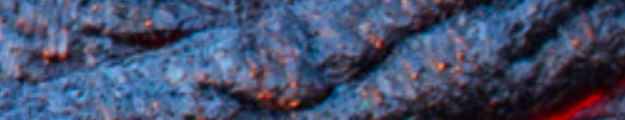

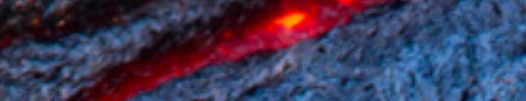

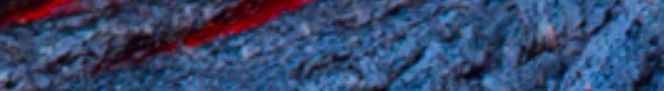




\section{Urban energy}

Urban development will play a dominant role in the mitigation of greenhouse gas (GHG) emissions in the Nordic region. About 85\% of the 26 million Nordic population live in urban areas, but $60 \%$ of the urban population live in urban areas with less than 100000 inhabitants. Nordic countries experienced rapid urbanisation during the 1950s and 60s, and a period of further rapid urbanisation is expected in the coming decades. Buildings and infrastructure from the 1950s are mostly still in use and particular effort is needed in the deep retrofitting of existing buildings and the decarbonisation of transport. Larger Nordic cities have a wider range of technology options available to mitigate climate change and offer leadership in the drive to achieve carbon neutrality across the Nordic region. This chapter builds on the analysis in Chapter 1 , covering both urban and rural aspects of the Nordic energy system and providing a deeper analysis of urban energy systems at the Nordic level, recognising the differences between urban areas in general. It also offers in-depth case studies of the Helsinki region of Finland and Oslo in Norway to demonstrate the differences between larger Nordic cities.

Key findings

- All Nordic capitals have ambitious GHG mitigation targets and most of them aim to achieve carbon neutrality. The level of ambition is high, even though the carbon dioxide $\left(\mathrm{CO}_{2}\right)$ intensity of Nordic urban buildings is as low as 0.13 tonnes of $\mathrm{CO}_{2}$ per gigawatt hour ( $\left.\mathrm{CO}_{2} / \mathrm{GWh}\right)$, compared with an average of $0.33 \mathrm{tCO}_{2} / \mathrm{GWh}$ in the European Union and $0.83+\mathrm{CO}_{2} / \mathrm{GWh}$ across member countries of the Organisation for Economic Co operation and Development (OECD). Copenhagen, Stockholm and Oslo are examples of Nordic cities that are aiming to reach carbon neutrality long before their national targets, showing Nordic urban leadership.
- Nordic capitals can be 30\% more efficient than average Nordic urban areas, and energy efficiency is one of the cornerstones to achieve carbon neutrality in urban areas. In the Carbon-Neutral Scenario (CNS), the per-capita energy demand of urban transport and buildings decreases by $20 \%$ between 2015 and 2030 and by another 20\% between 2030 and 2050. Buildings energy efficiency measures can decrease heating, cooling and electricity demand per capita in urban areas by $30 \%$ by 2050.

- In urban areas, up to $76 \%$ of the energy consumed in buildings and transport could be delivered through smart electricity and 
district heating and cooling grids by 2050 , compared to $61 \%$ today. In 2013, 35\% of the heating for urban buildings in the Nordic region was provided by district heating, while the corresponding numbers for the European Union and OECD were $9 \%$ and $3 \%$ respectively. In the Nordic capitals of Stockholm, Helsinki, Copenhagen and Reykjavik, the share of district heating is already between $80 \%$ and $100 \%$, shares that are to be maintained in the long term. District heating networks also offer significant flexibility for accommodating variable renewable energy.

- Electric cars, buses, bicycles and other electric vehicles (EVs) are adopted first in urban areas, where driven distances are shorter and urban density improves the economics of developing charging station infrastructure. After 2030, the CNS requires the adoption of both considerable energy efficiency measures and $90 \% \mathrm{CO}_{2}$-free fuels in urban transport. By 2050 EVs could cover 30\% of urban final energy for transport; biofuels are needed to decarbonise the remaining transport.

- The rapid development of solar photovoltaic (PV) systems in recent years has improved the prospects of solar power in the Nordic countries, despite still seeing modest investment compared with several other European countries. In Nordic urban areas, the production of energy from solar $P V$ could reach 4 gigawatts (GW) peak capacity by 2050 and produce 4 terawatt hours (TWh) annually. In the Metropolitan case study for Finland, nearly all of the estimated suitable rooftop potential becomes utilised by 2050 under the CNS, with solar power thereby accounting for over $20 \%$ of the total electricity supply.

- The Nordic region has considerable wind power potential close to urban areas, due to a largely coastal population and a large share of the urban population living in smaller cities and towns. In the CNS, the wind capacity near urban areas increases to 19 GW by 2030 and $37 \mathrm{GW}$ by 2050, accounting for 32\% of total urban electricity supply in 2050.

- The anticipated levels of urban growth offer a golden opportunity to mitigate GHG emissions and facilitate achieving the CNS. Investment is needed in any case for new buildings, retrofits of existing buildings, and new transport infrastructure to service the growing urban population. Therefore the additional costs to achieve the CNS targets are lower for the urban transition compared to rural areas.

\section{Opportunities for policy action}

- The large Nordic cities have the potential to become innovation hubs and demonstrate smart and clean energy technologies, new services and business opportunities. Nordic capitals and larger cities lead national climate policies by implementing more ambitious local strategies than their national governments have set.

- The case studies - Metropolitan Helsinki and Oslo - show that the technology mixes differ in the Nordic CNS pathways. Nordic cities could learn from each other in order to structure and implement the new policies required to increase the use of public transport (Stockholm) and cycling (Copenhagen and Malmö), and the roll-out of light duty EVs in Oslo and EV buses in Helsinki. Nordic stakeholders can also help other regions by multiplying and exporting sustainable smart city concepts.

- The role of district heating will increase under strict climate policy targets, but the role of co-generation might become less important ${ }^{1}$. Under the CNS the amount of cogeneration decreases by $40 \%$ in Nordic urban areas, indicating that the energy efficiency of energy production could decrease. As Nordic electricity markets are fully integrated, common policies could support Nordic co-generation in the future.

- Analysis of the urban energy system is challenged by the absence of common methodologies and, in particular, the lack of urban data. Investment in Nordic research 
into urban energy systems, as well as long-term statistical data capabilities, will provide more accurate and transparent urban analysis. It is also important to conduct ex-post analysis to evaluate the impacts and effectiveness of Nordic urban policies.

- Implementing common Nordic governance structures will strengthen the operating environment for clean and smart energy systems and technologies. Co-operation and collaboration between national and local policy makers would strengthen the Nordic transition by offering mitigation of costs by means of common infrastructure (highways, trains, etc.) and larger markets for clean technology companies (nearly zero-energy buildings [nZEBs], service companies, transport biofuel producers and retailers, etc.).
- Transition to carbon-neutral urban energy systems will require major changes in a wide range of governance measures, including not only market design, business models for energy companies and investment financing, but also new modes of public engagement and prosumer strategies using solutions that are now beginning to be applied. Investment in research and development (R@D) in core technologies, systems and business models at the Nordic level will be necessary for the transition to carbon-neutral urban systems. Formulation of a Nordic "action plan" to resolve the above governance challenges would favour both companies and private consumers by indicating the future development and competitiveness of clean energy systems.

\section{Introduction}

Urban energy supply and demand, and related GHG emissions, will be critical in attaining a global target to limit the average rise in temperatures to $1.5-2^{\circ} \mathrm{C}$ above pre-industrial levels. In 2013 energy demand in urban areas accounted for $58 \%$ of Nordic final energy demand. The share of urban energy is increasing due to urbanisation and increasing standards of living in cities both on a global and Nordic level. It is important that the planning and development of urban energy systems support, and in some cases lead, national emissions reduction targets.

Urban energy supply and demand have unique characteristics, as higher population density facilitates new low-carbon and smart technologies for energy supply and more efficient energy end use, especially in buildings and mobility. Nordic municipalities have, for example, developed extensive district heating networks and increasingly also district cooling networks, and invested in public transport and bicycle infrastructure. In the coming years more integrated solutions - supported by smart metering and intelligent systems for buildings, mobility, energy supply and waste handling - will increase energy efficiency and thereby decrease urban GHG emissions. In addition, smart service businesses are being developed to increase the wellbeing of urban citizens.

All Nordic capitals have ambitious GHG mitigation targets and most of them aim to become carbon neutral by 2025, 2030 or 2050, in some cases well before national targets. In total, 108 Nordic cities have joined the Covenant of Mayors movement, which encourages cities to increase energy efficiency and the use of renewable energy. In total, 105 of these cities have submitted an individually designed action plan to reduce their energy consumption and GHG emissions. These cities have made an inventory of their energy consumption and GHG emissions and set targets for the future, as well as suggesting measures for reaching their targets.

Despite the importance of the topic and a large number of city-level programmes and targets, no study has been conducted of all urban areas in the Nordic countries. This chapter focuses on the Nordic aspects of energy systems and climate change mitigation in urban areas. The topic stretches from the effects of migration within the countries, to energy efficiency in 
cities and urban planning. The analysis below builds on the overall Nordic scenarios shown in Chapter 1, providing a deeper analysis of urban energy systems at the Nordic level and recognising the contrasts between urban areas in general. In addition, it also offers in-depth case studies of the Helsinki region of Finland and Oslo in Norway. These demonstrate the differences between larger Nordic cities and their GHG mitigation pathways to reach carbonneutral urban energy systems by 2050.

\section{Overview of Nordic urban energy systems}

\section{The Nordic urban area is very broad but depends on the urban definition}

The urban energy system is a network of energy flows fulfilling the energy demands of urban areas. A more detailed definition of "urban" is needed to analyse these energy systems and generate conclusions.

The difficulty in defining urban starts with establishing the threshold size of the settlements that should be counted as urban. What people think of as a small or medium-sized city is quite different in Iceland, Germany and China. In addition, the size of the population is only one of the possible defining criteria. Some countries require that most of the jobs in the city are non-agricultural while few specify a minimum population density.

The definition of "urban energy system" requires a decision on which economic sectors to include in urban energy consumption. Stationary sectors are easier to exclude or include, but transport may consume energy in both urban and rural areas. It is also necessary to decide whether to calculate energy demand using a production-based approach or a consumptionbased approach. In production-based approaches, energy and related GHG emissions are allocated to the area where the producing unit is. In consumption-based approaches, the energy demand and GHG emissions are allocated to the area where the energy is consumed. For example, the emissions of electricity production are reported either in the area where the electricity installation is situated (production-based) or in the area where consumers use this electricity (consumption-based).

In this study, the urban population (Figure 2.1, Table 2.1) and gross domestic product (GDP) (Table 2.1.) are defined according to Nordic statistics agencies' definitions:

- In Denmark and Sweden, an urban area is a built-up area where buildings are no more than 200 metres apart and where at least 200 people live (Statistics Denmark, 2015a; Statistics Sweden, 2015).

- In Finland, urban areas are municipalities where at least 4000 inhabitants and $60 \%$ of the population live in the city centre (Statistics Finland, 2015a).

- In Iceland, urban areas are considered to be localities of over 200 inhabitants (Statistics Iceland, 2015).

- In 2013, Norway updated the definition of urban area to cover built-up areas where the distance between houses is less than 50 metres and where over 200 inhabitants live (Statistics Norway, 2014).

These definitions capture a large share of the population in a wide range of settlement sizes where the smallest urban settlements might not be intuitively thought of as urban. The applicability of different technologies varies between small towns at one end of the scale and the Nordic capitals at the other. The analysis includes two case studies (Helsinki region and the city of Oslo) to capture the potential in larger urban energy systems. 


\section{Figure 2.1}

Map of Nordic municipalities with population size and annual growth rate from 2005 to 2015

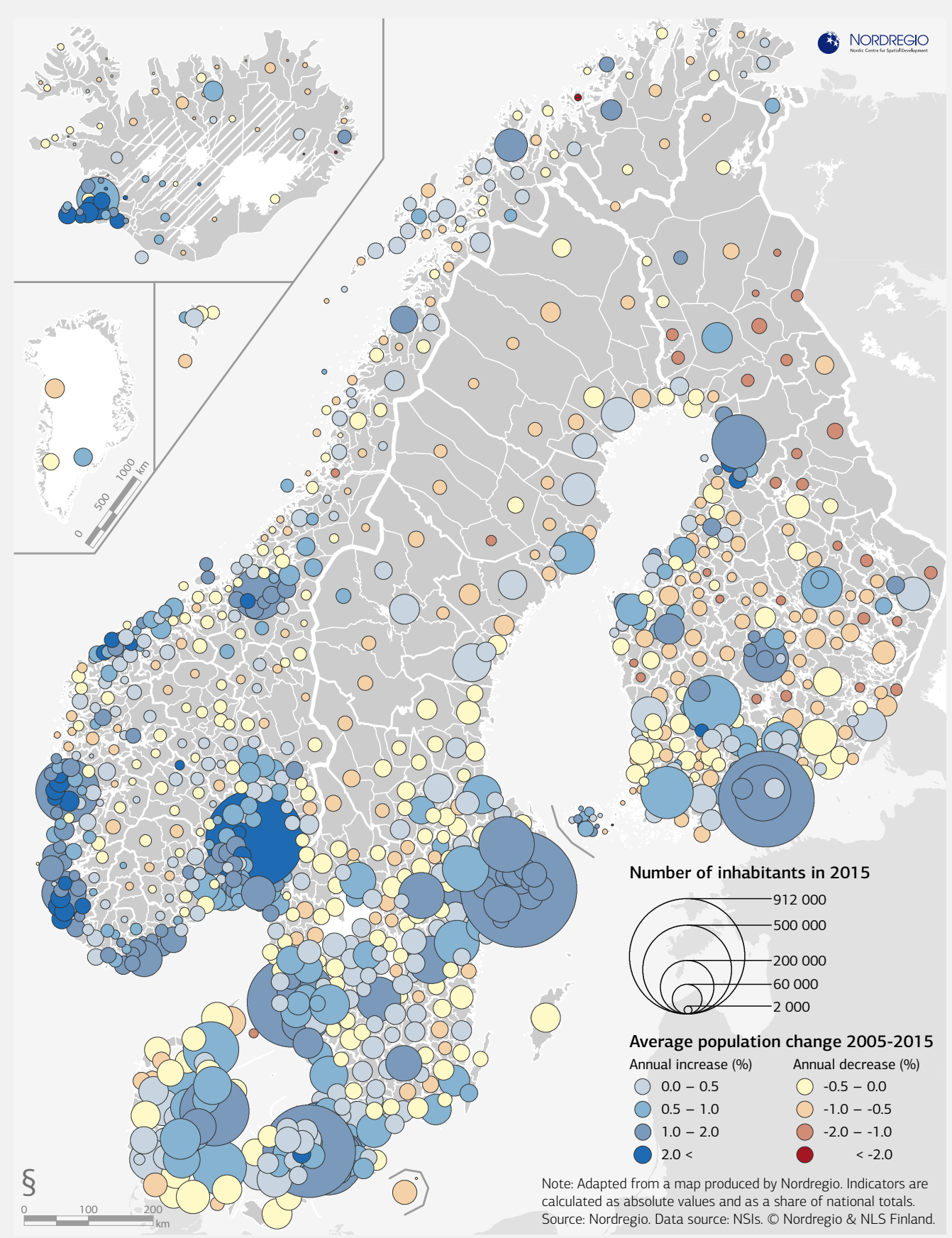

This map is without prejudice to the status of or sovereignty over any territory, to the delimitation of international frontiers and boundaries, and to the name of any territory, city or area.

Figures and data in this report can be downloaded at www.iea.org/etp/nordic.

Key point

The greatest urban growth has taken place in the Nordic region's largest cities, while population has been decreasing in many smaller cities 
The analysis of urban energy systems and $\mathrm{CO}_{2}$ emissions includes detailed modelling of urban energy supply and demand. Transport was modelled between urban and rural areas for each transport mode based on geographical information system (GIS) modelling. The urban and rural buildings sectors are analysed according to building stocks, floor areas and heating technologies. For urban renewable energy supply, GIS analysis of wind and solar potential has been used. National statistics were used for calculating the potential of renewable waste. The analytical framework is described in detail in Annex 1.

Urban regions are already more energy efficient than rural regions. Four major indicators are used in this chapter to understand urban areas: urban population; urban GDP; urban energy demand in buildings and transport; and urban $\mathrm{CO}_{2}$ emissions from buildings and transport sectors (Table 2.1). The analysis in this chapter focuses on transport, buildings and urban energy supply. The energy-intensive industrial sector is often located in smaller cities in the Nordic region and a large share of products goes to export markets. The electricity and industrial sectors are analysed briefly for the Nordic region and in detail for Helsinki and Oslo. Most agricultural activity takes place in the Nordic region's rural areas. Energy use and GHG emissions of the agricultural sector are included in the analysis shown in Chapter 1.

Across the Nordic region, the energy demand of buildings and transport is 30\% lower per person in urban areas than in rural areas. In contrast, the $\mathrm{CO}_{2}$ intensity of consumed energy in urban regions is 25\% higher than in rural regions in Finland. This is a result of availability of biomass resources in rural areas and higher consumption of coal for co-generation in larger cities. In Denmark and Iceland, the $\mathrm{CO}_{2}$ intensity of the energy mix is the same between urban and rural areas. Norway and Sweden have a 25\% less $\mathrm{CO}_{2}$-intensive fuel mix in their urban areas.

\begin{tabular}{|c|c|c|c|c|c|c|c|c|}
\hline \multirow{3}{*}{$\begin{array}{l}\text { Table } 2.1 \\
2013\end{array}$} & \multicolumn{8}{|c|}{$\begin{array}{l}\text { Four major indicators for Nordic urban areas: population; GDP; } \\
\text { energy demand in buildings and transport; and direct } \mathrm{CO}_{2} \\
\text { emissions }\end{array}$} \\
\hline & \multicolumn{2}{|c|}{ Urban population } & \multicolumn{2}{|l|}{ Urban GDP } & \multicolumn{2}{|c|}{$\begin{array}{l}\text { Urban energy demand in } \\
\text { buildings and transport }\end{array}$} & \multicolumn{2}{|c|}{$\begin{array}{l}\text { Urban } \mathrm{CO}_{2} \text { emissions } \\
\text { from buildings and } \\
\text { transport }\end{array}$} \\
\hline & Million & $\begin{array}{r}\% \text { of } \\
\text { national } \\
\text { total }\end{array}$ & $\begin{array}{r}\text { Billion } \\
\text { (USD 2014, } \\
\text { PPP) }\end{array}$ & $\begin{array}{r}\% \text { of } \\
\text { national } \\
\text { total }\end{array}$ & TWh & $\begin{array}{r}\% \text { of } \\
\text { national } \\
\text { total }\end{array}$ & $\mathrm{MtCO}_{2} \mathrm{e}$ & $\begin{array}{r}\% \text { of } \\
\text { national } \\
\text { total }\end{array}$ \\
\hline Denmark & 5.0 & $88 \%$ & 222 & $90 \%$ & 85 & $62 \%$ & 20 & $63 \%$ \\
\hline Finland & 4.6 & $84 \%$ & 192 & $87 \%$ & 95 & $63 \%$ & 22 & $77 \%$ \\
\hline Iceland & 0.3 & $94 \%$ & 13 & $94 \%$ & 11.6 & $96 \%$ & 0.8 & $77 \%$ \\
\hline Norway & 4.1 & $80 \%$ & 279 & $83 \%$ & 77 & $54 \%$ & 7 & $39 \%$ \\
\hline Sweden & 8.3 & $86 \%$ & 383 & $87 \%$ & 140 & $57 \%$ & 16 & $49 \%$ \\
\hline Nordic countries & 22 & $85 \%$ & 1090 & $87 \%$ & 410 & $59 \%$ & 65 & $58 \%$ \\
\hline
\end{tabular}

The case studies of two Nordic capitals, Helsinki and Oslo, are an important part of the analysis as the overall results for Nordic urban areas represent an average of all urban areas, which includes many small urban areas. According to the definitions of Nordic statistics agencies, 15\% of the Nordic population live in cities with over 1 million inhabitants and 60\% live in urban areas with fewer than 100000 inhabitants (Figure 2.2). In Iceland, all cities 
except the capital, Reykjavik, have fewer than 100000 inhabitants. The largest Nordic cities are the capitals, which offer an excellent environment for large-scale demonstration of clean and smart technologies and services. Notably, however, the two case studies show contrasting transition pathways to carbon neutrality by 2050, with different technology mixes.

\section{$\begin{array}{ll}\text { Figure 2.2 } & \text { Urban and rural populations in the Nordic countries }\end{array}$}

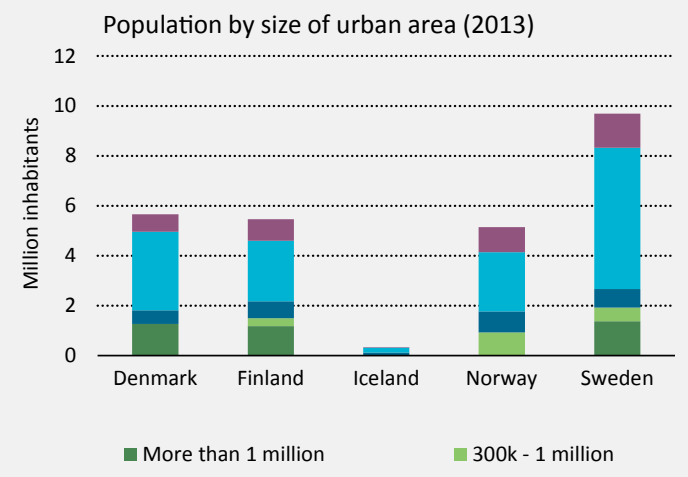

Source: United Nations (2014), Urban Population, compiled from National Statistics Agencies. Figures and data in this report can be downloaded at www.iea.org/etp/nordic.

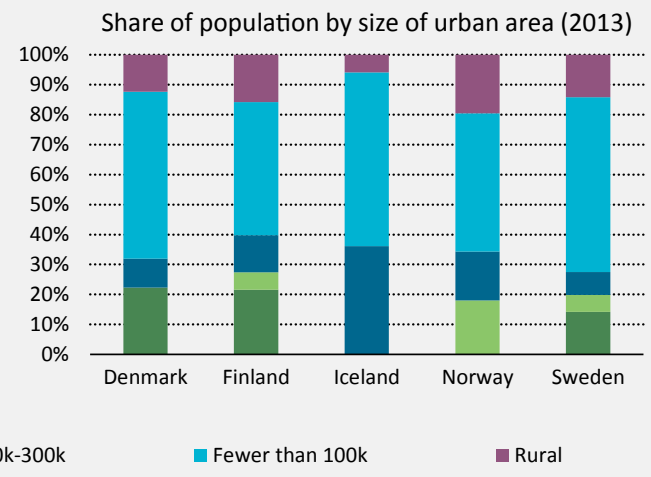

Share of population by size of urban area (2013)

Key point $62 \%$ of the Nordic urban population live in urban areas with fewer than 100000 inhabitants.

\section{The Nordic urban energy system is characterised by rapid expansion during the 1950 s and 60s}

The Nordic countries experienced a period of rapid urbanisation during the 1950s and 60s when the urban population increased by $2 \%$ per year. During those years, the urban population increased by 260000 annually. In 20 years the urban population increased by as much as in the 40 years between 1970 and 2010 (United Nations, 2014). The urbanisation of the European Union occurred at the same time. At a global level, however, the rate of urbanisation is increasing. The world's urban population grew by 54 million per year from 1950 to 1970, by 50 million per year from 1970 to 2000 and by 75 million per year from 2000 to 2013 .

The rate of urbanisation in the Nordic region was lower between 1970 and 2005, when the urban population grew, on average, by slightly more than $0.5 \%$ per year. However, the population of Reykjavik and its surrounding area grew on average during this time by $1.5 \%$ per year, compared to total Icelandic population growth of $1 \%$. In total, the annual growth of the urban population was slightly above 100000 in the Nordic region. The oil crisis and high oil prices during the 1970s and 1980s resulted in a rapid improvement in buildings energy efficiency and encouraged investment in other heating technologies and use of fuels other than oil, such as district heating and direct electricity heating (Statistics Denmark, 2015b; Statistics Norway, 2015; Statistics Finland, 2015b; Statistics Sweden, 2012).

Since 2005, the rate of urbanisation has increased again in Denmark, Finland and Norway, and in Iceland the growth rate continues at about the same level as earlier. Currently, the Nordic urban population is increasing by almost 200000 annually. This growth is projected 
to continue for the coming decades according to UN urban population projections, which are based on population projections from Nordic statistics agencies. This is both a challenge and a great opportunity for the cities, as more technological opportunities and services are available to improve their energy efficiency and decrease emissions. During recent years, many refugees have arrived in Nordic countries seeking asylum. These are mostly not included in official estimates and will slightly increase the pace of urbanisation.

\section{Buildings}

In the buildings sector, Nordic urban energy systems all face the same reality of cold and dark winters. Cities have responded to the challenges of a northern climate with a range of measures, often including well-insulated houses and district heating networks.

The rapid population growth experienced in Nordic urban areas during the 1950s and 60s required considerable amounts of new buildings and infrastructure, which are mostly still in use. Compared to current technologies, these buildings are often inefficient and require deep energy renovations, especially in low-carbon scenarios.

The average Nordic urban citizen consumes 30\% more energy in the buildings sector than the average $\mathrm{EU}$ citizen, but the corresponding $\mathrm{CO}_{2}$ emissions are $50 \%$ lower than the EU average (Table 2.2). The higher energy consumption is due to larger heating demand during winters and greater floor area per person. The lower emissions are enabled by a larger share of renewable electricity, district heating, electric heating (including heat pumps), geothermal energy and modern biomass in the heating mix. Indirect emissions from the power and heat sector form the major part of the emissions from the buildings sector in Nordic urban areas (see Chapter 1 for buildings, and power and heat).

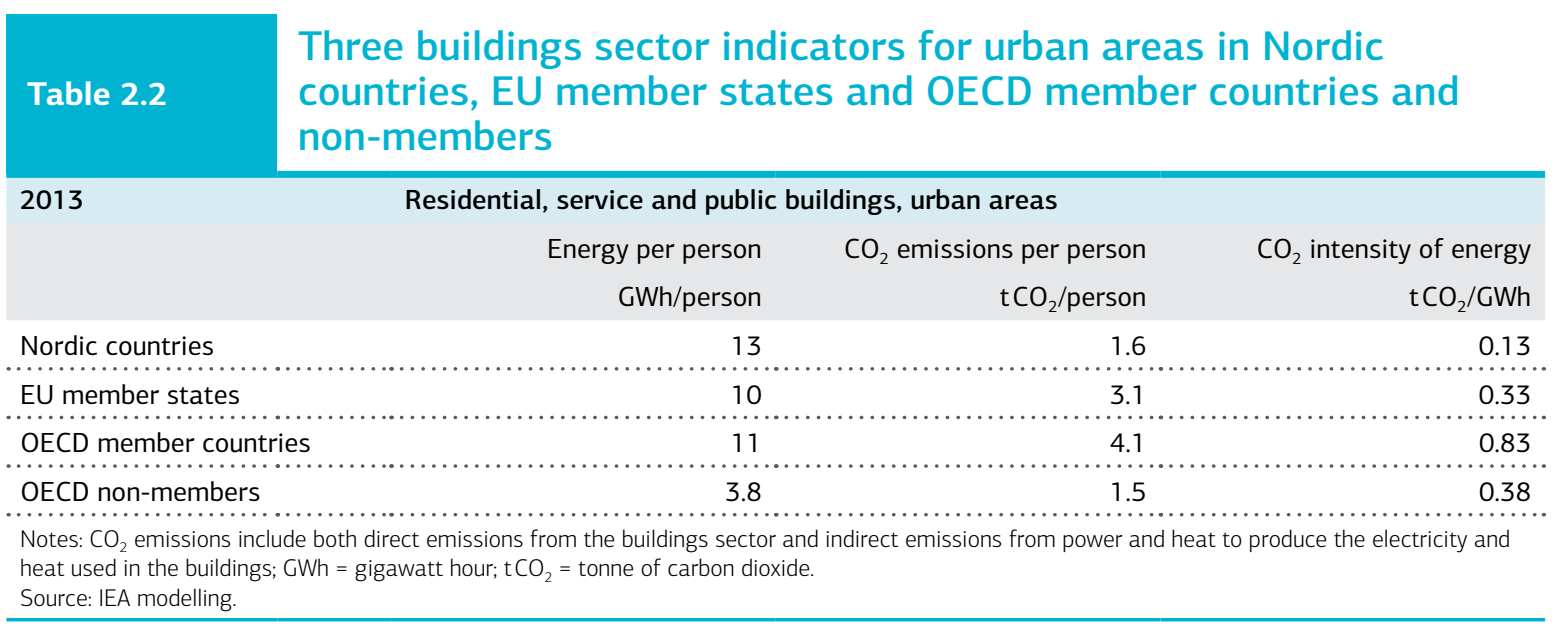

\section{Transport}

Nordic urban areas have higher transport demand per person than the EU average (Table 2.3). This reflects higher GDP per person, allowing Nordic citizens to travel more and own more cars as outlined in Chapter 1. Moreover, public transport options are more limited in the small and medium-sized urban areas that dominate the Nordic countries. In addition, Finland, Norway, Iceland and Sweden are sparsely populated and distances to travel are longer even in urban areas.

The numbers of cars increased considerably during the 1950s and 60s. In 1950 the Nordic region had only 700000 cars, but by 1970 this had already reached 5.5 million (Autoalan tiedotuskeskus, 2015; Brüde, 2013; Vejdirektoratet, 2013; University of Trondheim, 1990). 
Few statistics are available to show how large a share of these cars was registered in urban areas, but the city planning decisions of the 1950s and 60s still have a significant effect on transport demand and mobility options in the cities. According to Norden statistics, the number of cars in Nordic countries had increased to 19 million in 2013, counting all types of vehicle (Norden, 2013). While the number of buses doubled from 1960 to 2013, the number of private cars increased six-fold.

Urban passenger transport accounts for $51 \%$ of total passenger transport activity in the Nordic region, as explained in detail in Chapter 1 . Urban freight corresponds to only $1 \%$ of total freight tonnes and is not important from a tonnage perspective; however, $\mathrm{CO}_{2}$ emissions from urban freight are estimated to correspond to $20 \%$ of total urban transport emissions. This is due to the substantially higher energy intensity of light commercial vehicles and mid-duty trucks compared to other freight transport modes.

\begin{tabular}{|c|c|c|c|}
\hline Table 2.3 & $\begin{array}{l}\text { transport sector inc } \\
\text { ries, EU member sta } \\
\text { nembers }\end{array}$ & $\begin{array}{l}\text { ators in the urban } \\
\text { and OECD memb }\end{array}$ & $\begin{array}{l}\text { s of Nordic } \\
\text { ountries and }\end{array}$ \\
\hline \multirow[t]{3}{*}{2013} & \multicolumn{3}{|c|}{ Transport sector indicators, urban areas, all transport modes combined } \\
\hline & Energy per person & $\mathrm{CO}_{2}$ emissions per person & $\mathrm{CO}_{2}$ intensity of energy \\
\hline & $\mathrm{GWh} /$ person & $\mathrm{tCO}_{2} /$ person & $\mathrm{tCO}_{2} / \mathrm{GWh}$ \\
\hline Nordic countries & 5.7 & 1.4 & 0.24 \\
\hline EU member states & 5.0 & 1.2 & 0.24 \\
\hline OECD member countries & 7.1 & 1.8 & 0.25 \\
\hline OECD non-members & 1.6 & 0.4 & 0.25 \\
\hline Source: IEA modelling. & & & \\
\hline
\end{tabular}

\section{Urban energy supply}

At a national level, the share of renewables in final energy demand was the highest in Sweden (52\%) among all EU member states in 2013, followed by Latvia (37\%), Finland (37\%), Austria (33\%) and Denmark (27\%). The renewable share is much higher in Nordic countries than in the European Union as a whole (15\%) or compared to the global average $(16 \%)$. The main sources of the renewable energy in the Nordic region are biomass and hydropower, and geothermal power in Iceland.

One-third of buildings energy demand in Nordic urban areas was provided by district heating in the Nordic region in 2013, as outlined in Chapter 1, which is high compared with the EU average of 9\% (Table 2.4). However, the share varies between Nordic countries and especially between the urban and rural regions. The amount of district heat produced in Nordic countries grew by over 3\% per year between 1980 and 2000. Between 2000 and 2013, the annual rate of growth was between 1\% and 2\%. In addition to the Nordic region, OECD non-members have a relatively high share of district heating because of its prevalence in China and Russia.

In the Nordic region, the share of co-generation is higher in urban areas than in rural areas resulting in a slightly higher renewable share (46\%) in urban areas. In addition, rural areas require proportionately more oil for transport. In less-developed countries, the trend is the opposite and rural areas have a higher renewable share than urban areas, as rural areas have greater access to traditional biomass and coal is still a common fuel to heat buildings. 


\begin{tabular}{|c|c|c|}
\hline Table 2.4 & $\begin{array}{l}\text { of district heating and rene } \\
\text { of Nordic countries, EU mem } \\
\text { ries and non-members }\end{array}$ & $\begin{array}{l}\text { e energy in the urban } \\
\text { states and OECD member }\end{array}$ \\
\hline \multirow[t]{2}{*}{2013} & \multicolumn{2}{|c|}{ Energy supply indicators } \\
\hline & $\begin{array}{r}\text { Share of district heating in buildings energy } \\
\text { demand in urban areas }\end{array}$ & $\begin{array}{r}\text { Share of renewable energy in national final } \\
\text { energy demand }\end{array}$ \\
\hline Nordic countries & $33 \%$ & $40 \%$ \\
\hline EU member states & $9 \%$ & $15 \%$ \\
\hline OECD member countries & $3 \%$ & $9 \%$ \\
\hline OECD non-members & $15 \%$ & $16 \%$ \\
\hline Source: IEA modelling. & & \\
\hline
\end{tabular}

\section{Drivers of change in the urban context}

The drivers of change in urban energy consumption comprise not only political, technical and behavioural factors, but also changes in population and GDP, which influence urban energy patterns. Urban populations are expected to increase in the Nordic region due to continuing urbanisation and global demographic changes (Figure 2.3). Policy-level impacts include the decisions of individual cities and international and national policies that affect cities. Technological development both changes the competitiveness of existing technologies and brings in new services and solutions. Behavioural and societal drivers shape consumer choices and define trends for standards of living.
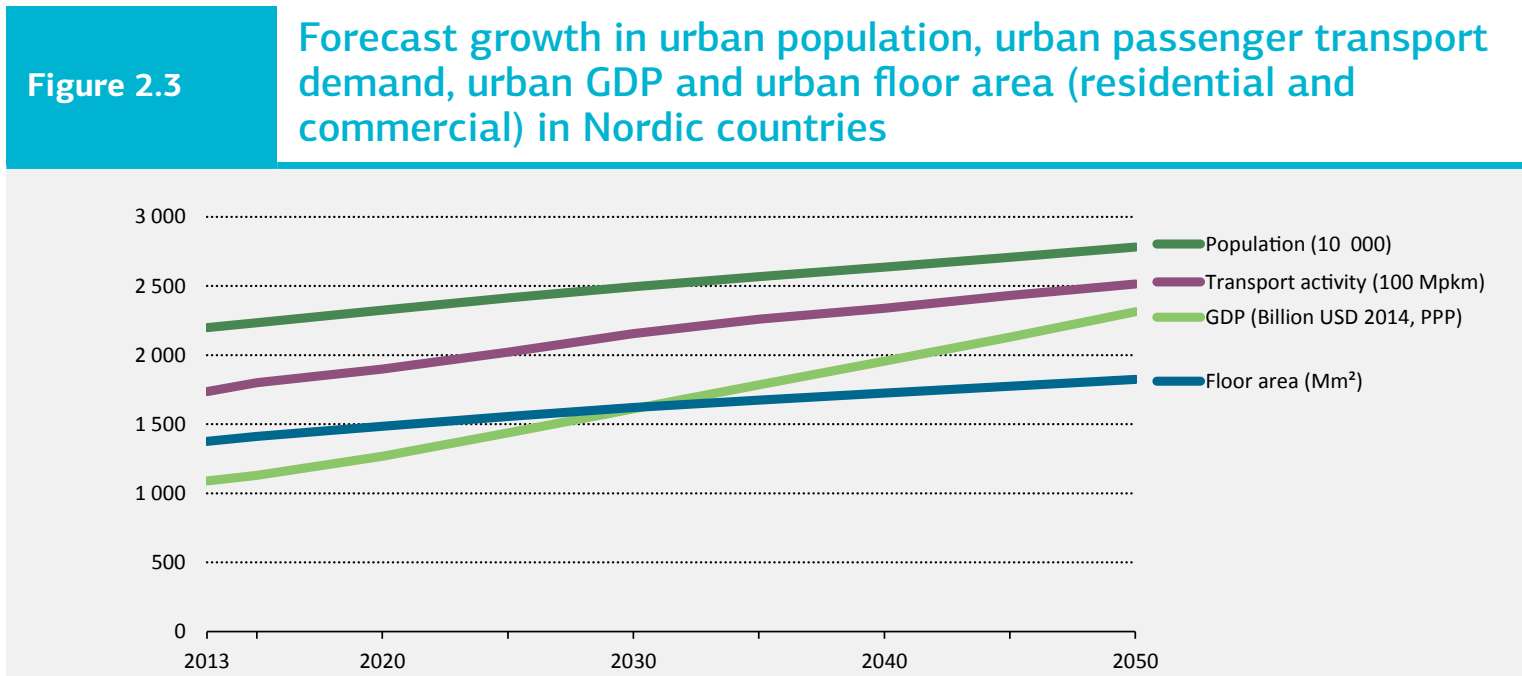

Notes: $\mathrm{Mm}^{2}$ = million square metres, Mpkm = million passenger kilometres.

Sources: Urban population: United Nations (2014), Urban Population, compiled from National Statistics Agencies; others: IEA modelling.

Figures and data in this report can be downloaded at www.iea.org/etp/nordic. urban passenger transport demand by $45 \%$, urban GDP by $110 \%$ and the urban floor area by 33\%. 


\section{Ambitious policy targets to give a clear signal for change}

The major EU-wide policies are the EU Emissions Trading System (EU ETS), the EU Effort Sharing Decision (EU ESD), the renewable energy target and energy efficiency targets. These are all important from an urban energy perspective. The EU ETS regulates the amount of $\mathrm{CO}_{2}$ emissions in the production of centralised electricity and district heating, while the EU ESD requires emissions reductions from sectors not included in the EU ETS, for example transport and direct emissions from buildings. Renewable energy targets demand a higher share of renewable energy, affecting urban regions. Energy efficiency targets affect multiple sectors, from transport to buildings, requiring new low-emission vehicles, new building codes, deep energy retrofits of existing building stock, and improved appliance energy efficiency.

The Nordic countries are committed to fighting climate change, a commitment visible in the action taken at a city level. In total 108 Nordic cities have promised to reduce their emissions as part of the Covenant of Mayors, where cities adopt a climate change mitigation target. However, this number is still relatively modest compared with some other EU countries, such as Italy with nearly 2000 commitments. Table 2.5 shows the number of Nordic cities taking part in the Covenant of Mayors by country. A typical emissions reduction commitment is around $20-30 \%$ by 2020 , with a few cities promising deeper emissions reductions of up to $80 \%$ by 2020 . The reference year for the emissions reductions varies considerably between cities, from 1990 to 2010.

\section{Table 2.5 \\ The number of Nordic cities taking part in the Covenant of Mayors and a typical reduction target}

\begin{tabular}{|c|c|c|c|}
\hline Country & $\begin{array}{r}\text { Covenant of Mayors } \\
\text { signatories }\end{array}$ & $\begin{array}{l}\text { Signatories submitting a } \\
\text { Sustainable Energy Action Plan }\end{array}$ & $\begin{array}{r}\text { Typical mitigation commitment } \\
\text { range by } 2020\end{array}$ \\
\hline Denmark & 37 & 34 & $20-50 \%$ \\
\hline Finland & 10 & 9 & $20-35 \%$ \\
\hline Iceland & 1 & 1 & $22 \%$ \\
\hline Norway & 8 & 7 & $20-38 \%$ \\
\hline Sweden & 52 & 50 & $20-65 \%$ \\
\hline \multicolumn{4}{|c|}{$\begin{array}{l}\text { Notes: Covenant of Mayors signatories commit to the programme; submitting a Sustainable Energy Action Plan commits the signatories } t \\
\text { reduction target. } \\
\text { Source: Covenant of Mayors (2016), database of signatories, webpage; database of submitted Sustainable Energy Action Plans, webpage. }\end{array}$} \\
\hline
\end{tabular}

All Nordic capitals are aiming for low-carbon energy systems. Copenhagen has the most ambitious target, to reach carbon neutrality by 2025 , and Oslo has published a target to reduce emissions by $95 \%$ by 2035 . Other capitals are aiming for low-carbon energy systems by 2050 with an emissions reduction target of $80 \%$. It is evident that Copenhagen's and Oslo's goals, while very ambitious, set excellent examples of urban leadership. The other capitals' targets largely follow national targets for reaching low-carbon energy systems by 2050.

In the cities' action plans, carbon neutrality is achieved with emissions reductions within the city borders. However, the phasing-out of coal or other fossil fuels within the borders of a capital region may increase energy imports from other regions, as capitals are densely populated without the resources necessary to support energy consumption entirely from renewable sources. Capitals are connected to national energy systems and all actions should be planned in recognition of the need for overall domestic reductions. 


\section{Transport}

Transition to low-carbon energy systems presents a huge challenge to both urban passenger and freight transport. Chapter 1 highlighted that it is necessary to both decarbonise passenger transport and make alternative transport modes more available, desirable and cost efficient to a larger number of citizens. For freight transport, the measures include both decarbonising fuels and increasing the energy efficiency of the transport chain. It is often easier to demonstrate these measures in urban areas where the population density is higher, travelled distances are shorter, new services have more customers, and new infrastructure is more compact to build.

Nordic countries have a strong track record of implementing policies to decarbonise transport and supporting public transport. Policies in all countries include support for public transport, cycling and walking, EVs, biofuels and tax incentives for low-carbon transport, but each Nordic country has its own focus areas. Denmark has promoted rail traffic, cycling and walking; Finland has invested in making advanced biofuels available; Iceland linked the carbon tax on transport fossil fuel to the EU ETS carbon price; Norway is making an aggressive push for EVs; and Sweden is supporting the roll-out of electric transport and biofuels. Additional actions at the city level include investment in public transport, road tolls, building new lanes for bicycles, investing in EV charging infrastructure, investing in larger parking areas near public transport hubs and supporting local alternative fuels, such as transport biogas from landfills. The transition to a low-carbon transport system requires systematic, co ordinated and sustained effort at all levels - EU, national and city.

\section{Buildings}

The energy consumption of buildings was estimated to account for $43 \%$ of the final energy consumption of Nordic urban areas in 2013. The transition to low-carbon energy systems requires both increasing the energy efficiency of buildings and decarbonising the supply of energy to buildings. Extensive efforts are needed, especially in the deep retrofitting of existing buildings. As estimated in Chapter 1, approximately 70\% of the building stock in 2050 is expected to be comprised of buildings that exist today. Low-carbon targets should encompass both accelerated renovation rates and more aggressive efficiency improvements.

New building stock should be efficient and new urban areas should be planned efficiently. All Nordic countries are demonstrating smart city projects, which aim to increase the efficiency of cities, save resources, and decrease the amount of time required for commuting and errands. These projects are in the early phase of implementation and other Nordic urban areas should learn from both their successes and failures where good data are available.

A considerable share of buildings emissions are indirect emissions from power and heat production, depending on the fuel mix of each urban area. Buildings energy efficiency measures are not sufficient alone if the energy supply is not also decarbonised. In many urban areas, renewable energy potential is insufficient to supply all consumption, as it is limited by the space available and the high density of buildings. A larger share of buildings energy will be delivered through the electricity grid and district heating and cooling grids.

\section{Urban energy supply}

Urban energy supply covers the delivery of electricity, heat, gasoline, diesel and many other fuels to end-use sectors requiring energy. Urban energy production covers most of the consumed district heat and also a part of the consumed electricity. Transport fuels are mostly produced in other regions and transported to urban areas. The main focus of decarbonising the urban energy supply is to decarbonise the supply of heat. Decarbonising electricity production is also crucial, but this benefits from greater flexibility and more policy options as electricity is easier to import to urban areas through transmission lines. 
In Nordic urban areas, the production of power and heat emits one-third of total urban $\mathrm{CO}_{2}$ emissions. This is largely from the co-generation of electricity and heat, but partially also from heat-only production during the cold winter months. At the moment, half of the heat produced in Nordic urban areas is from solid biomass. The remaining half is produced with coal, peat, natural gas and waste. Decarbonising the production of heat is both crucial for achieving carbon-neutral targets and challenging from a security-of-supply perspective.

One of the potential core technological solutions for future Nordic urban energy systems is fourth generation district energy network technology, which enables extensive co-generation and wide utilisation of district heat networks into the future. This is characterised by lowtemperature heat supply, integration of ambient, waste and solar heat as well as district cooling in the system, heat recycling, power-to-heat flexibility of co-generation, storage systems and intelligent control systems, as described in Table 2.6. The concept thus represents an extensive system integration solution covering a wide range of individual technologies. Without the enhancements of fourth generation technology, Nordic district heating networks may not be able to maintain viability as a long-term low-carbon solution. However, with new generation technology, it may well be possible to further develop and utilise the current extensive Nordic district heating infrastructure for achieving an efficient and sustainable carbon-neutral system.

With respect to the low-carbon policy targets, new district heat network technology offers several important advantages. First, energy efficiency is improved both on the production and distribution side. Second, the co-generation power-to-heat ratios can be raised, and renewable heat sources can be easily integrated into the system, both because of the lower supply temperatures. And finally, the system as a whole provides better flexibility in both electricity and heat supply, which is important for integrating variable renewables. 


\section{Table 2.6 Development of district energy systems by technology generation}

\begin{tabular}{|c|c|c|c|c|}
\hline Distribution & 1st generation & 2nd generation & 3rd generation & 4th generation \\
\hline Period of BAT & $1880-1930$ & $1930-80$ & $1980-2020$ & $2020-50$ \\
\hline Heat carrier & Steam & Hot water $>100^{\circ} \mathrm{C}$ & Hot water $<100^{\circ} \mathrm{C}$ & Warm water $30-70^{\circ} \mathrm{C}$ \\
\hline Piping & $\begin{array}{l}\text { In situ insulated steel } \\
\text { pipes }\end{array}$ & $\begin{array}{l}\text { In situ insulated steel } \\
\text { pipes }\end{array}$ & $\begin{array}{l}\text { Pre-insulated steel/ } \\
\text { plastic pipes }\end{array}$ & $\begin{array}{l}\text { Pre-insulated flexible } \\
\text { pipes }\end{array}$ \\
\hline Circulation & Steam pressure & Central pumps & Central pumps & Distributed pumps \\
\hline Buildings, typical SEC & $\begin{array}{l}\text { Multi-storey, } \\
>250 \mathrm{kWh} / \mathrm{m}^{2}\end{array}$ & $\begin{array}{l}\text { Multi-storey, } \\
200-300 \mathrm{kWh} / \mathrm{m}^{2}\end{array}$ & $\begin{array}{l}\text { Urban buildings, } \\
100-200 \mathrm{kWh} / \mathrm{m}^{2}\end{array}$ & $\begin{array}{l}\text { Any buildings, } \\
25-150 \mathrm{kWh} / \mathrm{m}^{2}\end{array}$ \\
\hline Metering & $\begin{array}{l}\text { Condensate meters for } \\
\text { steam }\end{array}$ & $\begin{array}{l}\text { Substation heat and } \\
\text { flow meters }\end{array}$ & $\begin{array}{l}\text { Heat and flow meters, } \\
\text { wireless reading }\end{array}$ & $\begin{array}{l}\text { Intelligent continuous } \\
\text { real-time monitoring }\end{array}$ \\
\hline Final distribution & $\begin{array}{l}\text { High-temperature, } \\
\text { steam or water, } \\
\text { radiators }\end{array}$ & $\begin{array}{l}\text { High-temperature, } \\
\text { water }\left(90^{\circ} \mathrm{C}\right) \text {, radiators }\end{array}$ & $\begin{array}{l}\text { Medium-temperature } \\
\text { water }\left(70^{\circ} \mathrm{C}\right) \text {, radiators/ } \\
\text { radiant floor heating }\end{array}$ & $\begin{array}{l}\text { Indirect low-temperature } \\
\text { radiators }\left(50^{\circ} \mathrm{C}\right) \text {, } \\
\text { radiant floor heating }\end{array}$ \\
\hline Cooling integration & - & $\begin{array}{l}\text { First large systems, } \\
\text { non-integrated }\end{array}$ & $\begin{array}{l}\text { Supply-side partially } \\
\text { integrated }\end{array}$ & Fully integrated \\
\hline Domestic hot water & $\begin{array}{l}\text { Tanks directly heated } \\
\text { by steam }\end{array}$ & $\begin{array}{l}\text { Tank directly heated to } \\
60^{\circ} \mathrm{C}\end{array}$ & $\begin{array}{l}\text { Heated by heat } \\
\text { exchanger to } 50-60^{\circ} \mathrm{C}\end{array}$ & $\begin{array}{l}\text { HP-enhanced heat } \\
\text { exchangers to } 40-50^{\circ} \mathrm{C}\end{array}$ \\
\hline Heat energy sources & Mainly coal & Mainly coal and oil & $\begin{array}{l}\text { Fossil and biofuels, } \\
\text { waste, electricity }\end{array}$ & $\begin{array}{l}\text { Biofuels, heat recycling } \\
\text { renewable electricity }\end{array}$ \\
\hline $\begin{array}{l}\text { Integration with } \\
\text { electricity supply }\end{array}$ & $\begin{array}{l}\text { Co-generation of heat } \\
\text { and power; no role on } \\
\text { balancing market }\end{array}$ & $\begin{array}{l}\text { Co-generation of heat } \\
\text { and power, no role on } \\
\text { balancing market }\end{array}$ & $\begin{array}{l}\text { Large-scale co- } \\
\text { generation, distributed } \\
\text { co-generation, electric } \\
\text { boilers, heat pumps; } \\
\text { rarely on balancing } \\
\text { market }\end{array}$ & $\begin{array}{l}\text { Low-temperature } \\
\text { co-generation systems } \\
\text { with power-to-heat } \\
\text { flexibility, integrated } \\
\text { with heat pumps, boilers } \\
\text { and solar collectors; on } \\
\text { balancing market }\end{array}$ \\
\hline Storage systems & - & $\begin{array}{l}\text { Tank thermal buffer } \\
\text { storage }\end{array}$ & $\begin{array}{l}\text { Tank, pit, borehole and } \\
\text { aquifer storage }\end{array}$ & $\begin{array}{l}\text { Combined storage } \\
\text { for heat and cooling }\end{array}$ \\
\hline \multicolumn{5}{|c|}{$\begin{array}{l}\text { Notes: BAT = best available technology; HP = heat pipe; } \mathrm{SEC}=\text { specific energy consumption; } \mathrm{kWh} / \mathrm{m}^{2}=\text { kilowatt hour per square metre. } \\
\text { Source: Based on Lund et al. (2014), "4th Generation District Heating }(4 \mathrm{GDH}) \text { : Integrating smart thermal grids into future sustainable energy systems” } \\
\text { Energy, Vol. 68, pp. 1-11. }\end{array}$} \\
\hline
\end{tabular}

\section{Behaviour change}

Consumer behaviour is an important aspect of energy systems that affects consumer choices and the use of technology. It is possible to use the same technology more or less energy efficiently. There is a long history of information campaigns aimed at citizens to promote eco-driving, using more public transport and saving energy in buildings. A good example of consumer behaviour campaigning comes from Copenhagen, where the number of people cycling increased by 25\% and the amount of kilometres cycled by 5\% between 2009 and 2014 (Copenhagen Green Accounts, 2014). The average distance cycled per person decreased during this period, but many new cyclists started to cycle at least part of the year. During the same period, the distance travelled by car decreased by 5\% from 4.9 million kilometres per year to 4.7 million kilometres per year.

Typical consumer behaviour means that more efficient technology combined with higher incomes result in greater energy consumption - this is called the rebound effect. As Nordic countries have become wealthier and technology has improved, distances travelled and floor area per capita have increased. In Nordic urban regions, passenger transport demand per person increased by 10\% from 2000 to 2015 and the amount of floor area per person 
increased by $9 \%$ over the same period. In total, energy consumption from buildings has decreased by $15 \%$ but energy demand for passenger transport has remained unchanged.

A number of emerging technological fields and business models may affect consumer behaviour in ways that are yet to be fully understood. Autonomous vehicles and the sharing economy (the Uber Pool ride sharing application being an oft-cited example) are two factors that, while not explicitly modelled in the scenarios, may lead to reductions in car ownership rates in urban areas and more efficient driving patterns, among other benefits. However, there is a risk that greater access to car-based mobility may create a rebound effect of increased car use, offsetting part of the efficiency gains.

\section{Urban scenarios: what is the role of Nordic cities and urban regions in reaching carbon neutrality?}

\section{Low-carbon urban areas - ambitious but realistic targets}

Nordic urban areas are facing an enormous challenge to decarbonise their energy systems, as their population is expected to increase by 30\% from 2013 to 2050. To become lowcarbon, urban areas require ambitious efforts to build a balanced combination of reducing energy demand, supplying low-carbon energy and integrating smart energy systems.

The Nordic urban scenarios presented in this report have been developed as an integral part of the global scenarios set out in the International Energy Agency (IEA) Energy Technology Perspectives 2016 (ETP 2016). Box 1.1 in Chapter 1 of this publication describes the scenarios in detail. The Nordic Carbon-Neutral Scenario (CNS) reflects the diverse stated aims of Nordic countries to have an energy system with net zero $\mathrm{CO}_{2}$ emissions. The CNS is very ambitious but possible to achieve. In the CNS, the final energy demand of Nordic urban areas decreases by $11 \%$ from 2013 to 2050 while direct $\mathrm{CO}_{2}$ emissions decrease by $89 \%$. The Nordic 4 Degree Scenario (4DS) serves as a less ambitious reference scenario for the analysis, but it still requires strategic policy action and mitigation efforts. In the 4DS, the final energy demand of Nordic urban areas increases by $9 \%$ and direct $\mathrm{CO}_{2}$ emissions decrease by 50\% from 2013 to 2050. Per-capita energy demand also decreases in the 4DS.

Nordic countries have both common challenges and their own characteristics and opportunities when searching for suitable solutions towards low-carbon urban areas. The transport sector is a challenge to decarbonise and requires both domestic measures and co-operation at international level to agree on stricter vehicle standards. Each Nordic country has to also decarbonise power and heat production, although Iceland has already achieved this and Norway is close to reaching this goal. The practical solutions for integrating power and heat production systems depend highly on national circumstances.

\section{Transport}

Urban transport is one of the core sectors where extensive transformation to an efficient low-carbon energy system should take place. Measures are required to improve transport energy efficiency, decarbonise transport fuels and support modal shift to public transport, cycling and walking.

Energy efficiency is one of the cornerstones of low-carbon urban areas. In the CNS, the percapita energy demand of urban transport and buildings decreases by 20\% between 2015 and 2030 and by a further 20\% between 2030 and 2050. Despite increasing population, 
final energy demand of transport in urban areas is 36\% less in 2050 compared to 2013. Per person, urban transport also consumes nearly $50 \%$ less energy in 2050 than it consumes in 2013. If urban transport can deliver greater energy savings, carbon neutrality will be easier to achieve. The energy efficiency gains are more moderate under the 4DS, with the amount of energy consumed slightly increasing from 2040 to 2050.

Roughly 90\% of transport fuels would be new transport fuels in the CNS. Energy-wise, drop-in biofuels and electricity have the highest share. When measured by passenger kilometres, the share of electricity is higher than biofuels, but biofuels are required to decarbonise the heavier traffic (e.g. freight). Were EV technology to improve more quickly than assumed, it would decrease the pressure on biomass resources and make it easier and cheaper to decarbonise other sectors and rural areas. From 2013 to 2030, the results for urban transport are very similar under both the 4DS and CNS. The CNS is more energy efficient and has a slightly higher share of alternative fuels, but after 2030, the CNS requires considerable energy efficiency measures and an increasing share of $\mathrm{CO}_{2}$-free fuels in transport (Figure 2.4).

\section{$\begin{array}{ll}\text { Figure 2.4 Final energy demand of urban transport in Nordic countries } & \text {. }\end{array}$}

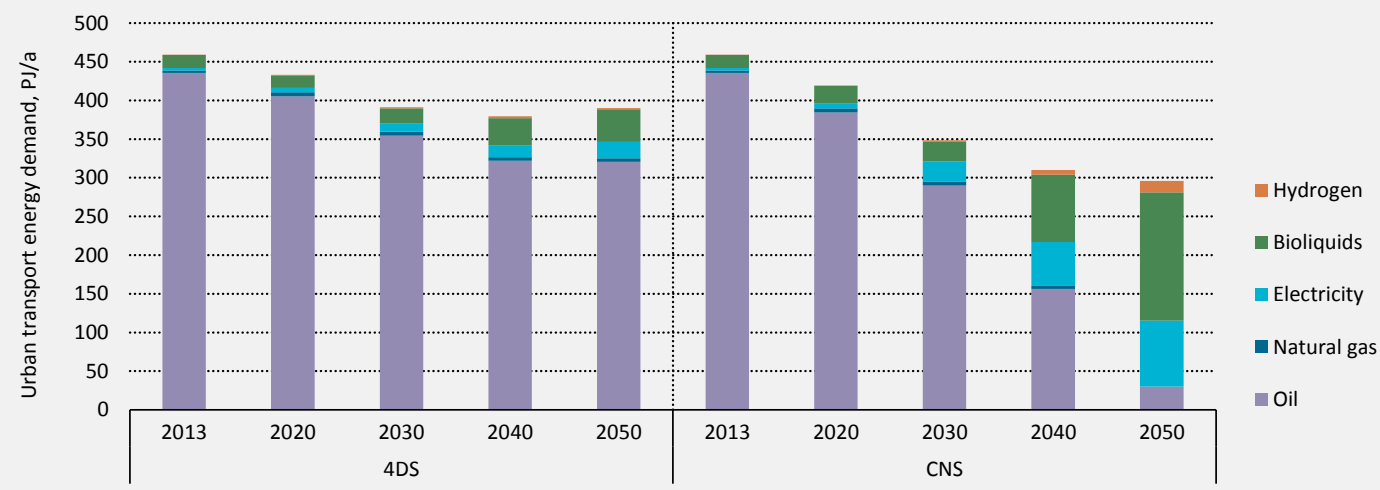

Note: $\mathrm{PJ} / \mathrm{a}=$ petajoules per annum.

Figures and data in this report can be downloaded at www.iea.org/etp/nordic

Key point

Final energy demand of urban transport in Nordic countries should fall by $36 \%$ in the CNS and shift to renewable fuels and electricity. Per person, urban transport should consume nearly 40\% less energy in 2050 than it consumed in 2013.

The most important measures to decarbonise the urban transport sector are energy efficiency, drop-in second-generation biofuels, and electric and hybrid vehicles. All of these technologies have a prominent role in achieving the carbon-neutral urban system by reducing transport sector emissions to close to zero and energy consumption by 35\% by 2050. For passenger travel, the core technologies are full-electric and plug-in hybrid vehicles, as well as modal shift to public transport (Table 2.7). For freight transport, second-generation drop-in biofuels, hybrid vehicles and logistical improvements make a significant contribution. In rural areas, distances travelled are longer and EVs do not play a similar role.

Both the 4DS and CNS project that transport activity will increase in Nordic urban areas due to increasing population and increased mobility of passengers and goods. Energy-efficient 
infrastructure is important to decrease the growth in transport demand. When the design of urban planning and infrastructure supports low-carbon targets, citizens have to travel shorter distances to take care of their daily needs and can use public transport, cycle or walk. In total, passenger transport activity (passenger kilometres) is estimated to increase by 50\% in Nordic urban areas from 2013 to 2050. In the CNS, 4\% of this passenger transport activity shifts to cycling and walking by 2050.

\section{Table 2.7}

\section{Effect of low-carbon technology options on urban transport in the Nordic CNS}

\begin{tabular}{|c|c|c|}
\hline \multicolumn{2}{|c|}{ Low-carbon technologies for urban transport } & Effect in scenarios \\
\hline Passenger car technologies & Efficient cars, hybrid and full EVs, flex-fuel vehicles, fuel-cell cars & High \\
\hline Freight vehicle technologies & Efficient transport vehicles, hybrid and flex-fuel vehicle technologies & Medium \\
\hline Passenger mode shifts & Shift from passenger cars to public transport, cycling and walking & Low \\
\hline Logistical improvements & $\begin{array}{l}\text { More efficient transport infrastructure for both passengers (pkm/vkm) } \\
\text { and cargo }(\mathrm{tkm} / \mathrm{vkm})\end{array}$ & Low \\
\hline
\end{tabular}

Notes: $\mathrm{pkm}$ = passenger kilometre; $\mathrm{tkm}$ = tonne kilometre; $\mathrm{vkm}$ = vehicle kilometre.

\section{Buildings}

The energy consumption of urban buildings is three times larger than that of urban transport. From this perspective, the buildings sector is much more important in carbon-neutral scenarios. On the other hand, direct emissions from urban buildings $\left(5 \mathrm{MtCO}_{2} \mathrm{e}\right.$ in $2013,3 \%$ of the Nordic total) are much smaller than those from urban transport (36 $\mathrm{MtCO}_{2} \mathrm{e}$ in $2013,18 \%$ of the Nordic total). The largest source of emissions in the buildings sector is indirect emissions from power and heat generation, which are four times larger than direct emissions.

One of the key characteristics of the buildings sector is a long lifetime. It is therefore crucial to improve not only standards for new buildings, but also the performance of existing infrastructure. The average heating intensity $\left(\mathrm{kWh} / \mathrm{m}^{2}\right)$ of the Nordic building stock improved by $0.5 \%$ per year between 1990 and 2013, but in the CNS the improvement in residential buildings is nearly $2.5 \%$ per year.

The most important energy efficiency measures of the buildings sector are retrofitting the existing building stock and implementing low-energy standards for new buildings (Table 2.8). If these measures are implemented rigorously, the average Nordic urban residential building might reach as low a heating demand as $40 \mathrm{kWh} / \mathrm{m}^{2}$ per year, which is 50\% less than in 2013 . At the same time, the urban floor area of residences and the service sector is expected to grow from $1400 \mathrm{Mm}^{2}$ in 2013 to $1800 \mathrm{Mm}^{2}$ in 2050. Per capita the rate of growth is lower, from 63 square metres $\left(\mathrm{m}^{2}\right)$ per person in 2013 to $66 \mathrm{~m}^{2}$ per person in 2050. The growing floor area offsets a considerable part of the energy efficiency gains. In total, the final energy demand of urban buildings would remain at its current level in the 4DS and decrease only after many energy efficiency measures are adopted in the CNS (Figure 2.5). 


\section{Figure 2.5}

\section{Final energy demand of urban buildings in Nordic countries in} 2013 (left) and in the scenarios (right)
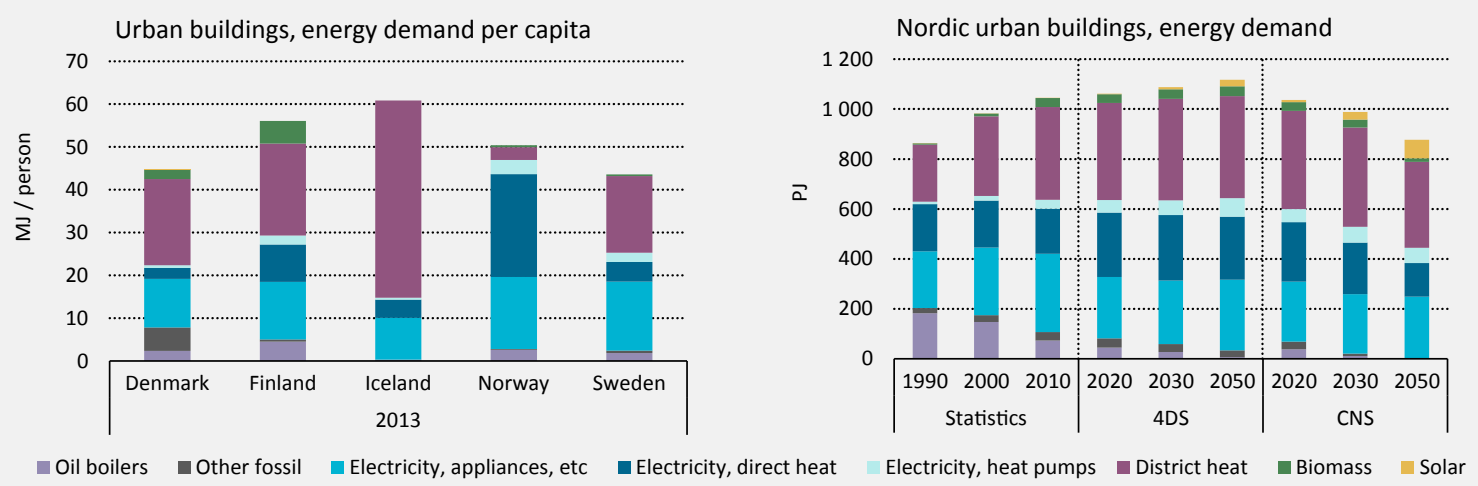

Notes: $\mathrm{MJ}=$ megajoule; $\mathrm{PJ}$ = petajoule.

Figures and data in this report can be downloaded at www.iea.org/etp/nordic

Key point

Heat demand of urban buildings in the Nordic countries reduces by $50 \%$ in the CNS, but the growing floor area offsets a considerable part of the energy efficiency gains. Therefore final energy sources for buildings should be changed to renewable fuels, district heat and electricity.

As an exception, the efficient heating of buildings is not that critical in Iceland, which has abundant geothermal heat available. The $\mathrm{CO}_{2}$ emissions from heating buildings are already negligible in Iceland and additional energy efficiency improvements are not required to reach carbon neutrality.

Increasingly efficient lighting and appliances play an important role in contributing to the carbon neutrality of Nordic urban areas. In the 4DS, the electricity consumption of the residential and service sectors increases by 43\% between 2013 and 2050, while in the CNS the electricity consumption of all these end uses increases by $25 \%$. The electricity consumption of the service sector, in particular, increases when the urban population grows as new types of business develop, such as large-scale servers for internet-based companies in the Nordic countries. Efficiency gains in the service sector and in appliances and cooking make it possible to use the potential of renewables to mitigate fossil fuels in other sectors.

The significance of advanced cooling and heating systems (small-scale heat pumps, solar heating, district cooling and advanced district heating) varies depending on existing infrastructure. Urban areas that currently have a high share of co-generation will benefit more from district cooling and advanced district heating. Areas with a high share of direct electric heating are likely to gain more from heat pumps. Solar heating requires large available surface areas and suits small urban areas better than large. Locally, each of these technologies may have a large impact, but the overall effect in the big picture is relatively small in urban areas. In rural areas the significance of small-scale heat pumps and solar heating is larger, as district heating is not an option to reduce emissions. 


\section{Table 2.8}

\section{Effect of low-carbon energy technologies in urban buildings in the Nordic CNS}

Low-carbon technologies for urban buildings

Effect in scenarios

New building efficiency standards

Implementation of low-energy standards for new buildings

High

Building retrofits

Implementation of strict efficiency standards for existing buildings

High

Energy-efficient appliances

Advanced lighting and low-energy appliance technologies

Medium

Advanced heating systems

Small-scale heat pumps, solar heating, low-temperature district heat

Advanced cooling systems

Small-scale heat pumps, district cooling

Low

Low

Under both the CNS and 4DS, electricity consumption per person decreases in urban areas as a result of all applied buildings sector measures. While electricity demand increases in transport, the decrease in the buildings sector is a stronger driver. As a result, urban areas will require less electricity per person in the future accounting both for the buildings and transport sectors (Figure 2.6). Electricity consumption per person decreases more in rural areas as direct electricity heating is replaced with small-scale heat pumps with much higher energy efficiency. In urban areas this effect is smaller as direct electricity heating accounts for only $21 \%$ of buildings electricity consumption.
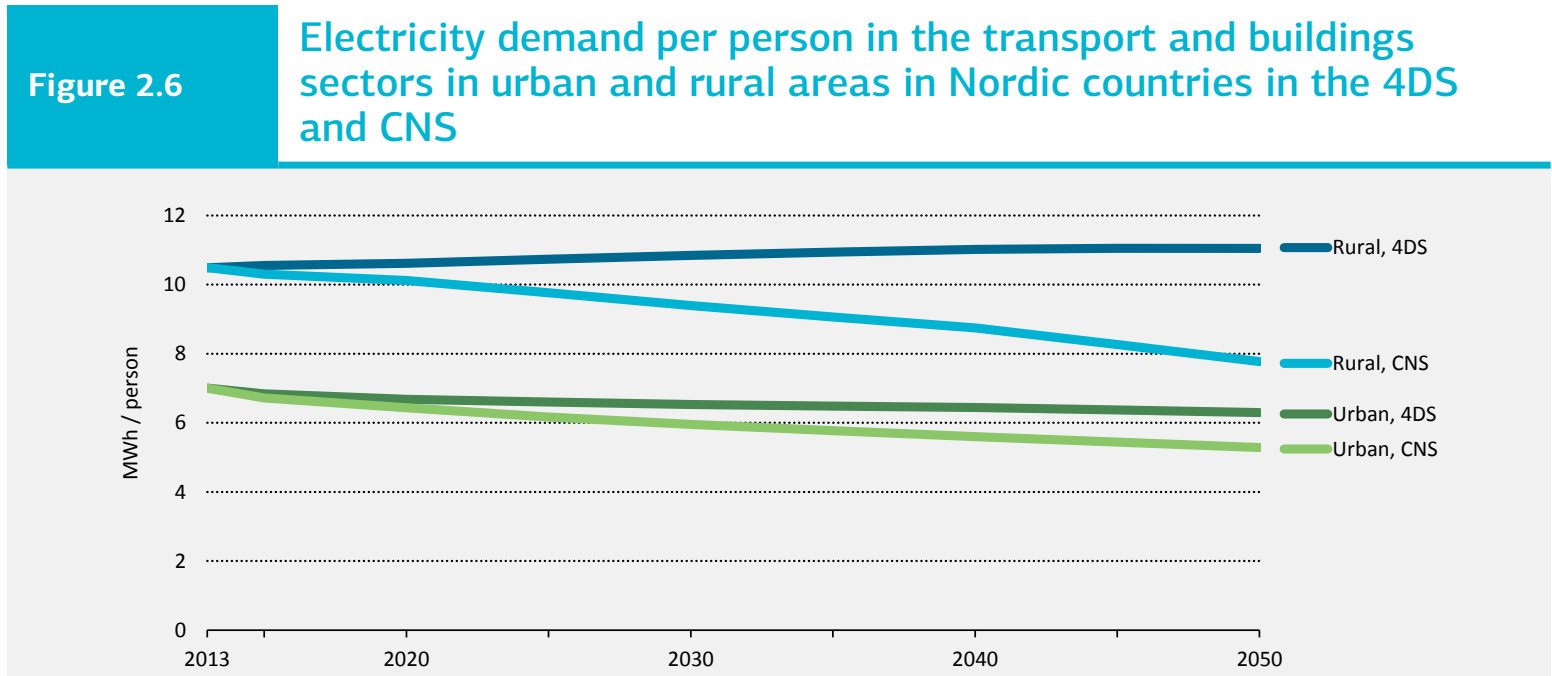

Note: $\mathrm{MWh}=$ megawatt hour

Figures and data in this report can be downloaded at www.iea.org/etp/nordic.

Key point Due to increasing population and electrification of the transport and buildings sectors in urban areas, electricity demand per person does not decrease markedly. By contrast, electricity consumption in rural areas under the CNS decreases by $25 \%$ compared to 2013 levels due to increased energy efficiency of the buildings sector. 


\section{Versatile low-carbon energy supply required in urban areas}

Urban areas have to utilise a large number of renewable energy sources and efficiency improvements to decarbonise their energy supply. Additionally, urban areas might have to import electricity to meet demand. The most significant low-carbon energy supply options in the CNS are co-generation, utility-scale heat pumps, solar PV, and geothermal heat in Iceland. The other low-carbon energy supply options cover a wide range of technologies, as listed in Table 2.9. The list is not exhaustive, but all those listed are needed to achieve the Nordic CNS.

\section{Table 2.9}

\section{Effect of low-carbon energy supply options in urban areas in the} Nordic CNS

\begin{tabular}{|c|c|c|}
\hline \multicolumn{2}{|c|}{ Urban low-carbon energy supply options } & \multirow{2}{*}{$\begin{array}{l}\text { Effect in scenarios } \\
\text { High }\end{array}$} \\
\hline Co-generation & Large- and small-scale low-carbon co-generation technologies & \\
\hline Solar PV & Distributed rooftop solar PV systems & High \\
\hline Utility-scale heat pumps & Integration of ambient and excess heat sources to district heat network & High \\
\hline Geothermal heat & Utilisation of high-temperature geothermal heat for power and heat & Locally high \\
\hline $\begin{array}{l}\text { Low-temperature district } \\
\text { heating networks }\end{array}$ & Decreased supply temperature for improved efficiency and flexibility & Medium \\
\hline Wind power & Onshore, near-shore and offshore wind power near urban areas & Medium \\
\hline District cooling & District heating and cooling as an integrated urban energy solution & Low \\
\hline Landfill gas capture & Enhanced capture of landfill gas from existing disposal sites & Low \\
\hline Solar district heat & Integration of solar heat to district heat network & Low \\
\hline Waste to energy & Refuse-derived fuel from processed municipal and industrial waste & Low \\
\hline
\end{tabular}

The enhanced district heating concepts provide increased flexibility, which is needed for the integration of renewable energy in the overall system, and closer integration with the electricity supply. Together with heat storage, co-generation plants with power-to-heat capability would contribute to the balancing of variable renewable generation.

Co-generation has long been one of the key technologies to increase the energy efficiency of the supply of electricity and heat to urban communities, but the total amount of co-generated heat decreases in the CNS by 40\% from 2020 to 2050. The amount of delivered district heat increases in the Nordic countries (Figure 2.7), but the role of large-scale co-generation is likely to decline under strict low-carbon policies, price competition with utility-scale heat pumps and competition for solid biomass from transport fuels. In the 4DS the amount of co-generation is larger than in the CNS as possibilities exist to produce some power and heat from coal and there is less competition for biomass from transport. In the CNS, coal has to be phased out and a larger share of biomass used to produce bioliquids for transport.

The results indicate that district heating networks would remain the dominant technology for the heating of buildings even though co-generation will lose some of its current significance in Nordic cities. That would be possible through the introduction of 4 th generation lowtemperature district heating networks and the integration of low-carbon co-generation with utility-scale heat pumps, electric boilers, solar heat collectors, district cooling, and new combined storage technologies for heating and cooling. 


\section{Figure 2.7}

\section{Production of district heat by fuel and technology in 2013 (left) and 2013-50 in scenarios (right)}

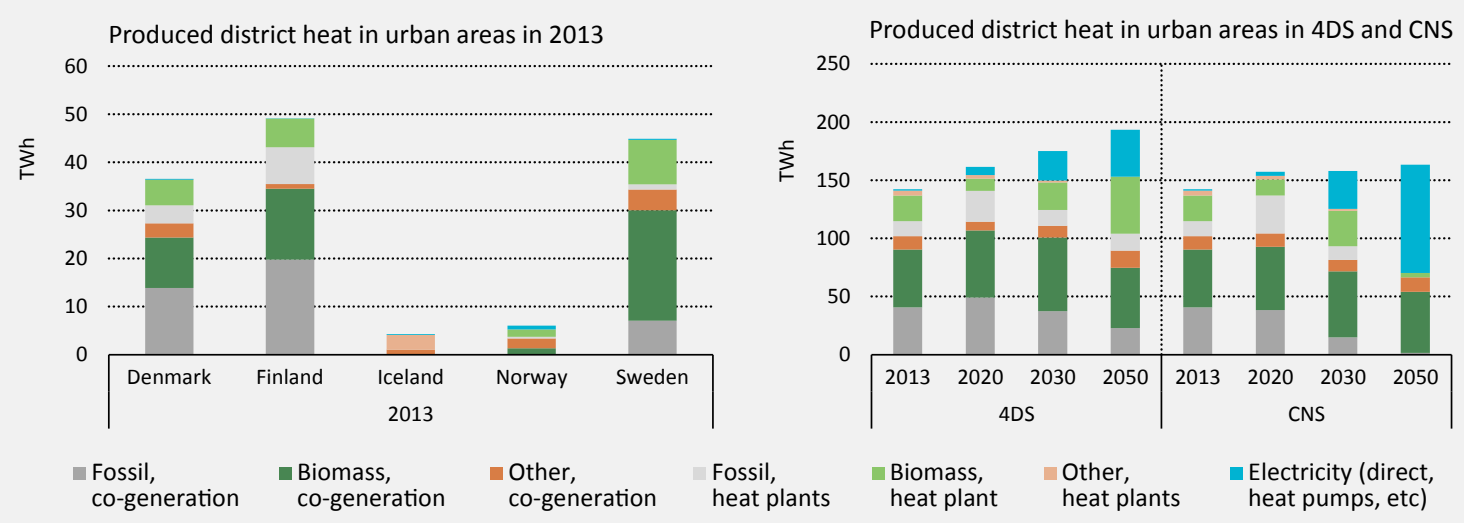

Figures and data in this report can be downloaded at www.iea.org/etp/nordic.

Key point

Utility-scale heat pumps and biomass-fired co-generation are the dominant technologies to produce district heat in the CNS in 2050.

Integrating utility-scale heat pump systems into the district heat supply appears to have great potential given the characteristics of new generation low-temperature networks, where they would be used to exploit available ambient and excess heat sources efficiently for both district heating and cooling. In addition, distributed solar heat collectors would provide further flexibility to the system.

The rapid development of solar PV systems in recent years has improved the prospects of solar power in the Nordic countries, even though the seasonal distribution is not favourable. In Nordic urban areas, PV production could reach $4 \mathrm{GW}$ peak capacity by 2050 and produce 4 TWh annually depending on the weather conditions of the year. This would correspond to $3 \%$ of total capacity in Nordic countries and 1\% of total electricity generation. Solar PV has high impact in urban areas, as demonstrated in the Helsinki case study, where nearly all the suitable rooftop potential might become utilised by 2050 under strict climate policies.

Onshore wind power potential is usually limited in large urban areas due to land-use considerations, but most large Nordic cities lie on the coastline and have a considerable near-shore wind power potential. Smaller urban areas also have onshore potential. In the CNS, the amount of wind power near urban areas grows rapidly and reaches $20 \mathrm{GW}$ capacity in 2030 and $40 \mathrm{GW}$ capacity by 2050. In 2050, wind power near urban areas produces 115 TWh of electricity, generating $44 \%$ of the electricity consumed in Nordic urban areas. In total, wind power generates 31\% of electricity consumed in the Nordic countries in 2050.

The CNS demands significant investment in $\mathrm{CO}_{2}$-free energy supply in both urban and rural areas (Figure 2.8). The share of $\mathrm{CO}_{2}$-free urban energy supply is already high in the Nordic countries, ranging from close to $100 \%$ in Iceland to $28 \%$ in Denmark in 2013. In the 4DS the share of fossil fuels decreases slowly after 2020, but in the CNS the fossil share decreases by $1 \%$ per year after 2020 . 


\section{Figure 2.8 \\ TPES in 2013 (left) and total for Nordic urban areas in the 4DS and CNS from 2013 to 2050}

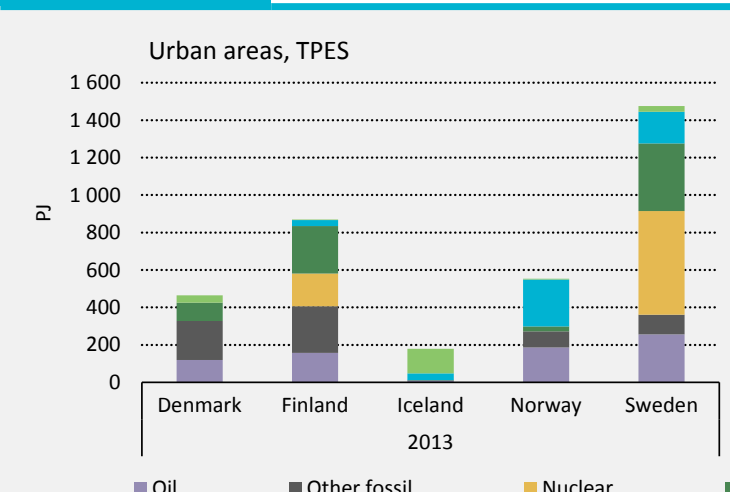

Oil

Nuclear

Biomass and waste

\section{Nordic urban areas, TPES}

\section{0}

4000

3500

3000

․ 2500

2000

1500

1000

500

0

\begin{tabular}{|l|l|l|l|}
\hline 20132020203020402050 & 20132020203020402050 \\
\hline
\end{tabular}

4DS

Hydro
CNS

Other renewables

Notes: Other renewables include geothermal heat (Iceland), ambient heat from heat pumps, and solar; TPES = total primary energy supply. Figures and data in this report can be downloaded at www.iea.org/etp/nordic.

Key point

The categories Biomass and waste and Other renewables (including heat pumps and solar) see the greatest increase in share of TPES in both the 4DS and CNS.

In the 4DS, the share of $\mathrm{CO}_{2}$-free energy supply in urban areas increases from $61 \%$ in 2013 to $75 \%$ in 2050 (Figure 2.9). In the CNS, the amount of fossil fuels used decreases due to energy efficiency measures and the additional deployment of renewable energy, causing the $\mathrm{CO}_{2}$-free energy supply to reach a share of $89 \%$ in urban areas by 2050 . The remaining fossil fuels are very difficult to mitigate as they are consumed in industry, transformation and, to a certain extent, also in transport. The $\mathrm{CO}_{2}$-free share of primary energy increases more in rural areas, as its share was considerably lower in 2013. In the CNS, the remaining fossil fuels are used mostly in international transport and in industry, applications that are technically difficult to fully decarbonise. These figures include all primary energy supply sources to all urban energy-consuming sectors.

\section{Smart system integration essential to match consumption and production}

The integration of large amounts of variable production in the system requires cross-sectoral technologies to balance supply and demand, such as distributed energy storage and demand monitoring and management systems (Table 2.10). Smart transmission and control systems can also be expected to make an important contribution to the integration of the buildings sector and mobility into the system, e.g. buildings could be prosumers and also use local electricity for charging the batteries of EVs. The integration of electricity supply and demand is described in detail in Chapter 3.

Effect of low-carbon energy supply options in Nordic urban areas in the CNS 


\section{Figure 2.9 \\ $\mathrm{CO}_{2}$-free share of TPES in urban and rural areas in the Nordic region in the 4DS and CNS}

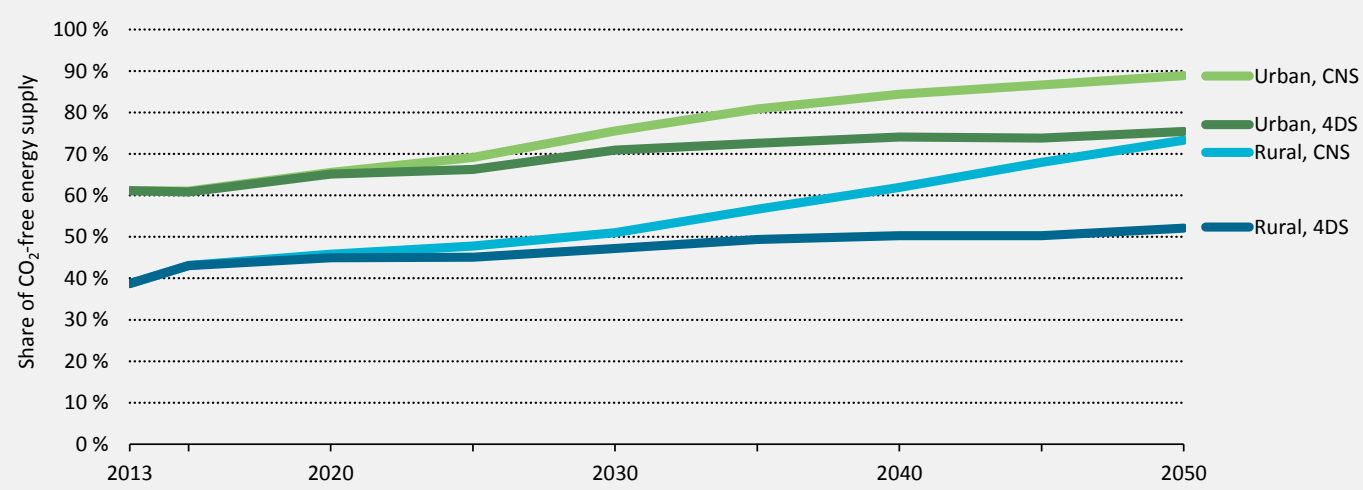

Figures and data in this report can be downloaded at www.iea.org/etp/nordic.

Key point In the CNS, the $\mathrm{CO}_{2}$-free share of urban energy supply reaches $87 \%$ by 2050 , with rural areas reaching only $71 \%$, demonstrating the importance of urban leadership in GHG mitigation.

The significance of energy system management and system integration is particularly important in large cities. In Nordic urban areas, $61 \%$ of the energy demand of the buildings and transport sectors is distributed through the electricity grid and district heating networks. By 2050 this share would increase to $76 \%$ in the CNS (Figure 2.10).

\section{Share of final energy to buildings and transport delivered through \\ Figure 2.10 electricity grid and district heating networks in Nordic region urban and rural areas in the 4DS and CNS}

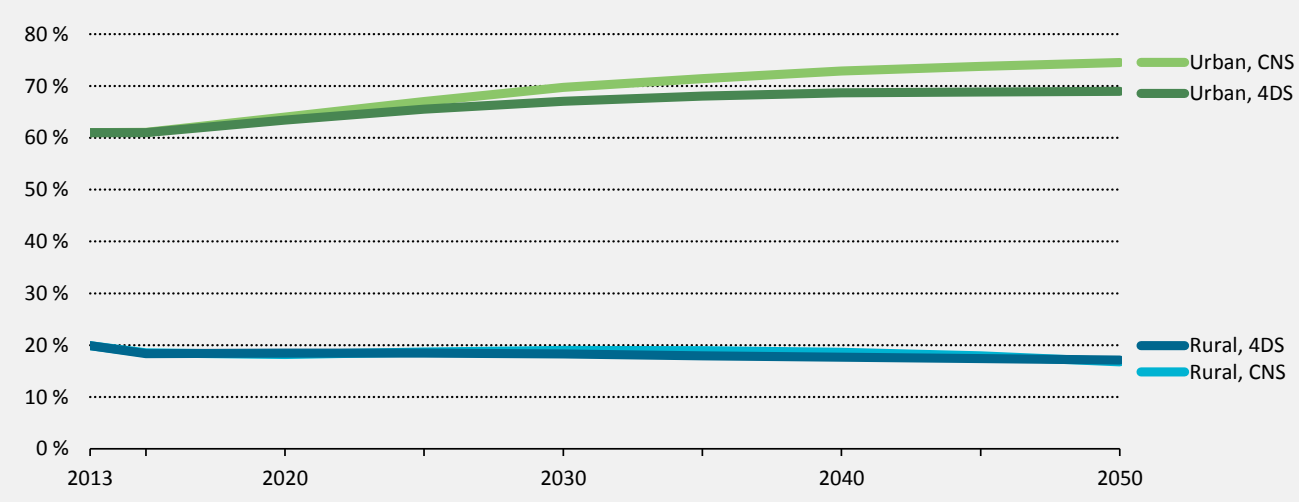

Figures and data in this report can be downloaded at www.iea.org/etp/nordic.

Key point

Urban energy systems will become highly integrated as the buildings and transport sectors optimise their supply and demand with the help of intelligent energy systems and new services. 
This share is considerably higher in the Nordic countries than in most other regions. In an average global urban area, only 26\% of final energy is delivered through electricity and heat grids. By 2050, the share is expected to increase to 36\% in an average urban area, with the European Union very close to these global averages. In 2013, only 27\% of urban final energy in the European Union was delivered though electricity and heat grids, with the share anticipated to increase to $40 \%$ by 2050 in the CNS

\section{Urban areas reduce $\mathrm{CO}_{2}$ emissions in all sectors}

Direct $\mathrm{CO}_{2}$ emissions in Nordic urban areas decrease from 2013 onwards (Figure 2.11), with a reduction of $90 \%$ by 2050 . The largest emission reductions in the CNS in urban areas are achieved in the transport sector, followed by power and heat production, industry and in transformation. Direct emissions from the buildings sector are abated already in the 4DS. Emission reductions in rural areas focus mostly on the transport sector, which is also the largest source of direct $\mathrm{CO}_{2}$ emissions in urban areas. Direct $\mathrm{CO}_{2}$ emissions from rural areas peak at 2015 and decrease after that both in the 4DS and the CNS.

\section{Figure 2.11}

Direct $\mathrm{CO}_{2}$ emission reductions in the Nordic region in the CNS as compared to the 4DS
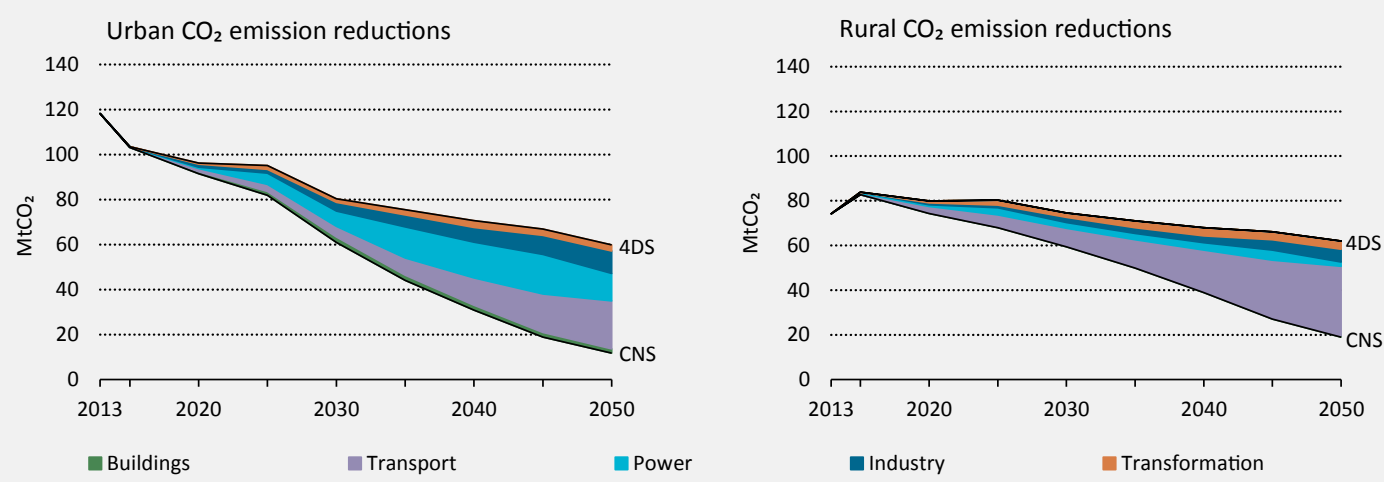

Note: $\mathrm{MtCO}_{2}=$ million tonnes of carbon dioxide.

Figures and data in this report can be downloaded at www.iea.org/etp/nordic

Key point The largest emissions reductions in the CNS are required in the transport sector, both in urban and rural areas. Emissions from the buildings sector are due to fall in the $4 D S$ due to the implementation of targets and regulations that are already in place. 


\section{Nordic capitals leading the low-carbon transition by example}

Sustainability has been integrated in the planning of many Nordic cities. Other regions' cities may learn from the success stories and challenges to sustainable urban development. This section compiles brief statistics for each Nordic capital, with case studies of Helsinki and Oslo using detailed TIMES-VTT and TIMES-Oslo models respectively².

A large proportion of the Nordic population live in the capitals. At the upper extreme is Reykjavik, where almost $40 \%$ of Iceland's population resides, with over $60 \%$ in the greater Reykjavik area. In other Nordic countries, the capital houses about 10\% of the population. In comparison, in France and Germany the capitals' share of the population stands at about 3-4\%.

There is relatively little industry in the capitals and most energy, electricity and heat are consumed in buildings and transport. In general, the Nordic capitals consume about 5-6\% of total domestic energy demand, but directly produce only 3\% of national GHG emissions. Indirectly the capitals' shares are larger, as they import electricity from other parts of the country. Reykjavik's share is higher in both (12\% of energy demand and 7\% of GHGs), but with a pattern similar to other Nordic countries. On the one hand, larger cities enable more efficient energy solutions, such as district heating and cooling, multi-storey buildings and public transport. On the other hand, all agriculture and most industry tend to be located in other areas, meaning that capitals import considerable amounts of goods and energy from the rest of the country.

All Nordic capitals have extensive district heating networks and lower emissions than the urban average in the region (Table 2.11). The share of district heating is the highest in Reykjavik, where $99.9 \%$ of buildings are heated with district heating. The lowest share of district heating is in Oslo, which has a high share of direct electric heating. The capital with the highest share of renewable energy consumption is Reykjavik, which has abundant geothermal energy. The lowest share of renewable energy is in Helsinki, which uses coal and natural gas for centralised power and heat production.

\section{Table 2.11}

\section{Comparison of Nordic capitals and urban average in the buildings} and transport sectors and energy supply

\begin{tabular}{|c|c|c|c|c|c|c|}
\hline \multirow[t]{3}{*}{2013} & \multicolumn{2}{|c|}{ Buildings sector } & \multicolumn{2}{|c|}{ Transport sector } & \multicolumn{2}{|c|}{ Energy supply } \\
\hline & $\begin{array}{l}\text { Energy demand } \\
\text { per person }\end{array}$ & $\begin{array}{r}\mathrm{CO}_{2} \text { emissions } \\
\text { per person }\end{array}$ & $\begin{array}{l}\text { Energy demand } \\
\text { per person }\end{array}$ & $\begin{array}{r}\mathrm{CO}_{2} \text { emissions } \\
\text { per person }\end{array}$ & $\begin{array}{r}\text { Share of } \\
\text { district heating }\end{array}$ & $\begin{array}{r}\text { Share of renew- } \\
\text { able energy in } \\
\text { final demand }\end{array}$ \\
\hline & GWh/perso & $\mathrm{tCO}_{2} /$ person & GWh/perso & $\mathrm{tCO}_{2} /$ perso & $\%$ & $\%$ \\
\hline Nordic urban average & 13 & 1.6 & 5.7 & 1.4 & $35 \%$ & $41 \%$ \\
\hline Copenhagen & 10 & 2.0 & 3.3 & 0.9 & $98 \%$ & $35 \%$ \\
\hline Helsinki & 14 & 1.6 & 3.9 & 1.0 & $90 \%$ & $10 \%$ \\
\hline Oslo & 16 & 0.8 & 4.5 & 1.3 & $20 \%$ & $67 \%$ \\
\hline Reykjavik & 26 & 0 & 7.9 & 1.9 & $100 \%$ & $77 \%$ \\
\hline Stockholm & 9 & 1.1 & 4.3 & 1.1 & $80 \%$ & $54 \%$ \\
\hline 2 & $\begin{array}{l}2 \text { The TIMES (The Int } \\
\text { Technology System } \\
\text { in-depth energy and } \\
\text { different, but compl } \\
\text { approach. TIMES is } \\
\text { energy system, opti } \\
\text { TIMES is used for, }\end{array}$ & $\begin{array}{l}\text { egrated MARKAL-E } \\
\text { Analysis Program, } \\
\text { environmental analy } \\
\text { mentary, systemati } \\
\text { a technology-rich, b } \\
\text { nised according to } \\
\text { the exploration of } p\end{array}$ & $\begin{array}{l}\text { OM System) model } \\
\text { an international con } \\
\text { ses (Loulou, Goldstein } \\
\text { approaches to mode } \\
\text { ttom-up model gener } \\
\text { number of user cons } \\
\text { ossible energy future }\end{array}$ & $\begin{array}{l}\text { generator was deve } \\
\text { munity which uses } \\
\text { and Noble, 2004). T } \\
\text { lling energy: a techr } \\
\text { ator, which uses line } \\
\text { raints, over medium } \\
\text { based on contrast }\end{array}$ & $\begin{array}{l}\text { oped as part of the II } \\
\text { ong-term energy sce } \\
\text { e TIMES model gene } \\
\text { cal engineering appr } \\
\text { ar-programming to } p \\
\text { to long-term time h } \\
\text { d scenarios" (Loulou }\end{array}$ & $\begin{array}{l}\text { A-ETSAP (Energy } \\
\text { larios to conduct } \\
\text { ator combines two } \\
\text { ach and an economic } \\
\text { duce a least-cost } \\
\text { rizons. In a nutshell, } \\
\text { et al., 2005). }\end{array}$ \\
\hline
\end{tabular}


The highest per-capita emissions among Nordic capitals are from district heating and electricity in Copenhagen and from transport in Reykjavik, which are both above the average for Nordic urban areas. Both Copenhagen and Helsinki have decided to stop using coal for power and heat production, which will lower the emissions of the buildings sector. Reykjavik's emissions reduction target might be more difficult to reach as electricity and heat are already derived from renewable resources.

\section{Helsinki Metropolitan Region of Finland has set ambitious targets}

The Helsinki Metropolitan Region includes the capital city of Helsinki and neighbouring cities of Espoo, Vantaa and Kauniainen. Together they are often referred to as the capital region of Helsinki. These four municipalities have adopted a common climate strategy since 2007 (HSY, 2010). The Helsinki Metropolitan Region Climate Strategy to the year 2030 seeks to reduce the region's per-capita $\mathrm{CO}_{2}$ emissions by 39\% of the 1990 level by 2030. This will mean reducing per-capita emissions by about one-third of the 2004 level by 2030. The strategy has been updated and extended in recent years to include the 2050 low-carbon target, with a GHG emission reduction of $80 \%$ corresponding to the national target. In addition, the capital region in this study includes a neighbouring mwunicipality, Kerava, which is connected to the district heating network of Helsinki, Espoo, Kauniainen and Vantaa.

The above five cities are highly interconnected. For example, public transport between the cities is highly flexible and their district heating systems are highly connected. Finland's largest international airport is sited in Vantaa, while its largest harbours are in Helsinki. It is commonplace for citizens to work and live in different cities, which increases the need for mobility. Over 120000 workers commuted to the capital region from the neighbouring municipalities in 2012 (Figure 2.12). A total of 31000 employees commuted from the capital region to neighbouring municipalities, increasing the number of commuters to 150000 . According to surveys, $48 \%$ of employees travelling to work within the capital region used private cars, while $56 \%$ of commuters into and out of the capital region used private cars.

However, there are also differences between the cities. Helsinki is the most densely populated, with blocks of flats predominant, while the other cities have more detached houses and areas of unbuilt land. Helsinki and Espoo are coastal cities, which increases the potential for offshore wind power. Finland's largest waste incineration plant is in Vantaa, where most of the burnable waste is transported from the whole capital region.

The government of Prime Minister Sipilä has set targets to phase out the combustion of coal for electricity production by 2030 and to increase the use of renewables in the transport sector to $40 \%$ by 2030. In addition, the use of imported oil should be halved from current levels and the use of domestic energy sources increased up to 55\%. All these targets will pave the way for urban energy investments and GHG mitigation. Phasing out coal will be especially challenging for Helsinki, as coal provides about one-third of its energy needs. However, several clean energy solutions are already in use in the capital region. For example, the Katri Vala heat pump plant in Helsinki is the largest in the world to produce heating and cooling. An interesting demonstration project in Espoo uses deep-hole drilling to produce district heating from ground heat. It has been estimated that ground heat from this project could cover 10\% of the district heating demand of the city of Espoo. All energy consumers in the capital region have smart metering (as in the rest of Finland), while the Kalasatama district of Helsinki is developing and demonstrating smart energy systems that include efficient urban planning, improved traffic logistics, local energy production, EV charging points and integrated district heating and cooling. 


\section{Figure 2.12 The share of employees commuting to the capital region in Finland.}

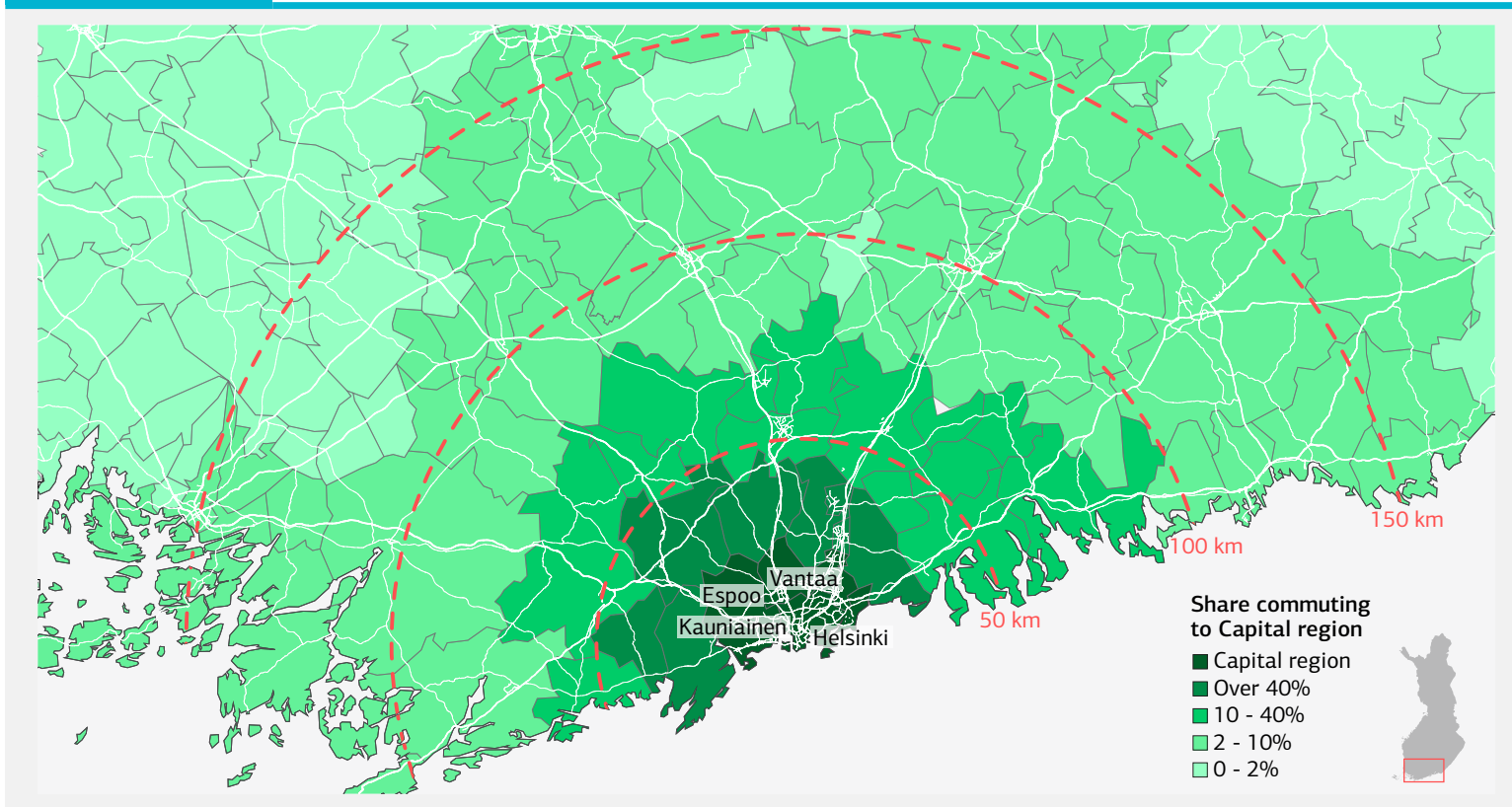

This map is without prejudice to the status of or sovereignty over any territory, to the delimitation of international frontiers and boundaries, and to the name of any territory, city or area.

Sources: Based on data from HSY (Helsingin Seudun Ympäristöpalvelut) (2015), “Katsaus pääkaupunkiseudun työmatkavirtoihin 2015”, [2015 Outlook on work related transport in the Capital Region of Finland] and Liikennevirasto (2016), Finnish Digiroad Download Service.

Figures and data in this report can be downloaded at www.iea.org/etp/nordic.

Key point

Over $40 \%$ of the workforce in neighbouring municipalities commute to the capital region for work, increasing congestion during peak hours and the amount of traffic in general.

This case study for the capital region has been modelled within the TIMES-VTT model (see Annex 1 for model description). For the purposes of this modelling, the Metropolitan Region is taken to be an agglomerate of five municipalities (Helsinki, Espoo, Vantaa, Kauniainen and Kerava), with a total population of about 1.14 million in 2015 (Table 2.12), which is about a quarter of the whole Finnish population. Kerava is included in the case study analysis because its district heating network is highly integrated with those of the other cities.

\begin{tabular}{|c|c|c|c|c|c|c|c|c|}
\hline Table 2.12 & $\begin{array}{l}\text { La } \\
\text { Re }\end{array}$ & $\begin{array}{l}\text { Id area, } \\
\text { jion (incl }\end{array}$ & $\begin{array}{l}\text { opulation } \\
\text { ding Ker }\end{array}$ & $\begin{array}{l}\text { and energy s } \\
\text { iva) }\end{array}$ & istics for & the Met & polit & \\
\hline \multirow[t]{2}{*}{ City } & Land area & \multicolumn{2}{|c|}{ Population } & \multirow{2}{*}{$\begin{array}{r}\text { Density, person } / \mathrm{km}^{2} \\
2014\end{array}$} & \multicolumn{4}{|c|}{ Final energy in 2013, TWh } \\
\hline & $\mathrm{km}^{2}$ & 2014 & $2050^{*}$ & & District heat & Electricity & Fuels & Total \\
\hline Helsinki & 214 & 621771 & 760000 & 2909 & 6.5 & 4.6 & 3.3 & 14.4 \\
\hline Espoo & 312 & 265500 & 368000 & 850 & 1.6 & 2.0 & 2.1 & 5.7 \\
\hline Kauniainen & 6 & 9139 & 12500 & 1552 & 0.1 & 0.1 & 0.1 & 0.2 \\
\hline Kerava & 31 & 35741 & 44000 & 1167 & 0.3 & 0.3 & 0.4 & 1.0 \\
\hline Vantaa & 238 & 210538 & 275000 & 883 & 1.9 & 1.8 & 1.9 & 5.7 \\
\hline Total & 801 & 1142689 & 1460000 & 1427 & 10.5 & 8.7 & 7.7 & 27.0 \\
\hline
\end{tabular}




\section{Pathways to a smart and clean Helsinki Metropolitan Region}

The development of the regional energy system has been studied under two scenarios, the Helsinki 4DS and the Helsinki CNS. The Helsinki 4DS can be viewed as a counterpart to the Nordic 4DS. However, because all energy end-use sectors are integrated in the TIMES-VTT model, and it also includes all the non-energy related GHGs listed in the Kyoto protocol, a more detailed modelling of the EU 2030 climate and energy policy package is possible. This is included in the Helsinki 4DS. The Helsinki CNS roughly corresponds to the Nordic CNS described in the Chapter 1. Here new policies are especially assumed to include strict energy efficiency standards for both new and existing buildings, and stronger support for public transport, particularly rail. In addition, a variant of the CNS has been studied, which assumes that the application of carbon capture and storage (CCS) will be limited in Europe, for example due to the poor acceptability of long-term $\mathrm{CO}_{2}$ storage and techno-economic barriers of large-scale CCS. This No Carbon Capture (Helsinki NCC) (i.e. no CCS in CNS) scenario is important to show the possible impacts of the government's targets to phase out coal and to limit the use of other fossil energy sources. Consequently, this scenario will entail still heavier reliance on variable renewable energy sources. Otherwise the assumptions in the Helsinki NCC scenario closely follow the Helsinki CNS.

\section{Figure 2.13 Final energy demand (excluding aviation) in the Metropolitan Region}

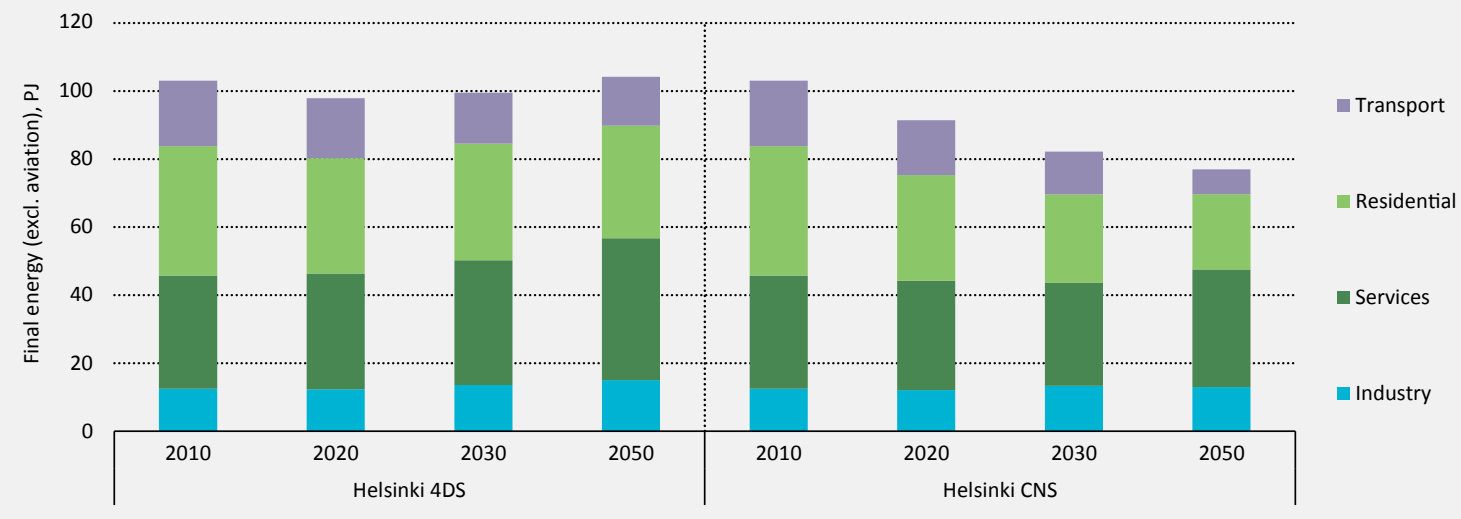

Figures and data in this report can be downloaded at www.iea.org/etp/nordic

Key point

The CNS requires a 25\% reduction in final energy from the current level by 2050. In the CNS the energy efficiency of buildings and transport increases most considerably, while the energy consumption of the service sector increases alongside higher GDP and urban population.

In the results, under the CNS overall final energy demand decreases by about 20\% by 2030 and by more than $25 \%$ by 2050 , while it increases slowly in the 4DS (Figure 2.13). In the 4DS, energy efficiency markedly increases due to 2020 and 2030 climate and energy policies set at national and EU levels, but the increase in population, floor area, and the need to transport goods and people, offset this progress. For example, the EU directives and regulations related to energy consumption in buildings and emissions of vehicles are included in the 4DS. 
However, the final burden sharing of the EU 2030 policies is not yet decided, and this will have a particular impact on GHG reductions in the transport and buildings sectors by 2030 under the 4DS. In the CNS, new clean and energy-efficient technologies are implemented in all the sectors, but the largest reductions in per-capita energy intensity take place in the transport and residential sectors. In the service and industrial sectors, final energy use may still show a small increase, largely due to the growth in economic activity in the Metropolitan Region.

Demand for space heating and hot water decreases quite dramatically due to more energyefficient buildings (Figure 2.14) both in the 4DS and CNS. In the 4DS, the EU regulation related to near-zero buildings drives the reduction. In the CNS, the renovation speed of old buildings is accelerated, such as the implementation of new and smart technologies in new building stock. In this case study it is also assumed that the building stock will be slightly different in the CNS, i.e. denser and higher buildings, which also make new solutions more competitive. Compared to 2010, demand decreases by more than $45 \%$ by 2030 and up to $55 \%$ by 2050 . Despite the declining demand, the results indicate that district heating is able to maintain its dominant share in the heat market, by taking advantage of the large existing infrastructure, synergies with district cooling, added flexibility provided by new supply options, and buffer storage integrated into the district heat network. In the CNS, the assumptions made on the building stock result in 4th generation district heating and cooling systems being more competitive as well. In all the scenarios and through the whole scenario period the share of district heating stays above $75 \%$ of final energy for heating. In the CNS and the NCC scenario, the share is even higher at approximately 85\% in 2030-50. Unlike heating demand, the demand for cooling shows a considerable increase in all scenarios and a large part of it is satisfied by district cooling.

\section{Figure 2.14}

Final energy for residential and service sector heating in the Metropolitan Region

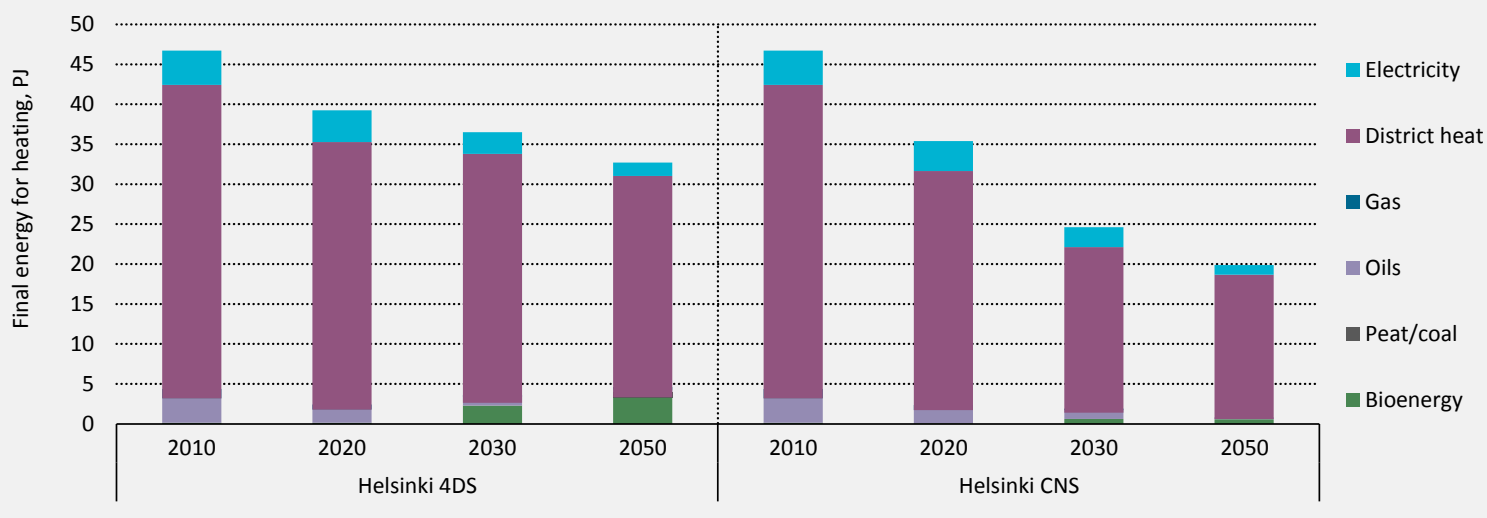

Figures and data in this report can be downloaded at www.iea.org/etp/nordic. 
Despite the limited availability of biomass resources in the Metropolitan Region, an increasing share of district heating and cooling is produced from renewable energy sources (Figure 2.15). Biomass and biofuels are mainly imported into the Metropolitan Region from other regions in Finland, although some biomass from Russia and biofuels from global markets will be imported in the CNS and NCC scenario ( 7 P) in 2050).

In addition to renewable bioenergy and waste, by 2050 both scenarios show a large contribution from heat recovery sources, which include ambient heat and excess heat utilised in utility-scale heat pumps connected to the network. Figure 2.15 also shows the NCC scenario, which includes one of the excess heat options for the Metropolitan Region, which uses lowgrade heat from the Loviisa nuclear power plant, situated about $80 \mathrm{~km}$ east of the region. In the CNS some fossil co-generation with CCS is shown in 2050, which is largely replaced with excess nuclear heat in the NCC scenario and also with increased investment in heat pumps. Policy makers, experts and the public have varying opinions on district heating from nuclear power. Here it is modelled as a technical option.

\section{Figure 2.15 Heat production in the Metropolitan Region by fuel used}

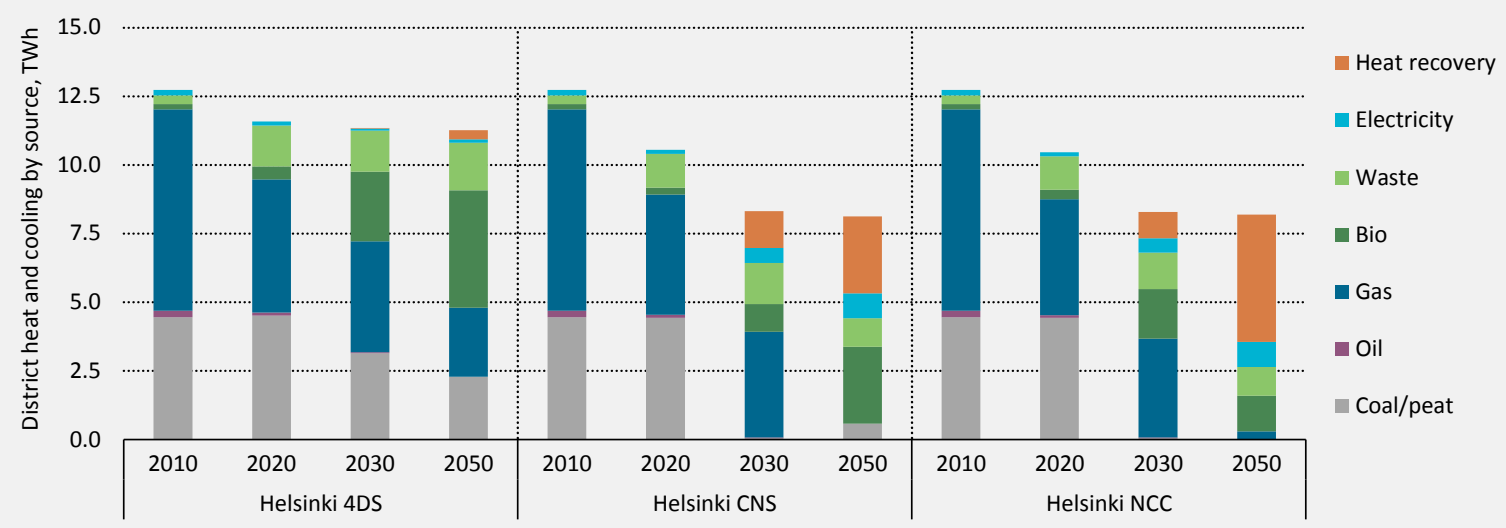

Note: In the NCC scenario fossil-fuelled co-generation is replaced with excess heat from the Loviisa nuclear plant and heat pumps. Figures and data in this report can be downloaded at www.iea.org/etp/nordic

Key point The variety of fuels and heat sources increases markedly in the long term in all scenarios as fossil fuels are phased out.

Electricity consumption has been increasing relatively rapidly in the Metropolitan Region over the past few decades. In the scenarios the growth trend resumes after the current stagnation, even though there is a major shift to new clean technologies (Figure 2.16). This is driven by the considerable increase in population, economic activity and income levels. Electricity consumption is projected to grow particularly in the service sector, due to increasing floor area.

In contrast, greater efficiency in applications and decreasing amounts of electricity for heating reduce electricity consumption, in particular in the CNS and NCC scenario. For example, light-emitting diode (LED) lighting and low-energy refrigeration and office equipment become dominant in these scenarios. Comparing electricity consumption in the 4DS with the CNS 
and NCC scenario, the difference is less than 10\%, indicating that a large share of these investments are already cost-competitive in the 4DS, as indicated above.

\section{Figure 2.16 Electricity consumption by sector in the Metropolitan Region}

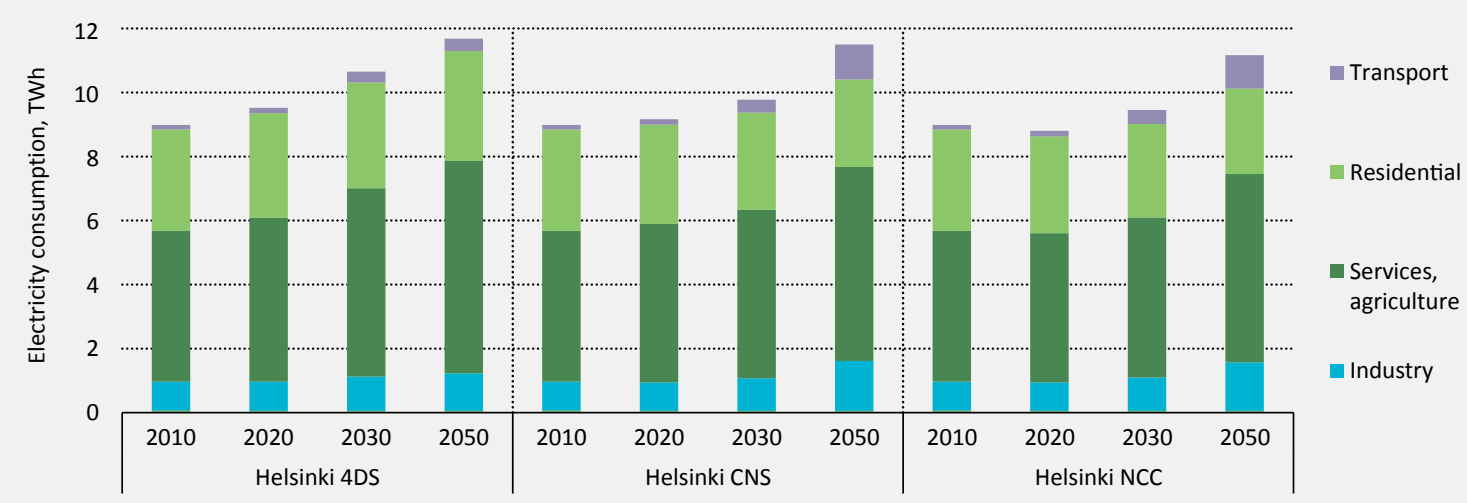

Figures and data in this report can be downloaded at www.iea.org/etp/nordic.

Key point Electricity consumption shows an increasing trend in the long term due to increased population and GDP, and electrification of the urban energy system. Service sector electricity demand is already the largest and its dominance becomes even more significant in the long term.

The self-sufficiency of the Metropolitan Region in the supply of electricity is likely to decrease for multiple reasons (Figure 2.17). First, the estimated techno-economic potential of renewable resources in the region is insufficient to both replace the existing electricity sources and cover new demand. In addition, many renewable energy sources, such as biomass and wind, have larger potential and are cheaper to exploit outside the region. Electricity is also increasingly imported from the Nordic markets, especially in the NCC scenario. However, in these scenarios no additional subsidies were introduced for solar or wind generation and therefore renewable electricity's share could be higher than that presented.

Even without subsidies, the breakthrough in solar occurs around 2030, and by 2050 about $90 \%$ of the total estimated rooftop potential of the Metropolitan Region is utilised for solar panels in the NCC scenario, where all the fossil-fuelled co-generation is phased out. Southern Finland, southern Sweden and Denmark have the best solar irradiance and grid parity will be reached somewhat later in the other areas of Finland. Considering the recent trend of very rapidly decreasing costs of PV panels and related systems it is, however, very challenging to model and analyse the role of solar in the national energy balance, including urban regions. New renewable hybrid solutions and flexibility options could increase the competitiveness of solar even further. In addition, the willingness of private citizens to pay for their own solar installations could also speed investment.

Solid biomass can be imported to the Metropolitan Region from rural Finland, but can also be consumed elsewhere in Finland, avoiding the high costs of long-distance transport. It could also be imported from international markets, but the increasing price of imported solid 
biomass limits its use in the Metropolitan Region in the CNS and NCC scenario. Interestingly, in the 4DS the lower price of solid biomass due to lower demand (less bioliquids in transport) results in solid bioenergy being a more attractive option for co-generation in the region.

The results thus indicate that the Metropolitan Region would become increasingly dependent on electricity imports without policies to support its own production. This is due to the fact that biomass is more abundant outside the region, where the investment conditions for wind are also better. This also means that the role of large-scale co-generation as a highly energyefficient solution to the metropolitan energy supply could decline due to higher costs of biomass supply, increasing the importance of distributed energy production even in the city region.

Nonetheless, given that the electricity imported from the rest of Finland or other Nordic countries would also essentially be carbon-free in the CNS and NCC scenario, the emissions from imported electricity would have little effect on the GHG balance even if allocated to the region (Figure 2.17). In fact, even today the municipal energy companies of the Metropolitan Region have notable shareholdings in electricity generation outside the area, which is an important part of their electricity supply portfolio.

\section{Figure 2.17 Metropolitan region electricity supply by energy source}

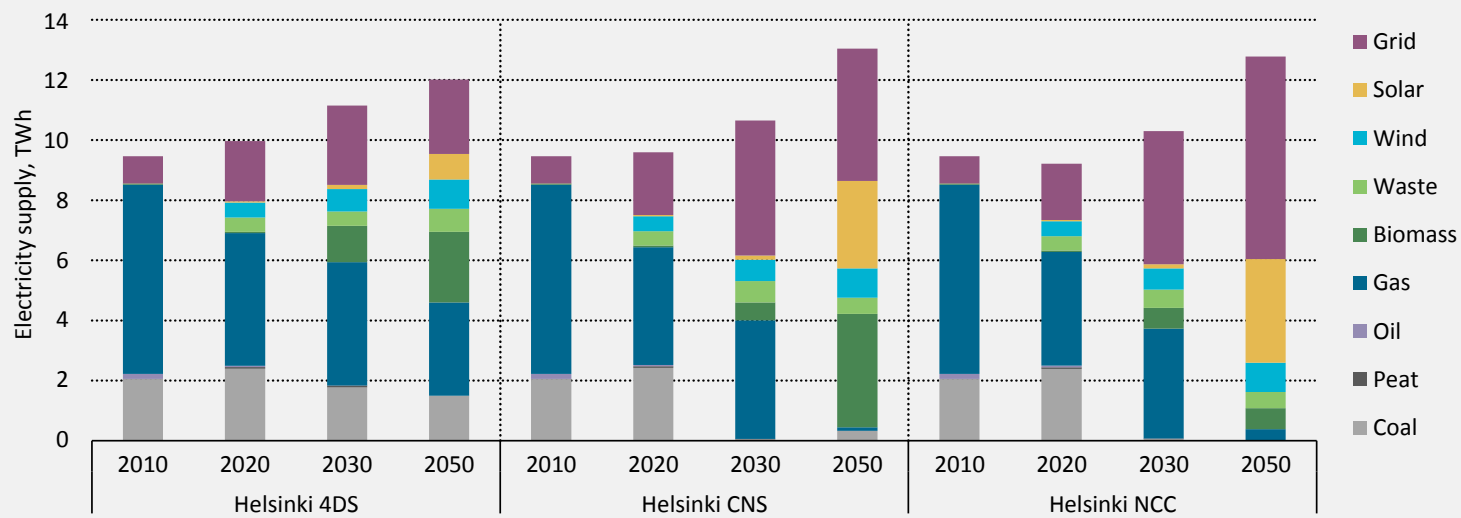

Note: Gas category includes biogas.

Figures and data in this report can be downloaded at www.iea.org/etp/nordic

Key point

The Metropolitan Region becomes increasingly dependent on electricity imports. By 2050 combustible fuels, i.e. both fossil and biomass, are burned almost entirely with CCS technology.

The transport sector is the second most important source of GHG emissions in the Metropolitan Region, after heating. The CNS requires huge efficiency improvements through extensive electrification of passenger transport, with freight moving to hybrid and biofuel vehicles (Figure 2.18). Fuels used in domestic or international aviation are excluded from the analysis. The results indicate that transport final energy in the capital region could be reduced by $20-30 \%$ by 2030 , and even $30-60 \%$ by 2050 , compared to current levels through tightening emissions reduction targets and assumed lower costs of new efficient 
technologies, such as electric, hybrid and fuel-cell vehicles. The highest reductions are observed in the CNS and NCC scenarios but the EU 2030 policies, which are included in the 4DS, would also have an impact on development by 2030 .

\section{Figure 2.18}

\section{Final energy in transport (excluding all aviation) in the Metropolitan Region}

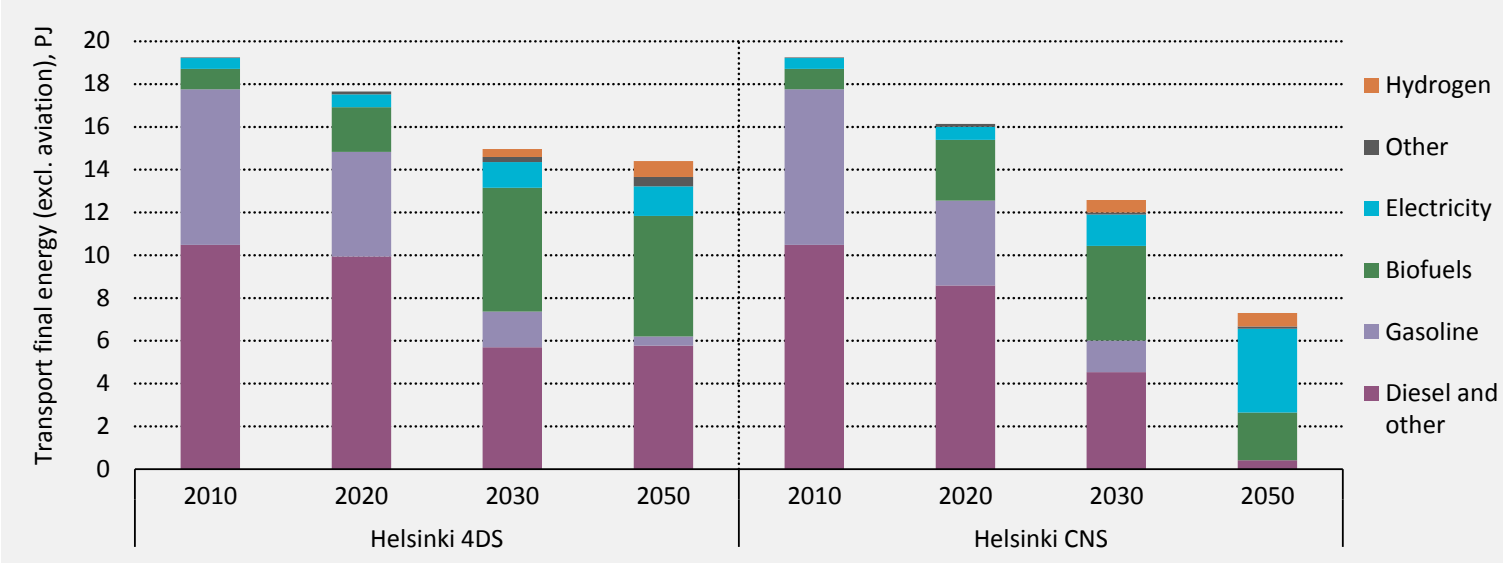

Note: Other includes natural gas and biogas.

Figures and data in this report can be downloaded at www.iea.org/etp/nordic.

Key point

Energy efficiency of mobility increases dramatically due to renewal of the transport stock with new high-efficiency vehicles, especially EVs. In addition, increased public transport use, cycling and walking would be needed to decrease the use of final energy in urban mobility.

The results also indicate that biofuels will be the most important energy source for transport by 2030 , but by 2050 mobility in the Metropolitan Region is highly electrified with a share of transport final energy above a 50\% share. Looking at demand for personal mobility, EVs would account for about $75 \%$ of metropolitan passenger car and bus transport in 2050 , with the expansion of the rail network bringing a further shift to electricity. In this case study 2 nd generation biofuels produced from domestic wood resources become competitive largely due to EU 2030 climate and energy policies and also because of the new national renewables targets for transport (40\% in Finland in 2030). These 2nd generation biofuels are so-called drop-in fuels, i.e. they may be used up to $100 \%$ in the existing vehicle fleet, which makes them a cost-effective solution by 2030. Looking at the results at national or Nordic levels, it is clear that 2nd generation biofuels dominate while the share of EVs is much lower (see Chapter 1), because long-distance freight, shipping and aviation are run with drop-in biofuels.

The GHG emissions of the Metropolitan Region decrease to 50\% below the 2010 level by 2050 even in the 4DS, thanks to EU 2030 policies and nationally decided policy measures (Figure 2.19). In the Helsinki CNS, bioenergy with carbon capture and storage (BECCS) would have a notable role in achieving negative emissions by combining the use of bioenergy with CCS in a large central co-generation plant for the region. However, even without the help of 
CCS, carbon neutrality also appears achievable in the Helsinki NCC scenario, albeit requiring larger imports of electricity.

\section{Figure 2.19 GHG emissions by sector in the Metropolitan Region}

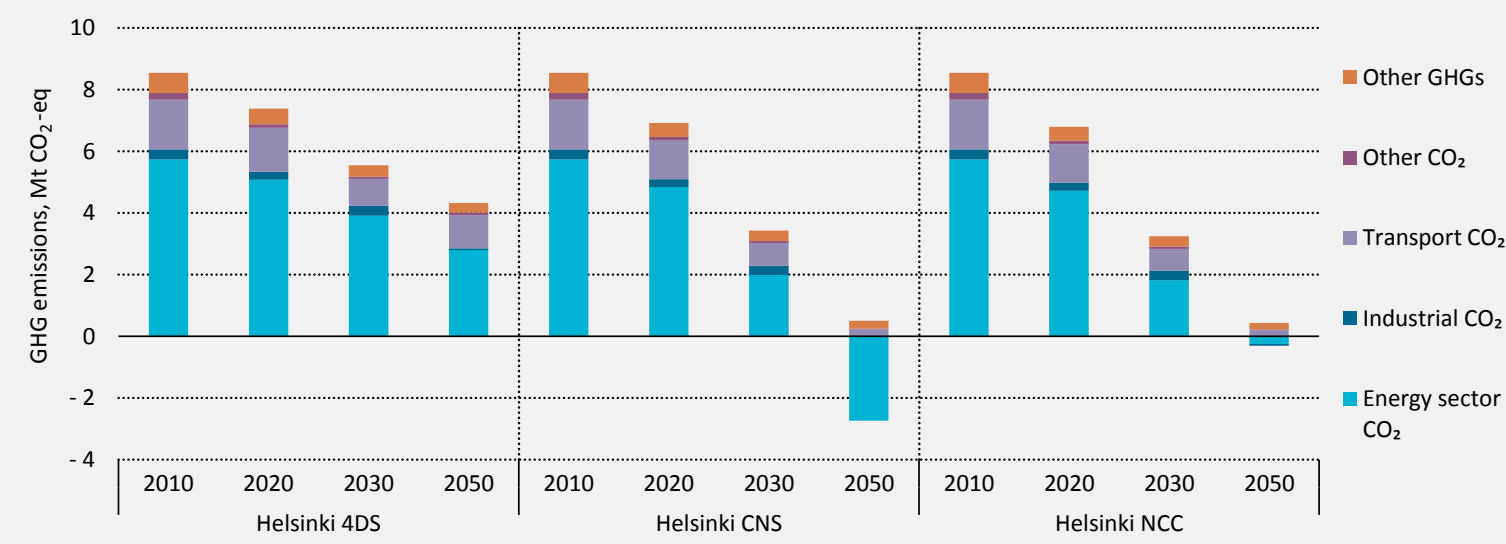

Note: It is assumed that BECCS enables negative emissions.

Figures and data in this report can be downloaded at www.iea.org/etp/nordic

Key point

The Metropolitan Region has a key role to play in reaching the national CNS targets. The largest $\mathrm{CO}_{2}$ source today, energy production, should become carbon neutral or even carbon negative, while the other emitting sectors also need to reach near-zero targets to ensure that national CNS targets are reached.

\section{Analysis of climate and energy measures for Oslo}

The city of Oslo has in recent years worked towards ambitious climate targets: to ensure public transport is climate neutral by 2020; to reduce $\mathrm{CO}_{2}$ emissions from fossil energy sources by $50 \%$ by 2020 ; and to become carbon neutral by 2050 . The new city council, which was elected in September 2015, updated the climate targets on 18 February 2016 to become even more ambitious: to reduce GHG emissions by $50 \%$ by 2020 , and by $95 \%$ by 2030 (compared to 1990 levels). These new targets have not been included in the case study for Oslo shown below.

Oslo has introduced "the Green Change", which implies addressing climate change challenges by changing the way energy is produced and used in the city, a transition to a renewable and sustainable society, and a focus on innovation, implementation of new technologies and using existing systems in new and innovative ways.

Oslo is a small city in a global context. However, the city council wants to focus on how cities can take responsibility for the development of sustainable energy systems for the future, and to show how cities can take leadership in the green transition and contribute with innovative ideas and solutions. Thus, Oslo, together with Stockholm and Copenhagen, has been an active partner in C40 (www.C40.org), which is a network where cities can collaborate, share knowledge and drive meaningful, measurable and sustainable action on climate change. 
The city of Oslo has developed a climate and energy strategy (Oslo-Kommune, 2015), which was recently strengthened. The strategy focuses on urban development through the planning of urban areas around public transport hubs, the building of new infrastructure for renewable transport fuelling (battery charging, hydrogen and biofuels), preparing for fossilfree transport (freight, public and private transport), increasing the use of public transport, cycling and walking, contributing to the increased utilisation of local energy resources, both for heating and electricity, and implementation of energy efficiency measures. The climate and energy strategy for Oslo has been developed in a process where the municipality involved more than 40 stakeholders from business, government and the local community.

\section{Energy system characteristics}

Oslo is the capital of Norway and is also the most populous city in the country. It constitutes both a county and a municipality, and is the economic and governmental centre of Norway. As of January 2015, the population of the city of Oslo exceeded 647000 (Table 2.13) (Statistics Norway, 2015a), with almost the entire population living in urban settlements. In addition, the metropolitan area of Oslo (referred to as the Greater Oslo region) has a population of just above 1500000 .

\section{Table $2.13 \quad$ Key figures for Oslo}

\begin{tabular}{|c|c|c|c|c|c|c|c|c|}
\hline \multirow[t]{2}{*}{ City } & \multirow{2}{*}{$\begin{array}{l}\text { Land area } \\
\mathrm{km}^{2}\end{array}$} & \multicolumn{2}{|c|}{ Population } & \multirow{2}{*}{$\begin{array}{l}\text { Density, } \\
\text { person/km² } \\
2015\end{array}$} & \multicolumn{4}{|c|}{ Final energy in 2010, TWh } \\
\hline & & 2015 & 2040 & & Electricity & $\begin{array}{l}\text { Fossil } \\
\text { fuels }\end{array}$ & $\begin{array}{l}\text { Biomass } \\
\text { and waste }\end{array}$ & Total \\
\hline Oslo & 454 & 647676 & 833733 & 1427 & 8.6 & 4.3 & 1.5 & 14.4 \\
\hline
\end{tabular}

Oslo has a varied economy, with enterprises covering several sectors. The number of employees is highest in the service sector at $90 \%$ of the workforce, with $6 \%$ of employees employed in the construction sector, $4 \%$ in various industrial sectors, and only $0.8 \%$ in primary industries.

The city's direct $\mathrm{CO}_{2}$ emissions have been slowly increasing, from $1 \mathrm{MtCO}_{2}$ in 1991 to $1.2 \mathrm{MtCO}_{2}$ in 2013. The transport sector accounts for more than half of Oslo's $\mathrm{CO}_{2}$ emissions. In recent years, the city has seen the large-scale rollout of charging stations for EVs (Figure 2.20). 


\section{Figure 2.20 Map of the Oslo area with public EV charging points}

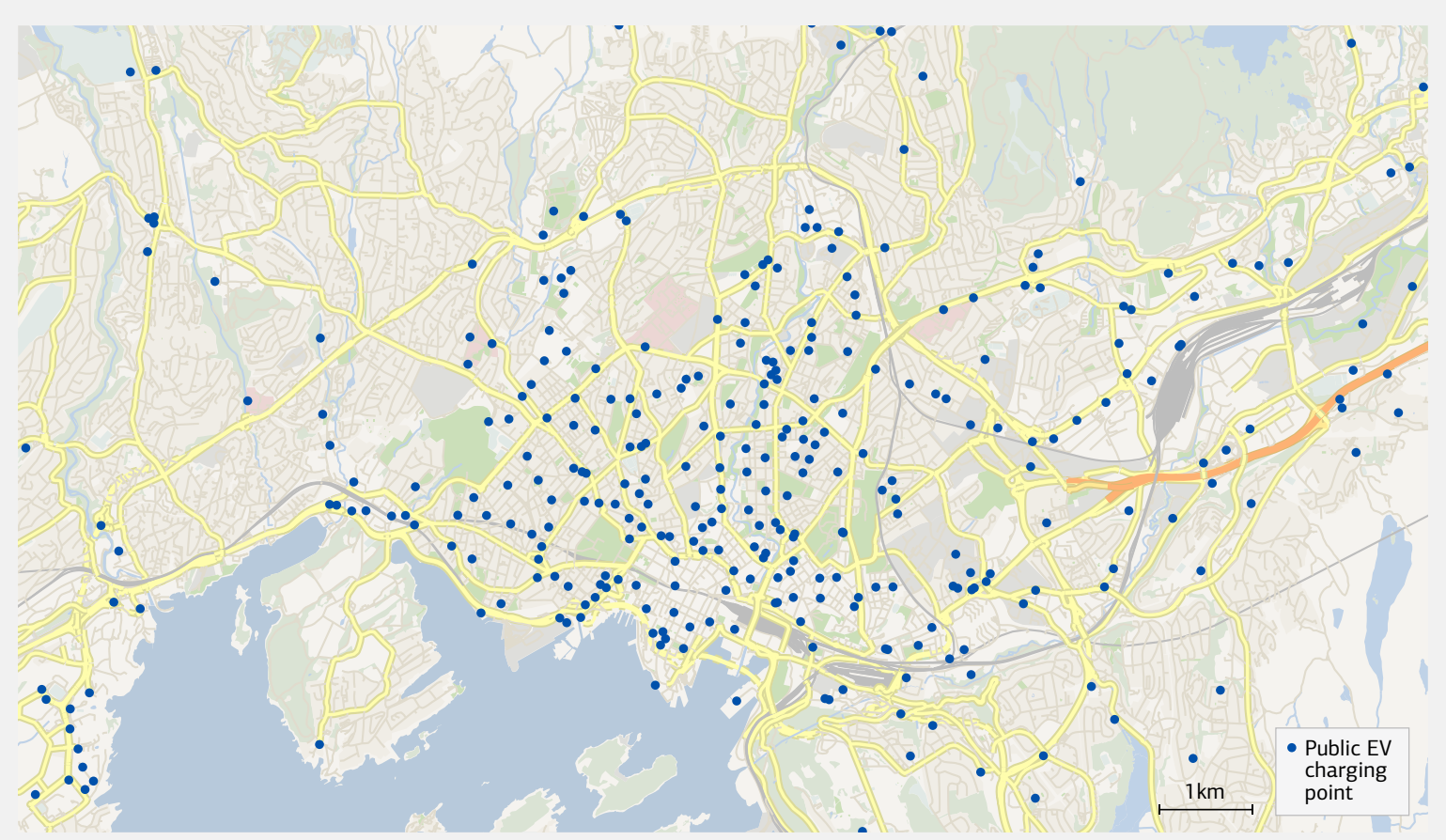

Notes: Blue dot indicates location of charging points for EVs. This map is without prejudice to the status of or sovereignty over any territory, to the delimitation of international frontiers and boundaries, and to the name of any territory, city or area.

Source: Data from www.ladestasjoner.no, accessed March 2016. Base map from OpenStreetMap and OpenVectorMaps.

Figures and data in this report can be downloaded at www.iea.org/etp/nordic.

Key point

Oslo is world-leading in EV roll-out. As of March 2016, Oslo had 1996 public EV charging points, a quarter of the national total and one for every 330 residents in the city

Future energy demand for the city of Oslo is projected to increase by 40\% from 2010 to 2050, due to population growth. As shown in Figure 2.21, households and services dominate energy consumption. Energy consumption related to heat production in district heating plants is included under industry in Figure 2.21. The energy consumption of the transport sector was 2.7 TWh in 2010, comprising all types of transport modes relevant to the city, including road, rail and navigation. Oslo harbour is an important part of the transport system, with domestic and international ferries for passenger transport and a large terminal for freight. Of the energy consumption in the transport sector, 89\% was based on fossil fuels and around $9 \%$ on electricity. The latter was mostly utilised for rail transport, but a small part was used in EVs. 


\section{Figure 2.21}

Energy consumption for the city of Oslo in 2009 for various enduse sectors

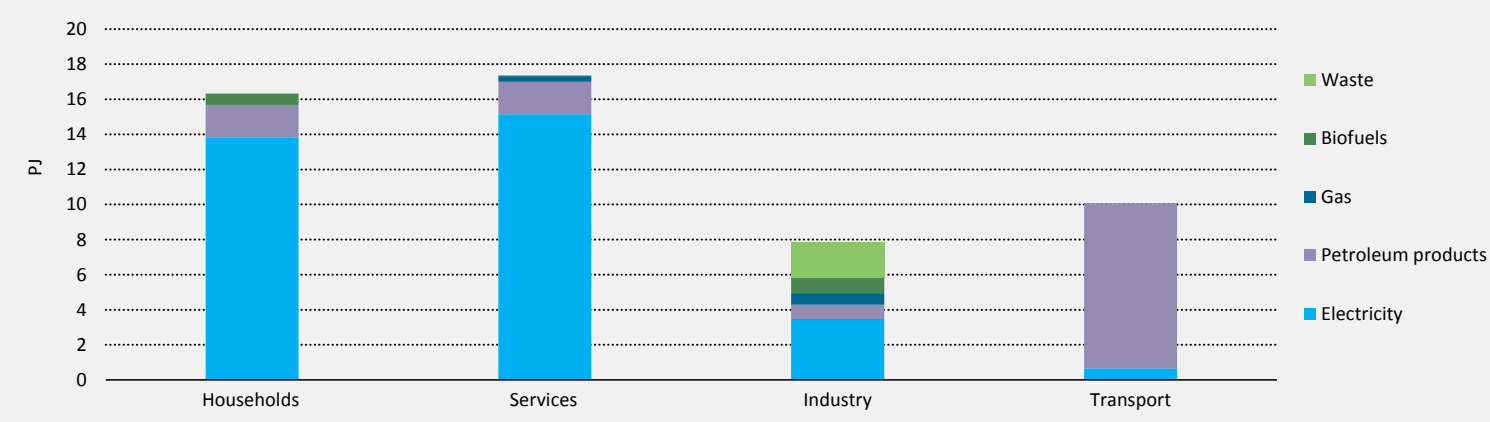

Source: Oslo commune and Statistics Norway.

Figures and data in this report can be downloaded at www.iea.org/etp/nordic.

Key point

Households and services are the two dominant sectors, while the transport sector is dominated by fossil fuels.

Energy production within Oslo is limited to the following:

- one small hydropower plant, with an installed capacity of 5 megawatts (MW), and an annual power output of $16 \mathrm{GWh}$

- a co-generation plant based on waste, with a maximum annual output of $160 \mathrm{GWh}$

- 12 district heating plants with a combined annual output of 1.7 TWh (providing 20\% of Oslo's heating demand)

- limited electricity production from solar PV.

Other local resources within the city boundary include 4 GWh from straw, 25 GWh from biomass from forestry, biogas produced from food waste which can fuel $150-200$ buses in Oslo, and biomethane.

\section{Analysis with TIMES-Oslo model}

The TIMES-Oslo model has been used in two alternative modes to analyse the transition to a sustainable urban area. The first approach consisted of running several measures, one at a time, in order to investigate each measure's impact on $\mathrm{CO}_{2}$ emissions and energy consumption in Oslo. The second approach consisted of using the full technological richness provided by the TIMES-Oslo optimisation model to analyse the impact of the CNS on Oslo. This second alternative corresponds to the analysis of the Helsinki Metropolitan Region earlier in this chapter.

Following the format of the energy and climate strategy for the city of Oslo, five focus areas were identified:

- urban development, including planning of urban areas and public transport hubs

- infrastructure, including energy stations for renewable fuels in transport (e.g. battery charging, hydrogen and biofuels)

- transport, with a focus on green transport fuels and reduced use of private cars 
- buildings, with a special focus on prohibiting the use of fuel oil and implementation of energy efficiency measures

- energy production and distribution, including new infrastructure for central heating and optimal utilisation of local energy resources.

The TIMES-Oslo model has been used to analyse a reference scenario (Oslo 4DS), the impact of various climate and energy measures on the local energy system, and the impact on $\mathrm{CO}_{2}$ emission reductions.

\section{Oslo 4DS (reference scenario)}

The Oslo 4DS is used to illustrate the effects of analysed policies and measures. The Oslo 4DS does not quite correspond to the Nordic 4DS scenario in this publication; despite these differences, the reference scenario for Oslo is called the 4DS. In the Oslo 4DS, total $\mathrm{CO}_{2}$ emissions in Oslo increase from 1.17 Mt in 2010 to $1.46 \mathrm{Mt}$ in 2050. The contribution of the transport sector becomes more dominant in the future under this scenario (increasing from approximately 50\% to 60\%). This is due to the projected demand for transport, which increases relatively more than stationary demand. In the Oslo 4DS, the implementation of new technologies is restricted for existing buildings. Energy demand under the reference scenario increases from 14 TWh in 2010 to almost 20 TWh in 2050. Electricity is the dominant energy carrier in Oslo, representing 60\% of final energy use in 2010.

\section{Climate and energy measures}

For this analysis, 12 different measures have been developed and analysed using the TIMESOslo model to investigate their impact relative to the five focus areas. A more detailed description of the measures can be found in Annex 1.

\section{Transport:}

- T1: limit the use of private cars by restrictions on the use of road network, limiting parking and increased taxes

- T2: improved infrastructure for public transport

- T3: establishment of new infrastructure for renewable transport fuels

- T4: support schemes for implementation of renewable transport fuels

- T5: introduction of a procurement scheme for renewable transport services

- T6: transfer of freight transport from road to rail and ship.

Buildings:

- B1: prohibition on use of fossil fuels for heating from 2020

- B2: regulatory measures to ensure areas for new energy solutions

- B3: support schemes for passive houses

- B4: financial support for energy efficiency measures.

Energy sector:

- E1: stimulation of renewable energy production from local resources

- E2: energy storage in buildings. 
The $\mathrm{CO}_{2}$ emissions and energy consumption for the most promising of the analysed measures are ranked and presented in Figure 2.22. Each measure is analysed independently, and if applied together their effects would interact and would not be the sum of their individual effects. Prohibition on use of fossil fuels for heating (B1) results in the greatest reduction in emissions with a reduction of $0.49 \mathrm{Mt}$ (more than 35\%) in 2050 compared to the Oslo 4DS.

\section{Figure 2.22}

\section{Relative $\mathrm{CO}_{2}$ emissions and energy consumption of various measures compared to the 4DS for 2050}

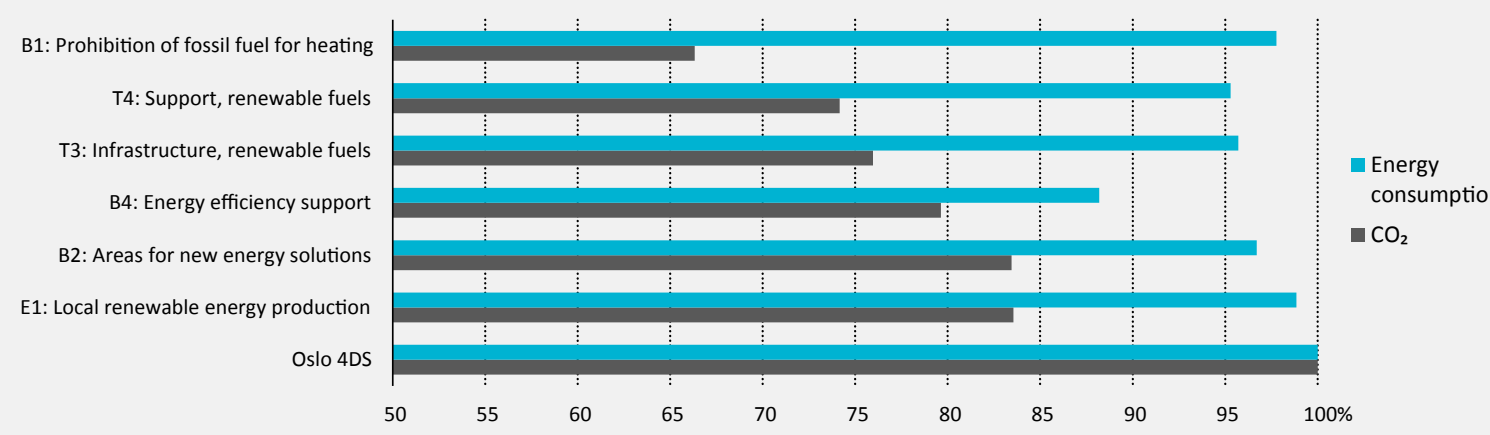

Note: Relative share (along the $\mathrm{x}$-axis) begins from $50 \%$.

Figures and data in this report can be downloaded at www.iea.org/etp/nordic.

Key point

Prohibition on use of fossil fuels for heating is the single measure that contributes most to reduced $\mathrm{CO}_{2}$ emissions.

Support schemes for implementation of renewable transport fuels (T4) are also important when considering $\mathrm{CO}_{2}$ emission reductions, resulting in a reduction of $0.38 \mathrm{MtCO}_{2}$ by 2050 compared to the 4DS. In 2050, energy consumption related to transport with T4 reaches $3.0 \mathrm{TWh}$, a decrease of 0.9 TWh compared to the 4DS. Various fossil fuels make up $61 \%$ of this consumption, electricity $26 \%$, biofuels $7 \%$, and hydrogen $6 \%$.

Establishing infrastructure for renewable transport fuels (T3) implies a reduction of $0.35 \mathrm{MtCO}_{2}$. Compared to the 4DS, a reduction in energy consumption of 0.9 TWh is achieved in 2050 for the transport sector. The reduction is related to increased use of EVs for short-distance travel, as well as the use of plug-in hybrids for long-distance travel.

Financial support for energy efficiency measures (B4) generates the greatest reduction in energy consumption of all 12 measures in 2050. For households, a reduction of 1.4 TWh in 2050 is achieved, while for the service sector, a reduction of 0.9 TWh is achieved in 2050 compared to the 4DS. Energy efficiency measures are implemented in order to reduce heating demand, cooling demand and electricity consumption. In this analysis approximately $25 \%$ of the theoretical energy efficiency potential is implemented. By increasing financial support, a higher share of this potential can be utilised, thereby reducing the energy consumption even further.

\section{Oslo CNS}

Further analysis was carried out using the TIMES-Oslo model. Called CNS, it roughly corresponds to the Nordic CNS in this publication. At the Oslo level, the analysis includes overall emission constraints in 2020 and 2050: 50\% emissions reduction in 2020, and 87\% reduction in 2050. 
No alternative technologies or substitution options are applied in the model to eliminate emissions related to agriculture and construction in 2050. On this basis, it is not feasible to achieve $\mathrm{CO}_{2}$ emissions below $0.15 \mathrm{Mt}$ (a 90\% emissions reduction) with the current version of TIMES-Oslo.

Figure 2.23 presents the limitation on GHG emissions that is used in the CNS. The figure also shows the relative contribution of emissions from the various end-use sectors. The relative share of emissions varies over the analysed period; however the transport sector and the district heating sector are the main contributors.

\section{Figure 2.23 GHG emissions in the CNS, by sector, 2010-50}

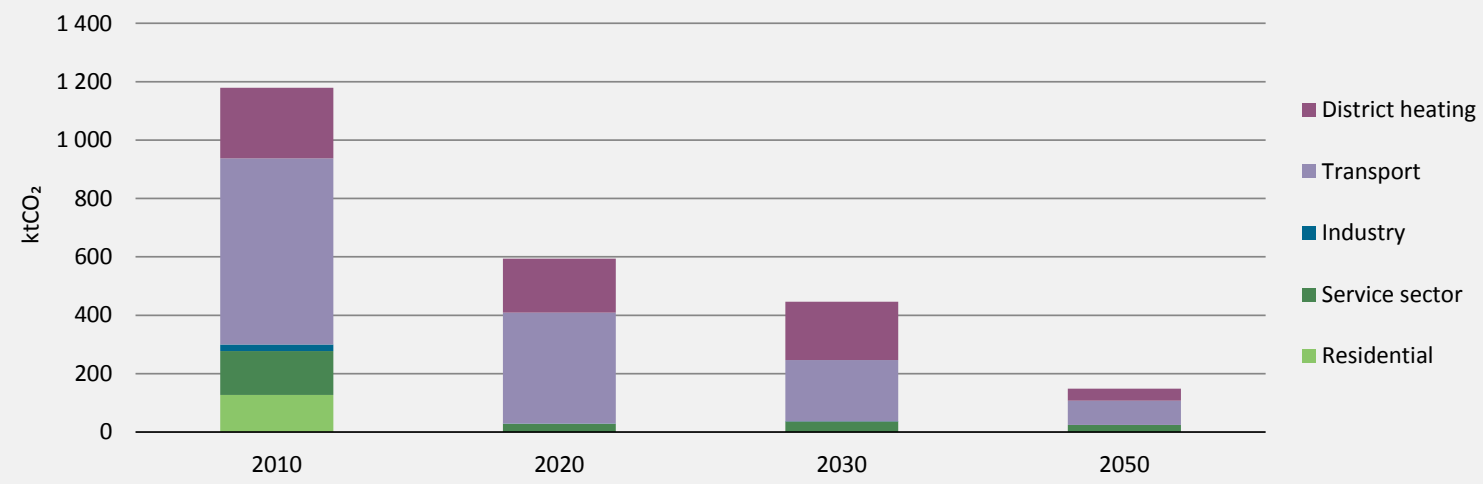

Figures and data in this report can be downloaded at www.iea.org/etp/nordic

Key point Even though its emissions decrease, the transport sector continues to be the main contributor to $\mathrm{CO}_{2}$ emissions in the future.

Figure 2.24

Total final energy consumption by energy carrier in 4DS and CNS, 2010-50

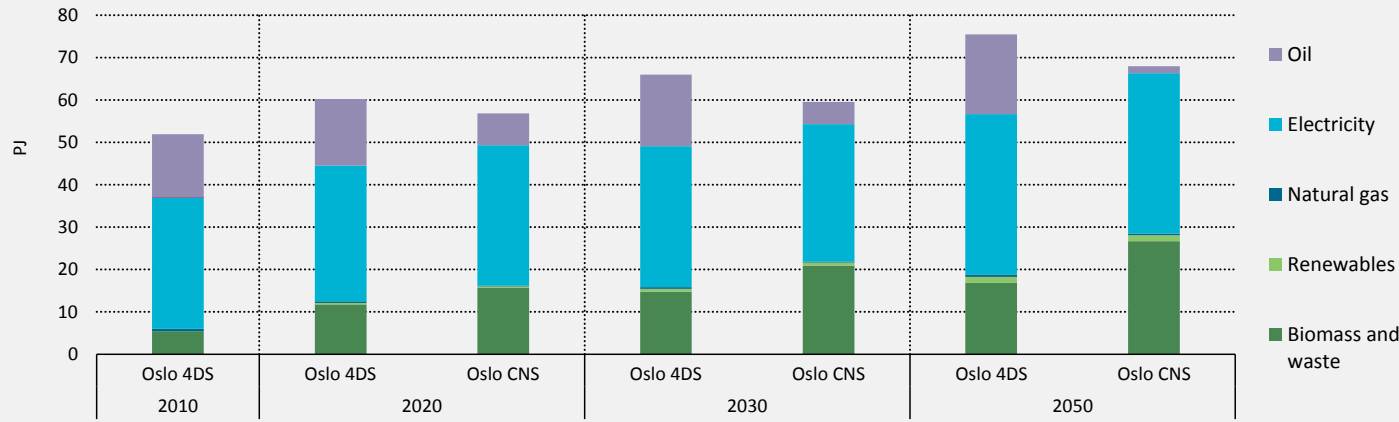

Figures and data in this report can be downloaded at www.iea.org/etp/nordic

Key point In the CNS the use of fossil fuels is gradually phased out and replaced by biomass and waste. 
Final energy consumption in Oslo increases from 14.4 TWh (51.8 PJ) in 2010 to 21 TWh in the 4DS and 18.9 TWh in the CNS in 2050. The reduced final energy consumption in the CNS compared to the $4 \mathrm{DS}$ is due to the use of more energy-efficient technologies in all sectors, but especially in the transport sector. The use of biomass and waste increases, while the use of petroleum products decreases significantly in the CNS compared to the 4DS (Figure 2.24).

Electricity consumption by sector in the 4DS and CNS is shown in Figure 2.25. In total, electricity consumption increases from 8.6 TWh in 2010 to 10.5 TWh in 2050. The main difference between the $4 \mathrm{DS}$ and CNS is electricity use in the residential sector, where electricity consumption is lower under the CNS, and in transport, where electricity consumption is higher.

\section{Figure $\mathbf{2 . 2 5}$ Electricity consumption by sector}

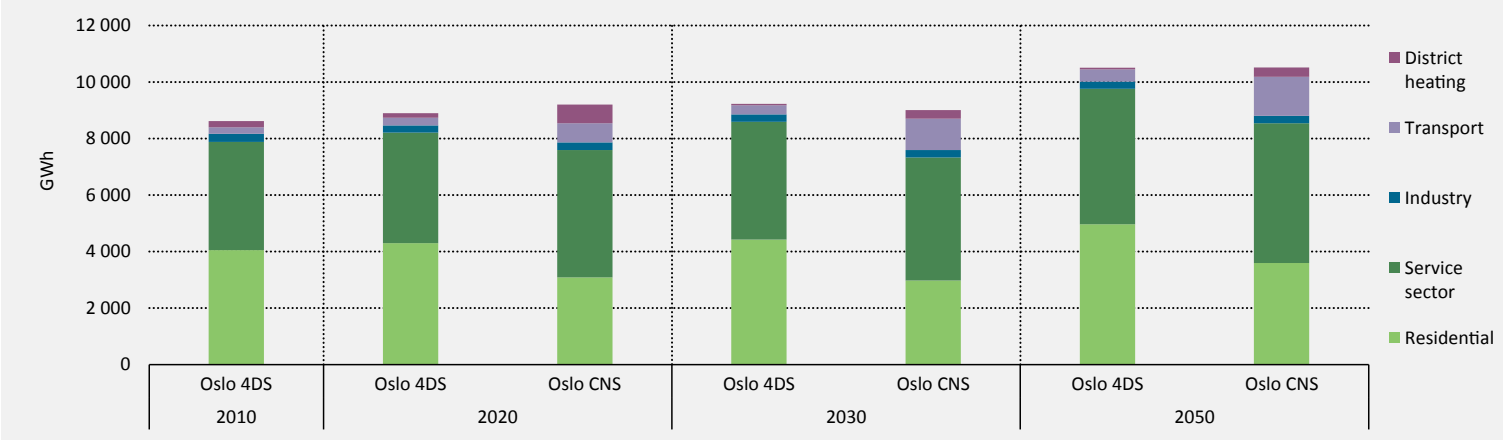

Figures and data in this report can be downloaded at www.iea.org/etp/nordic.

In the 4DS energy use in the residential sector increases from 19.8 PJ (5.5 TWh) in 2010 to 28.4 PJ (7.9 TWh) in 2050, with only a slightly smaller increase, to 27.4 PJ (7.6 TWh), in the CNS. In the CNS, the use of petroleum products for heating purposes in stationary applications (households and the service sector) is prohibited, and therefore the use of more efficient technologies in district heating, biomass and waste increases. In the CNS, the energy carriers for district heating are predominantly biomass and waste, with only a small share of electricity in heat pumps. In the 4DS oil continues to have a share in district heating in 2050. Figure 2.26 shows the energy consumption in the residential sector by energy carrier under the two scenarios. 


\section{Figure 2.26 Energy consumption in the residential sector by energy carrier}

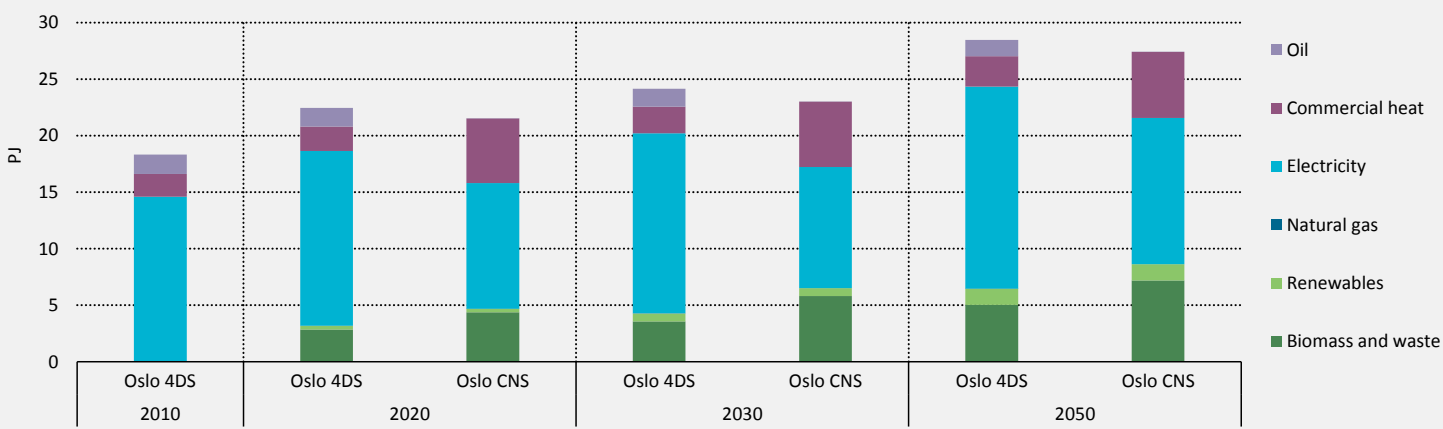

Figures and data in this report can be downloaded at www.iea.org/etp/nordic

Key point

To meet the emissions target, the use of biomass and district heating increases in the residential sector.

In the 4DS energy use in the transport sector increases form 9.7 PJ (2.7 TWh) in 2010 to 14 P) (3.9 TWh) in 2050, while it decreases to 8.3 P) (2.3 TWh) in the CNS, as illustrated in Figure 2.27. As the transport sector is the most important source of $\mathrm{CO}_{2}$ emissions in Oslo, this sector undergoes significant changes in the CNS, showing huge efficiency improvements through electrification. The use of electricity for transport is almost evenly divided between personal cars, lorries for freight and train, tram and metro. Freight uses a combination of electric, hybrid and biofuel vehicles (fuels used in domestic and international aviation are excluded).

\section{Figure 2.27 Use of energy carriers in the transport sector, aviation excluded}

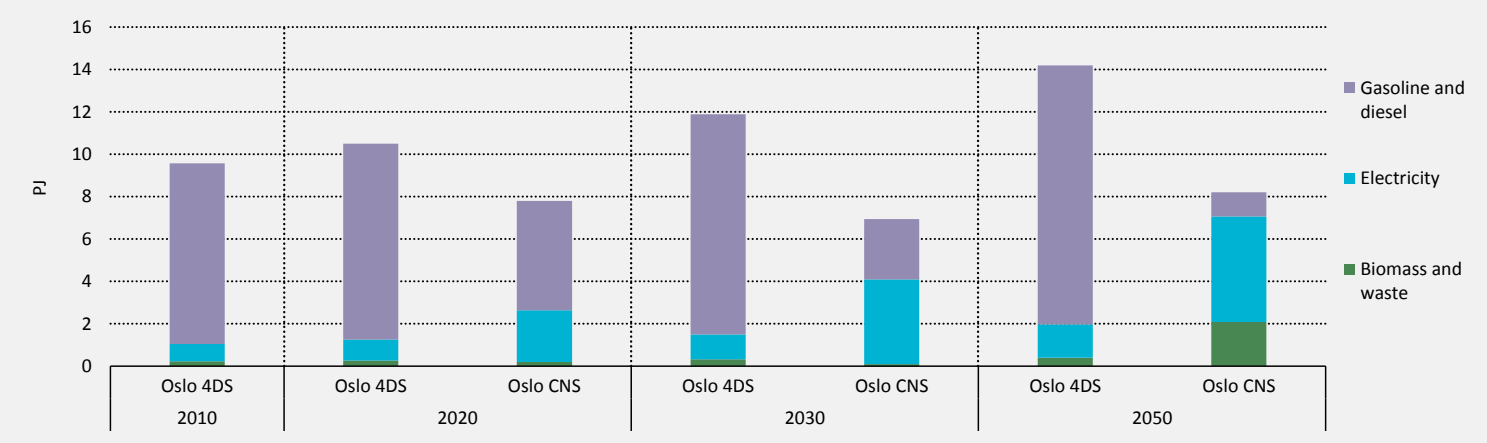

Figures and data in this report can be downloaded at www.iea.org/etp/nordic

Key point In the CNS the use of fossil fuels in transport is phased out and replaced mainly by electricity, resulting in improved efficiency compared to the 4DS. 


\section{Discussion of results}

The city of Oslo has ambitious climate targets: to halve GHG emissions by 2020, and to use no fossil fuels by 2050. None of the measures individually analysed here was able to reach the city's overall target. However, by combining independent measures, a larger reduction in the overall $\mathrm{CO}_{2}$ emissions can be obtained. The single measure with the highest $\mathrm{CO}_{2}$ reduction is a prohibition on the use of fossil fuels for heating purposes, resulting in a reduction of $33 \%$ $\left(0.49 \mathrm{MtCO}_{2}\right)$ in 2050 compared with the 4DS. When fossil fuels for heating are prohibited, heating demand is met by a mix of district heating, direct electricity, heat pumps and biomass.

The transport sector is the end-use sector that must undergo the greatest changes to meet the target for 2050. To reach the CNS emissions target, the transport sector must shift to zero-emission vehicles. To reduce or eliminate dependence on fossil fuels in road freight, deployment of alternative technologies is needed, such as plug-in hybrids, sustainable biofuels, compressed natural gas or hydrogen fuel cells. The latter is the only of these alternatives that has the potential to totally eliminate fossil-fuel dependence. In the analysis of the CNS for Oslo, it is clear that not only is a high utilisation of new fuels and technologies necessary, but also a change to other transport modes.

The number of battery electric vehicles (BEVs) in Oslo has increased from less than 1000 in 2010 to around 15000 in 2015. This increase will need to continue so as to meet the emissions target in the CNS, according to which the number of zero-emission cars in Oslo exceeds 400000 by 2050. The model results have a high share of BEVs; however, with the reduced cost of fuel cells and hydrogen in the future, a significant share could be fuel-cell EVs. The shift to zero-emission vehicles will require continuous effort to build new refuelling infrastructure throughout the city.

\section{Recommendations for action in urban areas}

Low-carbon urban areas are an essential part of sustainable low-carbon pathways in the Nordic region. Urban areas have higher population density and shorter distances, which facilitate technological solutions to increase energy efficiency and reduce emissions, such as district heating, EVs and effective public transport. Many technologies are easier to adopt first in urban areas, such as EVs or solar PV. The results of the case studies (Helsinki and Oslo) demonstrate two different pathways to carbon neutrality in urban regions. In the Helsinki Metropolitan Region, district heating is already the dominant heat source for buildings and will maintain its market share in the CNS. In Oslo's case, electric heating will remain the largest energy source for heating, despite increases in district heating fuelled by biomass and waste. In transport, Oslo is already showing leadership in the penetration of EVs which are expected to reach a dominant share of the vehicle stock by 2030. In the Helsinki Metropolitan Region, the penetration of EVs increases slowly and 2nd generation biofuels have a greater importance as a medium-term solution.

In 2013, one-third of the population in Nordic countries lived in cities over 100000 inhabitants and $50 \%$ of the population in urban areas below 100000 inhabitants. The rate of urbanisation was high in the 1950s and 60s and has been increasing again since 2000. Currently, the population of Nordic urban areas is growing by 200000 annually and the role of urban areas is also increasing in energy and climate policy making.

Nordic statistics show that urban areas are already more efficient than rural areas. Nordic urban areas host $85 \%$ of the population, consume $73 \%$ of total final energy and produce $67 \%$ of direct $\mathrm{CO}_{2}$ emissions. Larger Nordic cities have more technology options available to mitigate climate change and offer leadership to achieve carbon neutrality in the Nordic 
region. They have the potential to become innovation hubs and demonstrate smart and clean energy technologies, new services and business opportunities.

Energy efficiency was identified as a key measure in the low-carbon pathways, alongside renewable energy sources and integrated smart systems to balance varying consumption and production. New solutions are needed in all sectors in the CNS, and this chapter lists and ranks technological solutions by significance. The most important are new passenger car technologies, buildings energy efficiency, utility-scale heat pumps and low-carbon co-generation. All of these have the chance to provide improved energy efficiency and additional flexibility to the energy system.

In general, the Nordic capitals have a higher share of district heating and lower energy demand per capita in buildings and the transport sector than Nordic urban areas on average. Currently, district heating is largely produced by centralised co-generation plants with high levels of energy efficiency. However, there is an increasing risk that co-generation plants will lose their economic efficiency due to phasing out of fossil fuels, the increasing competitiveness of renewable electricity and separate heat production. At the same time the European Union is targeting an increase in co-generation, which should also be considered in Nordic policy making. As the Nordic electricity markets are fully integrated, common policies and regulation could also support Nordic co-generation into the future.

The most challenging urban sector to decarbonise is probably the transport sector. Electric cars, buses, bicycles and other EVs are adopted first in urban areas where driven distances are shorter and charging station infrastructure is more compact to build. In the CNS, urban transport should consume nearly 50\% less energy in 2050 than it consumed in 2013. After 2030, the CNS requires both considerable energy efficiency measures and $95 \% \mathrm{CO}_{2}$-free fuels in transport. By 2050 EVs could cover more than 50\% of urban final energy for transport and $75 \%$ share of passenger kilometres. Biofuels are needed to decarbonise the remaining transport. The availability and sustainability of bioenergy and biofuels are critical issues, as the Nordic region has great potential to produce bioenergy and 2nd generation biofuels from wood raw materials and biowaste. It would therefore be critical that future EU and post-Kyoto policies consider Nordic circumstances, given these versatile wood resources.

Analysis of the urban energy system is challenged by a lack of common methodologies and, in particular, of urban data. Investment in future Nordic research on urban energy systems, as well as long-term statistical data capabilities, will provide more accurate and transparent urban analysis. It is also important to undertake ex-post analysis to evaluate the impacts and effectiveness of Nordic urban policies. In addition, investment in research and development $(R \& D)$ in core technologies, systems, and business models at the Nordic level will be necessary for the transition to carbon-neutral urban systems. Finally, formulation of a Nordic "action plan" would favour both companies and private consumers by indicating what are the sectoral and other targets for sustainable development, and who the competitiveness of clean energy systems in the Nordic region will involve.

All Nordic capitals have a target to become carbon neutral, which is a clear sign of participation to policy makers and an encouragement to other Nordic urban areas to participate. The case studies - Metropolitan Helsinki and Oslo - show that Nordic pathways to carbon neutrality involve different technology mixes. The optimal technology choices and energy mixes depend on local circumstances, such as the potential for urban renewables, existing infrastructure for mobility and energy production, and existing building stock and community structures, including density. It is therefore important that city-level policy making carefully considers these issues, for example, to prevent carbon leakage outside the city borders. By the same token, Nordic countries could learn from each other and help other regions by multiplying and exporting sustainable smart-city concepts. Cities can and should have their own climate 
change mitigation plans or strategies, but implementing common Nordic governance structures will strengthen the operating environment for clean and smart energy systems and technologies. Co operation and collaboration between national and local policies would strengthen the Nordic energy transition by offering larger market areas for clean technology companies.

This analysis of Nordic urban energy systems and GHG mitigation options to reach the CNS target by 2050 indicates that large Nordic cities could offer an excellent platform for clean and smart energy systems. However, further research and analysis is needed not only in large cities, but also in smaller cities in rural areas, which will have even greater challenges in the long term due to their economic structure and lower GDP, as well as lower population densities and longer distances for mobility and transport.

Transition to carbon-neutral urban energy systems will require major changes in a wide range of governance measures, including not only market designs, business models for energy companies and investment financing, but also new modes of public engagement and prosumer strategies that are beginning to take hold. Investment in R\&D in core technologies and systems at the Nordic level will be necessary for the transition to carbon-neutral urban systems. Formulation of a Nordic action plan to solve the above governance challenges would favour both companies and private consumers by signalling the future development and competitiveness of clean energy systems. 


\section{Chapter 3}

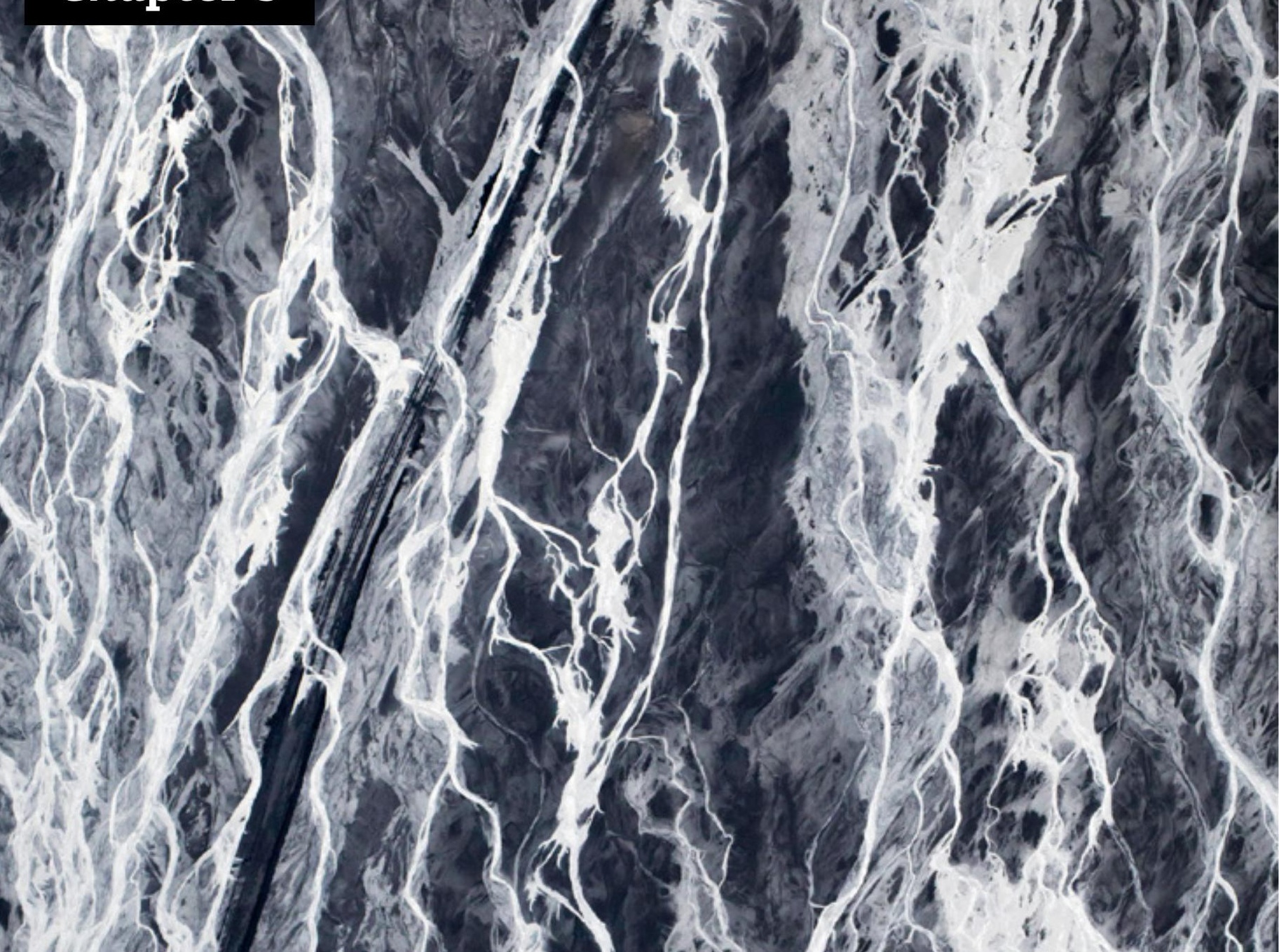

D.9.

a. (un ta 1

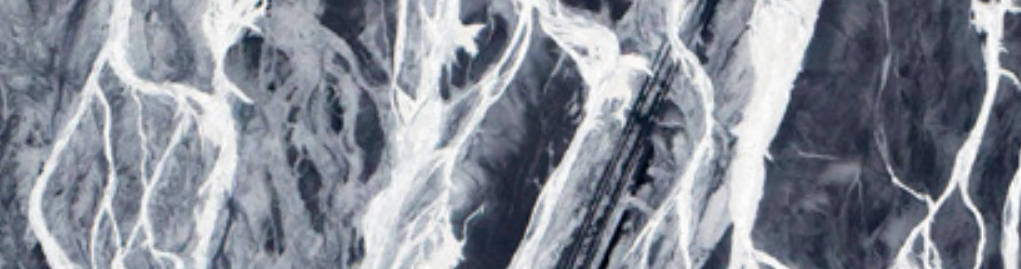
1. $12 x$ inder. (0) $12 \cos (0) 2$

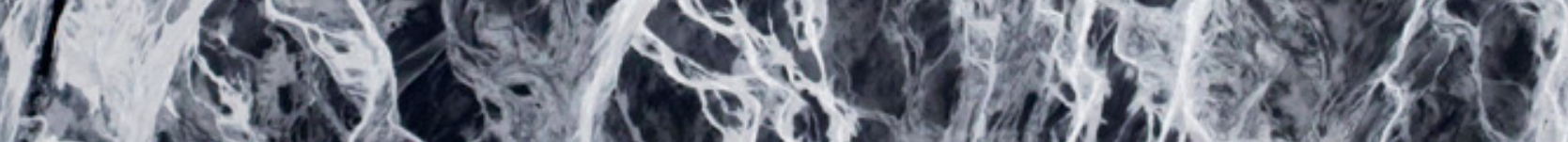

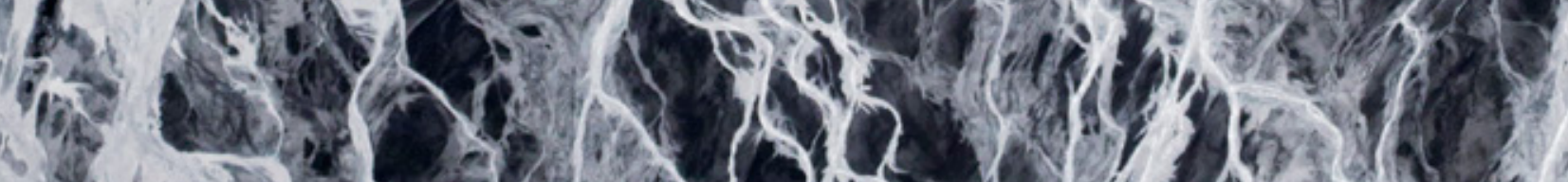
1.2 


\section{Electricity system integration}

Variable renewable energy (VRE) in the form of wind and solar power will play a major role in future Nordic and European energy systems. By 2050 in the $\mathrm{CNS}$-Balmorel ${ }^{1}$, VRE is expected to command a share of around $30 \%$ of electricity production in the Nordic countries on average (and more than 70\% in Denmark) and up to 60\% in continental Europe. These large amounts of VRE present a challenge to the electricity system because of their intermittent behaviour. To secure a balanced electricity system where supply can meet demand at any time, increasing amounts of flexible production and consumption must be introduced. This chapter describes the different means of adding flexibility, not only from a production and consumption perspective, but also by connecting geographical areas through increased transmission capacity.

\section{Key findings}

- The massive deployment of wind and solar capacity and the almost complete phase-out of coal-fired generation by 2030 are the key developments in a low-carbon European energy system. Wind power development mainly takes place onshore since the specific investment costs are considerably lower than for offshore wind turbines.

- In the Nordic countries, about $30 \%$ of electricity generation is projected to derive from VRE sources, mainly wind power, by 2050. In the other European countries included in the simulations, the similar figure is $60 \%$. The relatively lower share in the Nordic countries is due to the very large input from hydropower in the Nordic systems and the contribution from nuclear power stations in Finland. All nuclear capacity in Sweden is phased out by 2050. Biomass- and gas-fired power plants equipped with carbon capture and storage (CCS) provide intermediate load in Denmark and Sweden.
- A sharply increasing $\mathrm{CO}_{2}$ price is the fundamental driver of the transformation of the energy systems toward the Carbon-Neutral Scenario (CNS-B). In a setup where the transformation is driven by a combination of subsidies for renewable energy and $\mathrm{CO}_{2}$ pricing, incentives to deploy CCS would be less strong.

- Emissions from power and district heating generation in the Nordic countries decrease from about 50 million tonnes of $\mathrm{CO}_{2}\left(\mathrm{MtCO}_{2}\right)$ in 2014 to $10 \mathrm{MtCO}_{2}$ in 2050. The remaining $\mathrm{CO}_{2}$ emissions derive from gas-powered units (some being peak units without (CS) and municipal waste incineration. Biogas could replace part of the natural gas used and thereby reduce $\mathrm{CO}_{2}$ emissions, but this option was not included in the modelling in this chapter.

- Due to their ample renewable energy sources, the Nordic countries become strong electricity

1 The Carbon-Neutral Scenario-Balmorel (CNS-B) is a variant of the CNS outlined in Chapter 1, where a detailed optimisation model (the Balmorel model) provides an in-depth assessment of flexibility in the heat and power sector, including electricity trade. The CNS-B is designed to strengthen and feed into the CNS. 
exporters in the CNS-B, exporting 50-60 terawatt hours (TWh) per year to continental Europe from 2030 (Figure 3.1). This conceals a large individual difference between the Nordic countries, with Norway as the main export hub and Finland as a net importer.

- The considerable exports of electricity to continental Europe are dependent on energy efficiency measures in the Nordic countries curbing, in particular, the demand for electric heating, as well as large-scale utilisation of onshore wind resources. It is important to stress that the technical onshore wind power potential of the Nordic countries is abundant, but its realisation is subject to significant uncertainty due to planning constraints.

- The simulations indicate that it will become economically attractive to further expand interconnectors between the Nordic countries, continental Europe and the United Kingdom, both as means for Nordic exports and to give continental Europe access to balancing power from Nordic hydropower. At the same time interconnectors contribute to smoothing wind power production between Nordic regions.

- The Nord Pool area is extremely well suited to the integration of VRE production as wind and solar power. This is due to the presence of storable hydropower, adequate transmission capacity between the regions and a wellfunctioning electricity market. With increasing shares of VRE it will become economically attractive to increase transmission capacity not just in the Nordic region, but also across the whole of Europe. The analysis shows that the system can handle more than 70\% VRE in some countries.

- Besides adequate transmission capacity, other means are important to integrate and create as high a value as possible from the large shares of VRE. Thermal power plants need to be flexible in ramping up and down, while flexible electricity demand (load shifting) in transport, industries and buildings are all means to integrate more VRE with the same amount of transmission and thermal capacity. In the longer term, flexible electricity demand for the production of hydrogen and biofuels can become important for the replacement of fossil fuels in, for example, the transport sector and at the same time improve the integration of VRE.

- A combination of different flexibility resources can lead to reduced overall cost of integrating VRE. By introducing demand-side flexibility into the power system, the analysis shows that the electricity price stabilises and reduces the need for natural gas peak boilers.

- An early phase-out scenario for nuclear in Sweden and Finland shows that this will increase emissions from the Nordic area by $7 \mathrm{MtCO}_{2}$ in 2030 because of greater gas capacity and by $2 \mathrm{MtCO}_{2}$ in the rest of Europe, mainly due to reduced export potential from the Nordic countries.

\section{Opportunities for policy action}

- Many new transmission lines are needed in the future Nordic and European electricity systems. It is therefore important to continue strengthening European collaboration on infrastructure planning, to ensure optimal investments are made and to avoid bottlenecks in the grid.

- The huge expansion of wind power in the Nordic countries under the CNS-B stresses the need for regional planning to secure adequate and acceptable sites for wind parks.

- Rules, regulations, support schemes and taxes that hamper elements of the energy system in acting flexibly should be considered for removal to secure an economically optimal integration of VRE.
- Coherent regulatory frameworks and market designs are needed to facilitate market interaction and allow higher shares of VRE to be integrated into the energy system.

- Actions that intensify the electrification of the heating and transport sectors, e.g. heat pumps and electric vehicles (EVs), can provide greater flexibility to the power system.

- In a future Nordic energy system, a stronger linkage between elements of the energy system - transport, electricity use, heating and fuel production - will be needed to reduce the cost of reducing $\mathrm{CO}_{2}$ emissions and to integrate VRE. New policies, taxes and other measures therefore have to be assessed in a more holistic way to ensure they support this essential progress. 


\section{Introduction}

The results presented in this chapter are based on analysis of the Nordic and Northwestern European electricity and district heating systems using a detailed optimisation model. The underlying framework is a global $2^{\circ} \mathrm{C}$ scenario (2DS) as presented in the International Energy Agency (IEA) Energy Technology Perspectives 2016 (ETP 2016) (IEA, forthcoming). The main constraint in the modelling is the carbon dioxide $\left(\mathrm{CO}_{2}\right)$ price retrieved from the 2DS in ETP 2016. The only exogenous variables used in the model are committed and planned power plants and transmission capacity, fuel prices and technology costs, and the development of nuclear power (from CNS); other variables are subject to free optimisation across all the countries and regions in the model. The analyses are based on minimising total system costs over the whole model area. In general, national policies are not explicitly taken into account. The $\mathrm{CO}_{2}$ price is assumed to increase steeply in the scenarios and no subsidies, e.g. for renewable energy, are included. The results will therefore not reflect national targets and plans but simply illustrate the cheapest socio-economic solution for the whole model area under the given framework. All results and conclusions should be seen in the light of this framework.

The first edition of this report, Nordic Energy Technology Perspectives 2013 (NETP 2013), identified the development of electricity grids and wind power as one of its five central policy challenges (Nordic Energy Research and IEA, 2013). The analysis showed the potential for the Nordic region to benefit economically in facilitating a broader European decarbonisation, primarily through greater interconnection to the continental electricity grid and an expansion of Nordic wind power. The report pointed to the potential to increase Nordic wind power from $3 \%$ of the region's electricity generation in 2012 to $25 \%$ in 2050. In order to achieve this integration, a more flexible energy system is required, both on the demand and the supply side - alongside sufficient regional grid interconnections.

NETP 2013 analysis also revealed that the Nordic region could achieve annual exports of about 50 TWh, reaching more than 60 TWh over the longer term. Moreover, Nordic hydropower resources were expected to increase their value to regulating the Northern European power system.

This chapter examines the challenge of integrating VRE in the form of wind and solar photovoltaic (PV) in the Nordic region. Four groups of options for flexibility are discussed and analysed:

- flexible supply

- flexible demand

- storage

- electricity trade.

In a renewables-based future Nordic power system, flexible supply will mainly come from hydropower, as it does today, but it will also come from gas- or biomass-fired power plants, where the gas could be renewable converted to natural gas quality.

Flexible demand may come from many different end uses. Those with the greatest potential for integrating wind and PV are electric heating in individual buildings or for district heating, process heat from electricity, EVs and in the longer term electrolyser plants for the production of net carbon-free fuels.

Currently, the cheapest methods of energy storage are hydro reservoirs and co-generation with large heat storage (water containers); however, batteries, large-scale demand response and conversion of electricity to hydrogen, methane or liquid fuels are likely to become relevant in the future. 


\section{Figure 3.1a Overview of Nordic electricity trade, 2015}

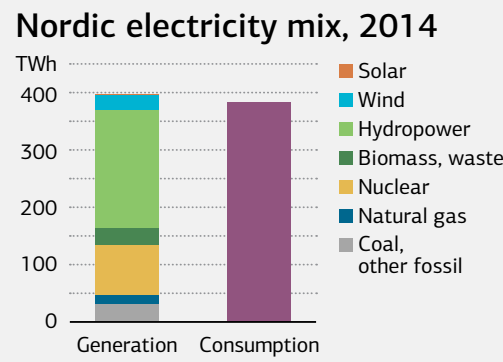

Nordic electricity trade, 2015

Domestic trade

Cross-border trade
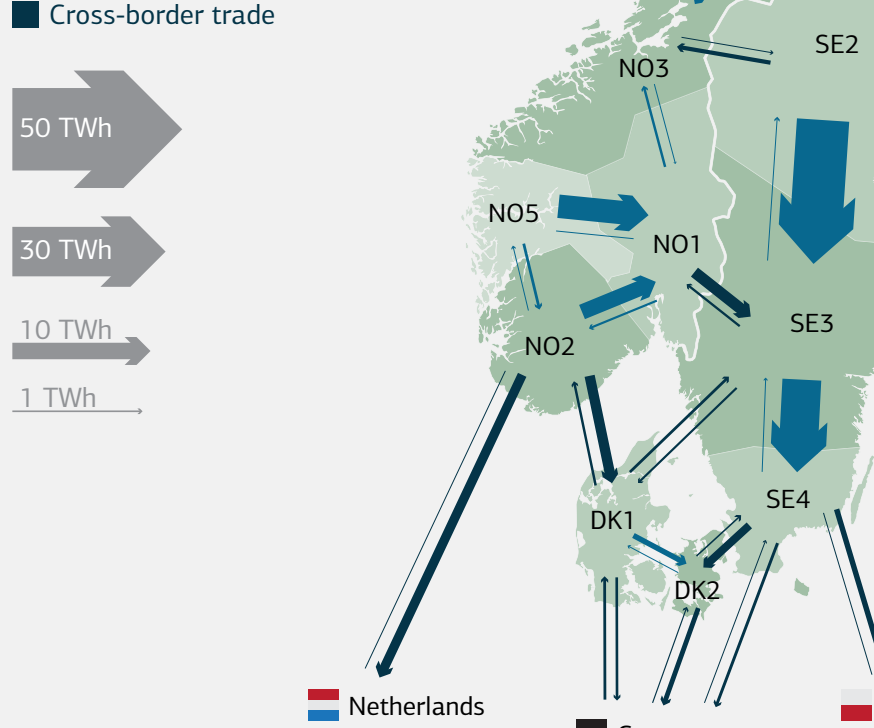

E1

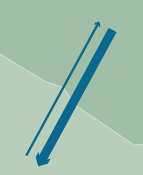

NO4
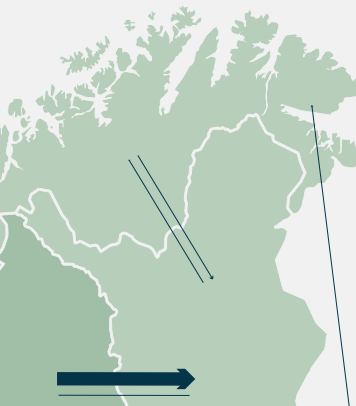


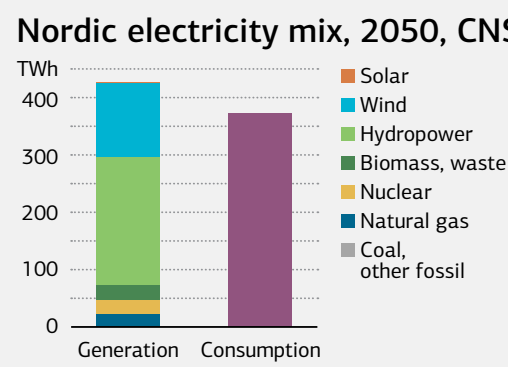

Nordic electricity trade, 2050

\section{Domestic trade}

Cross-border trade
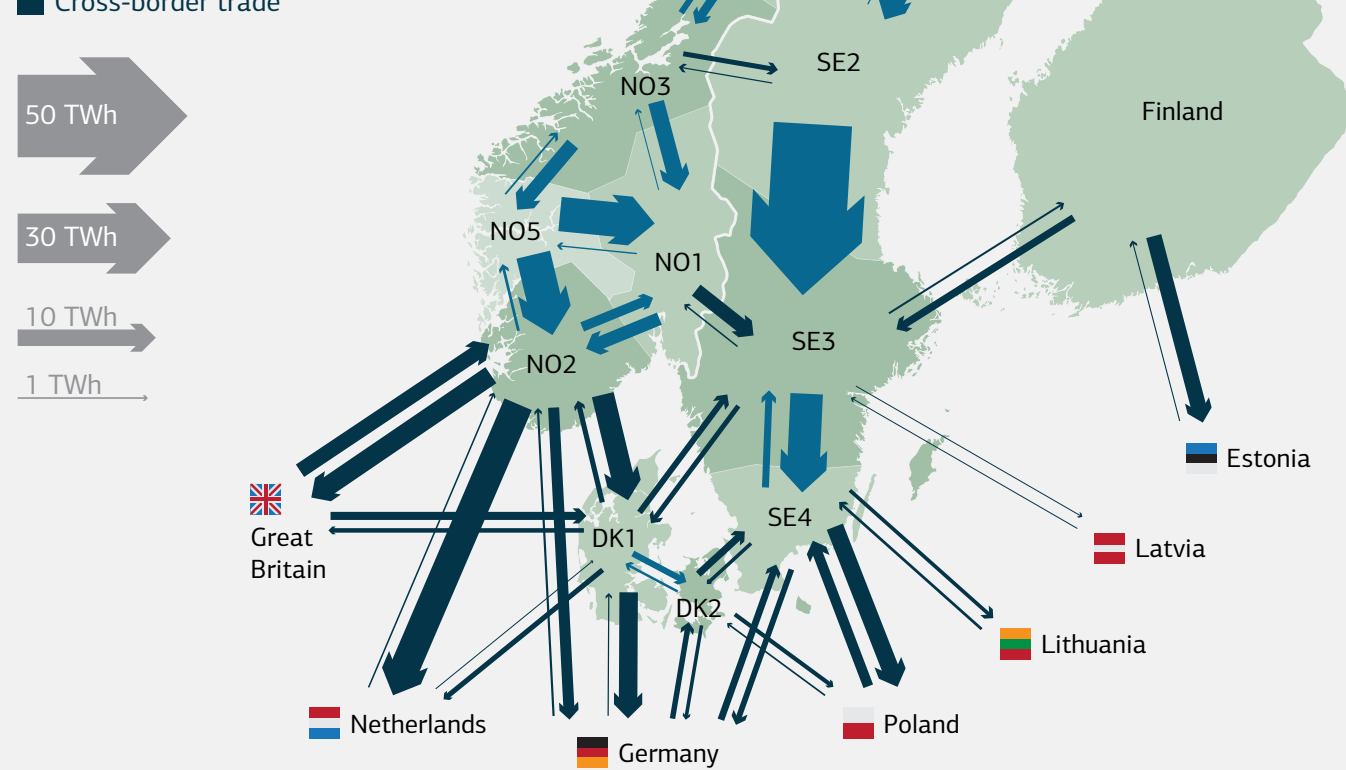

National electricity trade with all partners, 2050

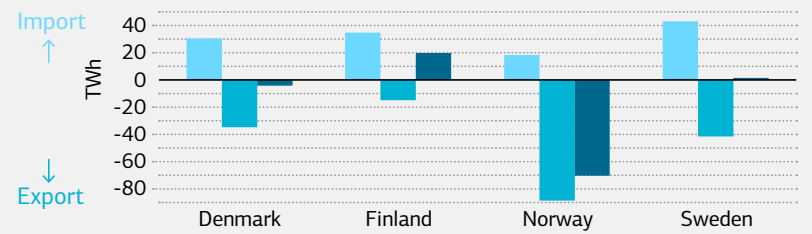

Nordic trade with Europe

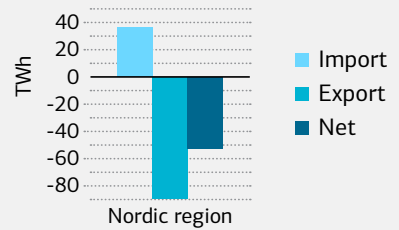

Notes: Nordic trade with Europe excludes trade between Nordic countries. Trade flows between non-Nordic countries are not shown. Trade with Russia is assumed to fall to zero in 2050. Iceland is not yet connected with any other electricity system and is therefore not included. This map is without prejudice to the status of or sovereignty over any territory, to the delimitation of international frontiers and boundaries, and to the name of any territory, city or area.

Source: All data from detailed optimisation modelling presented later in this chapter.

Figures and data in this report can be downloaded at www.iea.org/etp/nordic.

Key point

Anticipation that electricity prices in Europe will be higher than in the Nordic region in the CNS-B creates an attractive trade opportunity; expansion of variable renewables and interconnector capacity could lead to net Nordic exports of over 50 TWh in 2050. 
Finally, trading electricity between regions will lead to a higher value of renewable energy generation through smoothing effects and better access to integration resources.

All these options will complement each other and be in competition to deliver flexibility to the energy system. This chapter seeks to evaluate the need for them, and their potential, in a Nordic energy system heading towards the NETP 2016 CNS.

The amount of nuclear in the future Nordic power system will have considerable influence on investments in other technologies, both VRE and thermal renewables. Therefore, a special section in this chapter presents sensitivity analysis on the phase-out of nuclear in Sweden and Finland.

Iceland is not a part of the analysis presented in this chapter, as it is not included in the modelling framework used. However, the Icelandic power system and future interconnection to the United Kingdom are discussed as a spotlight theme in the section on electricity trading.

\section{Figure $3.2 \quad$ Flexibility options in the Nordic energy system}

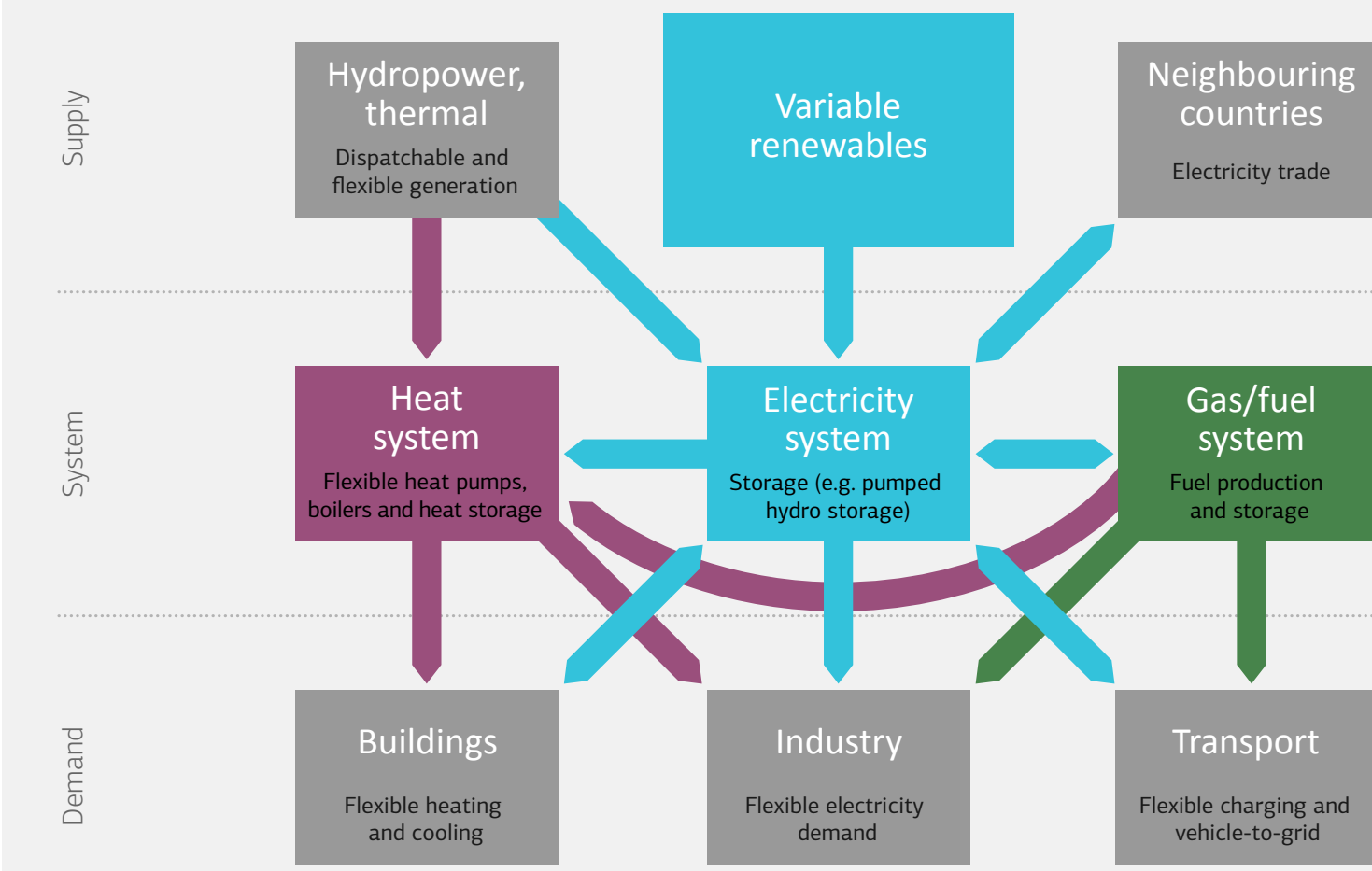

Notes: Illustration of where different types of flexibility can be found around the energy system; the blue arrows represent electricity, the purple arrows heat and the green arrows gas; on the supply side, certain power and heat plants can act flexibly; at the system level, grids and units can convert one energy carrier to another, with conversion and storage providing flexibility; and finally on the demand side, industry, households and transport can postpone or reschedule demand.

Figures and data in this report can be downloaded at www.iea.org/etp/nordic. and gases. In the conversion process from fuel to energy carrier, or from one energy carrier to another, flexibility can be introduced in the form of storage and control of the process. Flexibility can also occur from the consumer side by adjusting when a certain energy carrier is needed. 
Electricity is and will remain the main energy carrier in the Nordic energy system, binding together the different sub-systems, sectors and conversion technologies (Figure 3.2). The Nordic power grid and power market (Nord Pool) are the backbone of this system.

Hydrological conditions have a significant impact on Nordic price formation. In dry years, Sweden, Finland and Norway increase net imports to compensate for the lack of hydro generation. In wet years, the abundance of hydropower allows plant owners to lower the price of their supply offers. Besides the availability of hydropower, the main drivers of short-term movements in the power price are fuel prices and the price of $\mathrm{CO}_{2}$, as shown in Figure 3.3.

Recent developments in wholesale power prices and the expected prices over the next five to ten years provide little incentive for market-based investment in new capacity of any kind, as the price is currently below long-term marginal costs of most power-producing technologies.

\section{Figure 3.3 Historical electricity prices in the Nordic power market}

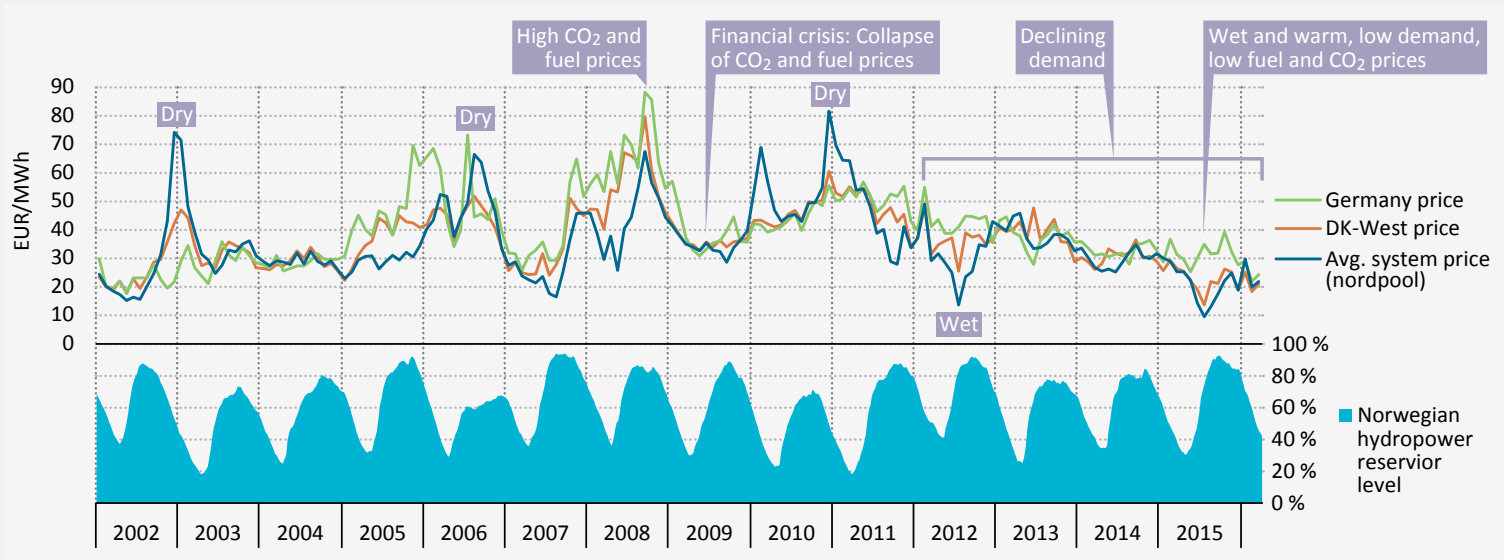

Note: $\mathrm{MWh}$ = megawatt hour

Source: Source, Nordpoolspot. Based on Ea (2015), The Danish Experience with Integrating Variable Renewable Energy, study on behalf of Agora Energiewende Figures and data in this report can be downloaded at www.iea.org/etp/nordic. precipitation, $\mathrm{CO}_{2}$ and fuel prices, and developments in electricity demand.

The scenarios analysed in NETP 2016 assume that both the Nordic and surrounding countries are striving to attain the 2DS. This influences the price of globally traded fuels - fossil-fuel prices moderate due to falling demand, while demand for biomass increases. The mitigation cost for reaching the 2DS can be translated into a global $\mathrm{CO}_{2}$ price, mirroring the $\mathrm{CO}_{2}$ tax needed to drive investment towards 2DS in a perfectly functioning global market. A steeply increasing global $\mathrm{CO}_{2}$ price will drive investment in non-carbonintensive power and heat-supplying technologies.

The system analysis in this chapter was prepared with the electricity market model Balmorel. The most important input assumptions, such as $\mathrm{CO}_{2}$ and fuel prices, have been aligned with the global ETP 2016 scenarios from the IEA. 
To study the impact of different flexibility options, a number of scenarios have been analysed using Balmorel2 ${ }^{2}$, combining means of flexibility and time resolution. Table 3.1 provides an overview of the scenarios. The alternative scenarios are further specified in the section entitled "Flexibility in the system and VRE integration".

\section{Table $3.1 \quad$ CNS-B scenario assumptions}

\begin{tabular}{|c|c|c|c|c|c|c|c|c|c|}
\hline Scenario name & Period & $\begin{array}{l}\text { Time } \\
\text { resolution }\end{array}$ & $\begin{array}{l}\text { Flexible } \\
\text { power } \\
\text { plants }\end{array}$ & $\begin{array}{l}\text { Flexible } \\
\text { district } \\
\text { heating }\end{array}$ & $\begin{array}{l}\text { Flexible } \\
\text { trans- } \\
\text { mission }\end{array}$ & $\begin{array}{l}\text { Flexible } \\
\text { demand }\end{array}$ & $\begin{array}{l}\text { Flexible } \\
\text { EV }\end{array}$ & $\begin{array}{l}\text { Flexible } \\
\text { individual } \\
\text { electric } \\
\text { heating }\end{array}$ & $\begin{array}{l}\text { Flexible } \mathrm{H}_{2} \\
\text { Production }\end{array}$ \\
\hline Baseline scenario & $2014-50$ & $72 / \mathrm{yr}$ & $x$ & $x$ & $x$ & - & - & - & $x$ \\
\hline Flex scenario & $2014-50$ & $72 / y r$ & $x$ & $x$ & $x$ & $x$ & $x$ & $x$ & $x$ \\
\hline Nuclear phase-out & $2014-50$ & $72 / \mathrm{yr}$ & $\mathrm{x}$ & $\mathrm{x}$ & $x$ & - & - & - & $x$ \\
\hline Hourly2030 & 2030 & $8760 / y r$ & $x$ & $x$ & $x$ & - & - & - & $x$ \\
\hline Hourly2030 +UC & 2030 & $8760 / y r$ & - & $x$ & $x$ & - & - & - & $x$ \\
\hline Hourly2030 +Flex & 2030 & $8760 / y r$ & $\mathrm{x}$ & $x$ & $x$ & $x$ & $x$ & $x$ & $x$ \\
\hline
\end{tabular}

\section{Box 3.1}

\section{Analytical framework}

The system analysis uses improved representation of the power transmission system and the prevalence of congestion compared to the system calculations performed for NETP 2013. Other improvements include higher time resolution (hourly for parts of the analysis), and better representation of the district heating system.

Analysis of integration options comprises a large range of technical solutions with different timeframes for implementation. In the longer term, to 2050, system changes in the power and district heating systems can be substantial, introducing new options for flexible generation and demand. In the short and medium term, it will be important to optimise and adapt current options to achieve a flexible system. For these reasons, the analysis of integration options is structured using two main components: one showing the development of the overall energy system from today towards 2050, and another analysing the options for flexible generation in more detail for the medium term, towards 2030, as outlined in Table 3.2.

\section{Table 3.2}

\section{Indicative timeline for integration solutions in the power and} district heating systems

\begin{tabular}{|c|c|c|}
\hline Relevant integration options & 2030 & 2050 \\
\hline Flexibility of thermal power plants & $\mathrm{xx}$ & $\mathrm{x}$ \\
\hline Integration with heat sector & $\mathrm{xx}$ & $\mathrm{xx}$ \\
\hline Transmission system integration & $x$ & $\mathrm{xx}$ \\
\hline Production of synthetic biofuels and large-scale implementation of flexible demand & - & $\mathrm{x}$ \\
\hline \multicolumn{3}{|c|}{$\begin{array}{l}\text { Notes: In the long-term analysis up to } 2050 \text { and with a less detailed time resolution, all flexibility options are available to the model; in the } \\
\text { medium term (in 2030) the model is run with one-hour resolution, with a principal focus on the flexibility of co-generation and integration with } \\
\text { district heating; } x x=\text { high importance; } x=\text { moderate importance. }\end{array}$} \\
\hline
\end{tabular}


The analysis towards 2050 focuses on opportunities for further integration of VRE within the Nordic countries and Northwestern Europe through largescale implementation of flexible demand, production for synthetic biofuels and closer integration of the transmission grid. This includes an analysis of investment potential for the transmission system beyond 2030. The model includes all existing power plants in the Nordic countries and most of Northwestern Europe, and it considers endogenous ${ }^{2}$ investments in new power plants (from 2020) and transmission lines (after 2030). For these analyses, the Balmorel model is run in the years 2014, 2020, 2030, 2040 and 2050, with 72 time steps annually. Simulations that consider investments in both generation and transmission capacity require a lot of computer power and a higher number of time- steps would yield too high a calculation time.

In the medium-term perspective, increased flexibility of thermal power plants and integration of the district heating and power sectors are expected to play an important role in the integration of VRE. Therefore, operation of the power system and integration of VRE are analysed in greater detail using hourly simulations for the year 2030 with different assumptions on options for power plant flexibility. The hourly simulations are based on the capacities found for 2030 from the previous long-term model run in Balmorel. The hourly simulations better capture the flexibility needs of VRE and they are particularly important to address the effects of demand response and energy storage technologies.

\section{Scenario framework}

The analysis of the integration options is based on the CNS for the Nordic countries, thereby setting an ambitious framework for the development of the Nordic energy system towards carbon-neutral status. Certain parameters are harmonised with the CNS to ensure consistency, while others are unique to the Balmorel model in order to analyse particular issues in detail.

The capacity for renewable energy sources for electricity (RES-E) in the Nordic power system and for the rest of the model area is determined exogenously for the base year. Demand in the surrounding countries follows a path from the ETP 2DS as outlined in Table 3.3. Demand in the Nordic countries is taken from the CNS presented in Chapter 1.

\begin{tabular}{|c|c|c|}
\hline & Nordic countries & Remaining countries $^{1}$ \\
\hline Demand & $\begin{array}{l}\text { Defined by CNS (Current setup: in } \\
\text { 2014; CNS from 2020) }\end{array}$ & $\begin{array}{l}\text { National plans/scenarios until } 2020 \\
\text { Future growth trends: CNS }\end{array}$ \\
\hline VRE deployment & $\begin{array}{l}\text { National plans/scenarios until } 2020 \\
\text { Model investments from } 2030\end{array}$ & $\begin{array}{l}\text { NREAP as a minimum as of } 2020 \text { and beyond Model } \\
\text { optimised beyond } 2020 \text { according to } \mathrm{CO}_{2} \text { price and subsidy }\end{array}$ \\
\hline $\begin{array}{l}\text { Conventional } \\
\text { generation capacity }\end{array}$ & $\begin{array}{l}\text { Nuclear development from CNS } \\
\text { Fossil development model optimised }\end{array}$ & $\begin{array}{l}\text { Nuclear development fixed: } \\
\text { Germany: phase-out until 2022, United Kingdom: average } \\
\text { between DECC's “Reference” and “Existing policies” } \\
\text { scenarios, Belgium: phase-out by } 2025 \text {, Other countries: } \\
\text { constant status quo Fossil development model optimised }\end{array}$ \\
\hline Fossil fuel prices & $\begin{array}{l}\text { Convergence from electricity market } \\
\text { futures until } 2020 \text { to CNS }\end{array}$ & As for the Nordic countries \\
\hline \multicolumn{3}{|c|}{$\begin{array}{l}\text { Notes: DECC = UK Department for Energy and Climate Change; NREAP = National Renewable Energy Action Plan. } \\
1 \text { Remaining countries are Germany, United Kingdom, Estonia, Latvia, Lithuania, Belgium, the Netherlands, Luxembourg, France, Italy, Austria, } \\
\text { Czech Republic and Poland. Further information on the geographical scope can be found in the modelling tool section below. } \\
2 \text { For solar, wind, biomass and biogas, a subsidy of EUR } 20.60 \text { per MWh applies in } 2014 \text { and EUR } 18.50 \text { per MWh in } 2020 \text {. No subsidies in the other ye }\end{array}$} \\
\hline
\end{tabular}

3 Endogenous investments mean that the model chooses what to invest in and when using an optimisation approach - this is used for new plants. Exogenous investments means that the model user manually implements capacity in the model this is used for pre-existing plants and manual selection of new plants. 


\section{Modelling tool \\ Balmorel}

The simulations of the operation of the Nordic and European power and district heating systems are carried out using the energy system model Balmorel, which is a partial equilibrium model determining the least-cost dispatch for the power system. The model is based on a detailed technical representation of the existing power system, incorporating power and heat generation facilities as well as the most important bottlenecks in the overall transmission grid. The main result in this case is a least-cost optimisation of investment in generation and transmission capacity and the production pattern of all power units. The model assumes foresight within one year on all important factors, such as the development of demand and availability of power plants and transmission lines, as well as generation patterns of VRE.

Balmorel, which was originally developed with a focus on the countries of the Baltic Sea region, is particularly strong in modelling co-generation production ${ }^{4}$. Hourly resolution is one of the important features of Balmorel in comparison with other models, such as the different versions of TIMES 5 . This feature allows the deep investigation of the value of dispatching and flexibility for the energy system. Balmorel is a myopic model as it can only see one year ahead when deciding on investment. This is in contrast to models with full foresight over the modelling period, such as most TIMES models (e.g. IEA ETP-TIMES). This means, for example, that Balmorel's model runs for a given year will not take into account the fact that a certain technology will become much cheaper in a few years time. A model with full foresight might hold back investment in that year while awaiting the new technology.

\section{Geographical scope}

The core countries in this study comprise the Nordic countries (Norway, Denmark, Sweden and Finland). The others included to account for interdependencies comprise Germany, the remaining countries of the Baltic Sea region (Estonia, Latvia, Lithuania and Poland) and surrounding countries (the Netherlands, Belgium, Luxembourg, France, Italy, Switzerland, Austria, the Czech Republic and Great Britain).

\section{Link to IEA ETP-TIMES model}

Balmorel's modelling of the Nordic power and district heating systems is much more detailed than the IEA ETP-TIMES model used to create the CNS. This means that system constraints not visible at the ETP-TIMES level can be studied in Balmorel. Hence, while both models are optimisation models, finding the cheapest investments and production commitment, there will be differences in the results. To avoid differences related to assumptions, several iterations between the models have been conducted to harmonise inputs and outputs. Annex B compares results from the two model systems.

As shown in Figure 3.4, the Balmorel model uses a number of outputs from the NETP CNS as input data, including assumptions on fuel and $\mathrm{CO}_{2}$ prices and results such as electricity demand (divided into classical, electrolysis, EVs and individual electrical heating) and district heating demand. In turn, inputs and outputs from Balmorel, such as transmission capacity, wind potentials and technical data for co-generation, are used in the ETP-TIMES model.

4 Co-generation refers to the combined production of heat and power.

5 The Integrated MARKAL-EFOM System. 


\section{Figure 3.4 Connection between ETP model results and Balmorel simulations}

\section{IEA ETP-TIMES global model}

Global model with 28 regions where the Nordic countries are individually represented.

The model framework covers all sectors and all fuels.

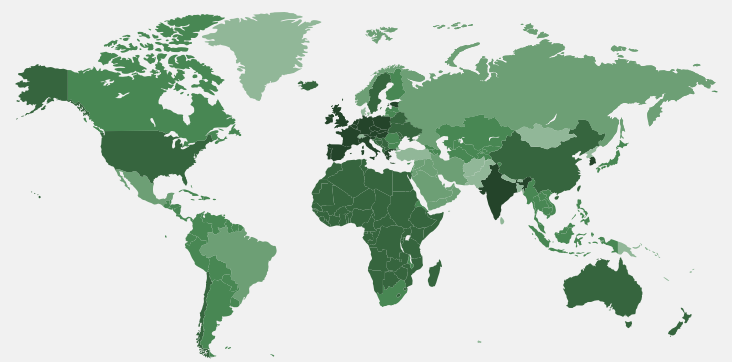

Model interaction

\section{Balmorel model}

Nordic and Northwestern Europe power sector model with each country individually represented.

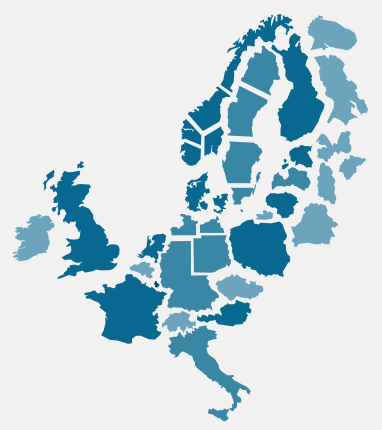

Transmission capacity

Wind potential

Co-generation production

Note: This map is without prejudice to the status of or sovereignty over any territory, to the delimitation of international frontiers and boundaries, and to the name of any territory, city or area.

Figures and data in this report can be downloaded at www.iea.org/etp/nordic.

Key point

The CNS assumptions and results, such as electricity demand, are used as input data for the Balmorel model; thereafter, Balmorel outputs, e.g. transmission capacities, are used in the ETP-TIMES model.

\section{Main assumptions}

\section{Fuel and $\mathrm{CO}_{2}$ price development}

The fuel and $\mathrm{CO}_{2}$ prices are based on market forward prices until 2020. By 2030, they align with the IEA assumptions in the CNS. This means that fossil-fuel prices remain at today's low levels until 2020 and then increase considerably to reach long-term equilibrium prices of the 2DS by 2030. Between 2030 and 2050 fossil-fuel prices decrease slightly as a result of decreasing demand. The $\mathrm{CO}_{2}$ price increases drastically from 2020 onwards to drive investment in low-carbon generation capacity, as depicted in Figure 3.5. By 2030, the $\mathrm{CO}_{2}$ price is EUR 75 per tonne, which is considerably higher than the price level expected by the EU Commission to comply with the $40 \% \mathrm{CO}_{2}$ reduction target in 2030.

As illustrated in Figure 3.6, biomass price projections are also based on assumptions from the CNS. Additional costs are taken into account for transport, based on the distance and share of biomass imported from overseas (deep-sea shipping) to differentiate between types of biomass. The prices also depend on whether the biomass is used in small- or largescale power plants, to reflect differences in transport costs.

As 2050 approaches, the prices of different types of biomass are expected to increase by 50-100\% compared to today's level. This reflects the increasing demand for biomass as fossil fuels are phased out in the 2DS. 


\section{Figure $3.5 \quad$ Development of fuel prices (left) and $\mathrm{CO}_{2}$ prices (right)}
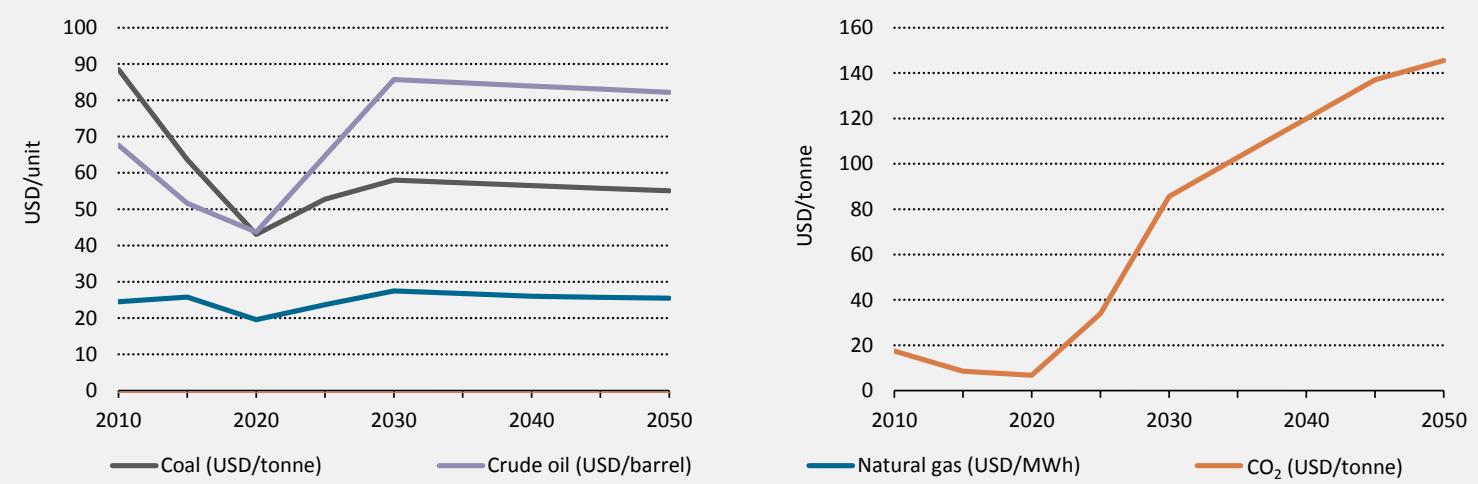

Notes: Fuel prices shown are market prices; fuel prices at the power plant will be slightly higher due to transport and logistics cost; coal is expressed in USD per tonne; crude oil is expressed in USD per barrel; natural gas is expressed in USD per MWh; the $\mathrm{CO}_{2}$ price is USD per tonne; these costs are based on the forward prices until 2020 and IEA projections in 2030 and 2040; all costs and prices are in real 2010 USD, i.e. excluding inflation.

Sources: Costs are based on forward prices until 2020; IEA projections by 2030 and 2040, IEA (forthcoming), Energy Technology Perspectives 2016.

Key point The fuel and $\mathrm{CO}_{2}$ prices are based on the market forward price until 2020. By 2030, they align with the IEA assumptions in the CNS.

\section{Figure $3.6 \quad$ Price projections for solid biomass fuels}

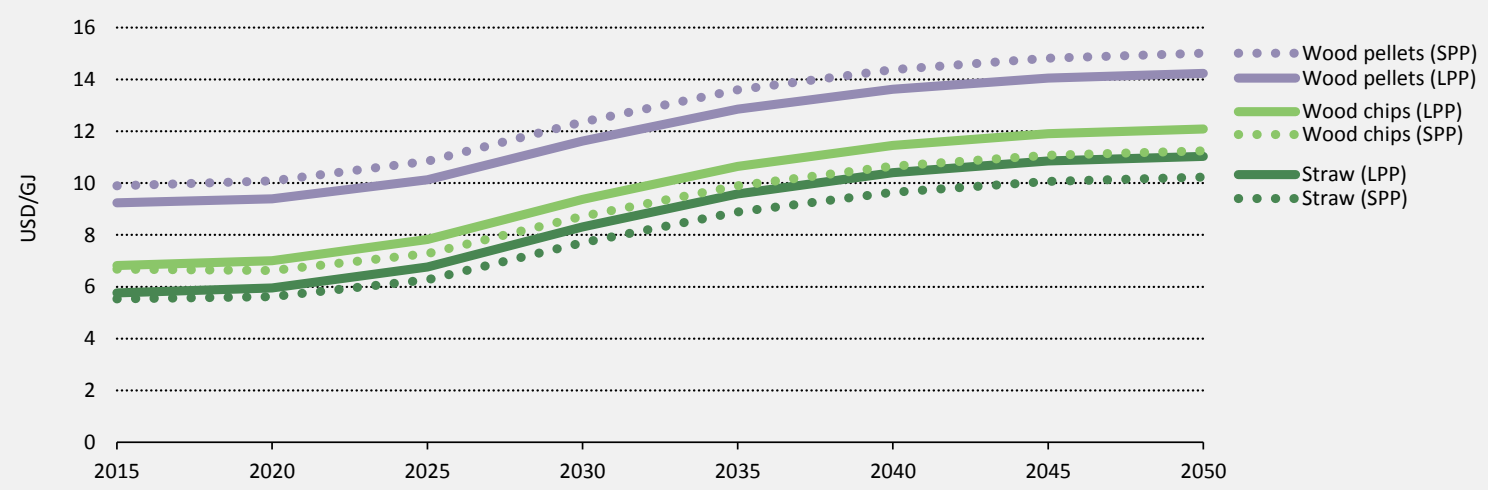

Notes: Biomass fuel prices include transport costs; GJ = gigajoule; LPP = large power plants, usually located at a harbour or river; SPP = small power plants, usually located closer to straw and wood chip resources; all costs and prices are in real 2010 USD, i.e. excluding inflation.

Sources: Biomass price projections are based on assumptions from IEA (forthcoming), Energy Technology Perspectives 2016; transport costs are based on Ea (2013), Analysis of Biomass Prices, Future Danish Prices for Straw, Wood Chips and Wood Pellets, and Ea (2014b), Biomass Pricing.

Figures and data in this report can be downloaded at www.iea.org/etp/nordic.

Key point $\quad$ Prices for solid biomass fuel are projected to increase steadily from 2014 to 2050.

\section{Electricity demand development}

For the Nordic countries, the development of electricity demand is based on national forecasts and scenarios in 2014-2020, while NETP 2016 assumptions are applied from 2020 onwards. This includes introduction of EVs as illustrated in Figure 3.7. In the CNS-B baseline 
scenario, demand flexibility is not modelled explicitly. However, EVs are considered to have a charging strategy, which leads to greater charging at night and less charging during daytime.

Electricity demand for individual heating is expected to decrease sharply over time due to better insulation of buildings and a shift from direct electric heating to heat pumps with higher efficiencies ${ }^{6}$.

\section{Figure 3.7 Nordic electricity demand as classical and flexible demand}

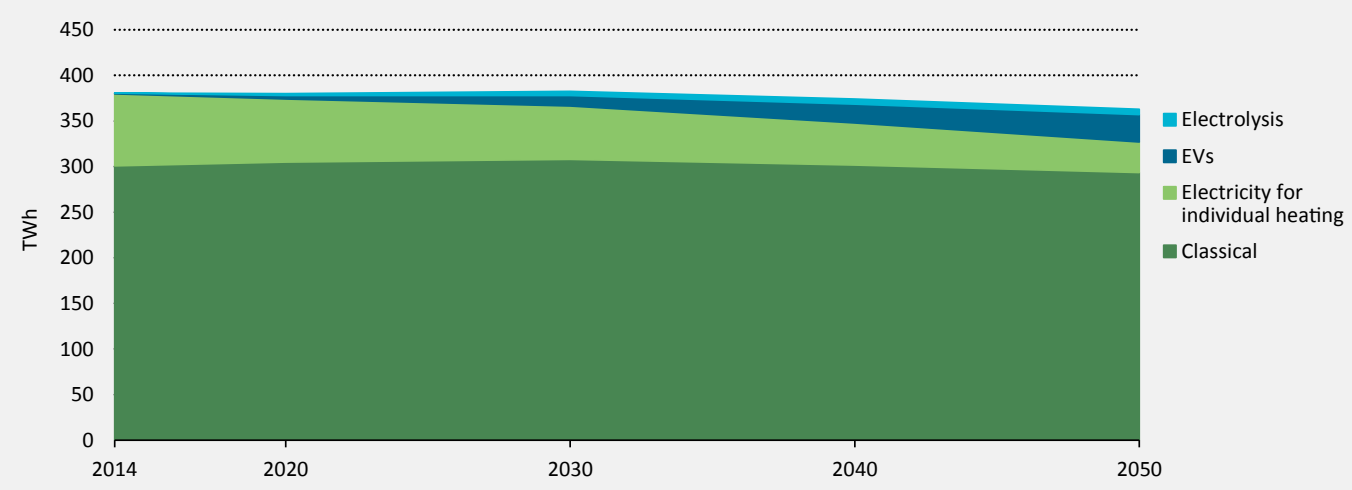

Notes: Nordic electricity demand is split into classical demand, electricity for individual heating, EVs and electricity for electrolysers in the CNS; classical electricity demand covers all remaining electricity demand used for for lighting, appliances, ventilation etc.

Source: Based on national forecasts and scenarios in 2014, and on assumptions from CNS from 2020, IEA (forthcoming), Energy Technology Perspectives 2016. Figures and data in this report can be downloaded at www.iea.org/etp/nordic.

Key point Classical electricity demand is expected to decrease when more flexible electricity demand comes into place.

\section{Transmission system development}

The representation of the current transmission system in Balmorel is based on transmission capacities between countries and estimates of the main internal bottlenecks as depicted in Figure 3.8. The development of the transmission system is based on the Ten-Year Network Development Plan (TYNDP) by the European Network of Transmission System Operators (ENTSO E) in the short and medium term (until 2030) (ENTSO-E, 2014). Assumptions from the plan have been updated based on recent announcements by transmission system operators (TSOs), as well assumptions from a recent study of the transmission systems in the Nordic countries and Germany (Ea, DTU and DIW, 2015). Further information is available in the tables in the annexes. German transmission capacity expansion is based on the grid development plan issued in 2014 by the four German TSOs (NEP, 2014); however some delay is included to take into account uncertainty about the time schedules of the planned interconnectors.

Major investments between 2016 and 2030 include two new transmission lines of 1.4 gigawatts (CW) from Norway to Great Britain and Germany respectively, two new transmission lines to connect Western Denmark with Great Britain (1.4 GW) and the Netherlands (0.7 CW), and a new transmission line to connect Sweden with Northeastern Germany (0.7 GW).

6 Individual heating means heating of individual homes and buildings with electricity, as opposed to heating by district heating. 


\section{Figure 3.8}

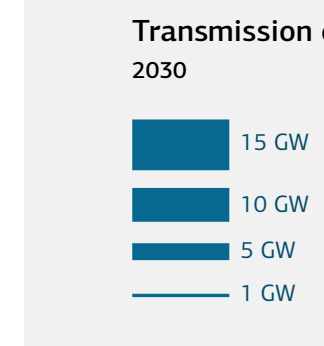

apacity
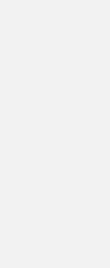
After 2030, the development of the transmission system is based on endogenous investment decisions. The cost of investing in new transmission capacity will depend on the technology applied, the distance covered, and other (internally) required reinforcements of the grid. Analysing the cost of specific grid expansions is therefore not an easy task, and cannot be done in detail without taking into account grid stability calculations and other factors. For the current analysis, investment decisions are based on an estimate of increasing grid capacity on the specific connections, and while this approach has its shortcomings with regard to defining how the technical layout for a certain connection should be designed, it will give a good indication of where additional market capacity would be beneficial.

The approach for defining the cost of investing in new transmission lines is based on a study of options for transmission investment in the Baltic Sea region (Ea, 2014c). Depending on the distance to be covered ${ }^{7}$, conventional overhead high-voltage alternating current (HVAC) lines would be able to provide the most cost-effective transmission technology. However, given the potential for local opposition to additional overhead lines in many countries, the cost estimates are based on high-voltage direct current (HVDC) cables as outlined in Table 3.4. As a general approach is applied for all connections, cost estimates will differ from the numbers used in the ENTSO-E TYNDP (ENTSO-E, 2014).

The length of an interconnection between two regions is defined as the distance between the two region's geographical centres. However, for projects on land, a maximum distance of 300 kilometres $(\mathrm{km})$ is included. This will lead to an overestimation of the length of the transmission projects themselves, but compensates for not taking into account the need for local grid reinforcements.

\section{Table 3.4}

\section{Cost assumptions for HVDC LCC connections}

\begin{tabular}{|c|c|}
\hline HVDC LCC Technology & Cost \\
\hline Converter substations & EUR 0.20 million per MW \\
\hline HVDC submarine cable & EUR 1250 per MW-km \\
\hline HVDC underground cable & EUR 1100 per MW-km \\
\hline HVDC overhead line & EUR 250 per MW-km \\
\hline \multicolumn{2}{|c|}{$\begin{array}{l}\text { Notes: Reference case is a connection with a rated capacity of } 600 \mathrm{MW} \text { and a voltage of } 400-500 \mathrm{kV} \text {; additional } 10 \% \text { contingency costs are taken into } \\
\text { account; } \mathrm{kV}=\text { kilovolt; } \mathrm{LCC}=\text { line-commutated converter; } \mathrm{MW}=\text { megawatt; MW-km = megawatt-kilometre. } \\
\text { Source: Ea (2014c), Electricity Grid Expansion in the Context of Renewables Integration in the Baltic Sea Region. }\end{array}$} \\
\hline
\end{tabular}

Figure 3.9 shows the assumed investment cost of expanding interconnection capacity between the regions in the model.

7 An HVDC transmission line costs less than an HVAC line for the same transmission capacity. However, it is also true that HVDC terminal stations are more expensive due to the fact that they must perform the conversion from $A C$ to $D C$, and $D C$ to AC. Over a certain distance, the so-called "break-even distance" (approximately 600-800 km), the HVDC alternative will always provide the lowest cost (ABB, 2015). 


\section{Figure 3.9 Investment costs for additional transmission line capacity}

\section{Investment costs for additional transmission capacity}

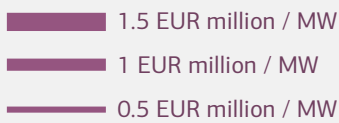

0.5 EUR million / MW 


\section{Main results}

\section{Development of the power system towards 2050}

The framework from the 2DS - in particular the high $\mathrm{CO}_{2}$ prices - leads to significant changes in the power system both in the Nordic region and in the other European countries. Most notably, thermal power capacity is reduced and replaced by wind and solar capacity.

All the results presented in this section are from the CNS-B baseline scenario.

\section{Figure 3.10}

\section{Development of electricity generation capacity in the overall} power system, CNS-B
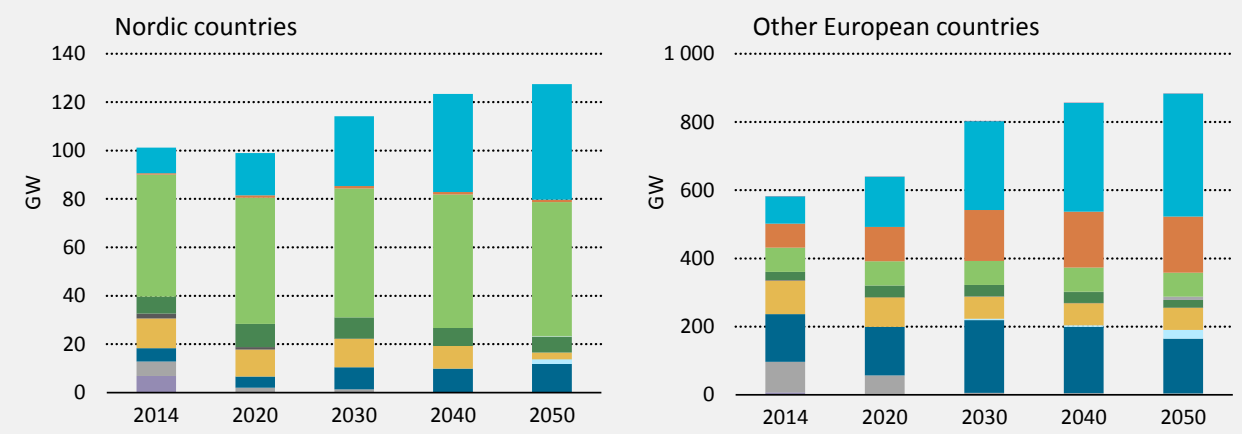

- Other renewables

Wind

Solar

Hydro

Biofuels + CCS

Biofuels and waste

- Other fossils

Nuclear

Natural gas with CCS

- Natural gas

Coal

- Oil

Figures and data in this report can be downloaded at www.iea.org/etp/nordic.

Key point

In both the Nordic and other European countries conventional generation decreases while wind capacity increases. Solar capacity increases in the other European countries in the long term.

The model shows VRE generation capacity (wind and solar) of about 40\% in the Nordic countries by 2050, as illustrated in Figure 3.10. By 2040, coal capacity has been eliminated from the Nordic system and thermal capacity at that point comprises nuclear, natural gas and biomass. When Sweden phases out its nuclear power, it is replaced by natural gas-powered capacity with significantly fewer operational hours. In the other European countries, the share of VRE capacity increases in a similar trend, although the level of thermal capacity remains at a higher level. In both the Nordic countries and the rest of Europe, CCS appears in the system by 2050. The model is allowed to use three fuels with CCS: coal, natural gas and biomass.

District heating demand is assumed to be almost constant as heat savings and more buildings connected to district heating outweigh each other. The production of district heating in the Nordic countries phases out coal, and gas is reduced by introduction of large heat pumps and solar heating (see Annex A).

Significant levels of investment are made in VRE between 2020 and 2030, mainly driven by the steep increase in the $\mathrm{CO}_{2}$ price, but also strengthened by ageing power plants in the Nordic countries that require replacement. The relatively higher share of investment in PV in the rest of Europe is due to lower full load hours (FLH) for wind in these areas and solar resources with higher FLH in comparison to the Nordic countries. 


\section{What is needed to secure VRE integration in the Nordic energy system?}

Based on the modelling in Balmorel, it is possible to identify the technology mix that is needed to follow the CNS-B pathway. The greatest increase in electricity production capacity is seen for wind power, and Table 3.5 shows where the model chooses to build new wind power. The model selects the cheapest technology available given the existing framework, hence the emphasis on onshore wind. It also optimises the whole Nordic energy system (and actually also for the rest of Europe), and as it minimises total system costs, it chooses to put up wind turbines at the best locations for the system.

\begin{tabular}{|c|c|c|c|c|c|c|c|c|}
\hline \multicolumn{2}{|l|}{ Table 3.5} & \multicolumn{7}{|c|}{$\begin{array}{l}\text { Wind power capacity in the CNS-B (Baseline, Flex) in the Nordic } \\
\text { countries }\end{array}$} \\
\hline Year & $\begin{array}{l}\text { Scenario } \\
\text { (MW) }\end{array}$ & $\begin{array}{c}\text { Denmark } \\
\text { Onshore }\end{array}$ & $\begin{array}{l}\text { Denmark } \\
\text { Offshore }\end{array}$ & $\begin{array}{l}\text { Finland } \\
\text { Onshore }\end{array}$ & $\begin{array}{l}\text { Finland } \\
\text { Offshore }\end{array}$ & $\begin{array}{l}\text { Norway } \\
\text { Onshore }\end{array}$ & $\begin{array}{l}\text { Sweden } \\
\text { Onshore }\end{array}$ & $\begin{array}{l}\text { Sweden } \\
\text { Offshore }\end{array}$ \\
\hline \multirow[t]{2}{*}{2020} & Baseline & 4069 & 2016 & 1600 & 900 & 3535 & 5210 & 215 \\
\hline & Flex & 4069 & 2016 & 1600 & 900 & 3535 & 5210 & 215 \\
\hline \multirow[t]{2}{*}{2030} & Baseline & 5209 & 2016 & 1600 & 1206 & 7023 & 11514 & 215 \\
\hline & Flex & 5209 & 2016 & 1600 & 1206 & 7023 & 14943 & 215 \\
\hline \multirow[t]{2}{*}{2040} & Baseline & 6344 & 2016 & 1600 & 1206 & 10512 & 18656 & 215 \\
\hline & Flex & 6344 & 2016 & 1600 & 1206 & 10512 & 24072 & 215 \\
\hline \multirow[t]{2}{*}{2050} & Baseline & 8000 & 2016 & 1600 & 1206 & 11602 & 23156 & 215 \\
\hline & Flex & 8000 & 2016 & 4303 & 1206 & 13548 & 31377 & 215 \\
\hline
\end{tabular}

Note: Coloured fields indicate a change in capacity compared to the previous period. Grey indicates an increase in the Baseline scenario and corresponding increase in the Flex scenario. Blue indicates an additional increase in the Flex scenario

The increasing share of VRE expected in the CNS-B can be handled in the Nordic energy system if different means for integration are present in an adequate amount and with the right timing. One of the most important means of integration is the linking together of the different regions with different resources and production facilities through the power grid. Demonstrating the need to strengthen the power transmission grid under the CNS-B, Table 3.6 shows extra transmission capacity installed by the model in the periods from 2030-40 and 2040-50, where Balmorel can make endogenous investments in the transmission grid.

In the CNS-B baseline scenario a range of flexible technologies are available: co-generation plants, large heat pumps, heat storage in district heating systems and hydrogen storage are all available (Table 3.7). In the Flex scenario, flexibility is increased by introducing flexible demand from buildings, industry, transport and fuel production. Adding further local flexibility options makes it easier to balance wind power locally, and therefore leads to fewer investments in the internal Nordic power grid. However, the greater flexibility also paves the way for higher investment in wind power in the Nordic countries (Table 3.5) and therefore an increased potential for exporting electricity to the rest of Europe. This then leads to an increase in electricity transmission capacity from the Nordic countries to rest of Europe. In the Flex scenario, the necessary gas capacity also decreases by $55 \%$. 


\begin{tabular}{|c|c|c|c|c|c|}
\hline Table 3.6 & \multicolumn{5}{|c|}{ Transmission capacity expansion in CNS-B baseline and Flex scenarios } \\
\hline Year & Unit & Scenario & $\begin{array}{l}\text { Nordic countries to } \\
\text { continental Europe }\end{array}$ & $\begin{array}{r}\text { Nordic countries to } \\
\text { Great Britain }\end{array}$ & $\begin{array}{r}\text { Within the Nordic } \\
\text { countries }\end{array}$ \\
\hline 2014 & MW & Baseline/Flex & 5140 & 0 & 30805 \\
\hline 2014-30 & MW & Baseline/Flex & 17256 & 2800 & 11150 \\
\hline \multirow[t]{2}{*}{$2030-40$} & MW & Baseline & 6079 & 2360 & 7966 \\
\hline & & Flex & 6911 & 2184 & 6287 \\
\hline \multirow[t]{2}{*}{$2040-50$} & MW & Baseline & 175 & 0 & 2966 \\
\hline & & Flex & 854 & 0 & 3264 \\
\hline $2030-40$ & Difference (MW) & Flex-Baseline & 832 & -176 & -1679 \\
\hline $2030-50$ & Difference (MW) & Flex-Baseline & 1511 & -176 & -1381 \\
\hline
\end{tabular}

Table 3.6 shows the capacity of electricity grids between the Nordic countries and continental Europe, from the Nordic countries to Great Britain and within the Nordic countries (linking all the price areas in Nord Pool together). 2014 values represent the existing grid. The rest of the table (from 2014 onwards) shows additional expansion within specific periods (exogenous expansion from 2014-30 and endogenous expansion from 2030-50). This means that to reach the total transmission capacity in 2050 in one of the scenarios, all the numbers for the relevant scenarios and for all periods must be aggregated.

Table 3.7 shows investments in some flexible technologies mainly in the district heating sector. Large heat pumps delivering district heating and heat storages linked to co-generations plants are important means to tie electricity and heat production together adding flexibility to the electricity system.

\section{Table 3.7}

Deployment of flexible technologies in the Nordic countries, CNS-B

\begin{tabular}{|c|c|c|c|}
\hline Year & Heat pumps (MW) & Heat storage (MW) & $\mathrm{H}_{2}$ storage (MW) \\
\hline 2014 & 1550 & 3957 & - \\
\hline 2020 & 4702 & 12111 & - \\
\hline 2030 & 7711 & 15911 & 23 \\
\hline 2040 & 9808 & 17830 & 61 \\
\hline 2050 & 11004 & 19388 & 212 \\
\hline
\end{tabular}

To give an indication of the relative competitiveness of technologies, Figure 3.11 provides a comparison of the levelised cost of electricity generation (LCOE), using technology, fuel and $\mathrm{CO}_{2}$ price assumptions for 2040. Onshore wind is the cheapest technology, followed by PV and offshore wind. Thereafter follow the three CCS technologies and natural gas, and finally the coal, biomass and wood power plants. Substantial uncertainties are linked to the projection of future technology costs; for example, if the LCOE of PV were reduced by $25 \%$ it would be on a level with onshore wind. It is important to stress that the LCOE only considers the cost of electricity generation and that the value of the electricity generated expressed by the earnings on the power market is not included. The Balmorel model selects the optimal portfolio of technologies taking into account the actual operational patterns and its earnings in the power market. Consequently, the need remains for thermal power plant capacity even though the LCOE is lower for wind turbines and solar PV. 


\section{Figure 3.11 LCOE}

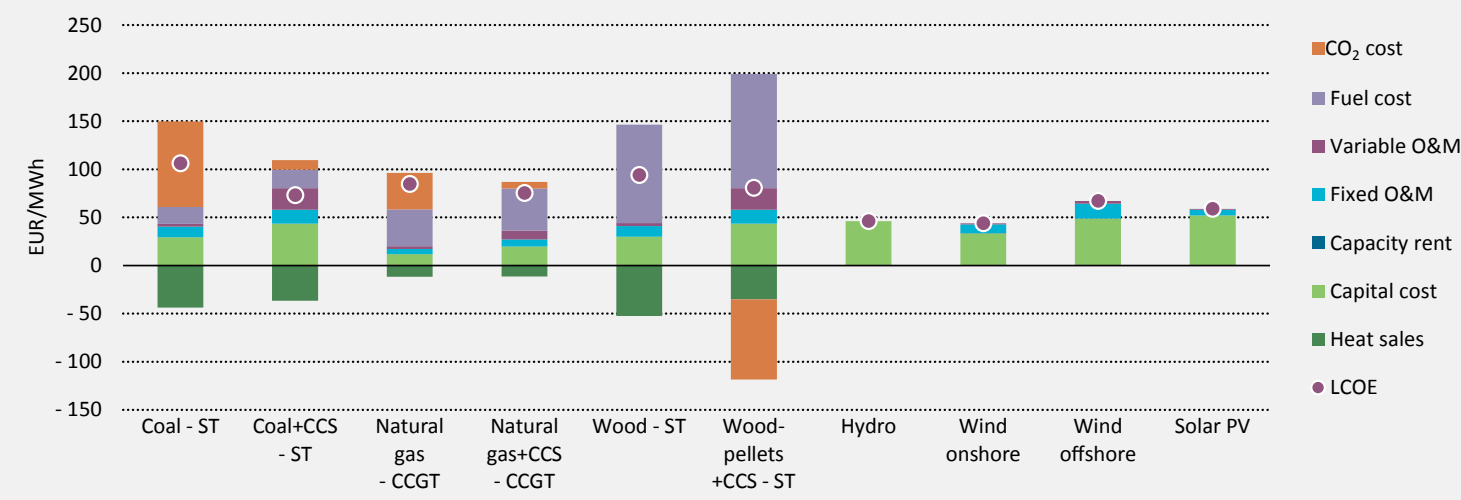

Notes: Assumes 6000 FLH for thermal power plants (all extraction plants), 3900 FLH for hydro, 2600 FLH for onshore wind, 4350 FLH for offshore wind and 1150 FLH for solar PV; discount rate 5\%; lifetime 20 years; the heat sales from co-generation plants reflect their actual income in the model simulations based on the marginal values of heat; hydropower is a combination of run-of-river and reservoir capacity; the fixed costs are included in the capital costs in this graph; CCGT = combined-cycle gas turbine; O\&M = operation and maintenance; $S T$ = steam turbine.

Figures and data in this report can be downloaded at www.iea.org/etp/nordic.

Key point $\quad$ Hydro, wind and solar power are expected to demonstrate the lowest LCOE by 2040.

The Nordic countries will increase electricity exports until 2030, when it stabilises. The other European countries import accordingly.

\section{Figure 3.12 Development of power generation in the overall system, CNS-B}
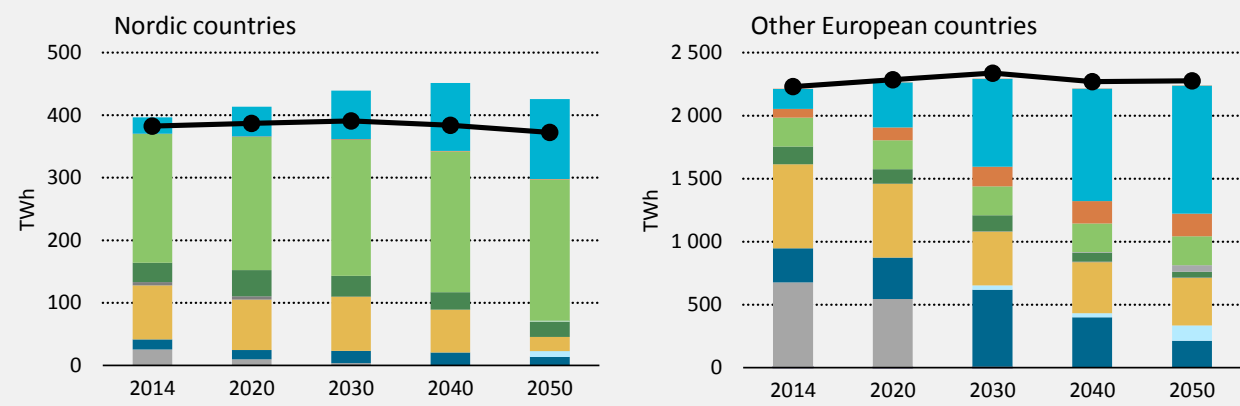

- Consumption Other renewables Wind

- Solar

Hydro

Biomass + CCS

Biomass and waste

- Other fossils

Nuclear

Natural gas with CCS

- Natural gas

Coal

Oil

Figures and data in this report can be downloaded at www.iea.org/etp/nordic.

Key point

By 2050 about 30\% of electricity generation is based on VRE and more than 50\% on hydropower in the Nordic countries. In the other European countries, almost $60 \%$ of electricity is generated from VRE. 
When looking at the generation mix in the Nordic countries, RES-E increasingly dominates and provides $90 \%$ of electricity generation in 2050 . Hydropower will continue to play an important role in the system, covering around 55\% as shown in Figure 3.12, while wind and PV cover $30 \%$ and biomass 5\% of generation. The remaining generation consists of 5\% natural gas and $6 \%$ nuclear.

Individual Nordic countries have wide variations in their power generation mix, which is linked to the historic development and availability of different resources in each country. Figure 3.13, which shows the composition of electricity generation for each of the four countries, underlines how different the systems are.

\section{Figure 3.13}

Development of electricity generation in individual Nordic countries, CNS-B
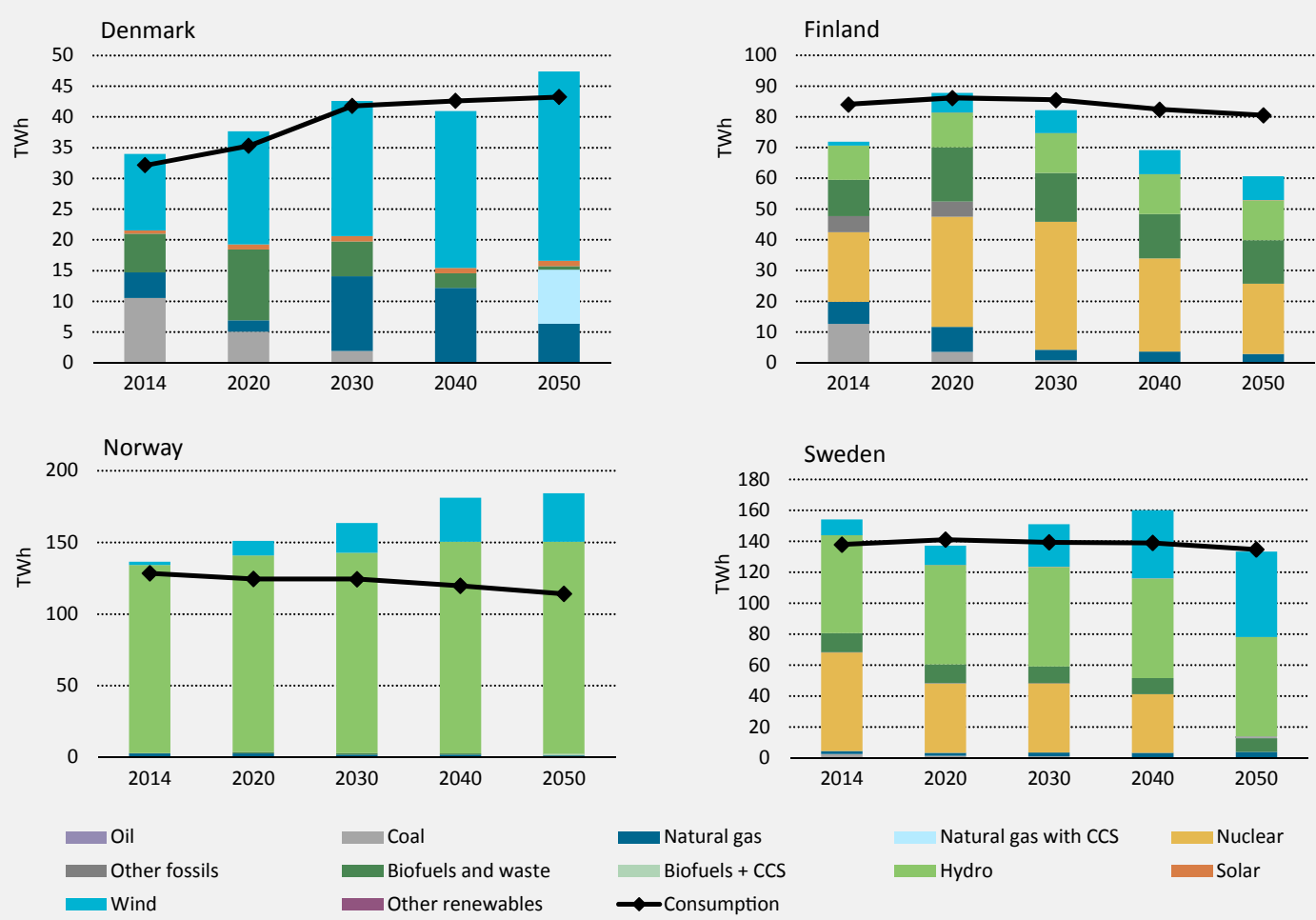

Figures and data in this report can be downloaded at www.iea.org/etp/nordic.

Key point

By 2050, Sweden will have phased out its nuclear capacity while Finland will have decreased its nuclear-based electricity generation. Denmark will have deployed significant generation capacity based on gas co-generation with CCS capability.

In Finland and Sweden, nuclear capacity decreases after 2030 (development taken from CNS in chapter 1), with a total phase-out for Sweden by 2050 as illustrated in Figure 3.13. The Swedish nuclear fleet is expected to live out its technical lifetime whereafter no new investment in nuclear power is anticipated. This development affects the total generation in both countries, 
making Finland a net importing country (25\% of total electricity demand is imported in 2050). Norway steadily increases hydro and wind power generation over the years, covering close to $160 \%$ of its own national demand by 2050 . In Denmark, natural gas co-generation with and without CCS becomes attractive towards 2050. Plants with CCS run as baseload, whereas plants without mainly provide peak power. A share of the gas used in these plants could be biogas, but this option is not included in the model setup. In the case of using biogas in a cogeneration plant with CCS, it would lead to a net reduction in $\mathrm{CO}_{2}$ instead.

The growth in Norwegian electricity exports is due to its outstanding hydro and wind resources, and an expectation of decreasing electricity demand - particularly for heating. In 2013, Norway produced $110 \%$ of its national power demand. This potential for electricity export from Norway will, however, rely heavily on Norway's ability to decrease its electricity demand through improvements in end-use efficiency, as well investment in wind turbines and additional hydropower plants.

Wind and solar resources are less favourable in Finland, which is why the model prefers to invest in these options in the other countries and then export the electricity to Finland.

It should be stressed that the simulations do not necessarily consider the differences in acceptance levels of onshore wind turbines from country to country. The political will to accept wind turbines may be less in Norway, which is dominated by open landscapes compared to Sweden or Finland, where forests predominate.

\section{Development of $\mathrm{CO}_{2}$ emissions from heat and power generation in the Nordic countries}

The increasing share of RES-E production and the resulting reduction in coal (and peat) consumption have a clear impact on $\mathrm{CO}_{2}$ emissions in the power and heating system. Between 2014 and 2030, emissions decrease drastically from around $50 \mathrm{MtCO}_{2}$ to well below $20 \mathrm{MtCO}_{2}$. Towards 2050, annual emissions in the Nordic countries are further reduced to approximately $10 \mathrm{MtCO}_{2}$ (net emissions), as shown in Figure 3.14.

\section{Figure 3.14 Development of $\mathrm{CO}_{2}$ emissions in the Nordic countries, CNS-B}

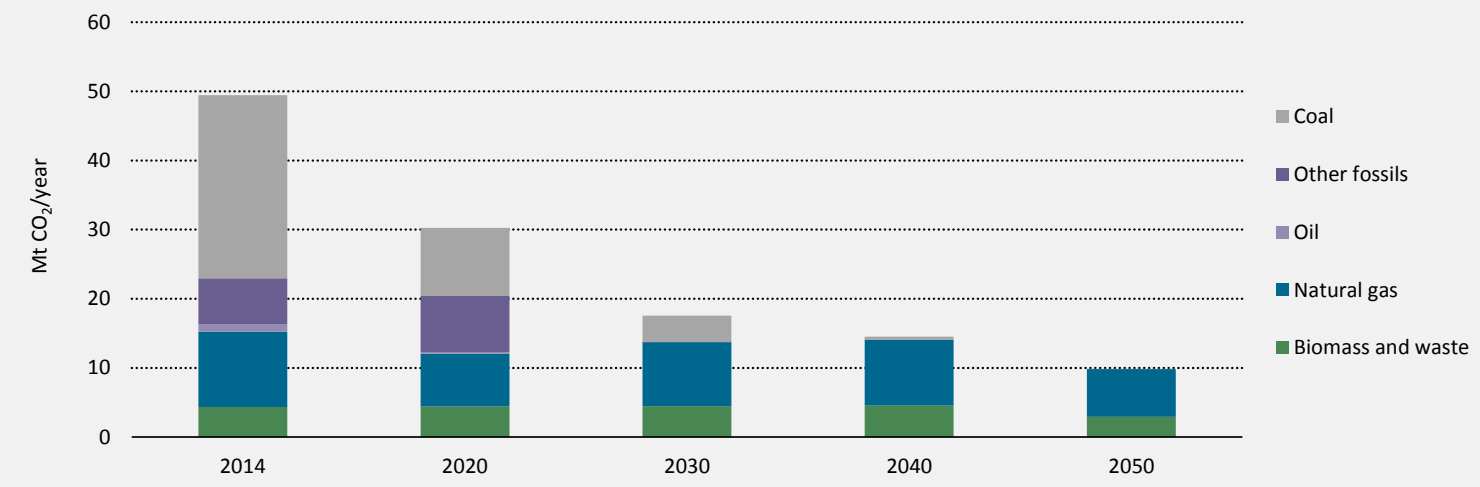

Note: In the Nordic countries, other fossils comprises almost exclusively of peat.

Figures and data in this report can be downloaded at www.iea.org/etp/nordic. 
Sensitivity analysis shows that the split between biomass and natural gas co-generation is very sensitive to the fuel and $\mathrm{CO}_{2}$ price assumptions. A small drop in the biomass price would change the picture and the model would invest in biogas plants instead of natural gas plants. This would significantly reduce $\mathrm{CO}_{2}$ emissions.

\section{Development of electricity prices in the system}

Increasing fuel prices and the surging $\mathrm{CO}_{2}$ price between 2020 and 2030 lead to a steep increase in electricity prices in the system, as illustrated in Figure 3.15. Despite the continued rise of the $\mathrm{CO}_{2}$ price in 2040 and 2050, electricity prices drop in Denmark and the other European countries. This is due to model-based transmission capacity investments, which are not allowed until after 2030, giving access to better renewable energy sources, with lower costs and improved system integration. Nordic electricity prices are generally lower due to higher VRE generation compared to continental Europe. The price in Denmark is higher than for the other Nordic countries because the Danish grid is closely tied to continental Europe and Great Britain.

\section{Figure 3.15} European countries, CNS-B
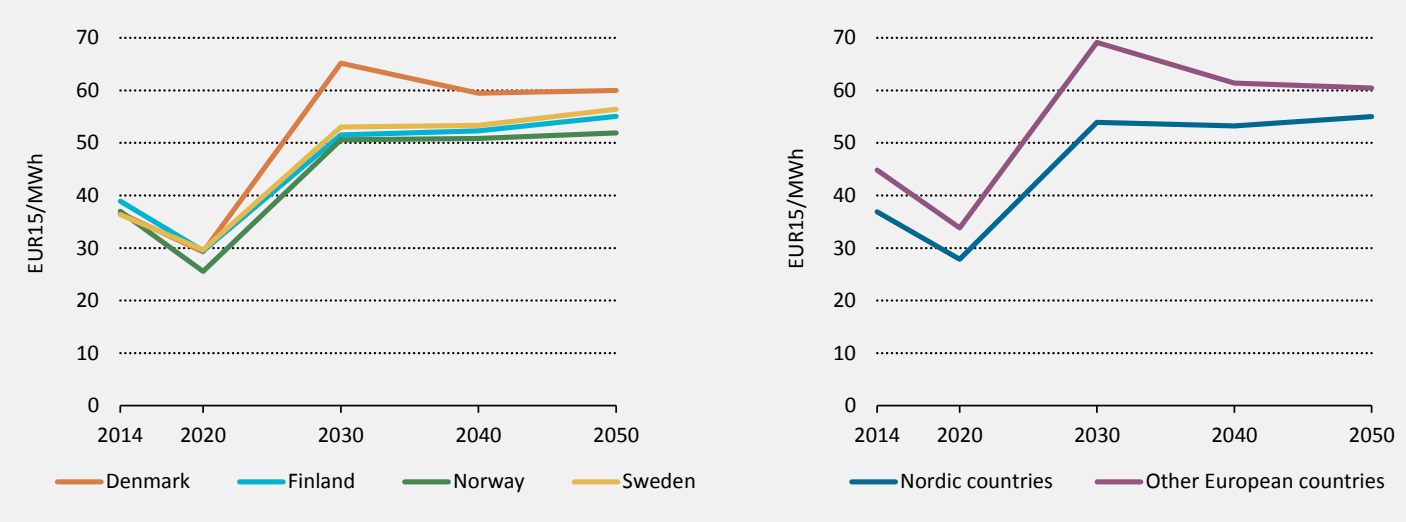

Note: EUR15 = prices in real 2015 EUR, i.e. excluding inflation.

Figures and data in this report can be downloaded at www.iea.org/etp/nordic.

\section{Key point}

In the Nordic countries, steep increases in the electricity price are envisaged between 2020 and 2030, due to the increase in $\mathrm{CO}_{2}$ prices. Denmark is more closely connected to continental Europe and therefore has a higher electricity price compared to the other Nordic countries.

\section{Market integration of VRE}

High penetration of wind power drives expensive power plants out of the electricity market, thus reducing the electricity price. The first megawatt of wind power capacity will often have a relatively high value - even higher than the average wholesale market price - because wind turbines usually produce more during the winter, when power prices tend to be higher. However, at higher shares wind begins to have an influence on market prices, driving expensive power plants out of the market, thereby lowering the market price of electricity. In this way, wind power reduces wholesale electricity prices during periods of high wind generation. 
The co-ordination of power supply in the Nordic power market traces its origins to Foreningen Samkjøringen, a power exchange formed by Eastern Norwegian electricity companies in 1932. In 1971 the exchange merged with the regional exchanges in other parts of Norway, and became Samkjøringen av kraftverkene (Samkjøringen). Samkjøringen was originally designed to balance out variations in precipitation and water inflow to hydropower stations, but in 1993 it became a market place open to all generators and consumers of electricity in Norway, and expanded to the other Nordic countries in the following years (Amundsen, E.S. and L. Bergman, 2007). It was developed to exploit beneficial interaction between hydropower and large thermal power plants located in Denmark, Finland and Sweden. This was shown to be highly effective. In low precipitation years, Norway and Sweden imported power from coal, gas and biomass-fired power plants in Denmark and Finland. In high precipitation years, Norwegian and Swedish hydropower was exported to Denmark and Finland (and later on also to other countries in Northern Europe).
Simultaneously with the liberalisation of the energy markets, a common exchange (Nord Pool) was introduced in 1996 and even small power suppliers were allowed to trade, providing a very liquid market with reliable prices. The Nordic power exchange, Nord Pool (from March 2010 within Nasdaq OMX Commodities), now covers Denmark, Norway, Sweden, Finland and the three Baltic countries.

Nord Pool operates a day-ahead spot market with regional hourly prices (Elspot), an intraday market with continuous power trading up to one hour prior to delivery (Elbas - Electricity Balance Adjustment Service), a regulating power market and a financial market for the coming days, weeks and months, and annual contracts up to five years, as illustrated in Figure 3.16. The participants in the markets are power producers, distributors, industries and brokers. Nord Pool Spot AS acts as counterpart in all contracts and all trades are physically settled with respective TSOs (Nord Pool, n.d.).

\section{Figure 3.16 Nord Pool market operation}

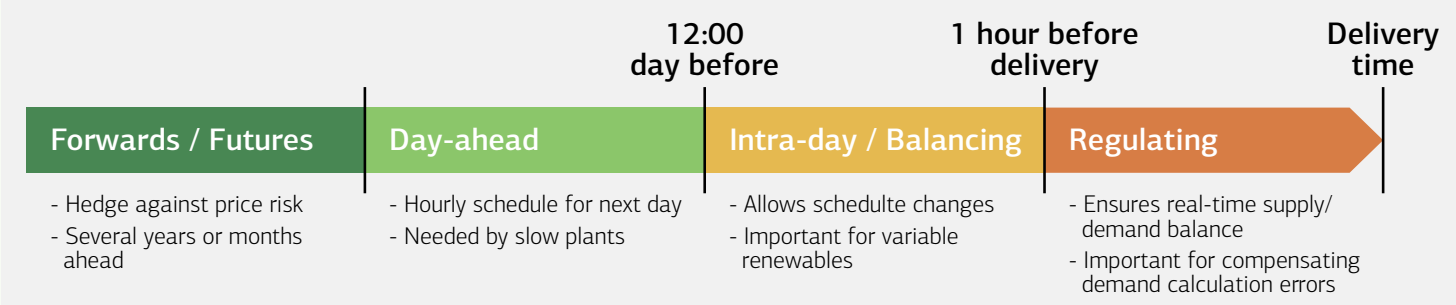

Source: Morales, J.M. (2015), Material from MSc. course, “Decision-making under uncertainty in electricity markets” https://sites.google.com/site/ decmakem/material.

Figures and data in this report can be downloaded at www.iea.org/etp/nordic. 
Deviations between planned supply and demand in real time must be covered by balancing power in the regulating power market. Therefore the fundamental reason for having a balancing market is uncertainty about supply and demand. Regulating power can be understood as production capacity or consumption that is offered by market players to the TSO during the actual day of operation.

Research has revealed the pattern of prices on the Nordic regulating power market (Skytte, 1999). The level of the regulating power price depends on the level of the corresponding spot price and the amount of regulation needed. Compared to the spot price there is a premium for readiness, which is independent of the amount of regulating power but dependent on the corresponding spot price. On the day-ahead market, a "system price" is calculated covering the whole Nord Pool area assuming no network constraints. In hours when congestion occurs on interconnections between bidding areas, separate day-ahead area prices are calculated on the basis of the bids from each area, with Finland, Sweden and Norway divided in two or more areas and Denmark divided into east and west. This means that congestion is managed by price differences resulting from these implicit auctions. The Nordic market is coupled to the power pools in Germany and the Netherlands through implicit auctions. The spot market bids are stated before noon for next day's operation (12-36 hours before delivery).

Sources: Amundsen, E.S. and L. Bergman (2007), "Integration of multiple national markets for electricity: The case of Norway and Sweden", Energy Policy, Vol. 35(6), pp. 3 383-3 394; Nordpool (n.d.), www.nordpoolspot.com (accessed 23 February 2016); Skytte, K. (1999), "The regulating power market on the Nordic power exchange Nord Pool: an econometric analysis", Energy Economics, Vol. 21, pp. 295-308.

Figure 3.17 shows the stylised supply and demand curve for the Nordic countries and Germany, in which wind power and hydro are the cheapest power plants, followed by nuclear, coal (applying the night-time electricity price), biomass, gas (applying the daytime electricity price), and finally the most expensive power plants fuelled by oil.

\section{Figure 3.17 Stylised supply and demand curve for the Nordic and German electricity markets}

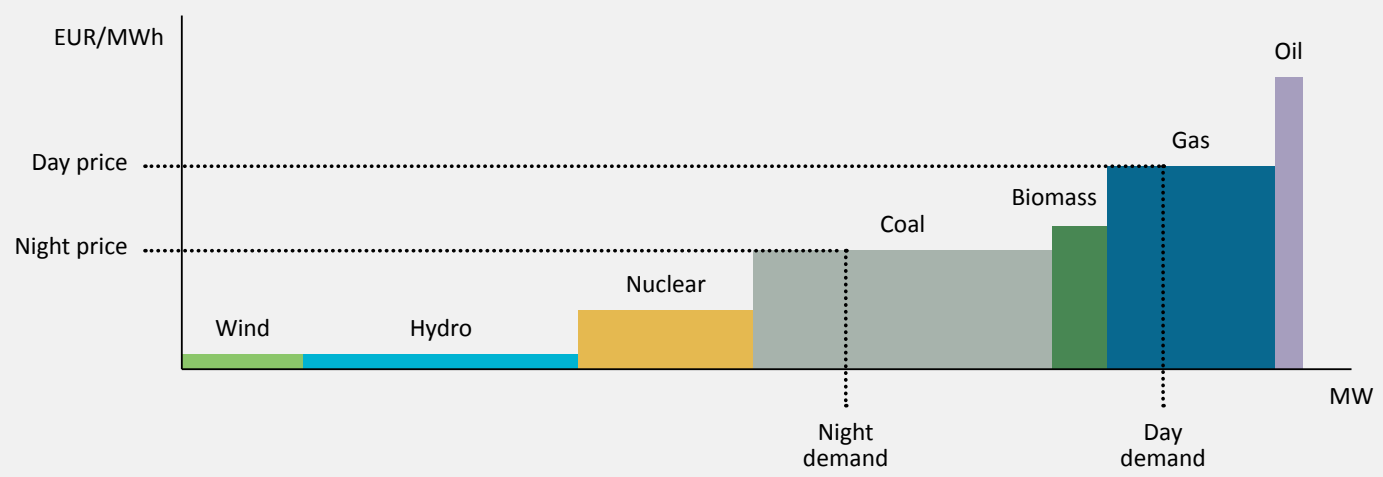

Source: Ea (2007), 50\% Wind Power in Denmark in 2025, www.eabalmorel.dk/files/download/Projects/50_per_cent_wind_power_in_Danmark_in_2025_ July_2007.pdf.

Figures and data in this report can be downloaded at www.iea.org/etp/nordic.

Key point $\quad$ VRE drives the expensive power plants out of the electricity market 
Figure 3.18 shows the difference between the average electricity wholesale market price (time-weighted) and the wind power price (power prices weighted by wind power generation) in Western Denmark in 2002-14 (line). This is compared to the share of the consumption covered by wind power (columns). Perhaps surprisingly, the price drop ${ }^{8}$ is relatively high in the beginning of the period, at around 10-14\% in 2002 and 2003, before dropping to about 5\% in 2009-11. This trend is attributed to the flexibility measures introduced during the same period in Denmark. As a noticeable example, the decentralised co-generation plants were provided with the incentive to move from fixed feed-in tariffs (graduated depending on the time of the day) to settling at the power market price. During the same period (2002-10), the share of wind power grew only moderately. Since 2011, the wind share has increased significantly, and during the last three years, the price difference has returned to around 10-14\%.

\section{Figure 3.18}

Price drop compared to the wind share in Western Denmark, statistical and model results, CNS-B

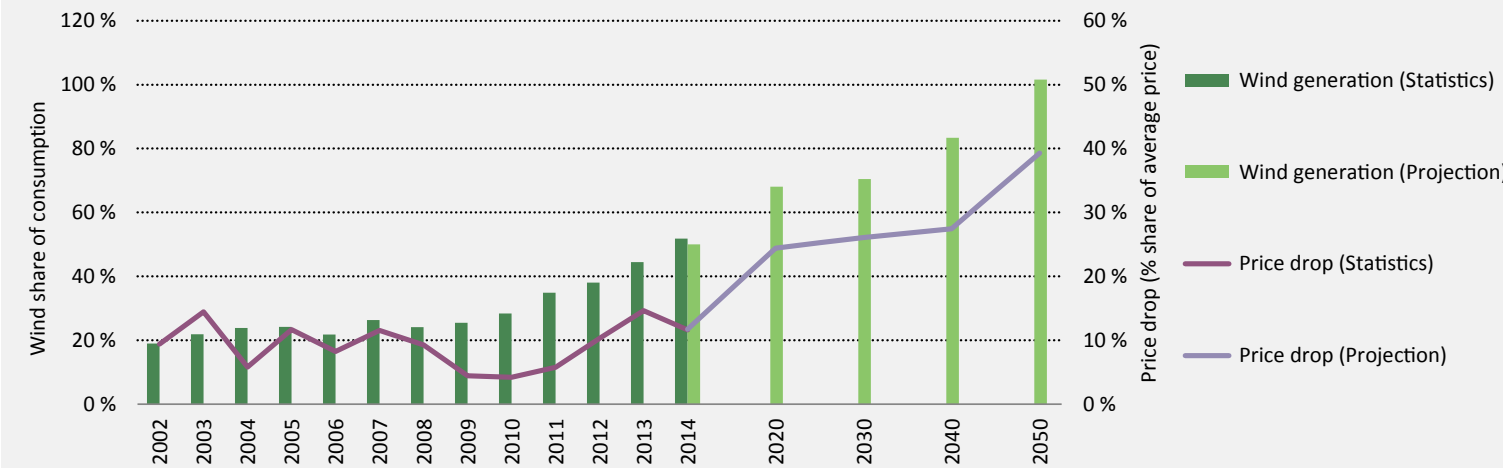

Note: For wind power generators, power price was weighted by wind power generation, and for average wholesale electricity market price, time was weighted for Western Denmark from 2002 to 2014.

Source: Ea (2015), The Danish Experience with Integrating Variable Renewable Energy, study on behalf of Agora Energiewende.

Figures and data in this report can be downloaded at www.iea.org/etp/nordic.

Key point
The greater the amount of wind power fed into the system, the more the system's price drops; however, this is not only dependent on increases in wind power, but also on the overall flexibility of the power system, such as links to hydropower systems, the flexibility of power plants and the availability of interconnectors. In Western Denmark, the price drop of wind power will increase as its share of generation increases towards to 2050. The wind share of about $100 \%$ by 2050 results in a $40 \%$ electricity price drop.

The power market model simulations show that the price drop caused by wind power will increase as its share of generation increases towards to 2050. The price drop may increase to around 25\% in Western Denmark as early as 2020 and by 2050, where wind power makes up $100 \%$ of total demand, the drop is projected to increase to more than $40 \%$ as illustrated in Figure 3.18.

8 The price drop for wind generation is the drop in electricity price that is seen when it is weighted for wind power generation. Generally, electricity prices are lower when there are large amounts of wind in the system. Therefore wind generators experience a lower than average electricity price. 
In other Nordic countries, the share of wind power is lower than the conditions for wind power allow. The price drops for wind are therefore lower. By 2050, the price drop is 19\% in Norway, 17\% in Sweden and only 13\% in Finland.

One would assume a lower price drop in Norway relative to Sweden, due to the lower wind share and greater possibilities of balancing with hydropower. However, by 2050 the southern parts of Norway are strongly interconnected to the United Kingdom, the Netherlands, Germany and Western Denmark, exhibiting even stronger wind price drops as illustrated in Figure 3.19.

\section{Figure 3.19}

Wind power price drop in the Nordic countries by 2050 relative to their share of wind power, CNS-B

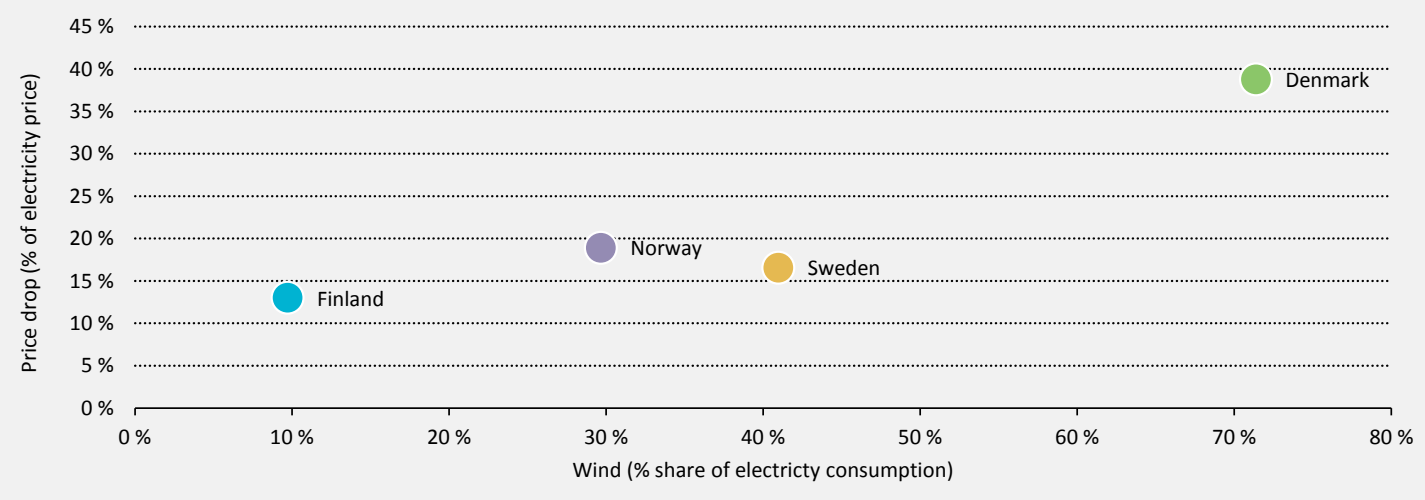

Source: Ea (2015), The Danish Experience with Integrating Variable Renewable Energy, study on behalf of Agora Energiewende. Figures and data in this report can be downloaded at www.iea.org/etp/nordic.

Key point Denmark has the highest share of wind and demonstrates the highest price drop. The relatively high Norwegian price drop is probably attributable to the strong connections to the United Kingdom, Germany, the Netherlands and Western Denmark.

If all relevant externalities, such as the cost of $\mathrm{CO}_{2}$ and local pollution, are internalised through taxes or quotas, the electricity price is a good proxy of the socio-economic value of electricity. If these conditions are fulfilled, the value that a wind turbine or any other electricity generation technology can obtain for its production on the market can also be regarded as the socio-economic value of its production?. 
High penetration of wind will, among other factors, lead to a significant price drop as shown in Figure 3.19. Hirth and Muller (2015) have shown that by installing "advanced wind turbines" 8 in Germany, the relative economic value of electricity from wind is $22 \%$ higher than classical wind turbines in a scenario with a $30 \%$ share of wind relative to demand. This study also demonstrated that future deployment of advanced wind turbines would reduce requirements for grid expansion, flexibility and storage. Therefore, the notion of systemfriendly wind power opens an important discussion concerning the design of future wind turbines, since the economic value of electricity from wind power depends directly on this factor.

Source: Hirth, L. and S. Müller (2015), "System-friendly wind power", presentation at Berlin Conference on Energy and Electricity Economics, 28 May, www.diw.de/documents/dokumentenarchiv/17/diw_01.c.506693.de/hirth_belec.pdf..

\section{Power market structure in the future}

Today, the Northern European electricity market is highly effective both within the Nordic region and also in its connectivity to the electricity markets of surrounding countries. The current infrastructure, technology mix and market organisation within the Nordic power market has, to date, been able to handle the current amount of VRE with, for example, wind power at more than 50\% of regional consumption in Western Denmark (Jacobsen, $\mathrm{H}$. and E. Zvingilaite, 2010) and (Grohnheit, P.E., F.M. Andersen and H.V. Larsen, 2011). The most important features that enable the region to handle the variability and unpredictability of wind power are its international transmission lines and its large number of hydropower and co-generation systems with heat storage.

This illustrates how well wind and hydropower complement each other in the Nordic area and how the Nordic power market design supports this. Hydropower generation is highly variable on an annual level, whereas annual wind power generation is much more predictable. The opposite is true in the short term (e.g. at the day-ahead market) where wind power is the variable generation and hydropower can be controlled according to the filling of the water reservoirs.

This synergy implies that on the one hand, hydropower can supply short-term power flexibility that facilitates the integration of wind power in the system. On the other hand, wind power can substitute hydropower during windy periods and thereby release more hydropower capacity that can be used to supply short-term power flexibility or be transmitted to neighbouring countries. This is beneficial to all. Hydropower helps lower the system integration costs of wind, which increases the value of wind. Wind helps increase the value of hydropower by releasing capacity that can be used during high price periods.

It has been questioned whether the energy-only market model is capable of providing proper incentives for investors as the proportion of generation technologies with no or very low marginal operating costs entering the market increases. Market theory and the model simulations in this study confirm that proper investment signals will be provided in the energyonly market. However, the price pattern will differ significantly from today (see Figure 3.20). It will result in more hours with very low prices and more hours with very high prices.

Investors in the market will have to adapt to this price picture. The demand for peak power units will increase, while investment in base power capacity will become less profitable. Similarly, low cut-in wind turbines, which are able to utilise low wind speeds, will have a higher

10 Wind turbines with a higher tower, lower specific rating (watts per square metre $\left[\mathrm{W} / \mathrm{m}^{2}\right]$ ) and increased capacity factor. 
value for the system than classical wind turbines since the low cut-in turbines will be less affected by the wind-induced price drop. As shown in Figure 3.20, the increasing difference in electricity prices will also make it more attractive to invest in technologies that are able to directly or indirectly store electricity from one hour to another.

\section{Figure 3.20}

\section{Duration curve of electricity prices in the Nordic countries in} 2030 (CNS-B model result)

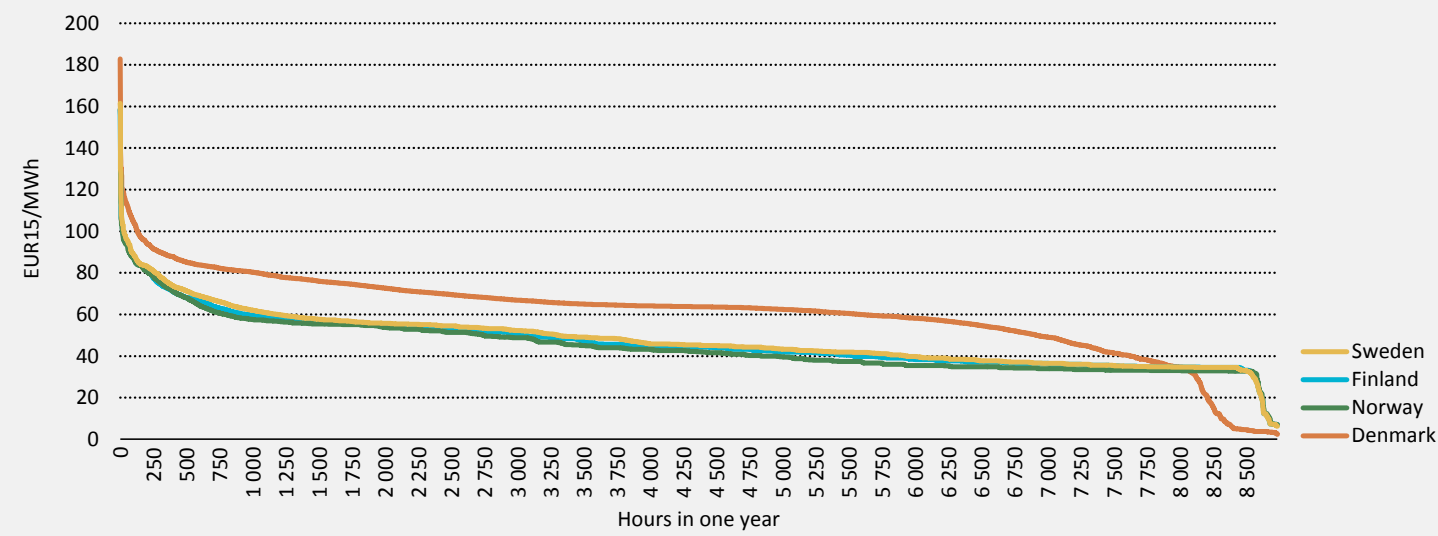

Figures and data in this report can be downloaded at www.iea.org/etp/nordic.

Key point

In the Nordic countries, the difference between electricity prices will make investment in storage technologies more attractive in the medium term.

The electricity market simulation assumes that $\mathrm{CO}_{2}$ prices will increase sharply to 2030 from current levels. In the scenarios the high $\mathrm{CO}_{2}$ price provides the key driver for the further deployment of renewable energy. In today's energy market the $\mathrm{CO}_{2}$ price is very low and investment in renewables is mainly incentivised by dedicated support schemes. Unfortunately many support schemes fail to support system-friendly renewable energy technologies.

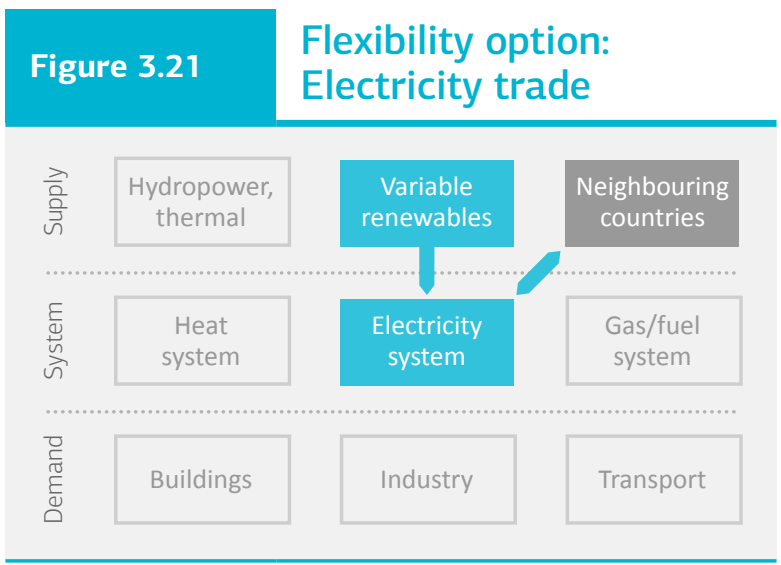

As an example, new onshore wind power projects in Denmark used to receive a nominal feed-in premium (FIP) of DKK 0.25 per kilowatt hour (kWh) (EUR 0.034/kWh) on top of the spot market price for the first 22000 full-load hours. ${ }^{11}$ After the equivalent of 22000 full-load hours was generated, the wind farm had to source its revenue solely from the electricity wholesale market price (Danish Energy Agency, 2015). This system provided incentives for developers to install high-rated and less system-friendly turbines in order to maximise support. For example, a $2 \mathrm{MW}$ wind turbine received the FIP for $44000 \mathrm{MWh}$ of generated power, whereas a $3 \mathrm{MW}$ wind turbine obtained the premium for $66000 \mathrm{MWh}$ of generation.

11 Also, a subsidy of DKK 0.0237/kWh (EUR 0.0032/kWh) was awarded for the technical lifetime of the wind power project to cover balancing costs (Energinet, 2015). 
The very high average capacity rating of wind turbines installed in Denmark (e.g. averaging $3 \mathrm{MW}$ in 2012) can be attributed to a certain extent to the onshore wind power support scheme that was in effect until the end 2013. As of 2014, the legislation was changed to cope with the above-mentioned challenges. The power production eligible for the FIP is now dependent on both the turbine generator size and the rotor size.

With the growing share of variable renewables in the energy system, it becomes increasingly important that system-friendly renewables are promoted. Moving from direct subsidies to indirect subsidies in the shape of $\mathrm{CO}_{2}$ and pollution taxes (or quotas) will give the proper incentives to investors. Conversely, indirect support for renewable energy technologies is likely to expose investments to higher risks compared to the support schemes that guarantee a fixed subsidy (FIP) or even a fixed tariff (feed-in tariff). In the end, this may lead to higher consumer prices. It will become an important challenge in the Nordic countries and the rest of Europe to develop incentive structures that send proper price signals to market players and at the same time providing high stability and security to investors in renewable energy.

The Nordic system has been adept at integrating wind power, in particular due to its flexible hydropower capacity. However, there are limitations to the flexibility of hydropower, and grid constraints also limit access to hydropower balancing. By 2030 situations arise where high wind generation and strong imports reduce hydropower generation to a minimum (see Figure 3.32). Looking ahead, it will be necessary to identify flexibility from other energy sectors at low cost, in particular demand response, stronger coupling to other energy markets (heat, gas and transport) and the use of new technologies, e.g. electricity storage or EVs (Mathiesen, B.V. and H. Lund, 2015).

\section{Electricity trade}

The Nordic countries are endowed with great renewable energy potential that could possibly lead to a green generation surplus in the coming years, which could then be exported to continental Europe. Exploiting this potential requires closer grid integration, which at the same time offers significant system benefits that will increase with higher shares of VRE in the European grids:

- Nordic hydropower plants have a limited water resource, but the plants may be operated in a very flexible way. In this way they act indirectly as storage of VRE generated in the Nordic countries or imported from other European countries.

- Closer integration of grids will lead to more stable renewable energy generation because wind power (and to some extent solar power) demonstrates significant geographic smoothing effects.

- Flexible resources in both generation and demand could be shared across regions to a greater extent. These include resources for back-up when wind and solar power plants are not actively generating, as well as ancillary services to ensure that the system operates smoothly.

\section{Power transmission system and balancing options}

The simulations conducted for this chapter foresee transmission capacity between the Nordic countries and the rest of Europe increasing drastically between 2014 and 2040, as shown in Figure 3.22. Until 2030, these numbers are exogenous inputs based on the ENTSO-E TYNDP (ENTSO-E, 2014). In 2040 and 2050, model-based investments in transmission are added. In 
2040, a steep increase in capacity is seen to accommodate increasing VRE generation. The value for 2050 remains about the same as net exports from the Nordic countries decrease (due to decreasing nuclear generation). It should be noted that the need for internal grid reinforcements might be underestimated somewhat with the presented expansion of interconnectors.

\section{Figure 3.22}

Development of the transmission capacity between the Nordic countries and their vicinity in the CNS-B
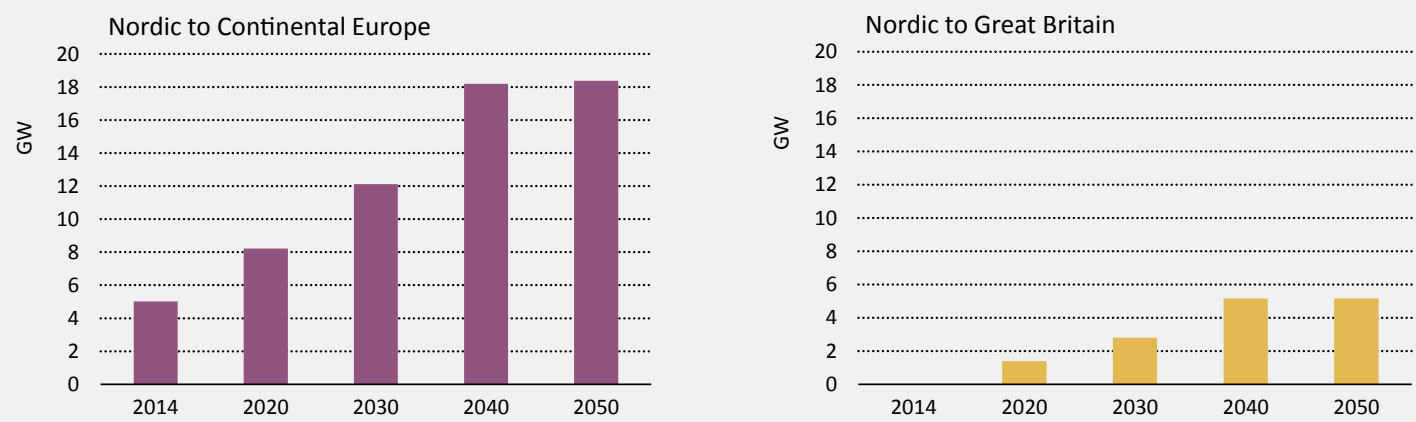

Figures and data in this report can be downloaded at www.iea.org/etp/nordic.

Key point

Transmission capacity between the Nordic countries and continental Europe will steadily increase from 2014 until 2040, while it will remain constant from 2040 until 2050. Similar behaviour is expected between the Nordic countries and Great Britain.

\section{Figure 3.23}

Development of electricity transmission from the Nordic perspective in the CNS-B
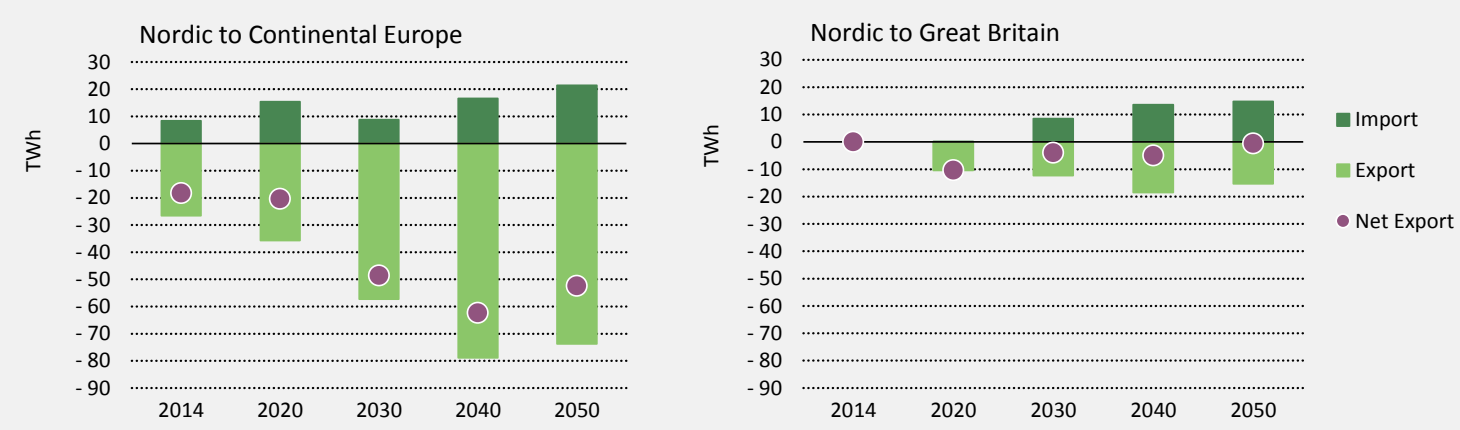

Note: Import = import into the Nordic countries.

Figures and data in this report can be downloaded at www.iea.org/etp/nordic.

Key point

The Nordic countries are net electricity exporters to continental Europe, with this role increasing in the long term, while transmission between the Nordic region and Great Britain is balanced. 
The transmission numbers show that the Nordic region is a net exporter for all the years modelled, with a maximum annual level in 2040 as depicted in Figure 3.23. Regarding the connections with continental Europe, the Nordic countries are an exporting region due to better wind conditions. The large hydro capacity also allows the Nordic countries to fit their generation to the needs of continental Europe. In 2050, there is a large drop in nuclear capacity in Sweden, which explains the lower export value.

Transmission between the Nordic region and Great Britain is of the same order in both directions, indicating that the transmission lines are used for balancing and smoothing wind generation between the two regions.

\section{Figure 3.24}

\section{Duration curves between the Nordic countries and surrounding} countries in 2030 in the CNS-B

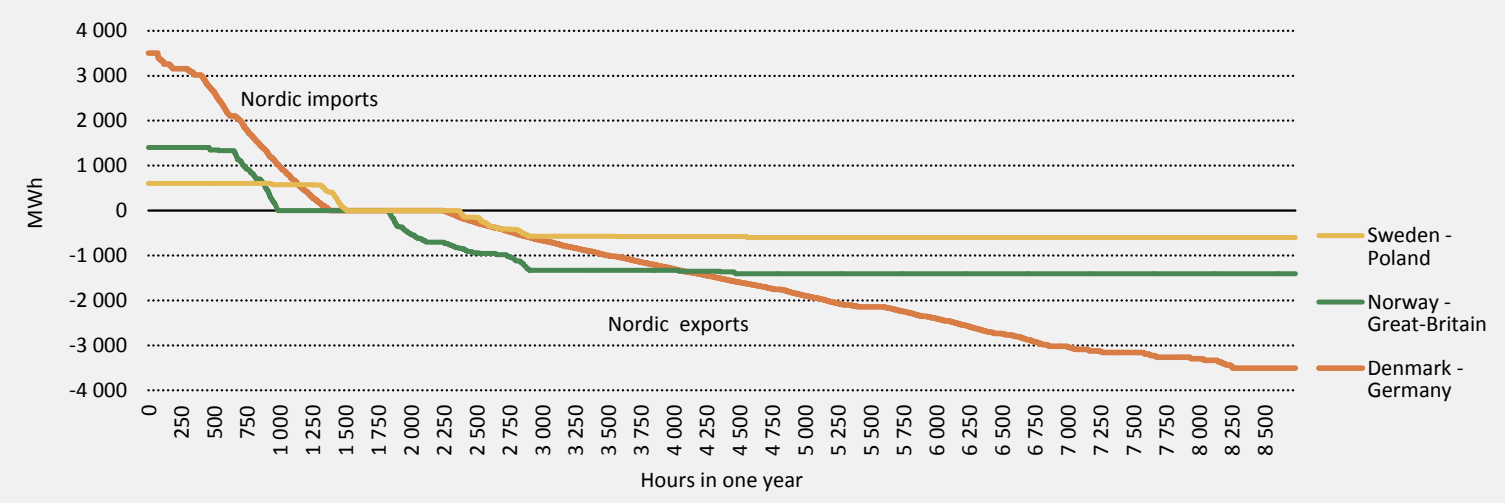

Note: Duration curves between the Nordic countries and the surrounding countries for the utilisation of selected transmission lines. Figures and data in this report can be downloaded at www.iea.org/etp/nordic. Germany, while it remains relatively constant most of the year from Norway to Great Britain and from Sweden to Poland.

The interconnectors between Denmark and Germany are rarely utilised at their full capacity, as shown in Figure 3.24. This is related to the high capacities available but it may also reflect that the generation portfolio in the electricity systems in Northern Germany and Denmark resemble each other. This reduces the benefits of trade. Moreover, wind power smoothing effects are relatively small due to the geographical proximity of the regions. On the other hand, the connections from Norway to Great Britain and Sweden to Poland are fully utilised for most hours of the year, indicating that significant benefits may be available from reinforcement.

For all three connectors, imports to the Nordic countries take place for around 2000 hours a year, with exports during the remaining hours. 


\section{Figure 3.25}
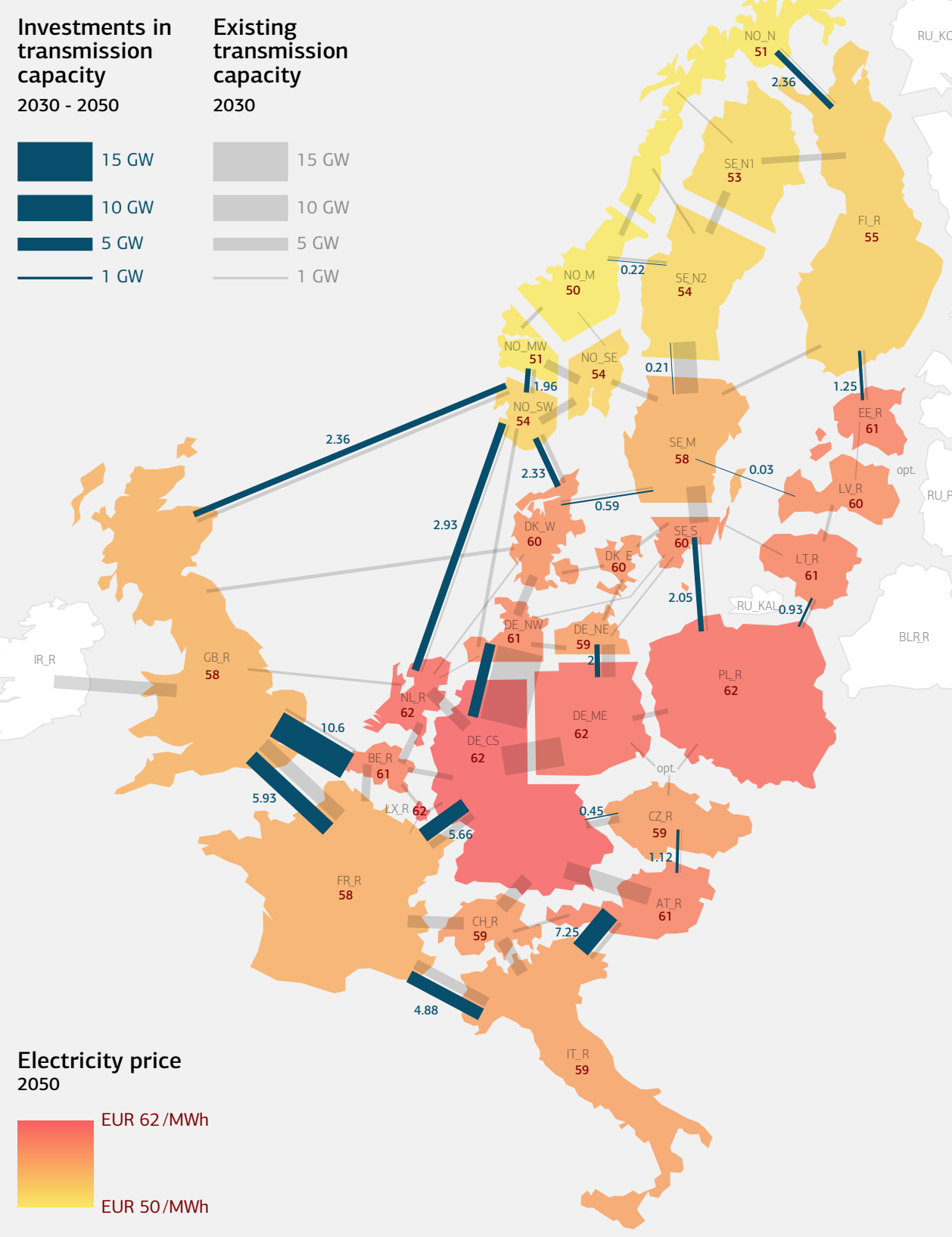

Note: Investments in transmission capacity between 2030 and 2050 and electricity price per region in 2050 are endogenous. This map is without prejudice to the status of or sovereignty over any territory, to the delimitation of international frontiers and boundaries, and to the name of any territory, city or area. Figures and data in this report can be downloaded at www.iea.org/etp/nordic.

Key point In 2050, access to hydropower and cheap balancing will lead to somewhat lower electricity prices in the Nordic countries than in other European countries. 
Between 2030 and 2050, the model chooses to invest in several important interconnectors to bridge large electricity price differences or improve balancing between regions, as shown in Figure 3.25. Great Britain is strongly connected to both the Nordic region and continental Europe due to its good wind resources (see wind FLHs in Annex A). A very large connection to Belgium, which has limited wind potential and a nuclear phase-out by 2025, allows Great Britain to export at times of high wind generation. Considering the long lead-time of interconnectors and the need for reinforcement in both Great Britain and Belgium, these specific results should be viewed with reservation. A more meshed development with stronger connections between Great Britain, France, Belgium and the Netherlands is probably more likely.

Strong connections between France (with high wind capacity and generation) and Germany (with lower penetration levels) are also established.

Norway becomes more strongly connected to Great Britain and the Netherlands by 2050, to better utilise Norwegian wind and hydro potentials and to balance wind power with hydro generation.

Figure 3.26 shows hourly transmission between the Nordic countries and their neighbours in two selected weeks in 2030. It is apparent that Germany is the most important trade partner for the Nordic countries.

\section{Figure 3.26}

\section{Hourly transmission between the Nordic region and surrounding} countries for two weeks in 2030 in the CNS-B

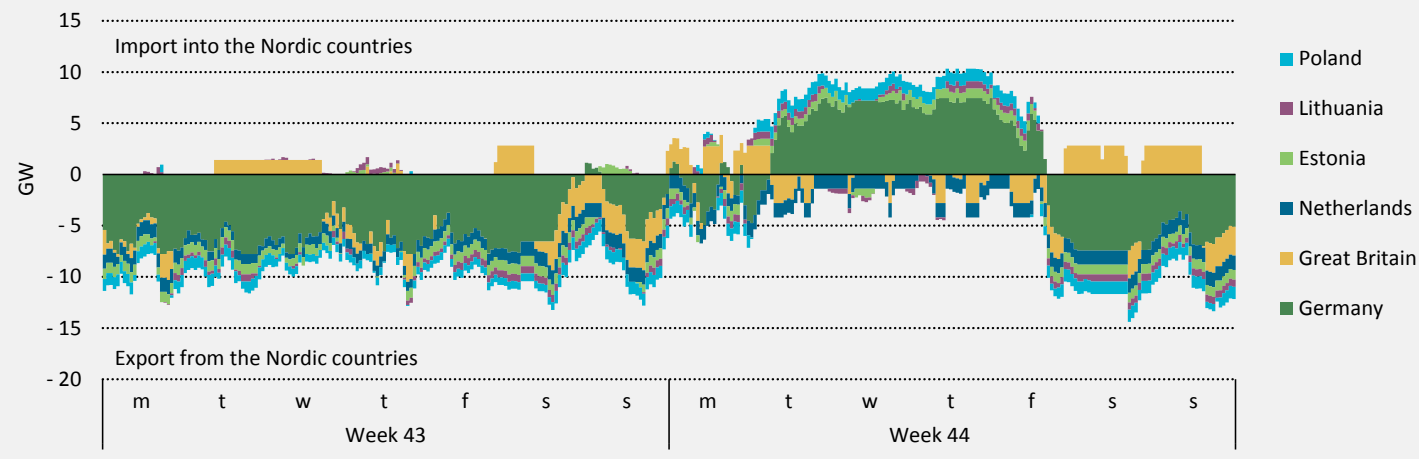

Notes: Positive $=$ import into the Nordic countries; negative $=$ export from the Nordic countries

Figures and data in this report can be downloaded at www.iea.org/etp/nordic

Key point

Germany plays the most important role in imports to and exports from the Nordic countries. 


\section{Nordic export drivers}

In addition to high $\mathrm{CO}_{2}$ and fuel prices, other export drivers include significant wind potential, great reservoir capacity (hydropower in Norway) and a flexible district heating system. All of these factors may contribute to creating the "Nordic power hub" in the future.

\section{Wind development}

Among the Nordic countries, Sweden and Norway will build out significant onshore wind capacity for 2050, while somewhat smaller onshore wind expansion is expected for Western Denmark, as illustrated in Figure 3.27. France, Germany, Great Britain, Italy and Poland will expand wind power capacity significantly towards 2050.

\section{Figure 3.27 Wind capacity build-outs for 2050 in the CNS-B}

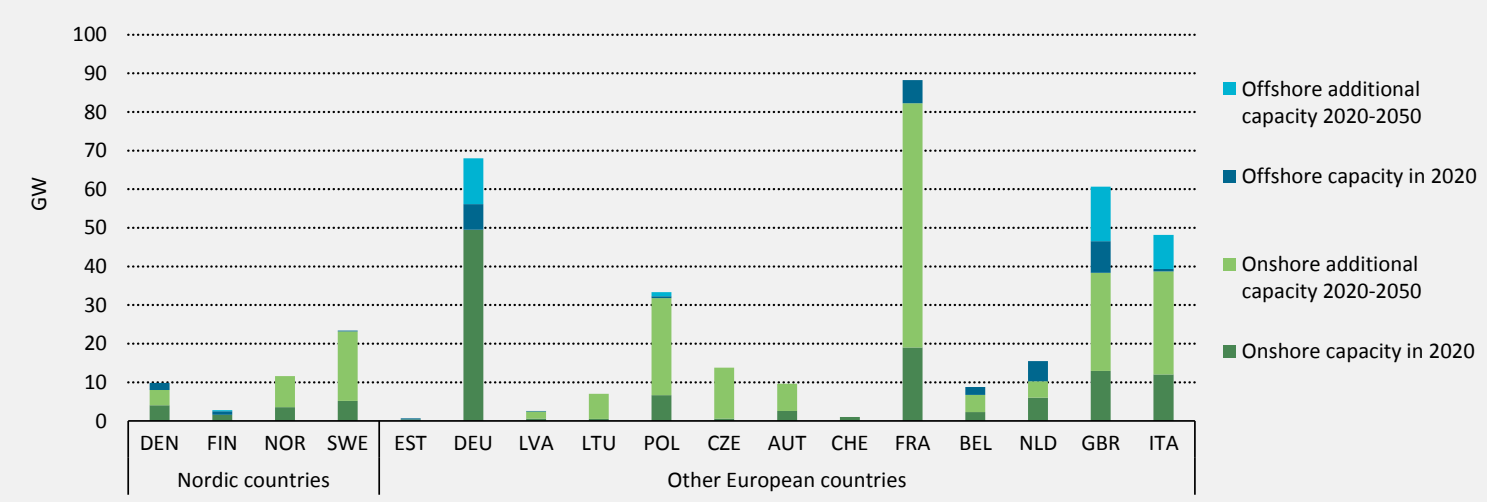

Notes: Capacity in 2020 is defined by current policies and is exogenous to the model. Capacity in 2020 that is retired towards 2050 is assumed to be replaced. Additional capacity 2020-2050 is endogenous, representing the modelís optimised investments.

Figures and data in this report can be downloaded at www.iea.org/etp/nordic.

Key point For 2050, France, Germany Great Britain and Italy will build out significant onshore wind capacity, as will Sweden and Norway among the Nordic countries.

It is a very complex exercise to determine realistic long-term onshore wind power potential for a country. The technical potential is usually very high but in practice it is constrained by local concerns and planning restrictions. When defining country-specific potential, this study has attempted to transfer the wind power acceptance level of Germany to other European countries in cases where good local estimates have not been available. This approach leads to a high wind power potential in a country like France, due to its size and relatively favourable wind conditions. If the acceptance level of onshore wind is lower than anticipated in the simulations, this would probably lead to a stronger wind power development offshore relative to onshore and an overall lower level of wind development since offshore wind is expected to remain more costly than onshore. 


\section{Figure 3.28}

\section{Development of wind penetration level (relative to demand) per country in the CNS-B}

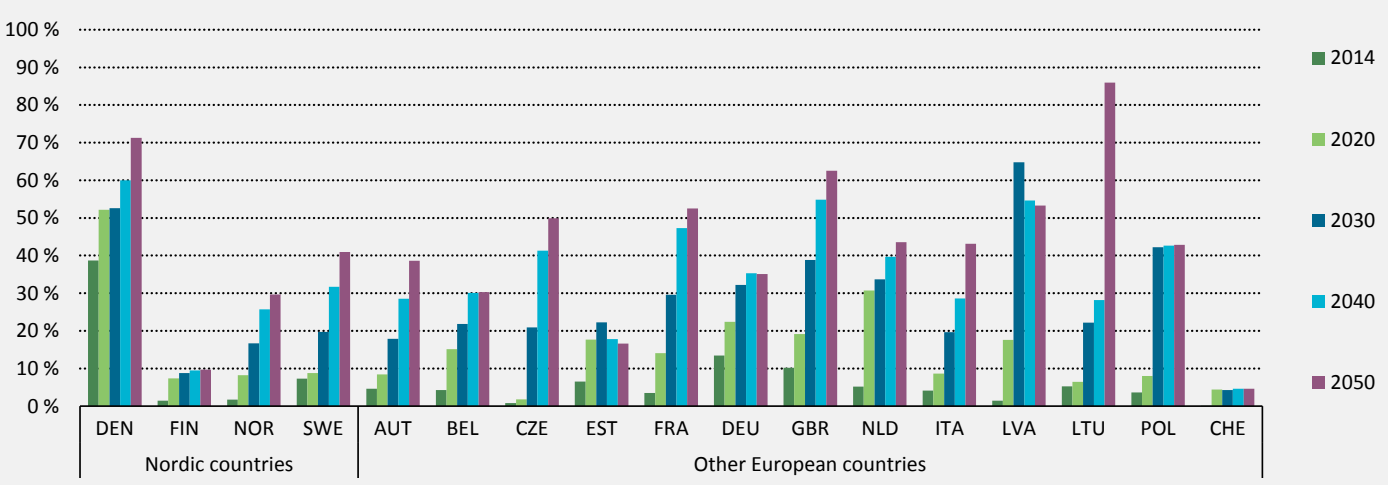

Figures and data in this report can be downloaded at www.iea.org/etp/nordic.

In most of the Nordic countries and in other European countries, the share of electricity consumption provided by wind resources will increase constantly from 2014 to 2050. By 2050, Denmark will have steadily deployed wind power, reaching about 70\% of total electricity consumption; Norway and Sweden will respectively see $30 \%$ and $40 \%$ wind penetration.

Denmark will steadily deploy wind power, reaching about $70 \%$ of total electricity consumption by 2050. Similar behaviour in Norway and Sweden is expected with 30\% and 40\% penetration respectively by 2050, as depicted in Figure 3.28. For most of the other European countries, wind's share of electricity consumption will increase consistently up to 2050.

\section{Norwegian hydropower potential}

NVE, the Norwegian Water Resources and Energy Directorate, estimates that the total potential for hydropower generation in Norway is approximately 214 TWh. Just above $60 \%$ of this potential is already utilised, while $24 \%$ is protected due to environmental concerns and other planning constraints (see Figure 3.29). A number of new plants have already been approved (2\% of total potental) and possible new capacity is assessed to be around 12\% of the total potential.

Utilising the fully remaining and unprotected potential will correspond to a $20 \%$ increase in annual generation from today's level. 


\section{Figure $3.29 \quad$ Categories of hydropower potential in Norway 2015}

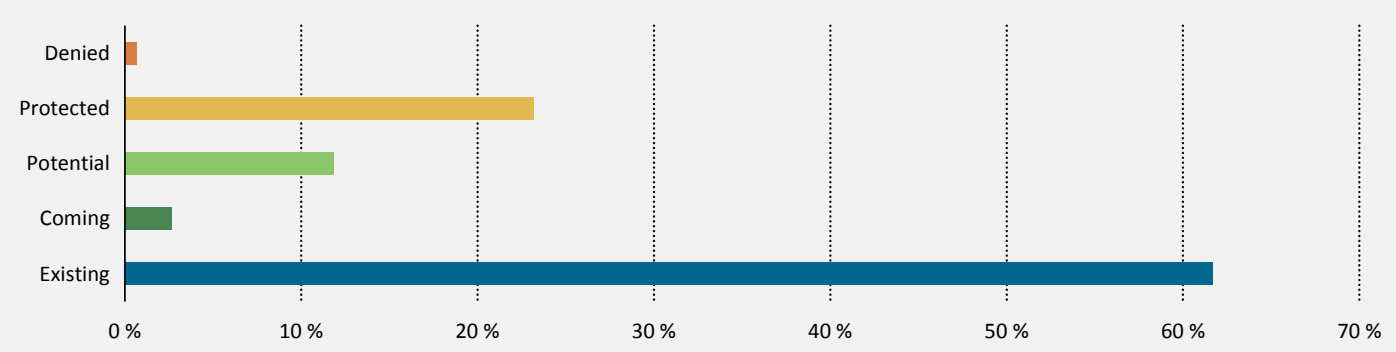

Source: Figure based on NVE (Norwegian Water Resources and Energy Directorate) (2016), "Hydropower potential by County”, www.nve.no/media/2384/ vannkraftpotensial-fylker-2015.pdf.

Figures and data in this report can be downloaded at www.iea.org/etp/nordic.

Key point About $12 \%$ of Norway's total hydropower potential to still to be deployed in the future.

The model is allowed to invest in this additional hydro potential in Norway, which is separated into $3.2 \mathrm{GW}$ run-of-river capacity and $1.7 \mathrm{GW}$ of reservoir capacity. Since the costs of hydropower are very site-dependent, a range of investment costs is applied based on NVE's research (NVE, 2015). Towards 2050, the model decides to invest in almost all capacity with reservoir (99\%), but only in $31 \%$ of the run-of-river potential. The resulting hydro generation is shown in Figure 3.30.

No further potential hydropower sites are included in Sweden or Finland in the model after 2030.

\section{Figure 3.30 Norwegian hydropower generation in the CNS-B}

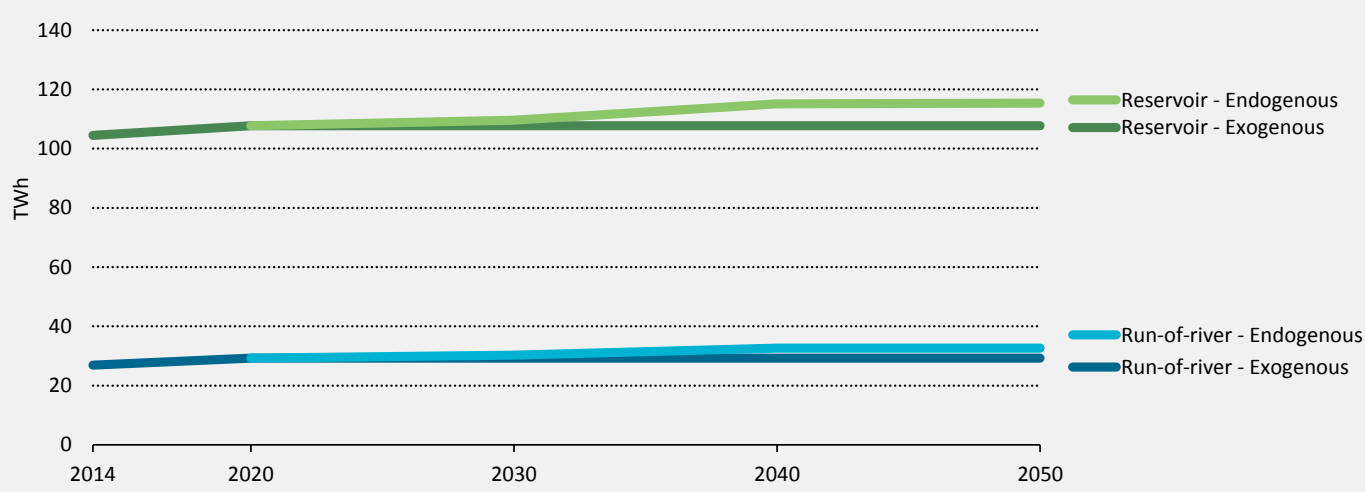

Notes: ROR = run-of-river hydropower; RES = reservoir hydropower

Figures and data in this report can be downloaded at www.iea.org/etp/nordic.

Key point $\quad$ Both ROR and RES generation increase relatively smoothly from 2014 to 2050. RES is more attractive as an investment. 


\section{The Icelandic electricity system and its future interconnection to the United Kingdom}

Iceland's electricity system is isolated as it has no connections to other markets. The system is built on renewable electricity generation in the form of hydropower and geothermal. About $71 \%$ of electricity production is from hydropower plants with production dependent on each year's hydrological conditions. The remaining electricity is from geothermal power plants. Electricity prices in Iceland are low compared to neighbouring countries. For example, the wholesale price from the Icelandic National Power Company to retailers was about 50\% lower in 2014 than the wholesale electricity price in Great Britain (Landsvirkjun, 2014) (DECC, 2015). The demand profile in Iceland is quite stable as $82 \%$ of the electricity is sold to power-intensive industry (mainly aluminium smelters), who's operations provide stable demand. The flexibility of the hydropower plants is therefore only used to a limited extent.

The flow of electricity between two connected markets can be expected to accord with the price differentials between them. Given that electricity prices in Iceland are comparatively low, an interconnector from Iceland will mainly be used for exporting electricity from Iceland.

Connecting Iceland to other markets via an interconnector has been analysed periodically in the past and deemed technically feasible but economically unviable because of technical costs. An interconnector from Iceland to Great Britain has been analysed in recent years. The interconnector would be roughly $1000 \mathrm{~km}$ long and have 800-1200 MW capacity (ENTSO-E, 2014). The building of additional generation capacity is likely to be required to use the interconnector efficiently unless sales to power-intensive industry decrease. It is, however, unclear whether the additional capacity would be built, as new generation projects need to be approved by the Master Plan for Nature Conservation and Energy Utilization. This is a multi-criteria planning tool that was created to reconcile nature conservation and energy utilisation on a national scale. In the plan all energy development choices are assessed with respect to the anticipated impact on nature and net economic benefit, with those choices that have significant impact on nature being excluded from development.

In addition to an increase in generation capacity, the transmission system will need to be strengthened further as a result of the interconnector, although this is dependent on the landfall of the cables in the south or east of the country and the overall development of the system. If additional generation capacity and transmission infrastructure is to be built, the environmental costs should be factored into the final interconnector decision.

Great uncertainty therefore still surrounds the use of resources in Iceland. The business plan is still being developed and is likely to need to rely, at least to a certain extent, on the United Kingdom low-carbon electricity support mechanism. Preliminary economic analysis indicates that the interconnector can bring potential economic gains to Iceland, amounting to ISK 4 billion to ISK 76 billion depending on various scenarios (loEs, 2013), indicating significant uncertainty regarding the potential extent of derived economic benefits. The interconnector is still at the planning stage and further analysis is underway on behalf of the Icelandic government with a focus on, for example, the impact on electricity prices for Icelandic households and businesses. Other interconnectors from, for example, Norway (1 $400 \mathrm{MW}$ ) and Denmark (1 000 MW) are expected to deliver electricity to Great Britain in 2020 and 2022 (Ofgem, 2015).

The main rationale for the interconnector from an Icelandic perspective is to gain access to a larger market and sell renewable electricity at a higher price, as well as increase the security of supply, as it will be possible to import electricity when the hydrological conditions are unfavourable in Iceland. The electricity exported from Iceland will be fully renewable and hence support the UK government's emissions reduction targets and possibly attract payments according to its Electricity Market Reform policies. Furthermore, when the 
hydrological conditions are favourable, it will be possible to export the electricity that would otherwise not have been produced because of storage limitations of the reservoirs. The potential drawbacks are the uncertainty regarding economic benefits, the potential impact on electricity prices to Icelandic households and businesses, and the uncertain impact on Icelandic energy resource development.

\section{ENTSO-E cost-benefit analysis of transmission projects}

The quantifiable benefits of interconnectors can be large and diverse for consumers, producers, interconnector owners and governments in the connected markets (Turvey, R., 2006). The benefits for certain parties may also create costs for others, depending on the flow of the interconnector.

The socio-economic welfare of a potential Iceland-Great Britain interconnector has been assessed as being high compared to other transmission projects. ENTSO-E has assessed various transmission Projects of Common Interest (PCIs) (projects with significant benefits to at least two EU member states) in its 2014 TYNDP, and this project has been assessed with the same methodology. The total socio-economic welfare of the interconnector is high compared to other transmission PCIs; between EUR 290 million and EUR 470 million depending on the four scenarios in the cost-benefit analysis. Yet, the relative impact on the affected populations differs. Furthermore, total emissions savings from connecting Iceland to Great Britain are comparatively high in relation to other PCls, again with differing impacts on the nations involved.

The Iceland-Great Britain interconnector provides a good opportunity to capitalise further on the flexibility of the hydropower plants and export renewable electricity to the United Kingdom. Many obstacles remain to be overcome, however, as the business plan has not been finalised, and given the inherent risk in laying a $1000 \mathrm{~km}$ cable across the Atlantic Ocean.

\section{Flexibility in the system and VRE integration}

\section{Flexible supply}

Table 3.8 outlines the framework for analysing flexibility from the supply side in the Nordic countries and in the other European countries.

\begin{tabular}{|c|c|c|c|c|c|c|c|c|c|}
\hline Scenario name & Period & $\begin{array}{l}\text { Time } \\
\text { resolution }\end{array}$ & $\begin{array}{l}\text { Flexible } \\
\text { power } \\
\text { plants }\end{array}$ & $\begin{array}{l}\text { Flexible } \\
\text { district } \\
\text { heating }\end{array}$ & $\begin{array}{l}\text { Flexible } \\
\text { transmission }\end{array}$ & $\begin{array}{l}\text { Flexible } \\
\text { demand }\end{array}$ & $\begin{array}{l}\text { Flexible } \\
\text { EVs }\end{array}$ & $\begin{array}{l}\text { Flexible } \\
\text { individual } \\
\text { electric heating }\end{array}$ & $\begin{array}{l}\text { Flexible } \mathrm{H}_{2} \\
\text { production }\end{array}$ \\
\hline $\begin{array}{l}\text { CNS-B baseline } \\
\text { scenario }\end{array}$ & $\begin{array}{l}2014- \\
50\end{array}$ & $72 / y r$ & $x$ & $x$ & $x$ & - & - & - & $x$ \\
\hline Hourly2030 & 2030 & $8760 / y r$ & $\mathrm{x}$ & $\mathrm{X}$ & $\mathrm{x}$ & - & - & - & $\mathrm{x}$ \\
\hline $\begin{array}{l}\text { Hourly2030 } \\
\text { +UC }\end{array}$ & 2030 & $8760 / y r$ & - & $\mathrm{x}$ & $x$ & - & - & - & $x$ \\
\hline
\end{tabular}




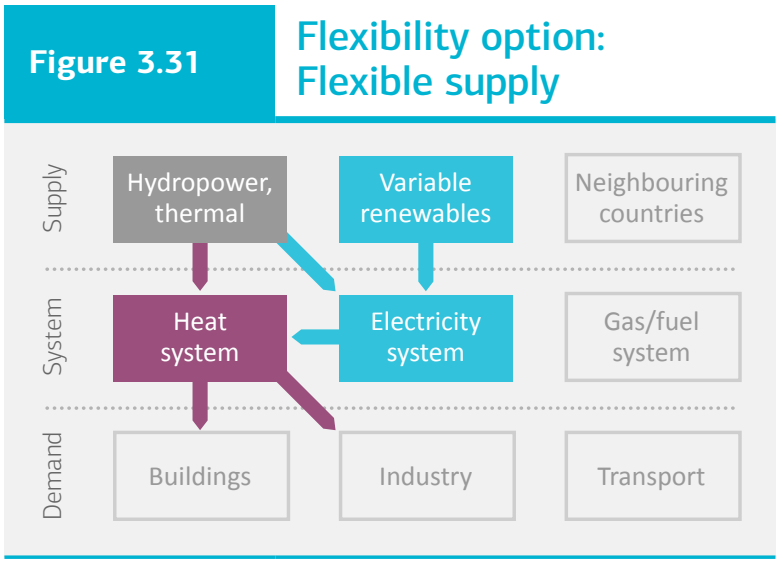

\section{Hydropower}

Hydropower plants are generally highly flexible and can adjust production within minutes. If the plant utilises reservoirs, energy can be stored and used later when needed. If no storage is attached (run-of-river), production can be adjusted by bypassing the turbines, in which case energy is lost. Approximately $75 \%$ of the hydro capacity in Norway has storage. The link between hydro-based power systems in Norway and Sweden and thermal systems in Denmark, Finland and continental Europe makes it possible to fully utilise hydropower's potential given its seasonal and yearly variations, as shown in Figure 3.3.

Figure 3.32 shows an hourly simulation for two weeks in 2030 for all the Nordic countries aggregated. Hydropower is shown to absorb the fluctuations in the system. Whenever there is plenty of wind, the hydropower plants reduce their production and vice versa. In the two periods with low electricity prices in Germany, the hydropower plants reduce generation to a very low level. In this situation the Nordic countries import from Germany, thereby minimising their own production.

\section{Figure 3.32} year 2030 in the CNS-B

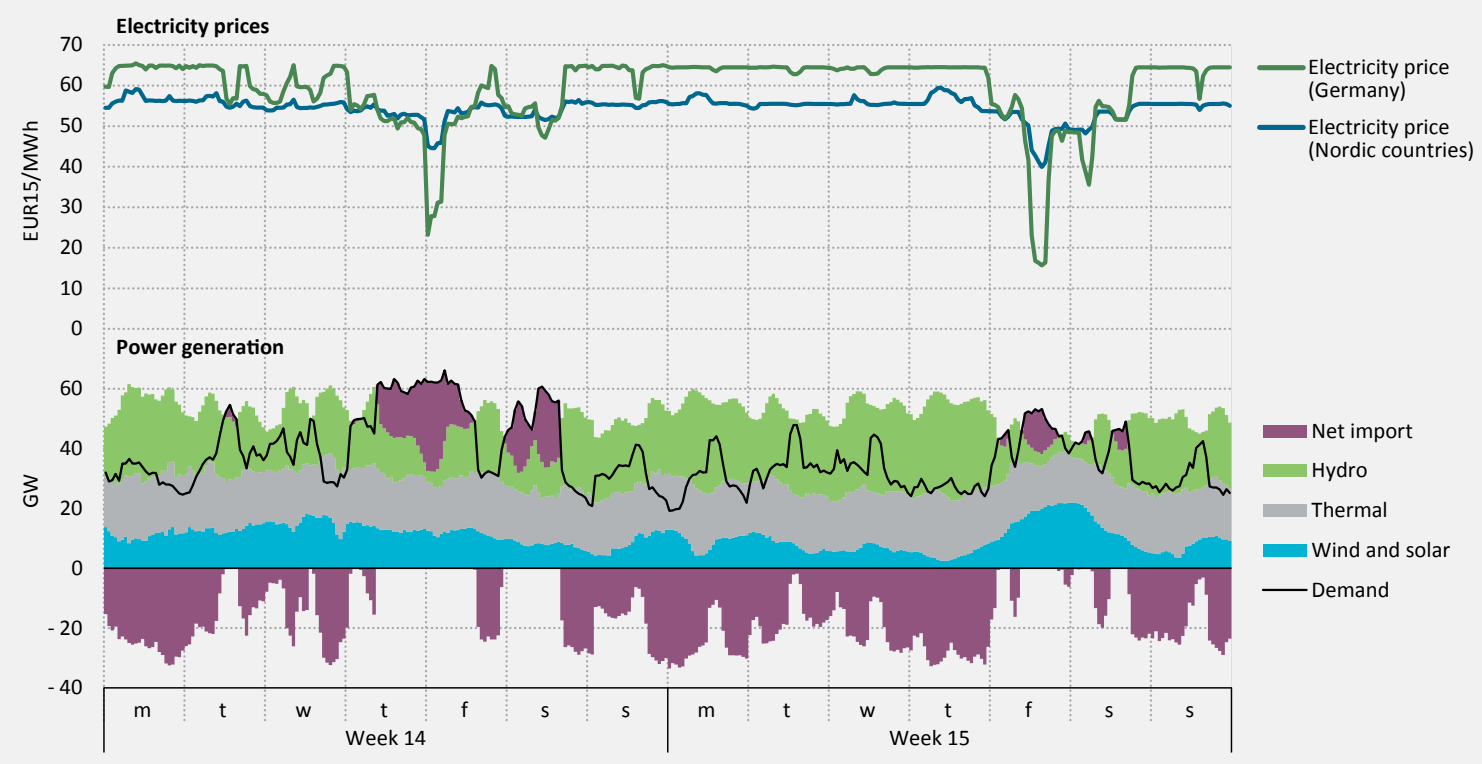

Figures and data in this report can be downloaded at www.iea.org/etp/nordic 


\section{Thermal power plants}

Increasing the flexibility of thermal power plants is also a key parameter to ensure integration of VRE, particularly with a medium-term perspective when coal and gas-based steam turbine plants are still expected to play a key role in the system. ${ }^{12}$ With increasing amounts of VRE, variations in residual load will increase, and thermal power plants will have to adjust generation to avoid low electricity prices at times of higher penetration from VRE. Lack of flexibility will ultimately lead to lower system value of VRE. Therefore, it is essential for the system that thermal power plants can adjust their generation according to the current system state. Key parameters are minimum load levels, start-up and shut-down times, and start-up cost. Within short time horizons, ramping constraints will also play an important role. In the Danish power system, power plant flexibility has improved considerably over recent decades (Ea, 2015). For example, Danish coal power plants can run at 10-20\% load compared to the normal 40-60\%. Future biomass-fired co-generation plants also have to be designed to be flexible.

Improving power plant flexibility is usually a stepwise approach, ranging from trial and error to detailed analysis and component redesign, as illustrated in Figure 3.33. However, the realisation of the flexibility potential requires the right incentives to be in place with regard to, for example, varying electricity prices, ancillary markets and regulatory incentives.

\section{Figure 3.33 A stepwise approach to improved power-plant flexibility}

Reduction of minimum load

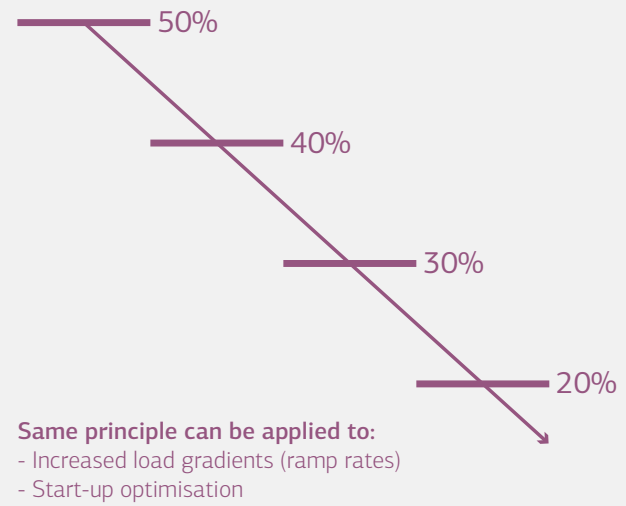

Optimisation approach

A 50-45-40\% minimum load may be achievable through trial and error.

An increasing number of alarms and trips must be addressed through control optimisation, careful component analyses and possibly component redesign, and eventually component replacement earlier than anticipated.

Typical challenges

- Firing stability

- Feed water pump flow stability

Minimum steam flow through turbines

Distributed Control System (DCS) programmable limitations

- Control room operators must participate actively

(Among others, challenges differ from power plant to power plant)

Sources: Blum, R. and T. Christensen (2013), "High flexibility power plants - 25 years of Danish experience", presentation at ENS-China workshop meeting on Future Flexible Power System for Renewable Energy Grid Integration, Beijing, 4 December; Ea (2015), The Danish Experience with Integrating Variable Renewable Energy, study on behalf of Agora Energiewende.

Figures and data in this report can be downloaded at www.iea.org/etp/nordic.

Key point $\quad$ Plant flexibility is optimised by improving certain part-load characteristics. Lack of flexibility in thermal power plant operation will ultimately lead to lower system value of VRE.

In Denmark, the optimisation of operational parameters in thermal power has been driven by a system with a high penetration of VRE. Table 3.9 provides an overview of the flexibility parameters of Danish and German power plants. The generally higher flexibility of gas-fired 
power plants in comparison to coal-fired power plants is apparent. Open-cycle gas turbines (OCGTs) and gas-fired STs are superior to CCGTs in terms of flexibility. However, the overall efficiency of CCGT power plants is higher, which is not reflected in the table. On average, Danish power plants are more flexible than their German counterparts in all of the considered categories.

\begin{tabular}{|c|c|c|c|c|c|}
\hline \multirow{2}{*}{ Table 3.9} & \multicolumn{5}{|c|}{$\begin{array}{l}\text { Flexibility parameters for thermal power plants in Denmark and } \\
\text { Germany }\end{array}$} \\
\hline & Country & Status & $\begin{array}{r}\text { Positive load } \\
\text { gradients }\left(\% \mathrm{P}_{\mathrm{N}} / \mathrm{min}\right)^{*}\end{array}$ & $\begin{array}{r}\text { Minimum stable } \\
\text { generation }\left(\% \mathrm{P}_{\mathrm{N}}\right)^{* *}\end{array}$ & Source \\
\hline \multirow[t]{3}{*}{ Coal ST } & Denmark & Prevailing & $3-4$ & $10-20$ & $\mathrm{a}$ \\
\hline & Germany & Prevailing & $2-3$ & $45-55$ & a \\
\hline & Germany & Optimisation & 6 & 20 & b \\
\hline Natural gas ST & Denmark & Prevailing & $8-10$ & $<20$ & a \\
\hline \multirow[t]{2}{*}{ Natural gas OCGT } & Germany & Prevailing & 8 & 50 & $b$ \\
\hline & Germany & Optimisation & 15 & $20^{* * *}$ & $b$ \\
\hline \multirow[t]{3}{*}{ Natural gas CCGT } & Denmark & Prevailing & 3 & $50-52$ & a \\
\hline & Germany & Prevailing & 2 & 50 & $b$ \\
\hline & Germany & Optimisation & 8 & $30^{* * *}$ & $b$ \\
\hline \multicolumn{6}{|c|}{$\begin{array}{l}\text { Note: \% } \mathrm{P}_{\mathrm{N}}=\text { per cent nominal power. } \\
\text { * Possible increase in power capacity per minute relative to the power plant's nominal capacity. } \\
\text { ** Percentage of the maximum effective power that a power station unit can supply continuously in normal operating conditions under nominal external } \\
\text { operating conditions and by observing the full-load voltage-frequency range at the connecting points. } \\
\text { *** The lower limit of minimum generation of gas turbines is constrained by emission threshold values for nitrous oxide and carbon monoxide. } \\
\text { Sources: Table adopted from Ea (2015), The Danish Experience with Integrating Variable Renewable Energy, study on behalf of Agora Energiewende; a } \\
\text { = Blum, R. and T. Christensen (2013), "High flexibility power plants - } 25 \text { years of Danish experience", presentation at ENS-China workshop meeting on } \\
\text { Future Flexible Power System for Renewable Energy Grid Integration, Beijing, } 4 \text { December (values refer to 2011); b = Feldmüller, A. (2013), "Wie flexibel ist } \\
\text { der heutige konventionelle Kraftwerkspark aus Herstellersicht?" [How flexible is today's conventional power plant from the manufacturer's viewpoint?]. }\end{array}$} \\
\hline
\end{tabular}

To study the impact of having flexible thermal power plants, hourly simulations for 2030 where carried out with and without unit commitment (UC) for the thermal plants. ${ }^{13}$ With UC the plants are less flexible and will tend to run more constantly, which can also be seen in Figure 3.34. The simulation including UC demonstrates more electricity price peaks, related to start-stop costs, and more variation in imports and exports due to the less flexible thermal plants.

13 UC tries to schedule generation to meet the system load for the next several hours at lowest cost while taking into account technical constraints, e.g. each generator must be within its real power ramping limits (Wood, A.J., B.F. Wollenberg and G.B. Sheble, 2012). 


\section{Figure 3.34}

Comparison of Nordic hourly generation in week 44 in 2030 with and without Unit Commitment (UC) in the CNS-B

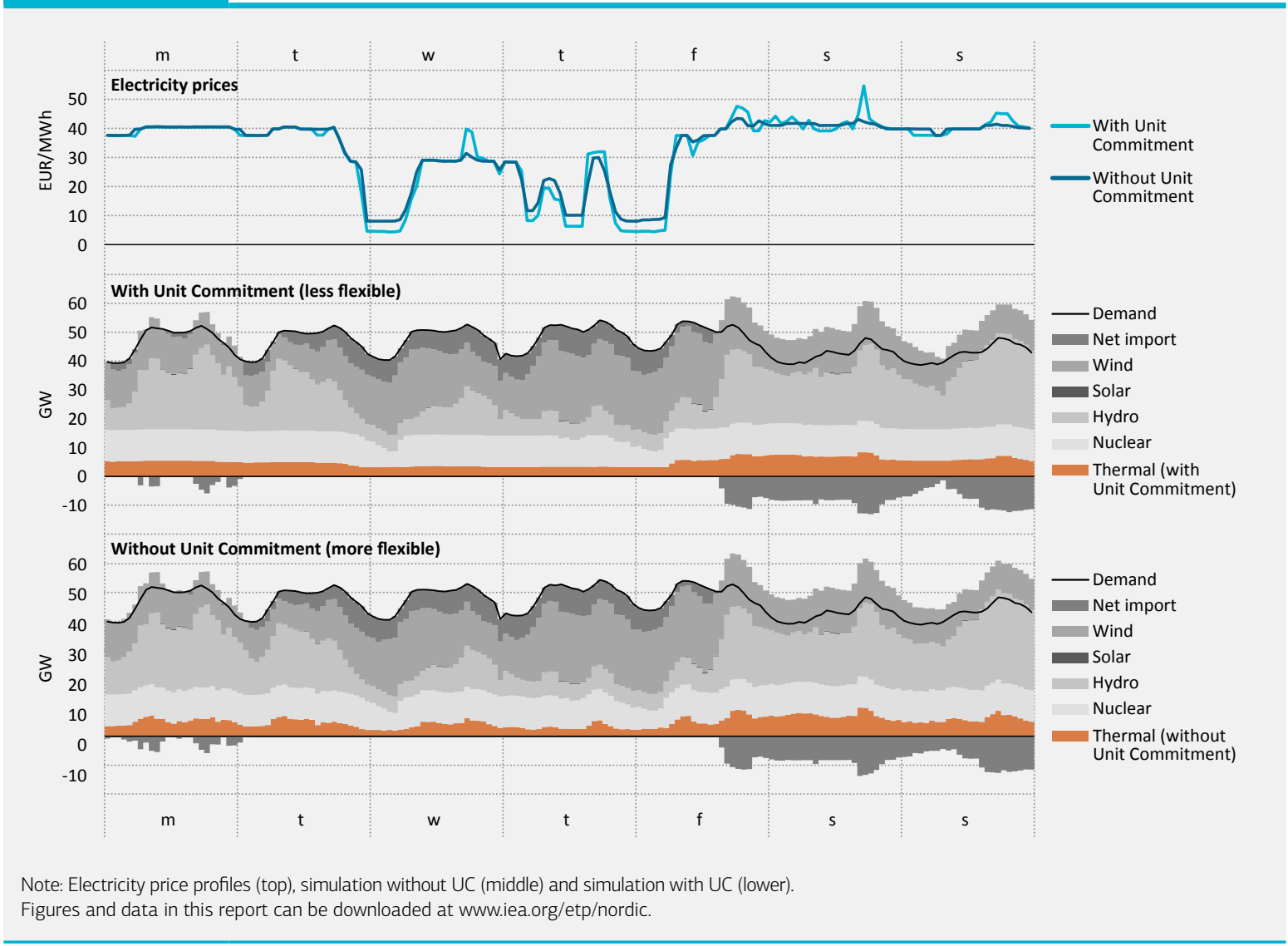

Key point UC exacerbates the impact on electricity prices when running the model.

Figure 3.35 zooms in on the impacts on the electricity price. It shows that including $U C$ in the simulations yields a higher variation in price levels, increasing both the number of very high prices and the number of very low prices. 


\section{Figure 3.35}

\section{Electricity price duration curve with and without Unit} Commitment (UC) in 2030 for Southern Sweden

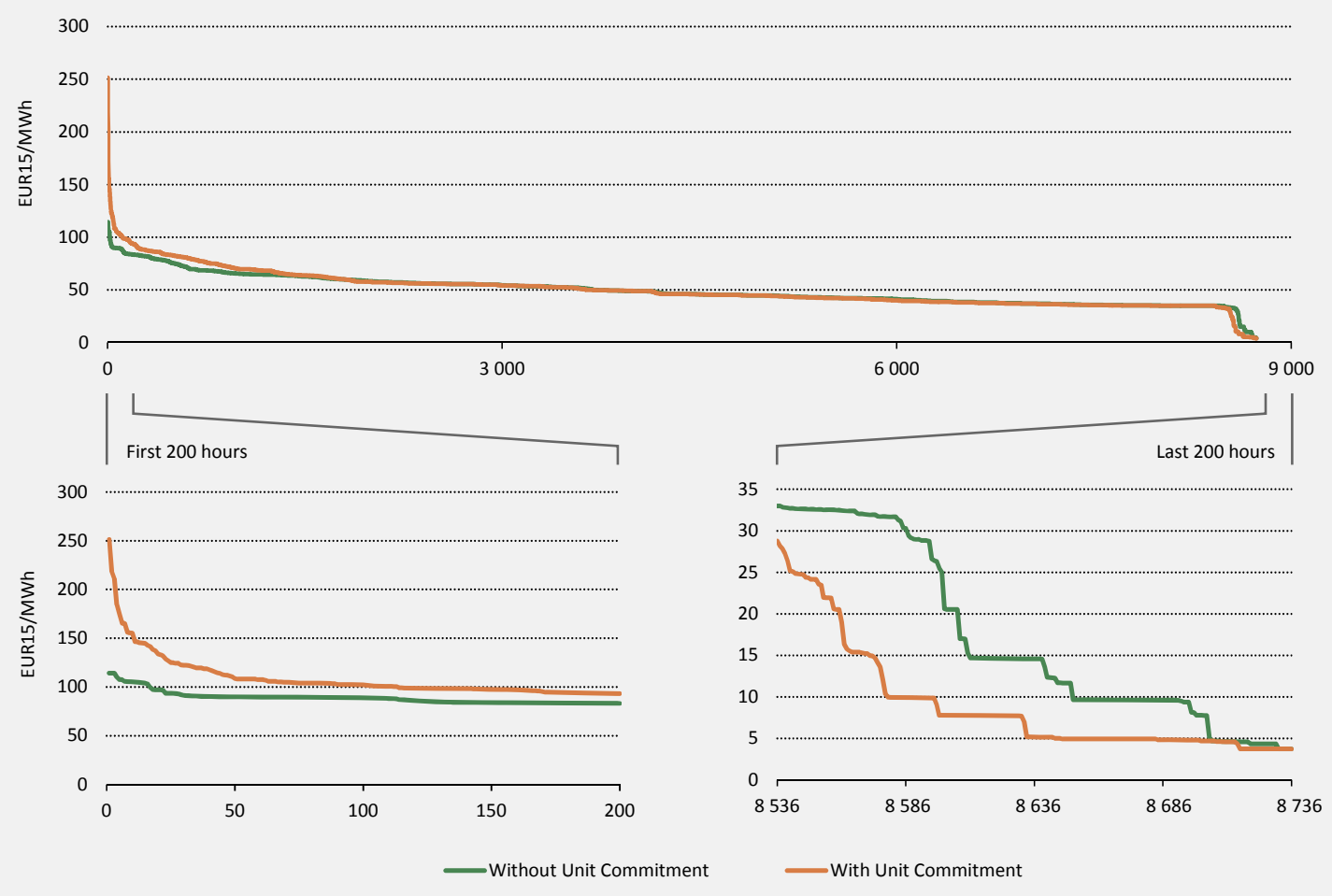

Notes: Full duration curve at the top; first 200 hours on the left; last 200 hours on the right.

Figures and data in this report can be downloaded at www.iea.org/etp/nordic.

UC leads to higher peak prices due to the inclusion of start-up costs, which particularly affect peak-load hours. Additionally, it causes more low prices since some power plants continue to operate at low prices over short time intervals to avoid expensive start-up costs.

Running the model with UC gives a more realistic picture of how power plants operate today. However, it increases the computation time very significantly and therefore it has not been possible to include when running the model with endogenous investments until 2050. Comparing simulations with and without UC is useful to illustrate the potential gain of having more flexible power plants.

\section{Flexibility by linking the electricity sector and district heating}

\section{Co-generation plants}

Co-generation plants can provide flexibility to an energy system by switching between producing only electricity (referred to as condensation mode), and producing both district heat and electricity. In combined heat and power mode, the low-pressure turbine can be bypassed, ensuring heat production at sufficient temperature (point MC in Figure 3.36). When extra power is needed, the low-pressure turbine will be used fully, and district heat 
generation will be omitted (point C). This flexibility offers the opportunity to increase power generation within a very short time horizon in order to, for example, balance fluctuations in the power system.

\section{Figure 3.36}

\section{Operation points with different electricity to heat ratios for a co-} generation plant

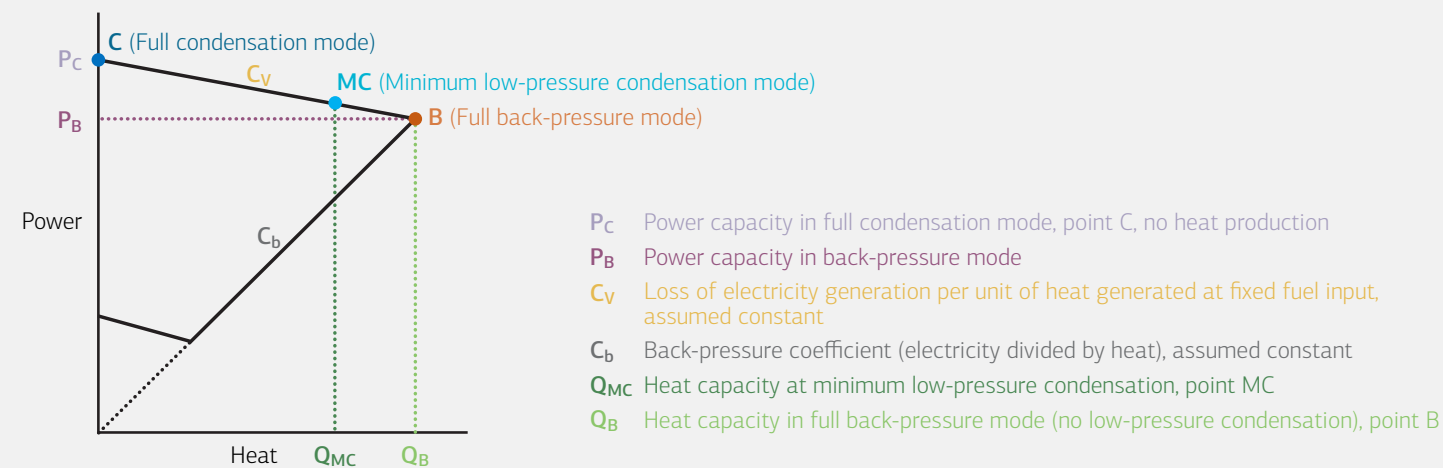

Source: Energinet.dk and Danish Energy Agency (2012), Technology Data for Energy Plants.

Figures and data in this report can be downloaded at www.iea.org/etp/nordic.

Key point The flexibility of co-generation offers the opportunity to increase or decrease power generation within a very short time horizon.

Some larger power plants have the option to bypass the steam turbines and produce only district heat. As such, when co-generation plants use steam bypass they effectively function like a boiler. This enables power plants to avoid electricity generation at times of low electricity prices (e.g. due to high wind penetration), while continuing with heat generation and avoiding a complete shutdown of the plant. Steam bypass can be implemented at low cost and is likely to become an increasingly attractive feature for co-generation plants.

In smaller decentralised power plants, power generation can be decoupled from heat supply by retrofitting backpressure power plants ${ }^{14}$ with cooling options (e.g. air coolers), thereby offering backup capabilities to the electricity system in situations when there is no demand for heat or heat storage units are full.

District heating systems can offer important flexibility options for balancing future energy systems with large shares of VRE. This includes options to ensure flexible operation of thermal power plants, as well as utilisation of power for heat production at times of low electricity prices.

\section{Power-to-heat}

A way to increase the value of variable electricity generation is to introduce new electricity consumption at times of high electricity production. One option is to use electricity for heat production (power-to-heat), for example through the use of large-scale electric boilers or high-efficiency heat pumps connected to the district heating system. In terms of energy input/output, heat pump systems can usually supply three to four times as much heat 
compared to the electricity they use, and can thereby contribute to a highly efficient overall energy usage. On the other hand, heat pump systems involve significant investment. An alternative with a substantially lower investment cost is electric boilers. However, they are also much less efficient than heat pumps, with electricity to heat efficiencies close to $100 \%$. The overall thermal efficiency of both heat pumps and boilers depends on the electricity production mix and the efficiency with which the electricity is generated. Heat pumps are well suited for applications with many operating hours, whereas electric boilers are more cost effective for applications involving fewer operating hours.

In some countries, the potential for using electricity to generate industrial process heat may also be significant.

\section{The link between electricity and heat generation}

The optimal operation of an integrated power and district heating system depends on the electricity price. Low electricity prices will often indicate high generation from VRE, while high prices indicate a need for additional power generation.

Figure 3.37 shows a comparison of the heat production cost of different units, depending on the electricity price. At low or negative electricity prices, heat pumps and electric boilers offer the cheapest heat. As electricity prices increase, it becomes cheaper to utilise the boiler or a turbine bypass ${ }^{15}$ and at electricity prices above approximately EUR 25/MWh the co-generation plant demonstrates the lowest cost.

If the co-generation plant is an extraction unit, ${ }^{16}$ opportunity cost will occur at very high electricity prices - since the plant could choose to produce more electricity by omitting heat production, thereby increasing income. Consequently, at very high electricity prices, the biomass boiler will provide the cheapest option.

15 Bypassing the steam turbines allows a co-generation plant to exclusively produce heat. This is convenient at low electricity prices.

16 With an extraction unit, all steam may be condensed (e.g. by sea water) to generate maximum electricity, or all steam may be extracted to be condensed at a higher temperature to generate district heat (Ea, 2015). 


\section{Figure 3.37 \\ Short-run marginal cost of heat production by technology depending on electricity price}

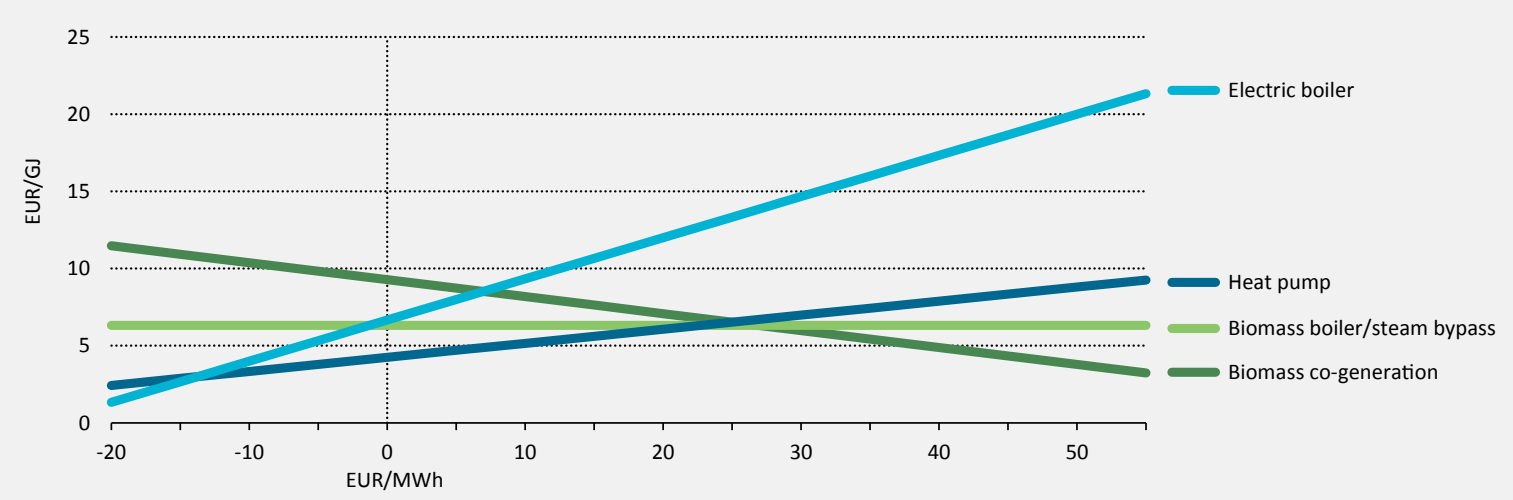

Notes: This is an illustrative example with 2020 price level for fuel and $\mathrm{CO}_{2}$; actual costs will also depend on taxes and subsidies.

Figures and data in this report can be downloaded at www.iea.org/etp/nordic.

Key point

Short-term marginal heat production cost is sensitive to changes in electricity prices.

District heating power plants benefit from both very low and very high electricity prices, which are expected to be seen in the future. District heating enables wind integration through heat pumps and electric boilers.

\section{Storage}

Storage can take up energy when there is surplus production and give it back to the system when it is needed. Heat and gas are relatively cheap to store, while local electricity storage is rather costly. Chemical storage in particular can be used to link together the different energy carriers in the system. The following section presents storage options relevant to the Nordic energy system.

\section{Heat storage}

Heat storage in district heating systems can increase the flexibility of thermal power plants, or other options for heat generation, by decoupling heat generation and heat consumption through time. Heat storage enables thermal power plants to produce heat when electricity prices are high, and allows electricity-to-heat technologies to produce heat when electricity

\section{Figure $3.38 \quad$ Flexibility option: Storage}

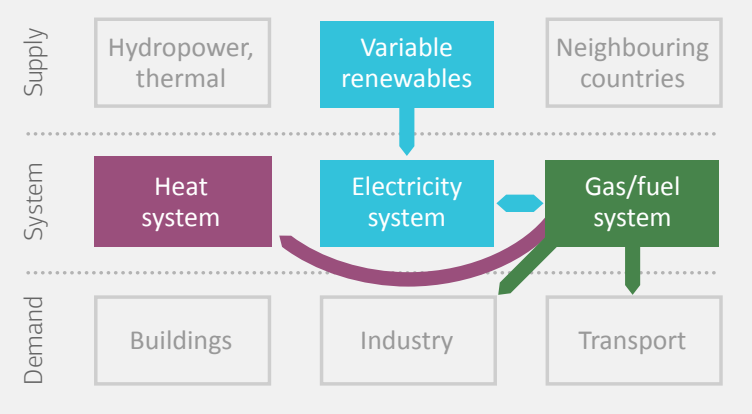

prices are low. The most common form of heat storage is large well-insulated water tanks placed next to the co-generation plant. Certain heat producers with large solar heating farms are also establishing seasonal heating storage, allowing heat produced in summer to be utilised in the winter months.

A typical co-generation plant in Denmark, for example, has heat storage capacity for approximately eight hours of generation.

In Balmorel, the Nordic countries are divided into district heating areas where demand and supply are balanced. This means that investments in district heat- 
producing units can be tracked to these areas and the balance between supply and demand studied. For example, Figure 3.39 shows district heat production in the model area "Central Sweden". The main supplier is biomass-based co-generation; heat pumps produce when the electricity price is low, solar heating when the sun is shining, and heat storage and boilers balance the rest.

\section{Figure 3.39} in the CNS-B

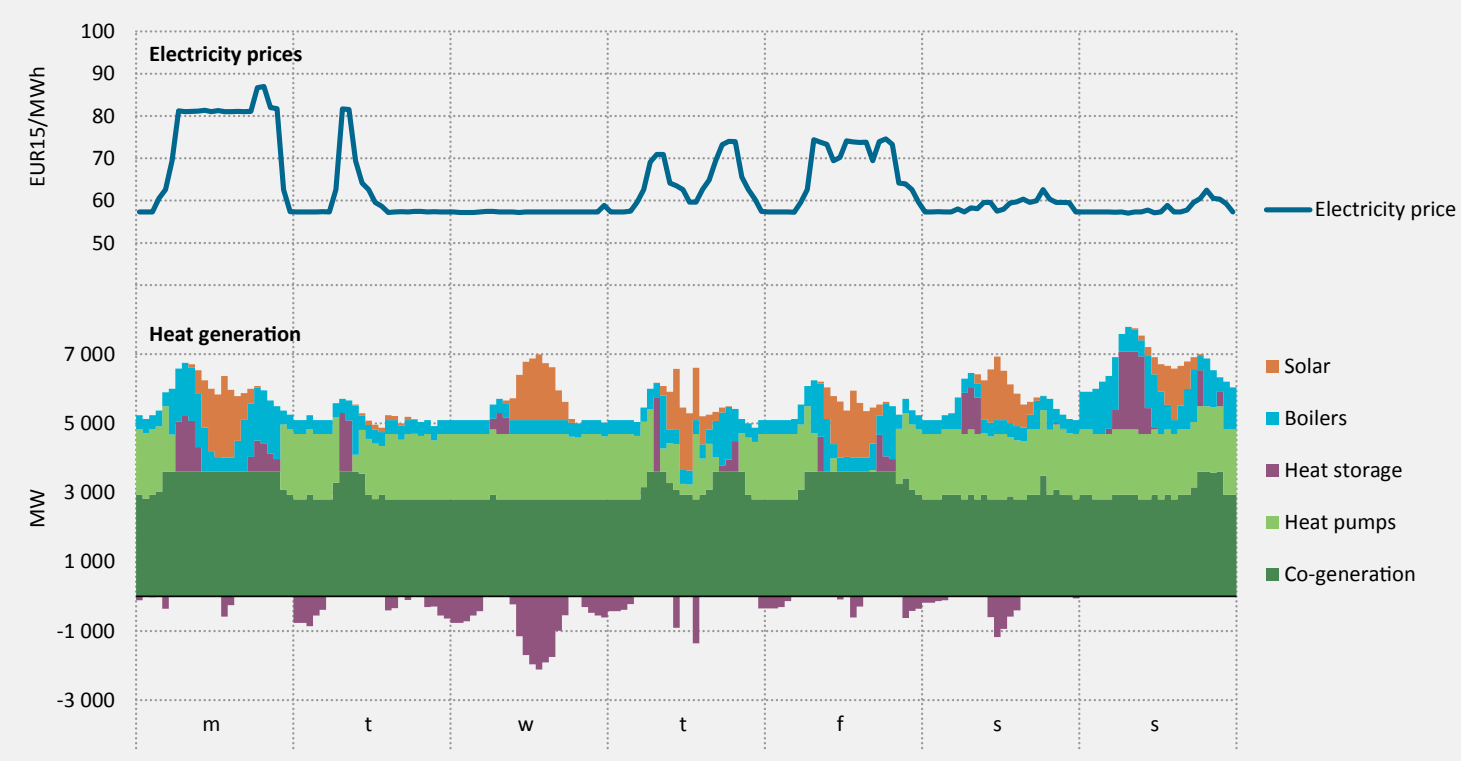

Figures and data in this report can be downloaded at www.iea.org/etp/nordic.

Key point

In Central Sweden in 2030, heat pumps shut down when the electricity price is high; under these conditions, mainly co-generation, boilers, solar and heat storage supply the heat demand.

\section{Biofuels: chemical storage}

Producers of renewable energy carriers for the transport sector (here called biorefineries) can become an important player in a future energy system with significant shares of VRE. When producing biofuels, process inputs can be electricity, heat and biomass, and - depending on the type of process - the outputs can be different kinds of fuel for transport, surplus heat and different types of by-product. In the 2050 CNS about $60 \%$ of the fuel for transport is expected to take the form of biofuels, while the contribution of hydrogen is negligible, as depicted in Figure 3.40. While the CNS sees hydrogen consumption as being negligible in the Nordic region, other studies in Denmark and Finland indicate that a very substantial electricity supply is needed for hydrogen production, in order to decarbonise the transport sector (Danish Energy Agency, 2014). 


\section{Figure 3.40 Final energy demand for transport in the Nordic countries in the CNS}
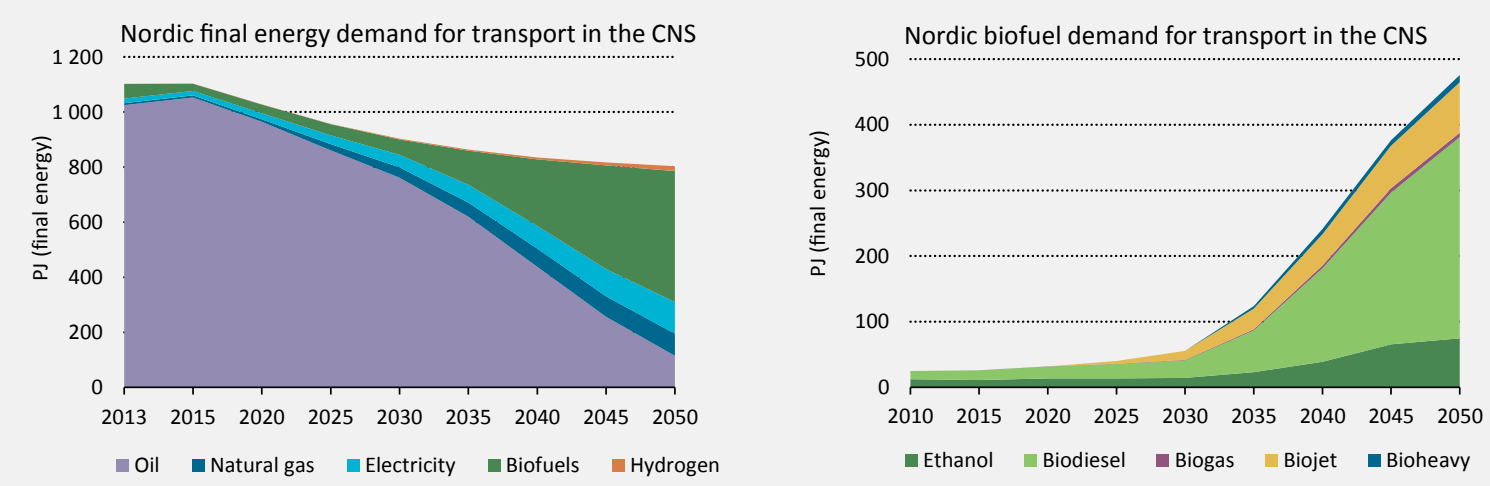

Source: Based on IEA (forthcoming), Energy Technology Perspectives 2016.

Figures and data in this report can be downloaded at www.iea.org/etp/nordic.

Key point By 2050, biofuels will play a critical role in phasing out oil use for transport in the Nordic countries.

The general concept of biorefineries is illustrated in Figure 3.41. The resources are different types of biomass and organic waste and, depending on the specific process, electricity and heat will also be needed to produce biofuels. Other outputs from the plants can be waste heat and residual products that can be used for fodder and fuel.

\section{Figure $3.41 \quad$ Biorefinery concept}
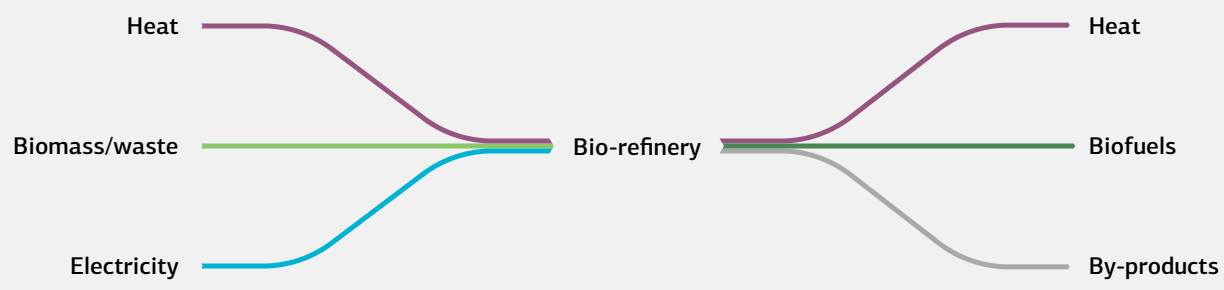

Source: Based on Danish Energy Agency (2013), Technology Data for Advanced Bioenergy Fuels.

Figures and data in this report can be downloaded at www.iea.org/etp/nordic.

Key point Waste heat and residual products from biofuel production can be used for fodder, fuel or fertiliser.

Biofuels can either be imported or produced locally in the Nordic region. If biorefineries are situated in the Nordic countries, they can be an active part of a future Nordic energy system linking power, transport and district heating sectors. From some processes, waste heat can be utilised for district heating, which implies that the plant should not be too far away from district heating networks. Another important link to the energy system derives from the fact 
that biofuels easily can be stored and, as the processes use electricity, production can be adjusted to the market price of electricity, thereby helping balance the system. This is not, however, straightforward as some of the processes must be run continuously, and to be flexible means investing in over-capacity and thereby more expensive plants.

Production of hydrogen by means of electrolysers has the highest potential to offer flexibility to the energy system, as it produces hydrogen (which can be stored) on the basis of water and electricity and also produces surplus heat. This potentially offers a link between electricity, district heat and transport fuel (Figure 3.42).

\section{Figure 3.42 Electrolysis, upgraded biogas and advanced bio-ethanol production}

\section{Electrolysis / hydrogen production}

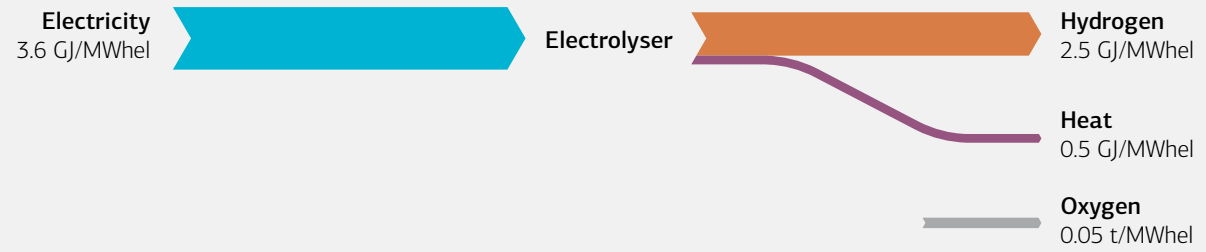

\section{Upgraded biogas production}

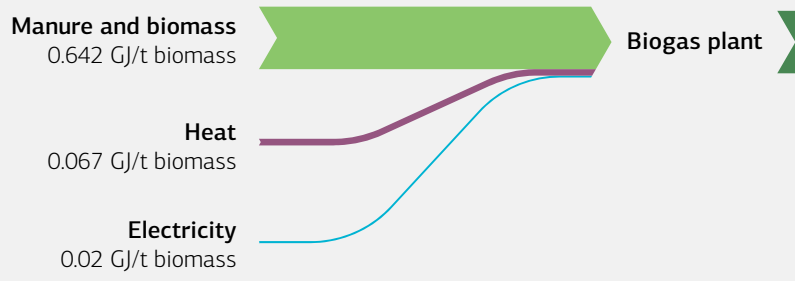

\section{Advanced bio-ethanol production}
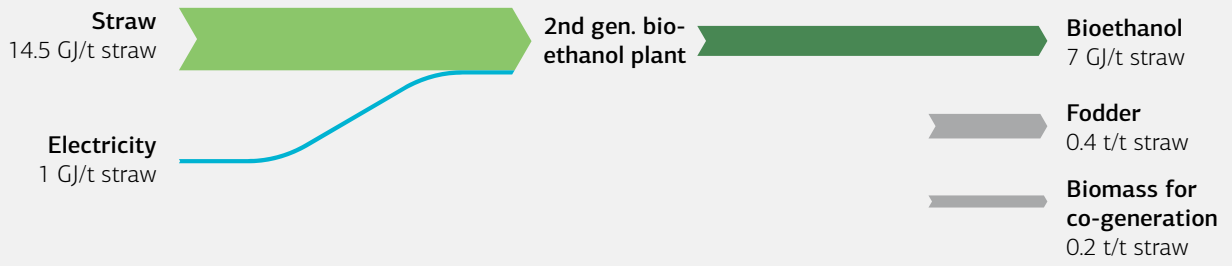

Notes: Upgrading biogas is a process to concentrate the methane in biogas to natural gas standards; the process removes $\mathrm{CO}_{2}$, hydrogen sulphide, water and contaminants from the biogas; $\mathrm{G} / \mathrm{t}$ = gigajoule per tonne; $\mathrm{GJ} / \mathrm{MWhe}=$ gigajoule per megawatt hour electric. Wood biomass is not explicitly mentioned here; however, it has an important potential for bioliquid production; $\mathrm{t} / \mathrm{t}$ straw = tonne of residual biomass per tonne of straw input

Source: Based on Danish Energy Agency (2013), Technology Data for Advanced Bioenergy Fuels.

Figures and data in this report can be downloaded at www.iea.org/etp/nordic energy system. Advanced bio-ethanol production can produce fuel for co-generation plants or boilers. 
Other biorefineries such as biogas plants have a demand for heat (Figure 3.42), while advanced bio-ethanol plants may produce fuel for co-generation plants or boilers as well as fodder for the agricultural sector.

Each of the mentioned processes creates a link between electricity, biomass resources, biofuels, and in some cases district heating. The system can be even further integrated, as there are potential synergies between some of the processes. Figure 3.43 illustrates potential interlinkages between the different main energy carriers.

\section{Figure 3.43}

\section{Interlinkages among the different energy carriers in the energy} system

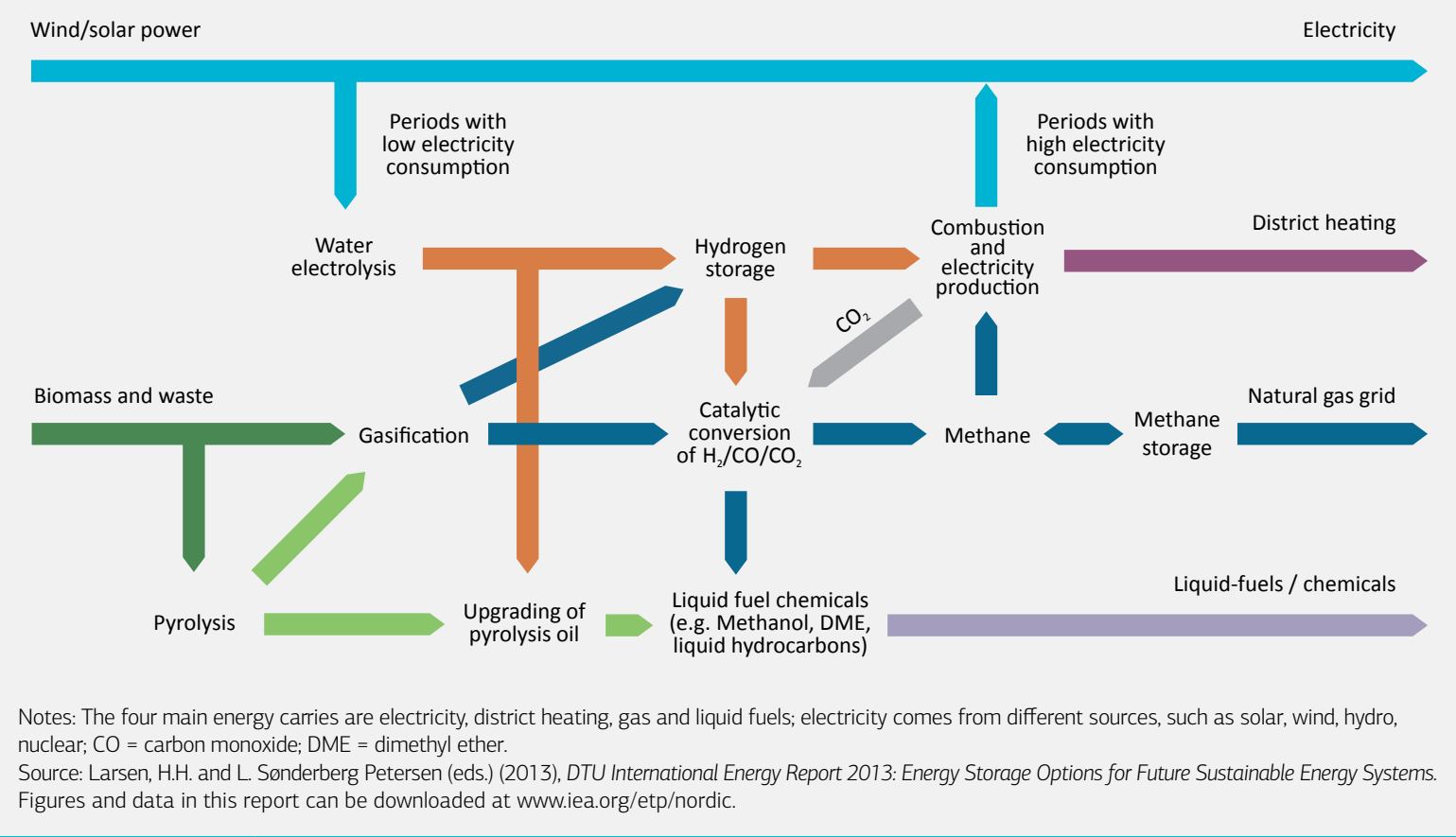

Key point

Chemical storage can connect four main energy carriers in the energy system.

\section{Electricity storage}

Electricity storage can be a way to secure the value of VRE generation by providing the option to decouple electricity generation and consumption over time, thus providing electricity when electricity prices are high. However, the efficiency and investment cost of storage technologies continue to be a challenge from an economic perspective.

For direct storage of electricity in forms where it can be retrieved as electricity again, five principal technology types are available, each with different characteristics. Pumped hydro and compressed air energy storage (CAES) offer a greater volume of storage, but can also provide short-term capacity. Flywheels and super capacitors mainly provide capacity in short timescales, while batteries can be in both categories depending on the battery technology. Table 3.10 shows in more detail the timeframes in which the different storage technologies work and what kind of application they serve. In the short timescale, from "voltage support" 
downwards, are the so-called system ancillary services, while upwards in the timescale are applications related to the day-ahead electricity market.

\begin{tabular}{|c|c|c|c|c|c|c|c|c|c|c|c|}
\hline \multirow[t]{4}{*}{ Table 3.10} & \multicolumn{11}{|c|}{$\begin{array}{l}\text { Storage technologies in the electricity grid, their maturity and } \\
\text { application }\end{array}$} \\
\hline & \multicolumn{10}{|c|}{ Application by response timeframe } & \multirow{3}{*}{$\begin{array}{l}\text { Discharge time/ } \\
\text { duration }\end{array}$} \\
\hline & \multicolumn{5}{|l|}{ Hours } & \multicolumn{3}{|c|}{ Minutes } & \multicolumn{2}{|c|}{ Seconds } & \\
\hline & 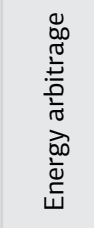 & 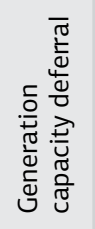 & 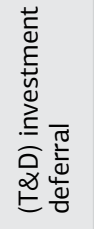 & 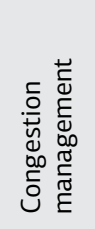 & 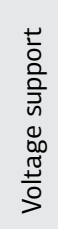 & 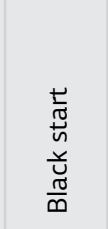 & 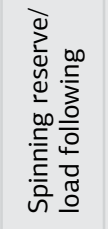 & 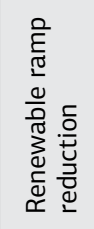 & 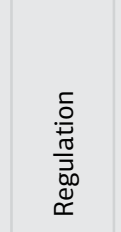 & 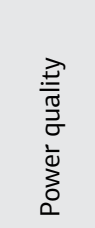 & \\
\hline Pumped hydro & (M) & (M) & (M) & (M) & (M) & M & (M) & M & (M) & & Hours \\
\hline CAES & C & C & C & C & C & C & C & C & & & Hours \\
\hline Flywheel & & & & & & (D) & (D) & (D) & (D) & (D) & Minutes \\
\hline Super capacitor & & & & & & & & & & (D) & Seconds \\
\hline Battery technology & & & & & & CD & CD & CD & CD & CD & Hours/minutes \\
\hline
\end{tabular}

Key point

Pumped hydro and CAES generally deliver capacity in minutes and hours, while other technologies, such as batteries, can delivery of capacity in seconds and minutes.

\section{Storage and flexibility}

The different energy storage options have varying timescales and volumes, and they can also address different problems in the energy system. Table 3.11 links flexibility timescales, analysis tools, system phenomena and storage technologies. The energy system model Balmorel, used for the analysis in this chapter, addresses technologies from the red line downwards in the table. Therefore all the storage options mentioned in that part are included in the analysis of integration of VRE in the Nordic energy system. 


\begin{tabular}{|c|c|c|c|c|}
\hline \multirow{2}{*}{$\begin{array}{l}\text { Table } 3.11 \\
\text { Timescale }\end{array}$} & \multicolumn{4}{|c|}{$\begin{array}{l}\text { Flexibility timescales, analysis tools, system phenomena and } \\
\text { storage technologies }\end{array}$} \\
\hline & Analysis tools and concerns & Phenomena & $\begin{array}{l}\text { Relevant storage } \\
\text { technologies }\end{array}$ & $\begin{array}{l}\text { Included in } \\
\text { Balmorel }\end{array}$ \\
\hline $\begin{array}{l}\text { Nanoseconds to } \\
\text { milliseconds }\end{array}$ & $\begin{array}{l}\text { Electromagnetic transients } \\
\text { and finite-element methods }\end{array}$ & $\begin{array}{l}\text { Lightning, switching and } \\
\text { wave propagation }\end{array}$ & - & No \\
\hline $\begin{array}{l}\text { Milliseconds to } \\
\text { seconds }\end{array}$ & Transient stability & $\begin{array}{l}\text { Faults and protection } \\
\text { systems }\end{array}$ & $\begin{array}{l}\text { Capacitors/inductors, inertia } \\
\text { (system inherent storage) }\end{array}$ & No \\
\hline Seconds to minutes & $\begin{array}{l}\text { Voltage and wide area } \\
\text { stability }\end{array}$ & $\begin{array}{l}\text { Propagation of faults; } \\
\text { Inter-area swings; cloud } \\
\text { passing; frequency } \\
\text { disturbances }\end{array}$ & $\begin{array}{l}\text { Generator primary } \\
\text { controllers, batteries, } \\
\text { thermal loads }\end{array}$ & No \\
\hline Minutes to hours & $\begin{array}{l}\text { System operation, including } \\
\text { balancing and reserves, } \\
\text { ancillary services, decision } \\
\text { support }\end{array}$ & $\begin{array}{l}\text { Plant outages, wind } \\
\text { fluctuations and forecast } \\
\text { errors, fast demand ramps, } \\
\text { shifts in market schedules }\end{array}$ & $\begin{array}{l}\text { Demand response and } \\
\text { building thermal storage, } \\
\text { electric vehicles, batteries, } \\
\text { district heating, etc. }\end{array}$ & Yes \\
\hline Hours to days & Energy markets & $\begin{array}{l}\text { Forecast errors, daily and } \\
\text { week-scale fluctuations }\end{array}$ & $\begin{array}{l}\text { Pumped hydro, compressed } \\
\text { air storage, gas network, } \\
\text { heat network }\end{array}$ & Yes \\
\hline Days to seasons & Energy futures markets & $\begin{array}{l}\text { Seasonal weather patterns; } \\
\text { social crises }\end{array}$ & Hydro; seasonal heat storage & Yes \\
\hline $\begin{array}{l}\text { Seasons to several } \\
\text { years }\end{array}$ & $\begin{array}{l}\text { Investment and asset } \\
\text { management }\end{array}$ & $\begin{array}{l}\text { Market price development; } \\
\text { regulatory change; climate } \\
\text { change }\end{array}$ & $\begin{array}{l}\text { Electrolysis; gaseous, liquid } \\
\text { and solid fuels }\end{array}$ & Yes \\
\hline
\end{tabular}

Source: Larsen, H.H. and L. Sonderberg Petersen (eds.) (2013), DTU International Energy Report 2013: Energy Storage Options for Future Sustainable Energy Systems.

Key point Balmorel includes all storage technologies in the table at the "minutes to hours" timescale or greater.

\section{Flexible demand}

Table 3.12 outlines the scenario frame for the flexible demand analysis.

\begin{tabular}{|c|c|c|c|c|c|c|c|c|c|}
\hline Scenario name & Period & $\begin{array}{l}\text { Time } \\
\text { resolution }\end{array}$ & $\begin{array}{l}\text { Flexible } \\
\text { power } \\
\text { plants }\end{array}$ & $\begin{array}{l}\text { Flexible } \\
\text { district } \\
\text { heating }\end{array}$ & $\begin{array}{l}\text { Flexible } \\
\text { transmission }\end{array}$ & $\begin{array}{l}\text { Flexible } \\
\text { demand }\end{array}$ & $\begin{array}{l}\text { Flexible } \\
\text { EVs }\end{array}$ & $\begin{array}{l}\text { Flexible } \\
\text { individual } \\
\text { electric heating }\end{array}$ & $\begin{array}{l}\text { Flexible } \mathrm{H}_{2} \\
\text { production }\end{array}$ \\
\hline $\begin{array}{l}\text { CNS-B baseline } \\
\text { scenario }\end{array}$ & $2014-50$ & $72 / \mathrm{yr}$ & $x$ & $x$ & $x$ & - & - & - & $x$ \\
\hline Flex scenario & $2014-50$ & $72 / y r$ & $x$ & $x$ & $x$ & $x$ & $x$ & $x$ & $x$ \\
\hline Hourly2030 & 2030 & $8760 / y r$ & $x$ & $x$ & $x$ & - & - & - & $x$ \\
\hline $\begin{array}{l}\text { Hourly2030 } \\
+ \text { +Flex }\end{array}$ & 2030 & $8760 / y r$ & $x$ & $x$ & $x$ & $x$ & $x$ & $x$ & $x$ \\
\hline
\end{tabular}


Traditionally, electricity consumption has been viewed as given parameter to be served by adjusting production. However, from an economic point of view serving any load irrespective of cost does not make sense. Certain consumers may prefer to reduce or stop consumption if confronted with higher costs. In addition, at sufficiently low cost some consumers may prefer to increase their consumption.

Demand response will become increasingly important in the future power systems to:

- Provide cost-efficient back-up when variable renewables are not producing.

- Increase the value of variable renewables in situations with high production.

- Balance VRE minute-by-minute and hour-by-hour.

\section{The need for demand response will increase}

It is a basic assumption behind market liberalisation that market forces will produce the required power capacity and thereby ensure the adequacy of the production side. However, this assumes that consumers are willing to pay for power at very high prices. In scarcity situations, these consumers will set the price of electricity at a higher level than the short-run marginal costs of peak power plants and thereby create the margin to cover the fixed costs of these plants.

While these considerations are valid in any power system, they become increasingly relevant with the large-scale introduction of variable generation from renewable sources. As dispatchable production is pushed out of the market, the cost of serving peak loads at times of low variable production will have to rise.

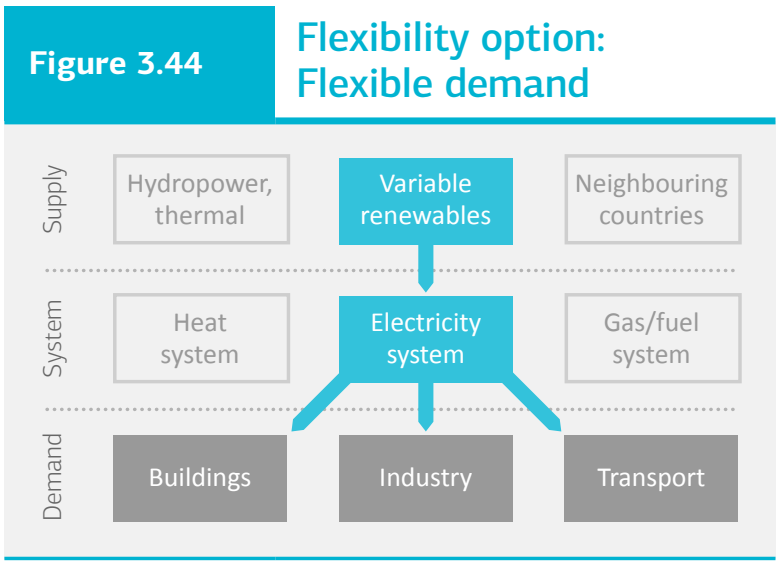

In the Nordic electricity market, the price ceiling is EUR 3000 per MWh. If the price ceiling is reached, involuntary disconnection of consumers is needed, socalled brown-outs, unless back-up capacity (strategic reserves) is procured by the system operator. Contrary to a blackout - a system collapse - a brown-out is a controlled disconnection of pockets of customers. This is usually done according to a schedule protecting consumers that are believed to have a particularly high willingness to pay for electricity, such as hospitals, railways and certain industries.

Assuming - unrealistically - that there is no demand response (or other sources with no or very low capital costs) in the market, disconnections could on average

take place for around 17 hours a year. The rationale is that it takes 17 hours with a profit contribution of approximately EUR 2900 per hour (price ceiling minus short-run marginal cost of approximately EUR 100 per MWh for a peak power plant) to recover the fixed capital costs of new peak power capacity of around EUR 50000 per MW per annum. If the marginal unit is an existing gas or oil-fired power plant the fixed cost is lower, around EUR 10000 15000 per annum, and the price ceiling would only have to be reached 3-5 hours a year.

By analysing the load curve in a power system, it is possible to estimate the amount of demand response required to have a functioning market without brown-outs.

The graphs in Figure 3.45 below show duration curves for the Nordic electricity system (Denmark, Finland, Norway and Sweden) for demand as well as residual demand, i.e. demand minus wind generation in $2015 .{ }^{17}$ In 2015 , wind power made up just $8.9 \%$ of electricity generation in the

17 Other sources of inflexible generation are solar and run-of-river hydro, but these are not included in the graph. 
Nordic countries. The left-hand graph in Figure 3.45 zooms in on the 100 hours with the highest demand, showing that the residual peak demand curve is steeper than the curve in a system without wind power. The reason for this is the presence of a few hours with very high demand and very low wind power contribution. Therefore, the maximum residual demand is only slightly lower than the maximum demand. Run-of-river hydropower is likely to have a similar impact, but production data has not been available to quantify this.

Consequently, a higher level of demand response (both in terms of MW and in terms of MWh) or a larger strategic reserve is required to have a well-functioning market in a system with high levels of wind and solar. If demand response is activated at a price very close to the price ceiling, around $2200 \mathrm{MW}$ are required in the current system with 9\% wind power. However, only $1500 \mathrm{MW}$ would have been required had there been no wind power in the system.

\section{Figure 3.45}

Duration curves for the Nordic system for demand and residual demand in 2015
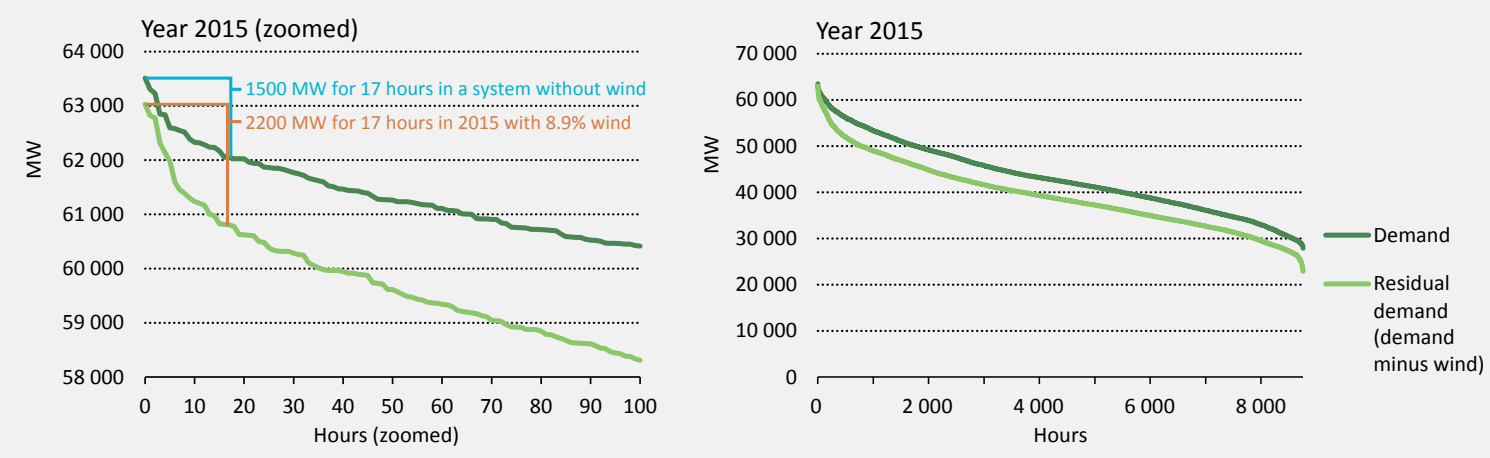

Notes: Residual demand means demand minus wind power; the left-hand graph zooms in on the 100 hours with highest demand.

Figures and data in this report can be downloaded at www.iea.org/etp/nordic.

Key point

A greater proportion of wind and solar power in the energy supply mix will increase demand for peak power while decreasing demand for baseload power.

Researchers have summarised recent analysis of the potential for demand response in the Nordic countries (Thema Consulting Group, 2014). With the current composition of electricity demand, the potential in industry is between 5000 and $6000 \mathrm{MW}$, and between 4000 and 7000 MW in households. These numbers account for the Nordic region as a whole. The potential within the household sector is largely related to the control of electric heating and water heaters, which are important in Norway, Sweden and Finland. Thus, the potential for demand response in the Nordic countries is very significant compared to the volumes required for a well-functioning market. However, the research emphasises that the volumes are uncertain, with economic, technical and practical barriers to realising their potential.

In order to quantify the impact of demand response for the future electricity system, a separate sensitivity analysis has been undertaken where a share of demand is assumed to be flexible. There are different ways of increasing demand flexibility (Ea, 2011): 
Load shifting: This refers to the shifting of demand by household consumers (e.g. for cooling) and industrial customers away from a period with high electricity prices to a period with low wholesale electricity prices.

- Peak shaving: This refers to a reduction in peak demand during times of high prices. This may comprise of consumption that is simply reduced, but not shifted to another period (e.g. lighting turned off in shop windows when the shops are closed).

- Fuel shift in industries: This is the substitution of currently utilised fuel (oil or gas) to electricitybased process heat when electricity prices are low.

The sensitivity analysis addresses only load shifting, i.e. elastic demand, which can for example shift electricity consumption from high-price hours to low-price hours. The flexible demand is modelled as virtual electricity storage, as a proxy for load shifting, without associated losses or costs, i.e. total demand is unaffected over a longer period, but load is shifted within the period without costs. The maximum amount of electricity storage corresponds to four hours of loading. The available demand response capacities are depicted in Figure 3.46, and are gradually phased in so that by 2050 they resemble those identified in the research (Thema Consulting Group, 2014). Of the total potential, $6 \mathrm{GW}$ are related to nominal electricity demand (for example within the industry sector), and a further $6 \mathrm{GW}$ are related to electrical heating (direct heating as well as heat pumps in buildings). Moreover, a potential for flexible charging of EVs is included. This potential is very limited at the beginning of the period but grows to more than $1.5 \mathrm{GW}$ by 2050 in accordance with the increasing deployment of EVs in the CNS.

\section{Figure $3.46 \quad$ Development of demand response in the sensitivity analysis}
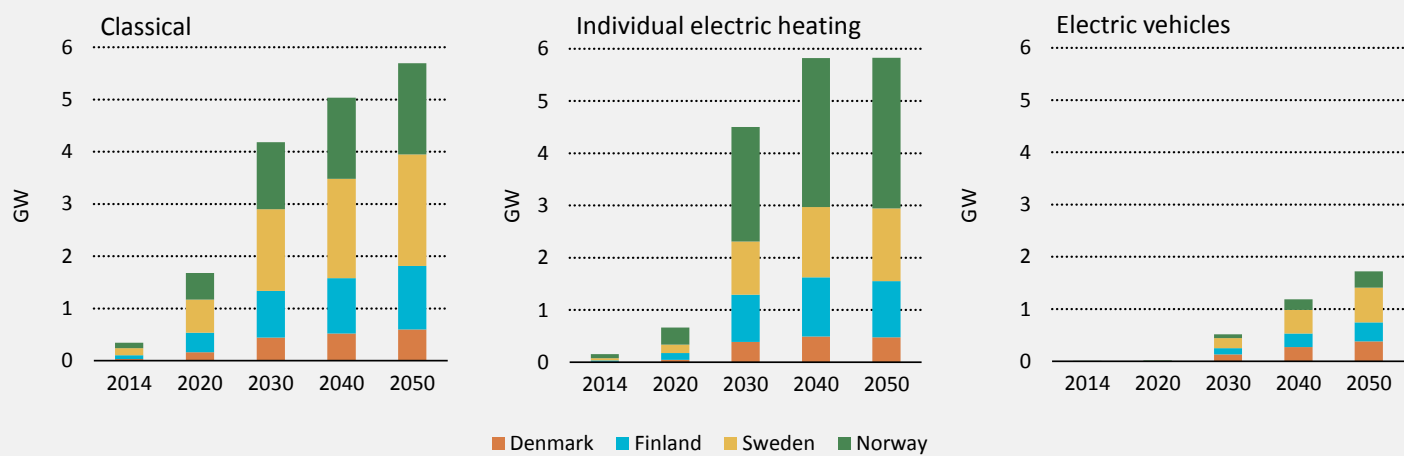

Note: These capacities are exogenous inputs from CNS to CNS-B.

Figures and data in this report can be downloaded at www.iea.org/etp/nordic

Key point The demand response capacities are gradually phased in up to 2050.

\section{Impact of flexible demand on capacity development}

In the Nordic region and surrounding European countries, flexible demand is not changing the big picture in the deployment of power capacity until 2050, as illustrated Figure 3.47. However, from 2030 and onwards it has a growing influence on the need for flexible gas power capacity. In 2050, the need for gas power capacity is reduced by $50 \%$ when introducing flexible demand. Within the Nordic countries, this is mainly reflected in the Danish power system. 


\section{Figure 3.47}

Comparison of development of power capacity with and without flexible demand, in the CNS-B baseline and flex scenarios
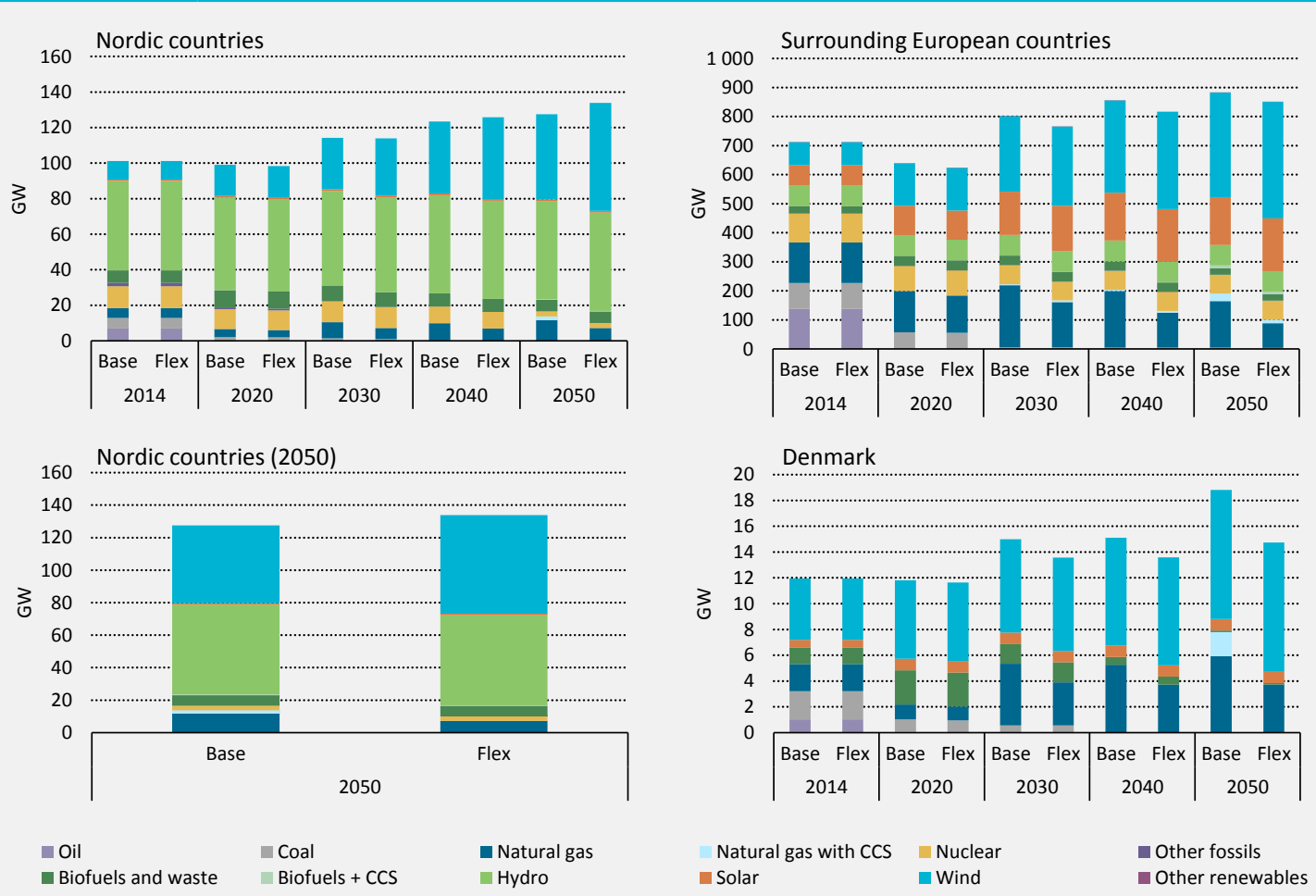

Figures and data in this report can be downloaded at www.iea.org/etp/nordic.

Key point

In the Nordic countries, the impact of flexible demand on capacity development is rather limited (from 2014 until 2040), but it has a big impact in gas power capacity by 2050. Meanwhile in the other European countries this impact is reflected from 2030 onwards.

Impact of flexible demand on electricity trade

Flexible electricity demand will have a larger impact on net exports to continental Europe than to Great Britain as shown in Figure 3.48. 


\section{Figure 3.48}

Comparison of electricity export and import from the Nordic countries to continental Europe and Great Britain with and without flexible demand, in the CNS-B baseline and flex scenarios
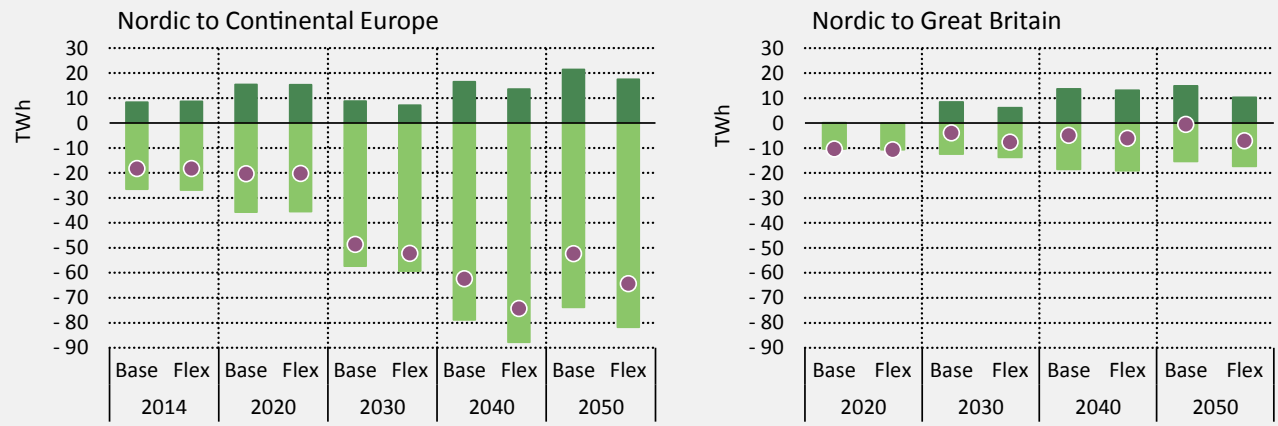

- Import

Export

- Net export

Figures and data in this report can be downloaded at www.iea.org/etp/nordic

Key point

Flexible demand contributes to increasing net exports from the Nordic countries to continental Europe, in the long term, while the effect is somewhat limited with respect to net exports to Great Britain.

The extra flexibility provided to the Nordic power system when introducing flexible demand stabilises the electricity price and reduces the need for natural gas peak boilers. Figure 3.49 illustrates how flexible demand is modelled as electricity storage, moving demand from peak to off-peak periods. 


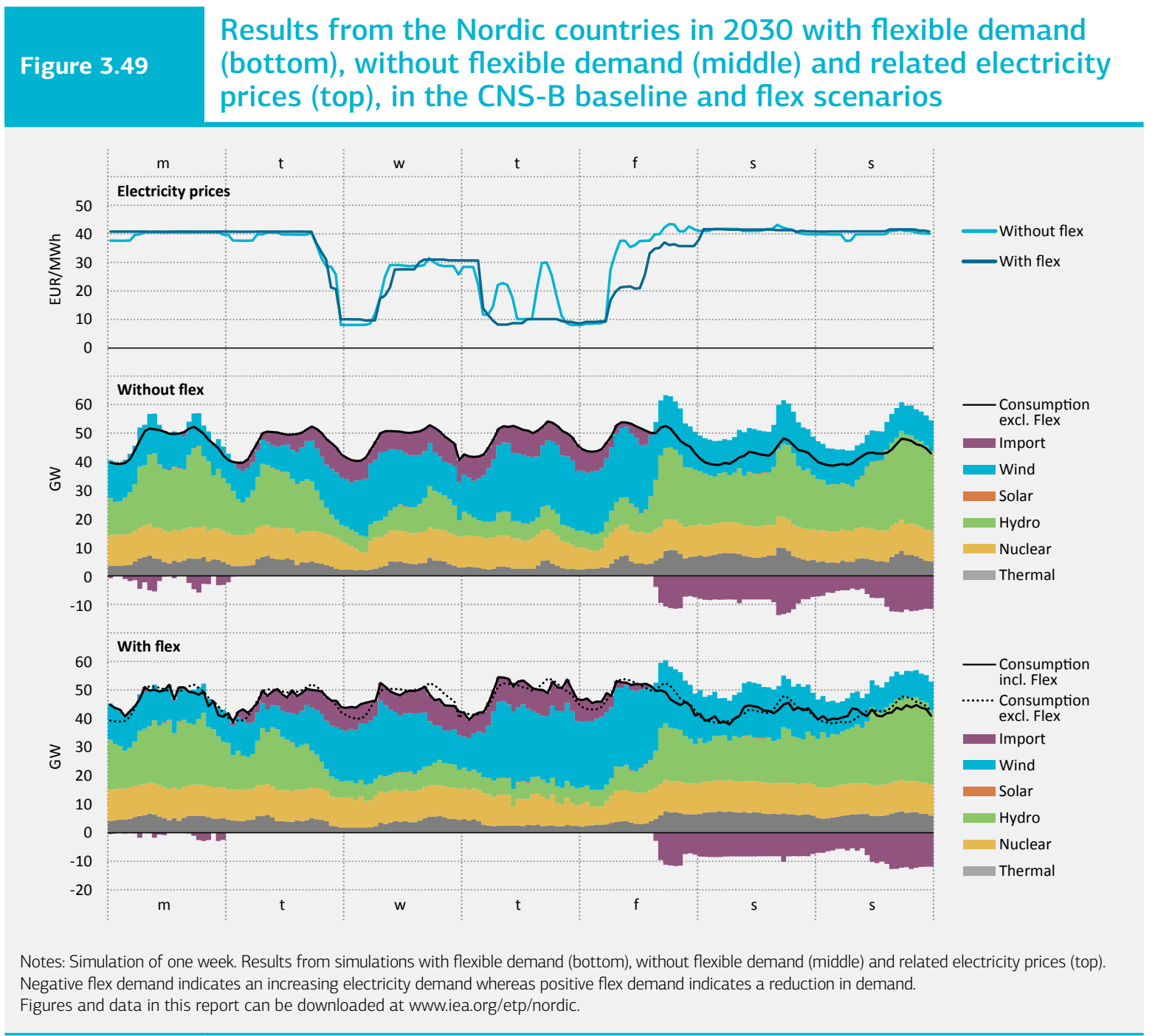

Key point Flexible demand moves demand from high-price hours to low-price hours and reduces peak prices and volatility. 


\section{The role of nuclear in the Nordic energy system}

In 2013, nuclear power plants in Sweden and Finland accounted for 23\% of total electricity generation in the Nordic countries (NordREG, 2014). The future role of nuclear power in the Nordic system is associated with a high level of uncertainty.

Finland is planning to increase its nuclear capacity. Construction of the $1600 \mathrm{MW}$ Olkiluoto 3 was begun in 2005 , but the project has suffered from severe delays and currently the plant is not expected to be commissioned until 2018 (World Nuclear News, 2014). The Finnish government has granted permits for construction of two additional reactors for Teollisuuden Voima and Fennovoima. Fennovoima is expected to start construction of a $1200 \mathrm{MW}$ reactor in 2018 (Power Technology, 2016).

In Sweden, the situation is the reverse. In 2015, power plant owners announced decisions to close four older reactors by 2020 (two units at Ringhals and two units at Oskarsham), removing in total $2700 \mathrm{MW}$ of capacity; further decisions on closures may follow. Nuclear power plants in Sweden are faced with considerable reinvestment in order to improve the safety of the plants and are also subject to taxes in the order of EUR 7/MWh (World Nuclear Association, 2016). Considering the prevailing very low price of electricity, these factors pose a challenge to the economics of the reactors. Industry experts estimate that the long-term electricity price needs to be at around EUR 30/MWh to avoid the decommissioning of existing plants and at EUR 40/MWh to cover lifetime extensions and/or capacity increases at existing plants (Krönert, F, 2016). The levelised cost of electricity generation of new nuclear generation capacity is approximately EUR 65/MWh according to the IEA Projected Costs of Generating Electricity (IEA, 2015). This number corresponds well with the reported numbers for Finland in the same publication, ${ }^{18}$ whereas the Fennovoima 1 nuclear power plant has been contracted at a maximum price of just EUR 50/MWh for the first 12 years of operation according to the media (Taloussanomat, 2014).

In the CNS-B baseline simulation, Swedish nuclear capacity is expected to drop from above 9000 MW in 2014 to just above 6000 MW by 2020, as shown in Figure 3.50. This reflects the abovementioned decisions to close capacity, and this level is projected to be sustained until 2040, after which all remaining nuclear power plants are closed. As a consequence of investment decisions and the on-going construction of Olkiluoto 3, nuclear capacity increases to $5000 \mathrm{MW}$ in Finland by 2030. Thereafter capacity reduces again as the existing power plants reach their technical lifetime (figure 3.50).

Considering these uncertainties for the outlook for nuclear power, a fast phase-out scenario is also analysed, where all nuclear capacity in Sweden is phased out by 2030 and the Fennovoima plant in Finland is not built after all, resulting in Finnish nuclear capacity being 3855 MW in 2030 and 1600 MW in 2050 (see Annex for complete data). The development of nuclear power in the CNS-B baseline scenario and the sensitivity analysis with fast phaseout are depicted in Figure 3.51.

18 Median value of reported nuclear power plants using a 7\% discount is approximately USD 85/MWh (2013 value). Converted to EUR (2015 value) by applying an exchange rate of EUR 0.74/USD for 2013 and 2\% inflation. 


\section{Figure 3.50}

\section{Nuclear capacity in the Nordic countries in CNS-B baseline and} fast phase-out scenarios
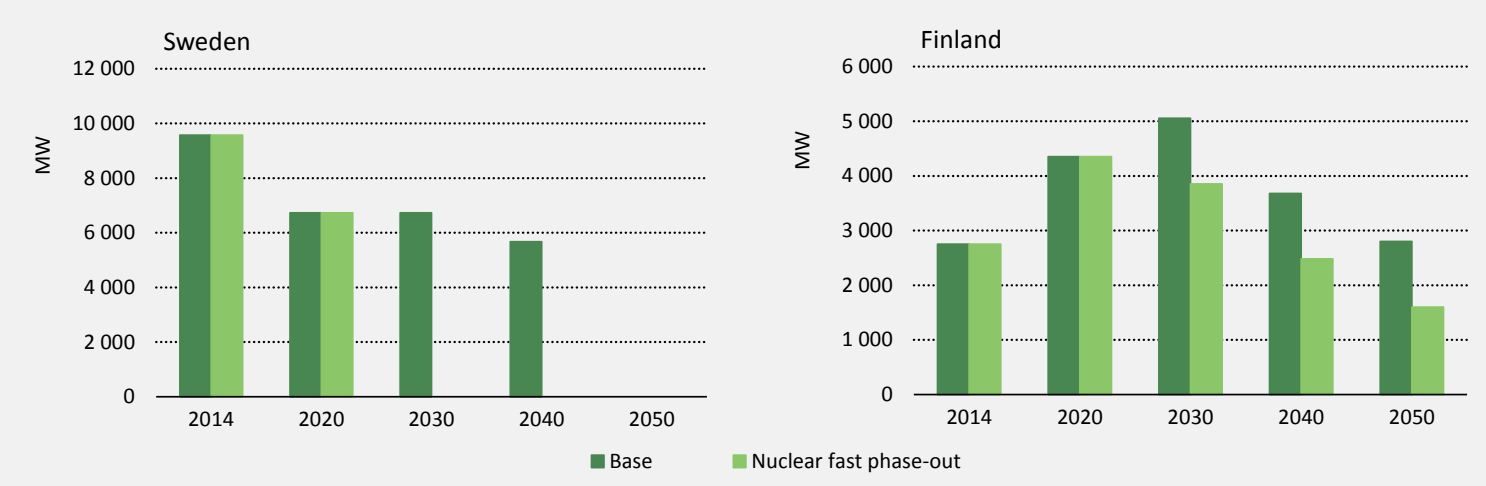

Figures and data in this report can be downloaded at www.iea.org/etp/nordic.

Key point

In a fast phase-out scenario, Sweden will phase out its nuclear installed capacity by 2030, while Finland will increase its nuclear installed capacity (2014-20) and then decrease its capacity until 2050.

The simulations show that with the significant reduction in nuclear power capacity in 2030 and 2040, the model invests in additional wind and natural gas capacity in the Nordic countries, especially in Sweden. The total dispatchable capacity (including all hydropower plants) is reduced from $84 \mathrm{GW}$ to $81 \mathrm{GW}$. Total electricity generation in the Nordic countries is also reduced, leading to a drop in net electricity exports from 62 TWh in the 2030 CNS-B baseline case to 52 TWh in the fast phase-out scenario.

\section{Figure 3.51}

\section{Development of capacity in the Nordic countries with and} without fast phase-out, in the CNS-B

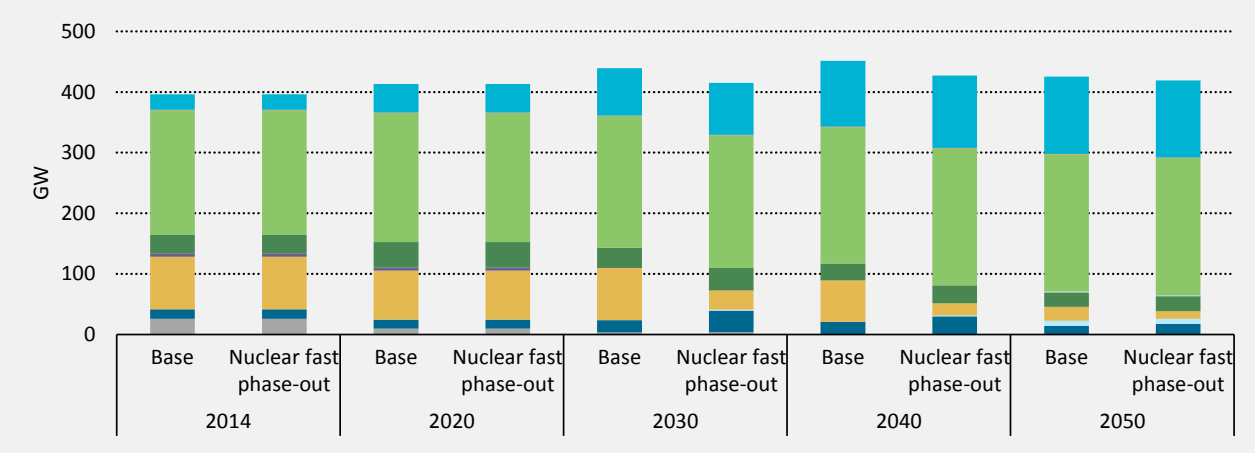

Oil

coal

- Natural gas

Natural gas with CCS

Nuclear

- Other fossils

- Biofuels and waste

Biofuels + CCS

Hydro

- Solar

Wind

- Other renewables

Figures and data in this report can be downloaded at www.iea.org/etp/nordic. 
Due to the greater role of natural gas in the fast phase-out scenario, $\mathrm{CO}_{2}$ emissions in the Nordic countries increase by 7 million tonnes in 2030. In the surrounding European countries, the fast phase-out scenario increases emissions by $2 \mathrm{MtCO}_{2}$ due to reduced export potential from the Nordic countries.

A significant impact on electricity prices is observed in the Nordic countries in 2030, which on average increase by approximately EUR 8/MWh, as depicted in Figure 3.55. The price influence is strongest in Sweden, where average prices increase by EUR 10/MWh.

\section{Figure 3.52}

Electricity price and $\mathrm{CO}_{2}$ emissions in the Nordic countries with and without fast nuclear phase-out, in the CNS-B
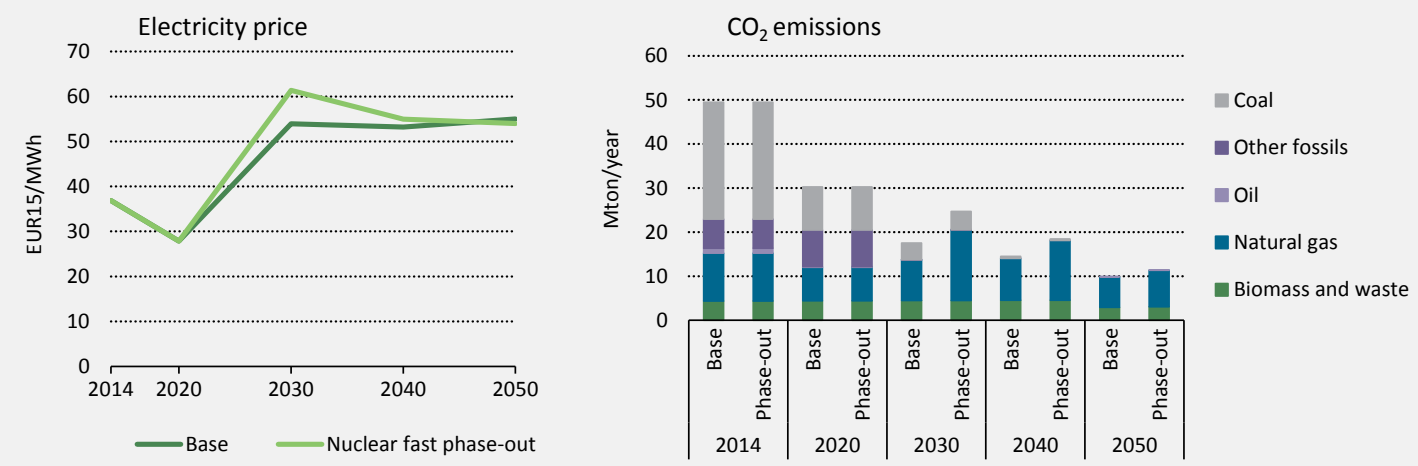

Figures and data in this report can be downloaded at www.iea.org/etp/nordic.

Key point In the fast nuclear phase-out scenario, $\mathrm{CO}_{2}$ emissions will increase due to greater deployment of natural gas capacity, and electricity prices will increase (on average) by EUR 8/MWh in the Nordic countries.

To give an indication of the profitability of nuclear power in the future power system, the projected electricity prices in the simulations can be compared with the aforementioned costs to cover lifetime extensions or increases in capacity at existing or new power plants. Towards 2020, electricity prices are likely to remain below EUR 30/MWh, which is hardly sufficient to cover the running cost of existing nuclear power plants in Sweden, when taxes are included. After 2020, the price shoots up and reaches around EUR 55/MWh by 2030, and stays at this level towards 2050. This is adequate to cover lifetime extensions as well as capacity extensions at existing power plants, but it is barely enough to make investment in new nuclear generation capacity viable.

In addition, it is important to stress that the power price projection is highly sensitive to the assumption about a steeply increasing $\mathrm{CO}_{2}$ price between 2020 and 2030. Even though, the European Union would like to see the EU Emissions Trading System as the main driver for the transformation of the electricity system, it is probably more likely that the driving forces will be a combination of renewable energy subsidies and a more moderate $\mathrm{CO}_{2}$ price. Previous analysis has shown that future support for low-carbon technologies has a significant influence on power market prices if it takes place through renewable energy subsidies rather than the $\mathrm{CO}_{2}$ price $(\mathrm{Ea}, 2 \mathrm{2014a}$ ). This is crucial to have in mind when assessing the future profitability of nuclear power from the perspective of a power company. 


\section{Recommendations and near-term actions}

This analysis of integration of VRE in the Nordic region is based on a specific framework based on the assumption that international agreement secures an average increase in global temperatures of below $2^{\circ} \mathrm{C}$. Fuel prices and a resulting $\mathrm{CO}_{2}$ price are derived from this assumption, reflecting the marginal abatement costs for reducing $\mathrm{CO}_{2}$, which, together with energy demand projections for the countries covered, function as exogenous inputs to the Balmorel model used in this chapter. These prices and energy demands are taken from the 2DS in the IEA global ETP-TIMES model (and sub-models), but in a specific model run with more detailed representation of the Nordic countries (the Nordic CNS).

An important message before reaching a conclusion on the results is the choice of using "free" optimisation of future investment in and running of the Nordic electricity and district heating systems. This means that the model can freely choose when to invest and in which technologies, and what fuels to use, as long as the demand is met. Only national policies on renewable energy until 2020 are forced on the model, and therefore some existing national targets in later years might not be met in the scenarios. One technology has, however, been treated differently - namely nuclear. Nuclear power plants have an extremely long lead time and investment costs are very uncertain. This makes them difficult to handle in an optimisation model such as Balmorel. At the same time, the future amount of nuclear in the Nordic system has a significant influence on the system, and therefore a sensitivity study has been undertaken for this chapter to compare the impacts of two different development paths for nuclear in Sweden and Finland.

With all this in mind, very interesting findings result from this special focus on and analysis of integration of VRE in the Nordic energy system.

The Nord Pool area is extremely well suited to the integration of VRE production in the form of wind and solar power. This is due to the presence of a storable hydropower, adequate transmission capacity between the regions and a well-functioning electricity market. With increasing shares of VRE, transmission capacity has to be updated not just in the Nordic region but all through Europe. The analysis shows that the future system can handle up to $80 \%$ VRE in certain regions.

For optimal utilisation of VRE, the electricity transmission grid both within the Nordic countries, from the Nordic countries to continental Europe and Great Britain, as well as between European countries, has to develop in a consistent manner. This means that European and Nordic countries have to co-ordinate future reinforcement of the power grid and renewable energy targets.

The Nordic countries are endowed with very significant renewable energy resources (particularly hydro and wind power). In the CNS-B the value of renewable energy is seen to increase and offer export potential in the order of 50-60 TWh for the Nordic countries as whole.

Developing this export potential is dependent on the active development of Nordic policies, ensuring:

- That wind power opportunities are developed onshore, which may involve innovative measures to compensate neighbours affected by wind turbines.

- That energy efficiency measures to curb electricity use are adopted to allow for an increase in the Nordic region's export potential. In particular, there is a potential for higher energy efficiency in buildings using direct electric heating.

- The construction of stronger interconnectors to continental Europe and the United Kingdom. 
Price patterns can be expected to change in a market dominated by renewable energy. The occurrence of very low electricity prices and very high prices will be more frequent. The need for conventional thermal baseload power plants will decrease significantly, whereas the need for peak power plants and demand response will increase. The value of electricity storage will also increase.

The hourly price signals in the Nordic energy market will provide incentives for market players and investors to adapt their portfolios, investments and research activities to these changing patterns. For example, the benefit of system-friendly wind power will increase, calling for wind power plants designed for low wind speeds.

Flexible electricity consumption offers untapped potential to integrate variable wind power in the Nordic countries, for example by means of district heat generation. In some countries, this potential may be hampered by taxes on electricity consumption and distribution tariffs that do not reflect actual costs.

The CNS-B simulations assume that a sharply increasing $\mathrm{CO}_{2}$ price is the main driver of the transformation of the energy system. This is in accordance with the polluter pays principle. In practice, however, the transformation is more likely to be driven by a combination of renewable subsidies and carbon pricing, at least in the medium-term. As an increasing share of generation comes to rely on subsidies, it becomes particularly important that these support schemes are well designed to ensure that renewable energy technologies are also exposed to the price signals provided by the market. 



\section{Annexes}

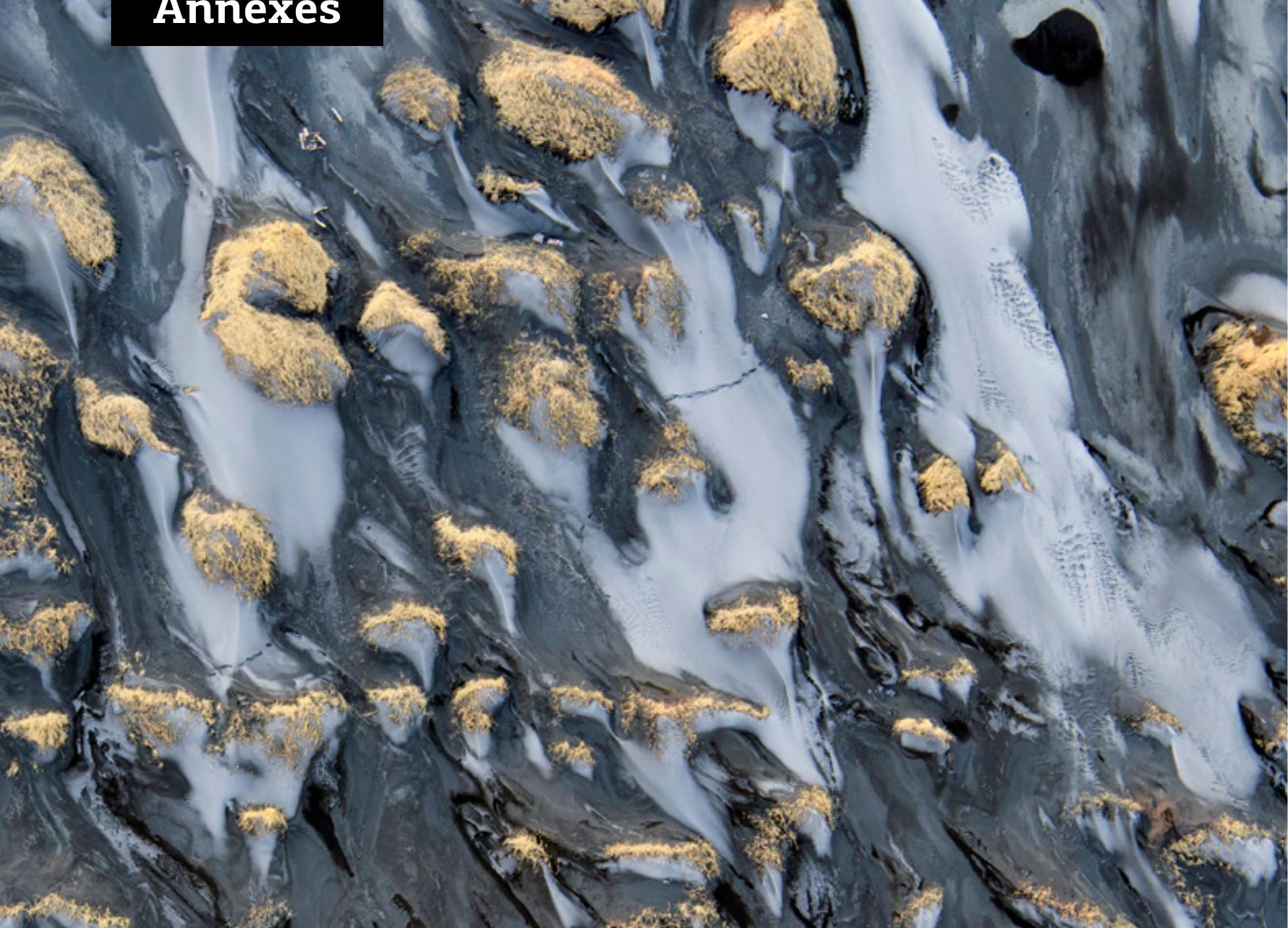

itosing

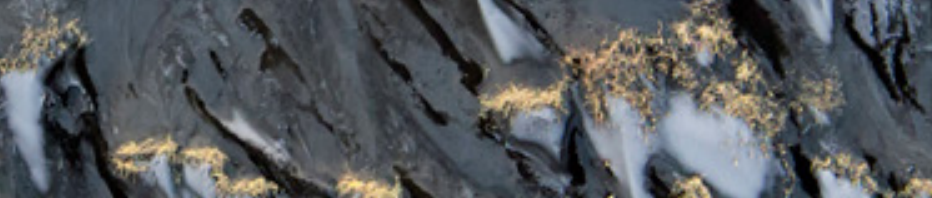

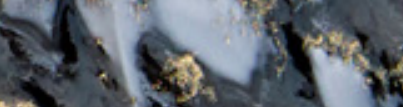$$
\text { in } x \text { a }
$$

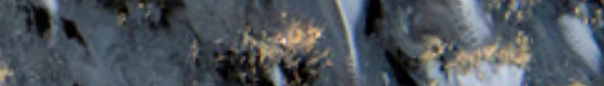

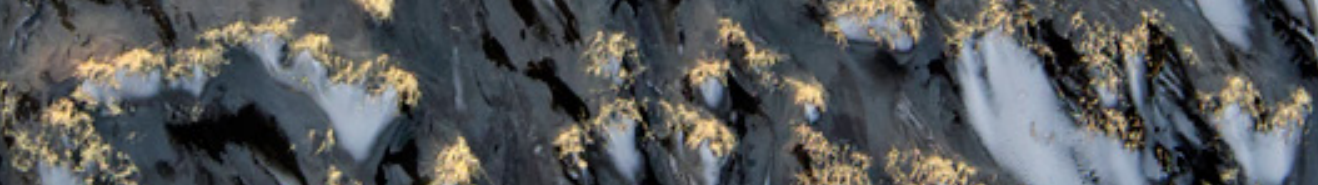

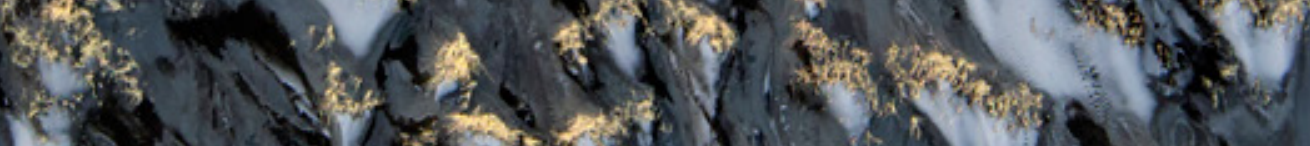
(3) क

(1)

(3)

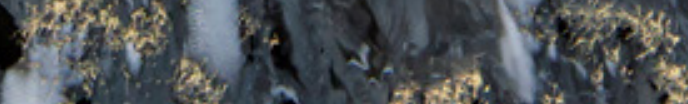

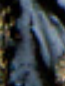




\section{Annex A (Chapter 1) Analytical Approach}

Nordic Energy Technology Perspectives 2016 (NETP 2016) follows the same analytical approach as Energy Technology Perspectives 2016 (ETP 2016) (www.iea.org/etp). It applies a combination of back casting and forecasting over three scenarios from now to 2050. Back casting lays out plausible pathways to a desired end state. It makes it easier to identify milestones that need to be reached, or trends that need to change promptly, in order for the end goal to be achieved. The advantage of forecasting, where the end state is a result of the analysis, is that it allows greater considerations of short-term constraints.

The analysis and modelling aim to identify the most economical way for society to reach the desired outcome, but for a variety of reasons the scenario results do not necessarily reflect the least-cost ideal. Many subtleties cannot be captured in a cost optimisation framework: political preferences, feasible ramp-up rates, capital constraints and public acceptance. For the end-use sectors (buildings, transport and industry), doing a pure least-cost analysis is difficult and not always suitable. Long-term projections inevitably contain significant uncertainties, and many of the assumptions underlying the analysis will likely turn out to be inaccurate. Another important caveat to the analysis is that it does not account for secondary effects resulting from climate change, such as adaptation costs. By combining differing modelling approaches that reflect the realities of the given sectors, together with extensive expert consultation, NETP 2016 obtains robust results and in-depth insights.

Achieving the NETP scenarios does not depend on the appearance of breakthrough technologies. All technology options introduced in NETP 2016 are already commercially available or at a stage of development that makes commercial-scale deployment possible within the scenario period. Costs for many of these technologies are expected to fall over time, making a low-carbon future economically feasible.

The NETP analysis acknowledges those policies that are already implemented or committed. In the short term, this means that deployment pathways may differ from what would be most cost-effective. In the longer term, the analysis emphasises a normative approach, and fewer constraints governed by current political objectives apply in the modelling. The objective of this methodology is to provide a model for a cost-effective transition to a sustainable energy system.

To make the results more robust, the analysis pursues a portfolio of technologies within a framework of cost minimisation. This offers a hedge against the real risks associated with the pathways: if one technology or fuel fails to fulfil its expected potential, it can more easily be compensated by another if its share in the overall energy mix is low. The tendency of the energy system to comprise a portfolio of technologies becomes more pronounced as carbon emissions are reduced, since the technology options for emissions reductions and their potentials typically depend on the local conditions in a country. At the same time, uncertainties may become larger, depending on the technologies' maturity levels and the risks of not reaching expected technological development targets. 


\section{The ETP model}

The ETP model, which is the primary analytical tool used in NETP 2016, supports integration and manipulation of data from four soft-linked models:

- energy conversion

- industry

- transport

- buildings (residential and commercial/services).

It is possible to explore outcomes that reflect variables in energy supply (using the energy conversion model) and in the three sectors that have the largest demand, and hence the largest emissions (using models for industry, transport and buildings). The following schematic illustrates the interplay of these elements in the processes by which primary energy is converted to the final energy that is useful to these demand-side sectors (Figure A.1).

\section{Figure A.1 Structure of the ETP model}

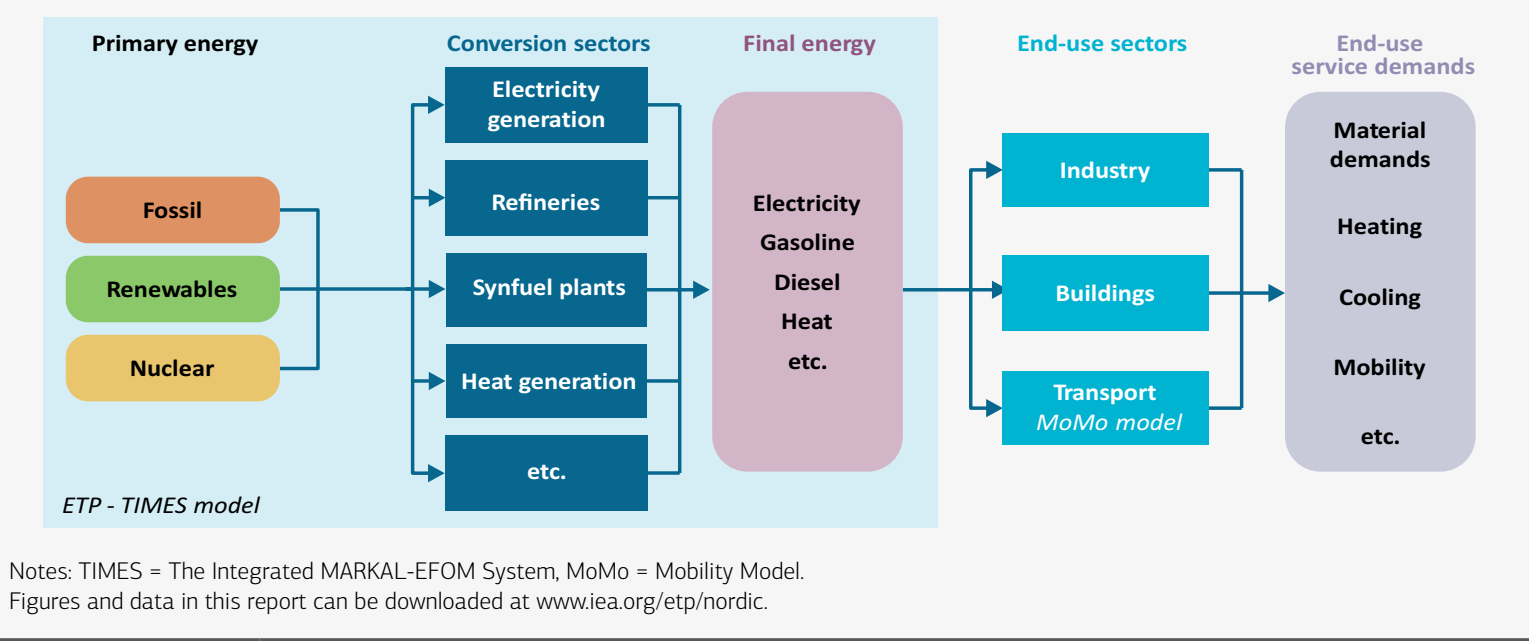

Key point The ETP model enables a technology-rich, bottom-up analysis of the global energy system.

\section{ETP-TIMES model for energy conversion sector}

The conversion sector (i.e. power and heat generation as well as fuel transformation) in NETP 2016 is analysed using the global ETP-TIMES model, which explicitly includes the five Nordic countries (Denmark, Finland, Iceland, Norway and Sweden) as separate model regions and depicts, in a technology-rich fashion, the supply side of the Nordic energy system. The global ETP-TIMES model spans the spectrum for primary energy supply and conversion to final energy demand up to 2075 for 28 world's regions or countries, including the five Nordic countries. The model is based on the TIMES (The Integrated MARKAL EFOM System) model generator, which has been developed by the Energy Technology Systems Analysis Programme (ETSAP) implementing agreement of the International Energy Agency (IEA) and allows an economic 
representation of local, national and multi-regional energy systems on a technology-rich basis (Loulou et al., 2005).

Starting from the current situation in the conversion sectors (e.g. existing capacity stock, operating costs and conversion efficiencies), the model integrates the technical and economic characteristics of existing technologies that can be added to the energy system. The model can then determine the least-cost technology mix needed to meet the final energy demand calculated in the ETP end-use sector models for industry, transport and buildings (Figure A.2).

\section{Figure A.2 Structure of the ETP-TIMES model for the conversion sector}

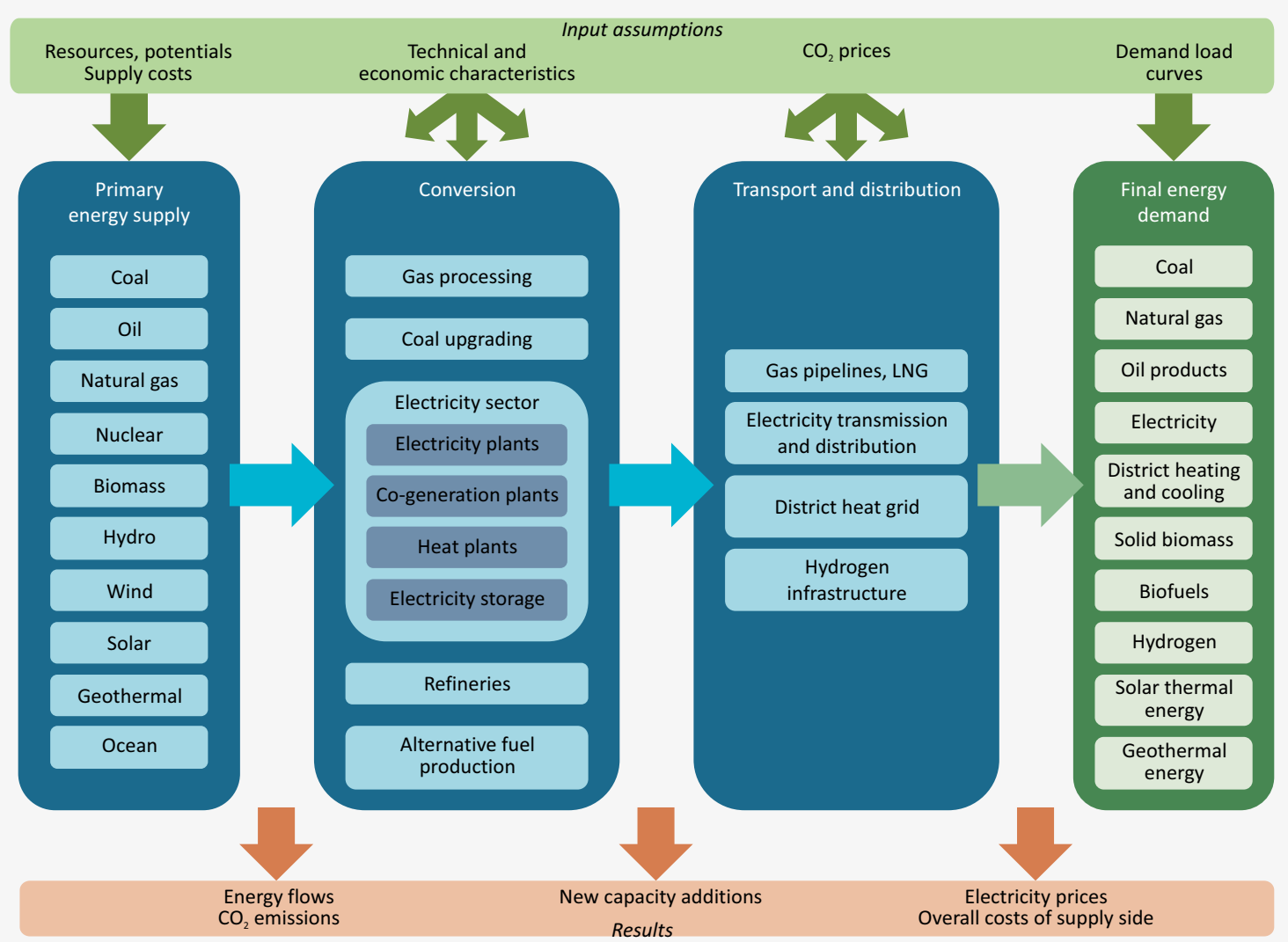

Notes: $\mathrm{CO}_{2}=$ carbon dioxide; $\mathrm{LNG}=$ liquefied natural gas; co-generation refers to the combined production of heat and power Figures and data in this report can be downloaded at www.iea.org/etp/nordic

Key point ETP-TIMES determines the least-cost strategy in terms of supply-side technologies and fuels to cover the final energy demand vector from the end-use sector models.

Technologies are described by their technical and economic parameters, such as conversion efficiencies or specific investment costs. Learning curves are used for new technologies to link future cost developments with cumulative capacity deployment.

The ETP-TIMES model also takes into account additional constraints in the energy system (such as fossil fuel resource constraints or emissions reduction goals) and provides detailed 
information on future energy flows and their related emissions impacts, required technology additions and the overall cost of the supply-side sector.

To capture the impact of variations in electricity and heat demand, as well as in the generation from some renewable technologies on investment decisions, a year is divided into four seasons, with each season being represented by a typical day, which again is divided into eight daily load segments of three hours' duration.

For a more detailed analysis of the operational aspects in the electricity sector, the long-term ETP-TIMES model has been supplemented with a linear dispatch model. This model uses the outputs of the ETP-TIMES model for the 2050 electricity capacity mix for a specific model region and analyses an entire year with one-hour time resolution using datasets for wind production, solar photovoltaic production, and hourly electricity demand for a year. Given the hourly demand curve and a set of technology-specific operational constraints, the model determines the optimal hourly generation profile. To increase the flexibility of the electricity system, the linear dispatch model can invest in electricity storage or additional flexible generation technologies (gas turbines). Demand response by modifying the charging profile of electric vehicles $(E V)$ is a further option depicted in the model in order to provide flexibility to the electricity system.

This linear dispatch model represents storage in terms of three steps: charge, store, discharge. The major operational constraints included in the model are capacity states, minimum generation levels and time, ramp-up and -down, minimum downtime hours, annualised plant availability, cost considerations associated with start-up and partial-load efficiency penalties, and maximum storage reservoir capacity in terms of energy (megawatt hours [MWh]).

Model limitations include challenges due to a lack of comprehensive data with respect to storage volume (MWh) for some countries and regions. Electricity networks are not explicitly modelled, which precludes the study of the impacts of spatially dependent factors such as the aggregation of variable renewable outputs with better interconnection. Further, it is assumed that future demand curves will have the same shape as current curves. A bottom-up approach starting from individual energy service demand curves by end-use technology would be useful in refining this assumption, but is a very data-intensive undertaking that faces the challenge of a lack of comprehensive data.

The modelling of electricity trade flows in the five Nordic countries and to the rest of Europe within the ETP-TIMES model is linked to the Balmorel model, which projects electricity trade flows and transmissions capacity in the Nordic region. Data on transmission capacity from the Balmorel model were used as upper bounds in the ETP-TIMES modelling of power infrastructure in the Nordic region.

\section{Industry sector model}

Industry is modelled using TIMES-based linear optimisation models for three energy-intensive sectors (iron and steel, cement and aluminium), and technology-rich stock accounting simulation models ${ }^{1}$ that cover the remaining two energy-intensive sectors (chemicals and petrochemicals, and pulp and paper). The five sub models characterise the energy performance of process technologies from each of the energy-intensive sub-sectors, including 39 countries and regions. The five Nordic countries are each modelled individually within the global model. Typically, raw materials production is not included within the boundaries of the model, with the exception of the iron and steel sector, in which energy use for coke ovens and blast furnaces is covered. Due to the complexity of the chemicals and petrochemicals sector, the model focuses on five

1 The ETP Industry model is currently in a transition phase as it is being migrated to the TIMES modelling platform. 
products that represent about $47 \%$ of the energy use of the sector: ethylene, propylene, BTX², ammonia and methanol.

Demand for materials is estimated based on country- or regional-level data for gross domestic product (GDP), disposable income, short-term industry capacity, current materials consumption, regional demand saturation levels derived from historical demand intensity curves, and resource endowments (Figure A.3). Total production is simulated by factors such as process, age structure (vintage) of plants and stock turnover rates. Overall production levels are similar across scenarios, but means of production differ considerably. For example, the same level of crude steel production is expected in both the $6^{\circ} \mathrm{C}$ Scenario (6DS) and the 2DS, but the 2DS reflects a much higher use of scrap (which is less energy-intensive than production from conventional raw materials).

\section{Figure A.3 Structure of ETP-Industry model}

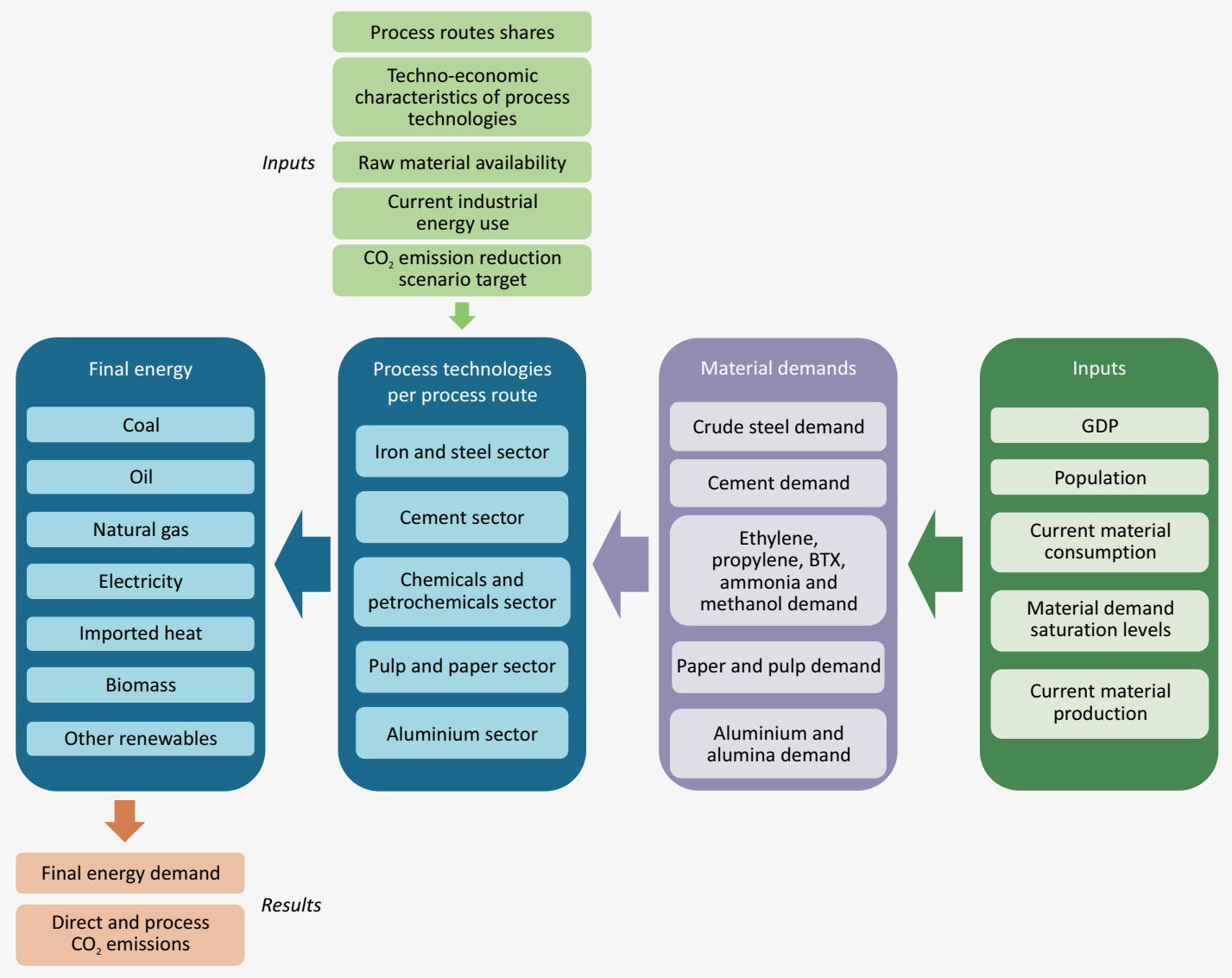

Figures and data in this report can be downloaded at www.iea.org/etp/nordic.

\section{Key point}

Based on socio-economic assumptions and statistical information, the industry model projects material demands, which are then used to determine the final energy consumption and direct $\mathrm{CO}_{2}$ emissions of the sector, depending on the energy performance of process technologies and technology choice within each of the available production routes. 
Each industry sub-model is designed to account for sector-specific production routes for which relevant process technologies are modelled. Industrial energy use and technology portfolios for each country or region are characterised in the base year based on relevant energy use and material production statistics for each energy-intensive industrial sub-sector. Changes in the technology and fuel mix as well as efficiency improvements are driven by exogenous assumptions on penetration and energy performance of best available technologies (BATs), constraints on the availability of raw materials, techno-economic characteristics of the available technologies and process routes, and assumed progress on demonstrating innovative technologies at commercial scale. Thus, the results are sensitive to assumptions on how quickly physical capital is turned over, relative costs of the various options, and incentives for the use of BATs for new capacity.

For NETP 2016, model inputs for the Nordic countries, such as production levels, country-specific technology characterisation and performance data, and technical potential for future energy performance improvement and progress in innovative technology demonstration in the Nordic region, were discussed with Nordic industry sector experts to provide an additional in-depth review of publicly available data sources for these five countries.

The industry model allows analysis of different technology and fuel switching pathways in the sector to meet projected material demands within a given related $\mathrm{CO}_{2}$ emissions envelope in the modelling horizon.

\section{Modelling of the transport sector in the Mobility Model (MoMo) Overview}

The mobility model (MoMo) is a technical-economic database spreadsheet and simulation model that enables detailed projections of transport activity, vehicle activity, energy demand, and wellto-wheels GHG and pollutant emissions according to user-defined policy scenarios to 2050.

MoMo comprises:

- 27 countries and regions (with the five Nordic countries included in two of these regions, "EU-Nordic" and "Non-EU Nordic") ${ }^{3}$, which are aggregated into 4 OECD regional clusters and 11 groups of non-OECD economies

- historic data from 1975 to 2013 (or 1990 to 2013 for certain countries)

- simulation model in five-year time steps, for building scenarios to 2050 based on "what if" analysis and back casting

- disaggregated urban versus non-urban vehicle stock, activity, energy use and emissions all major motorised transport modes (road, rail, shipping and air), providing passenger and freight services

- wide range of powertrain technologies (internal combustion engines, including gasoline, diesel, and compressed and liquefied natural gas, as well as hybrid electric, and electric vehicles [including plug-in hybrid electrics - PHEVs, and battery-electric vehicles - BEVs], and fuel-cell electric vehicle [FCEV] powertrains)

- associated fuel supply options (petroleum gasoline and diesel, biofuels [ethanol and biodiesel via various production pathways] and synthetic fuel alternatives to liquid fuels [coal-to-liquid CTL and gas-to-liquid - GTL], gaseous fuels including natural gas [compressed natural gas CNG and liquefied petroleum gas - LPG] and hydrogen via various production pathways, and electricity [with emissions according to the average national generation mix as modelled by the ETP TIMES model in the relevant scenario]).

3 Results for each of the Nordic countries take into account the values obtained for the Nordic MoMo regions and additional country-level information. 
MoMo further enables estimation of scenario-based costs of vehicles, fuels and transport infrastructure, as well as the primary material inputs required for the construction of vehicles, related energy needs and resultant GHG emissions.

To ease the manipulation and implementation of the modelling process, MoMo is split into modules that can be updated and elaborated upon independently. Figure A.4 shows how the modules interface with one another. By integrating assumptions on technology availability and cost in the future, the model reveals, for example, how costs could drop if technologies were deployed at a commercial scale and allows fairly detailed bottom-up "what-if" modelling, especially for passenger light-duty vehicles and trucks (Fulton et al. 2009).

\section{Figure A.4 MoMo structure}

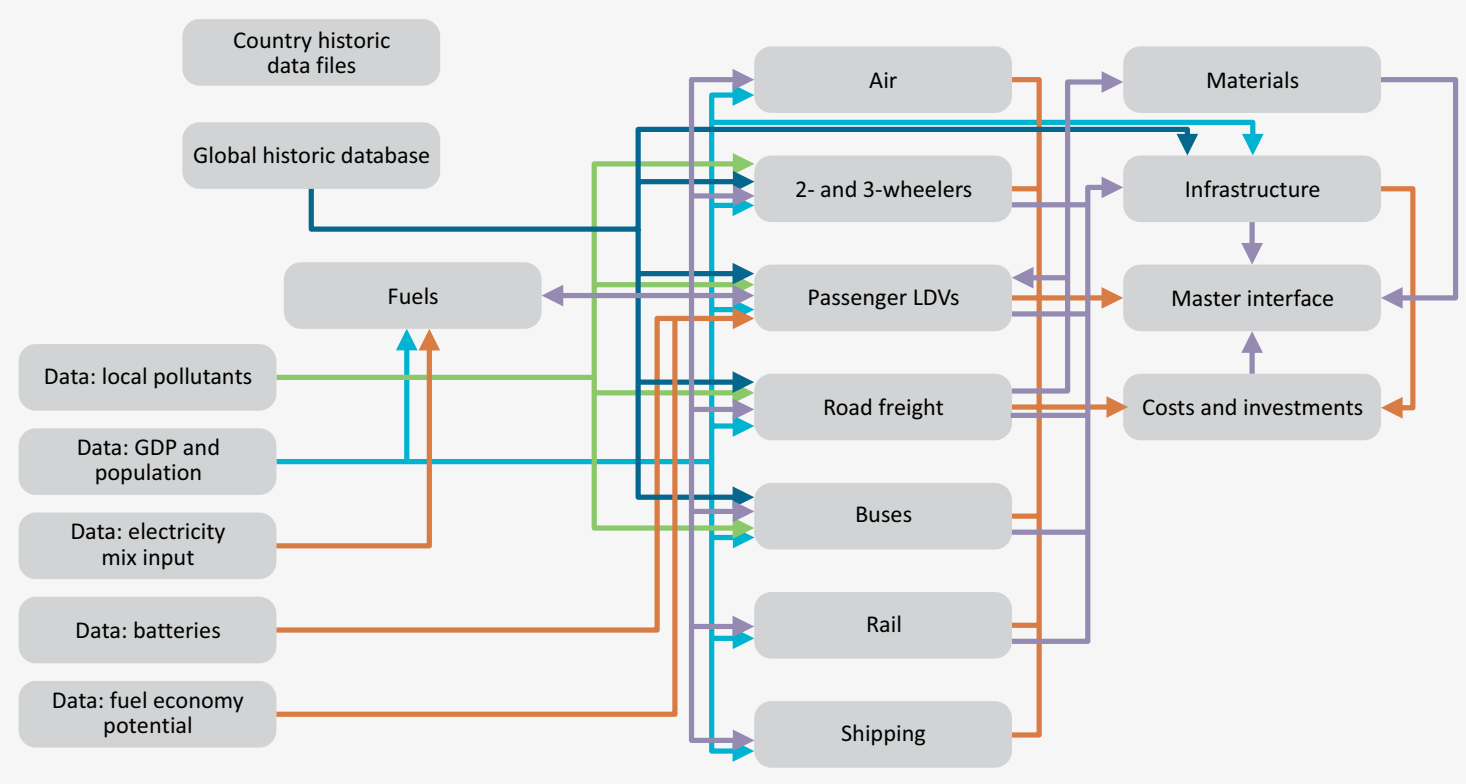

Note: LDV = light-duty vehicle.

Figures and data in this report can be downloaded at www.iea.org/etp/nordic

Key point

MoMo covers all transport modes and includes modules on local air pollutants and on the costs of fuels, vehicles and infrastructure as well as analysis on the material needs for new vehicles.

\section{Data sources}

The MoMo modelling framework relies upon compiling and combining detailed data from various sources on vehicles in each of the countries/regions to estimate aggregate energy consumption, emissions and other energy-relevant metrics at the country/regional level.

Historic data series have been collected by MoMo modellers from a wide variety of public and proprietary data sources for more than a decade. National data are gathered primarily from the following organizations: (1) national and international public institutions (e.g. the World Bank, the Asian Development Bank and Eurostat); (2) national government ministries (e.g. departments 
of energy and/or transport, and statistical bureaus); (3) federations, associations, and nongovernmental organizations (e.g. JAMA, KAMA and Naamsa); (4) public research institutions (e.g. peer-reviewed papers and reports from universities and national laboratories); (5) private research institutions (e.g. ICCT); and (6) private business and consultancies (e.g. POLK, Segment Y, and other major automotive market research and analysis organisations, in addition to major energy companies and automobile manufacturers themselves). Full details on data sources on a national or regional basis are documented in the regional data files of MoMo.

\section{Calibration of historical data with energy balances}

The framework of estimating average and aggregate energy consumption for a given vehicle class i can be neatly summarised by the ASIF identity (Schipper, 2000):

$F=\sum_{i} F_{i}=A \sum_{i}\left(\frac{A_{i}}{A}\right)\left(\frac{F_{i}}{A_{i}}\right)=A \sum_{i} S_{i} I_{i}=F$

where: $F$ = total fuel use [MJ/year]; $A$ = vehicle activity [vkm/year]; I = energy intensity [MJ/vkm]; $S=$ structure (shares of vehicle activity) [\%]; and $i$ is an index of vehicle modes and classes MoMo models vehicles belonging to several modes. Vehicle activity can also be expressed as the product of vehicle stock [vehicles] and mileage [km/year]. The energy used by each mode and vehicle class in a given year [MJ/year] can, therefore, be calculated as the product of three main variables: vehicle stock (S) [vehicles], mileage (M) [km/year] and fuel economy (FE) [MJ/vkm].

To ensure a consistent modelling approach is adopted across the modes, energy use is estimated based on stocks (via scrappage functions), utilisation (travel per vehicle), consumption (energy use per vehicle, i.e. fuel economy) and emissions (via fuel emission factors for $\mathrm{CO}_{2}$ and pollutants on a vehicle and well-to-wheel basis) for all modes. Final energy consumption, as estimated by the "bottom-up" approach described above, is then validated against and calibrated as necessary to the IEA energy balances (IEA, 2015a).

\section{Vehicle platform, components and technology costs}

Detailed cost modelling for passenger light-duty vehicles (PLDVs) accounts for initial (base year) costs, asymptotic (i.e. fully learned-out) costs and an experience parameter that defines the shape of cost reductions. These three parameters define learning functions that are based on the number of cumulative units produced worldwide. Cost functions define various vehicle configurations, including vehicle component efficiency upgrades (e.g. improved tyres, A/C controls, etc.), material substitution and vehicle downsizing, conventional spark- and compression ignition engine improvements, conventional and plug-in hybrid powertrain configurations, batteries, electric motors and fuel cells. These configurations are added to a basic glider cost. The ratios of differences in vehicle technologies deployed in PLDVs are extrapolated to other road vehicle types (i.e. two- and three-wheelers and freight trucks).

The primary drivers of technological change in transport are assumptions on the cost evolution of the technology, and the policy framework incentivising adoption of the technology. Oil prices and the set of policies assumed can significantly alter technology penetration patterns. For each scenario, the model supports a comparison of marginal costs of technologies and aggregates to total cost across all modes and regions.

\section{Infrastructure and fuel costs}

MoMo estimates future (2010-2050) infrastructure costs according to scenario-based projections on modal activity and fuel use. Infrastructure cost estimates include capital costs, operations and maintenance, and reconstruction costs - split by geography according to the location of the investments into urban and non-urban regions. Fuel costs are also estimated based on scenario-specific projections of urban and non-urban consumption, and include all fuel types (fossil-derived fuels, biofuels, electricity and hydrogen). 


\section{Elasticities}

Key elasticities have been included in MoMo from 2012. Price and income elasticities of fuel demand, for light-duty road (passenger) activity as well as road freight, based upon representative "consensus" literature values, are used to model vehicle activity and fuel consumption responses to changes in fuel prices - which are themselves driven by projections and policy scenarios (i.e. GHG or fuel taxes). Elasticities also enable vehicle ownership to vary according to fuel prices and income, as proxied by GDP per capita.

The 2015-2016 updates for NETP 2016 include an expanded treatment of the above elasticities to encompass the urban / non-urban split, and to include the potential for municipal level policies to reduce transport energy use $\mathrm{e}^{4}$.

\section{Buildings sector model}

The buildings sector is modelled using a global simulation stock accounting model, split into the residential and services subsectors for the countries in the Nordic region(Figure A.5). The residential subsector includes all energy-using activities in apartments and houses, including space and water heating, cooling, lighting and the use of appliances and other electronic plugloads. The services subsector includes activities related to trade, finance, real estate, public administration, health, food and lodging, education and other commercial services. This subsector is also commonly referred to as the commercial and public service sector. It covers energy used for space and water heating, cooling and ventilation, lighting and a number of other miscellaneous energy-consuming equipment such as commercial appliances, office equipment, cooking devices and medical equipment.

For both subsectors, the model uses socio-economic drivers, such as income (approximated by GDP) and population, to project the major building energy demand drivers, including residential and service floor space, number of households and residential appliance ownership. As far as possible, country statistics are used for historical floor area and appliance ownership rates. Building floor area is then differentiated by vintage, where approximations based on other indicators (e.g. historical population) are used to estimate the vintage distributions if no statistical data are available for a country.

Differentiated stock accounting is used to estimate historical useful energy intensity across the various building end-uses with respect to assumed technology shares and efficiencies. Whenever possible, historical data on country technology shares and efficiencies are applied. These useful energy intensities (e.g. demand for space heating per unit of floor area in terms of final delivered [i.e. useful] energy service) are then applied across the building end-uses with the projections for floor area, households and appliance ownership. The model takes into account the vintage of the building stock as well as the ageing or refurbishment of the buildings through corresponding degradation and improvement rates for the useful energy intensities.

For each of these derived useful energy demands, a suite of technology and fuel options are represented in the model, reflecting their current techno-economic characteristics (e.g. efficiencies) as well as their future improvement potential. Depending on the current technology stock as well as assumptions on the penetration and market shares of new technologies, the buildings sector model allows exploration of strategies that cover the different useful energy demands and the quantifying of the resulting developments for final energy consumption and related $\mathrm{CO}_{2}$ emissions.

4 Further details on the newly added national and municipal policies, the elasticities that are used to model transport activity, stock, and mode share responses to these policies, and the demand generation module can be found at www.iea.org/etp/etp2016/annexes. 


\section{Figure A.5 Structure of the buildings sector model}

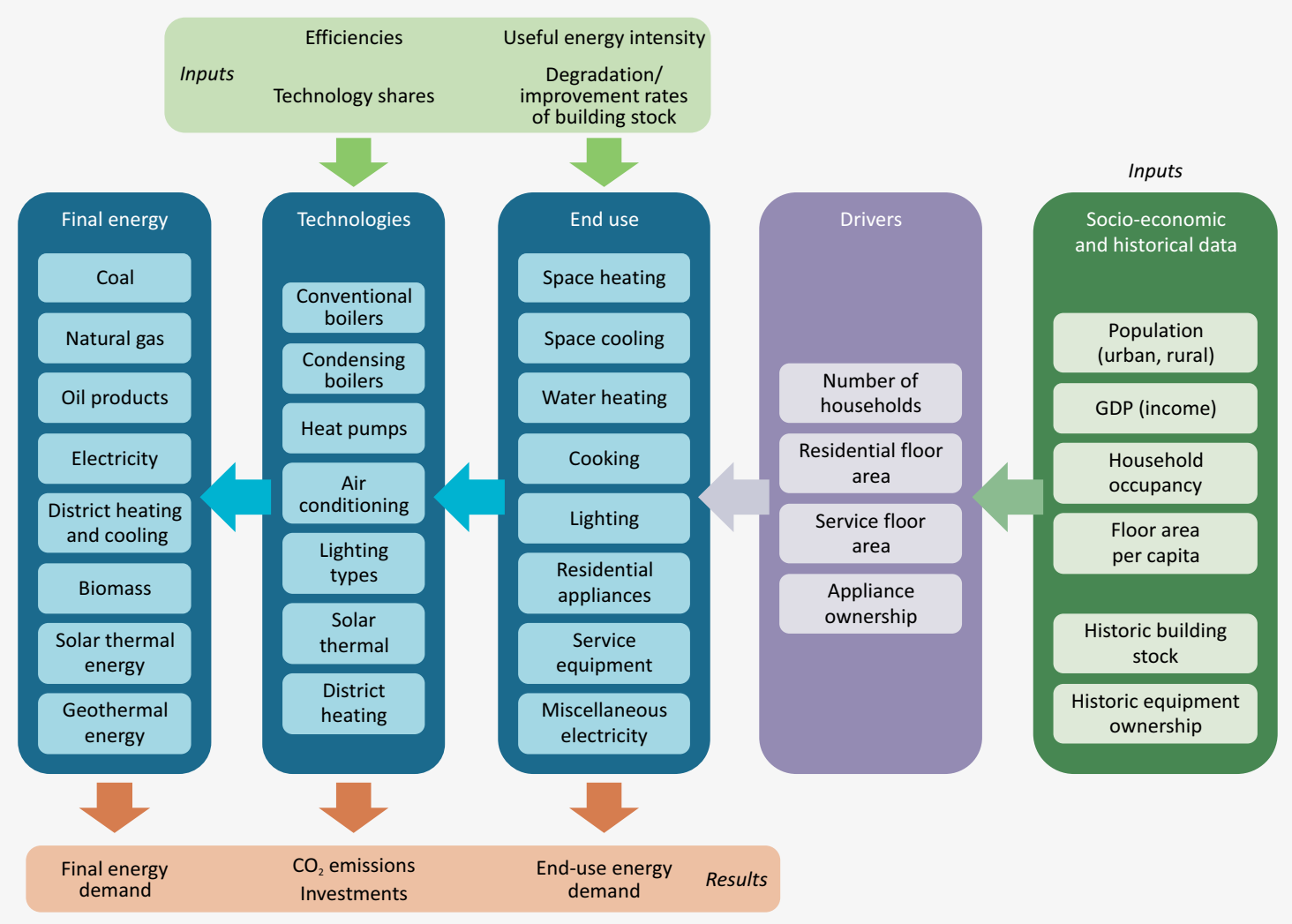

Figures and data in this report can be downloaded at www.iea.org/etp/nordic.

Key point Starting from socio-economic assumptions, the buildings sector model determines demand drivers and the related useful energy demands, which are then applied across the building end-uses and technology choices to calculate final energy consumption across the 33 model regions.

\section{Framework assumptions}

Economic activity (Table A.1) and population (Table A.2) are the two fundamental drivers of demand for energy services in NETP scenarios. These are kept constant across all scenarios as a means of providing a starting point for the analysis, and facilitating the interpretation of the results. Under the ETP assumptions, global GDP will more than triple between 2013 and 2050; uncertainty around GDP growth across the scenarios is significant, however. The climate change rate, and even in the $4^{\circ} \mathrm{C}$ Scenario (4DS), is likely to have profound negative impacts on the potential for economic growth. These impacts are not captured by ETP analysis. Moreover, the structure of the economy is likely to have non-marginal differences across scenarios, suggesting that GDP growth is unlikely to be identical even without considering secondary climate impacts. The redistribution of financial, human and physical capital will affect the growth potential both globally and on a regional scale. 


\begin{tabular}{|c|c|c|c|c|}
\hline \multirow{2}{*}{$\begin{array}{l}\text { Table A.1 } \\
\text { CAAGR (\%) }\end{array}$} & \multicolumn{4}{|c|}{$\begin{array}{l}\text { Real GDP growth projections in NETP } 2016 \text { (assumed identical } \\
\text { across scenarios) }\end{array}$} \\
\hline & 2013-20 & $2020-30$ & $2030-50$ & $2013-50$ \\
\hline World & 3.7 & 3.8 & 2.8 & 3.2 \\
\hline OECD & 2.2 & 2.0 & 1.6 & 1.8 \\
\hline Non-OECD & 4.9 & 4.9 & 3.3 & 4.1 \\
\hline European Union & 1.9 & 1.8 & 1.5 & 1.6 \\
\hline Denmark & 1.9 & 2.09 & 1.57 & 1.78 \\
\hline Finland & 1.26 & 2.09 & 1.57 & 1.65 \\
\hline Iceland & 2.74 & 2.73 & 2.01 & 2.34 \\
\hline Norway & 1.79 & 2.73 & 2.01 & 2.16 \\
\hline Sweden & 2.53 & 2.09 & 1.57 & 1.89 \\
\hline Nordic 5 & 1.99 & 2.27 & 1.7 & 1.91 \\
\hline
\end{tabular}

\begin{tabular}{|c|c|c|c|c|c|}
\hline Table A.2 & \multicolumn{5}{|c|}{ Population projections used in NETP 2016} \\
\hline Country/Region & 2013 & 2020 & 2030 & 2040 & 2050 \\
\hline World & 7102 & 7652 & 8354 & 8962 & 9468 \\
\hline OECD & 1265 & 1312 & 1367 & 1403 & 1425 \\
\hline Non-OECD & 5837 & 6340 & 6987 & 7559 & 8043 \\
\hline European Union & 524 & 532 & 538 & 538 & 536 \\
\hline Denmark & 5.6 & 5.8 & 6 & 6.2 & 6.4 \\
\hline Finland & 5.4 & 5.6 & 5.7 & 5.7 & 5.7 \\
\hline Iceland & 0.3 & 0.3 & 0.4 & 0.4 & 0.4 \\
\hline Norway & 5 & 5.4 & 5.8 & 6.2 & 6.6 \\
\hline Sweden & 9.6 & 10 & 10.7 & 11.3 & 11.9 \\
\hline Nordic 5 & 26 & 27 & 29 & 30 & 31 \\
\hline
\end{tabular}

Energy prices, including those of fossil fuels, are a central variable in the ETP analysis (Table A.3). The continuous increase in global energy demand is translated into higher prices of energy and fuels. Unless current demand trends are broken, rising prices are a likely consequence. However, the technologies and policies to reduce $\mathrm{CO}_{2}$ emissions in the NETP 2016 scenarios will have a considerable impact on energy demand, particularly for fossil fuels. Lower global demand for oil in the 4DS and the 2DS means there is less need to produce oil from costly fields higher up the supply curve, particularly in non-members of the Organization of the Petroleum Exporting Countries (OPEC). As a result, oil prices in the 4DS and 2DS (and thus in the CNS, which uses the same framework assumptions as the global 2DS unless specifically noted) are lower than in the 6DS. In the 2DS, oil prices even slightly decline after 2030. 
Prices for natural gas will also be affected, directly through downward pressure on demand, and indirectly through the link to oil prices that often exists in long-term gas supply contracts. ${ }^{5}$ Finally, coal prices are also substantially lower owing to the large shift away from coal in the 2DS.

\begin{tabular}{|c|c|c|c|c|c|c|c|c|c|}
\hline Table A.3 & prices & cena & & & & & & & \\
\hline Oil (2014 USD/bbl) & Scenario & 2014 & 2020 & 2025 & 2030 & 2035 & 2040 & 2045 & 2050 \\
\hline \multirow[t]{3}{*}{ IEA crude oil import price } & 2DS & 97 & 77 & 87 & 97 & 96 & 95 & 94 & 93 \\
\hline & 4DS & 97 & 80 & 97 & 113 & 121 & 128 & 133 & 137 \\
\hline & 6DS & 97 & 83 & 107 & 130 & 140 & 150 & 158 & 164 \\
\hline Coal (2014 USD/t) & Scenario & 2014 & 2020 & 2025 & 2030 & 2035 & 2040 & 2045 & 2050 \\
\hline \multirow{3}{*}{$\begin{array}{l}\text { OECD steam coal import } \\
\text { price }\end{array}$} & 2DS & 78 & 80 & 80 & 79 & 78 & 77 & 76 & 75 \\
\hline & 4DS & 78 & 94 & 98 & 102 & 105 & 108 & 111 & 114 \\
\hline & 6DS & 78 & 99 & 107 & 115 & 119 & 123 & 127 & 131 \\
\hline Gas (2014 USD/MBtu) & Scenario & 2014 & 2020 & 2025 & 2030 & 2035 & 2040 & 2045 & 2050 \\
\hline \multirow[t]{3}{*}{ US price } & 2DS & 4.4 & 4.5 & 5.1 & 5.7 & 5.8 & 5.9 & 5.8 & 5.8 \\
\hline & 4DS & 4.4 & 4.7 & 5.5 & 6.2 & 6.9 & 7.5 & 7.8 & 8.0 \\
\hline & 6DS & 4.4 & 4.7 & 5.5 & 6.3 & 7.1 & 7.8 & 8.2 & 8.5 \\
\hline \multirow[t]{3}{*}{ Europe import price } & 2DS & 9.3 & 7.5 & 8.5 & 9.4 & 9.2 & 8.9 & 8.8 & 8.7 \\
\hline & 4DS & 9.3 & 7.8 & 9.5 & 11.2 & 11.8 & 12.4 & 12.9 & 13.3 \\
\hline & 6DS & 9.3 & 8.1 & 10.3 & 12.5 & 13.2 & 13.8 & 14.5 & 15.1 \\
\hline \multirow[t]{3}{*}{ Japan import price } & 2DS & 16.2 & 10.7 & 11.3 & 11.8 & 11.5 & 11.1 & 11.0 & 10.9 \\
\hline & 4DS & 16.2 & 11.0 & 12.0 & 13.0 & 13.6 & 14.1 & 14.7 & 15.1 \\
\hline & 6DS & 16.2 & 11.4 & 13.2 & 14.9 & 15.5 & 16.0 & 16.9 & 17.5 \\
\hline Liquid biofuels (2014 USD/GJ) & Scenario & 2014 & 2020 & & 2030 & & 2040 & & 2050 \\
\hline \multirow[t]{2}{*}{ Nordic import price } & 2DS & $26-30$ & $26-30$ & & $27-32$ & & $27-31$ & & $28-30$ \\
\hline & 4DS & $26-30$ & $26-30$ & & $26-31$ & & $27-32$ & & $30-34$ \\
\hline
\end{tabular}

\begin{tabular}{|c|c|c|c|c|}
\hline Table A.4 & Marginal abatement cc & electr & in th & CNS \\
\hline$\left(2014\right.$ USD/t CO $\left.{ }_{2}\right)$ & 2020 & 2030 & 2040 & 2050 \\
\hline 4DS & 20 & 30 & 40 & 50 \\
\hline CNS & 25 & 100 & 140 & 180 \\
\hline
\end{tabular}

5 This link is assumed to become weaker over time in the ETP analysis, as the price indexation business model is gradually phased out in international markets. 


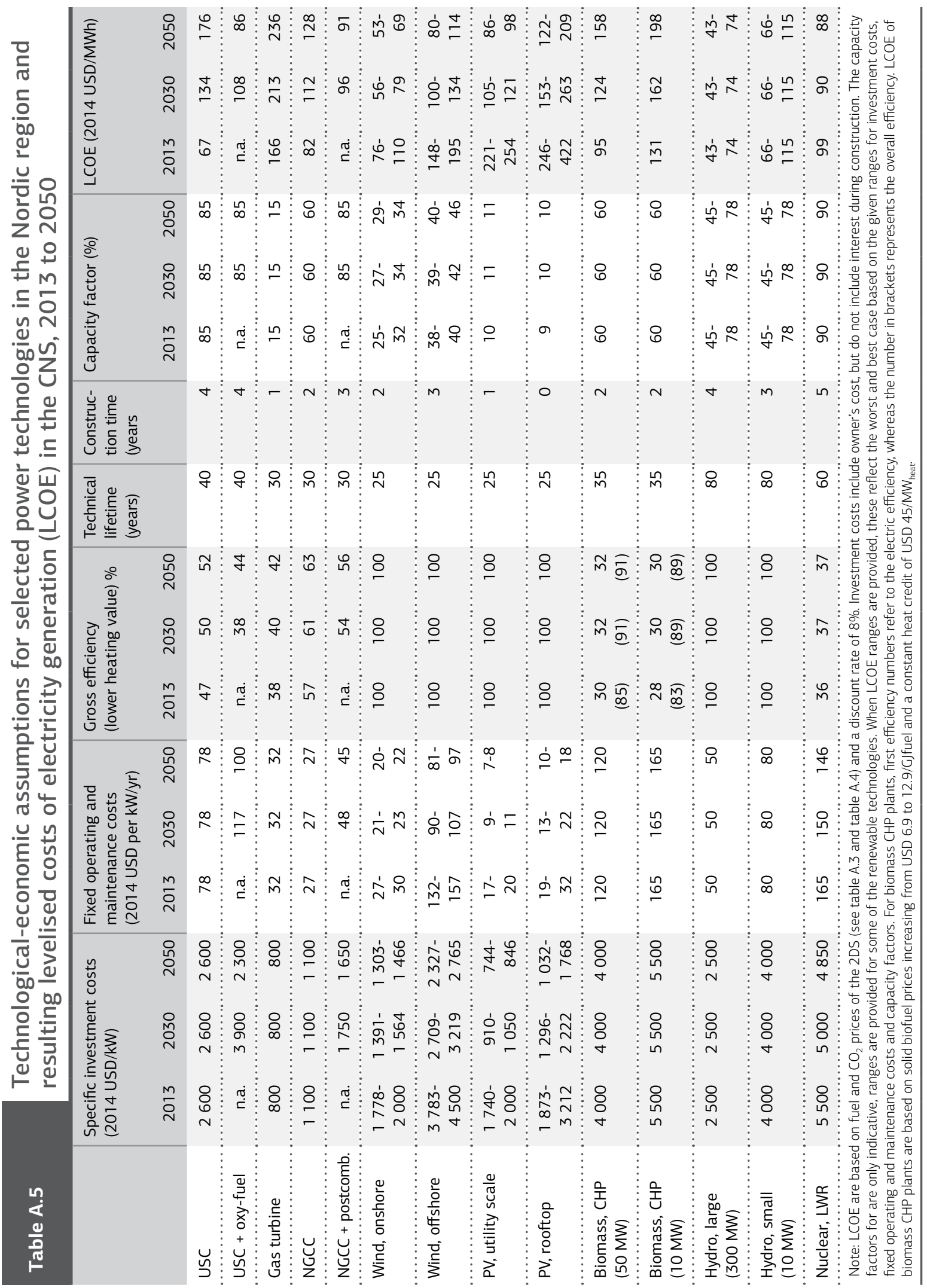




\section{Annex B (Chapter 2)}

\section{TIMES-VTT}

The TIMES-Helsinki-Metro model has been implemented in a fully integrated way into the global TIMES-VTT model. In its primary structure, the model is based on the original Finnish sub-model within the global model, and has been split into two closely inter-connected regions, Helsinki Metropolitan Region and Rest of Finland. The integrated model can be applied for the analysis of various energy and climate policies on the global, regional and Nordic levels and of their impacts specifically on the Helsinki Metropolitan Region. Currently, the model has only a limited sub-annual time resolution (up to 20 time slices per year for the Nordic regions), but it is fully flexible in terms of the model horizon to be analysed, which can be extended to 2100 . The base year of the model is 2010. The functional structure of the model is illustrated in Figure B.1 below, with the Helsinki Metropolitan Region brought into focus.

\section{Figure B.1}

\section{Overview of the functional structure of the TIMES-Helsinki-Metro model}

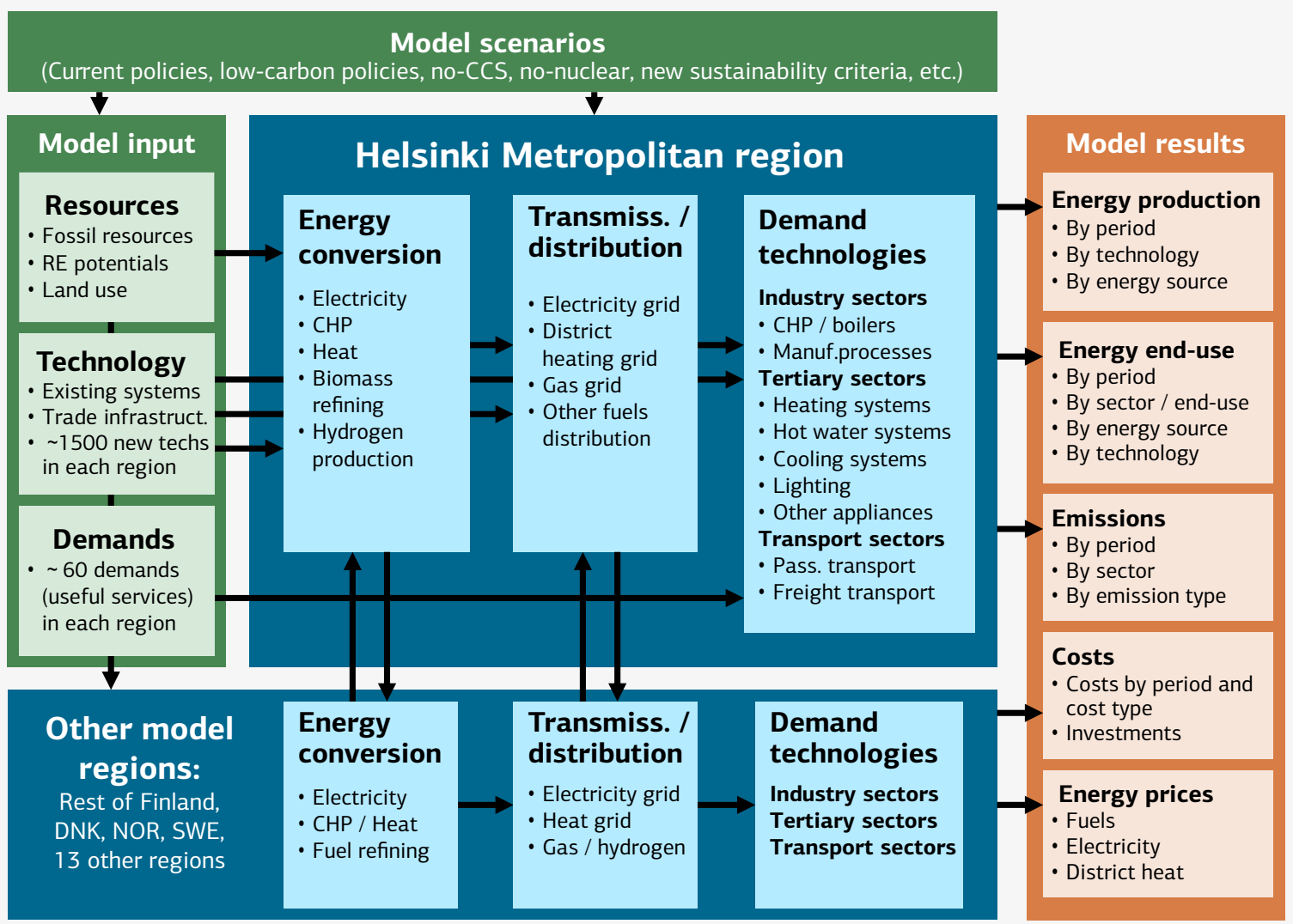

Notes: CCS = carbon capture and storage; RE = renewable energy; $\mathrm{CHP}=$ co-generation of heat and power.

Figures and data in this report can be downloaded at www.iea.org/etp/nordic. 
The Urban analysis requires assumptions on same variables than the global TIMES models. The most important assumptions are development of GDP, population, transport demands, industry production and building floor areas. Other main inputs include energy resource potentials (quantities, marginal costs of extraction), energy and emissions reduction technology development (investment costs, lifetimes, running costs, efficiencies, availability factors, emissions factors) and energy and environmental/climate policy (e.g. taxes and emission targets).

As a partial equilibrium model, TIMES-VTT maintains equilibrium between the supply and demand of all commodities and determines their prices. The projections for the final demands of commodities are exogenous only in the Reference scenario (Helsinki 4DS), while in policy scenarios the demands are elastic to their own prices, according to price elasticities derived from the literature. In the policy scenarios, the demands of all commodities are thus affected by their prices, and vice versa.

The model database can be divided into qualitative and quantitative data. The qualitative data includes, for example, the specification of regions, time-periods and commodities considered in the model, as well as the existing and new technologies that are assumed to be available in each of the model regions. Commodities to be considered in the model may include any energy carriers, material and immaterial commodities, wastes and emissions.

The main model outputs for urban analysis are:

- Flows of energy and emissions, per energy source/emissions type, region and time step

- Investment, capacity and activity of energy and emissions reduction technologies

- Marginal values of different energy sources /emission types (as shadow prices from the optimisation). 


\section{TIMES-Oslo}

The TIMES-Oslo model is used to analyse the impact of various climate and energy measures on the local energy system in the city of Oslo. This model is developed for Oslo area and all methodologies presented below are used for the urban analysis of Oslo region. The model has a high time resolution (260 time slices per year) and a model horizon from 2010 to 2050. The base year of the model is 2010, whereas all costs, prices, etc. in the model are given in NOK2005. The Oslo model is based on, and is part of, the TIMES-Norway model, and the structure of the TIMES-Oslo model is illustrated in Figure B.2.

\section{$\begin{array}{ll}\text { Figure B.2 } & \text { Principal drawing of TIMES-Oslo model }\end{array}$}

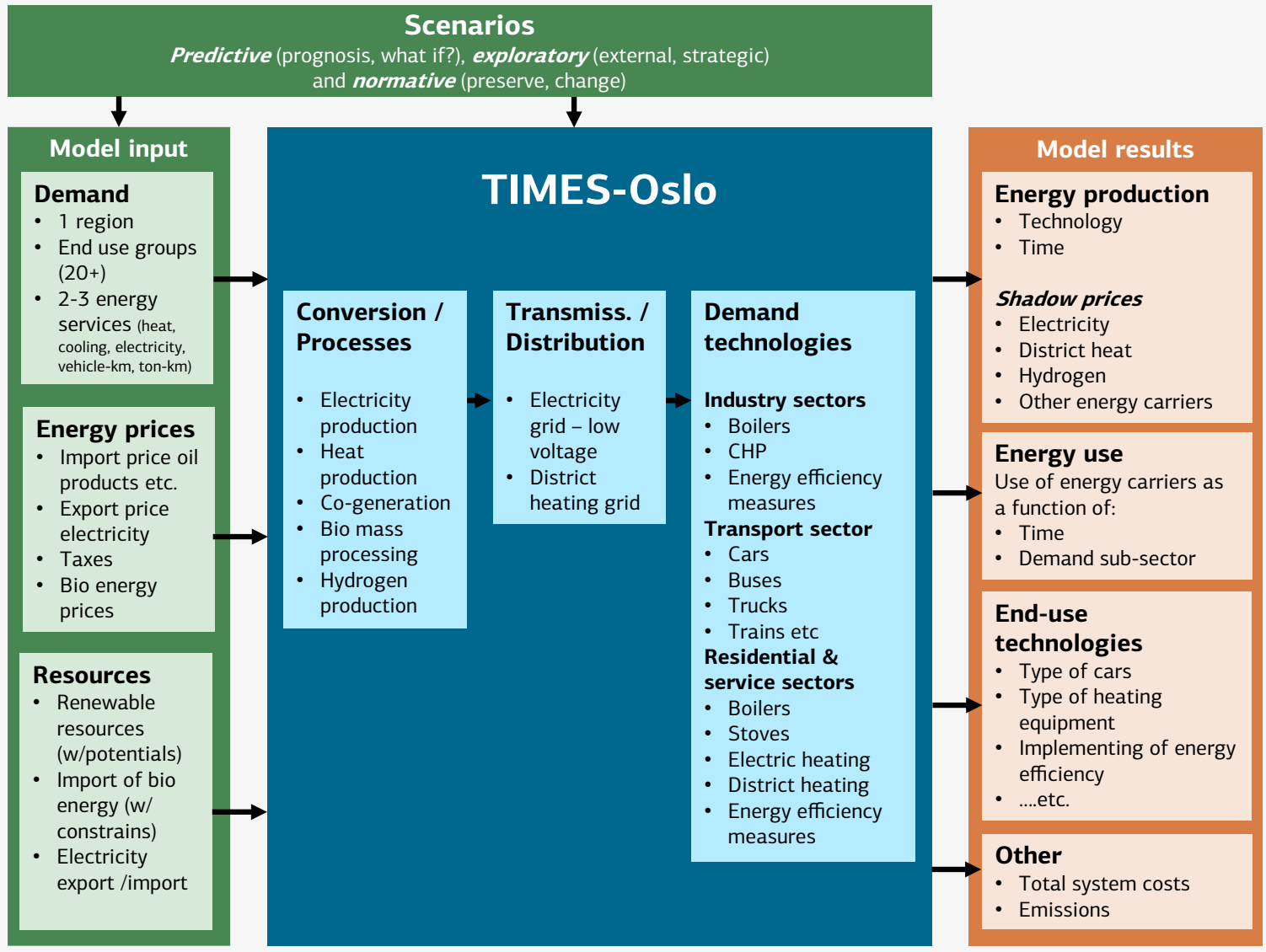

Note: $\mathrm{CHP}=$ co-generation of heat and power.

Figures and data in this report can be downloaded at www.iea.org/etp/nordic

Energy service demand in each sub-sector is exogenous input to TIMES-Oslo, and is based on projections of change in population, value added, floor area etc. The use of final energy will change between the scenarios, due to substitution effects (between different energy carriers), and due to investment in more efficient technologies, such as heat pumps or electric vehicles. 
The main model outputs are:

- Flows of energy and $\mathrm{CO}_{2}$-emissions, per energy source/emissions type and time step

- Investment, capacity and activity of different technologies

- Marginal values of different energy sources/emission types

The TIMES-Oslo model has been used to analyse a reference scenario (Oslo 4DS), different energy-saving and emissions-reduction measures, and to analyse the CNS.

The single measures analysed with TIMES-Oslo are described as follows:

\section{Transport}

- limit the use of private cars (limited parking and increased taxes)

- improved infrastructure for public transport

- establishment of new infrastructure for renewable transport fuels

- supporting actions to increase use of renewable transport fuels

- introduction of a procurement scheme for renewable transport services

- freight transport from road to rail and ship.

T1: "Limit the use of private cars by restrictions on the use of the road network, limiting parking and increased taxes." This is analysed by keeping the demand for vehicle kilometres for private cars constant from 2014 to 2050. Compared to the reference scenario, 90\% of the increased demand for private cars is assumed to be covered by public transport. The remaining $10 \%$ is covered by the use of bicycles.

T2: "Improved infrastructure for public transport." It is assumed that local and national authorities, as well as private companies, contribute to increased use of public transport in the city of Oslo. This is analysed by assuming that the vehicle kilometre demand for private cars is kept constant from 2014 to 2020, before declining by 5\% per year until 2050. This decline is compensated by an increased demand for public transport.

T3: "Establishment of new infrastructure for renewable transport fuels." The energy service demand for all sectors is identical to the reference scenario. However, it is assumed that hydrogen refuelling stations will be fully subsidised (if built), and that all short-distance car travel can be covered by EVs. This scenario does not cover measures related to public transport.

T4: "Support schemes for implementation of renewable transport fuels." This is analysed by assuming a certain percentage of zero-emission vehicles (20\% in 2030 and 50\% in 2050) for both short and long-distance car travel. From 2030 conventional internal combustion engine cars based on gasoline or diesel are prohibited. However, hybrid and plug-in hybrid vehicles are still allowed.

T5: "Introduction of a procurement scheme for renewable transport services." All transport services in conjunction with the city of Oslo must be $100 \%$ renewable. For cars, the measure is valid from 2015, whereas for construction machines, public transport and taxis, the measure is applied from 2023.

T6: "Freight transport from road to rail and ship." Freight on road (trucks) is limited to the 2020 level. The growth in freight volumes from 2020 is in ship and on rail. 


\section{Buildings}

- prohibition on use of fossil fuels for heating from 2020

- regulatory measure to ensure areas for new energy solutions

- support scheme for passive houses

- financial support for energy efficiency measures.

B1: "Prohibition on use of fossil fuels for heating." The use of fossil fuels for heating purposes is not possible from 2020.

B2: "Regulatory measure to ensure areas for new energy solutions." The potential to integrate energy production (PV) is included in houses and other buildings. The potential increases from 2020 to 2050.

B3: "Support scheme for passive houses." This measure implies a new energy demand projection, where all newly built houses are passive houses from 2020.

B4: "Financial support for energy efficiency measures." This analysis includes the possibility to invest in energy efficiency measures.

\section{Energy sector}

- local renewable energy production

- energy storage in buildings.

E1: "Local renewable energy production." The implementation of PV is subsidised (subsidies on the investment cost, different levels of subsidy are tested).

E2: "Energy storage in buildings." To analyse the impact of energy storage, the demand profile of buildings is evened out. 


\section{Annex C (Chapter 3) Analytical Approach}

\section{A. CNS-Balmorel assumptions and complementary data}

\section{Transmission system development tables}

\begin{tabular}{|c|c|c|c|c|c|c|}
\hline Project & From & To & $\begin{array}{r}\text { Capacity } \\
\text { (MW) }\end{array}$ & Year & $\begin{array}{l}\text { Estimated cost } \\
\text { (EUR million) }\end{array}$ & $\begin{array}{r}\text { Estimated cost } \\
\text { (EUR million/MW) }\end{array}$ \\
\hline Skagerrak IV & DK_W & NO_SW & 700 & 2015 & - & \\
\hline 3rd AC Finland-Sweden & SE_N1 & FI_R & 1000 & 2025 & $64-120$ & $0.06-0.12$ \\
\hline Sydvastlanken & SEM & SE_S & 1200 & 2016 & - & $\ldots$ \\
\hline $\begin{array}{l}\text { RES/SoS Norway/Sweden } \\
\text { phase } 1\end{array}$ & $\begin{array}{l}\text { SE_M } \\
\text { NO_M }\end{array}$ & $\begin{array}{l}\text { SE_N2 } \\
\text { NO_MW }\end{array}$ & $\begin{array}{r}700 \\
1500\end{array}$ & $\begin{array}{l}2019 \\
2020\end{array}$ & $560-930$ & $0.37-0.62$ \\
\hline NordLink cable & NO_MW & NO_SW & 1000 & 2020 & & \\
\hline NordBalt Cable Phase 2 & SE_S & SE_M & 700 & 2023 & $170-270$ & $0.24-0.39$ \\
\hline Res in mid-Norway & NO M & NON & 1200 & 2023 & $870-1500$ & $0.73-1.25$ \\
\hline $\begin{array}{l}\text { Note: MW = megawatt. } \\
\text { Sources: ENTSO-E (2014), TYND } \\
\text { Electricity Systems - Modelling a } \\
\text { Renewable Energies (Full Version) }\end{array}$ & ssessme & omic and & $\begin{array}{l}\text { of Enhan } \\
\text { on }\end{array}$ & $\begin{array}{l}\text { 5), Incre } \\
\text { l Interco }\end{array}$ & $\begin{array}{l}\text { Integration of the } \\
\text { ion and the Additio }\end{array}$ & $\begin{array}{l}\text { dic and German } \\
\text { I Deployment of }\end{array}$ \\
\hline
\end{tabular}

\begin{tabular}{|c|c|c|c|c|c|c|}
\hline \multirow{2}{*}{$\begin{array}{l}\text { Table C.2 } \\
\text { Project }\end{array}$} & \multicolumn{6}{|c|}{$\begin{array}{l}\text { ternational connections between the Nordic countries and } \\
\text { urrounding countries }\end{array}$} \\
\hline & From & To & $\begin{array}{r}\text { Capacity } \\
\text { (MW) }\end{array}$ & Year & $\begin{array}{r}\text { Estimated cost } \\
\text { (EUR million) }\end{array}$ & $\begin{array}{l}\text { Estimated cost } \\
\text { (EUR million/MW) }\end{array}$ \\
\hline NordLink Cable & NO_SW & DE_NW & 1400 & 2020 & 2500 & 1.79 \\
\hline West Denmark to Germany & $\begin{array}{l}\text { DK_W } \\
\text { DE_NW }\end{array}$ & $\begin{array}{l}\text { DE_NW } \\
\text { DK_W }\end{array}$ & $\begin{array}{r}860 \\
1000\end{array}$ & 2019 & $220-270$ & $0.22-0.27$ \\
\hline Kriegers Flak & $\begin{array}{l}\text { DK_E } \\
\text { DE_NE }\end{array}$ & $\begin{array}{l}\text { DK_KF } \\
\text { DE_KF }\end{array}$ & 600 & 2019 & 300 & 0.21 \\
\hline NordBalt Cable Phase 1 & SE_S & LT_R & 700 & 2015 & $690-1200$ & $0.99-1.71$ \\
\hline Westcoast & DK_W & DE_NW & 500 & 2022 & $170-210$ & $0.34-0.42$ \\
\hline Hansa PowerBridge & SE_S & DE_NE & 700 & 2025 & $200-400$ & $0.29-0.57$ \\
\hline \multicolumn{7}{|c|}{$\begin{array}{l}\text { Sources: ENSSO-E (2014), TYNDPP Ten-Year Network Development Plan) } 2014 \text {; Ea, DTU and DiW (2015), Increased Integration of the Nordic and German } \\
\text { Electricity Systems - Modellin and Assessment of Economic and Climate Effects of Enhanced Electrical Interconnection and the Additional Deployment of } \\
\text { Renewable Energies (Full Version). }\end{array}$} \\
\hline
\end{tabular}




\section{Table C.3 International connections between surrounding countries}

\begin{tabular}{|c|c|c|c|c|c|c|}
\hline Project & From & To & $\begin{array}{r}\text { Capacity } \\
\text { (MW) }\end{array}$ & Year & $\begin{array}{r}\text { Estimated cost } \\
\text { (EUR million) }\end{array}$ & $\begin{array}{r}\text { Estimated cost } \\
\text { (EUR million/MW) }\end{array}$ \\
\hline \multirow[t]{2}{*}{ LitPol Link Stage 1} & $P L \_R$ & LT_R & 0 & \multirow[t]{2}{*}{2015} & \multirow[t]{2}{*}{510} & \multirow[t]{2}{*}{1.02} \\
\hline & LT_R & $P L \_R$ & 500 & & & \\
\hline Doetinchem-Niederrhein & $N L \_R$ & DE_CS & 1400 & 2016 & $190-220$ & $0.07-0.08$ \\
\hline ElexLink & GB_R & FR_R & 1000 & 2016 & $260-440$ & $0.26-0.44$ \\
\hline \multirow[t]{2}{*}{ GerPol Improvements } & PL_R & DE_ME & 1500 & \multirow[t]{2}{*}{2017} & \multirow[t]{2}{*}{150} & \multirow[t]{2}{*}{0.1} \\
\hline & DE_ME & $P L \_R$ & 500 & & & \\
\hline Luxembourg-Belgium Interco & BE_R & LX_R & 700 & 2017 & $150-170$ & $0.21-0.24$ \\
\hline Nemo & BE_R & GB_R & 1000 & 2018 & $600-700$ & $0.86-1$ \\
\hline Greenconnector & $\mathrm{CH} \mathrm{R}_{-}$ & IT_R & 800 & 2018 & - & 0 \\
\hline Cobra Cable & DK_W & $N L \_R$ & 700 & 2019 & $560-680$ & $0.8-0.97$ \\
\hline ALEGRO & BE_R & DE_CS & 1000 & 2019 & $450-570$ & $0.45-0.57$ \\
\hline \multirow[t]{2}{*}{ Italy-France } & FR_R & IT_R & 1200 & \multirow[t]{2}{*}{2019} & \multirow[t]{2}{*}{1 100-1300 } & \multirow[t]{2}{*}{$0.92-1.08$} \\
\hline & IT_R & FR_R & 1000 & & & \\
\hline \multirow[t]{2}{*}{ LitPol Link Stage 2} & PL_R & LT_R & 1000 & \multirow[t]{2}{*}{2020} & \multirow[t]{2}{*}{310} & \multirow[t]{2}{*}{0.31} \\
\hline & LT_R & $P L \_R$ & 500 & & & \\
\hline Estonia-Latvia & EE_R & LV_R & 500 & 2020 & $105-195$ & $0.21-0.39$ \\
\hline Norway-Great Britain & NO_SW & GB_R & 1400 & 2020 & 1700 & 1.21 \\
\hline Austria-Germany & AT_R & $D_{-} C S$ & 2900 & 2020 & $830-1400$ & $0.29-0.48$ \\
\hline Belgian North Border & $N L \_R$ & BE_R & 1500 & 2020 & $350-450$ & $0.23-0.3$ \\
\hline IFA2 & GB_R & FR_R & 1000 & 2020 & $540-830$ & $0.54-0.83$ \\
\hline \multirow[t]{2}{*}{ Lake Geneva West } & FR_R & CH_R & 500 & \multirow[t]{2}{*}{2020} & \multirow[t]{2}{*}{$8-12$} & \multirow[t]{2}{*}{$0.02-0.02$} \\
\hline & $\mathrm{CH} \mathrm{CH}$ & FR_R & 200 & & & \\
\hline France-Belgium & BE_R & FR_R & 1300 & 2021 & $110-170$ & $0.08-0.12$ \\
\hline \multirow[t]{2}{*}{ GerPol Power Bridge } & PL_R & DE_ME & 500 & \multirow[t]{2}{*}{2022} & \multirow[t]{2}{*}{$390-400$} & \multirow[t]{2}{*}{$0.26-0.27$} \\
\hline & DE_ME & $P L \_R$ & 1500 & & & \\
\hline St. Peter-Pleinting & AT_R & DE_CS & 1500 & 2022 & $130-190$ & $0.09-0.13$ \\
\hline \multirow[t]{2}{*}{ Area of Lake Constance } & $\mathrm{CH} \_\mathrm{R}$ & DE_CS & 1400 & \multirow[t]{2}{*}{2022} & \multirow[t]{2}{*}{$390-530$} & $0.11-0.16$ \\
\hline & DE_CS & $\mathrm{CH}_{-} \mathrm{R}$ & 3400 & & & \\
\hline France-Alderney-Britain & GB_R & FR_R & 1400 & 2022 & $470-1100$ & $0.36-0.85$ \\
\hline Italy-Switzerland & IT_R & CH_R & 950 & 2022 & 1080 & 1.08 \\
\hline & $\mathrm{CH} \_\mathrm{R}$ & IT_R & 1000 & & & \\
\hline Italy-Austria & AT_R & CH_R & 1450 & 2023 & $780-1180$ & $0.54-0.81$ \\
\hline & CH_R & AT_R & 1350 & & & \\
\hline Lake Geneva South & FR_R & $\mathrm{CH} \_\mathrm{R}$ & 1000 & 2025 & $110-140$ & 0.07-0.09 \\
\hline & $\mathrm{CH} \_\mathrm{R}$ & FR_R & 1500 & & & \\
\hline Dutch Ring & $N L \_R$ & DE_NW & 500 & 2025 & $1800-3100$ & $3.6-6.2$ \\
\hline $\begin{array}{l}\text { Note: VikingLink omitted from table } \\
\text { Sources: ENTSO-E (2014), TYNDP ( } \\
\text { Electricity Systems - Modelling and A } \\
\text { Renewable Energies (Full Version). }\end{array}$ & xpansion Ita & ria omitted & $\begin{array}{l}\text { able. } \\
\text { 4; Ea, DTU a } \\
\text { cts of Enhan }\end{array}$ & $\begin{array}{l}\text { 15), Incr } \\
\text { cal Interc }\end{array}$ & $\begin{array}{l}\text { d Integration of the N } \\
\text { ction and the Addition }\end{array}$ & $\begin{array}{l}\text { ordic and German } \\
\text { al Deployment of }\end{array}$ \\
\hline
\end{tabular}




\section{Table C.4}

National connections within Germany

\begin{tabular}{|c|c|c|c|c|c|c|}
\hline Project & From & To & $\begin{array}{r}\text { Capacity } \\
\text { (MW) }\end{array}$ & Year & $\begin{array}{r}\text { Estimated cost } \\
\text { (EUR million) }\end{array}$ & $\begin{array}{r}\text { Estimated cost } \\
\text { (EUR million/MW) }\end{array}$ \\
\hline TTG-009 & DE_NW & DE_CS & $1000(\mathrm{AC})$ & 2014 & - & - \\
\hline $50 \mathrm{HzT}-001$ & DE_ME & DE_CS & $1000(\mathrm{AC})$ & 2015 & - & - \\
\hline TTG-007 & DE_NW & DE_CS & $1000(\mathrm{AC})$ & 2018 & - & - \\
\hline P36 & DE_NE & DE_ME & $1000(\mathrm{AC})$ & 2018 & - & - \\
\hline P34 & DE_NE & DE_ME & $1000(\mathrm{AC})$ & 2020 & - & - \\
\hline P21 & DE_NW & DE_CS & 1000 (AC) & 2022 & - & - \\
\hline P24 & DE_NW & DE_CS & $1000(\mathrm{AC})$ & 2022 & - & - \\
\hline A01, C05 & DE_NW & DE_CS & 4000 & 2022 & - & - \\
\hline EOGmod & DE_NWH & BE_ES & 2000 & $2022^{*}$ & - & - \\
\hline D18 & DE_ME & DE_CS & 2000 & 2022 & - & - \\
\hline P33 - M24a & DE_ME & DE_CS & $1000(\mathrm{AC})$ & 2022 & - & - \\
\hline EOGWDL & BE_NWH & $B E_{-} C S$ & 2000 & $2023^{*}$ & - & - \\
\hline P37 & DE_ME & $\mathrm{DE} \_\mathrm{CS}$ & $7000(A C)$ & $2023^{*}$ & - & - \\
\hline$P 33-M 24 b$ & DE_ME & BE_CS & $7000(A C)$ & $2024^{*}$ & - & - \\
\hline \multicolumn{7}{|c|}{$\begin{array}{l}\text { Notes: AC = alternating current; AC capacities are not given by the source and are therefore generally assumed to be } 1000 \mathrm{MW} \text {. } \\
\text { "For the model runs, the struck-through lines (CO6mod, CO6WDL, P37 and P33-M24b) have been manually removed in order to account for potential } \\
\text { delays due to unresolved political controversies. } \\
\text { Source: NEP (2014), Network Development Plan } 2014 \text { (Scenario B). }\end{array}$} \\
\hline
\end{tabular}

\section{Flexible demand shares used in CNS-Balmorel}

Tables C.5 and C.6 outline the input values for the Balmorel model.

\begin{tabular}{|c|c|c|c|c|c|}
\hline \multirow{2}{*}{$\begin{array}{l}\text { Table C.5 } \\
\text { Sectors }\end{array}$} & \multicolumn{5}{|c|}{ Flexible demand shares for the Nordic countries (excluding Denmark) } \\
\hline & 2013 & 2020 & 2030 & 2050 & Duration time \\
\hline Transport & $1 \%$ & $5 \%$ & $40 \%$ & $50 \%$ & $4 \mathrm{hr}$ \\
\hline Industry* & $1 \%$ & $5 \%$ & $20 \%$ & $29 \%$ & $1-2 \mathrm{hr}$ \\
\hline Residential & $1 \%$ & $8 \%$ & $15 \%$ & $15 \%$ & $1-2 h r$ \\
\hline Service & $1 \%$ & $8 \%$ & $15 \%$ & $15 \%$ & $4 \mathrm{hr}$ \\
\hline Agriculture & $1 \%$ & $1 \%$ & $1 \%$ & $1 \%$ & $4 \mathrm{hr}$ \\
\hline \multicolumn{6}{|c|}{$\begin{array}{l}\text { Notes: Table C.5 does not include Denmark because it was considered that the Danish flexibility potential differed to the rest of the Nordic countries; } \\
\text { for instance, in Denmark there is little heavy industry while in Sweden there are an important number of electricity-intensive industries such as pulp and } \\
\text { paper, metal, and chemical industries; hr = hour. } \\
\text { "The major contribution to flexibility comes from electricity-intensive industries, such as pulp and paper, metal, and chemical industries. } \\
\text { Source: Assumptions based on Thema Consulting Group (2014), Demand Response in the Nordic Electricity Market: Input to Strategy on Demand } \\
\text { Flexibility. https://www.tem.f/files/43979/THEMA_Final_report_2014-24_Input_to_strategy_on_demand_flexibility_in_the_Nordic_countries.pdf }\end{array}$} \\
\hline
\end{tabular}




\section{Table C.6 Flexible demand shares for Denmark in CNS-B}

\begin{tabular}{|c|c|c|c|c|c|}
\hline Sectors & 2013 & 2020 & 2030 & 2050 & Duration time \\
\hline Transport & $1 \%$ & $5 \%$ & $40 \%$ & $50 \%$ & $4 \mathrm{hr}$ \\
\hline Industry & $1 \%$ & $1 \%$ & $2 \%$ & $2 \%$ & $1-2 h r$ \\
\hline Residential & $1 \%$ & $8 \%$ & $15 \%$ & $15 \%$ & $1-2 h r$ \\
\hline Service & $1 \%$ & $8 \%$ & $15 \%$ & $15 \%$ & $12 \mathrm{hr}$ \\
\hline Agriculture & $1 \%$ & $1 \%$ & $1 \%$ & $1 \%$ & $4 \mathrm{hr}$ \\
\hline
\end{tabular}

Note: It is important to note that to estimate the flexible electricity demand shares in industry, 2013 industrial electricity demand was considered constant throughout the year.

Sources: Assumptions based on Thema Consulting Group (2014), Demand Response in the Nordic Electricity Market: Input to Strategy on Demand Flexibility https://www.tem.fi/files/43979/THEMA_Final_report_2014-24_Input_to_strategy_on_demand_flexibility_in_the_Nordic_countries.pdf. And based on Kwon, PS \& Østergaard, P (2014), 'Assessment and evaluation of flexible demand in a Danish future energy scenario'. doi:10.1016/j. apenergy.2014.08.044.

\begin{tabular}{|c|c|c|c|c|c|c|c|c|}
\hline \multirow{3}{*}{$\begin{array}{l}\text { Table C.7 } \\
\text { TWh }\end{array}$} & \multicolumn{8}{|c|}{$\begin{array}{l}\text { Electricity trade between the Nordic countries and to the rest of } \\
\text { Europe in } 2015 \text { and } 2050 \text { in the CNS-B }\end{array}$} \\
\hline & \multirow[b]{2}{*}{ From } & \multirow[b]{2}{*}{ To } & \multicolumn{3}{|c|}{2015} & \multicolumn{3}{|c|}{2050} \\
\hline & & & $\begin{array}{r}\text { Export } \\
\text { (forward) }\end{array}$ & $\begin{array}{r}\text { Import } \\
\text { (back) }\end{array}$ & Net export & $\begin{array}{r}\text { Export } \\
\text { (forward) }\end{array}$ & $\begin{array}{r}\text { Import } \\
\text { (back) }\end{array}$ & Net export \\
\hline \multirow[t]{3}{*}{ Denmark } & Denmark & All partners & 9,2 & 15,7 & $-6,6$ & 34,7 & 30,6 & 4,1 \\
\hline & Denmark & Other Nordic & 4,4 & 13,2 & $-8,8$ & 11,6 & 19,9 & $-8,3$ \\
\hline & Denmark & Non-Nordic & 4,8 & 2,6 & 2,2 & 23,0 & 10,6 & 12,4 \\
\hline \multirow[t]{3}{*}{ Finland } & Finland & All partners & 5,1 & 21,4 & $-16,3$ & 14,8 & 34,7 & $-19,9$ \\
\hline & Finland & Other Nordic & 0,1 & 17,5 & $-17,4$ & 4,8 & 34,0 & $-29,2$ \\
\hline & Finland & Non-Nordic & 5,0 & 4,0 & 1,1 & 10,0 & 0,7 & 9,3 \\
\hline \multirow[t]{3}{*}{ Norway } & Norway & All partners & 21,8 & 7,2 & 14,7 & 88,6 & 18,4 & 70,2 \\
\hline & Norway & Other Nordic & 15,8 & 7,0 & 8,8 & 50,0 & 6,4 & 43,6 \\
\hline & Norway & Non-Nordic & 6,0 & 0,1 & 5,9 & 38,7 & 12,0 & 26,7 \\
\hline \multirow[t]{3}{*}{ Sweden } & Sweden & All partners & 34,7 & 12,1 & 22,6 & 41,5 & 43,1 & $-1,6$ \\
\hline & Sweden & Other Nordic & 29,3 & 11,9 & 17,3 & 24,2 & 30,3 & $-6,1$ \\
\hline & Sweden & Non-Nordic & 5,4 & 0,2 & 5,3 & 17,4 & 12,9 & 4,5 \\
\hline Nordic & Nordic & Non-Nordic & 21,2 & 6,8 & 14,4 & 89,1 & 36,3 & 52,9 \\
\hline
\end{tabular}




\begin{tabular}{|c|c|c|c|c|c|c|c|c|}
\hline Table C.8 & $\begin{array}{l}\text { Elec } \\
\text { to } t\end{array}$ & $\begin{array}{l}\text { trade b } \\
t \text { of Eurc }\end{array}$ & $\begin{array}{l}\text { een pri } \\
\text { in } 201 \text { ? }\end{array}$ & $\begin{array}{l}\text { e are } \\
\text { and } 2\end{array}$ & $\begin{array}{l}\mathrm{s} \text { in the } \\
550 \text { in tr }\end{array}$ & $\begin{array}{l}\text { lordic C } \\
\text { CNS-B }\end{array}$ & untrie & s and \\
\hline \multirow[t]{2}{*}{ TWh } & & & & 2015 & & & 2050 & \\
\hline & From & To & $\begin{array}{r}\text { Export } \\
\text { (forward) }\end{array}$ & $\begin{array}{r}\text { Import } \\
\text { (back) }\end{array}$ & Net export & $\begin{array}{r}\text { Export } \\
\text { (forward) }\end{array}$ & $\begin{array}{l}\text { Import } \\
\text { (back) }\end{array}$ & Net export \\
\hline \multirow[t]{9}{*}{ Denmark } & DK2 & DK1 & 0,1 & 3,5 & $-3,4$ & 1,6 & 4,0 & $-2,4$ \\
\hline & & Germany & 3,1 & 0,8 & 2,3 & 2,3 & 3,5 & $-1,1$ \\
\hline & & Poland & - & - & - & 2,7 & 1,1 & 1,5 \\
\hline & & SE4 & 1,0 & 5,1 & $-4,1$ & 4,5 & 2,3 & 2,2 \\
\hline & DK1 & Germany & 1,7 & 1,8 & $-0,1$ & 11,9 & 0,8 & 11,1 \\
\hline & & Great Britain & & & & 2,9 & 5,2 & $-2,3$ \\
\hline & & Netherlands & - & - & - & 3,3 & 0,1 & 3,2 \\
\hline & & SE3 & 1,8 & 1,4 & 0,4 & 3,8 & 3,2 & 0,6 \\
\hline & & $\mathrm{NO2}$ & 1,6 & 6,6 & $-5,0$ & 3,3 & 14,4 & $-11,1$ \\
\hline \multirow[t]{5}{*}{ Finland } & $\mathrm{FI}$ & Estonia & 5,0 & 0,0 & 5,0 & 10,0 & 0,7 & 9,3 \\
\hline & & $\mathrm{NO} 4$ & 0,1 & 0,1 & $-0,1$ & - & 18,5 & $-18,5$ \\
\hline & & SE3 & 0,0 & 8,7 & $-8,7$ & 4,8 & 1,3 & 3,5 \\
\hline & & SE1 & 0,0 & 8,6 & $-8,6$ & - & 14,2 & $-14,2$ \\
\hline & & Russia & 0,0 & 3,9 & $-3,9$ & - & - & $\therefore$ \\
\hline \multirow[t]{14}{*}{ Norway } & NO3 & NO5 & - & - & - & 9,1 & 1,2 & 7,9 \\
\hline & & $\mathrm{NO4}$ & 0,0 & 3,3 & $-3,3$ & 3,9 & 5,8 & $-1,9$ \\
\hline & & NO1 & 0,1 & 1,6 & $-1,5$ & 10,4 & 0,4 & 10,0 \\
\hline & & SE2 & 0,4 & 2,7 & $-2,3$ & 3,2 & 0,8 & 2,4 \\
\hline & NO5 & NO1 & 15,1 & 0,0 & 15,1 & 22,1 & 0,9 & 21,3 \\
\hline & & $\mathrm{NO2}$ & 1,8 & 0,2 & 1,7 & 22,2 & 1,8 & 20,4 \\
\hline & NO4 & SE1 & 1,2 & 0,7 & 0,4 & 1,2 & 0,2 & 1,0 \\
\hline & & SE2 & 0,3 & 0,5 & $-0,2$ & 3,7 & 1,1 & 2,5 \\
\hline & & Russia & - & 0,1 & $-0,1$ & - & - & - \\
\hline & NO1 & $\mathrm{NO2}$ & 1,4 & 9,9 & $-8,5$ & 8,4 & 6,3 & 2,0 \\
\hline & & SE3 & 7,3 & 1,5 & 5,8 & 9,1 & 1,0 & 8,0 \\
\hline & NO2 & Germany & - & - & - & $\begin{array}{r}7,1 \\
\ldots .1\end{array}$ & 1,4 & 5,7 \\
\hline & & Great Britain & & & & 12,5 & 9,6 & 2,8 \\
\hline & & Netherlands & 6,0 & 0,0 & 6,0 & 19,1 & 1,0 & 18,1 \\
\hline \multirow[t]{7}{*}{ Sweden } & SE3 & Latvia & & & & 0,1 & 0,1 & 0,1 \\
\hline & & SE2 & 0,2 & 33,7 & $-33,5$ & - & 50,5 & $-50,5$ \\
\hline & & SE4 & 25,0 & 0,1 & 24,9 & 20,9 & 4,5 & 16,4 \\
\hline & SE1 & SE2 & 5,8 & 1,5 & 4,2 & 12,8 & 0,8 & 12,0 \\
\hline & SE4 & Germany & 1,9 & 0,1 & 1,8 & 3,7 & 4,4 & $-0,6$ \\
\hline & & Lithuania & & & & 2,4 & 1,8 & 0,6 \\
\hline & & Poland & 3,5 & 0,0 & 3,5 & 11,1 & 6,6 & 4,5 \\
\hline $\begin{array}{l}\text { Note: Electricity } \\
\text { Source: } 2015 \text { da }\end{array}$ & $\begin{array}{l}\text { CNS is } \\
\text { rdpoolsp }\end{array}$ & $\begin{array}{l}\text { th with trade in th } \\
\text { data from CNS-B }\end{array}$ & & & & & & \\
\hline
\end{tabular}




\section{Figure C.1 Onshore wind full load hours (FLHs) (2030-49)}

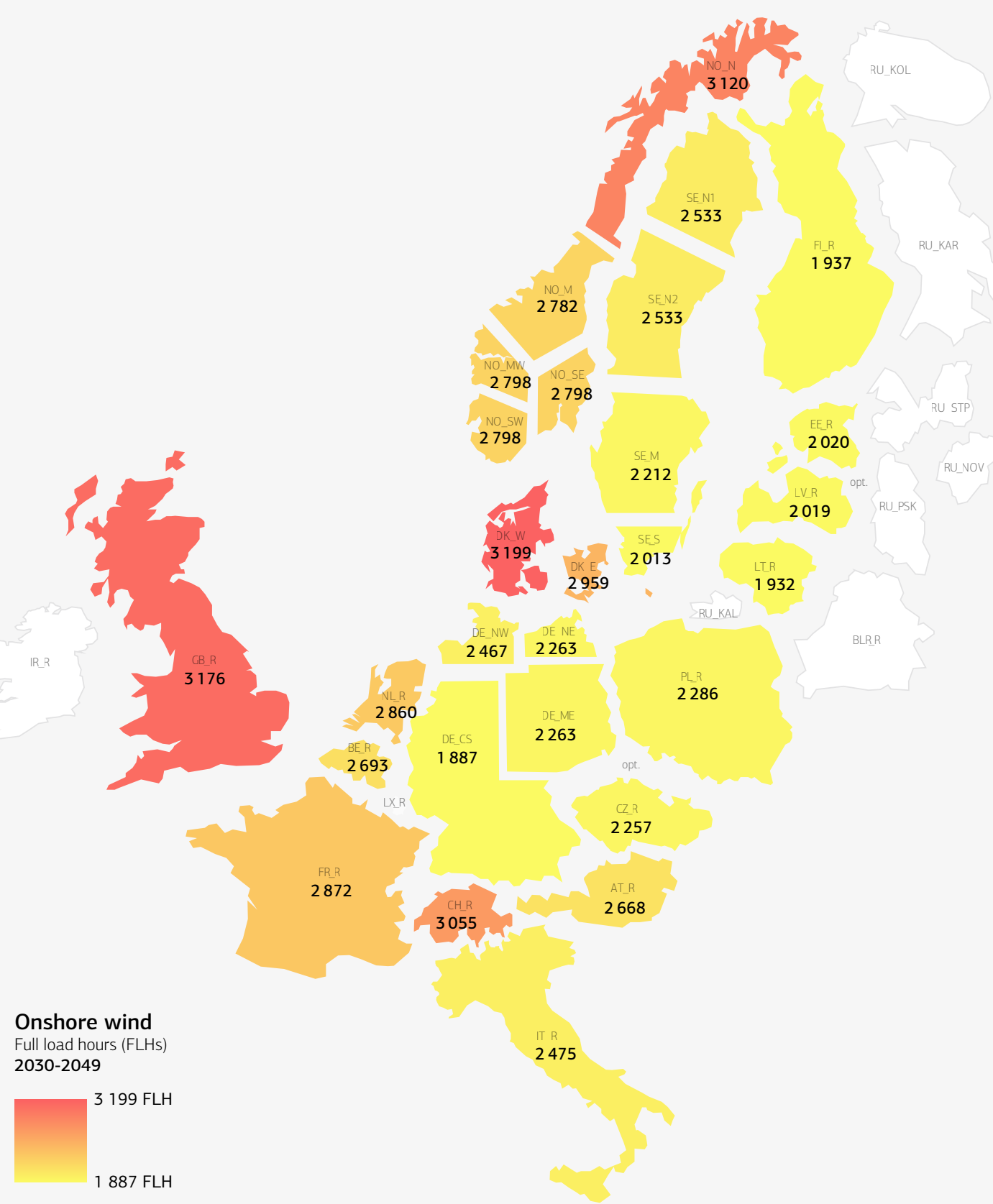

This map is without prejudice to the status of or sovereignty over any territory, to the delimitation of international frontiers and boundaries, and to the name of any territory, city or area. Figures and data in this report can be downloaded at www.iea.org/etp/nordic. 


\section{$\begin{array}{ll}\text { Figure C.2 } & \text { Offshore wind full load hours (FLHs) (2030-49) }\end{array}$}

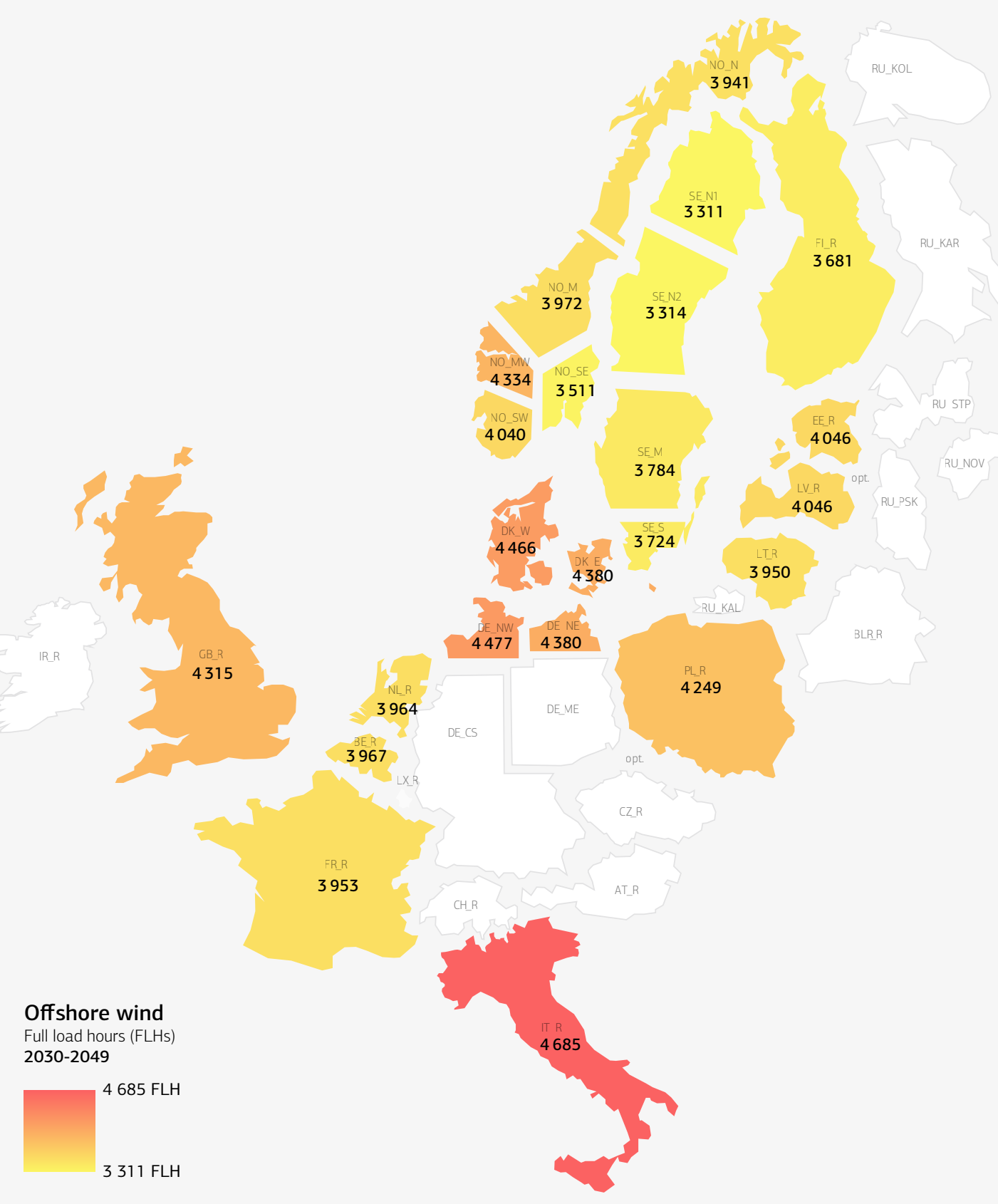

This map is without prejudice to the status of or sovereignty over any territory, to the delimitation of international frontiers and boundaries, and to the name of any territory, city or area. Figures and data in this report can be downloaded at www.iea.org/etp/nordic. 


\section{Table C.9 Wind potential}

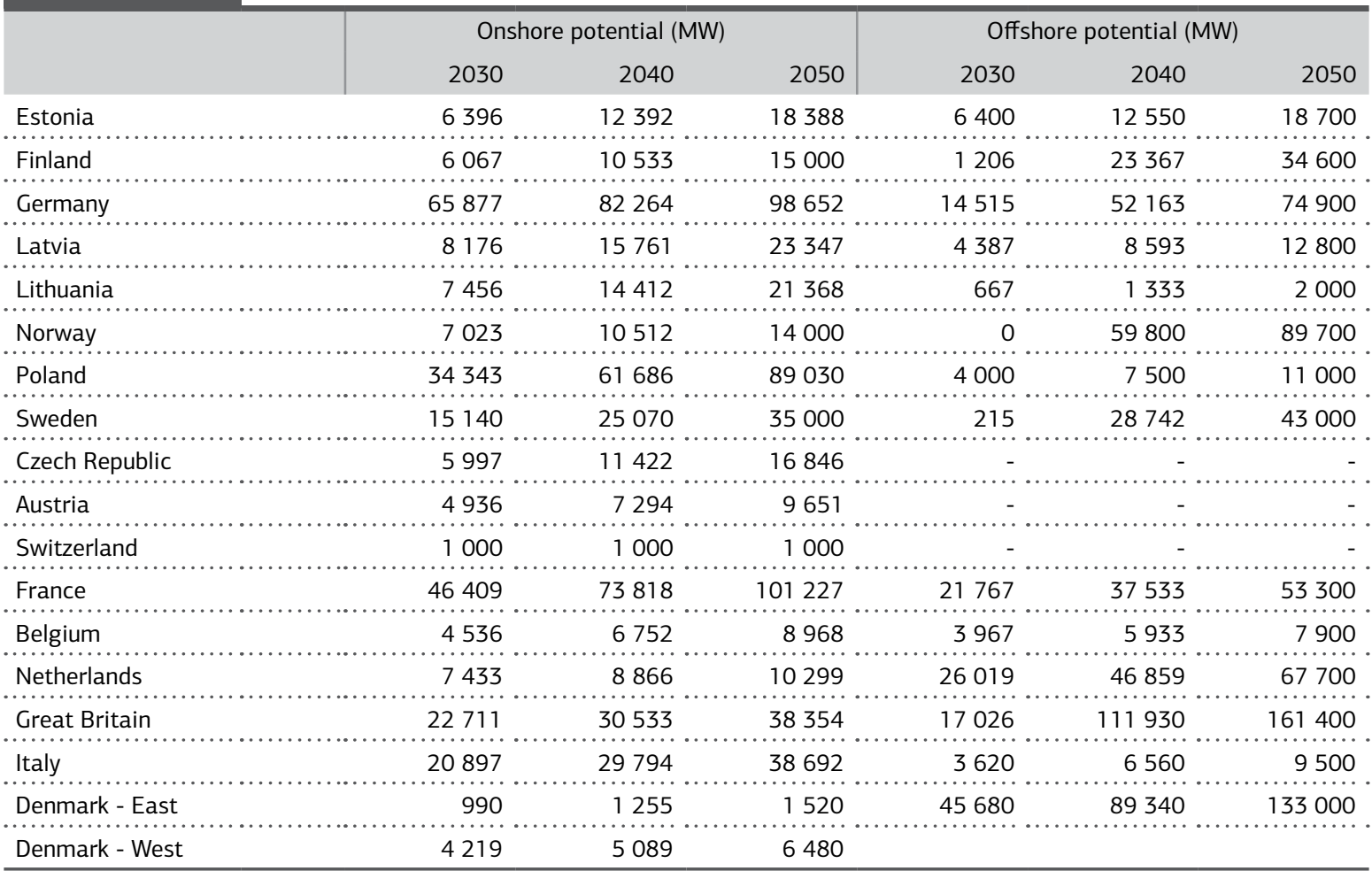

\section{$\begin{array}{lll}\text { Figure C.3 District heating demand in the Nordic countries in the CNS-B } & \text { D }\end{array}$}

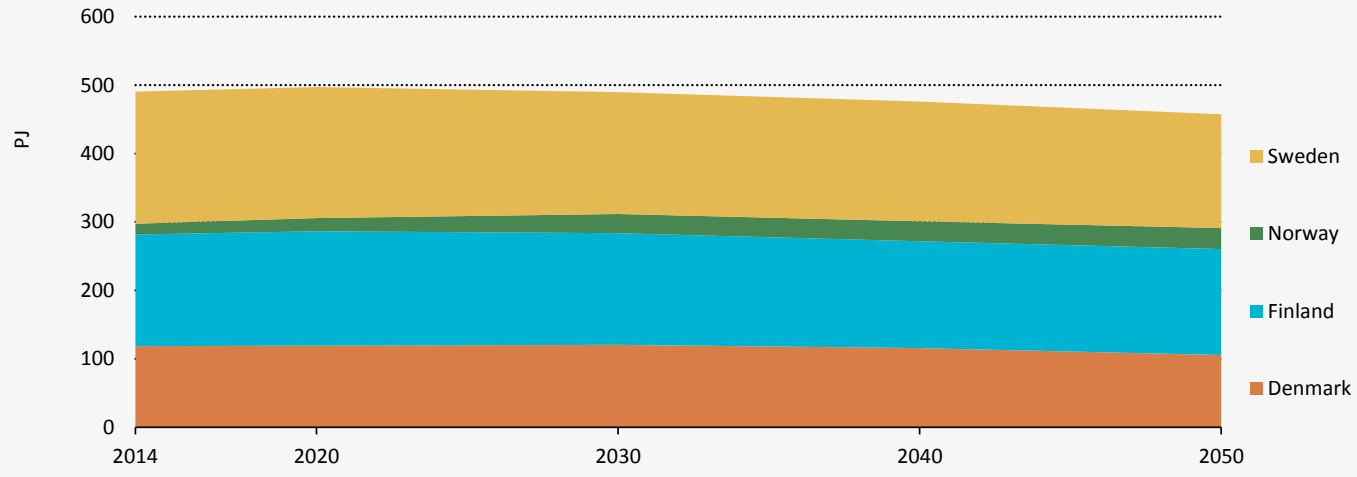




\section{Figure C.4 District heating generation in Nordic countries in the CNS-B}

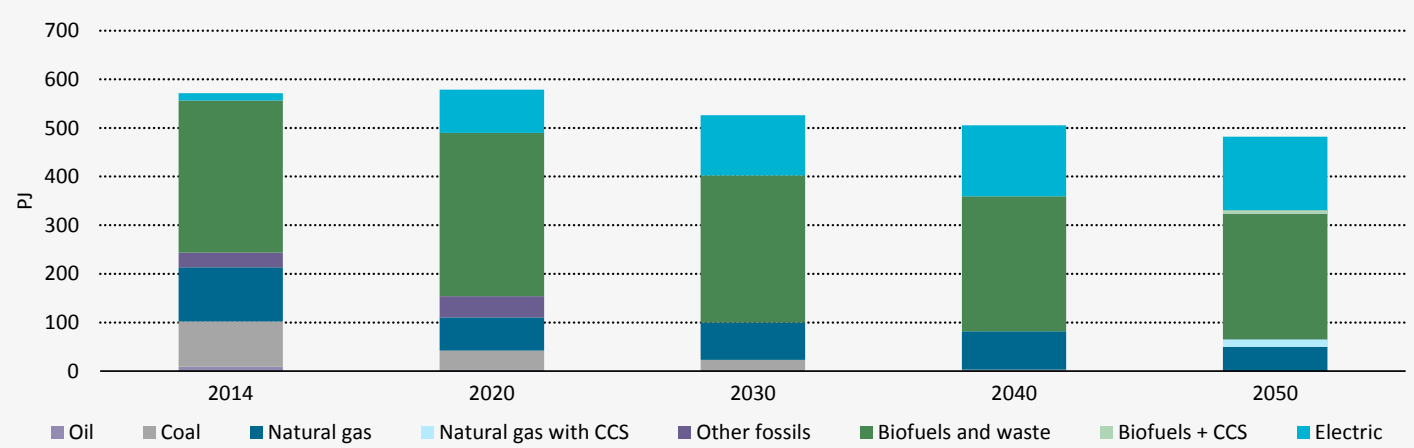

Figures and data in this report can be downloaded at www.iea.org/etp/nordic.

\begin{tabular}{|c|c|c|c|c|c|}
\hline \multirow[t]{2}{*}{ Table C.10 } & \multicolumn{5}{|c|}{$\begin{array}{l}\text { Nuclear Capacities in the CNS-B Baseline and Fast phase-out } \\
\text { scenarios (MW) }\end{array}$} \\
\hline & 2014 & 2020 & 2030 & 2040 & 2050 \\
\hline \multicolumn{6}{|l|}{ Baseline } \\
\hline Finland & 2750 & 4350 & 5055 & 3680 & 2800 \\
\hline Sweden & 9568 & 6727 & 6727 & 5677 & 0 \\
\hline \multicolumn{6}{|l|}{ Fast phase-out } \\
\hline Finland & 2750 & 4350 & 3855 & 2480 & 1600 \\
\hline Sweden & 9568 & 6727 & 0 & 0 & 0 \\
\hline
\end{tabular}

\section{NETP 2016 vs. Balmorel model results}

\section{Figure C.5 Electricity generation in the CNS compared to the CNS-B}

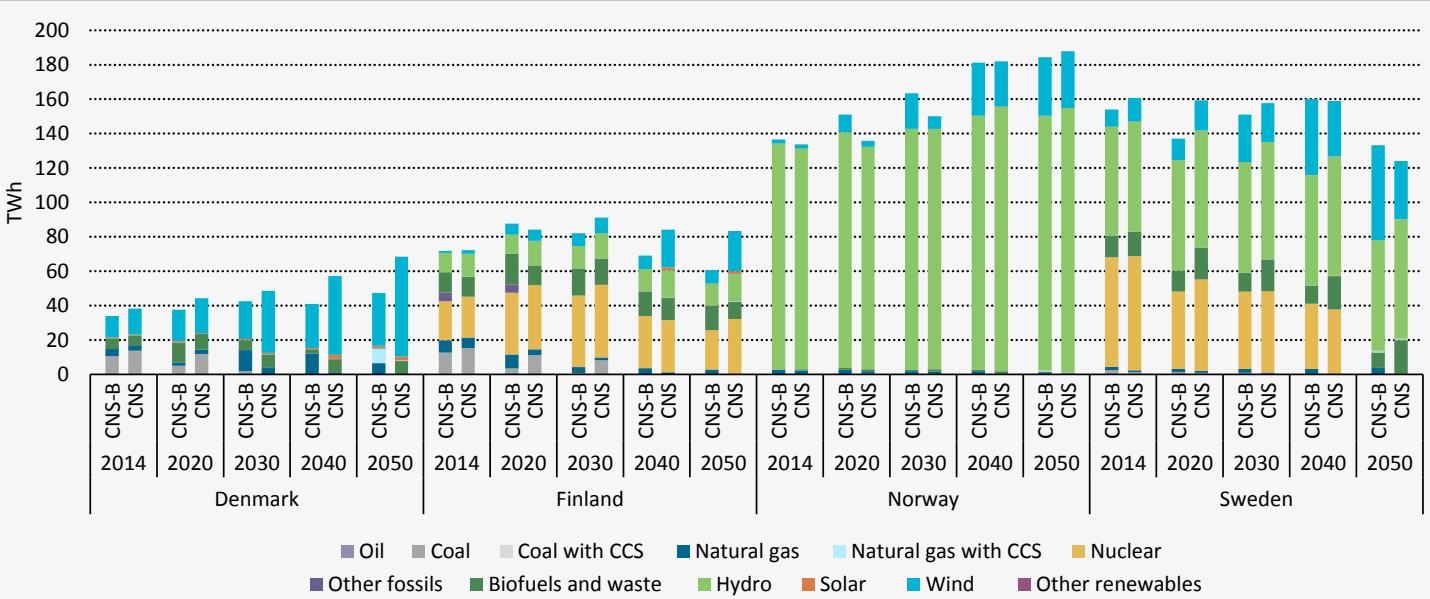

Note: TWh = Terawatt hour.

Figures and data in this report can be downloaded at www.iea.org/etp/nordic. 


\section{Figure C.6}

Net exports from the Nordics in the ETP model (sensitivity analysis) compared to the CNS-B

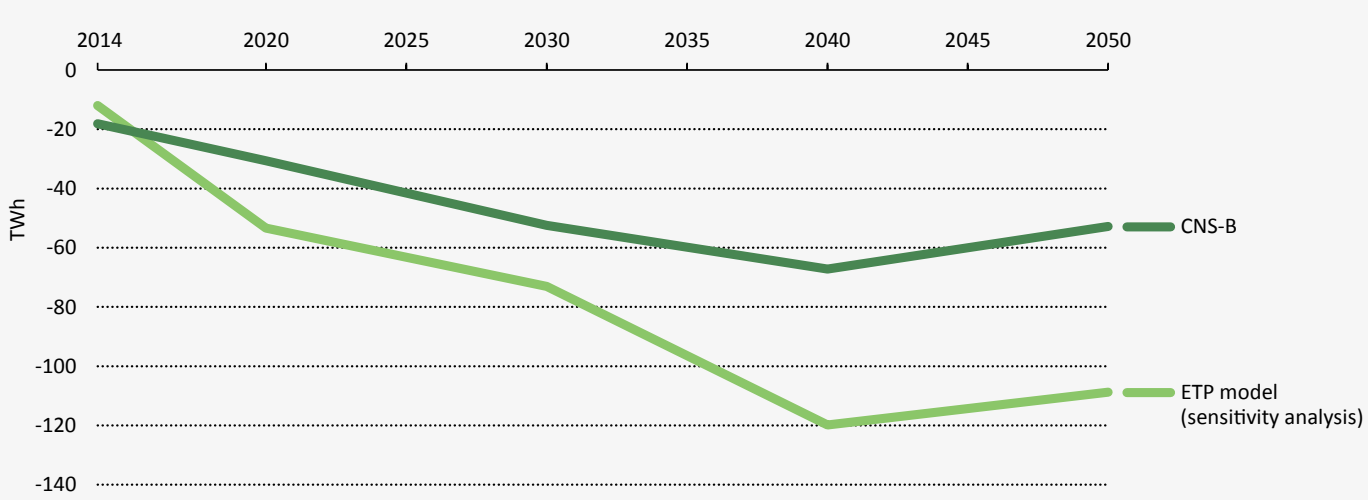

Notes: Net Nordic exports to non-Nordic countries (excluding trade among Nordic countries) are lower in the CNS-B (using the Balmorel model, and feeding into the CNS), than under a sensitivity analysis conducted using the ETP model (TIMES). The electricity trade numbers of the CNS are consistent with the CNS-B. Figures and data in this report can be downloaded at www.iea.org/etp/nordic

\section{Figure C.7 \\ Power sector $\mathrm{CO}_{2}$ emissions from the Nordics in the CNS compared to the CNS-B}

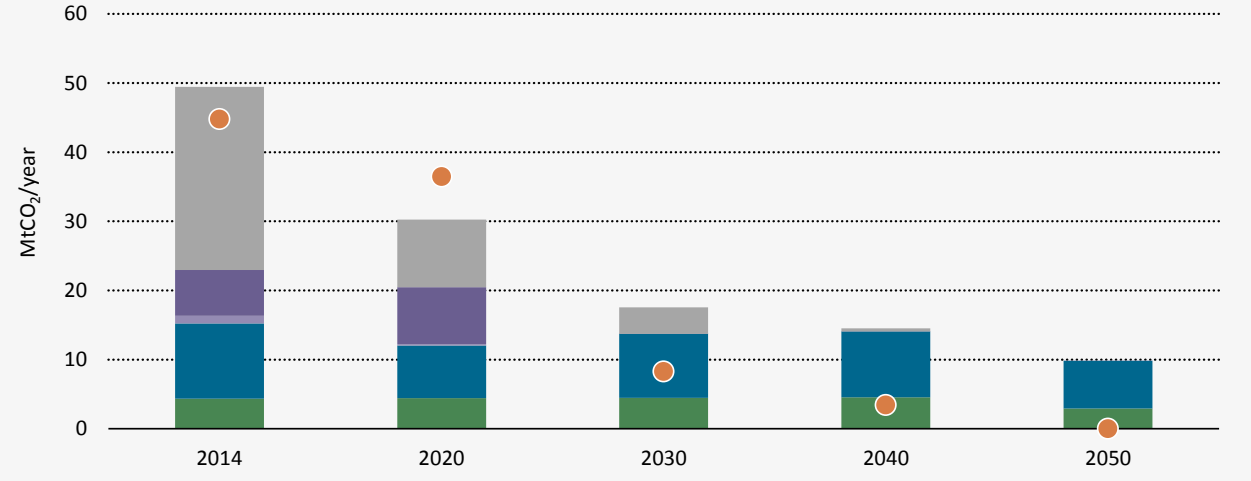

CNS-B

- Coal

- Other fossils

Oil

natural gas

Biomass and waste

- CNS

Notes: In the CNS-B, $\mathrm{CO}_{2}$ emissions are higher than in the CNS due to greater utilisation of natural gas.

Figures and data in this report can be downloaded at www.iea.org/etp/nordic. 


\section{References}

\section{Chapter $1 \quad$ Nordic choices in a global world}

Adolfsson, K. and S. Breivik (2014), "World's first battery-driven car ferry”, www.dnvgl-source. com/assets/documents/src/ferry_update_1_2014.pdf.

Bu, C. (2015), "Experience to date with EV policy in Norway", presentation at KAPSARC workshop: Drivers of Transportation Fuel Demand: Is Policy Expanding the Research of Alternative and Fuel Efficient Vehicles? King Abdullah Petroleum Studies and Research Center (9 November).

Danish Energy Agency (2015), Denmark's Energy and Climate Projection 2015 (in Danish).

Davidsdottir, B. and S. Agnarsson (2010), "The cost effectiveness of mitigating greenhouse gas emissions in Iceland", pp. 1 - 14, Djódarspegillinn 2010.

EC (European Commission) (2014), Facts and Figures of the Common Fisheries Policy. Publications Office of the European Union, Luxembourg.

EC (2013). Scientific, Technical and Economic Committee for Fisheries (STECF), The 2013 Annual Economic Report on the EU Fishing Fleet (STECF-13-15), Publications Office of the European Union, Luxembourg, 302 pp.

EEA (European Environment Agency) (2015a), "New cars' $\mathrm{CO}_{2}$ emissions well below Europe's 2015 target”, www.eea.europa.eu/highlights/new-cars2019-co2-emissions-well.

EEA (2015b), Renewable Energy in Europe - Approximated Recent Growth and Knock-on Effects, EEA Technical Report No. 1/2015.

Eurostat (2014), "SHARES", Online database of the share of energy from renewable sources in the European Union, http://ec.europa.eu/eurostat/web/energy/data/shares, accessed 10 February, 2016.

FAO (Food and Agriculture Organisation of the United Nations) (2015), Data from Forestry Statistics, FAO.

FAO (2014), The State of World Fisheries and Aquaculture, Food and Agricultural Organization of the United Nations, Rome.

FAO (2013), Fishery and Aquaculture Country Profiles (Norway, Denmark), Food and Agricultural Organization of the United Nations, Rome.

Florentinus, A. et al. (2012), "Potential of biofuels for shipping”. Ecofys, Netherlands.

FPAC (Forest Products Association of Canada) (2012), Investment and Partnership Opportunities in a Transforming Canadian Forest Products Industry, FPAC, Ottawa.

Geels, C. et al. (2016), Future air quality and related health effects in a Nordic perspective, Nordic Council of Ministers, Copenhagen.

$\mathrm{GIZ}$ (Deutsche Gesellschaft für Internationale Zusammenarbeit) (2014), International Fuel Prices 2012/2013, Eighth Edition, Deutsche Gesellschaft für Internationale Zusammenarbeit (Federal Ministry for Economic Cooperation and Development), Bonn, www.giz.de/expertise/downloads/ giz2014-en-international-fuel-prices-2013.pdf 
GBPN (Global Buildings Performance Network) (2013), What Is a Deep Renovation Definition?, Technical Report, GBPN, Paris.

Gronnbil (2015), www.gronnbil.no/statistikk.

Holthe, J. F. (2015), “Speech on Norway's EV policy framework”, delivered 8 December at COP21 High-Level Event on Zero-Emission Vehicles.

Holtsmark, B. and A. Skonhoft (2014), The Norwegian Support and Subsidy Policy of Electric Cars. Should It Be Adopted by Other Countries? Environmental Science \& Policy, Vol. 42, Elsevier, www.svt.ntnu.no/iso/anders.skonhoft/Environmental\%20Science\%20and\%20Policy\%20814. pdf.

Hydro (2015), Hydro Technology, www.hydro.com/upload/Documents/Presentations/Investor/ Hydro\%20Technology\%20Update.pdf.

IAI (The International Aluminium Institute) (2015), Estimates from IAI Global Mass Flow Model, IAI. IEA (International Energy Agency) (2016a), Energy Technology Perspectives, OECD/IEA, Paris.

IEA (2016b), "Mobility Model (MoMo) for the transport sector", www.iea.org/etp/etpmodel/ transport/, January 2016 version.

IEA (2015a), $\mathrm{CO}_{2}$ Emissions from Fuel Combustion 2015, www.iea.org/bookshop/ 669-CO2_Emissions_from_Fuel_Combustion.

IEA (2015b), "Energy balances and statistics", www.iea.org/statistics/topics/energybalances.

IEA (2015c), Storing $\mathrm{CO}_{2}$ through Enhanced Oil Recovery, OECD/IEA, Paris.

IEA (2015d), Technology Roadmap: Hydrogen and Fuel Cells, OECD/IEA, Paris, www.iea.org/ publications/freepublications/publication/TechnologyRoadmapHydrogenandFuelCells.pdf.

IEA (2015e), "World energy balances", IEA World Energy Statistics and Balances (database), http://dx.doi.org/10.1787/data-00512-en (accessed 11 November 2015).

IEA (2015f), World Energy Outlook, IEA/OECD, Paris.

IEA (2014), Linking Heat and Electricity Systems: Co-generation and District Heating and Cooling Solutions for a Clean Energy Future, OECD/IEA, Paris, www.iea.org/publications/freepublications/ publication/LinkingHeatandElectricitySystems.pdf.

IEA (2013), Nordic Energy Technology Perspectives, www.nordicenergy.org/wp-content/uploads/ 2012/03/Nordic-Energy-Technology-Perspectives.pdf.

Kenworthy, J. and F. Laube (2001), UITP Millennium Cities Database for Sustainable Transport (CDDatabase), International Union (Association) of Public Transport (UITP), Brussels.

Lagercrantz, J. (2015), "Norge först under $100 \mathrm{~g} \mathrm{CO} / \mathrm{km}$, visar vägen till fossiloberoende fordonsflotta", http://2030-sekretariatet.se/2030-sekretariatet-norge-forst-under-100-gco2km-visar-vagen-till-fossiloberoende-fordonsflotta/.

Le Quéré, C. et al. (2015), "Global carbon budget 2015", Earth Syst. Sci. Data, Vol. 7, No. 2, pp. 349-396. Liljeblad, A., M. Jansson, and I. Noghlgren (2015), Regional district heating collaboration: Drivers and success factors, Report 2015:102.

Martini, R. (2012), Fuel Tax Concessions in the Fisheries Sector, OECD Food, Agriculture and Fisheries Papers, No. 56, OECD Publishing, Paris. 
Mazzetti, M. J., N. H. Eldrup, K. L. Anthonsen, H. A. Haugen, K. Onarheim, P. Bergmo, J. Kjarstad, F. Johnson, P. Stigson, S. R. Gislason and N. A. Røkke (2013), NORDICCS CCS Roadmap, 7th Trondheim CCS Conference, TCCS-7, 5-6 June 5-6, Trondheim, Norway.

Meyer, G., J. Dokic, H. Jürgens, and S. Stagl (2014), Hybrid and Electric Vehicles - The Electric Drive Delivers, IEA Implementing Agreement for Co-operation on Hybrid and Electric Vehicle Technologies and Programmes, www.ieahev.org/assets/1/7/Report2015_WEB.pdf.

Mjøs, N. (2014), "Battery-powered ferries - Economic and greener", www.dnvgl-source.com/ assets/documents/src/ferry_update_1_2014.pdfwww.dnvgl-source.com/assets/documents/ src/ferry_update_1_2014.pdf.

MoE (Finnish Ministry of Environment) (2015), Finland's Second Biennial Report under the UNFCCC, http://unfccc.int/files/national_reports/biennial_reports_and_iar/submitted_biennial_reports/ application/pdf/fi_br2_tk_20151217_final.pdf.

NVE (Norwegian Water Resources and Energy Directorate) (2014), Bioenergy in Norway (in Norwegian), report 41.

Nykvist, B. and M. Nilsson (2015), "Rapidly falling costs of battery packs for electric vehicles", Nature Climate Change, Vol. 5, pp. 329-332, doi:10.1038/nclimate2564, www.nature.com/nclimate/ journal/v5/n4/full/nclimate2564.html.

OECD (2014a), OECD Environmental Performance Reviews: Iceland 2014, OECD Publishing, http://dx.doi.org/10.1787/9789264214200-en.

OECD (2014b), OECD Environmental Performance Reviews: Sweden 2014, OECD Publishing, http://dx.doi.org/10.1787/9789264213715-en.

OECD (2008), Environmental Performance Reviews: Denmark (2008), OECD Publishing, http://dx.doi.org/10.1787/9789264039582-en.

Open District Heating (2015), www.opendistrictheating.com/, accessed 28 October 2015.

Palm, M. (2015), "Sweden: Towards a global EV market”, International Energy Agency (IEA) and Electric Vehicle Initiative (EVI) workshop, session on experiences from EVI members, www.iea.org/media/workshops/2015/towardsaglobalevmarket/A.3Sweden.pdfwww.iea.org/ media/workshops/2015/towardsaglobalevmarket/A.3Sweden.pdf.

Parry, I., D. Heine, E. Lis, and S. Li (2014), Getting Energy Prices Right: From Principle to Practice, International Monetary Fund, http://dx.doi.org/10.5089/9781484388570.071.

Peters, G. P. et al. (2011), "Growth in emission transfers via international trade from 1990 to 2008", Proceedings of the National Academy of Sciences, Vol. 108, pp. 8903-8908.

Røe, M. (2014), "All-electric zerocat famous long before entering service", www.dnvgl-source.com/ assets/documents/src/ferry_update_1_2014.pdfwww.dnvgl-source.com/assets/documents/ src/ferry_update_1_2014.pdf.

Rytter, L., K. Andreassen, J. Bergh, P-M. Ekö, A. Kilpeläinen, D. Lazdina, P. Muiste, and T. NordLarsen (2014), Land Areas and Biomass Production for Current and Future Use in the Nordic and Baltic countries, Nordic Energy Research report.

SCB (Statistics Sweden) (2015), Statistical database, Statistics Sweden, http://www. statistikdatabasen.scb.se/pxweb/en/ssd/?rxid=6ec418e3-3939-4dd5-b343-b8625e934e32.

Schau, E.M., H. Ellingsen, A. Endal, and S.A. Aanondsen (2009), "Energy consumption in the Norwegian fisheries”, Journal of Cleaner Production, 17(3): pp. 325-334. 
SEA (Swedish Energy Agency) (2013a), Energistatistik för flerbostadshus (Energy Statistics for Multifamily Buildings) 2012, SEA, Eskilstuna.

SEA (2013b), Energistatistik för småhus (Energy Statistics for Detached Houses) 2012, SEA, Eskilstuna.

SEA and SNBHBP (Swedish National Board of Housing, Building and Planning) (2013), "Förslag till nationell strategi för energieffektiviserande renovering av byggnader - Gemensamt uppdrag Energimyndigheten och Boverket" ("Draft national strategy for building energy efficiency refurbishment - Joint mission of the Energy Agency and National Board of Housing”), ET 2013, Vol. 24.

Shafiei, E., B. Davidsdottir, J. Leaver, H. Stefansson, and E.I. Asgeirsson (2014), "Potential impact of transition to a low-carbon transport system in Iceland's energy policy”, Vol. 69, pp. 127-142.

Siemens (2015), Siemens Builds First eHighway in Sweden, www.siemens.com/press/ PR2015060246MOEN.

Skogforsk (2014), "Skogsbränslets metoder, sortiment och kostnader 2013" (in Swedish).

Späth, N. (2015), "Seatrade award for DNV GL classed Ampere, World's first fully electric vessel", DNV GL, www.dnvgl.com/news/seatrade-award-for-dnv-gl-classed-ampere-world-s-first-fullyelectric-vessel--24038.

Sumaila, U.R. et al. (2010), “A bottom-up re-estimation of global fisheries subsidies”, Journal of Bioeconomics. Vol. 12, pp. 201-225.

Swedish Energy Agency (2015), Short-term Prognosis (in Swedish), Report ER 2015:19.

Swedish Energy Agency (2014), Scenarios for Swedish Energy System (in Swedish), Report ER 2014:19.

Tesla (2014), “Tesla gigafactory”, www.teslamotors.com/gigafactory (accessed 23 November 2015).

Tomani, P. (2009), The LignoBoost Process, Innventia AB, Stockholm.

UN (2016), National Accounts Main Aggregates Database, http://unstats.un.org/unsd/snaama/ introduction.asp.

UN DESA (United Nations Department of Economic and Social Affairs) (2014), World Urbanization Prospects: The 2014 Revision, CD-ROM edition, UN DESA Population Division, New York.

UN DESA (2013), World Population Prospects: The 2013 Revision, Medium-Fertility Variant, CDROM edition, UN DESA Population Division, New York.

USGS (The U.S. Geological Survey) (2015), Minerals Yearbook Volume I - Metals and Minerals, USGS. Valmet (2016), "First LignoBoost plants producing large volumes of kraft lignin to the market place", Valmet Corporation, Espoo, Finland.

Wagner, A. (2014), International Fuel Prices 2014, Deutsche gesellschaft für Internationale Zusammenarbeit (GIZ), www.giz.de/expertise/html/4317.htmlwww.giz.de/expertise/html/4317.html.

Waldo, S. et al. (2014), Reducing Climate Impact from Fisheries. TemaNord 2014, p. 533.

World Bank (n.d.), World Integrated Trade Solution (WITS); dataset. http://wits.worldbank.org/ about_wits.html.

World Bank and FAO (2009). The Sunken Billions - The Economic Justification for Fisheries Reform. The International Bank for Reconstruction and Development, Washington DC.

Worldsteel (The Worldsteel Association) (2015), Steel Statistical Yearbook 2015, Worldsteel.

Worldsteel (2014), Worldsteel $\mathrm{CO}_{2}$ Database, personal communication. 
Autoalan tiedotuskeskus (2015), “Automäärän kehitys” [Development of the Amount of Cars in Finland], www.autoalantiedotuskeskus.fi/tilastot/autokannan_kehitys/automaaran_kehitys.

Brüde, Ulf (2013), "Sveriges trafiksäkerhet i ett 100-årigt perspektiv" [The Traffic Safety in Sweden from 100 year perspective], www.mittitrafiken.se/upload/bnrimg/document/36454Barometer-100year.pdf.

Copenhagen Green Accounts (2014), http://kk.sites.itera.dk/apps/kk_pub2/pdf/1393_x6fHiBE3UX.pdf.

Covenant of Mayors (2016), database of signatories, webpage, www.covenantofmayors.eu/ about/signatories_en.html; database of submitted Sustainable Energy Action Plans, webpage, www.covenantofmayors.eu/actions/sustainable-energy-action-plans_en.html.

HSY (Helsingin Seudun Ympäristöpalvelut) (2015), “Katsaus pääkaupunkiseudun työmatkavirtoihin 2015", [2015 Outlook on work related transport in the Capital Region of Finland] www.hsy.fi/ fi/asiantuntijalle/seututieto/tyopaikat/Documents/Sukkulointikatsaus\%202015_Versio\%20 8.6.2015_3.pdf.

HSY (2010), Helsinki Metropolitan Area Climate Strategy to the Year 2030, www.hsy.fi/sites/ Esitteet/EsitteetKatalogi/Raportit/Helsinki_Metropolitan_Area_Climate_strategy_summary.pdf.

Liikennevirasto (2016), Finnish Digiroad Download Service, https://extranet.liikennevirasto.fi/ extranet/web/public/latauspalvelu.

Loulou, R. et al. (2005), Documentation for the TIMES Model - PART I 1-78, IEA-ETSAP.

Loulou, R., G. Goldstein and K. Noble (2004), Documentation for the MARKAL Family of Models, Energy Technology Systems Analysis Program (ETSAP), IEA-ETSAP.

Lund, H. et al. (2014), “4th Generation District Heating (4GDH): Integrating smart thermal grids into future sustainable energy systems" Energy, Vol. 68, Elsevier, pp. 1-11, www.sciencedirect.com/ science/article/pii/S0360544214002369.

Norden (2013), Statistics from 1962 to 2012, www.norden.org/en/theme/former-themes/ theme-2012/nordisk-statistik-i-50-aar-1/statistics-from-1962-2012.

Nordregio (2015), Municipal Population Size in 2015 and Change 2005-2015, www.nordregio.se/ en/Maps--Graphs/01-Population-and-demography/Municipal-population-size-in-2015-andchange-2005-2015/.

Oslo-Kommune (2015), "Klima- og energistrategi for Oslo" [Climate and Energy Strategy of Oslo], www.oslo.kommune.no/politikk-og-administrasjon/miljo-og-klima/miljo-og-klimapolitikk/ klima-og-energistrategi-for-oslo/.

Statistics Denmark (2015a), Documentation of Statistics for Urban Areas 2015, http://tinyurl.com/StatisticsSweden2015a.

Statistics Denmark (2015b), Dwellings by County, Type of Resident, Type of Dwelling, Year of Construction, Heating, Toilet Facilities, Bath Facilities and Kitchen Facilities, www.statbank.dk/ statbank5a/SelectVarVal/Define.asp?MainTable=BOL102\&PLanguage $=1 \&$ PXSId=0\&wsid= cfsearch.

Statistics Finland (2015a), Definitions of Municipality Classifications (in Finnish); www.stat.fi/ meta/luokitukset/kuntaryhmitys/001-2010/2.html. 
Statistics Finland (2015b), Number of Buildings by Intended Use, Year of Construction and Fuel (database), http://pxnet2.stat.fi/PXWeb/pxweb/en/StatFin/StatFin_asu_rakke/?tablelist=true.

Statistics Finland (2014), Population by Gender and Municipality from 1990 to 2013 , http://pxnet2.stat.fi/PXWeb/pxweb/fi/StatFin/StatFin_vrm_vaerak/?tablelist=true.

Statistics Iceland (2015), Statistics on Municipalities and Urban Nuclei, http://www.statice.is/ statistics/population/inhabitants/municipalities-and-urban-nuclei/.

Statistics Norway (2015), Population and Housing Census, Dwellings, http://tinyurl.com/ StatisticsNorway2015.

Statistics Norway (2014), Population and Land Area in Urban Settlements, 1 January 2013, http://www.ssb.no/en/befolkning/statistikker/beftett/aar/2014-07-01.

Statistics Sweden (2015), Statistics Database of Localities, Areas, Population, www.scb.se/ en_/Finding-statistics/Statistics-by-subject-area/Environment/Land-use/Localities-areas-population/.

Statistics Sweden (2012), "Bostads- och byggnadsstatistisk årsbok 2012" [Statistics yearbook 2012 of Dwellings and Buildings], www.scb.se/statistik/_publikationer/B00801_2012A01_BR_ B001BR1201.pdf.

United Nations (2014), Urban Population, compiled from National Statistics Agencies, http://esa.un.org/unpd/wup/.

University of Trondheim (1990), “De Gyldne Årene - Massebilisme på 1960-tallet” [The Golden years - Mass Motoring in the 1960s], STS-arbeitnotat nr. 10/90, www.ntnu.no/c/document_ library/get_file?uuid=4c481 fb8-63e9-462a-84ba-c0bdb8ace013\&groupld=10265.

Vejdirektoratet (2013), "Biltrafikkens vækst" [Car Traffic Growth], www.vejdirektoratet.dk/DA/ vejprojekter/Funder-Laasby/OmProjektet/Documents/Vejhistorie_del-02.pdf.

\section{Chapter 3 Electricity system integration}

ABB (2015), "Why HVDC - Economic and environmental advantages", webpage, http://new.abb.com/ systems/hvdc/why-hvdc/economic-and-environmental-advantages (accessed 6 March 2016).

Amundsen, E.S. and L. Bergman (2007), "Integration of multiple national markets for electricity: The case of Norway and Sweden", Energy Policy, Vol. 35(6), Elsevier, pp. 3 383-3 394.

Blum, R. and T. Christensen (2013), "High flexibility power plants - 25 years of Danish experience", presentation at ENS-China workshop meeting on Future Flexible Power System for Renewable Energy Grid Integration, Beijing, 4 December.

Danish Energy Agency (2015), "Procedures and permits for offshore wind parks", www.ens.dk/ node/3206/procedures-permits-offshore-wind-parks (accessed 25 February 2016).Danish Energy Agency (2014), Energy Scenarios for 2020, 2035 and 2050, Danish Energy Agency Publishing, Copenhagen

Danish Energy Agency (2013), Technology Data for Advanced Bioenergy Fuels, Force Technology, Kongens Lyngby.

DECC (2015), Updated Energy and Emissions Projections 2015, Department of Energy and Climate Change, London, www.gov.uk/government/uploads/system/uploads/attachment_data/file/ 501292/eepReport2015_160205.pdf (accessed 9 March 2015). 
Ea (2015), The Danish Experience with Integrating Variable Renewable Energy, study on behalf of Agora Energiewende, Energianalyse, Copenhagen.

Ea (2014a), Future EU Energy and Climate Regulation - Implications for Nordic Energy Development and Nordic Stakeholders, Energianalyse, Copenhagen.

Ea (2014b), Biomass Pricing (on behalf of Danish Energy Agency), Energianalyse, Copenhagen.

Ea (2014c), Electricity Grid Expansion in the Context of Renewables Integration in the Baltic Sea Region, Energianalyse, Copenhagen.

Ea (2013), Analysis of Biomass Prices, Future Danish Prices for Straw, Wood Chips and Wood Pellets, Energianalyse, Copenhagen.

Ea (2011), Survey of the Potential for Flexible Demand within Industries and the Trade and Service Sectors, Energianalyse, Copenhagen.

Ea (2007), 50\% Wind Power in Denmark in 2025, Energianalyse, Copenhagen, www.eabalmorel.dk/ files/download/Projects/50_per_cent_wind_power_in_Danmark_in_2025_July_2007.pdf (accessed 9 March 2016).

Ea, DTU and DIW (2015), Increased Integration of the Nordic and German Electricity Systems Modelling and Assessment of Economic and Climate Effects of Enhanced Electrical Interconnection and the Additional Deployment of Renewable Energies (Full Version), study on behalf of Agora Energiewende and Global Utmaning.

Energinet (2015), “Afregning” [Settlement], webpage, www.energinet.dk/DA/El/Vindmoeller/ Afregning/, (accessed 25 February 2015).

Energinet.dk and Danish Energy Agency (2012), Technology Data for Energy Plants, Energinet.dk, Copenhagen.

ENTSO-E (2014), TYNDP (Ten-Year Network Development Plan) 2014, European Network of Transmission System Operators for Electricity, Brussels.

Feldmüller, A. (2013), "Wie flexibel ist der heutige konventionelle Kraftwerkspark aus Herstellersicht?" [How flexible is today's conventional power plant from the manufacturer's viewpoint?], Siemens AG.

Grohnheit, P.E., F.M. Andersen and H.V. Larsen (2011), "Area price and demand response in a market with 25\% wind power”, Energy Policy, Vol. 39(12), Elsevier, pp. 8051-8061.

Hirth, L. and S. Müller (2015), "System-friendly wind power", presentation at Berlin Conference on Energy and Electricity Economics, 28 May, www.diw.de/documents/dokumentenarchiv/17/ diw_01.c.506693.de/hirth_belec.pdf (accessed 5 April 2016).

IEA (International Energy Agency) (forthcoming), Energy Technology Perspectives 2016, OECD/ IEA, Paris.

IEA (2015), Projected Cost of Generating Electricity, OECD/IEA, Paris.

loES (2013), "Pjóðhagsleg áhrif sæstrengs" [Macroeconomic effects of submarine cable], Institute of Economic Studies, University of Iceland, www.atvinnuvegaraduneyti.is/media/saestrengurtil-evropu/Skyrsla-HHI-26-juni-2013.pdf

Jacobsen, H. and E. Zvingilaite (2010), "Reducing the market impact of large shares of intermittent energy in Denmark”, Energy Policy, Vol. 38(7), Elsevier, pp. 3403-3413.

Krönert, F. (2016), It's Crunchtime for Swedish Nuclear, Sweco Publishing, Sweden.

Kwon, PS \& Østergaard, P (2014), 'Assessment and evaluation of flexible demand in a Danish future energy scenario' Applied Energy, vol 134, pp. 309-320., 10.1016/j.apenergy.2014.08.044 
Landsvirkjun (2014), Annual Report 2014, Landsvirkjun (National Power Company of Iceland), www.landsvirkjun.com/finance/annualreport/?from $=01.01 .2015 \&$ to=01.01.2016 (accessed 8 March 2015).

Larsen, H.H. and L. Sønderberg Petersen (eds.) (2013), DTU International Energy Report 2013: Energy Storage Options for Future Sustainable Energy Systems, Technical University of Denmark, Roskilde. (accessed 9 March 2016).

Mathiesen, B.V. and H. Lund (2015), "Smart energy systems for coherent 100\% renewable energy and transport solutions”, Applied Energy, Vol. 145, Elsevier, pp. 139-154.

Morales, J.M. (2015), Material from MSc. course, “Decision-making under uncertainty in electricity markets" https://sites.google.com/site/decmakem/material.

NEP (2014), Network Development Plan 2014, Netzentwicklungsplan.

Nordic Energy Research and IEA (2013), Nordic Energy Technology Perspectives 2013, OECD/ IEA, Paris.

Nordpool (n.d.), www.nordpoolspot.com (accessed 23 February 2016).

NordREG (2014), Nordic Market Report 2014, Nordic Energy Regulators.

NVE (Norwegian Water Resources and Energy Directorate) (2016), "Hydropower potential by County", www.nve.no/media/2384/vannkraftpotensial-fylker-2015.pdf (accessed 8 March 2016).

Ofgem (Office of Gas and Electricity Markets) (2015), "Electricity interconnectors”, webpage, www.ofgem.gov.uk/electricity/transmission-networks/electricity-interconnectors (accessed 9 March 2015)

Power Technology (2016), "Hanhikivi 1 Nuclear Power Plant, Finland”, www.power-technology.com/ projects/hanhikivi-1-nuclear-power-plant/ (accessed 10 March 2016).

Skytte, K. (1999), "The regulating power market on the Nordic power exchange Nord Pool: an econometric analysis”, Energy Economics, Vol. 21, Elsevier, pp. 295-308.

Taloussanomat (2014), “Talouselämä: Fennovoiman osakkaille takuusähköä 12 vuotta” [Economy: Fennovoima's shareholders receive 12-year electricity commitment] www.taloussanomat.fi/ politiikka/2014/09/26/talouselama-fennovoiman-osakkaille-takuusahkoa-12-vuotta/ 201413372/12 (accessed 10 March 2016)

Thema Consulting Group (2014), Demand Response in the Nordic Electricity Market: Input to Strategy on Demand Flexibility, Norden Publishing, Copenhagen.

Turvey, R. (2006), “Interconnector economics”, Energy Policy, Vol. 34(13), Elsevier, pp. 1457-1472.

Wood, A.J., B.F. Wollenberg and G.B. Sheble (2012), Power Generation, Operation and Control, John Wiley, New York, NY, pp. 131-171.

World Nuclear Association (2016), "Nuclear power in Sweden”, webpage, www.world-nuclear.org/ information-library/country-profiles/countries-o-s/sweden.aspx (accessed 9 March 2016).

World Nuclear News (2014), "Olkiluoto 3 startup pushed back to 2018", www.world-nuclearnews.org/NN-Olkiluoto-3-start-up-pushed-back-to-2018-0109147.html. 


\section{Annexes}

Fulton L., P. Cazzola and F. Cuenot (2009), "IEA Mobility Model (MoMo) and its use in the ETP 2008", Energy Policy, Vol. 37, No. 10, Elsevier, Amsterdam, pp. 3758-3768.

IEA (International Energy Agency) (2015a), "World energy balances”, IEA World Energy Statistics and Balances 2015, www.iea.org/statistics/ (accessed 4 February 2016).

IEA (2015b), World Energy Outlook 2015, IEA/OECD, Paris.

IMF (International Monetary Fund) (2015), World Economic Outlook Database, April 2015, www.imf.org/external/pubs/ft/weo/2015/01/weodata/index.aspx

Loulou, R., U. Remme, A. Kanudia, A. Lehtilä, G. Goldstein (2005), Documentation for the TIMES Model - PART I, www.iea-etsap.org/web/Docs/TIMESDoc-Intro.pdf.

Schipper L., C. Marie-Lilliu, and R. Gorham (2000). "Flexing the Link between Transport and Greenhouse Gas Emissions: a Path for the World Bank" International Energy Agency/OECD, Paris.

UN DESA (United Nations Department of Economic and Social Affairs) (2014), World Urbanization Prospects: The 2014 Revision, CD-ROM Edition, United Nations Department of Economic and Social Affairs, Population Division, United Nations, New York.

ENTSO-E (2014), TYNDP (Ten-Year Network Development Plan) 2014; Ea, DTU and DIW (2015), Increased Integration of the Nordic and German Electricity Systems - Modelling and Assessment of Economic and Climate Effects of Enhanced Electrical Interconnection and the Additional Deployment of Renewable Energies (Full Version).

NEP (2014), Network Development Plan 2014 (Scenario B).

Thema Consulting Group (2014), Demand Response in the Nordic Electricity Market: Input to Strategy on Demand Flexibility. https://www.tem.fi/files/43979/THEMA_Final_report_2014-24_ Input_to_strategy_on_demand_flexibility_in_the_Nordic_countries.pdf

Kwon, PS \& Østergaard, P (2014), 'Assessment and evaluation of flexible demand in a Danish future energy scenario'. doi:10.1016/j.apenergy.2014.08.044. 


\section{List of Figures}

Figure 1.1 Nordic GDP, energy-related $\mathrm{CO}_{2}$ emissions and total primary energy demand 32

Figure 1.2 $\mathrm{CO}_{2}$ intensity of total primary energy demand in the Nordic countries (CNS) and OECD Europe (2DS)

Figure 1.3 Reduction pathway for energy-related $\mathrm{CO}_{2}$ in the 4DS, 2DS and CNS 33

Figure 1.4 Direct Nordic GHG emissions in 2010

Figure 1.5 Nordic primary energy supply, 2013 and 2050 in the CNS 34

Figure 1.6 Nordic GDP and carbon dioxide emissions by sector in the CNS.

Figure 1.7 Historic and future final energy consumption per capita, Nordic countries (CNS) and OECD average (2DS)

Figure 1.8 Final energy demand by sector in the Nordic countries, 1990-2013

Figure 1.9 Nordic direct energy-related $\mathrm{CO}_{2}$ emissions in the CNS, by sector and country

Figure 1.10 Nordic $\mathrm{CO}_{2}$ emissions reported to the UNFCCC compared to $\mathrm{CO}_{2}$ emissions allocated to consumption (left). Production and consumption $\mathrm{CO}_{2}$ emissions relative to GDP (right)

Figure 1.11 Global carbon intensity of electricity supply $\left(\mathrm{gCO}_{2} / \mathrm{kWh}\right)$

Figure 1.12 Electricity generation in the Nordic countries, 2013

Figure 1.13 Primary energy supply in the Nordics: Fuels for electricity and heat production (2013)

Figure 1.14 Electricity and heat mix in Nordic countries in 2013

Figure 1.15 Heating deliveries to residential buildings in Nordic countries, by technology type (TWh)

Figure 1.16 District heating deliveries in Nordic countries, by energy source (terajoules) 46

Figure 1.17 Nordic electricity generation mix in the 4DS and CNS (TWh) 47

Figure 1.18 Net electricity trade of the Nordic Region (TWh) 48

Figure 1.19 Key technologies to reduce power sector $\mathrm{CO}_{2}$ emissions between 4DS and CNS 49

Figure 1.20 Heat production in DH networks 50

Figure 1.21 Use of biomass (including renewable waste but excluding peat) for energy supply as a share of total gross energy consumption, 2014 
Figure 1.22 Bioenergy use in 2013, by sector in TWh (including waste but excluding peat) 53

Figure 1.23 Net import share of domestic bioenergy use in 2013 (including waste but excluding peat), by sector (\%).

Figure 1.24 Net import of biofuels for transportation as share of each country's total primary energy demand of biomass and waste for all sectors according to the CNS scenario (2015-2050)

Figure 1.25 Passenger (pkm) and freight (tkm) activity mode shares in 2013

Figure 1.26 Fuel taxes as percentage of total fuel price, 2011-2013

Figure 1.27 Energy flows in Nordic transport, 2015 and 2050 in the CNS

Figure 1.28 Technology penetration in the urban and non-urban vehicle stock in the CNS and 4DS

Figure 1.29 Decoupling of transport GHG emissions and passenger and freight services in the CNS

Figure 1.30 GHG emission reductions in the CNS in transport, by country and mode 70

Figure 1.31 Energy flows in Nordic industry, 2013

Figure 1.32 Nordic final industrial energy use and aggregated industrial direct $\mathrm{CO}_{2}$ intensity, 4DS and CNS

Figure 1.33 Energy flows in Nordic industry, 2050 - CNS

Figure 1.34 Nordic direct industrial $\mathrm{CO}_{2}$ emissions reductions by sector, 4DS and CNS

Figure 1.35 Nordic 2020-2050 cumulative direct industrial $\mathrm{CO}_{2}$ emitted, and captured and stored in the CNS by sector

Figure 1.36 Nordic industrial stationary $\mathrm{CO}_{2}$ emissions sources

Figure 1.37 Icelandic fishing industry, 2013

Figure 1.38 Evolution of the Icelandic fleet's fuel intensity (per unit harvested) and world oil prices

Figure 1.39 Abatement cost for renewable energy options

Figure 1.40 Energy by end-use and average building energy use per person

Figure 1.41 Final energy consumption in the Nordic buildings sector by fuel

Figure 1.42 Buildings sector energy by fuel and space heating intensities to 2050

Figure 1.43 Building energy savings by end-use, urban and non-urban buildings

Figure $1.44 \quad \mathrm{CO}_{2}$ emissions reduction in urban buildings to 2050

Figure 1.45 Costs and energy and emissions savings to 2050 for integrated buildings in Stockholm

Figure 1.46 Cumulative investments by sector, 2016-2050 
Figure 2.1 Map of Nordic municipalities with population size and annual growth rate from 2005 to 2015

Figure 2.2 Urban and rural populations in the Nordic countries

Figure 2.3 Forecast growth in urban population, urban passenger transport demand, urban GDP and urban floor area (residential and commercial) in Nordic countries

Figure 2.4 Final energy demand of urban transport in Nordic countries

Figure 2.5 Final energy demand of urban buildings in Nordic countries in 2013 (left) and in the scenarios (right)

Figure 2.6 Electricity demand per person in the transport and buildings sectors in urban and rural areas in Nordic countries in the 4DS and CNS

Figure 2.7 Production of district heat by fuel and technology in 2013 (left) and 2013-50 in scenarios (right)

Figure 2.8 TPES in 2013 (left) and total for Nordic urban areas in the 4DS and CNS from 2013 to 2050

Figure $2.9 \quad \mathrm{CO}_{2}$-free share of TPES in urban and rural areas in the Nordic region in the 4DS and CNS

Figure 2.10 Share of final energy to buildings and transport delivered through electricity grid and district heating networks in Nordic region urban and rural areas in the 4DS and CNS

Figure 2.11 Direct $\mathrm{CO}_{2}$ emission reductions in the Nordic region in the CNS as compared to the $4 \mathrm{DS}$

Figure 2.12 The share of employees commuting to the capital region in Finland.

Figure 2.13 Final energy demand (excluding aviation) in the Metropolitan Region

Figure 2.14 Final energy for residential and service sector heating in the Metropolitan Region

Figure 2.15 Heat production in the Metropolitan Region by fuel used

Figure 2.16 Electricity consumption by sector in the Metropolitan Region

Figure 2.17 Metropolitan region electricity supply by energy source

Figure 2.18 Final energy in transport (excluding all aviation) in the Metropolitan Region 
Figure 2.19 GHG emissions by sector in the Metropolitan Region 138

Figure 2.20 Map of the Oslo area with public EV charging points 140

Figure 2.21 Energy consumption for the city of Oslo in 2009 for various end-use sectors

Figure 2.22 Relative $\mathrm{CO}_{2}$ emissions and energy consumption of various measures compared to the 4 DS for 2050

Figure 2.23 GHG emissions in the CNS, by sector, 2010-50

Figure 2.24 Total final energy consumption by energy carrier in 4DS and CNS, 2010-50

Figure 2.25 Electricity consumption by sector

Figure 2.26 Energy consumption in the residential sector by energy carrier

Figure 2.27 Use of energy carriers in the transport sector, aviation excluded

Figure 3.1a Overview of Nordic electricity trade, 2015

Figure 3.1b Overview of Nordic electricity trade in the CNS-B, 2050

Figure 3.2 Flexibility options in the Nordic energy system

Figure 3.3 Historical electricity prices in the Nordic power market

Figure 3.4 Connection between ETP model results and Balmorel simulations

Figure 3.5 Development of fuel prices (left) and $\mathrm{CO}_{2}$ prices (right)

Figure 3.6 Price projections for solid biomass fuels

Figure 3.7 Nordic electricity demand as classical and flexible demand

Figure 3.8 Modelled transmission system in 2030 with price zones and transmission lines (existing and planned transmission lines until 2030)

Figure 3.9 Investment costs for additional transmission line capacity

Figure 3.10 Development of electricity generation capacity in the overall power system, CNS-B

Figure 3.12 Development of power generation in the overall system, CNS-B 
Figure 3.13 Development of electricity generation in individual Nordic countries, CNS-B 171

Figure 3.14 Development of $\mathrm{CO}_{2}$ emissions in the Nordic countries, CNS-B

Figure 3.15 Development of power prices in the Nordic countries and other European countries, CNS-B

Figure 3.16 Nord Pool market operation

Figure 3.17 Stylised supply and demand curve for the Nordic and German electricity markets

Figure 3.18 Price drop compared to the wind share in Western Denmark, statistical and model results, CNS-B

Figure 3.19 Wind power price drop in the Nordic countries by 2050 relative to their share of wind power, CNS-B

Figure 3.20 Duration curve of electricity prices in the Nordic countries in 2030 (CNS-B model result)

Figure 3.21 Flexibility option: Electricity trade

Figure 3.22 Development of the transmission capacity between the Nordic countries and their vicinity in the CNS-B

Figure 3.23 Development of electricity transmission from the Nordic perspective in the CNS-B

Figure 3.24 Duration curves between the Nordic countries and surrounding countries in 2030 in the CNS-B

Figure 3.25 Investments in transmission capacity between 2030 and 2050 and electricity prices in 2050 in the CNS-B

Figure 3.26 Hourly transmission between the Nordic region and surrounding countries for two weeks in 2030 in the CNS-B

Figure 3.27 Wind capacity build-outs for 2050 in the CNS-B

Figure 3.28 Development of wind penetration level (relative to demand) per country in the CNS-B

Figure 3.29 Categories of hydropower potential in Norway 2015

Figure 3.30 Norwegian hydropower generation in the CNS-B

Figure 3.31 Flexibility option: Flexible supply

Figure 3.32 Operation of the Nordic power system during week 14 and 15 in year 2030 in the CNS-B 
Figure 3.33 A stepwise approach to improved power-plant flexibility

Figure 3.34 Comparison of Nordic hourly generation in week 44 in 2030 with and without Unit Commitment (UC) in the CNS-B

Figure 3.35 Electricity price duration curve with and without Unit Commitment (UC) in 2030 for Southern Sweden

Figure 3.36 Operation points with different electricity to heat ratios for a co-generation plant

Figure 3.37 Short-run marginal cost of heat production by technology depending on electricity price

Figure 3.38 Flexibility option: Storage

Figure 3.39 Hourly heat generation for one week in Central Sweden in 2030 in the CNS-B 198

Figure 3.40 Final energy demand for transport in the Nordic countries in the CNS 199

Figure 3.41 Biorefinery concept

Figure 3.42 Electrolysis, upgraded biogas and advanced bio-ethanol production 200

Figure 3.43 Interlinkages among the different energy carriers in the energy system 201

Figure 3.44 Flexibility option: Flexible demand

Figure 3.45 Duration curves for the Nordic system for demand and residual demand in 2015

Figure 3.46 Development of demand response in the sensitivity analysis

Figure 3.47 Comparison of development of power capacity with and without flexible demand, in the CNS-B baseline and flex scenarios

Figure 3.48 Comparison of electricity export and import from the Nordic countries to continental Europe and Great Britain with and without flexible demand, in the CNS-B baseline and flex scenarios

Figure 3.49 Results from the Nordic countries in 2030 with flexible demand (bottom), without flexible demand (middle) and related electricity prices (top), in the CNS-B baseline and flex scenarios

Figure 3.50 Nuclear capacity in the Nordic countries in CNS-B baseline and fast phase-out scenarios

Figure 3.51 Development of capacity in the Nordic countries with and without fast phase-out, in the CNS-B

Figure 3.52 Electricity price and $\mathrm{CO}_{2}$ emissions in the Nordic countries with and without fast nuclear phase-out, in the CNS-B 
Figure A.1 Structure of the ETP model

Figure A.2 Structure of the ETP-TIMES model for the conversion sector

Figure A.3 Structure of ETP-Industry model

Figure A.4 MoMo structure

Figure A.5 Structure of the buildings sector model

Figure B.1 Overview of the functional structure of the TIMES-Helsinki-Metro model

230

Figure B.2 Principal drawing of TIMES-Oslo model

Figure C.1 Onshore wind full load hours (FLHs) (2030-49)

Figure C.2 Offshore wind full load hours (FLHs) (2030-49)

Figure C.3 District heating demand in the Nordic countries in the CNS-B

Figure C.4 District heating generation in Nordic countries in the CNS-B

Figure C.5 Electricity generation in the CNS compared to the CNS-B

Figure C.6 Net exports from the Nordics in the ETP model (sensitivity analysis) compared to the CNS-B

Figure C.7 Power sector $\mathrm{CO}_{2}$ emissions from the Nordics in the CNS compared to the CNS-B

\section{List of Boxes}

Box 1.1 Current Nordic energy system and Nordic ETP scenarios

Box 1.2 Do consumption emissions debunk Nordic $\mathrm{CO}_{2} / \mathrm{GDP}$ decoupling? 
$\begin{array}{lll}\text { Box } 3.1 & \text { Analytical framework } & 158\end{array}$

$\begin{array}{lll}\text { Box } 3.2 & \text { The Nordic power market } & 174\end{array}$

Box 3.3 Advanced wind turbines can add value to wind power in the market 178

Box $3.3 \quad$ Advanced wind turbines can add value to wind power in the market 178

\section{List of Tables}

$\begin{array}{lll}\text { Chapter } 1 & \text { Nordic choices in a global world } & 28\end{array}$

Table $1.1 \quad$ Materials production in Nordic countries 74

Table 1.2 Status of technology and key indicators for the industrial sector under 4DS and CNS

Table 1.3 Drivers for energy consumption in buildings (urban and national) across the Nordic region

Table 1.4 Building energy efficiency and district heating investment scenarios for Stockholm

Table 1.5 Policy areas for near-term action and long-term objectives

Table 2.1 Four major indicators for Nordic urban areas: population; GDP; energy demand in buildings and transport; and direct $\mathrm{CO}_{2}$ emissions

Table 2.2 Three buildings sector indicators for urban areas in Nordic countries, EU member states and OECD member countries and non-members

Table 2.3 Three transport sector indicators in the urban areas of Nordic countries, EU member states and OECD member countries and non-members

Table 2.4 Share of district heating and renewable energy in the urban areas of Nordic countries, EU member states and OECD member countries and non-members

Table 2.5 The number of Nordic cities taking part in the Covenant of Mayors and a typical reduction target 
Table 2.6 Development of district energy systems by technology generation

Table 2.7 Effect of low-carbon technology options on urban transport in the Nordic CNS

Table 2.8 Effect of low-carbon energy technologies in urban buildings in the Nordic CNS

Table 2.9 Effect of low-carbon energy supply options in urban areas in the Nordic CNS

Table 2.10 Effect of low-carbon energy supply options in Nordic urban areas in the CNS

Table 2.11 Comparison of Nordic capitals and urban average in the buildings and transport sectors and energy supply

Table 2.12 Land area, population and energy statistics for the Metropolitan Region (including Kerava)

Table 2.13 Key figures for Oslo

Table 3.1 CNS-B scenario assumptions

Table 3.2 Indicative timeline for integration solutions in the power and district heating systems

Table 3.3 Model setup in CNS-B baseline scenario

Table 3.4 Cost assumptions for HVDC LCC connections

Table 3.5 Wind power capacity in the CNS-B (Baseline, Flex) in the Nordic countries

Table 3.6 Transmission capacity expansion in CNS-B baseline and Flex scenarios

Table 3.7 Deployment of flexible technologies in the Nordic countries, CNS-B

Table 3.8 Deployment of flexible technologies in the Nordic countries

Table 3.9 Flexibility parameters for thermal power plants in Denmark and Germany

Table 3.10 Storage technologies in the electricity grid, their maturity and application

Table 3.11 Flexibility timescales, analysis tools, system phenomena and storage technologies 
Table A.1 Real GDP growth projections in NETP 2016 (assumed identical across scenarios)

Table A.2 Population projections used in NETP 2016 227

Table A.3 Fuel prices by scenario

Table A.4 Marginal abatement costs in the electricity sector in the 4DS and CNS 228

Table A.5 Technological-economic assumptions for selected power technologies in the Nordic region and resulting levelised costs of electricity generation (LCOE) in the CNS, 2013 to 2050

Table C.1 National connections within the Nordic region

Table C.2 International connections between the Nordic countries and surrounding countries

Table C.3 International connections between surrounding countries 236

Table C.4 National connections within Germany

Table C.5 Flexible demand shares for the Nordic countries 237

Table C.6 Flexible demand shares for Denmark in CNS-B

Table C.7 Electricity trade between the Nordic countries and to the rest of Europe in 2015 and 2050 in the CNS-B

Table C.8 Electricity trade between price areas in the Nordic countries and to the rest of Europe in 2015 and 2050 in the CNS-B

Table C.9 Wind potential

Table C.10 Nuclear Capacities in the CNS-B Baseline and Fast phase-out scenarios (MW) 


\section{Also from the IEA}

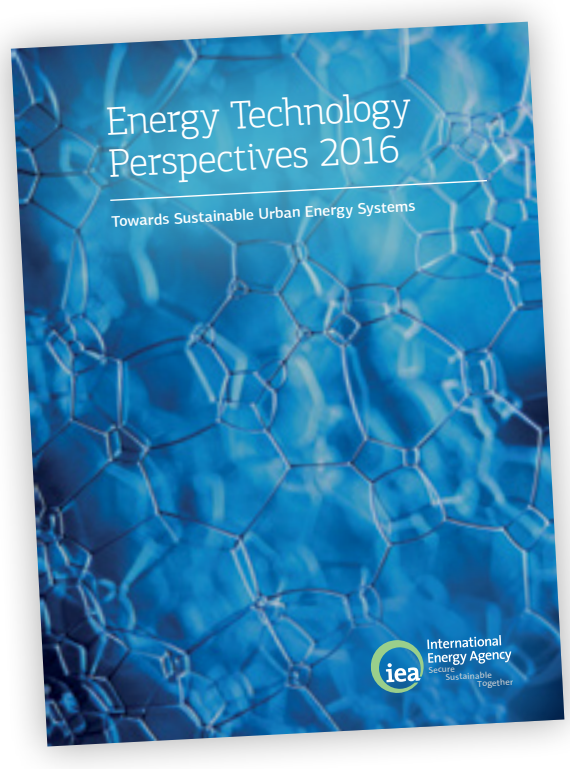

Energy Technology Perspectives is the International Energy Agency's most ambitious project on the potential for energy technologies to contribute to a secure energy system that enables stable economic growth while minimising environmental impacts. Energy Technology Perspectives 2016 looks at the technology and policy opportunities available to accelerate the transition to sustainable urban energy systems. The potential for low-carbon technology deployment in cities could be the key to successfully driving an energy transition that many still think impossible, provided that local and national actions can be aligned to meet the sustainability objectives at both levels.

www.iea.org/etp2016

\section{New releases}

The IEA Policies and Measures Databases contain information on policies and measures to reduce greenhouse gas emissions, improve energy efficiency and support renewable energy. This online service complements the policy analysis carried out by the IEA and covers all IEA member countries as well as many non-member countries. Delegates from IEA member countries are given the opportunity to review the information twice a year.

www.iea.org/policiesandmeasures

IEA Technology Roadmaps help set the agenda for development and deployment of key lowcarbon energy technologies. These free publications identify pathways and priorities to support technological advances and uptake in alignment with ETP scenarios of energy system decarbonisation. Twenty-one different technologies have been covered, embracing energy supply, energy demand, integration, industry sectors and mitigation. These are complemented by the How2Guides - a series of manuals for policy and decision makers to plan and implement technology roadmaps that are tailored to national or regional frameworks.

www.iea.org/roadmaps

Four decades ago, the IEA founders had the foresight to create a multilateral mechanism for governments and industry to accelerate energy technology innovation worldwide that has stood the test of time. Today, it is more relevant than ever to delivering solutions to global energy challenges. The publication Technology Collaboration Programmes: Highlights and Outcomes provides an overview of the activities and recent accomplishments of these experts groups. www.iea.org/tcp/ 
This work is available under the Creative Commons Attribution-NonCommercial-ShareAlike 3.0 IGO license (CC BY-NC-SA 3.0 IGO) http://creativecommons.org/licenses/by-nc-sa/3.0/ igo/deed.en_US, you are free to copy, redistribute and adapt the material, provided the use is for non-commercial purposes, under the following conditions:

Attribution - Please cite the work as follows: OECD/IEA, Nordic Energy Research, Technical University of Denmark, Ea Energianalyse A/S, VTT Technical Research Centre of Finland, University of Iceland, Institute For Energy Technology, Profu Ab and IVL Swedish Environmental Research Institute 2016, Nordic Energy Technology Perspectives, IEA Publishing.

License: Creative Commons Attribution CC BY-NC-SA 3.0

ShareAlike - If you remix, transform, or build upon the material, you must distribute your modified material under the same Creative Commons license terms as the original (CC BY-NC-SA).

Translations - If you create a translation of this work, please let us know about the translation by sending an email to rights@iea.org and also add the following disclaimer to your translation along with the attribution referred to above: This translation was not created by any of the International Energy Agency, Nordic Energy Research, Technical University of Denmark, Ea Energianalyse A/S, VTT Technical Research Centre of Finland, University of Iceland, Institute For Energy Technology, Profu Ab and IVL Swedish Environmental Research Institute (the Authors) and should not be considered an official translation of any of the Authors. The Authors shall not be liable for any content or error in any translation.

Adaptations - If you create an adaptation of this work, please add the following disclaimer along with the attribution: This is an adaptation of an original work by the International Energy Agency, Nordic Energy Research, Technical University of Denmark, Ea Energianalyse A/S, VTT Technical Research Centre of Finland, University of Iceland, Institute For Energy Technology, Profu Ab and IVL Swedish Environmental Research Institute (the Authors). Responsibility for the adaptation, including any views and opinions expressed in it, rests solely with the author(s) of the adaptation. The adaptation is not endorsed by any of the Authors.

Third-party content - Each of the International Energy Agency, Nordic Energy Research, Technical University of Denmark, Ea Energianalyse A/S, VTT Technical Research Centre of Finland, University of Iceland, Institute For Energy Technology, Profu Ab and IVL Swedish Environmental Research Institute (the Authors) do not necessarily own each component of the content contained within this work. Therefore, none of the Authors warrant that the use of any third-party owned individual component or part contained in the work will not infringe on the rights of those third parties. The risk of claims resulting from such infringement rests solely with you. If you wish to re-use a component of the work, it is your responsibility to determine whether permission is needed for that re-use and to obtain permission from the copyright owner. Examples of components can include, but are not limited to, tables, figures, or images. 


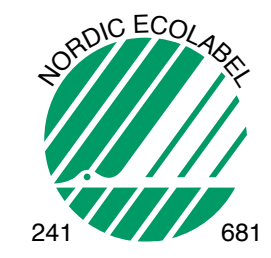

Ecolabelled printed matter, 241681

The printing process of this publication is certified according to the regulations of the Nordic Ecolabel

IEA PUBLICATIONS, 9 rue de la Fédération, 75739 Paris Cedex 15

PRINTED IN NORWAY BY ROLF OTTESEN AS (http://ottesen.no), May 2016

All photos: (c) Justinreznick/iStockphoto

The cover shows an aerial view of a river delta in Iceland. 


\section{Nordic Energy Technology Perspectives 2016}

\section{Cities, flexibility and pathways to carbon-neutrality}

Nordic Energy Technology Perspectives 2016 presents a clear technological and economical pathway for the Nordic region towards a nearly carbon-neutral energy system in 2050. Nordic countries' success can send a strong signal to the global community that the ambitions of the Paris Agreement from COP21 are achievable.

The report identifies opportunities for policy makers and the private sector in three strategic areas:

1. Incentivise and plan for a significantly more distributed, flexible and interconnected Nordic electricity system. A decentralised electricity supply with a high share of wind is likely to achieve a carbon-neutral system at lower cost than a system reliant on nuclear and thermal generation. But the shift will require flexibility measures beyond those now provided by Nordic hydropower, as well as a significant increase in cross-border electricity trade.

2. Ramp up technologies to decarbonise energy-intensive industries and long-distance transport. Emissions from industries like steel and cement are the most challenging to reduce, requiring rapid advances in the demonstration and deployment of carbon capture and storage (CCS) and other innovative technologies. Electrification will be at the core of most low-carbon transportation, but long-distance transport will likely require large volumes of biofuels.

3. Tap into cities' positive momentum to strengthen national decarbonisation and enhance energy efficiency in transport and buildings. Driven in part by air quality, health and congestion objectives, many Nordic cities lead their countries' decarbonisation efforts, with more ambitious targets and advanced roll-out of electric vehicles.

Visit www.iea.org/etp/nordic for more extensive data coverage and information.

\section{(I/IIII) norden}

Nordic Energy Research Nordic Council of Ministers

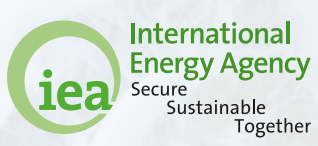

Together
Toble (a) ivl

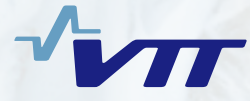

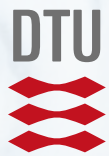

UNIVERSITY OF ICELAND
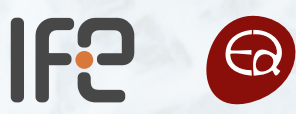

Ea Energy Analyses
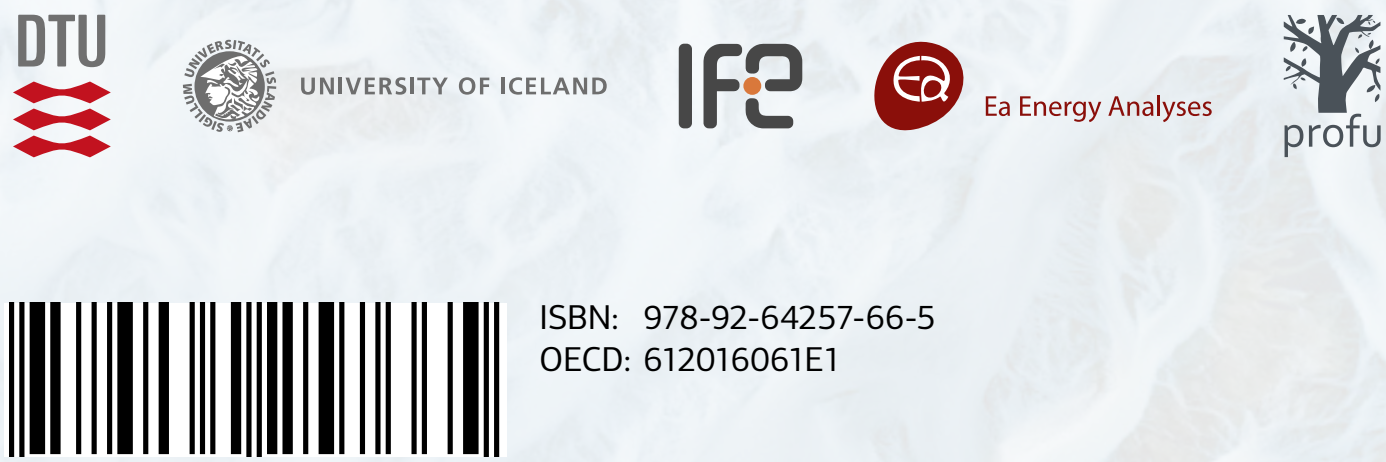